\title{
IntechOpen
}

\section{New Knowledge in a New Era of Globalization}

Edited by Piotr Pachura 



\section{NEW KNOWLEDGE IN A NEW ERA OF GLOBALIZATION}

Edited by Piotr Pachura 


\section{New Knowledge in a New Era of Globalization}

http://dx.doi.org/10.5772/982

Edited by Piotr Pachura

\section{Contributors}

Akbar Valadbigi, Shahab Ghobadi, Patricia Lynn Fox, Stephen Hundley, Mario Azevedo, Barbara H. Johnson, Hidehiko Hayashi, Akinori Minazuki, Toshiko Asai, Vera Becvarova, Bjoern Jaeger, Berit Irene Helgheim, Cheng-Ta Wu, Gregory Siy Ching, Chia-wei Tang, Dian-Fu Chang, Lin Xiao, Lemja Chabbouh -Aksamija, Ronald Welch, Renato Mariani Costantini, Massimo Barberis, Claudio G. Clemente, Pasquale De Blasio, Agostino Faravelli, Marco Forni, Piergiovanni Grigolato, Lorenzo Leoncini, Karin Schuerfeld, Vincenzo Stracca Pansa, Ahmed Mohamedani, Khalid Dafaallah Awadelkarim, Mario Di Gioacchino, Sandra Rosini, Giuseppe Lattanzio, MAHADEVI BANAD, Miguel GonzálezCarbajal, Ludmila Martínez Leyva, Peter Horton, Bernur Açıkgöz, Sophie Caillon, François-Michel Le Tourneau, Ludivine Eloy, Claire Couly, Anna Greissing, Florent Kohler, Guillaume Marchand, Stephanie Nasuti, Dorothee Serges

\section{(c) The Editor(s) and the Author(s) 2011}

The moral rights of the and the author(s) have been asserted.

All rights to the book as a whole are reserved by INTECH. The book as a whole (compilation) cannot be reproduced, distributed or used for commercial or non-commercial purposes without INTECH's written permission.

Enquiries concerning the use of the book should be directed to INTECH rights and permissions department (permissions@intechopen.com).

Violations are liable to prosecution under the governing Copyright Law.

\section{(c) BY}

Individual chapters of this publication are distributed under the terms of the Creative Commons Attribution 3.0 Unported License which permits commercial use, distribution and reproduction of the individual chapters, provided the original author(s) and source publication are appropriately acknowledged. If so indicated, certain images may not be included under the Creative Commons license. In such cases users will need to obtain permission from the license holder to reproduce the material. More details and guidelines concerning content reuse and adaptation can be foundat http://www.intechopen.com/copyright-policy.html.

\section{Notice}

Statements and opinions expressed in the chapters are these of the individual contributors and not necessarily those of the editors or publisher. No responsibility is accepted for the accuracy of information contained in the published chapters. The publisher assumes no responsibility for any damage or injury to persons or property arising out of the use of any materials, instructions, methods or ideas contained in the book.

First published in Croatia, 2011 by INTECH d.o.o.

eBook (PDF) Published by IN TECH d.o.o.

Place and year of publication of eBook (PDF): Rijeka, 2019.

IntechOpen is the global imprint of IN TECH d.o.o.

Printed in Croatia

Legal deposit, Croatia: National and University Library in Zagreb

Additional hard and PDF copies can be obtained from orders@intechopen.com

New Knowledge in a New Era of Globalization

Edited by Piotr Pachura

p. cm.

ISBN 978-953-307-501-3

eBook (PDF) ISBN 978-953-51-5102-9 


\section{We are IntechOpen, \\ the world's leading publisher of Open Access books}

Built by scientists, for scientists

\section{$4,000+$ \\ Open access books available \\ $116,000+$ \\ International authors and editors

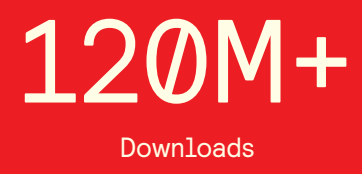

Our authors are among the

151

Countries delivered to

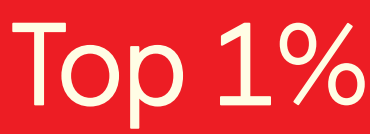

most cited scientists

Contributors from top 500 universities

$12.2 \%$

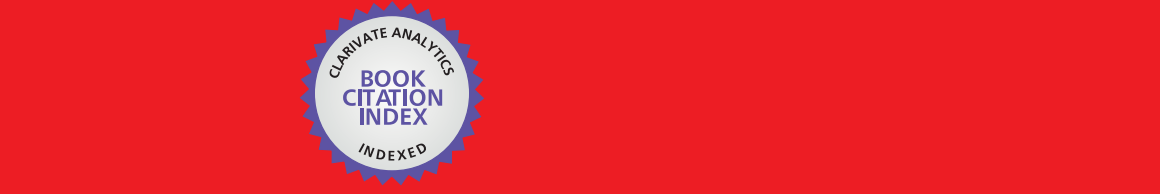

WEB OF SCIENCE ${ }^{\mathrm{M}}$

Selection of our books indexed in the Book Citation Index in Web of Science ${ }^{\mathrm{TM}}$ Core Collection (BKCI)

\section{Interested in publishing with us? \\ Contact book.department@intechopen.com}





\section{Meet the editor}

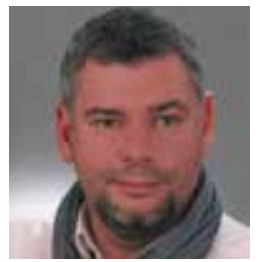

Piotr Pachura (assoc. prof. dr. hab.), European academic and scientist, the reader at Częstochowa University of Technology (Poland) and University of Presov (Slovak Rep.). Academic degrees achieved in: social science (MA), economic sicence (PhD) and geograpy (dr hab.). Consultant in regional innovation policy and practice. Author of over 80 books and articles, participant in many international research projects, originator of several scientific international journals as e.g.: Springer Journal of Innovation and Entrepreneurship: A Systems View Across Time and Space and Polish Journal of Management Sudies. Engaged in interdyscyplinary research on: network and global economy, glocalization, economic geography, theory of regional and local change and development. 



\section{Contents}

Preface XI

Part 1 Globalization and Education 1

Chapter 1 The Importance of Globalization in Higher Education $\mathbf{3}$

Patricia Fox and Stephen Hundley

Chapter 2 Globalization Creates

New Challenges in Higher Education - Two

New Educational Activities Addressing the Challenges 21

Bjoern Jaeger and Berit I. Helgheim

Chapter 3 Globalization and Higher Education in Taiwan 35

Dian-Fu Chang, Cheng-Ta Wu,

Gregory Ching, Chia-wei Tang and Lin Xiao

Chapter 4 Professional Skills: The Globalization Equalizer 49

Ronald Welch

Chapter 5 Impact of Globalization on

Indian Technical Education System $\mathbf{7 3}$

Mahadevi. S. Banad and Mahadev. Talawar

Chapter 6 How to Discover a New World

Without Being in Danger of Wreck 97

Miguel González-Carbajal Pascual and Ludmila Martínez Leyva

Chapter 7 Sport in Asia: Globalization, Glocalization, Asianization 119 Peter Horton

Part 2 Globalization and Human Being 147

Chapter 8 Simularizing Tradition and Foreign:

Osmotic Production of Justice in the Milieu

of Hong Kong Anti-Domestic Violence Law 149

Chiu Man-chung 
Chapter 9 The Impact of Globalization

Determinants and the Health of the World's Population 165

Mario J. Azevedo and Barbara H. Johnson

Chapter 10 Ups and Downs of Ethnic

Identity in the Era of Globalization

(Focusing on the Middle East Region) 183

Akbar Valadbigi and Shahab Ghobadi

Chapter 11 Fostering a "Monozukuri

(Manufacturing)" Organization

Suitable for the $21^{\text {st }}$ Century Digital Economy 199

Toshiko Asai, Hidehiko Hayashi and Akinori Minazuki

Chapter 12 Globalization and Global Public Goods 225

Bernur Açıkgöz Ersoy

Chapter 13 Building Sustainable Capacity for

Disease Diagnosis in Sub-Saharan Africa:

Case Studies of Cooperation in Diagnostic Pathology

Renato Mariani-Costantini, Khalid Dafaallah Awadelkarim,

Massimo Barberis, Claudio Clemente, Pasquale De Blasio,

Mario Di Gioacchino, Agostino Faravelli, Marco Forni,

Piergiovanni Grigolato, Lorenzo Leoncini, Karin Schuerfeld,

Ahmed Abdalla Mohamedani, Giuseppe Lattanzio,

Sandra Rosini and Vincenzo Stracca Pansa

Part 3 Globalization and Space 267

Chapter 14 Globalization in the

Brazilian Amazon Region: Conflicting

Answers from "Quilombo" Communities 269

Florent Kohler, Ludivine Eloy, François-Michel Le Tourneau,

Claire Couly, Stéphanie Nasuti, Dorothée Serges, Sophie Caillon,

Guillaume Marchand and Anna Greissing

Chapter 15 The European Model of

Agricultural Policy in the Global Context 285

Věra Bečvářová

Chapter 16 Future of Heritage - A Condition for Space Integrity $\mathbf{3 1 1}$

Lemja Chabbouh Akšamija 


\section{Preface}

To better understand the contemporary world, the world of innovation and technology, the science should try to synthesize and assimilate the social science and humanities in the development of our civilization.

Evolution of scientific research and knowledge creation show that the center of science until 17th century was located in Italy, then moved to Britain, France and Germany and finally in the 20th century to the USA (Ben-David Joseph, , Centers of Learning: Britain, France, Germany, United States, New York, MacGrow Hill 1977) 20th century relocation of centers of science can be pictured by geographical location of Nobel Prize winners in chemistry, physics and medicine.

Simultaneously, the evolution shows a transition starting with individual findings and scientific works in times when modern science was born (Newton, Galileo, Darwin, Einstein) through the beginning of the 20th century characterized by cooperation of small research teams Skłodowska and Curie - (radioactive elements), Crick and Watson (DNA structure) and finally collaboration networks. At present, a research and knowledge creation paradigm dominates based on wide collaboration networks. As it is remarked by Albert-Laszlo Barabasi (Science, Vol. 308, 29th of April 2005) modern findings and development of knowledge do not result from brilliance of an individual but from quality and nature of cooperation between units in collaboration networks. The resulting new values, ideas and discoveries originate from system's emergence.

The genesis of this book results from INTECH mission of interdisciplinarity augmentation in scholar publications. Does the new era require new knowledge? Does the age of globalization demands new education, new human attitudes? This book at least possibly tries to gauge on this questions.

The book New Knowledge in a New Era of Globalization consists of 16 chapters divided into three sections: Globalization and Education; Globalization and Human Being; Globalization and Space. The Authors of respective chapters represent great diversity of disciplines and methodological approaches as well as a variety of academic culture. This is the value of this book and this merit will be appreciated by a global community of scholars. 
XII Preface

As editor of this book I would like to express gratitude for the trust endowed by the Publisher, but most of all I would like to express my appreciation for the Authors of all chapters.

June 2011

Prof Piotr Pachura

Częstochowa, Poland 


\section{Part 1}

Globalization and Education 



\title{
The Importance of Globalization in Higher Education
}

\author{
Patricia Fox and Stephen Hundley \\ Indiana University Purdue University Indianapolis \\ United States of America
}

\section{Introduction}

Globalization is about the interconnectedness of people and businesses across the world that eventually leads to global cultural, political and economic integration. It is the ability to move and communicate easily with others all over the world in order to conduct business internationally. The word, globalization, is relatively new, coined in the late 1970's. The airplane, the telephone, and the Internet are just three inventions, which are attributable to the spread of globalization. Due to the increased demand in the high tech industry around the world, business and industry have potential for huge profits working globally. So in today's world, globalization is an important concept for students in higher education to understand and appreciate because of the demand in business and industry to hire people who can work with people of other nations and cultures and if need be can travel independently internationally to promote their business or industry. In addition, the world faces global challenges that will take interdisciplinary groups to solve these challenges; providing access to clean water for everyone on this planet and making clean renewable energy affordable just to name a few. These global challenges will need to be solved through the gathering and sharing of knowledge across disciplines, institutions, and other entities institutions on a global scale. Creating meaningful relationships that work globally is in itself challenging. In this chapter, we will look at global challenges, the makeup of model collaborative international teams; the importance of teaching globalization in higher education, how to best teach globalization, and discuss best practices in this area.

\section{Recent history of globalization}

How did our world become so global? In a book titled, The World is Flat, Thomas Friedman describes ten forces in the world that flattened the world and made it global. Those ten flatteners of the world include:

- 11/9/89 -The New Age of Creativity: When the Walls Came Down and the Windows Went Up

- 8/9/95 The New Age of Connectivity: When the Web Went Around and Netscape Went Public

- Work Flow Software

- Uploading: Harnessing the Power of Communities

- $\quad$ Outsourcing and $\mathrm{Y} 2 \mathrm{~K}$ 
- $\quad$ Offshoring: Running with Gazelles, Eating with Lions

- $\quad$ Supply Chaining --Eating Sushi in Arkansas

- Insourcing --What the Guys in the Funny Brown Shorts Are Really Doing

- In-Forming --Google, Yahoo, MSN Web Search

- $\quad$ The Steroids - Digital, Mobile, Personal and Virtual.

The first force to flatten the world was on 11/9/89, the fall of the Berlin Wall. Freidman calls this, The New Age of Creativity: When the Walls Came Down and the Windows Went Up. While the fall of the Wall liberated the Soviet citizens, it changed the balance of power towards democratic, free market government from authoritarian rule with central planned economies. In addition, there were ripple effects felt all over the world from the fall of the Wall one of those places was India. In 1991, India abolished trade controls after years of being almost bankrupt and then it started to prosper and grow all because of the fall of the Wall. Around the same time, May 22, 1990, IBM shipped Windows 3.0, a breakthrough version that made PCs easier to use. This version allowed millions of people for the first time to be authors of their own content in digital form, and share their content with others. As the Berlin Wall went down, Window went up. Freidman say, "The fall of the Berlin Wall didn't just help flatten the alternatives to free-market capitalism and unlock enormous pent-up energies for hundreds of millions of people in places like India, Brazil, China, and former Soviet Empire. It allowed us to think about the world differently - to see it as more of a seamless whole. Because the Berlin Wall was not only blocking our way; it was blocking our sight-our ability to think about the world differently - to see it more as a seamless whole" (Freidman, 2007, pg. 54).

The second flattener of the world according to Freidman was 8/9/95 The New Age of Connectivity: When the Web Went Around and Netscape Went Public. The Internet was developed by Tim Berners-Lee in 1991, a British Computer Scientist. However, the Internet alone was not enough to manage the second flattening. The Internet coupled with Netscape, which went public in 1995, was the second flattener. Netscape made the Internet accessible to almost everyone. Fifteen days after Netscape was released, Windows 95 was released as the first operating system with a built-in Internet support system (Freidman, 2007).

The third world flattener was Work Flow Software as demonstrated by a company named Wild Brain, which makes animated movies. This company has been taking advantage of the flattened world by making animated films through a global supply chain. To see how this works, look at an example of one show called, Higglytown Heroes. The recording for the show is done in New York city or Los Angeles, California. The design and direction for the show is done in San Francisco, California. The writers network with each other from Florida, London, New York, Chicago, Los Angeles, and San Francisco. While the animation characters are done in Bangalore, India with edits in San Francisco, California. All of these groups work together on a virtual private network (VPN) system. Freidman said, "When the walls went down, and then the PC and Netscape browser enabled people to connect with other people as never before, it did not take long before all these people who were connecting wanted to do more than just browse and send email, instant messages, pictures and music over this Internet platform. They wanted to shape things, design things, create things, sell things, buy things, keep track of inventories, do somebody else's taxes, and read somebody else's X-rays from half a world away (2007, pg 79.). Everything to do with computers and the Internet has transformed our lives as they are today. What is also important to note is we have evolved to where different types of computers can talk to each other over the Internet using standardized protocols that have been developed. What a drastic change from when the first personal computer went public in 1981. 
Uploading: Harnessing the Power of Communities was Freidman's fourth world flattener. Apache is an open-source web tool that allows a single server machine to host thousands of different virtual websites-music, data, text or anything. Apache proved to be an excellent product that was developed by a group of computer geeks who gave it away for free. IBM couldn't design anything better so it decided to join the group. IBM made a deal to help form a legal structure for Apache so there would be no copyright issues in using other products developed to be used with Apache. IBM's buy-in also indicated to the computer community that this new way of building software that was trustworthy and valuable. In another example, a 19 year old from Stanford and a 24 year old from New Zealand developed Firefox 1.0 as an open-source community software for free in 2004 (Freidman, 2007). Freidman said, “.... the reason, I think community-developed software is also here to stay is that while it may not be sustainable without an economic incentive at some point, as a sheer tool for making breakthroughs and spreading those breakthroughs virally, it has proved to be very powerful" (2007, pg.111).

Freidman's fifth world flatteners are Outsourcing and Y2K. By the late 1990's, good things started happening in India; first the fiber optic cable linking India and the United States was exploding and the $\mathrm{Y} 2 \mathrm{~K}$ was on the horizon for January 1, 2000. The Y2K centered on a bug in computers and their internal clocks. When computers were first built to save memory space, internal clocks had two digits for the month, two digits for the day, and two digits for the year. So the issue with $\mathrm{Y} 2 \mathrm{~K}$ was that these internal clocks would mess up the entire computer because it could not go forward to the year 2000. America and India started having a relationship in a sense that started the huge flattener because with the fiber optic cable and the Internet this created a collaborative value added sources, so that businesses could source globally to the cheapest and smartest location, thus the relationship between India and America strengthened. The $\mathrm{Y} 2 \mathrm{~K}$ computer problem was fixed by low cost Indian labor and thus also a relationship between American business and Indian IT companies had been established. Therefore, the cheaper very good Indian IT companies prospered from these two events, the fiber optic networks and Y2K. Freidman said, " ...I believe that Y2K should be a national holiday in India, a second Indian Independence Day, in addition to August 15. .... because it was India's ability to collaborate with Western companies, thanks to the interdependence created by fiber-optic networks, that really vaulted it forward and gave more Indians than ever some real freedom of choice in how, for whom and where they worked" (2007, pg.136).

Freidman's sixth flattener of the world was Offshoring: Running with Gazelles, Eating with Lions. China joined the World Trade Organization (WTO) on December 11, 2001. They agreed to follow the same global rules governing imports, exports and foreign investments that other WTO countries in the world were following. This opened China up for a huge influx of companies working inside of China. Offshoring is when a company takes a whole factory and relocates it to another country (offshore). An example of offshoring is when, a whole factory moves from Fargo, North Dakota to Canton, China where it would produce the exact same product in the same way only much cheaper. Outsourcing is unlike offshoring, which is taking just one part of a business; for example, accounts receivable and having another company perform the exact same functions for a much cheaper cost, which the original company was doing in-house and reintegrating their work back into the original company's operation. By China joining the WTO, China ultimately became a challenge to the whole world with its mass of low-wage unskilled and semi-skilled workers. Other poor countries like Malaysia, Thailand, Ireland, Mexico, Brazil and Vietnam have to compete for 
better tax breaks, subsidies, and other factors to encourage offshoring to their shores. Another problem that exists is workplace standards, lax labor laws, and low wages just to name a few. In talking about offshoring, Freidman tells a story about a friend of his who is an American-trained Chinese manager of a fuel pump factory in Beijing. Shortly after China joined the WTO, his friend posted the following proverb from Africa translated into Mandarin on the factory floor:

Every morning in Africa, a gazelle wakes up.

It knows it must run faster than the fastest lion or it will be killed.

Every morning a lion wakes up.

It knows it must outrun the slowest gazelle or it will starve to death.

It doesn't matter whether you are a lion or a gazelle.

When the sun comes up, you better start running (Freidman, 2007).

Friedman concludes by saying, ".... if Americans and Europeans want to benefit from the flattening of the world and the interconnecting of all the markets and knowledge centers, they will all have to run at least as fast as the fastest lion-and I suspect that lion will be China, and I suspect that will be pretty darn fast" (2007, pgs.150-151).

Freidman's seventh flattener was Supply-Chaining - Eating Sushi in Arkansas. Wal-Mart is undoubtedly the largest retail company in the world and it does not manufacture a single product it sells. At Wal-Mart's headquarters in Bentonville, Arkansas they have a 1.2 million square foot distribution center that has a sophisticated global supply chain. This supply chain moves 2.3 million general merchandise cartons a year down its supply chain and into its stores. As one box gets transported through the supply chain, the engineering system keeps track of it coming in, where it is needed, if it needs to be supplied again, and if it does it sends the order in all automatically. Supply chaining allows suppliers, retailers, and customers to create value by collaborating horizontally. Supply chaining also forces common standards between companies so that every process can interface with the next. These types of global supply chains have become important all over the world, the challenges are global optimization and coordination disruption prone supply with hard to predict demand. Wal-Mart is very good at redirecting its products when there is a change in demand. If demand is low in Texas then products can be redirected midstream to Indiana. What does sushi in Arkansas have to do with supply chaining? With its role as one of the ten forces that flattened the world, Wal-Mart in Bentonville, Arkansas was one of those places Thomas Friedman needed to see for himself. Freidman said, "I was thinking, Boy I would really like some sushi tonight. But where am I going to find sushi in northwest Arkansas? And even if I found it, would I want to eat it? Could you really trust eel in Arkansas? When I arrived at the Hilton near Wal-Mart's headquarters, I was stunned to see, like a mirage, a huge Japanese steak house-sushi restaurant right next door (2007, pg156). As it turned out there were three new Japanese restaurants opening soon in Bentonville. The demand for sushi in Arkansas was not an accident, it had to do with the fact that all of the suppliers of Wal-Mart had also opened up shop in Bentonville, which is now referred to as "Vendorville" (Freidman, 2007).

Freidman's eighth flattener was Insourcing- What the Guys in Funny Brown Short Are Really Doing. It seems that UPS and FedEx both are synchronizing global supply chains for small and large companies. UPS headquarters is located in Atlanta but the UPS Worldport distributions hub is located next to the Louisville International Airport, which at night is taken over by the UPS fleet of cargo jets (270 aircraft) as packages are flown all over the world, sorted, and flown back out again a few hours later. However, UPS is much more 
than just a delivery company of packages. It does much more, for example, when you send your Toshiba laptop to be fixed via UPS what actually happens is that UPS is fixing the computers at its hub in Louisville in a special clean room where UPS employees are wearing blue smocks and replacing broken motherboards in Toshiba computers and shipping them out again. They are doing the same kinds of services for other companies like Papa John's Pizza. UPS employees are driving Papa John's Pizza trucks delivering supplies to various stores. UPS does work for Nike, Jockey and HP by having warehouses of products where they can fill the orders and the orders can be shipped via UPS. This type of business started around 1996, when UPS created a whole new global business opportunity. The term "Insourcing" fits the best for this work because UPS engineers go inside a business, analyze its manufacturing, packaging, and delivery processes; and then designs, redesigns, and manages the whole global supply chain. If a company needs it, UPS will finance part of the business. Freidman says, "UPS is creating enabling platforms for anyone to take his or her business global or to vastly improve the efficiency of his or her global supply chain" (2007, pg 175).

The ninth flattener was In-Forming- Google, Yahoo, MSN Web Search. According to Freidman, In-Forming is the individual or personal analog to uploading, outsourcing, insourcing, supply-chaining, and offshoring (2007). Whether it is Google, Yahoo, or MSN Web Search, when these search engines were new, people would react with eureka moments when they found the something in a search that was really good. Now people presume they will find the data they are looking for when they are doing a search. It is staggering the amount of information that is out to be mined. In-forming also involves searching for friends, allies, and collaborators. Search engines are businesses too. Freidman said, "Everyone can now be Googled-but everyone now can also Google. Google also equalizes access to information - it has no class boundaries, few education boundaries, few linguistic boundaries, and virtually no money boundaries" (2007, pgs.184-185).

The tenth and final flattener of the world was The Steroids- Digital, Mobile, Personal, and Virtual. In this flattener there are six steroids. The first steroid has to do with computing and the computational capacities, storage capacity, and input/output capacity of computers. In 1971, the Intel 404 processor produced only 60,000 instructions per seconds. Today's processor does over 20 billion instructions per second. Not only are the chips faster they are also smaller. The second steroid is the breakthroughs in instant messaging and file sharing. The third steroid is the ability to make phone calls over the Internet. The fourth steroid is videoconferencing. The fifth steroid is the advances in computer graphics driven by computer games. The sixth steroid is the most impressive; it's the wireless technology and all the devices. Freidman said, "As a result of these steroids, engines can now talk to computers, people can talk to computers, and people can talk to computers farther, faster, more cheaply, and more easily than ever before. And as that has happened, more people from more places have started asking one another the same two questions: Can you hear me now? Can we work together now?"(2007, pg. 198-199).

\section{Global challenges}

Over the last century, amazing inventions and innovations have transformed many lives around the world, they include: the airplane; automobile; radio and television; electrification; water supply and distribution; electronics; telephony; air condition and refrigeration; highways; spacecrafts; computers; Internet; imaging; household appliances; 
health technologies; petroleum and petroleum technologies; laser and fiber optics; nuclear technologies; and high performance materials (Constable \& Somerville, 2003). None of these inventions would have been possible without mathematicians, scientists, engineers, and technologists working together. The world needs all of these professions to collaborate globally on global challenges and create the inventions that will make our lives better in the $21^{\text {st }}$ century.

Many groups have weighed in on the global challenges Scientist, Engineers, Futurist, etc. Scientist in the InterAcademy Panel, a global network of the world's science academies, a group of 70 scientist from various academies around the world, were recently polled at a conference hosted by the Royal Society in London, they listed the following in order as the global challenges for the world in 2020:
1. Climate Change
2. Food Security
3. Loss of Biodiversity
4. Water Shortages
5. Global Population
6. Education
7. Nuclear Issues
8. Pandemics
9. Ageing
10. Poverty
11. Terrorism (Highfield \& Lawton, 2010).

Engineers in the United States (U.S.) through a panel convened by the U. S. National Academy of Engineering (NAE) on the other hand have another list of Global Challenges. These are their challenges:

1. Make solar energy economical

2. Provide energy from fusion

3. Develop carbon sequestration methods

4. Manage the nitrogen cycle

5. Provide access to clean water

6. Restore and improve urban infrastructure

7. Advance health informatics

8. Engineer better medicines

9. Reverse-engineer the brain

10. Prevent nuclear terror

11. Secure cyberspace

12. Enhance virtual reality

13. Advance personalized learning

14. Engineer the tools of scientific discovery (Grand Challenges for Engineering Committee, 2008).

The Millennium Project, which is a global think tank, founded in 1996. This think tank connects international experts in universities, corporations, NGOs, UN agencies and governments all around the world. The Millennium project has list of 15 Global Challenges. Their Global Challenges, which are more extensive than the other groups, are as follows:

1. How can sustainable development be achieved for all while addressing global climate change? 
2. How can everyone have sufficient clean water without conflict?

3. How can population growth and resources be brought into balance?

4. How can genuine democracy emerge from authorization regimes?

5. How can policymaking be made more sensitive to global long-term perspectives?

6. How can the global convergence of information and communication technologies work for everyone?

7. How can ethical market economies be encouraged to help reduce the gap between rich and poor?

8. How can the threat of new and reemerging diseases and immune micro-organisms be reduced?

9. How can the capacity to decide be improved as the nature of work and institutions change?

10. How can shared values and new security strategies reduce ethnic conflicts, terrorism, and the use of weapons of mass destruction?

11. How can the changing status of women help improve the human condition?

12. How can transnational organized crime networks be stopped from becoming more powerful and sophisticated global enterprises?

13. How can growing energy demands be met safely and effectively?

14. How can scientific and technological breakthrough be accelerated to improve the human condition?

15. How can ethical considerations become more routinely incorporated into global decisions? (Glenn, Gordon \& Florescu, 2010)

If you look at all three of these global challenging lists, many of them are similar which tells us that these truly are important global challenges and they have been thought out by a number of different groups. The question is how do we solve these challenges? That is the billion dollar question.

One way to solve global challenges would be for mathematicians, scientists, engineers, and technologist all over the world to work on these global challenges together, some of that is happening now, but not to the extent that it could or should be happening. Unfortunately, in the U.S. higher education institutions are focused on becoming the best research institutions. The university's traditional rewards for faculty engaged in research are for individual accomplishments. While lip service is given to rewarding faculty who collaborate in research, collaborating doesn't get a faculty member promoted or tenured at research universities. There has been a call to change the way university's reward faculty, however, there has been no change in the way faculty are tenured and promoted. It probably will take a world crisis for America's best and brightest to realize the potential for working with others globally in a range of fields to solve the world's greatest challenges.

What would it take to educate our college students today to feel comfortable in working with any group of individuals around the world on a project? Are our university students being prepared for this type of work? The answer today would be no for a majority of undergraduate students, however, in order to accomplish this, some skills for the future need to be entrenched into higher education institutions. As an example, a recent report from the Center for the Advancement of Engineering Education (CAEE) stated that undergraduate engineering education students reported a considerable increase in intellectual growth, but reported lower personal growth and fewer opportunities to study abroad than other college students (Atman et.al, 2010). 


\section{What skills are needed to succeed in the globalized world?}

In preparing for a global career, students in their undergraduate studies should try to acquire global competencies and multicultural skills. Included in the global competencies would be workable knowledge of global leadership skills which are essential to succeed in a globalized world. If you intend to be a global leader, you should know the answers to the following questions. These questions were provided by working professionals at the IBM Corporation:

- What skills are required in a global environment?

- What to do and what not to do when leading in a global environment?

- How to identify \& tackle problems in a global team?

- How to think outside the box and use innovative \& creative ideas in a global team?

- How to leverage the assets within a global team? (Gandhi, 2009)

IBM, described as world's top provider of computer products and services, defines six competencies that global leaders should possess when managing global teams:

- The ability to leverage global assets or managing global resources effectively and efficiently.

- The ability to serve distinct global markets and seek new client opportunities.

- The ability to address with the team; who has control to make decisions, how are risks, successes, and accountabilities shared within the team.

- The ability to build collaboration within your global team through traditional methods or new collaborative tools.

- The ability to understand and manage the different specialization in the team, utilize and componentized the skills as needed.

- The ability to identify the key skills in the global team and utilize them in such a way that you get the most value from the project (Gandhi, 2009).

Gandhi goes on to indicate global team barriers that can hamper a team's development, they are: cultural differences; differences in expertise levels; geographic time zones differences; trust issues; language and communication differences; and work style differences. These are all further explained below:

- Cultural differences - There are differences in countries, educational systems, religious backgrounds, environments, and cultures. Just in the cultural differences there are differences in individual verses collective orientation which come into play too. The best way to handle this is to build a cultural awareness, and acceptance in the team.

- Differences in expertise level - The differences in expertise in a team can lead to ego issues. This is a challenge for the leader because ego problems can cause distrust issues. It is the leader's role to understand the expertise of each of the team members.

- Geographic time zones differences - The lead must consider a common time but also take into consideration cultural considerations. Allow flexible work schedules to accommodate individuals. And if needed allow for a share the pain approach so that everyone suffers equally. Always clearly communicate the acceptable time range to host a meeting. Perhaps it is not necessary for all to participate in all the meetings, make sure the right people are included in the right meetings.

- Trust issues - Leaders must build the trust in the team. The leader should have at least one face to face meeting so that everyone can meet. Introduce a break the ice type scenario so that individuals can meet and learn about each other in a relaxed atmosphere before the team starts on the project. Clearly communicate team objectives, 
team responsibilities, team member accountabilities, project timelines, risks, etc to all team members. To build trust, communication is extremely important.

- Language and communication differences- English words have different meaning in different languages so this is an area that can be extremely difficult. The use of colloquials can be very complicated in conversations. Encourage clarifications, and use a lot of pauses in communications to make sure everyone to clear.

- Work style differences- Each member of the team will have different work styles and this will reflect their culture. Even a local team of individuals will have different work styles. As long as individuals can work independently and they are aware of the project deadline, goals, risks and accountability then they can still succeed (Gandhi, 2009).

Building collaborative teams in the university setting can be simulated to some extent. Some of the tools available today that can be used to accomplish this are: WIKIs; Chat Rooms, Forums, Discussion Boards, Lotus Notes; Instant Messaging; Video Chats or Web Video Conferences; and Virtual Workspace Tools. These tools can be used to connect with one member of the global team or have a whole global team meeting. They can also be used for informal get together or so called global team coffee breaks for non work related talk or to celebrate team events (i.e., team member birthday, etc.).

\section{Identify model collaborative international teams}

Today international corporations and industries are looking for individuals who can work in a global world. International organizations have offices all over the world or may work with other organizations in order to get innovative products or services to market at the fastest possible speed. These individuals will need to know how to work successfully in international, multicultural, and interdisciplinary teams. For example, most engineering institutions produce one-disciplined technically successful skilled engineers; however, they don't all produce engineers that are capable of working outside their discipline let alone working in a global world.

Engineering can be used as an example of one of these professions where industry has emphasized the need for more soft skills from the engineering graduate, who usually graduates with a multitude of technical skills in their related field of study and very little in the way of teamwork, communication, flexibility, multidisciplinary team work, leadership, and hardly any thoughts to multicultural and global awareness.

One example of teaching multidisciplinary team skills to engineering students was conducted in Europe with a group of six European university institutions from five European countries; Denmark, Czech Republic, Poland, Portugal, and The Netherlands. This group of universities working with an industry partner in Denmark developed a summer school for engineering students, which was specifically designed to include innovation, as well as the following:

- Team- oriented Activities- Students worked collaboratively in teams to develop and engineer a product.

- Multidisciplinary Approach- Teams were composed of students with different discipline backgrounds, but whose skills, knowledge, and experiences were important to achieve the project's goal.

- Multicultural Approach -Teams were composed of students from different countries.

- Problem-based Learning -Learning was centered on students, using open assignments with several solutions possible and professors served as tutors. 
- Intensive Schedule -Students worked solely on the project because of the short three week summer term.

- Industry-oriented - Summer school takes place in an industrial setting and the assignments given to the students are closely aligned with the industry requirements (Larsen et al., 2009).

The students, who participated in the multidisciplinary, multicultural project, summer school were pleased with the course. The industry partner was very impressed with the quality of the innovative ideas, the animations and the prototypes. The faculty involved planned to improve the technical analysis from industry partners and plan to add more multidisciplinary activities in cost and marketing analysis. The most valuable outcomes of the summer school was the new ideas, recruitment potential, and inspiration that the young students' received out of the experience. There was no doubt that it was a very successful summer school (Larsen, et al., 2009). Another model program named, International Networked Teams for Engineering Design (INTEnD) program involves Michigan State University (MSU) and the University of Texas Pan American is meeting the challenges of globalization by offering collaborative, multidisciplinary, and innovative engineering education programs. The research and education program was started in 1998 by a multidisciplinary team of educators from MSU and other engineering educators from a variety of universities around the world; Technical University Deft, University of Utrecht, Eindhoven University, Kaiserslautern University, Tsinghua University, Catholic University of Leuven, St. Petersburg Technical University, Carlos III University, and Monterrey Institute of Technology and Higher Education (ITESM) (Mariasingan et al, 2007).

In addition, the University of Michigan has also added an Engineering Global Leadership Program, Global Product Development Course, and a partnership with a Chinese university, Shanghai Jiao Tong University in order to prepare their engineering students for a global career. Other engineering school's such as Purdue University created a Global engineering program in 2005, which focuses on preparing students for a global world. The University of Wisconsin- Madison has a certificate in International Engineering (Mariasingan et al, 2007). All of these changes in engineering education show that the faculty and administration in these universities are at the forefront of educating a global workforce.

Brigham Young University received a National Science Foundation (NSF) grant to implement a global virtual team's course taught concurrently with an international capstone experience in an engineering school. This course provided students with an opportunity to be in a productive cross-cultural experience in an effective manner. This course was not meant to replace face to face interaction in different cultures (study abroad opportunities) but was meant to supplement students practice in international virtual teams and to successfully use their engineering skills. The global virtual team's course increased the understanding of other cultures (Zaugg et al, 2010).

\section{Discuss the importance of teaching globalization in higher education}

In 2010 a global study entitled Attributes of a Global Engineer was performed by the American Society for Engineering Education (ASEE) and the International Federation of Engineering Education Societies (IFEES) to determine the skills and experiences that today's engineering student need to develop in school and throughout their career to successfully compete in a global workplace. ASEE's Board of Directors established the ASEE Corporate Member 
Council (CMC) to convey the ideas and views of corporations to ASEE. With over 120 corporate and non-academic institutional members, the $\mathrm{CMC}^{\prime} \mathrm{s}$ mission is to foster, encourage, and cultivate the dialogue between industry and engineering educators. Its strategic goals are:

- Diversity in engineering education

- Enhancing the K-12 educational pipeline/future workforce

- Reforming engineering education

- Collaborating on engineering research and intellectual property

- Liaison with engineering, technology, and the Society

CMC has several Special Interest Groups (SIGs), which exist to share information and advance key priorities of the CMC. The International Engineering Education SIG is the CMC sponsor of the Attributes of a Global Engineer Survey Project.

The Attributes of a Global Engineer Survey Project grew out of an expressed need by CMC members to identify and validate specific knowledge, skills, abilities, and perspectives that would be required of an engineer living and working in an increasingly global context. Specifically, the goal was to refine a list of attributes that would be applicable to engineers regardless of specialty, location, or background.

The process began in early-2008, led by the International Engineering Education SIG, and involved CMC members developing a list of competencies derived from representative job descriptions, literature reviews, and other reports. This initial list was consolidated through a series of SIG meetings and events throughout 2008 and 2009; thus, here are the attributes that emerged through this process (Hundley et al, 2011):

- $\quad$ Engineering Science Fundamentals

- Mathematics (including statistics)

- Physical and Life Sciences

- Political and Socio-economic Sciences

- Information Technology - Digital Competency

- $\quad$ Engineering

- Understanding of Design and Product Processes

- Understanding of Product Life Cycle Development

- Effective Teamwork/Common Goals

- Possess a Multi-Disciplinary, Systems Perspective

- Maintain Focus with Multiple Project Assignments

- Context in which Engineering is practiced

- Economics/Finances of Projects

- $\quad$ Basic Supplier Management Principles

- Customer and Societal Emotions and Needs

- Cultures, Languages, and Business Norms

- Societal, Economic, and Environmental Impacts of Engineering Decisions

- An International/Global Perspective

- Communication

- Written (Memos, reports, email, letters, etc.)

- Verbal (Technical \& non-technical presentations plus an effective "elevator" speech)

- Foreign Language (Technically fluent in at least two languages acknowledging English is considered a key global language) 
- Graphic (Design drawings, charts \& graphs, presentation, and basic brochure design)

- Digital Competency

- Competent at Internet Collaboration and Communication Tools (Web-based meeting tools, team rooms, teleconferencing; file sharing, E-mail, etc.)

- $\quad$ Listening

- Teamwork

- $\quad$ Active and Effective Participation in Team Efforts

- A Willingness to Respect the Opinions of Others and Support Team Decisions

- Leadership

- An Acceptable Personal Image and a Positive Personal Attitude

- Treating People with Fairness, Trust, and Respect

- Respect for Diversity

- Courtesy and Respect

- An Eagerness to Help Others

- Flexibility

- Self-Confidence to Adapt to Rapid/Continuous/Major Change

- Thinking Both Critically and Creatively - Independently and Cooperatively

- Curiosity and Desire to Learn - For Life (Show initiative, Inquire \& Learn)

- Seeking Advice and Forming Daily Questions to Discover New Insights.

- Commitment to Quality, Timeliness, and Continuous Improvement

- Understanding Basic Project and Risk Management and Continuous Improvement Concepts (like LEAN+)

- $\quad$ Ethical Standards and Professionalism

- Operate in Accordance With Acceptable Business, Societal, and Professional Norms

- Maintain the Highest Level of Integrity, Ethical Behavior, and Professional Competence

- Understand and Applies Good Personal Judgment

At the ASEE Annual Conference in 2010, SIG stakeholders attempted to translate the attributes into specific competencies that could be identified by levels of importance and proficiency at certain intervals of an individual's education and professional development. The initial list totaled 48; however, through in-person meetings at the Conference, and through bi-weekly telephone conference calls and other electronic communication, the list was ultimately synthesized and consolidated. After further review and validation from $\mathrm{CMC}$ members, a total of 20 competencies associated with the attributes of a global engineer emerged (Hundley et al., 2011). These are:

1. Demonstrates an understanding of engineering, science, and mathematics fundamentals

2. Demonstrates an understanding of political, social, and economic perspectives

3. Demonstrates an understanding of information technology, digital competency, and information literacy

4. Demonstrates an understanding of stages/phases of product lifecycle (design, prototyping, testing, production, distribution channels, supplier management, etc.)

5. Demonstrates an understanding of project planning, management, and the impacts of projects on various stakeholder groups (project team members, project sponsor, project client, end-users, etc.) 
6. Demonstrates an understanding of the ethical and business norms and applies norms effectively in a given context (organization, industry, country, etc.)

7. Communicates effectively in a variety of different ways, methods, and media (written, verbal/oral, graphic, listening, electronically, etc.)

8. Communicates effectively to both technical and non-technical audiences

9. Possesses an international/global perspective

10. Possesses fluency in at least two languages

11. Possesses the ability to think both critically and creatively

12. Possesses the ability to think both individually and cooperatively

13. Functions effectively on a team (understands team goals, contributes effectively to team work, supports team decisions, respects team members, etc.)

14. Maintains a positive self-image and possesses positive self-confidence

15. Maintains a high-level of professional competence

16. Embraces a commitment to quality principles/standards and continuous improvement

17. Embraces an interdisciplinary/multidisciplinary perspective

18. Applies personal and professional judgment in effectively making decisions and managing risks

19. Mentors or helps others accomplish goals/tasks

20. Shows initiative and demonstrates a willingness to learn

The Attributes of a Global Engineer study indicated that a majority of the respondents, 52.5\%, indicated that it was important, that an engineer functions effectively upon graduation from Tertiary/College/University on a team (understands team goals, contributes effectively to team work, supports team decisions, respects team members). As well, the same study indicated that, $48.4 \%$, indicated that it was important, that engineers possess an international/global perspective upon graduation from Tertiary/College/University. In addition, the study indicates that a majority, $53.8 \%$, indicated that it was important, that an engineer embraces an interdisciplinary/multidisciplinary perspective. This international study indicates that it is important for engineers to develop global skills while they attend Tertiary/College/University (Hundley et al, 2011).

A study by the National Academy of Engineering, The Engineer of 2020, calls for future engineers in the U.S to have complex social, global and professional skills to be successful in the future. There are a number of underlying guiding principles that lead the authors of this study to their conclusions, they are: (1) the continued pace of accelerating technological innovation; (2) the fact that technology deployed will continue to be intensely globally interconnected; (3)those affected or involved with technology will be increasingly diverse and multidisciplinary; (4) technological innovation will be shaped and affected by social, cultural, political, and economic forces; and (5) technology in everyday lives will be more seemingly transparent and more significant than it is today. Given those underlying principles the authors of the study suggested strongly that engineers of the future should have the following team skills in a global context: collaborate in a multidisciplinary and multicultural team of experts across multiple fields; have excellent communication skills with both technical and non-technical individuals; be able to communicate with technology, have an understanding for complex global markets and social context, be flexible, be receptiveness to change, and have mutual respect for everyone (Committee on the Engineer of 2020, 2004). In the past, the engineering profession use to respond as technology and society changes, but today technology is changing very rapidly and society is continually changing. We need to know how to work in a faster more global society. 


\section{Discuss the best practices in teaching globalization}

To best teach globalization, students need to experience it, so it goes without saying that university students must take advantage of studying abroad, international internships, or research opportunities abroad. Another best practice opportunity for students is to be proficient in at least one foreign language, while it is common to be proficient in several languages in Europe this is not widely practiced in the U.S. During a graduate program, students should take advantages of enrolling in foreign universities and pursuing a dual degree, especially one that has an agreement with the university you are attending. Faculty should create sustainable networks with a foreign university in education or research in order to provide their students with these options. The institution should have a formal process or framework for globalization. It might include a discussion on how will the curriculum be restructured to include globalization, what teaching methods will be best used, and/or should international interdisciplinary research centers be established. Global competencies need to be a part of every undergraduate's education and all barriers should be removed so that more work can be done on global research (Widdig \& Lohmann, 2007).

The Wharton School of Business is changing its curriculum to better prepare its graduates for a fast changing global business environment. Changes to their curriculum include several focused short term courses in the U.K., India, Brazil, China, Israel and South Africa. For example, the course in Brazil is about the environment, the one in Israel is about technology, etc. Wharton has also added courses to their curriculum in global finance, management and an increased focus in soft skills like writing, leadership and multicultural understanding (Korn, 2011). These types of curriculum changes are happening in other elite business schools as well.

In Finland, globalization is integrated in the curriculum to promote internationalization of higher education. However, specialization and depth is more important in engineering education in the United States than internationalization. In Finland, internationalization is defined through three areas: mobility, multiculturalism, and networking. The key areas for internationalization in the engineering education in Finland are through:

- $\quad$ student, teacher, and researcher mobility;

- international R\&D projects;

- development of joint and double degrees with other institutions in other countries;

- increase in foreign students and researchers in Finland;

- measures in supporting the integration of foreign students and personnel in Finland;

- development of the exportation competencies;

- enhanced study opportunities for non-native speakers and those with immigrant backgrounds; and

- more efficient use of the international organizations and cooperation arrangements (Tossavainen, 2009, p.528).

All of these key areas cover mobility, multiculturalism and networking.

Another excellent example of best practices of readying students to work in the global world has been practiced in The Georgia Institute of Technology since the late 1990's when Georgia Tech's President, Dr. G. Wayne Clough, took office in 1994. President Clough realized fast that there were a number of talented students on campus who were multi-dimensional. These students were good in music, sports or some other area and in addition these students also were interested in engineering. These students were not the 
best engineering students, these students were able to communicate, they were more socialized, they asked for help when needed, they thought horizontally, and most of all these students were able to tie things together from different disciplines and fields. These students made great engineering students because of these other qualities. Since that finding in the late 1990's, Georgia Institute of Technology started targeting a unique group of freshmen, till 50\% of the entering freshman in engineering played musical instruments, or participated in a musical group. This was so prevalent that President Clough had to build more recital and concert areas on campus. President G. Wayne Clough created a different kind of graduate. The students that graduate from the Georgia Institute of Technology in engineering are adaptable and can think across the disciplines and therefore are ready for a global flat world (Freidman, 2007).

Thomas Friedman said in his book, The World is Flat, that the one ability students should have when leaving college is the ability to, "learn how to learn - and to constantly absorb, and teach yourself, new ways of doing old things or new ways of doing new things" (2007, pg 309). Friedman goes on to say that what you know today will soon be out of date. Thus, university students need to be aware that lifelong learning is a skill that they will need to incorporate throughout their life whether it is exploring globalization or broader aspects of a specific discipline.

Recently, there has been a call in engineering education to supplement the current curriculum with globalization, team work and multi-culture learning. However, there is also a call to bring back the excitement that an engineering profession use to enjoy, especially in a world where society needs sustainable supplies of energy, water, food, and healthcare with trends toward globalization (Turner, 2010). Turner goes on to say, "The curriculum must incorporate active, engaging and relevant learning, teaching and assessment strategies to develop, self-aware, well-motivated, enterprising and independent learners" (2010, pg 36.).

Some university students learn the lessons of globalization by studying internationally. Some 3 million international students study abroad. Meaning they study at universities outside their home countries. Newly created or expanded universities in China, India, and Saudi Arabia are competing with the same students, faculty and research pre-eminence of that of Harvard and Oxford. A good example of this would be the President of King Abdullah University Science and Technology (KAUST), a brand new graduate school in Saudi Arabia. The President, who is originally from Singapore but who had a global trotting career path through Canada, United States and back to Singapore before taking the President's position in Saudi Arabia. The renowned international business school INSEAD, has campuses, in France, Singapore, Israel, and Abu Dhabi. Students study on several campuses. (Wildavsky, 2010).

Finally, there are some pragmatic strategies to facilitate, encourage, and sustain globaloriented teaching in higher education-approaches that are adaptable to a variety of disciplines and institutional contexts. These include:

- Increasing the size of the international student body population

- Increasing the size of foreign-born faculty members

- Developing or expanding partnerships with international institutions

- Providing for robust study abroad experiences of varying lengths and contexts

- Engaging students in classroom, co-curricular, and other educational activities that heighten their awareness of internationalization

- Fostering service learning, undergraduate research, and experiential education that includes an international component 
- Leveraging the partnerships of other stakeholders (e.g., alumni, business/industry organizations, professional associations and societies, community members) to provide a platform for students to participate in international learning opportunities.

\section{Conclusion}

By 2025, internationalization will have sharpened the hierarchy in world higher education, with a handful of university "transnational corporations" in the highest tier alongside private firms and local community college-style institutions in the lowest. This is one of the predictions made by Felix Maringe, Senior Lecturer in education at the University of Southhampton and Nick Foskett, Vice Chancellor of Keele University in a book they edited titled, Globalization and Internationalization in Higher Education. So while there is a concern of just how to teach globalization in higher education, there is also a big push for universities to go global (Morgan, 2010). Vice Chancellor Foskett says that the key theme of the book is the failure of universities to understand higher education internationalization in the context of the globalization of the world economy, rather than as a simple recruitment of international students. The book indicates that internationalization will be innate for universities at the top of the tier through crosscultural programs, overseas campuses or distance learning (Morgan, 2010). This is only one small solution for globalizing students.

In the world today, there are over 1 billion people who don't have adequate supplies of clean water, countless who don't have access to medical care, millions who live without enough to eat. We live in a world that is more interconnected and more vulnerable than ever before. Infectious diseases can be transmitted easily across countries because we are so mobile. The grand challenges, no matter what group they are hailed from, in this century are huge. The young people, who are in universities and colleges, are the ones that can work towards solving these grand challenges, but it is the responsibility of those teaching these students to make sure they are equipped with right set of skills to make sure they are able to work with multicultural multidisciplinary teams to solve the problems that face the world. In pursing the grand challenges of the century, the world is much smaller and more inclusive and more connected. The challenges of the century are not that of isolated locales but of the planet as a whole. Therefore, globalization of education must be a necessary part of higher education. Business and engineering schools alike in the United States have added or are considering globalization as an important addition to a student's higher education package. Globalization is already an important part of European education. Globalization is not a passing phenomenon. It is here to stay. Universities and colleges throughout the world need to recognize that every student needs to have global skills.

\section{References}

Atman, C.J., Sheppard, S.D., Turns, J., Adams, R. S., Fleming, L.N., Stevens, R. Streveler, R.A., Smith, K.A., Miller, R. L., Leifer, L.J., Yasuhara, K., \& Lund, D. (2010). Enabling Engineering Student Success: The Final Report for the Center for the Advancement of Engineering Education. Morgan \&Claypool Publishers. 
Constable, G., \& Somerville, B. (2003). A Century of Innovation: Twenty Engineering Achievements That Transformed Our Lives. John Henry Press, Washington, D.C.

Committee on the Engineer of 2020. (2004). The Engineer of 2020:Visions of Engineering in the New Century. The National Academies Press. Washington, D.C.

Freidman, T. (2007). The World is Flat. Picadorusa. New York, NY.

Gandhi, L. (2009). Breaking the Ice: Cutting through Geographic, Cultural, and Time Zone Barriers to Effectively Lead in a Global Environment. American Society for Engineering Education, AC 2009-694.

Glenn, J. C, Gordon, T.J. \& Florescu, E. (2010). 2010 State of the Future (The Millennium Project), ISBN: 978-0-9818941-3-3.

Grand Challenges for Engineering Committee. (2008). Grand Challenges for Engineering. National Academy of Engineering. Published by the National Academies of Engineering.

Highfield, R., \& Lawton, G. (April 14, 2010). Global Challenges: What the World's Scientist Say, NewScientist Magazine. Magazine Issue 2756.

Hundley, S., Brown, L., Jacob, A., Fox, P., Didon, K., Sayre, D., \& Hoyer, H (2011). Attributes of a Global Engineer: Results of a Work-in-Progress International Survey. American Society for Engineering Education. AC 2011-205.

Korn, M. (February 3, 2011). Business Education: As World Turns, Wharton Adapts. Wall Street Journal (Eastern Edition). New York, N.Y.pg.9.

Larsen, P.G., Fernadez, J.M., Habel, J.M., Lehrskov, H., Voc, R.J.C., Wallington, O. \& Zidek, J. (2009). A multidisciplinary engineering summer school in an industrial setting. European Journal of Engineering Education. Vol.34, No.6, December 2009, 511-526.

Mariasingam, M., Couter, S., Smith, T., \& Moses, G., (2007). Globalization and Engineering Education for 2020. American Society for Engineering Education. AC 2007-2962.

Morgan, J. (September 30, 2010). Face of higher education to change forever in 15 years. The Times Higher Education Supplement. TSL Education Limited. Issue 1967. pg 12.

Sterling, B. (July 17, 2010). Futurist ponder planet, avoid despairing, In: Beyond The Beyond. Wired. Com. Just another WordPress Weblog, Date of access, March 10, 2011, Available from:

(http://www.wired.com/beyond_the_beyond/2010/07/futurists-ponderplanet-avoid-despairing/)

Tossavainen, P.J. (2009). Institutionalising internationalization strategies in engineering education. European Journal of Engineering Education. Vol. 34, No.6, December 2009, 527-543.

Turner, J.D. (2010). Putting the world back in working order. The Times Higher Education Supplement. London. April 29, 2010, Issue 1945: pg 36.

Wildavsky, B. (2010). The Great Brain Race. Princeton University Press., Princeton, New Jersey. ISBN 978-0-691-14689-8. 
Widdig, B., \& Lohmann, J. (2007). Educating Engineers for the Global Workforce. American Society for Engineering Education. AC 2007-854.

Zaugg, H., Davies, R., Parkinson, A. R., Magleby, S.P., Jensen, G., \& Ball, A.B. (2010). American Society for Engineering Education. AC 2011-291. 


\title{
Globalization Creates New Challenges in Higher Education - Two New Educational Activities Addressing the Challenges
}

\author{
Bjoern Jaeger ${ }^{1,2}$ and Berit I. Helgheim ${ }^{1}$ \\ ${ }^{1}$ Molde University College \\ ${ }^{2}$ Curtin University, Perth \\ ${ }^{1}$ Norway \\ ${ }^{2}$ Australia
}

\section{Introduction}

This chapter explores how educational institutions are faced with changes in the modern global business environment, and how this leads to a need for changes in curricula for universities in general and for business schools and information systems (IS) schools in particular. Most of academia still uses a strict disciplinary model of education resulting in a high degree of specialization within each discipline, while modern business environments require knowledge workers who can address problems that cut across disciplines on an increasingly global scale. Both researchers and governments observing this trend have called for a change in higher education over the last decade. Although suggestions vary for what such a change should encompass, all agree that there is a need to increase the focus on the following three topics: (1) globalization, (2) collaborative skills and (3) information literacy. How to incorporate these topics into curricula has been a subject of debate and this is still an open question, but it is clear that especially topics 2) and 3) need to be based on students' experience and training instead of typical classroom lectures. We take a practical approach by introducing two new multinational educational activities to develop skills related to the three topics of globalization, collaborative skills and information literacy. Activity 1 is global supply chain management using an ERP system and Activity 2 is a Virtual Team Role Play using virtual world software. Results from several pilot studies using these techniques in two universities in Norway and Australia are discussed.

\section{Globalization creates new challenges for business and IS schools}

The development of the world economy over the last decades has been strongly influenced by the increase in international trade. According to the World Trade Organization (WTO), the yearly growth rate in international trade from 1960 to 2008 was around 6\%, which is higher than the world gross domestic product (GDP) growth rate of around $4 \%$. The latest numbers from WTO show an accelerating trend with a global trade rate expected to reach 13.5\% in 2011 (Economic Times, 2010). WTO statistics also show a shift in trade patterns among geographical areas. For example, the export rate for the least developed countries 
shows an average growth rate of more than $20 \%$ over the $2000-2008$ period, out-performing the global trends in the world trade rate of $12 \%$ growth, and in 2009 China overtook Germany as the lead exporter of merchandise, with the United States in third position. This evolution of global trade affects not only companies and countries but also the competencies needed to work in the increasingly international business environment. Competencies are defined here as a combination of theoretical knowledge and practical skills. A discussion of competencies can be found in Eurydice (2002). Universities have a long tradition in providing theoretical knowledge with a curriculum typically organized around disciplines such as accounting, marketing, operations management and organizational theory for business schools, while for IS schools typical disciplines are: data and information management, systems analysis and design, project management, and IS strategy, management, and acquisition (Topi, 2010). In this chapter we argue for adding a relatively small amount of practical skills to the curriculum in both business and IS schools. The addendum is a cross-functional approach where the practical operations performed by students are organized by the instructors according to established theories previously covered in the curriculum. This can be seen as a practical and extended variation of the capstone course principle used in many business schools, where capstone courses are used to integrate materials from different topics (Rajkumar, 2007). We do not make an explicit link between the practical topics and the previously theoretical knowledge. It is up to the student to make this connection. Our idea is that any graduate student should be able to complete the practical assignments, but the more of the foundation theory the student knows the more valuable the practical skill part will be. This is also why we target the postgraduate level, since postgraduate students are better equipped with foundation theory than undergraduates. Our aim is to combine practice and knowledge in a manner that will give students relevant job competencies.

As mentioned, the literature and investigations point in particular to three topics that should be addressed more by academia: (1) globalization, (2) collaborative skills and (3) information literacy. We discuss the skills required in general for each of these before turning to the two new activities.

\subsection{Globalization skills}

We define globalization skills as skills that give the ability to work in an international context, to see the big picture and understand how an organization works as a whole. More specifically, we use globalization in a business context related to worldwide buying and selling of goods and services. Information systems allow organizations around the world to communicate as if they were geographically collocated. Physical distance becomes less significant, organizations can broaden their supplier and customer bases to buy, transport, store, manufacture, sell and distribute products and services in a single worldwide market. Our aim is to give students a set of practical assignments that illustrate how this can typically be done by many businesses and, as an extension of this, how the global outlook opens new possibilities.

\subsection{Collaborative skills}

We define collaborative skills as the skills that give the ability to function as an effective part of a team where one understands one's own role as well as the roles of others for a common purpose or benefit. Collaborative skills are the specific ways in which actors are 
expected to behave in order to comply with norms. Having collaborative skills mean one can work together with others to achieve a goal. In principle, these could be skills for playing in an orchestra in order to reach the goal of giving a good performance. In our case, we relate this to business norms and skills for reaching business goals. Our activities make use of collaborative skills at two management levels: first at the operational level in Activity 1 when students do business transactions by exchanging formal documents like purchase orders and invoices with the goal of completing a specific sales transaction. Relevant skills are how to operate an ERP system in order to complete the business process. Second, at the tactical level, in Activity 2 a complex interaction takes place when sales and purchasing teams negotiate with the goal of closing the sale of a sophisticated product. Relevant skills are related to behavior that supports concepts like trust, sharing, belonging and respect.

\subsection{Skills related to information literacy}

We define information literacy skills as skills that give the ability to determine what information is needed, where to find it, how to get it and how to use it. Again this is from a business perspective.

The remainder of this chapter describes two particular activities that address the need for an approach to business and IS education that focuses on the ability to synthesize several techniques, giving experience to deal with various situations that one could not handle by depending on a single theory (e-Skills Demand, 2009; Harvard, 2008; Topi, 2010). We provide this by suggesting the two new educational activities 1) Global Supply Chain Management using ERP systems and 2) Virtual Team Role Play using Virtual Worlds.

\section{Activity 1: Global Supply Chain Management using ERP-systems}

The first new activity focuses on teaching Global Supply Chain Management concepts by letting students run an international value chain in cooperation with students at another university using a real ERP system provided by SAP. The demand-driven global supply chain business process role play was developed for students to collaborate in pairs to perform various purchasing and sales operations. The global supply chain shown in Figure 1 was used. This is a supply chain network for trading bikes with customer demand represented by the End Customer Demand. Molde Bike Shop does not carry any inventory, and when they receive a customer order this triggers the different operations in the supply

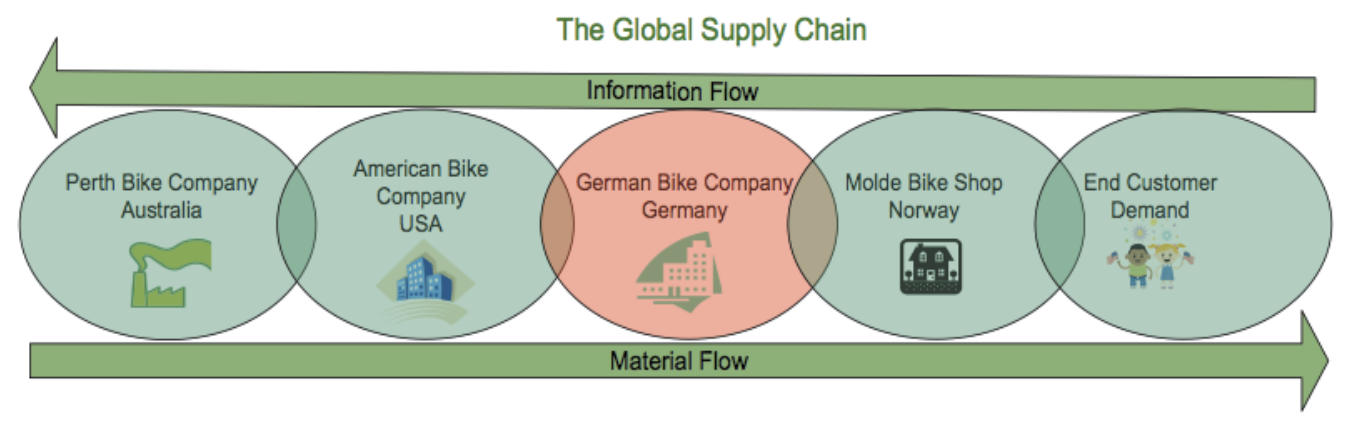

Fig. 1. Setup of the Global Supply Chain used in the SAP exercises 
chain. Molde Bike Shop sends an order to the German Bike Company, which builds a purchase order to their US supplier, the American Bike Company, which finally buys the bikes from its Australian vendor, the Perth Bike Company. The scenario played by the students is a situation where the end customer market is increasing for the particular bike product, Kids Bike, with the unique characteristic of high quality at a low price. In order to stick to the low price high quality strategy, we assume the partners have agreed to optimize the information and material flow along the supply chain. A common goal for the partners is not to carry any finished product inventory that ties capital to inventory along the chain. All partners deliver based on an incoming order.

The Perth Bike Company Australia is a fictive company that is assumed to be operated by the Australian student whose main task is to play the American Bike Company USA role. The partner, being a Norwegian student, plays the German Bike Company Germany role. The teachers play the fictive Molde Bike Shop Norway which we assume receives the End Customer Demand, and start the operation of the chain by generating purchase orders. Each role is described. For example, the role played by the Australian student in the first round is as Head of the Logistics Department in the American Bike Company, located in the US. The customer is the German Bike Company located in Germany, which means that the student must export the product from the US to Germany. The vendor is the Bike Company located in Perth, Australia. Thus the student needs to import from this company. Further, since the Head of Logistics wants to look for possibilities to decrease costs, the student is asked to run both the purchasing and selling processes. The other roles were given a similar description. Communications between the companies in the form of incoming customer order, invoicing, purchase order, invoice payment and acknowledgement are effected via e-mail external to SAP. Each company does its internal business processes in SAP. The SAP exercises consist of three main parts: initial setup of master data, procurement by doing Material Management (MM), and fulfillment of sales by doing Sales and Distribution (SD).

\subsection{Import, export and customs handling}

The SAP hands-on exercises for operating the Global Supply Chain included handling of all import and export operations. The SAP operative cockpit (SAP Cockpit, 2008) was used to guide the management of the inbound business processes (procurement, import). The cockpit shows whether replies from the customs authorities are received for any messages sent, and it keeps track of whether any follow-up actions are needed. Similarly, in the monitoring of the outbound business processes (sales, export), the cockpit was used to report status with regard to communication with the customs authorities, and of replies from the authorities or indications of business processes that need to be executed.

\subsection{Evaluation}

Activity 1 has been run three times; a pilot run and two full scale runs, in three teaching periods (February-April) in years 2009, 2010 and 2011. To evaluate the activity we used two methods; a questionnaire to measure the students' perceived knowledge gain, and discussions with lecturers at both campuses to get their perceptions and experiences. The questionnaire used was a modified version of a questionnaire developed by Seethamraju (2007) to study the design and instructional strategies in the delivery of ERP/SAP courses. It contained five knowledge dimensions: General Background, Business Knowledge, Process Knowledge, SAP Transaction Skills and Global Business Knowledge (in the questionnaire, 
Global Business Knowledge included questions on both theoretical knowledge and practical skills). The students were asked at the end of the course to report on both pre-course and post-course knowledge and skills by entering a number on a 5-point Likert scale (1 lowest, 5 highest). The responses for the Global Business Knowledge dimension from the study in 2010 were:

\begin{tabular}{|l|l|l||l|l|l|}
\hline Australia & \multicolumn{2}{||l|}{ Norway } \\
\hline Pre-Avg & Post-Avg & Difference & Pre-Avg & Post-Avg & Difference \\
\hline 3.04 & 5.05 & 2.01 & 2.00 & 5.00 & 3.00 \\
\hline
\end{tabular}

Table 1. 2010 Mean Scores of Pre- and Post-Survey for Australian and Norwegian students for the Global Business Knowledge dimension.

Both the Australian and the Norwegian students reported a perceived gain in global business knowledge with Norwegians reporting a somewhat higher gain than Australians. This may be a result of the particular cohort in Australia consisting of students in Information Systems while the Norwegians were students in Supply Chain Management/Logistics. As a result, the Norwegian students had a theoretical foundation with a closer match to the practical business operations that could explain the higher gain. Future studies will investigate this further. All results on the other knowledge domains from the pilot study in 2009 and the full study in 2010 can be found in our paper (Jaeger, 2011). Generally, the students reported an increase in competence for all the knowledge dimensions. Some students did a similar set of exercises locally with intra-university partners. Observations from the lecturers were that those students who participated in the international role play exercise performed better and showed better understanding of the transactional aspects of the sales order processing, while those working locally had some issues with the clarity of these concepts. Reasons may be that those working with international partners spent much more time with their exercises. They had to wait for their partners to post documents such as invoices and purchase orders for transactions. Having experienced being in another time zone, students had to work on their own to figure out how to organize their work better to avoid or reduce problems. The time lag, not wanted in a real business environment, became an advantage in the educational setting since it allowed students to reflect more upon the problem at hand, and since the separation of tasks enforced by the distributed operations helped to clarify the processes. The lecturers affirm the valuable experience gained on how the exercises were set up, the actual contents and the overall learning experience encountered by all parties.

\subsection{Relation to skills in globalization, collaboration and information literacy}

We illustrate how students acquire skills related to globalization, collaboration and information literacy by relating these topics to the description below of the build-up of the assignment for the sales process and the steps the students must carry out. The purchasing process follows exactly the same setup so we do not describe the details here.

Figure 2 shows the basic steps of the sales process, assuming a sell-from-stock strategy. The five steps cover the business cycle from sales order to receiving cash: first a sales order is created, then a delivery note is created before doing picking and packing followed by the shipment of the goods. The two last steps create an invoice and receive the payment. The students run sales processes first in a local environment in various ways as described below. By this they get experience in running the sales process itself. Then the students operate the sales process as part of the global supply chain. 


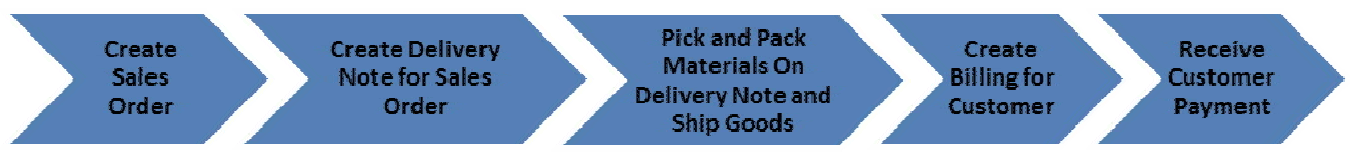

Fig. 2. The main steps of the sales process

Figure 2 is a simple figure capturing the basic steps of the sales process. However, it is a deceptively simple figure. When we add details it becomes more complex. In the assignments, students first run this process as a manual paper-based process using five documents, as shown in Figure 3.
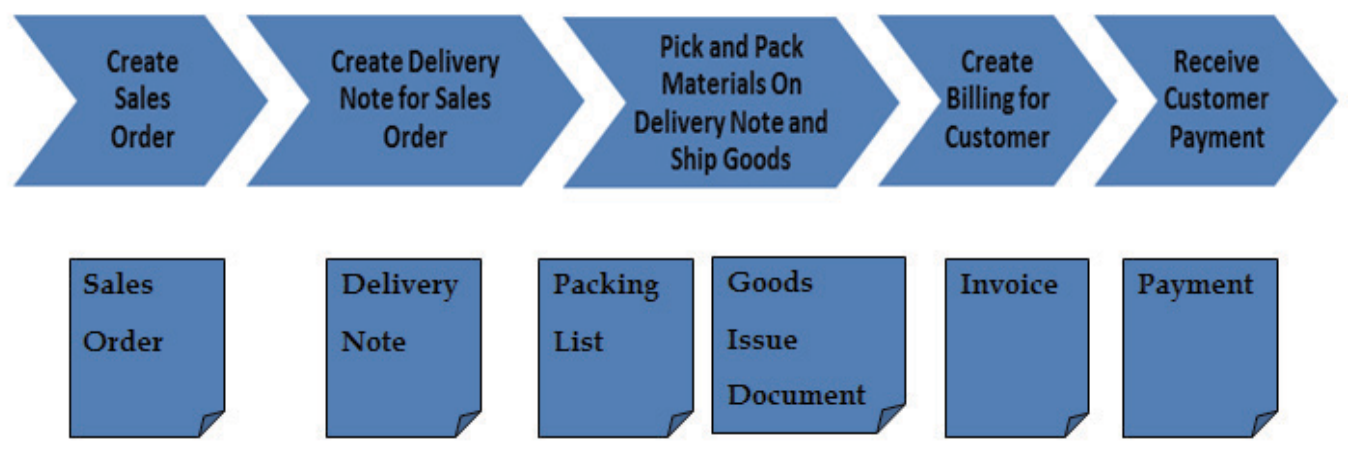

\section{Sales \\ Department}

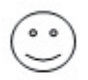

Warehouse

Department

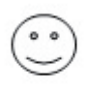

Accounting
Department

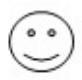

Fig. 3. Adding paper documents to run a manual sales process and typical departments involved

In a company the sales process would typically be handled by several persons in various departments, like a sales manager, a warehouse manager and an accountant: the Sales department create the Sales Order, the Warehouse the delivery note, picking and packing and shipment of goods, and lastly the Accounting Department performs the two last steps, creating an invoice and receiving the payment. The students had to play these roles filling in information by hand in each document.

Next the students run the complete sales process again, now by using the SAP ERP system playing the roles of first the sales manager, then the warehouse manager and at last the accountant. The major elements of the information flow in and out of the ERP system is illustrated in Figure 4. In step 1 the student retrieves information from the ERP system regarding the products to be entered into the sales order. Other data such as date and the person filling out the sales order are also retrieved. This is master data in the ERP system previously configured by the students in another exercise. The students enter the remaining information required to create a new sales order, typically customer details and the set of sales order lines, one for each product ordered with details of the product. The total 
information for the sales order consists of 19 data items. In step 2 the students must retrieve information from the ERP system regarding the previously created sales order to create a Delivery Note. Information for the new Delivery Note is inserted. Likewise, information is retrieved and entered into the ERP system to complete the remaining steps. By doing this the students get a hands on experience in following the information flow across the departments involved. This is a unique experience possible in an educational context since in a typical job situation in a real business each employee will only be allowed to operate the parts of the process that belongs to the responsibility of the employee in the specific department where he or she is employed.

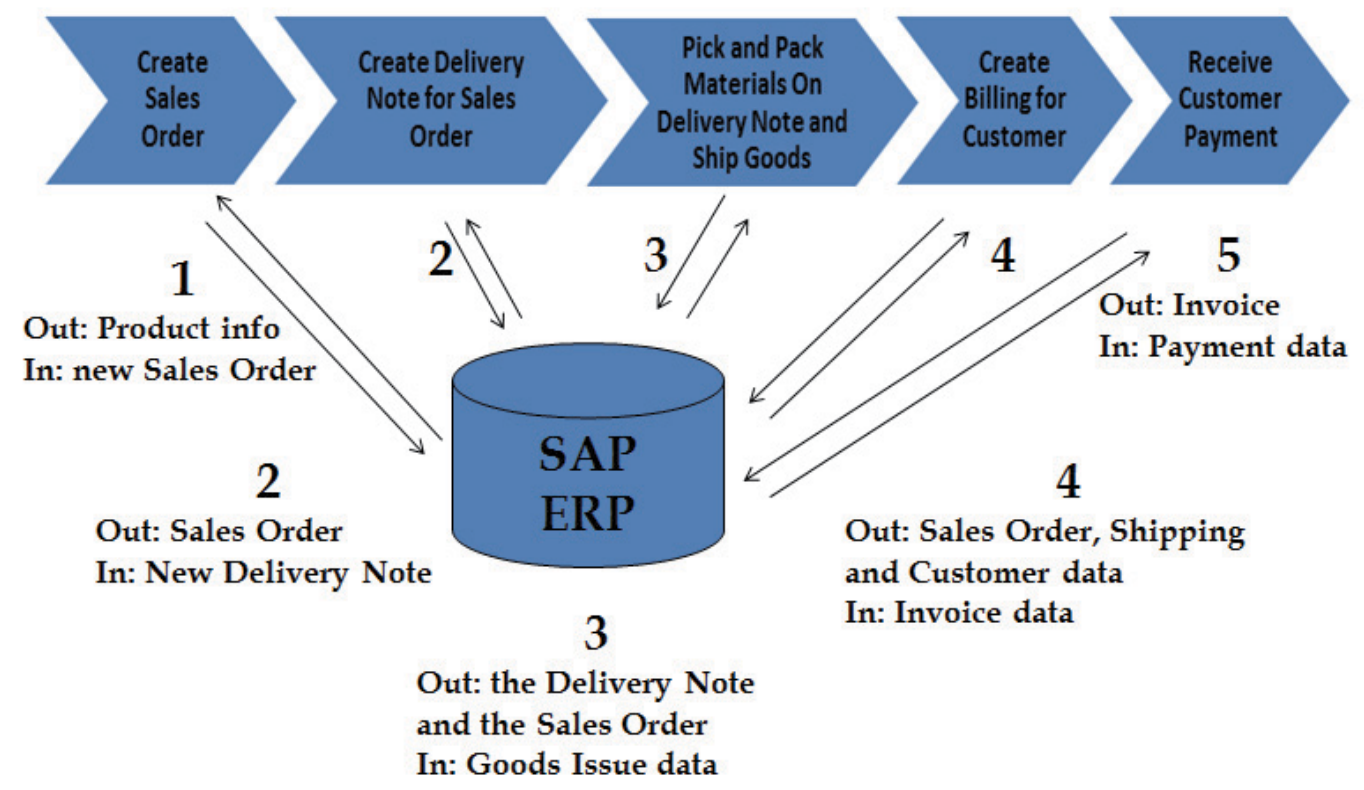

Fig. 4. Information flow in and out of the ERP-system when running the Sales Process using the SAP ERP system

The purchasing process, following a purchase-to-stock strategy, is introduced in exactly the same manner as the sales process for all students: first as a paper-based process where each student fills in paper documents, then by using the SAP ERP system to run the purchasing process. Also for purchasing each student does the job for employees in all departments when using the ERP system. That is the purchasing department, the warehouse department and the accounting department giving experience in following the information flow across the departments involved.

After the students have gained some experience in running the basic steps of the sales process as described, the students start to operate the process as part of the global supply chain adding hands on operations of export and import using the SAP cockpit. This gives experience in following the information flow across companies operating in different countries.

To do this each student is assigned a fellow student in a class at the partner university acting as a customer. The student playing the customer at the other university runs the purchasing process of the company buying (importing) the goods sold (exported) as 
illustrated in Figure 5. Both companies A and B use the SAP cockpit to support their export and import processes. The business-to-business messages are exchanged via e-mail between the companies. The "Order" in Figure 5 is a purchase order created by company A, and inserted in an e-mail that is sent to company B who based on this creates a sales order. The dotted line represents a presumed delivery of the goods ordered. Using an e-mail in the exercises simulates this. An Invoice is created in the ERP system, and sent via e-mail. Company A pays the Invoice after verifying that the purchase order, the goods receipt and the Invoice corresponds to each other. The payment is inserted in Accounts Payable in the Financial Accounting part of the ERP system. The transfer of payment usually handled by a bank transfer is simulated by an e-mail to company B who, upon receiving the e-mail, updates the Accounts Receivable in the Financial Accounting module.
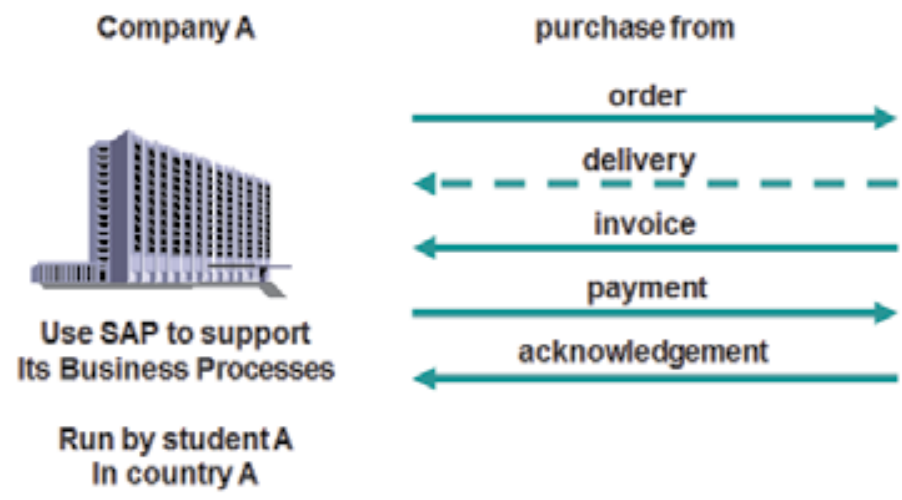

Company B

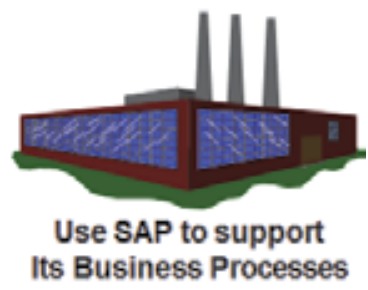

Run by student $B$ In country B

Fig. 5. Business-to-business communication between two companies in two countries. Company A runs the purchasing process, buying (import) from company B who runs the sales process (export).

Returning to the Global Supply Chain displayed in Figure 1, we let company A be the American Bike Company located in the USA and the German Bike Company located in Germany as described above. Note that in the Global Supply Chain each student is part of a chain, and so has to do both sales (export) and procurement (import) exercises with their respective partners. This gives experience in following the information flow across several departments within the company and the related information for operating between countries.

\subsubsection{Globalization skills}

Running the paper-based process illustrated in Figure 3 shows in a clear and explicit manner the tedious work involved in a paper-based process. A student has to fill in and deliver each document he or she is responsible for and send or give it to the next student, who is responsible for another department. For this to happen in a smooth manner, they must be geographically collocated.

Introducing the ERP system in Figure 4 gets rid of the paperwork, and most importantly: the various departments can be geographically distributed; the physical distance becomes irrelevant regarding when the information is available for the next step in the process. Once a student has entered e.g. a sales order into the system, others get this information 
immediately. At this stage, the students should draw parallels to their theoretical knowledge obtained in previous classes in accounting, marketing, operations management, IS strategy, management, and acquisition. For example, using the ERP system to decouple the process from geographical locations shows how companies can outsource and offshore parts of their operation in an efficient manner. By experiencing how the ERP system makes information immediately available, they will understand that this can be an advantage for other business operations like transport, payment handling, integration with the customs authorities, and several others. Being responsible for the sales (export) and purchasing (import) processes in a company in the supply chain in Figure 1 demonstrates several issues and details when performing international transactions supported by an ERP system. This includes currency conversions, time and location adoption, consolidation across diverse accounting standards, multilingual facilities, legal control, and import-export issues. This lets the students experience how information flows along the chain, and by comparing commercial information like price and availability along the chain, they get a real experience of seeing how the price increases along the chain, for example. By using the ERP system students also get an understanding of how information exchange with authorities can be done in an efficient way and even automated for standard operation according to trade agreements. This applies in particular for students who have had classes in international business from which they should be able to draw parallels with their theoretical knowledge.

\subsubsection{Collaborative skills}

This activity makes use of collaborative skills at the operational level when students do business transactions by exchanging formal documents like purchase orders and invoices with the goal of completing a specific sales transaction. Relevant skills are how to operate an ERP system in order to complete the business process within a company across departments, and further how to collaborate with business partners (customers and suppliers) by exchanging orders and formal business messages. The communication can be said to be primarily transaction oriented: communicating information that is formal, precise, structured, and in an asynchronous manner. It is asynchronous in the sense that a response to, for example, a purchase requisition that is sent to the purchase manager via the ERP system is not expected to be responded to immediately. Each student plays the role of all departments involved in the business processes of the company the student represents; i.e. the Warehouse, Sales, Purchasing and Accounting Departments. In this way the student will get to know how his responsibility relates to the responsibility of others later on when entering a specific job in a specific department. By exchanging business messages with international partners, the students experience operating across different time zones, across different native languages with different national and international trade rules for import and export.

\subsubsection{Information literacy skills}

For this activity information literacy skills are mainly related to hands-on operation of the SAP ERP system. The student needs to log in, look up data, create master data, and perform sales and purchasing transactions, etc., by using the ERP system as illustrated in Figure 4. Skills in using other tools like word processing, e-mail and the Learning Management System to download and hand in their assignments are also required. 


\section{Activity 2: Virtual team role play using virtual worlds}

This work describes the use of a virtual world environment to facilitate a role play assignment for buying and selling Enterprise System solutions in a distributed environment. The exercise involved the use of Second Life to facilitate the virtual presentation and meeting among vendors and a purchaser of an Enterprise System. Students from Molde University College in Norway and Curtin University of Technology in Australia participate in a procurement role play involving presentations and negotiations in Second Life. This is incorporated into information systems and business classes at both universities.

Students playing sellers and purchasers were organized into teams who meet, collaborate, and negotiate business transactions in the virtual environment. In the role play a combination of open ended play and manuscript were used, letting the students fill in open parts. The students were exposed to practical experience of selling and buying ERP systems and also in operating virtual world software for business purposes. Using virtual world software like Second Life provides the students with a tool to work in an international context. Second Life, being an Internet-based virtual world, uses an avatar as the primary interaction object to represent a user. The users of Second Life can be distributed all over the world as long as they have an Internet connection. Real-time interaction is done through text, voice chatting and embedded video tools. An avatar has human characteristics, including speech and facial expressions which enables transfer of expressions in the affective domain making Second Life a suitable medium for conducting role play.

Other technology such as video conferencing is a common technology used for distance education. However, video conferencing does not support the concept of a common place to meet and interact when each participant is in a separate geographical location. Typically, the video conferencing environment facing each participant is a screen of "talking heads", each with a different background. Making efficient team presentations, performing negotiations, showing group membership and coordinating activities are difficult and ineffective in a video conferencing environment when all participants are distributed in separate places.

Virtual worlds, on the other hand, offer a common place to meet. The participants express team membership by grouping themselves together in much the same way as in real life. Analyst firm Gartner Inc (2009), commenting on the future use of virtual worlds, says: "Looking at real benefit, rather than the hyped expectations, we see a number of potentially transformational technologies that will hit the mainstream in less than five years, including Web 2.0, cloud computing, Internet TV, virtual worlds and service-oriented architecture". In year 2010 Gartner selected nTeams as that year's cool vendor. nTeams is the publisher of an enterprise virtual world solution built on top of Second Life that is designed to help widely distributed teams collaborate.

The role play in activity 2 is called Response to Request-For-Proposal for an ERP system. It has been frequently used in classes worldwide for addressing the complex issue of buying an ERP system, as described in the text book by Mary Sumner (2005). The context of the role play is a fictional mid-sized manufacturing company, Wingate Electric, which has a set of computer applications handling their information management needs. Their applications have become fragmented over time and costly to operate and maintain, and consequently the company considers buying a new ERP system to solve these problems. The company develops a request-for-proposal that describes their needs of a new system. There are three competing ERP vendors who respond to the request-for-proposal; SAP, Microsoft and Oracle. After a presentation by each vendor, Wingate Electric goes through a decision 
process to decide upon a system. During the preparation each sales team conducts a literature search together with additional activities to gather information, while the purchasing team has to set up a score matrix based on a set of selection criteria from the request proposal, and a scoring method for evaluation of alternative ERP systems. Each sales team develops a sales presentation which is made to the purchasing team, who ask questions and use the score card to record their marks. When all the sales teams have completed their presentations the purchasing team provides feedback to each sales team before announcing the winning ERP vendor.

A class using the role play can be organized into several sets of teams in many ways. As an example, one way to organize it is to have one sales team with four members for each of the three vendors (i.e. 12 students), and one purchasing team with four members representing a panel of managers from the buying company, Wingate Electric (4 students). In this way 16 students participate in each such set. The number of teams and the number of participants in each team can easily be adjusted by adding or deleting vendors and roles.

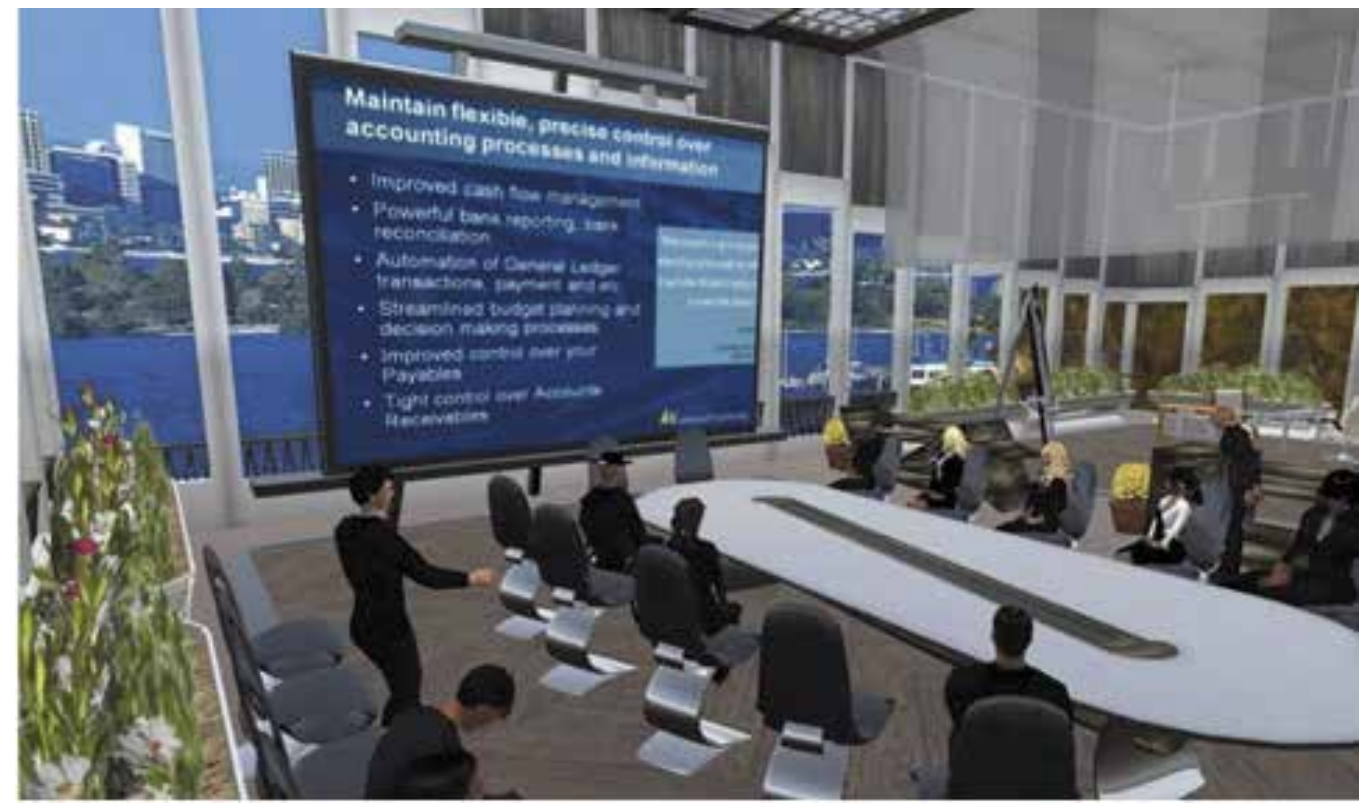

Fig. 6. Virtual meeting room for sales presentations. The Microsoft Dynamics ERP vendor is presenting their solution for the Wingate Electric purchasing team. Each participant is at a separate geographic location.

In Figure 6 all participants are at different geographic locations connected to the virtual meeting room in Second Life through a PC running Second Life. The sessions in Second Life can easily be recorded for students to review their performance and for instructors to provide feedback. The role play has been run regularly in Second Life for the last four years. Students from one class in Molde, Norway and one class in Perth, Australia participated in the same role play, forming true virtual teams. In order to make the role play as realistic as possible, the students were asked to familiarize themselves with the business etiquette and code of conduct required in business dealings and negotiations. This includes requiring avatars to have a formal dress code in a typical executive style aligned with the real world 
environment. The students in Norway and Australia did not know each other beforehand which made the virtual team role play more realistic.

\subsection{Evaluation}

Activity 2 has been run a number of times, of which three were among students at the two universities in Australia and Norway in the years 2009, 2010 and 2011. To evaluate the activity we used a qualitative approach combining three methods. A questionnaire with both numbered answer alternatives and open-ended questions was used to get an impression of student reflections on using Second Life for the role play. The second method was discussions with students and teachers at both campuses to get their view, and the third method was the use of playback of recorded sessions in Second Life to facilitate analysis of the sessions and to give feedback to students in a debriefing session. The questions were related to i) the impression of using Second Life for doing the Virtual Team Role Play and its potential for a real business situation, ii) the level of presence felt with the other geographically distributed participants, and iii) the amount of workload experienced compared with similar on-campus role plays. The results in the two countries were nearly identical. For topic i) the results showed that the students considered the role play as useful and that it could be used by real businesses. For ii) the students perceived that they got a feeling of presence, and for iii) they considered the amount of work required for the role play in Second Life as about the same or less than performing the role play at campus. A detailed presentation of the results is presented in our paper (Rudra, 2011).

\subsection{Our suggestion relates to skills in the three topics as follows 4.2.1 Globalization skills}

The students participated in activities that introduced them to a collaborative tool to do negotiations in a distributed environment. These students had to organize themselves in the environment and settle into their roles. The leaders directed their group towards a common goal of selling the ERP system for the sales team, and making a purchasing decision for the buying team using imperfect information. The communication was synchronous real-time communication across several time zones. Compared to the communication in Activity 1, it can be said to be less formal, less precise, and unstructured. Second Life supports a combination of a real and a virtual presence of users. Real presence is achieved by voice communication and to some extent control of the body language including lip synchronization and a set of simple gestures of the avatar. The presence by avatars allows for simulated face-to-face interaction combined with voice, where ideas and knowledge are shared. Although still very limited compared to a real life face-to-face meeting, doing the team-oriented role play in Second Life gave the students experience of meeting in a virtual environment to conduct business negotiations.

\subsubsection{Collaborative skills}

This activity makes use of collaborative skills at the tactical level in the complex interaction that takes place when sales and purchasing teams negotiate with the goal of closing the sale of a sophisticated product. Relevant skills are related to behaviour that supports concepts like trust, sharing, belonging and respect. As noted above, we do not make an explicit link between the practical performance of the students and the theory related to collaborative skills, as this is for the student to experience, based on theory covered in previous classes. 


\subsubsection{Information literacy skills}

For this activity the information literacy skills are twofold. One relates to the management side, where skills for information handling are more open-ended than in Activity 1. This is related to handling information for business needs, product offerings and the financial situation. The second part relates to skills to operate IT tools like Second Life and standard office support software.

\section{Conclusion}

This chapter has presented two new educational activities addressing the need for educational activities that provide competencies that cuts across disciplines on a global scale. The activities are targeted at the postgraduate level in business and Information systems schools. We suggest running these activities as hands on exercises giving students practical skills in doing typical business operations at both the operational and the tactical management level of an organization doing business in an international setting. The practical skills gained in combination with the theoretical knowledge previously covered in other courses will give students competencies highly sought in the job market.

Our results indicate a gain in competencies in the three domains of (1) globalization, (2) collaboration and (3) information literacy. Activity 1, Global Supply Chain Management using ERP systems, the students had to understand both how to do the exact import and export operations in SAP and how to manage their business processes in the global supply chain.

In Activity 2, Virtual Team Role Play using Virtual Worlds, students got competencies needed at the tactical level in an organization both by operating the virtual world software, and by participating in the role play in a negotiation between sales and purchasing teams. We believe these two new educational activities can be added to existing curricula with only small changes to the total curriculum. We think the combined effect of practical skills and theoretical knowledge will contribute to more relevant programs addressing the growing needs for these competencies by businesses and organizations.

\section{References}

e-Skills Demand (2009). e-Skills Demand Developments and Challenges, Sectoral e-Business Watch Study Report No. 05/2009.

http://www.ebusiness-watch.org/studies/special_topics/2009/documents/FR052009_eSkills.pdf

Economic Times (2010). The Economic Times, 20 Sep, 2010.

http://economictimes.indiatimes.com/news/economy/foreign-trade/WTO-seesrecord-trade-growth-of-135-pc-this-year/articleshow/6595080.cms Accessed March 20. 2011.

Eurydice (2002). Key Competencies. A developing concept in general compulsory education, Eurydice, The information network on education in Europe, Survey 5. October 2002. www.see-educoop.net/education_in/pdf/compulsary-edu-oth-enl-t05.pdf Accessed April 26. 2011.

Gartner (2009). Gartner: Virtual Worlds, a Long-Term Play. Retrieved from http://www.engagedigital.com/2009/08/20/gartner-virtual-worlds-a-longtermplay/ 
Gartner (2010). nTeams Named Cool Vendor By Gartner. Retrieved from http:/ /www.engagedigital.com/2010/06/03/nteams-named-cool-vendor-bygartner/

Harvard (2008). Harvard Business School Discusses Future of the MBA, Harvard Bulletin, Retrieved 23 June 2009 from http:/ / www.exed.hbs.edu/cgi-bin/wk/6053.html

Jaeger, B., Rudra, A., Aitken, A., Chang, V. \& Helgheim, B. I. (2011). Teaching Business Process Management in Cross-Country Collaborative Teams Using ERP. Accepted at ECIS-2011, Finland.

Mintzberg, H. (2004). Managers Not MBAs: A Hard Look at the Soft Practice of Managing and Management Development, Berrett-Koehler Publishers, San Francisco, ISBN: 1576752755.

Mintzberg, H. (2005). The Magic Number Seven: Plus or Minus a Couple of Managers. Academy of Management Learning E Education, Vol. 4, No. 2 (Jun. 2005), pp. 244-247. ISSN: $1537260 X$

Porter, L. W. \& McKibbin, L. E. (1988). Management education and development: Drift or thrust into the 21st century? McGraw-Hill, ISBN 0070505217 New York.

Rajkumar, T. M. \& Sarma, M. (2007). Teaching ERP concepts in a Capstone Course, Ch VI, In: Enterprise Systems education in the 21 ${ }^{\text {st }}$ Century, Targowski, A. S. and Tarn, J. M., Information Science Publishing, Idea Group. ISBN 1599043491, Hershey.

Rudra, A., Jaeger, B., Aitken, A., Chang, V. \& Helgheim, B. (2011). Virtual Team Role Play Using Second Life for Teaching Business Process Concepts. HICSS-44: Hawaii International Conference on System Sciences, Kauai, ISBN 978-0-7695-4282-9, Hawaii, Jan 4-7, 2011.

SAP Cockpit (2008). Retrieved 15 June, 2009, from http://help.sap.com/saphelp_gts71/helpdata/en/03/323a426ea5b26be10000000a1 55106/content.htm

SAP (2009). SAP 2009 Sustainability Report, Retrieved from www.sapsustainabilityreport.com/2009/overview/commitment Accessed April 26. 2011.

Seethamraju, R. (2007). Enterprise Systems (ES) Software in Business School Curriculum Evaluation of Design and Delivery, Journal of Information Systems Education, Vol. 18, No.1, pp. 69-84.

Sumner, M. (2005). Enterprise Resource Planning, Prentice Hall, ISBN-13: 9780131403437, Upper Saddle River, New Jersey.

Topi, H., Valacich, J. S., Wright, R. T., Kaiser, K., Nunamaker Jr, J. F., Sipior, J. C. \& de Vreede, G. J. (2010). IS 2010: curriculum guidelines for undergraduate degree programs in information systems, Communications of the Association for Information Systems, Vol. 26, No. 1, p. 18.

Wild, J. J., Wild, K. L. (2008). International Business: The Challenges of Globalization, Pearson Education, ISBN 0131747436, Cambridge, MA. 


\title{
Globalization and Higher Education in Taiwan
}

\author{
Dian-Fu Chang 1 , Cheng-Ta Wu², \\ Gregory Ching, Chia-wei Tang and Lin Xiao ${ }^{1}$ \\ ${ }^{1}$ National Chi Nan University, \\ ${ }^{2}$ National Cheng Chi University, \\ Taiwan
}

\section{Introduction}

Within the last decade, Taiwan's higher education system has experienced transformation along the lines of decentralization and marketization (Mok, 2000). The pressure to compete internationally and to attain global recognition has become one of the major benchmarks in evaluating university performance (Mok, 2003; Song \& Tai, 2007). Together with rising concerns about the value of money, public accountability has already changed the way higher education is governed (Welch, 2004). Advanced nations, such as the UK (with its University Appropriations Committee) and the US (with its Higher Education Project Funds in the Department of Education), along with Japan and Germany, have all allocated funds to assist in the development of key universities.

In Taiwan, the government has realized that globalization has accelerated competition among universities around the world (Lo \& Weng, 2005; Lu, 2004; MOE, 2006). A series of large-scale projects were launched in order to catch up with the rest of the world's higher education systems amid the powerful trend of globalization (Song \& Tai, 2007). With the revision of the University Act in 1994, which prompted the restructuring of state owned higher education institutions (HEIs) into independent legal entities (Mok, 2006), thereby reducing the control of the Ministry of Education (MOE) over HEIs and making campus operations more flexible. In the following years, Taiwan's government, acknowledging that the state alone can never satisfy the pressing demand for higher education, decided to revise its education ordinances and create room for the expansion of private higher education (Mok, 2000; Mok \& James, 2005). This sparked a growth in the number of HEIs over the decades. Currently, the number of HEIs has increased dramatically from 7 in 1950 to 164 in 2008, among which are 100 universities, 49 colleges, and 15 junior colleges (MOE, 2008). This sudden increased in numbers of HEIs did not only inflame the competition among HEIs, but also hasten the internationalization of Taiwan's HEIs.

Among the major projects Taiwan's MOE organized the Plan to Develop First-class Universities and Top-level Research Centers is the project with largest competitive fund. The empirical part of this paper analyzes the outcome of this project, adopted by the Taiwan Ministry of Education, in creating world-class universities and research centers. The prospective performances of the funded universities were evaluated with official data from the Department of Higher Education in Taiwan. The following section shall discuss the definition of globalization and internationalization of Taiwan's higher education, which is 
then followed by the details of the Plan to Develop First-class Universities and Top-level Research Centers and lastly the empirical findings of the efficiency of the MOE's effort of producing world class universities.

\section{Globalization and internationalization}

The examination of globalization and internationalization as distinct processes is essential for serious scholarship addressing contemporary trends in higher education. Scholars agree that processes of globalization are unalterable while those representing internationalization remain fluid and changeable. Elkin, Devjee and Farnsworth (2008) note that, internationalization is not something that is either achieved or not achieved; rather it is an engagement with a range of dimensions (indicators). Internationalization represents university policy, initiatives, and practices that are adopted in response to the affects of globalization (Scott, 1998).

Internationalization at the national, sector, and institutional levels is defined as the process of integrating an international, intercultural, or global dimension, into the purpose, functions or delivery of higher education (Knight, 2004). Ellingboe (1998) added that internationalization is the ongoing process of integrating an international perspective into HEIs. It should encompass a multi-dimensional, inter-disciplinary, and future-oriented leadership vision, which involves the many stakeholders of the institution, in order to respond and adapt appropriately to the ever increasingly diverse and global environment. Hence, the many definitions and dimensions of internationalization have definitely given grounds to its complexity.

On the other hand, globalization is considered a multi-dimensional term (Levin, 1999). Commonly, globalization is defined as the closer integration of the countries and peoples of the world, brought about by the enormous reduction of costs of transportation and communication, and the breaking down of artificial barriers to the flows of goods, services, capital, knowledge, and people across borders (Stiglitz, 2002). It also refers to the process and consequences of instantaneous communication and technological advancement, which brought about the tremendous growth in the quantity of information and integration (Grunzweig \& Rinehart, 2002). While academic systems and institutions may make different accommodations to these trends, however neither one can ignore its impetus and implications. Globalization, as it applies to higher education, involves information technology and the use of a common language for scientific communication (Altbach, 2005). In effect, the rapidly changing world thus requires students to possess broad international knowledge and strong intercultural skills, in addition to the more traditional disciplinary knowledge gained from university education (Paige, 2005).

\section{Effects of globalization in Taiwan}

Education system in Taiwan, similar to other education systems in East Asia, has undergone an enormous transformation over the last two decades. Education has become interconnected with trends of globalization and internationalization, development of information communications technology, and a set of political, sociological, economic, and management changes. These changes together produce multifaceted influences on Taiwanese education. In particular, the ideology of globalization and localization acts as one of the driving policy agenda in Taiwan. The notion of globalization encompasses a plethora 
of meanings. According to Mok and Lee (2000: 362), globalization is "the processes that are not only confined to an ever growing interconnectedness and interdependency among different countries in the economic sphere but also to tighter interactions and interconnections in social, political, and cultural realms". Governments in Taiwan have endeavored to follow the trend of globalization, especially in education.

In the efforts of Taiwanese educational globalization, English instruction was very much emphasized throughout primary and secondary education. In earlier history of education in Taiwan, English was only instructed in secondary schools as one of the compulsory classes. However, as to follow the trend of globalization and to connect with the world internationally, Taiwanese government started to push second language instruction into primary schools, targeting fifth and sixth graders in the elementary level in 2001, in order to cultivate their youth to become internationally competitive. In 2008, Taipei County's Ministry of Education even launched a program that adds three extra courses to the current elementary school curriculum that focuses on English learning, which was met with harsh criticism from teachers, claiming that the current Taiwanese curriculum for elementary school students already takes up too much of children's free time (Lu, 2010).

In the past several decades, the development of communicational technology made it possible to view Taiwanese television programs in many parts of the world; transportation technology has also dramatically changed the face of Taiwanese education. Now, foreign students, international students, sister schools, and exchange programs are quite common in Taiwanese higher education. According to statistics, in 2007 there were at least 86 Taiwanese universities, colleges, and vocational schools that had established a sister school relationship with around 173 Chinese schools (Yu, 2007). It is also not uncommon for a post secondary school to have a large number of sister schools from all over the world; for example, the National Chengchi University in Taiwan has around 234 sister schools from 35 countries as of November, 2009 (National Chengchi University, Office of International Cooperation). Chengchi University also has a renowned IMBA (International Master of Business Administration) program which offers all of its courses completely in English, with students from over 30 countries in 5 continents.

The effect of globalization on Taiwanese education can be clearly observed not only in Taiwan, but in other parts of the world as well, as globalization is not just a one-way process. As Taiwan joins WTO (World Trade Organization) and signs the ECFA (Economic Cooperation Framework Agreement) with China, the opening of trade between China and Taiwan has created a number of Taiwanese schools in China that caters to the children of Taiwanese businessmen working in Chinese companies, such as Taiwan Businessmen's Dongguan School, Shanghai Taiwanese Children School, and HuaDong Taiwan Businessmen's School. In 2010, Taiwan also plans to start recognizing diplomas from 41 specified Chinese universities and colleges, and accept Chinese students into the Taiwanese post secondary education system with strict regulation, which has generated mixed responses from the public due to political reasons and a fear of competition in the job market.

Other than China, there are also Taiwanese schools in Vietnam's Ho Chi Ming City, Indonesia's Surabaya City and Jakarta City, and Malaysia's Seberang Perai and Kuala Lumpur. While Taiwan is opening up to the world, the world is also learning about the culture of Taiwan. Currently, the Taiwanese government is planning to establish Taiwanese Institutes in other parts of the world, starting with the United States of America's Los Angeles and Houston (Tsai, 2010). The goal of such institutes is to promote Taiwanese 
culture and language, very much like China's Confucius Institutes which already has over 282 institutes in 88 countries as of November 2009. Another the key unique issues in Taiwanese education are the minority population, such as aboriginal children and children of foreign spouses. There are around five hundred thousand aboriginal people in Taiwan; in the school year of 2008, their rate of enrollment at the elementary school level is $99.22 \%$, the rate at the level of high school and below is $85.88 \%$, and the rate of enrollment at post secondary education is $41.46 \%$ (compared to $84.30 \%$ in the general population). A 2009 poll of the aboriginal population over 15 years of age showed that $85.88 \%$ of all aboriginal people have a level of education at or below high school and vocational schools. The reason that aboriginal students have a significantly lower enrollment rate is often linked with family or economic problems, along with troubles fitting in at school.

Another significant measure under the influence of globalization is the nine-year spiral curriculum reform in secondary education taken place in 2001. The objective of this curriculum reform program is considered the backbone of the major educational reform during the last decade. Its major goals are to promote cultural learning and international understanding as well as other demanding abilities for the 21st century. In order to achieve educational globalization, related issues and ideas were implemented within secondary curriculum in subjects such as civil and social studies. The Taiwanese Ministry of Education (MOE) also stressed globalization in higher education.

Taiwan follows the world trend of higher education globalization, redirecting the aim of education toward a more market-oriented one. Lessening government control and integrating social demand with market forces, Taiwanese education in the 1990s has been influenced by globalization to a great extent. Similarly, beginning in 2003, MOE started to promote a "World Class Research University" project, proposing to upgrade at least one of the universities in Taiwan to be ranked among the top 100 leading international institutions of higher education within the next 10 years. Universities are required to establish a system of evaluation using methods such as the SCI, SSCI, and the EI, or to be in accordance with the standards that meet international recognition for awards, achievements, and contributions within their field of expertise. In 2005, MOE granted NT\$50 billion (equals US $\$ 1.56$ billion) to 12 universities for five years to empower their research capacity in order to reach the world class level. This paper shall ultimately analyze the efficiency of having embark in such efforts to become recognized as the so-called World Class Universities.

\section{Plan to develop first-class universities and top-level research centers}

In virtue of the already limited resources that were further diminished by the growth in higher education and its attendant pursuit of excellence, MOE was aware of that instead of assisting all HEIs; they needed to invest extra funding in selected promising institutions. Based on this concern, Plan to Develop First-class Universities and Top-level Research Centers was put forth according to suggestions made in the Higher Education Macroscopic Planning Report prepared by the Higher Education Macroscopic Planning Committee, which proposed strategies that would raise the level of competitiveness among institutions of higher education. The plan was comprised of two sub-plans: Plan to Develop First-class Universities and Plan to Develop Top-level Research Centers. The purpose of these plans was to assist universities through competitive funding and thus improve their worldwide academic competitiveness. The main objectives of this project can be summarized as follows (MOE, 2006): 
1. In ten years, at least one university will become one of the world's top one hundred universities. In fifteen to twenty years, that university will become one of the world's top fifty universities, with several research centers in that university having the potential of becoming some of the world's Top-level research centers.

2. At least ten outstanding fields, departments, or research centers will become Asia's First-class areas within five years. In ten years, these will have the potential of becoming among the top fifty in their respective fields.

3. The R\&D quality of universities will be raised, as will their influence on and visibility in international academic circles.

4. Distinguished foreign teaching and research individuals will be recruited to train students in cutting-edge industries.

5. Substantive exchange and cooperation will be established among transnational academic organizations.

\section{Project application and review procedure}

This project targeted the promotion of excellence in promising HEIs. The selection of recipients required HEIs to submit a written preliminary project proposal for review. After a list of passing HEIs was posted, each school briefed the review committee. If several schools were going to consolidate, they had to submit a joint consolidation proposal. The items required in each project proposal included current status and self-assessment of the school's competitive edge, year-by-year assessment indicators, strategies to achieve objectives, and financial planning with year-by-year funding requirements.

Proposal reviews were held thrice, in 2005, 2007, and the most recent 2010. The review committee consisted of highly esteemed academics and experts, from both Taiwan and abroad, who were responsible for identifying the HEIs that had the potential to become firstclass in their respective fields. The review standards and criteria for Plan to Develop Firstclass Universities included the management and organizational operating system of the school as well as the school infrastructure, staffing quality, and research performance. The review standards and criteria for Plan to Develop Top-level Research Centers included the quality of teaching and research personnel; steps taken to recruit distinguished individuals; the rise in teaching performance, creative mechanisms, and methods of academic research; the methods used to cooperate with domestic and foreign schools, research institutions, and results; the school's overall support resources; and qualitative indicators designated by the review committee (MOE, 2006).

In the first round of review during 2005, twenty-nine universities submitted proposals for funding under the program, with twelve selected (two universities as the recipients of Plan to Develop First-class Universities and ten key universities or research centers were also selected for Plan to Develop Top-level Research Centers). These twelve universities are during that time have been thought of as (but not universally shared) the twelve best universities in Taiwan. Among the twenty-nine universities, seven submitted applications for funding as world class universities, with twenty-two universities putting forward research centre proposals16.

During the second round of review in 2007, only eleven universities remained. While the latest results of the 2010 review resulted in only ten universities (all national universities) are funded by the Taiwanese MOE. The main purpose of this study was to evaluate the effects and outcomes of the project called Plan to Develop First-class Universities and Top-level 
Research Centers, which has brought in selected universities since its implementation in 2005. Descriptive statistics and the data envelopment analysis (DEA) method were adopted during data analysis to weigh the relative performance of twelve recipient universities in Taiwan between and to 2007. (Please see table 1 for funding details)

\begin{tabular}{ccccccc}
\hline \multicolumn{7}{c}{ Year-by-year budgets for various sub-plans of the Plan (in NT\$ $100 \mathrm{M}^{1}$ ) } \\
\hline Phase 1 & 2005 & 2006 & 2007 & 2008 & 2009 & Total \\
Total Budget & 100 & 100 & 100 & 100 & 100 & 500 \\
First-class Universities & $35-60$ & $35-60$ & $35-60$ & $35-60$ & $35-60$ & $175-300$ \\
Top-level Research Centers & $40-65$ & $40-65$ & $40-65$ & $40-65$ & $40-65$ & $200-325$ \\
\hline Phase 2 & 2010 & 2011 & 2012 & 2013 & 2014 & Total \\
Total Budget & 100 & 100 & 100 & 100 & 100 & 500 \\
First-class Universities & $35-60$ & $35-60$ & $35-60$ & $35-60$ & $35-60$ & $175-300$ \\
Top-level Research Centers & $40-65$ & $40-65$ & $40-65$ & $40-65$ & $40-65$ & $200-325$ \\
\hline
\end{tabular}

Source: Plan to Develop First-class Universities and Top-level Research Centers, MoE, 2006. Retrieved July 3, 2008, from http://english.MoE.gov.tw/ct.asp?xItem=7131\&ctNode=505\&mp=1

Note: 1 Exchange rate: US\$ $1=30$ NT\$

Table 1. Year-by-year budgets for Plan to Develop First-class Universities

The analysis asked and answered the following research questions:

1. Did the project promote the global competitiveness of selected recipients in terms of research and development activities and internationalization?

2. Among the twelve recipients, which universities are comparatively efficient and inefficient?

\section{An overview of DEA method}

DEA has developed considerably since its inception by Farrell in 1957. It is a powerful method widely used in the evaluation of the performance of DMUs. DEA evaluates efficiency, i.e. the relationship between inputs and outputs. It thereby determines overall efficiency, which consists of both purely technical efficiency and allocative efficiency. The classical efficiency measure of Farrell (1957) was generalized by Charnes, Cooper, and Rhodes (1978) as a response to the need to evaluate the efficiency of not-for-profit organizations. They introduced the ratio definition of efficiency, which generalizes the single-output to single-input ratio definition used by Farrell (1957) to multiple outputs and inputs. In this model, DMU efficiency measurement is defined as each organization's mathematical position as it relates to the frontier of best performance, which is established by the ratio of weighted sum of outputs to weighted sum of inputs.

$$
\max \frac{\text { sum of weighted outputs }}{\text { sum of weighted inputs }}
$$

Each DMU uses $m$ inputs and $s$ outputs. DMUj $(j=1, \ldots, n)$ takes the quantity $x_{i j}$ of input $\mathrm{i}$ and the quantity $\mathrm{y}_{r j}$ of output $r$. This means that $x_{i} \geq 0$ and $\mathrm{y}_{\mathrm{rj}} \geq 0$, and each DMU has at least one positive input and output value. Let $u_{r}$ and $v_{i}$ be the weight of output $r$ and of input $i$, respectively, $y r_{k}$ and $x i_{k}$ being the observed values of the DMU $k$ under evaluation. The weights are fixed at the beginning and are calculated within the analysis. The mathematical model for a DMUk, is defined by: 
$\operatorname{Max} E_{k}=\frac{\sum_{r=1}^{s} u_{r} Y_{r k}}{\sum_{i=1}^{m} v_{i} X_{i k}}$

$$
\begin{gathered}
\text { Subject to } \frac{\sum_{r=1}^{s} u_{r} Y_{r j}}{\sum_{i=1}^{m} v_{i} X_{i j}} \leq 1 \quad j=1,2, \ldots, n \\
u_{r}, v_{i} \geq \varepsilon \quad r=1,2, \ldots, s \quad i=1,2, \ldots, m
\end{gathered}
$$

This model focuses on proportional improvement and reduction potentials. $\theta$ is the proportional decrease in inputs possible for the k-th DMU. $\varepsilon$ is a very small positive constant. An efficiency score of $\theta$ (the reduction factor of the inputs) will be assigned to its respective DMU. For $\theta<1$, the DMU is inefficient (Leitner, Schaffhauser-Linzatti, Stowasser, \& Wagner, 2005).

\section{Empirical findings}

To answer the research questions of this study, descriptive statistics and the DEA method were adopted in data analysis. For descriptive statistics, survey data from the Higher Education Department and the MOE were adopted, which projected an overview of the outcome of this project after two years' implementation. In order to gain further insight into the efficiency of funding recipients, the DEA method was adopted. One input and six outputs have been incorporated into the Charnes, Cooper, and Rhodes (CCR) model. The sole input of this project was monetary funding. According to MOE (2006), in 2005, NT\$100 million was allocated for twelve recipients. Funding received by schools in 2005 (NT\$ 100 million) is shown in Table 2.

\begin{tabular}{ccc}
\hline Code & School & Amount \\
\hline 1 & National Taiwan University & 30 \\
2 & National Cheng Kung University & 17 \\
3 & National Tsing Hua University & 10 \\
4 & National Chiao Tung University & 8 \\
5 & National Central University & 6 \\
6 & National Sun Yat-Sen University & 6 \\
7 & National Yang Ming University & 6 \\
8 & National Chung Hsing University & 6 \\
9 & National Taiwan University of Science and Technology & 6 \\
10 & National Chengchi University & 3 \\
11 & Chang Gung University & 3 \\
12 & Yuan Ze University & 3 \\
\hline
\end{tabular}

Source: Plan to Develop First-class Universities and Top-level Research Centers, MoE, 2006. Retrieved July 3, 2008, from http:/ / english.MoE.gov.tw/ct.asp?xItem $=7131 \& c t N o d e=505 \& m p=1$

Note: ${ }^{1}$ NT\$100 million approximately equal to US\$ 3 million (based on US\$1 $=$ NT\$30)

Table 2. Funding received by schools in 2005 (NT\$100 million) ${ }^{1}$ 
According to the MOE (2006), the goal of the project was to enhance the performance of selected universities in terms of research and development (R\&D) quality and internationalization. In consideration of this objective and of the availability of related data, the outputs included in this study's DEA model were: number of degree-seeking international students; number of international exchange students; number of international collaborations; number of visiting international scholars; number of articles published in international journals that are indexed in the Science Citation Index (SCI), Social Science Citation Index (SSCI), and Arts and Humanities Citation Index (A\&HCI) databases; and national scientific and educational collaboration expenditures in the form of new Taiwan dollars.

Results as shown in figures 1 through 6 show the growth rates of selected output measures in 2006. In general, it is suggested that substantial progress was made within the year that the project launched. Negative growth rates only appeared in the two right-hand columns, which show the number of articles published in international journals and the national scientific and educational collaboration expenditures (see Figure 6). As for the former, the rate of decline was rather slight. One possible reason that some of the universities gained fewer opportunities for national scientific and educational collaboration expenditures than others did was that the total number of such opportunities was usually constant. If one university acquired money through cooperation, it created a loss for others. In sum, although it was only the first year of the MOE's project, twelve universities experienced immediate and apparent improvement in many aspects of internationalization and $R \& D$ development.

Both Chang Gung and Yuan Ze Universities experienced an increase in the growth rate of degree-seeking international students (see Figure 1), while Yang Ming University experienced an increase in the growth rate of international exchange students (see Figure 2). As was discovered after further analysis of these schools' internationalization strategies, some of their policies included scholarships for foreign students, dual bachelor's and master's degree programs, and foreign language courses.

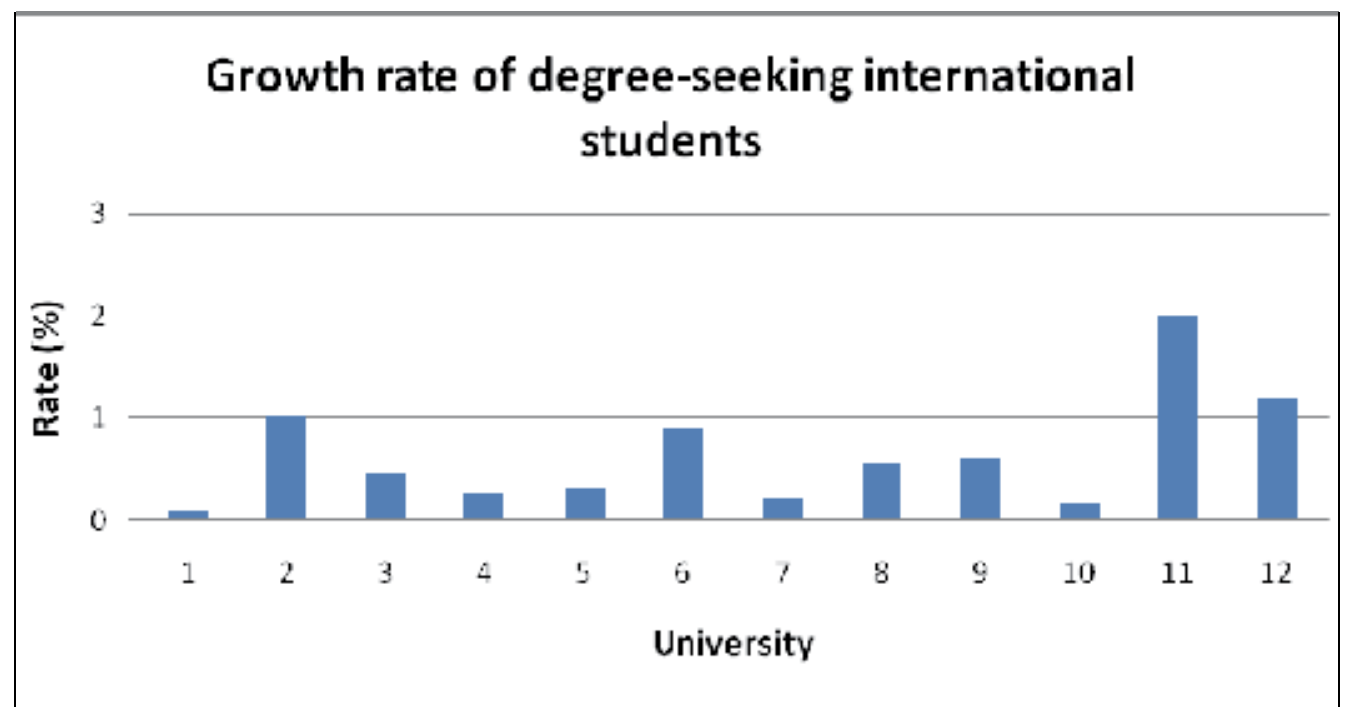

Fig. 1. 


\section{Growth rate of international exchange students}

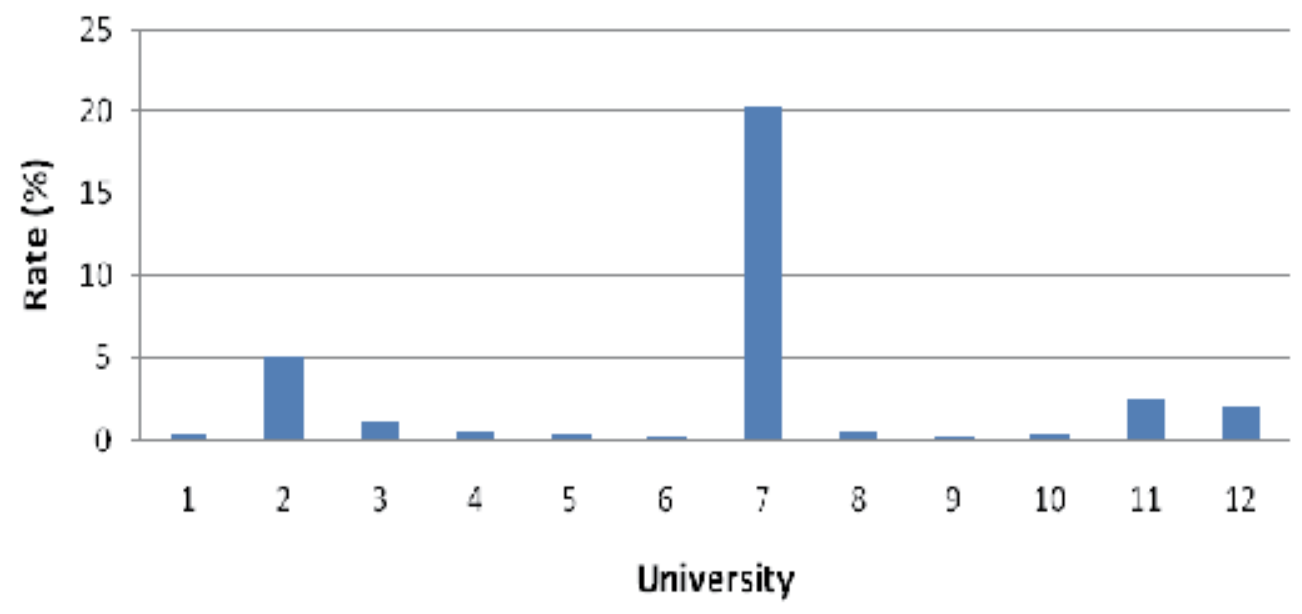

Fig. 2.

As for international collaboration, most of the universities experienced large growth rates during the one-year period (see Figure 3). Common strategies included establishing international sister schools, organizing international research teams, hosting international academic conferences, and making flexible degree programs available. Chung Hsing University showed particularly outstanding performance in the number of visiting international scholars (see Figure 4) and adopted policies such as flexible compensation in order to attract international and world-class scholars and to create scholarship opportunities for foreign faculty.

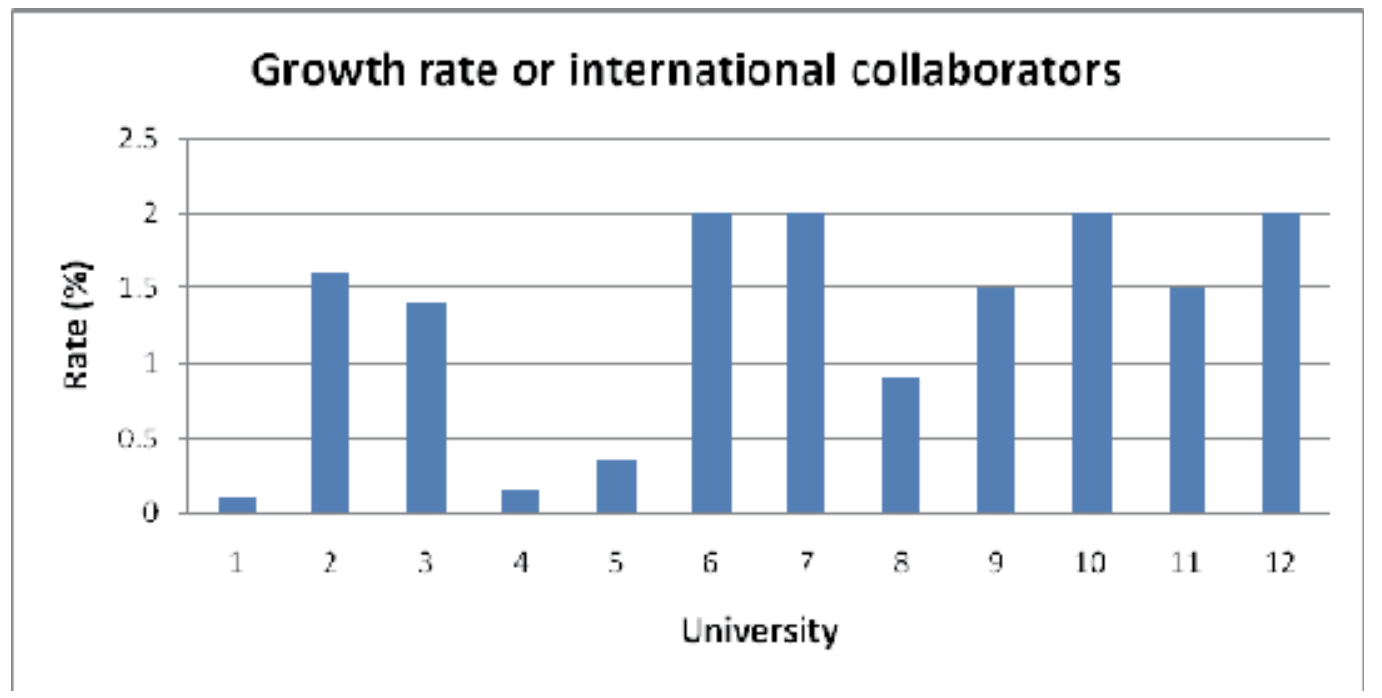

Fig. 3. 


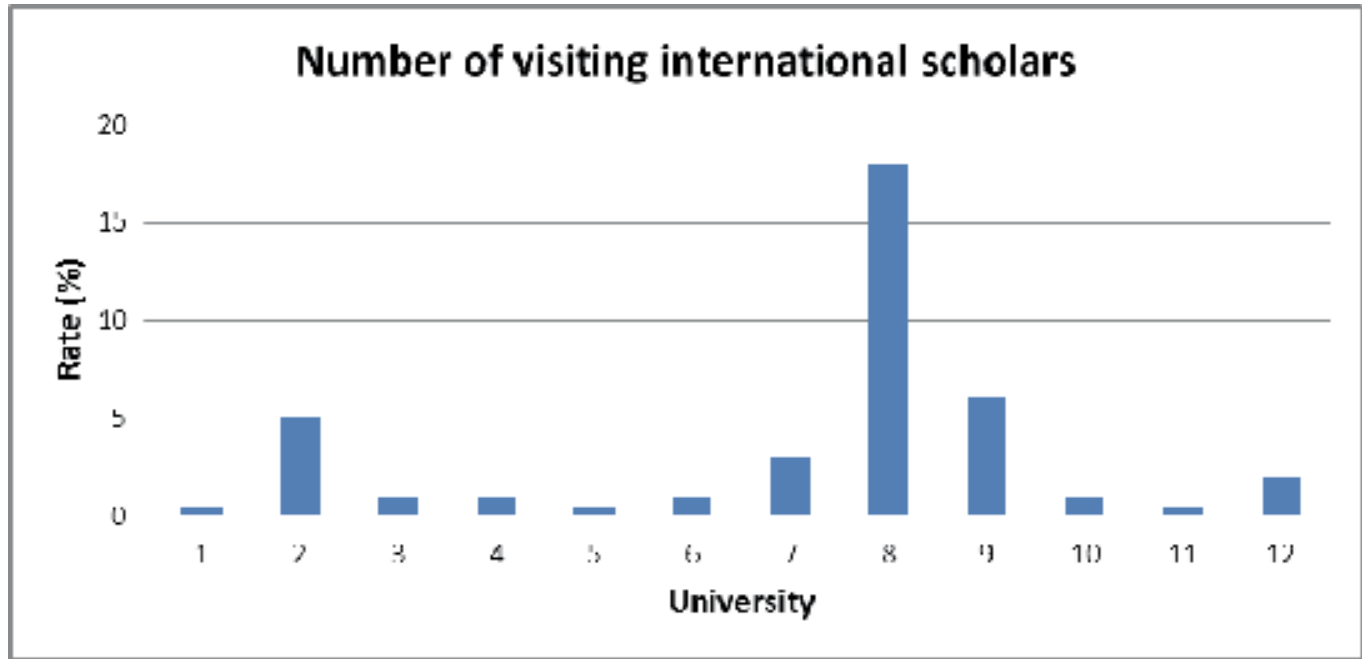

Fig. 4.

An overall similarity among the above-mentioned schools was the existence of an international education exchange center that handles all of the university's internationalization tasks. This setup not only increases the visibility of the university in the international arena, but also maintains good relations with foreign institutions and students. It helps better facilitate the activities of inbound foreign students and outbound local students. It also helps coordinate exchange opportunities and provides an array of services that prepare students for whatever challenges they may face when coming to Taiwan to study or when leaving Taiwan to study abroad.

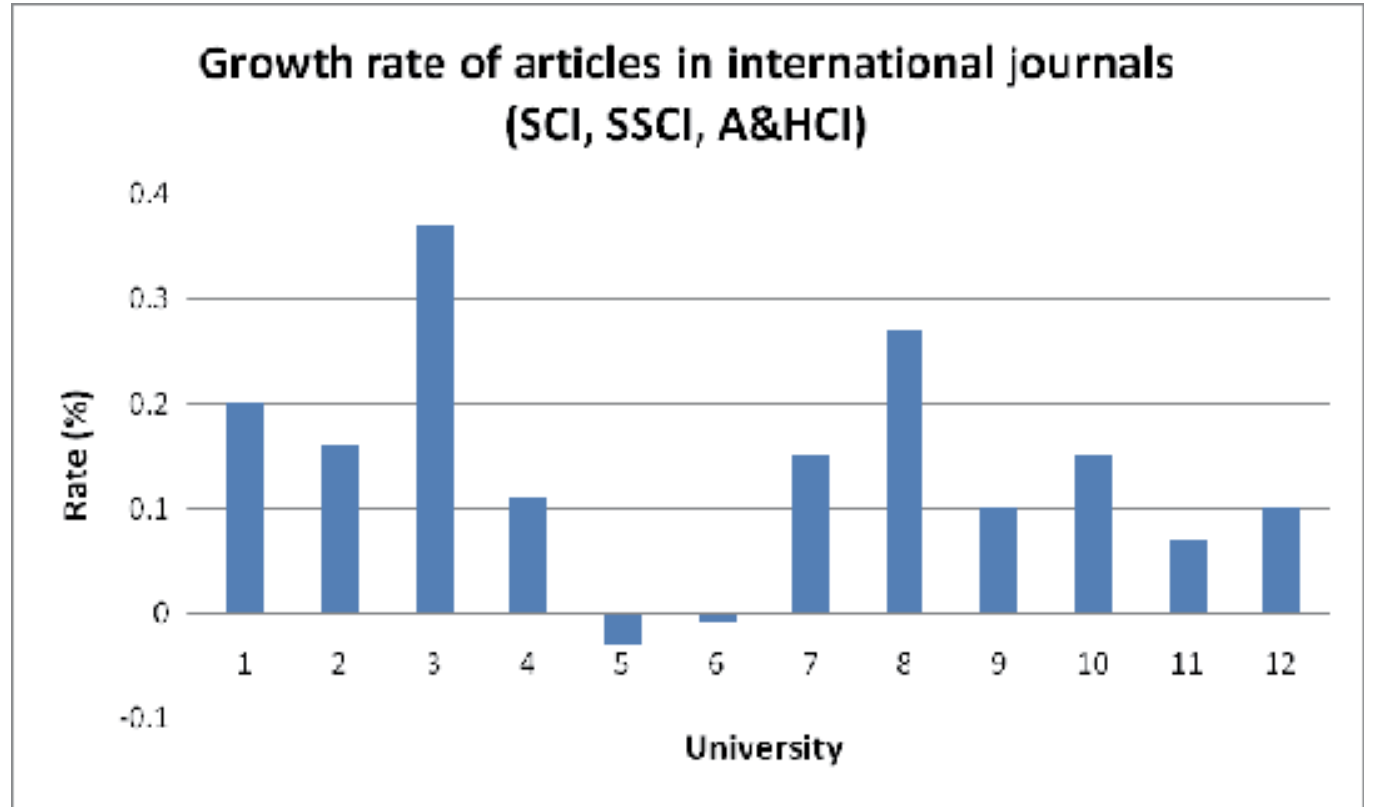

Fig. 5. 
With regard to publications in foreign international journals, most schools showed an increased growth rate; Tsing Hua, Chung Hsing, and National Taiwan Universities showed the highest increases (see Figure 5). These schools adopted policies such as funding assistance for research projects and additional monetary incentives for each publication in an international journal, especially those indexed in SCI/SSCI/A\&HCI. These have sparked an increase in the number of Taiwanese scholars in the international academe.

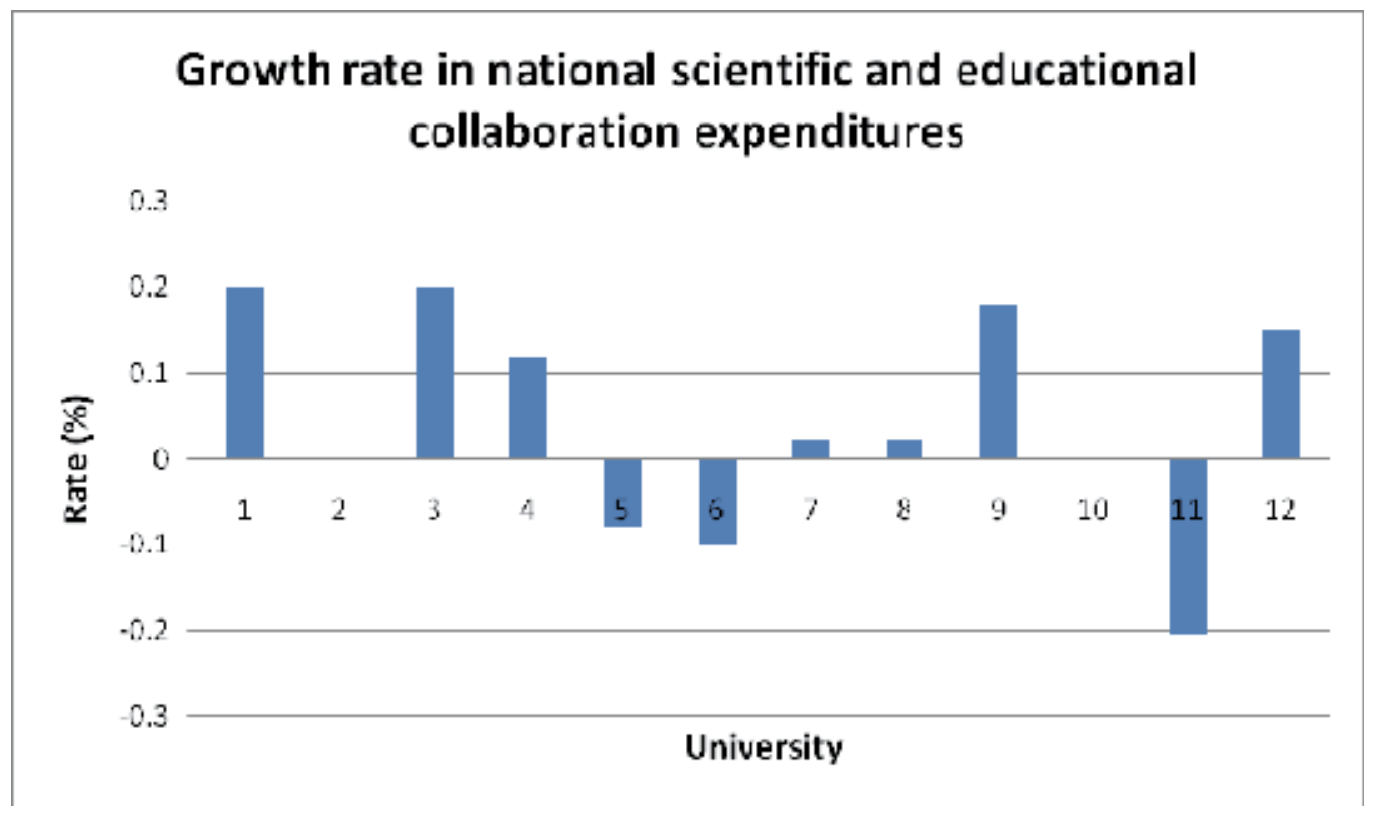

Fig. 6.

\section{Conclusions}

The development of first-class universities and top-level research centers requires a large investment of time and money, and yearly performance evaluation is crucial in order for the recipients to move in the right direction and to be accountable for their actions (MOE, 2006). This section includes a glimpse at the overall performance of the twelve recipients one year after this project launched. The end of this section will address information that compares efficient Decision Making Units (DMUs) with inefficient DMUs.

The empirical results of the DEA analysis provided valuable diagnostic information. First, based on the six output measures and the single input (total amount of funding received), we calculated the efficiency score for twelve universities with reference to other efficient DMUs. Moreover, the surplus analysis provided suggestions for managerial auditing. As Table 3 indicates, five universities were relatively efficient; these are marked with an efficiency score of 100, which implies that their resource utilization was comparatively efficient. That score represents the percent of outputs one DMU produced in comparison with efficient DMUs when the same efficiency level was predicted. Taiwan University is a good example: its efficiency score was 71.44 , which shows that it attained $71.44 \%$ efficiency as compared with the efficient DMUs. That is to say, Taiwan University only produced $71.44 \%$ of the output that efficient universities produced with the same level of input. 


\begin{tabular}{|l|c|c|c|}
\hline \multicolumn{1}{|c|}{ DMU } & Efficiency Score & Reference Frequency & Rank \\
\hline 1. National Taiwan University & 71.44 & 0 & 9 \\
\hline 2. National Cheng Kung University & 67.78 & 0 & 10 \\
\hline 3. National Tsing Hua University & 81.33 & 3 & 8 \\
\hline 4. National Chiao Tung University & 88.35 & 3 & 7 \\
\hline 5. National Central University & 100 & 7 & 1 \\
\hline 6. National Sun Yat-Sen University & 65.52 & 0 & 11 \\
\hline 7. National Yang Ming University & 56.41 & 0 & 12 \\
\hline 8. National Chung Hsing University & 100 & 6 & 4 \\
\hline 9. Nat. Taiwan Univ. of Science \& Tech. & 92.95 & 0 & 6 \\
\hline 10. National Chengchi University & 100 & 7 & 1 \\
\hline 11. Chang Gung University & 100 & 7 & 1 \\
\hline 12. Yuan Ze University & 100 & 2 & 5 \\
\hline
\end{tabular}

Table 3. Relative efficiency of DMUs

With the recent rise in globalization and the increasing trend toward placing importance on university rankings, governments worldwide have started to focus on developing first-class universities. This study focused on Taiwan's experience with the project Plan to Develop First-class Universities and Top-level Research Centers. DEA was utilized in order to analyze the comparative performance of the twelve universities involved in the project. Data were gathered from before and after project implementation. The results indicate that even though this project had only been implemented for a single year, all the universities involved showed tremendous increase in the growth rates of their R\&D performance and their internationalization progress. Although some universities, such as National Chengchi University and Chang Gung University, received much less funding from the MOE than others did, they managed to outperform other universities that received much more. Similarly, two of the other efficient DMUs (Yuan Ze University and Chung Hsing University) received only NT\$600 million, while most DMUs with lower rankings received more funding from the MOE. This suggests the possibility that, due to limited recourses, universities tend to use their funding carefully and thus rapidly reach their prospective development goal. On the other hand, more input did not ensure better output, which might be cause by deterioration due to the overinvestment or misuse of budgets. Further longitudinal studies are necessary in order to attain a broader view of the whole project. An additional analysis of the factors behind the strategies used by those universities that performed best are also encouraged.

\section{References}

Altbach, P. G. (2005). Globalization and the university: Myths and realities in an unequal world. In The NEA 2005 Almanac of Higher Education (pp. 63-74). Washington, DC: National Education Association.

Charnes, A., Cooper, W. W., \& Rhodes, E. (1978). Measuring the efficiency of decision making units. European Journal of Operational Research, 2, 429-444.

Elkin, G., Farnsworth, J., \& Templer, A. (2008). Strategy and the internationalisation of universities. International Journal of Educational Management, 22(3), 239-250. 
Ellingboe, B. J. (1998). Divisional strategies to internationalize a campus portrait: Results, resistance, and recommendations from a case study at a US university. In J. A. Mestenhauser \& B. J. Ellingboe (Eds.), Reforming the higher education curriculum: Internationalizing the campus (pp. 198-228). Washington, DC: American Council on Education.

Farrell, M. J. (1957). The measurement of productive efficiency. Journal of the Royal Statistical Society, 120, 253-281.

Grunzweig, W., \& Rinehart, N. (Eds.). (2002). Rocking in red square: Critical approaches to international education in the age of cyberculture. Berlin: Lit Verlag.

Knight, J. (2004). Internationalization remodeled: Definition, approaches, and rationales. Journal of Studies in International Education, 8(1), 5-31.

Leitner, K.-H., Schaffhauser-Linzatti, M., Stowasser, R., \& Wagner, K. (2005). Data envelopment analysis as method for evaluating intellectual capital. Journal of Intellectual Capital, 6(4), 528-543.

Levin, J. S. (1999). Missions and structures: Bringing clarity to perceptions about globalization and higher education in Canada. Higher Education, 37, 377-399.

Lo, Y. W., \& Weng, F. Y. (2005). Taiwan's responses to globalization: Internationalization of higher education. In K. H. Mok \& R. James (Eds.), Globalization and higher education in East Asia. Singapore: Marshall Cavendish Academic.

Lu, M. L. (2004). The blueprint and competitiveness of Taiwan's higher education. Paper presented at the Cross Strait Seminar on Review and Prospect of the Policy of University Excellence.

MOE. (2006). Plan to develop first-class universities and top-level research centers. Retrieved July 3, 2008, from

http:/ / english.moe.gov.tw/ct.asp?xItem=7131\&ctNode=505\&mp=1

MOE. (2008). 2008 Educational statistical indicators. Retrieved May 25, 2008, from http:/ / english.moe.gov.tw/lp.asp?ctNode $=816 \& C t U n i t=507 \& B a s e D S D=7 \& m p=1$

Mok, K. H. (2000). Reflecting globalization effects on local policy: Higher education reform in Taiwan. Journal of Education Policy, 15(6), 637-660.

Mok, K. H. (2003). Similar trends, diverse agendas: Higher education reforms in East Asia. Globalisation, Societies and Education, 1(2), 201-221.

Mok, K. H. (2006, January 13-14). Questing for internationalization of universities in East Asia: Critical reflections. Paper presented at the International symposium, Osaka University, Japan.

Mok, K. H., \& James, R. (Eds.). (2005). Globalization and higher education in East Asia. Singapore: Marshall Cavendish Academic.

Paige, R. M. (2005). Internationalization of Higher Education: Performance Assessment and Indicators. Nagoya Journal of Higher Education, 5, 99-122.

Scott, P. (1998). Massification, internationalization and globalization. In P. Scott (Ed.), The globalization of higher education. Buckingham: SRHE and Open University Press.

Song, M.-M., \& Tai, H.-H. (2007). Taiwan's responses to globalisation: Internationalisation and questing for world class. Asia Pacific Journal of Education, 27(3), 323-340.

Stiglitz, J. E. (2002). Globalization and its discontents. New York: W. W. Norton \& company. 
Welch, A. (2004). Accountability or accountability? Governance and university evaluation systems in an era of performativity. COE Publication Series, 11, 117-138. 


\title{
Professional Skills: The Globalization Equalizer
}

\author{
Ronald Welch \\ The University of Texas at Tyler \\ United States of America
}

\section{Introduction}

According to the International Monetary Fund (IMF Staff, 2008), globalization "refers to the increasing integration of economies around the world, particularly through the movement of goods, services, and capital across borders." This integration can be positive or negative depending on one's point of view. The current trade deficits and job losses for the United States as companies outsource their work to countries where the labor costs are extremely low can be seen as negative (e.g., The North American Free Trade Agreement or NAFTA), while the economic development of these poorer nations can be seen as positive. Friedman's (2005) Book, The World is Flat, highlights how technology has allowed many countries to include China and India to become part of the global supply chain for manufactured goods as well as services such as engineering. Of course, globalization not only affects economics, but there are also broader political, environmental, and cultural dimensions which have resulted in globalization becoming a major focus for many companies and universities as well as nations.

What are the skills needed to compete in the global economy? How does one gain these skills? The European Union is currently studying how to not only improve the workforce skills through "New Skills for New Jobs" (European Commission, 2011), but to ensure they have a unified employment strategy that builds upon successful cooperation between higher education and businesses to modernize educational preparation of new graduates with skills for the global markets of the future. Many schools point toward their International Studies programs as the gateway to a "broad, interdisciplinary program with a flexible curriculum that emphasizes the development of knowledge and analytical approaches needed to understand the contemporary global system." (UW-Parkside, 2011) Others require a semester abroad or the completion of a team project abroad. Some schools require the faculty to travel abroad in hope they will pass along their global perspectives to their students. One Dean has stated that "international study shouldn't be elective." (Goinglobal, 2011)

Career counselors highlight the need to be not only strong in one's discipline expertise using cognitive skills such as problem-solving, decision making, and knowing how to learn, but also through the use of social skills such as working in multi-cultural teams and personal skills such as being flexible and innovative. (Peters-Behrens, 2011) Work experience during summer internships as well as semester abroad experiences provides real-world opportunities for applying these skills. Even the prime minister of the United Kingdom called for expanded apprenticeships to aid in Britain's "global skills race" to remain internationally competitive. (Brown, 2008) 
These same questions have been the source of discussions among US engineering firms and societies for many years leading to new ABET EC2000 (adopted in 1997) criteria supported by the engineering societies. (ABET, 2011) A quick look at these criteria depicts the importance of professional and global skills by their inclusion within ABET Criterion $3 \mathrm{a}-\mathrm{k}$. The generally recognized ABET professional skills are: ability to function on a multidisciplinary team (3.d), understanding professional and ethical responsibility (3.f), ability to communicate effectively (3.g), broad curriculum (3.h), recognition of need by an ability to engage in life-long learning (3.i), and knowledge of contemporary issues (3.j). Investigation of program criteria provides insight into additional professional skills being required within the Civil Engineering program criteria - leadership, business practices, public policy and administration, and asset management. All of these professional and global skills point to the growing importance of the management of engineering services over a focus solely on number crunching work. Are these not some of the same skills desperately needed within engineering companies as they move toward international markets?

If these professional skills are possibly a globalization equalizer and initial understanding and skill development occurs within university curriculum, then academic programs must provide the correct emphasis of these professional skills within their programs. (Steering Committee, 2006; Downey et.al., 2006) Based on the author's experience teaching senior design courses and as an ABET program evaluator (PEV), students applying professional skills for the first time in the curriculum during the senior design will not attain the level of performance desired in the professional skills (ABET Outcome $3 \mathrm{~d}, \mathrm{f}, \mathrm{g}, \mathrm{i}, \mathrm{j}$ ). These topics are sometimes relegated to a senior seminar during the last semester before graduation. If they are important enough to be elevated to outcomes, and some feel they are difficult to master and assess, then why are they sometimes addressed and demonstrated only once in the curriculum? PEV experience highlights that programs tend to focus only on what they understand.

\subsection{Professional outcomes}

What is the current emphasis of professional outcomes within curriculums? The ABET criteria are based on input from the numerous professional societies that are continuously evolving the required skills of future employees. The Engineering Accreditation Commission (EAC) works with the professional engineering societies to establish the skills required for future engineers. After many years of discussion and negotiation, EC2000 Criterion 3 a-k were adopted in 1997. The ABET EC2000 professional skills are: ability to function on a multi-disciplinary team (3.d), understanding professional and ethical responsibility (3.f), ability to communicate effectively (3.g), broad curriculum (3.h), recognition of need by an ability to engage in life-long learning (3.i), and knowledge of contemporary issues (3.j). Even though the EC2000 criteria and the professional skills have been part of the assessment process for two assessment cycles for many programs, programs are still experimenting with how best to assess and demonstrate accomplishment of these professional skills. The difficulty arises in how students demonstrate or fully understand what these outcomes are asking when the demonstration is occasionally left to a single event such as a seminar within the senior year.

These professional outcomes have been referred to as "soft" outcomes by many when they were first presented as part of ABET EC2000 Criterion 3. (ABET, 2011; Shuman et. al., 2005) Others have used the word "squishy" when considering how difficult it is to assess professional skills compared to the "hard" skills of engineering. (Welch et. al, 2005) "Soft" or "Squishy", the professional skills are not as easily assessed and many times require multiple assessment 
methods, multiple activities within the academic setting as well as possible activities like Engineers Without Borders (EWB) or other service activities to be able to properly demonstrate accomplishment of the outcome. (Shuman et. al., 2005) However, not every student will participate in EWB or other service activities unless a program requires participation as part of their graduation requirements. Another example of the difficulty is that students may properly assess a situation based on proper ethical reasoning, but there is no assurance that they will actually act ethically. Some define professional skills as how we perform in professional settings, but how do educators develop and assess such skills? Does the educator possess professional experience and a professional engineer (PE) license? Even a PE needs a methodology understood by all to properly and continually assess professional practice skills. Even though EC2000 was newly adopted and programs were investigating how best to demonstrate accomplishment of all new criteria, ASCE recognized the lack of certain knowledge and skills among civil engineering graduates. ASCE took the lead in education reform and formed a committee to study and develop a Civil Engineering Body of Knowledge (BOK) (ASCE 2004) to document the requisite knowledge, skills, and attitudes necessary for future civil engineers. This new civil engineering BOK included the ABET EC2000 3 a-k outcomes. Two key factors associated with the BOK were: 1) a lack of a clear definition of expected performance levels by these new engineers even though the wording was consistent with ABET definitions which are generally difficult to define clearly, and 2) the addition of four new outcomes focused on additional professional topics and discipline depth.

Very quickly it was determined by most programs and ASCE that the discipline depth could only occur at the Master's level with larger breadth occurring at the undergraduate level. The addition of professional skills above what even ABET EC2000 requires reflects greater recognition of the importance of the development of professional skills at the bachelor's level. How/Where are these supplementary professional topics to be included in current curriculums? How are these additional topics to be covered when some programs are required to decrease credit hours for faster graduation rates without decreasing the required Core courses? The engineering programs within the University of Texas System decreased their credit hours to 128 or less in 2007 based on legislative requirements to decrease time to graduation. Currently, there are discussions to possibly decrease the number of credit hours to 120 credit hours for all programs within publically supported programs to decrease the amount of funding being sent to schools of higher education as part of state-wide cost cutting measures. Many universities are facing similar conditions while needing to meet global skills of future engineers.

ASCE also realized that adjustments to the first edition of the BOK (ASCE, 2004) were needed based on the comments that arose from the ASCE Curriculum Committee (ASCE, 2007) investigating how to implement the outcomes. The central issue was the lack of a methodology to determine how well and at what level a program needed to demonstrate accomplishment of outcomes. Some of the schools on the ASCE Curriculum Committee working towards implementation of the outcomes decided after reviewing numerous taxonomies that Bloom's Taxonomy (Bloom et. al., 1956) should be used to define the proper level of demonstration of outcomes. One of the first orders of business of the new BOK II committee (ASCE, 2008) was to apply Bloom's Taxonomy (read action verbs) to define the level of demonstration of each outcome at not only the undergraduate level, but master's and experience levels as well. This level of definition of demonstration was applied to ABET Outcomes 3 a-k as well. Another focus as a result of the earlier ASCE Curriculum Committee's work was the splitting of ABET outcomes into a larger number of smaller 
outcomes. For example, ABET Criteria 3.a is "an ability to apply knowledge of mathematics, science, and engineering," (ABET, 2011) which became in BOK II outcomes 1 Mathematics, 2 Natural Sciences, 5 Materials Science, and 6 Mechanics. (ASCE, 2008)

Graduates:

1. Can apply knowledge of traditional mathematics, science, and engineering skills, and use modern engineering tools to solve problems.

2. Can design and conduct experiments, as well as analyze and interpret data in more than one civil engineering sub-discipline.

3. Can design systems, components, and processes and recognize the strengths and areas for possible improvement of their creative designs within realistic constraints such as regulatory, economic, environmental, social, political, ethical, health and safety, constructability, and sustainability.

4. Can work independently as well as part of a multidisciplinary design team.

5. Can identify, formulate, solve and evaluate engineering design problems using engineering models in the four of the six sub-disciplines civil engineering: structural engineering, transportation engineering, construction management, geotechnical engineering, hydrology and/or environmental engineering.

6. Can analyze a situation and make appropriate professional and ethical decisions.

7. Can demonstrate effective oral, written, and graphical communication skills.

8. Can demonstrate a commitment to learning and continued professional development outside the classroom, incorporate contemporary issues and historical issues during problem solving, and determine the impact of engineering solutions in a global and societal context.

9. Can explain professional practice attitudes, leadership principles and attitudes, management concepts and processes, and concepts of business, public policy, and public administration.

10. Can demonstrate the importance of humanities in the professional practice of civil engineering.

11. Can demonstrate the incorporation of social sciences knowledge into the professional practice of civil engineering.

12. Can use the knowledge of material sciences to solve problems appropriate to civil engineering.

13. Can analyze and solve problems in solid and fluid mechanics

14. Can apply principles of sustainability to the design of traditional and emergent engineering systems.

15. Can apply the principles of probability and statistics to solve problems containing uncertainties and risk assessment.

Table 1. UT Tyler CE program outcomes

The previous discussion surrounding the addition of new outcomes to BOK I, when reviewing skills needed by graduating engineers, resulted in the addition of outcomes to BOK II when necessary entry level skills were readdressed. The new outcomes are: sustainability, historical perspectives, globalization, humanities, social sciences, risk and uncertainty, and breadth in civil engineering areas. Some of these new outcomes may be considered professional practice skills such as humanities, social sciences, historical perspectives, sustainability and, of course, globalization. The ASCE Fulfillment Committee (Fridley, 2010) is currently studying implementation techniques for the new outcomes as well as implementation of adjusted levels 
of outcome demonstration at the undergraduate level using Bloom's Taxonomy. It is only a matter of time before these new outcomes and levels of demonstration occur within ABET general program criteria as is being called for by some (Ressler, 2010) or CE program criteria as the new outcomes in BOK I did in 2008 just four years after BOK I was in print. Some even hint that changes every six years are reasonable to consider. (Ressler, 2010) This current BOK II list of professional skills is a mixture of the skills gained through many international studies, management, business, and engineering programs.

The current CE program criteria professional outcomes are leadership, public policy and administration, business practices and asset management (adopted in 2008). What are the best methodologies and location for demonstrating these outcomes? Can programs successfully demonstrate these professional outcomes at the Bloom's Taxonomy levels indicated in the BOK II?

As a case study, this chapter will provide an in-depth look at the CE program at The University of Texas at Tyler (UT Tyler). The professional topics emanate from Program Outcomes (PO) 4, 6, 7, 8, 9, 10, 11, and 14 (Table 1 (Bold)) which are derived from ABET Outcomes (3.d), (3.f), (3.g), (3.h), (3.i), and (3.j) (Table 2 (Bold)) and the CE program criteria with additions and adjustments based on BOK II. PO 9 specifically incorporates the new undergraduate professional requirements located within the current $\mathrm{CE}$ program criteria (from BOK I). Outcomes 10-15 in Table 1 are the new program outcomes emanating from BOK II. Like a number of programs, UT Tyler has added the new outcomes and adjusted others to begin experimenting with how best and where to implement and demonstrate them. (Fridley, 2010)

Demonstration (incl. Process \& Measurements) that Graduates have:

(a) ability to apply knowledge of math, engineering, and science

(b) ability to design and conduct experiments

(b) ability to analyze and interpret data

(c) ability to design system, component or process to meet needs within realistic constraints such as regulatory, economic, environmental, social, political, ethical, health and safety, constructability, and sustainability.

(d) ability to function on multi-disciplinary teams

(e) ability to identify, formulate, and solve engineering problems

(f) understanding of professional and ethical responsibility

(g) ability to communicate effectively

(h) broad education

(i) recognition of need by an ability to engage in life-long learning

(j) knowledge of contemporary issues

(k) ability to use techniques, skills, and tools in engineering practice

Table 2. ABET criterion 3 a-k

\subsection{Alumni and employer assessment of professional skills}

How important are current professional outcomes to recent graduates working within the civil engineering profession? The importance of professional skills to engineering is clear through the inclusion of professional outcomes within ABET EC2000 and the civil 
engineering profession through the inclusion of professional outcomes within the program criteria in 2008. An available data source for investigating the importance of professional skills is surveys from recent alumni of UT Tyler and their employers within East Texas. As expected, the return rates were much better for the alumni (82 percent) than the employers (33 percent). Using these results presented in Table 3 (professional outcomes are bold), it is clear that the alumni felt they had improved their professional skills through their one year of experience and that the demonstration of the professional skills as worded was highly appropriate. The employers also rated highly the alumni professional skills and felt that even in East Texas that the assessment of these professional skills as worded was highly appropriate.

\begin{tabular}{|c|c|c|c|c|c|}
\hline & ڤัँ & 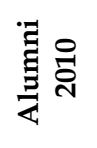 & 롤 울 & 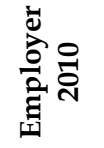 & 峁。 \\
\hline & 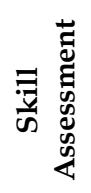 & 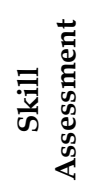 & 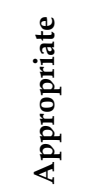 & 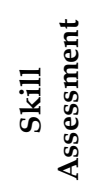 & 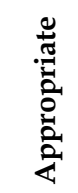 \\
\hline $\begin{array}{l}\text { 1a. Can apply knowledge of traditional mathematics } \\
\text { to solve problems }\end{array}$ & 4.8 & 4.8 & 4.9 & 4.5 & 4.5 \\
\hline $\begin{array}{l}\text { 1b. Can apply knowledge of traditional science } \\
\text { (calculus-based physics, Chemistry, additional } \\
\text { science) to solve problems }\end{array}$ & 4.4 & 4.8 & 4.6 & 4.5 & 4.5 \\
\hline $\begin{array}{l}\text { 1c. Can apply knowledge of traditional engineering } \\
\text { skills to solve problems }\end{array}$ & 4.8 & 4.6 & 4.8 & 5.0 & 4.5 \\
\hline $\begin{array}{l}\text { 1d. Can use modern engineering tools (excel, } \\
\text { MathCAD, etc.) to solve problems }\end{array}$ & 4.7 & 4.5 & 4.8 & 4.5 & 4.5 \\
\hline $\begin{array}{l}\text { 2. Can design and conduct experiments, as well as } \\
\text { analyze and interpret data in more than one civil } \\
\text { engineering discipline }\end{array}$ & 4.6 & 4.4 & 4.5 & 4.5 & 4.5 \\
\hline 3a. Can design systems, components, and processes & 4.5 & 4.5 & 4.1 & 4.0 & 4.0 \\
\hline $\begin{array}{l}\text { 3b. Can recognize the strengths and areas for } \\
\text { possible improvement of their creative designs } \\
\text { within realistic constraints such as economic, } \\
\text { political, social, constructability, sustainability, } \\
\text { public health and safety, environmental, and ethical. }\end{array}$ & 4.5 & 4.6 & 4.8 & 4.5 & 5.0 \\
\hline $\begin{array}{l}\text { 4. Can work independently as well as part of a } \\
\text { multidisciplinary design team }\end{array}$ & 4.7 & 4.8 & 4.8 & 4.5 & 4.5 \\
\hline $\begin{array}{l}\text { 5a. Can identify, formulate, and solve engineering } \\
\text { design problems using engineering models in the } \\
\text { discipline of structural engineering }\end{array}$ & 4.4 & 4.6 & 4.8 & 4.5 & 4.5 \\
\hline
\end{tabular}




\begin{tabular}{|c|c|c|c|c|c|}
\hline & 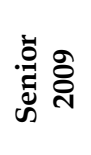 & 葛 울 & 串 & 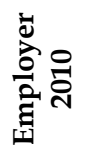 & 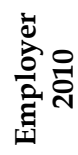 \\
\hline & 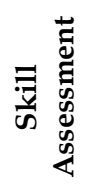 & 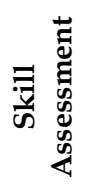 & 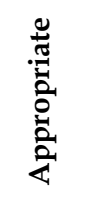 & 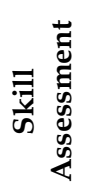 & 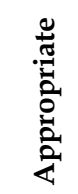 \\
\hline $\begin{array}{l}\text { 5b. Can identify, formulate, and solve engineering } \\
\text { design problems using engineering models in the } \\
\text { discipline of transportation engineering }\end{array}$ & 4.2 & 4.1 & 4.4 & 4.5 & 4.5 \\
\hline $\begin{array}{l}\text { 5c. Can identify, formulate, and solve engineering } \\
\text { design problems using engineering models in the } \\
\text { discipline of construction management }\end{array}$ & 4.3 & 4.6 & 4.6 & 4.5 & 4.5 \\
\hline $\begin{array}{l}\text { 5d. Can identify, formulate, and solve engineering } \\
\text { design problems using engineering models in the } \\
\text { discipline of hydrology and hydraulic design }\end{array}$ & 4.2 & 4.4 & 4.8 & 4.0 & 4.5 \\
\hline $\begin{array}{l}\text { 5e. Can identify, formulate, and solve engineering } \\
\text { design problems using engineering models in the } \\
\text { discipline of environmental engineering }\end{array}$ & 3.1 & 3.4 & 4.0 & 4.0 & 4.5 \\
\hline $\begin{array}{l}\text { 6a. Can analyze a situation and make appropriate } \\
\text { professional decisions }\end{array}$ & 4.6 & 4.6 & 4.6 & 5.0 & 5.0 \\
\hline $\begin{array}{l}\text { 6b. Can analyze a situation and make appropriate } \\
\text { ethical decisions }\end{array}$ & 4.4 & 4.6 & 4.8 & 5.0 & 5.0 \\
\hline $\begin{array}{l}\text { 7. Have effective oral, written, and graphical } \\
\text { communication skills }\end{array}$ & 4.6 & 4.6 & 4.9 & 4.5 & 4.5 \\
\hline $\begin{array}{l}\text { 8a. Demonstrate a commitment to learning and } \\
\text { continued professional development outside the } \\
\text { classroom }\end{array}$ & 4.7 & 4.8 & 4.9 & 4.5 & 4.5 \\
\hline $\begin{array}{l}\text { 8b. Incorporate contemporary issues during } \\
\text { problem solving }\end{array}$ & 4.3 & 4.8 & 4.4 & 4.5 & 4.5 \\
\hline $\begin{array}{l}\text { 8c. Determine the impact of engineering solutions } \\
\text { in a global and societal context }\end{array}$ & 4.2 & 4.5 & 4.8 & 4.0 & 4.0 \\
\hline 9a. Can explain professional practice attitudes & 4.3 & 4.3 & 4.6 & 4.0 & 4.5 \\
\hline 9b. Can explain leadership principles and attitudes & 4.4 & 4.5 & 4.5 & 4.0 & 4.5 \\
\hline $\begin{array}{l}\text { 9c. Can explain management concepts and } \\
\text { processes }\end{array}$ & 4.4 & 4.6 & 4.6 & 4.5 & 4.5 \\
\hline 9d. Can explain concepts of business practices & 4.4 & 4.5 & 4.6 & 4.5 & 4.5 \\
\hline $\begin{array}{l}\text { 9e. Can explain public policy and public } \\
\text { administration }\end{array}$ & 4.7 & 4.8 & 4.6 & 4.5 & 4.5 \\
\hline
\end{tabular}

Table 3. Alumni and employer assessment of program outcomes 
The employers did feel that the alumni did not have the same skill development as the other outcomes in demonstrating the impact of engineering solutions in a global and societal context, professional attitudes, and leadership principles and attitudes. The local focus of the firms and the limited leadership opportunities for new Engineering-in-Training (EIT) engineers would severely limit rapid development through on-the-job experiences. The results did highlight for the program that these outcomes may require more emphasis within the curriculum such that alumni may more aggressively take on leadership roles when opportunities arise. The employers also did not feel that demonstrating the impact of engineering solutions in a global and societal context was as appropriate, and from the East Texas focus of the firms the result is expected. As with any survey, the perception of those being surveyed must be considered.

The transition to a need to understand and demonstrate the impact of engineering solutions in a global and societal context within all engineering firms is somewhat similar to the transition by structural engineers from Allowable Stress Design (ASD) to Load Resistance and Factored Design (LRFD) for steel and reinforced concrete design a number of years ago. A major portion of the transition work was completed within universities through their preparation of the next generation of employees. (ASCE, 2004) The universities researched the methodologies, developed new techniques, and taught the new LRFD techniques that are now the standard in most structural firms. The firms were able to make the necessary senior level hires to manage new hires through a successful transition to the new structural analysis and design techniques. Could a similar process that provides some level of stability within a company be used during the development of required global skills in all employees?

A key point from the data in Table 3 is that the employers did not feel that an outcome such as demonstrating the impact of engineering solutions in a global and societal context was inappropriate at all, just not as important for their firm. On the other hand, the employers provided a maximum score not only on the alumni demonstration, but the appropriateness of demonstrating proper analysis of a situation and making appropriate professional and ethical decisions. A large step towards the desired global skill set. Many programs are still investigating, applying, and assessing how, where, and how much demonstration of each professional skill is required within engineering problem solving.

\section{A possible process to improve professional skills}

Can professional (global) skills be taught? Should ABET use Bloom's taxonomy to elevate and demonstrate the professional outcomes? What techniques are best to assess professional outcomes? Every program is challenged with how best to teach and then assess the demonstration of each outcome, but especially professional outcomes. As a PEV, the data and assessment of professional outcomes were the hardest to interpret and evaluate for proper demonstration based on the wording used by ABET (ability, recognize, understand). The use of action verbs with each outcome would greatly decrease the uncertainty of whether a program has demonstrated accomplishment of an outcome.

The UT Tyler program used the following process to teach and then assess the professional outcomes. First, action verbs were associated with an appropriate Bloom's level, and more recently with the levels proscribed within the BOK II (Table 1). The ABET professional outcomes (3.d) multi-disciplinary teams, (3.g) communicate effectively, (3.i) life-long learning, and (3.j) contemporary issues are being addressed in multiple courses and the two- 
semester senior design (capstone) courses (CENG 4115/4315). ABET outcome (3.h) broad education is addressed within the confines of the healthy Core (44 credit hours) program at UT Tyler, but are students making the connection between the humanities and social sciences that they are taking and how these disciplines influence engineering design? This type of questioning most likely led to the adjustments from BOK I to BOK II where humanities and social sciences were elevated to an outcome. The BOK II has led many programs to begin the process of demonstrating all newly proposed outcomes. ABET Outcome (3.f) professional and ethical responsibility is addressed in the senior design and an Introduction to Ethics Course (sophomore year), but could students miss fully understanding and demonstrating this outcome when completing an engineering design since all of the work within the senior design is completed in teams?

The UT Tyler Civil Engineering Program decided to add a required course to the curriculum to ensure coverage of the professional topics in the title as well as integration of the other professional skills. The course is CENG 4341 Leadership, Public Policy, Business Practices, and Asset Management (Figure 1, second semester, senior year) which provides coverage of the three new outcomes in the BOK I (represented by PO 9) as well as demonstration of parts of PO 6, 7, and 8 (Welch, 2010a; 2010b; CENG, 2009). Formal assignment of embedded indicators to courses based on ability to demonstrate an outcome as well as annual assessment of these embedded indicators collected not only provided BOK compliance, but also accreditation through ABET (Welch, 2009a). CENG 4341 synergistically assisted students in seeing the big design picture and the nuances of teamwork, leadership and management required in internships prior to the senior year, and within the two-semester senior design (CENG 4115/4315) by analyzing and discussing solutions to leadership issues seen during the one credit hour CENG 4115 in the fall and current public policy affecting engineering projects in Texas, business practices that could constrain their capstone project design as well as how well they have been managing their personnel assets within their team during CENG 4315 in the spring. Even though some public policy is being covered in environmental engineering, the in-depth coverage of public policy and administration within CENG 4341 along with leadership, business practices, asset management and other professional skills provides a synergistic meshing of these multiple professional practice issues as they occur within practice. The course also provides demonstration of ethical responsibility, contemporary issues, and life-long learning.

\subsection{Leadership, public policy, business practices, asset management, CENG 4341}

CENG 4341 is comprised of four modules each with papers and an exam leading to a comprehensive final exam. The original idea was to draw upon the expertise across campus and have the individual teaching a course covering the topic to develop a 10 lesson block with an exam (i.e., team teaching). When the issue of how to give credit for one-fourth of a course became a stumbling block, the author decided to develop each block himself. Upon reflection of the order of topics to develop a richer experience as well as provide linkage to additional professional topics, it was obvious that all of the professional topics focus on the engineer being a leader within their firm - so it is covered first. Public policy affects a firm's business practices and it takes leaders within government for public policy to be enacted. So it was taught next followed by business practices. The key focus in small business practices (a large number of civil engineering firms are considered small) is the development of a business plan which is affected by public policy and the leaders within the firm. Once the business plan is in place, leaders manage firm assets to accomplish assigned tasks and 
missions to meet the desired level of business performance. Sometimes a single focused nontechnical course is more synergistic for the learning process than inserting single or multiple lessons into existing technical courses.

\subsection{Senior design, CENG 4115/4315}

The senior design experience (CENG 4115/4315) within the UT Tyler CE Program (many programs refer to this as a 'capstone' course) is a 4 credit, 2 semester Senior Design course that has been conceived to do the following:

1. Give students a real-world, design office design experience tackling an open-ended design scenario that encompasses high level (Bloom et. al., 1956) cognitive thinking across seven CE sub-disciplines

2. Ensure students wrestle with professional issues such as communication with engineers, policy makers and the public

3. Ensure students are faced with issues associated with typical design constraints such as regulatory, economic, environmental, social, political, ethical, health and safety, constructability, and sustainability in a multi-disciplinary design.

4. Provide a platform where student performance against the ABET general criteria for engineering programs (3 a-k ) (ABET 2011) and civil engineering program specific criteria can be assessed (basically BOK I now and BOK II in the future).

The senior design experience was tailored to ensure coverage of the appropriate program material - items (1) - (3) in the above list suggests this. In some ways, constructing the appropriate assessment vehicle(s) was a more considerable challenge. The open-ended nature of realistic design does not always lend itself to concrete assessment methodologies. So the creation of a time effective assessment scheme that forces an experience that includes coverage of all outcomes to include professional skills was a focus.

The UT Tyler CE Program's senior design experience is a two course sequence, with CENG 4115 a one credit fall offering that introduces the students to the year's project through activities up to $35 \%$ design completion, and CENG 4315 a three credit spring offering that takes the project to $100 \%$ design completion. The experience centers on a multidisciplinary design project. Ideally, this project is aligned with an actual project being designed or constructed in the local area, so that at the end of the project students can review parallel plans and designs that have been professionally produced. The 2007-2008 project was a new UT Tyler art complex (completed in 2009), 2008-2009 project was renovation and expansion of the University Center (completed in 2010), 2009-2010 project was an outdoor multi-use amphitheater at UT Tyler, the 2010-2011 project is a realignment of Lazy Creek and Patriot Avenue at the south-west corner of campus, and the 2011-2012 project will be the development of a parcel of university property for an intramural complex and campus shops and eateries.

CENG 4115 begins with a review of the 9 step engineering design process (Woodson, 1966) and primarily revolves around targeted submittals at typical early project milestones - $10 \%$ and $35 \%$ submittals. A discussion of nine primary constraints to engineering design (sustainability, environmental, constructability, economics, ethics, political, social, technology, and public health and safety) follows, and these are emphasized throughout the experience such that the program requires consideration of all nine. In preparation for the $10 \%$ submittal, the course involves client meetings during which students gather needs, functionality requests and client driven constraints. A site orientation visit follows, and the class becomes fully enmeshed in the design project for the rest of the academic year. Each 
Department of Civil Engineering

Bachelor of Science in Civil Engineering 2008-2009 Curriculum

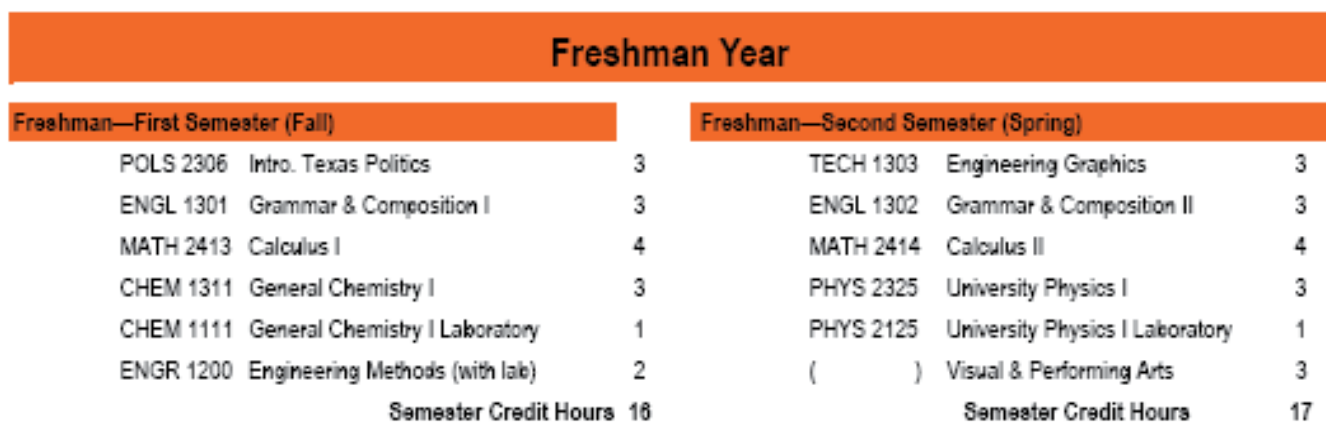

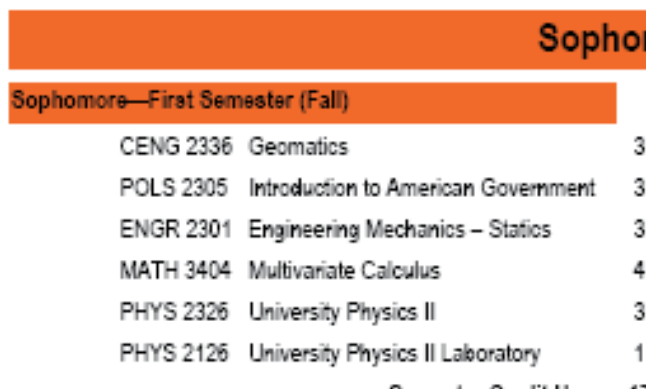

Semester Credit Hours 17

\begin{tabular}{|c|c|c|}
\hline \multicolumn{3}{|c|}{ Sophomore-Second Semester (Spring) } \\
\hline CENG 2353 & Civil Engineering Measurement & 3 \\
\hline MENG 3306 & Mechanics of Materials & 3 \\
\hline MATH 3305 & Differential Equations & 3 \\
\hline ENGR 2302 & Engineering Mechanics - & 3 \\
\hline ECON 2302 & Microeconomics & 3 \\
\hline PHIL 2306 & Introduction to Ethics & 3 \\
\hline & Semester Credit Hou & 18 \\
\hline
\end{tabular}

\begin{tabular}{ll}
\multicolumn{2}{c}{ Junior } \\
\hline Junior-First Semeater (Fall) \\
CENG 3434 Civil Engr. Materials, Codes \& Specs & 4 \\
MENG 3310 Fluid Mechanics & 3 \\
ENGR 3301 Probakility \& Statistics for Engineers & 3 \\
CENG 4339 CE Construction Management & 3 \\
( ) Adaitional Science Elective & 3
\end{tabular}

Semester Credit Hours 16

\section{Junior-Second Semester (Spring)}

CENG 3361 Acpled Engineering Hydrology 3

CENG 3351 Transportation Engr. Systems 3

CENG 3371 Intro to Environmental Engineering 3

CENG 3336 Soil Mechanics 3

CENG 3325 Structural Analysis 3

Semester Credit Hours 15

\begin{tabular}{lr} 
& \multicolumn{2}{c}{ Senior } \\
\hline Senior-First Semester (Fali) & 3 \\
CENG 4351 Trafic Eng: Opns \& Ctrl (w Lab) & 3 \\
CENG 4317 Structural Steel Design & 3 \\
CENG 4371 Environmental Engineering Design & 1 \\
CENG 4115 Serior Design I & 3 \\
HIST 1301 United States History I & 1 \\
ENGR 4109 Serior Seminar &
\end{tabular}

Semester Credit Hours 14
Senior-Second Semeater (Spring)

$\begin{array}{lll}\text { CENG } 4341 & \text { Leadership, Business, Pub Pol, } & 3 \\ \text { CENG } 4315 & \text { Senior Design II } & 3 \\ \text { HIST } 1302 & \text { United States History II } & 3 \\ \text { ( ) Tech Elective } & 3 \\ \text { ( ) World European Literature } & 3\end{array}$

Semester Credit Hours 15

Total Program Credit Hours:128

Fig. 1. UT Tyler curriculum 
senior design course (CENG 4115/4315) includes lessons, assignments and other activities supplemental to the design project. These are additional advanced design topics that prepare students to complete the design project (such as activities around wetland identification, ESA development, etc.) or that bridge sub-disciplines covered in other courses (such as parking lot material and roadway section design that bridges structural, geotechnical and transportation concerns). These advanced topics also close holes in the program identified through other assessment vehicles or the previous year's senior design assessment. Other successful features of the experience are 'fact finding missions' (FFM) that task student design teams with finding information (e.g., local code requirements regarding architectural features, ADA building requirements, ESA interviews, traffic signaling requirements, etc.) on their own that has not been covered elsewhere in the curriculum. FFM simulate real-world design practice and give an opportunity for self directed learning (lifelong learning 3.i.). (Welch \& McGinnis, 2010) CENG 4115 culminates with the submission of a 35\% design package that is graded over the semester break.

The students are immediately enmeshed back in the project when they receive feedback on the $35 \%$ design package on the first day of CENG 4315 the next semester. They are required to present this design to faculty and clients within the two weeks, after making necessary changes and developing an architectural and/or site model, a K'Nex structural model if a bridge, building, etc. is required, and a stand-alone presentation board. CENG 4315 continues to $100 \%$ design completion with an intermediate review at $65 \%$ that is structured to simulate a desk-side review with an engineering supervisor in a design office. The $65 \%$ review gives students practice in identifying the critical parts of a project to relay to a supervisor - there will usually not be time to cover every detail in a design review meeting, and identifying what is important is a critical skill. At $100 \%$ design completion, students submit their design package and deliver a final oral presentation. At this time they field questions from working engineers (evaluation panel) regarding their design, receive feedback from clients and faculty, and review actual plans from existing designs if they exist and time permits. (Welch \& McGinnis, 2010)

\subsection{Demonstration of outcomes}

A portion or the entire assignment in every course can be used as an embedded indicator for an outcome if the assignment is properly designed. In CENG 4341 the use of action verbs (Table 4) ensures that the assignment focuses the students work to demonstrate their knowledge, skills and attitudes at the given Bloom's level desired by the program even prior to the levels being defined within BOK II. As a departmental team, embedded indicators are assigned to each course based on first the perceived ability of the course projects to demonstrate the outcome, and after annual assessments based on the need to spread the coverage of outcomes across the curriculum. (Welch, 2009b)

Grading of each major milestone in the senior design (10\% design report, 35\% design report, $35 \%$ oral presentation, $65 \%$ Review Reports, $100 \%$, and $100 \%$ oral presentation) is done using 'cut sheets' - rubrics that incorporate the key features of the design. Figure 2 (professional skill - asset management, construction management schedule) shows a portion of the grading cut sheet from the $35 \%$ design submission as an example (modified from rubrics used at the United States Military Academy (Meyer \& Bert, 2007)). The grading of the senior design is accomplished by the assigned instructor and the discipline expert in the department for each discipline section. Industry partners review the design using the rubrics for comment during the final presentation and submission. 


\begin{tabular}{|l|c|}
\hline \multicolumn{1}{|c|}{ Assignment } & Outcome \\
\hline Paper 1 - define your leadership skills and attitudes. & $9 \mathrm{~b}$ - Leadership \\
\hline $\begin{array}{l}\text { Paper 3 - define your leadership strategies for ensuring your } \\
\text { Capstone team is successful. }\end{array}$ & $9 \mathrm{~b}$ - Leadership \\
\hline $\begin{array}{l}\text { Paper 4 - Define public policy while considering T. Boone Pickens } \\
\text { and West Texas Water rights }\end{array}$ & $9 \mathrm{e}$ - Public Policy \\
\hline $\begin{array}{l}\text { Paper 5 - Define and provide the pros and cons for wetland public } \\
\text { policy }\end{array}$ & $9 \mathrm{e}$ - Public Policy \\
\hline $\begin{array}{l}\text { Paper 6 - define a business plan through the eyes of a junior } \\
\text { engineer }\end{array}$ & $9 \mathrm{~d}$ - Business \\
\hline $\begin{array}{l}\text { Paper 7 - explain how you would improve the efficiency of assets } \\
\text { used within the company you worked for this past summer }\end{array}$ & $9 \mathrm{c}$ - Management \\
\hline $\begin{array}{l}\text { Exam 3, Question 1, define and explain business practices } \\
\text { Exam 3, Question 4, Define and explain asset management though } \\
\text { lean six sigma and waste limitation }\end{array}$ & $9 \mathrm{~d}$ - Business \\
\hline
\end{tabular}

Table 4. Portion of embedded indicators in CENG 4341

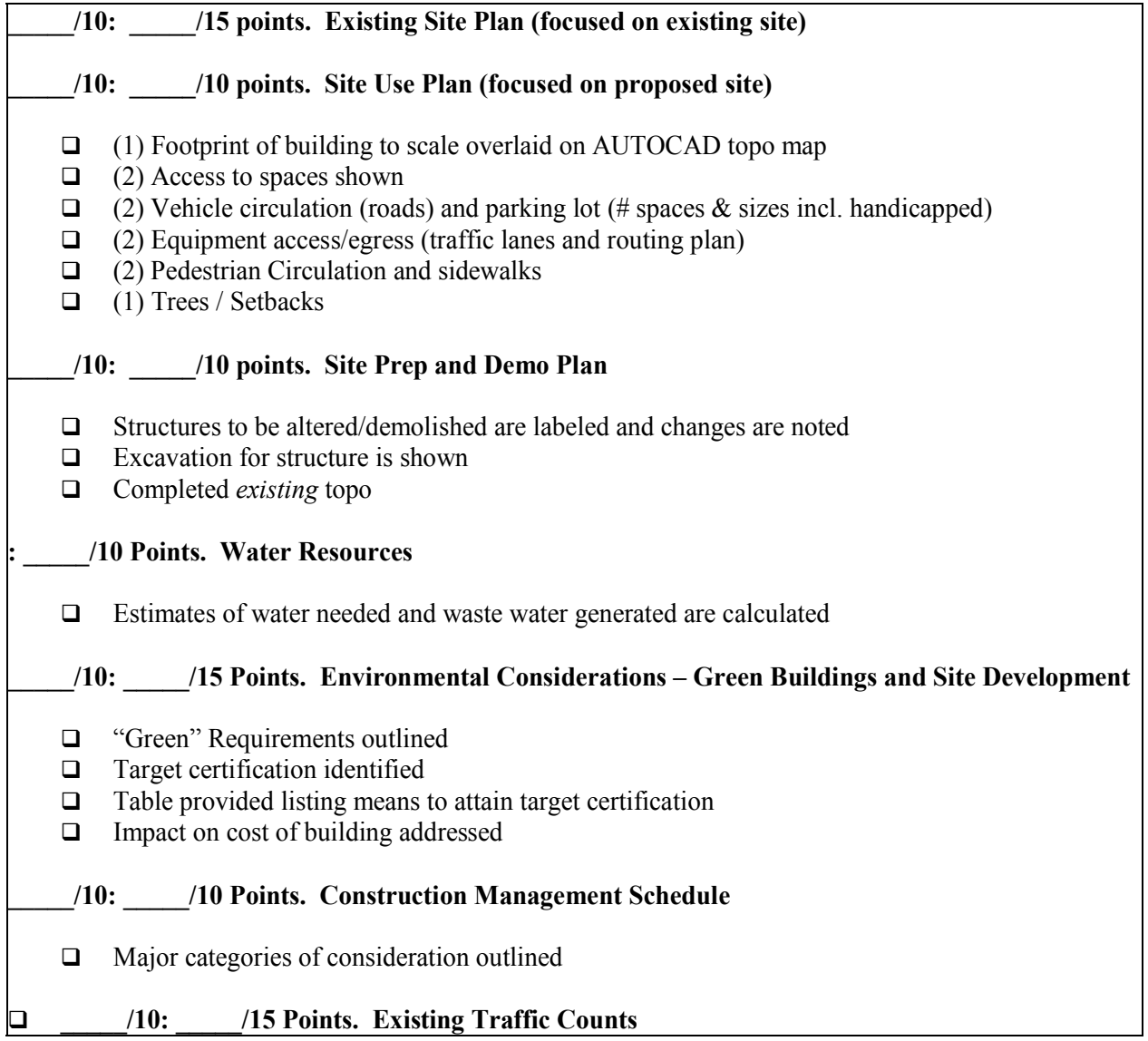

Fig. 2. Portion of the grading rubric for $35 \%$ design submission 


\section{Assessment activities and results}

\subsection{CENG 4341}

The students feel that their understanding of professional topics improved due to in-class discussions defining these skills, how these skills were applied in their internships with indepth analysis of their supervisors and companies, and then applying their understanding to their senior design teams using the newly acquired skills. Figure 3 displays the Fall 2007 (071S) and 2008 (081S) and Spring 2010 (092S) data of the students perception of how well they understood and demonstrated the new professional skills within the CE program criteria. Student comments from Fall 2007 pointed to the need to increase the number of papers of smaller length to allow greater specificity for each paper when studying the numerous topics within the course. They also asked for case studies and guest speakers. (CENG, 2009) The suggestions were applied during the next offering of the course with the resulting improvements (081S, Figure 3). Additionally, it must be noted that teaching the course the second time could have had some effect on the results. Student comments on the leadership section highlighted the limited ability to reflect on what was happening within the capstone teams (CENG 4115) with the leadership portion at the beginning of the fall semester, so CENG 4341 was moved to the spring semester of the senior year (Figure 1) and the second environmental engineering course was moved to the fall to improve environmental content coverage prior to the fall FE exam. Even though the course was moved to the spring and the instructor taught three courses during that semester, the assessment remained fairly consistent with the ability to apply leadership principles being rated the highest (Figure 3).

\section{CENG 4341 Muti-Year Course Objectives}

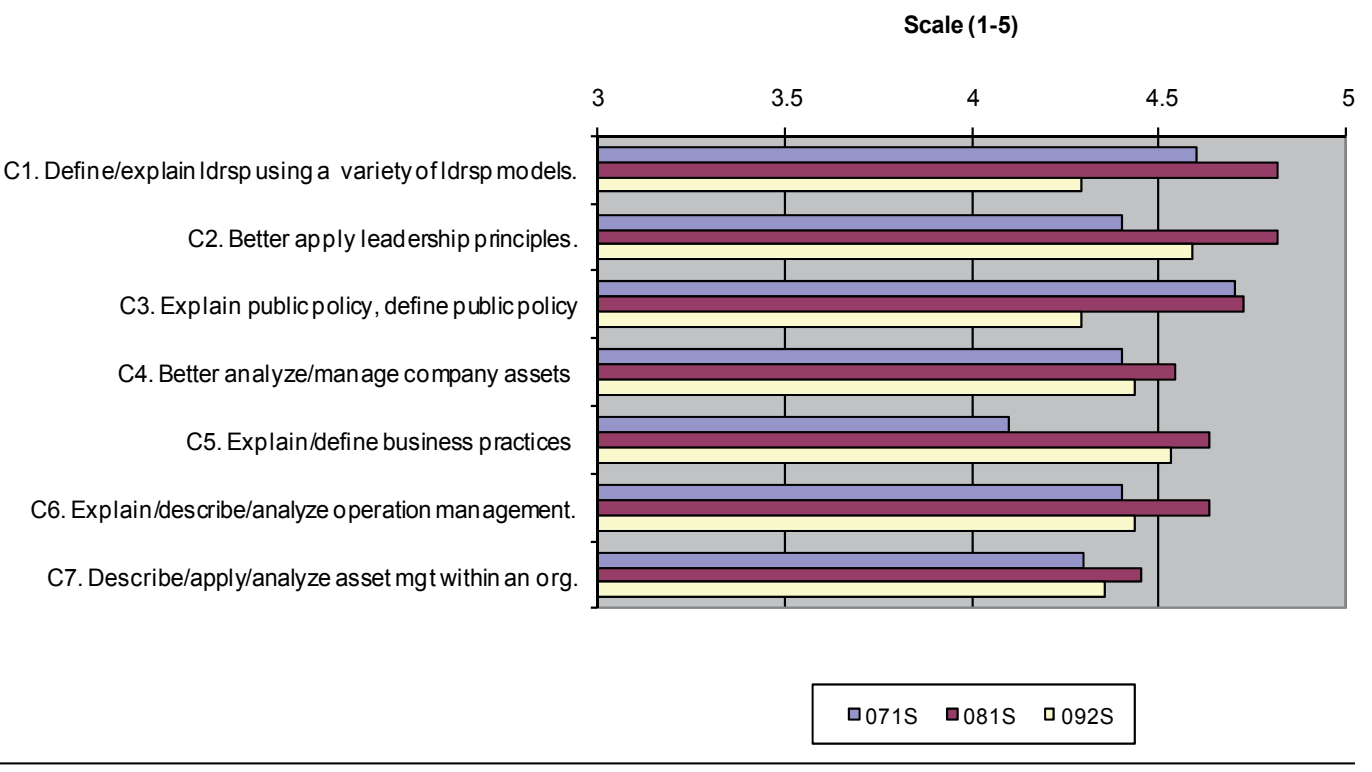

Fig. 3. CENG 4341 Course Objectives Assessment 


\subsection{Senior design}

As noted, the UT Tyler CE program has embraced the 'embedded indicator' approach to assessment (supplemented by several other methods of assessment such as capstone, external exams, internal gateway exams, and surveys). However, in a large, open-ended design project, a dilemma results if too many separate submissions are required. Too many assignments can cause the problem to be over-defined. A key part of open-ended design problems is that students must develop skills to properly define the scope and natural breaking points of the problem themselves. Assessment methods requiring subdividing the project into multiple predefined problem sets were thus eliminated. Furthermore, grading, managing and providing feedback to multiple student design teams as they pursue different solution strategies is already a time consuming endeavor for the course director. The program administrator strongly desired an assessment method that did not add an undue administrative burden on to the course director.

\begin{tabular}{|c|c|c|c|c|c|c|c|c|}
\hline \multirow{2}{*}{$9 \mathrm{c}$} & 10\%R Long Lead & 0 & 5 & 0.0 & $10 \% \mathrm{R}$ & 8 & 0 & $14 \quad 57.1$ \\
\hline & $10 \% \mathrm{R}$ Cost Estimate & 8 & 9 & 88.9 & $35 \%$ & 5 & / & 5100.0 \\
\hline & $35 \%$ Cost Estimate & 5 & 5 & 100.0 & $65 \%$ & & & \\
\hline & $100 \%$ Cost & 5 & 5 & 100.0 & $100 \%$ & 5 & / & $\begin{array}{ll}5 & 100.0\end{array}$ \\
\hline & $35 \%$ OP Prep & 30.0 & 40.0 & 75.0 & $35 \%$ Oral & 72.0 & & 90.080 .0 \\
\hline & $35 \%$ OP Method & 42.0 & 50.0 & 84.0 & $100 \%$ Oral & 47.5 & & 55.086 .4 \\
\hline & 100\% OP Prep & 21.3 & 25.0 & 85.0 & Total & 137.5 & / & 16981.4 \\
\hline & 100\% OP Method & 26.3 & 30.0 & 87.5 & & & & \\
\hline & & & & & & & & \\
\hline $9 \mathrm{e}$ & $10 \%$ R Set-backs & 0.0 & 5 & 0.0 & $10 \% \mathrm{R}$ & 18.4 & 0 & 2963.4 \\
\hline & 10\%R Access/Eggress & 2.4 & 5 & 48.0 & $35 \%$ & 73.6 & 0 & $86 \quad 85.6$ \\
\hline & 10\% R ESA1 not used in 2010 & 0.0 & 0 & \#DIV /0! & $65 \%$ & & & \\
\hline & 10\%R Life Safety & 8.0 & 10 & 80.0 & $100 \%$ & 34.2 & 0 & 38.289 .5 \\
\hline & 10\% R Constraint (Politics) & 3.0 & 4 & 75.0 & $35 \%$ Oral & & & \\
\hline & $10 \% \mathrm{R}$ ADA & 5.0 & 5 & 100.0 & $100 \%$ Oral & & & \\
\hline & $35 \%$ Trees-Setbacks & 1.0 & 1 & 100.0 & Total & 126.2 & / & 153.282 .4 \\
\hline & $35 \%$ Life Safety & 4.0 & 5 & 80.0 & & & & \\
\hline & 35\% Green Buildings & 11.0 & 15 & 73.3 & & & & \\
\hline & 35\% Constraint (Politics) & 4.6 & 5.0 & 92.0 & & & & \\
\hline & $35 \%$ ESA 1 & 23.0 & 25.0 & 92.0 & & & & \\
\hline & $35 \%$ SPPP & 30.0 & 35 & 85.7 & & & & \\
\hline & $100 \%$ setbacks & 0.2 & 0.2 & 100.0 & & & & \\
\hline & $100 \%$ Life Safety & 3.0 & 3 & 100.0 & & & & \\
\hline & 100\% Env. Green Bldgs & 11.0 & 15 & 73.3 & & & & \\
\hline & $100 \%$ Asbestos Not Used 20 & & & \#DIV /0! & & & & \\
\hline & 100\% Constrain (Politics) & 5.0 & 5.0 & 100.0 & & & & \\
\hline & 100\% Social, Politica & 15.0 & 15 & 100.0 & & & & \\
\hline
\end{tabular}

Table 5. Matrix 'bucket' for program outcome 9c and 9e (portion of CE Program Criteria Professional Outcomes). Dark Green - Acceptable, Light Green - Not enough points as assigned, Yellow - Marginal, Red - Not Acceptable, \#Div/0! - highlights items not currently considered 
Fortunately the faculty were able to evaluate a process followed at USMA for assessing their capstone course that focused heavily on four CE sub-disciplines. (Meyer \& Bert, 2007) Inspired by the USMA approach, the UT Tyler CE Program created a matrix that tied specific portions of the grade to specific program outcomes while covering seven CE subdisciplines. Items on each cut-sheet (Figure 2) were linked in the matrix to one or more program outcomes. As each item in a cut-sheet is graded, these grades accumulate in 'buckets' for each outcome. Table 5 depicts an excerpt of the matrix showing the activities accumulating in the $9 \mathrm{c}$ and $9 \mathrm{e}$ bucket (construction management and public policy and administration). The benefits of this approach are numerous:

1. The overall weight of the grade that is ultimately assigned to each program outcome can be readily identified. Like most of us, students typically focus their efforts where they identify the greatest impact on their grade can be made (i.e., the activities with the most points assigned). Thus, a review of all of the points assigned to each program outcome can reveal if areas without enough focused attention exist within the capstone. Of course, this must be done in conjunction with other methods of assessment that look at the whole program. Sometimes areas that are covered extensively in other areas of the program can be lightly covered in the capstone to allow effort and the limited time within the capstone to be expended properly.

2. Areas where students achieve below an accepted standard of performance can be readily identified. Within the UT Tyler CE Program the performance standard is currently set as $70 \%$ - scores above the threshold are considered to demonstrate successful completion of an outcome. This allows a simple determination of which program outcomes need more attention within the program.

Table 6 shows the assessment matrix from 2007-2008 and 2008-2009. It is shaded in several ways to show key features related to the two points noted above (color scheme within titles). The overall points allocated to a particular outcome is coded to show outcomes below 50 and 100 points (note that the exact number of points for this threshold is somewhat arbitrary and can vary from year to year depending on the overall points for the senior design project) to clearly show areas with minimal points assigned that need more emphasis in future years.

\subsection{Assessment results}

Since the senior design experience is being used to try and assess all program outcomes, points are shifted to reflect the proper distribution or desired effort across the outcomes. Additionally, the percentages earned by each design team and overall are shaded differently for scores below and above $70 \%$ and above $80 \%$. This methodology provides a visual determination of areas where students do not achieve an acceptable standard on an outcome and areas where students are excelling in achieving outcomes. Note, the format changed in Table 6 from 2007-2008 to 2008-2009 because of the program's assessment of the assessment process and how the data should be displayed (i.e., closing the loop).

The strength of this approach is perhaps best illustrated by discussing the changes made as a result of this assessment vehicle. Several major changes to the course sequence from year 1 (2007) to year 2 (2008) to year 3 (2009) resulted, but only the one for professional skills is provided here: more Emphasis Needed in Professional Practice Skills (Outcomes 4, 6-9); faculty not totally pleased with overall professional skills development in 20082009 so increased total points in outcomes 4 and 6-9 and moved CENG 4341 to spring semester. 


\begin{tabular}{|c|c|c|c|c|c|c|c|c|c|}
\hline & \multicolumn{3}{|c|}{ BS } & \multicolumn{3}{|c|}{ NU } & \multicolumn{3}{|c|}{ Average } \\
\hline & Raw & Avail & Avg & Raw & Avail & Avg & Raw & Avail & Avg \\
\hline $1 a$ & $130.0 /$ & 157.0 & 82.8 & $130.0 /$ & 157.0 & 82.8 & $130.0 /$ & 157.0 & 82.8 \\
\hline $1 b$ & $0.0 /$ & 0.0 & \#DIV/0! & $0.0 /$ & 0.0 & \#DIV/0! & $0.0 /$ & 0.0 & \#DIV/0! \\
\hline 1c & $193.0 /$ & 225.0 & 85.8 & $195.5 /$ & 225.0 & 86.9 & $194.3 /$ & 225.0 & 86.3 \\
\hline $1 d$ & $493.2 /$ & 633.2 & 77.9 & $492.1 /$ & 633.2 & 77.7 & $492.7 /$ & 633.2 & 77.8 \\
\hline 2 & $44.5 /$ & 61.0 & 73.0 & $42.4 /$ & 61.0 & 69.5 & $43.4 /$ & 61.0 & 71.2 \\
\hline $3 a$ & $195.0 /$ & 206.0 & 94.7 & $175.3 /$ & 206.0 & 85.1 & $185.1 /$ & 206.0 & 89.9 \\
\hline $3 b$ & $10.0 /$ & 10.0 & 100.0 & $9.3 /$ & 10.0 & 92.7 & $9.6 /$ & 10.0 & 96.4 \\
\hline 4 & $0.0 /$ & 0.0 & \#DIV/0! & $0.0 /$ & 0.0 & \#DIV/0! & $0.0 /$ & 0.0 & \#DIV/0! \\
\hline $5 a$ & $333.4 /$ & 438.8 & 76.0 & $329.6 /$ & 438.8 & 75.1 & $331.5 /$ & 438.8 & 75.5 \\
\hline $5 b$ & $32.3 /$ & 51.3 & 62.9 & $31.2 /$ & 51.3 & 60.8 & $31.7 /$ & 51.3 & 61.9 \\
\hline $5 c$ & $153.3 /$ & 177.8 & 86.2 & $148.4 /$ & 177.8 & 83.5 & $150.8 /$ & 177.8 & 84.9 \\
\hline $5 d$ & $139.7 /$ & 169.7 & 82.3 & $140.0 /$ & 169.7 & 82.5 & $139.8 /$ & 169.7 & 82.4 \\
\hline $5 e$ & $111.4 /$ & 118.3 & 94.2 & $97.3 /$ & 118.3 & 82.3 & $104.4 /$ & 118.3 & 88.2 \\
\hline $6 a$ & $402.2 /$ & 440.4 & 91.3 & $369.9 /$ & 440.4 & 84.0 & $386.1 /$ & 440.4 & 87.7 \\
\hline $6 b$ & $50.0 /$ & 55.0 & 90.9 & $49.8 /$ & 55.0 & 90.5 & $49.9 /$ & 55.0 & 90.7 \\
\hline 7 & $593.7 /$ & 643.7 & 92.2 & $542.4 /$ & 643.7 & 84.3 & $568.1 /$ & 643.7 & 88.3 \\
\hline $8 a$ & $0.0 /$ & 0.0 & \#DIV/0! & $0.0 /$ & 0.0 & \#DIV/0! & $0.0 /$ & 0.0 & \#DIV/0! \\
\hline $8 b$ & $113.8 /$ & 125.0 & 91.0 & $112.4 /$ & 125.0 & 89.9 & $113.1 /$ & 125.0 & 90.5 \\
\hline $8 c$ & $114.5 /$ & 126.2 & 90.7 & $113.1 /$ & 126.2 & 89.6 & $113.8 /$ & 126.2 & 90.1 \\
\hline $9 a$ & $436.7 /$ & 475.4 & 91.9 & $387.8 /$ & 475.4 & 81.6 & $412.3 /$ & 475.4 & 86.7 \\
\hline $9 b$ & $0.0 /$ & 0.0 & \#DIV/0! & $0.0 /$ & 0.0 & \#DIV/0! & $0.0 /$ & 0.0 & \#DIV/0! \\
\hline $9 c$ & $171.1 /$ & 180.9 & 94.6 & $143.4 /$ & 180.9 & 79.3 & $157.3 /$ & 180.9 & 86.9 \\
\hline $9 d$ & $271.9 /$ & 290.4 & 93.7 & $236.3 /$ & 290.4 & 81.4 & $254.1 /$ & 290.4 & 87.5 \\
\hline $9 e$ & $111.2 /$ & 124.2 & 89.5 & $105.8 /$ & 124.2 & 85.2 & $108.5 /$ & 124.2 & 87.4 \\
\hline
\end{tabular}

Table 6. Assessment matrix: (a) 2007-2008; (b) 2008-2009

Table 6. (a) Dark Green - Acceptable, Light Green - Not enough points as assigned, Yellow - Marginal, Red - Not Acceptable, \#Div/0! - highlights items not currently considered

\begin{tabular}{|c|c|c|c|c|c|c|c|c|c|c|c|c|}
\hline Outcome & \multicolumn{3}{|c|}{ Sekai } & \multicolumn{3}{|c|}{ AAA } & \multicolumn{3}{|c|}{ GMC } & \multicolumn{3}{|c|}{ Average } \\
\hline & Raw & Avail & Avg & Raw & Avail & Avg & Raw & Avail & Avg & Raw & Avail & Avg \\
\hline $1 \mathbf{a}$ & $139.0 /$ & 152.0 & 91.4 & $145.0 /$ & 152.0 & 95.4 & $140.7 /$ & 152.0 & 92.6 & $141.6 /$ & 152.0 & 93.1 \\
\hline 1b & $0.0 /$ & 0.0 & \#DIV/0! & $0.0 /$ & 0.0 & \#DIV/O! & $0.0 /$ & 0.0 & \#DIV/O! & $0.0 /$ & 0.0 & \#DIV/0! \\
\hline 1c & $192.1 /$ & 220.0 & 87.3 & $205.0 /$ & 220.0 & 93.2 & $197.1 /$ & 220.0 & 89.6 & $198.1 /$ & 220.0 & 90.0 \\
\hline 1d & $593.8 /$ & 668.2 & 88.9 & $592.2 /$ & 668.2 & 88.6 & $541.7 /$ & 668.2 & 81.1 & $575.9 /$ & 668.2 & 86.2 \\
\hline 2 & $101.8 /$ & 131.0 & 77.7 & $75.8 /$ & 131.0 & 57.9 & $95.4 /$ & 131.0 & 72.8 & $91.0 /$ & 131.0 & 69.5 \\
\hline $3 a$ & $253.6 /$ & 281.0 & 90.2 & $230.6 /$ & 281.0 & 82.1 & $229.3 /$ & 281.0 & 81.6 & $237.8 /$ & 281.0 & 84.6 \\
\hline $3 b$ & $114.5 /$ & 135.0 & 84.8 & $114.7 /$ & 136.0 & 84.4 & $128.8 /$ & 135.0 & 95.4 & $119.4 /$ & 135.0 & 88.2 \\
\hline 4 & $1061.3 \%$ & 1285.1 & 82.6 & $1035.7 /$ & 1285.1 & 80.6 & $1069.0 /$ & 1285.1 & 83.2 & $1055.3 /$ & 1285.1 & 82.1 \\
\hline $5 a$ & $415.2 /$ & 450.5 & 92.2 & $420.1 /$ & 450.5 & 93.2 & $383.3 /$ & 450.5 & 85.1 & 406.21 & 450.5 & 90.2 \\
\hline $5 b$ & $138.2 /$ & 199.6 & 69.2 & $118.3 /$ & 199.6 & 59.3 & $181.7 /$ & 199.6 & 91.0 & $146.1 /$ & 199.6 & 73.2 \\
\hline $5 c$ & $234.8 /$ & 294.0 & 79.9 & 218.2 / & 294.0 & 74.2 & $232.0 /$ & 294.0 & 78.9 & $228.3 /$ & 294.0 & 77.7 \\
\hline $5 d$ & $137.2 /$ & 178.0 & 77.1 & $161.1 /$ & 178.0 & 90.5 & $134.6 /$ & 178.0 & 75.6 & $144.3 /$ & 178.0 & 81.1 \\
\hline $5 e$ & $136.0 /$ & 163.0 & 83.4 & $118.0 /$ & 163.0 & 72.4 & $137.3 /$ & 163.0 & 84.3 & $130.4 /$ & 163.0 & 80.0 \\
\hline $6 a$ & 445.7 I & 535.0 & 83.3 & $450.0 /$ & 536.0 & 84.0 & $448.2 /$ & 535.0 & 83.8 & $448.0 /$ & 535.0 & 83.7 \\
\hline $6 b$ & $34.0 /$ & 39.0 & 87.2 & $33.8 /$ & 39.0 & 86.6 & $36.1 /$ & 39.0 & 92.5 & $34.6 /$ & 39.0 & 88.8 \\
\hline 7 & $626.4 /$ & 672.0 & 93.2 & $590.3 /$ & 672.0 & 87.8 & $572.2 /$ & 672.0 & 85.1 & $596.3 /$ & 672.0 & 88.7 \\
\hline $8 a$ & $15.0 /$ & 20.0 & 75.0 & $14.0 /$ & 20.0 & 70.1 & $16.3 /$ & 20.0 & 81.3 & $15.1 /$ & 20.0 & 75.4 \\
\hline $8 b$ & $99.0 /$ & 110.0 & 90.0 & $188.0 /$ & 246.0 & 76.4 & $215.0 /$ & 245.0 & 87.8 & $167.3 /$ & 245.0 & 84.7 \\
\hline $8 c$ & $131.3 /$ & 159.2 & 82.5 & $115.0 /$ & 159.2 & 72.2 & $133.0 /$ & 159.2 & 83.5 & $126.4 /$ & 159.2 & 79.4 \\
\hline $9 a$ & 482.2 / & 545.0 & 88.5 & $484.1 /$ & 545.0 & 88.8 & $444.7 /$ & 545.0 & 81.6 & $470.3 /$ & 545.0 & 86.3 \\
\hline $9 b$ & $0.0 /$ & 0.0 & \#DIV/O! & $0.0 /$ & 0.0 & \#DIV/0! & $0.0 /$ & 0.0 & \#DIV/0! & $0.0 /$ & 0.0 & \#DIV/0! \\
\hline $9 c$ & 167.2 / & 189.0 & 88.5 & $167.4 /$ & 189.0 & 88.6 & $159.6 /$ & 189.0 & 84.5 & $164.8 /$ & 189.0 & 87.2 \\
\hline 9d & $279.8 /$ & 314.0 & 89.1 & $278.3 /$ & 314.0 & 88.6 & $264.3 /$ & 314.0 & 84.2 & $274.1 /$ & 314.0 & 87.3 \\
\hline $9 e$ & $132.2 /$ & 163.2 & 81.0 & $120.0 /$ & 163.2 & 73.5 & $130.9 /$ & 163.2 & 80.2 & $127.7 /$ & 163.2 & 78.2 \\
\hline
\end{tabular}

Table 6. (b) Light Green - Acceptable, Yellow - Marginal, Red - Not Acceptable, \#Div/0! highlights items not currently considered 
With the possible addition of new outcomes in the future, the program assessment is looking for more efficient methods of teaching and assessing outcome demonstration. Experience teaching CENG 4341 has provided insight into how much coverage is needed to actually demonstrate at the required BOK II level and with the possible requirement to decrease the number of credit hours even further due to budget constraints, the program is analyzing the possible conversion of the current ten hours on leadership in CENG 4341 to five hours with three hours in CENG 4115 and two hours in CENG 4315. Public policy could be completely covered in the two course environmental sequence with one hour in CENG 4315 to focus the senior design solution based on the current public policy issues. The program could convert ten hours on business practices in CENG 4341 to five lessons culminating in each team developing a business plan as part of the 100 percent submission in CENG 4315. The program could convert eight hours on asset management to four hours culminating in each team developing a construction management plan as part of the 35 and 100 percent submissions in CENG 4315 that includes management of people within the team. However, individual assignments from CENG 4341 could be used within the senior design courses to ensure each student can demonstrate accomplishment of the professional outcome before the team uses their combined skills to accomplish a team product within senior design. The increased requirements within the senior design to provide coverage of the professional outcomes will be reflected with increased point totals and requirements, both individual and team.

\begin{tabular}{|c|c|c|c|c|}
\hline \multicolumn{5}{|c|}{ Outcome 9c: Can explain management concepts and processes. } \\
\hline Direct Measures & Tab & Standard & $\begin{array}{c}\text { 2009-10 } \\
\text { Performance }\end{array}$ & $\begin{array}{c}\text { Historical } \\
\text { Average }\end{array}$ \\
\hline CENG 4339, HW 3, Pr 2 & 1 & 80.0 & 81 & \\
\hline CEG 4339, Final Exam, Question \#26 & 2 & 80.0 & 99.0 & 100 \\
\hline CENG 4341, Paper 7 & 3 & 80.0 & 89.7 & \\
\hline CENG 4341, Exam 3, Question 4 & 4 & 80.0 & 88.8 & \\
\hline CENG 4341, Final Exam Question & 5 & 80.0 & 94.5 & 81.7 \\
\hline CENG 4315, 100\% Submittal & & 80.0 & 87.2 & 86.9 \\
\hline Indirect Measures & & Standard & $\begin{array}{c}2009-10 \\
\text { Performance }\end{array}$ & $\begin{array}{c}\text { Historical } \\
\text { Average }\end{array}$ \\
\hline Question A22. Senior survey & & $4 / 5$ & $4.4 / 5$ & $4.35 / 5$ \\
\hline Question A22. Faculty survey & & $4 / 5$ & $4.2 / 5$ & $4.0 / 5$ \\
\hline Question A22. Alumni survey & & $4 / 5$ & $4.6 / 5$ & $4.2 / 5$ \\
\hline Question A22. Employer survey & & $4 / 5$ & $4.5 / 5$ & $3.75 / 5$ \\
\hline Curriculum Measures & & Standard & $\begin{array}{c}2009-10 \\
\text { Performance }\end{array}$ & $\begin{array}{c}\text { Historical } \\
\text { Average }\end{array}$ \\
\hline Completion of CENG 4341, CENG 4339 & & 5 & 5 & 5 \\
\hline \multicolumn{5}{|c|}{ 2009-10 Assessment: } \\
\hline
\end{tabular}

Table 7. Performance measures and results for Outcome 9c. 
Table 7 presents a representative excerpt from the annual program assessment for professional outcomes where the results of each assessment method are collated to allow an aggregate review of each outcome. As can be seen the outcome assessment within CENG 4341 and senior design (CENG 4315) are critical pieces demonstrating accomplishment of the professional outcomes. Note also the use of survey results as part of the multiple assessment methods used to provide a clearer picture. Due to the age of the department, the survey data is from alumni and employees within one year of graduation. The alumni and their employers will be assessed at the four and eight year marks as well.

\subsection{Results}

The program presented has been able to adequately demonstrate knowledge, skills and attitudes associated with professional topics demonstrated within CENG 4341, the senior design experience and other senior year courses. The program continues to fully integrate professional topics across the curriculum and has already seen improvement in student skill development within each group of seniors as compared to the previous graduating classes. As can be seen from Table 6, there were a number of professional outcomes not being assessed and number below 80 percent in 2007-2008, while more were being assessed and only two with below 50 points in 2008-2009 (PO 6b \& 8b). 2009-2010 results are not provided in this chapter due to the table's size; however, there was only one outcome with a result barely less than 80 percent and two with less than 100 points. The students are simply more comfortable with using their new skills due to more required repetition and focus within their undergraduate curriculum. The CE program has determined that the best method to integrate and assess demonstration of professional skills is to insert embedded indicators in appropriate courses. Requirements to consider professional skills are needed within the sophomore and junior years, while the seniors must address the professional skills within the 10,35 , and 100 percent design submittals.

The key has been identification of the required embedded indicators for each course before the assessment cycle begins and for each faculty member to establish which assignments before the semester begins will include demonstration of program outcomes, but especially professional outcomes such as leadership, the impact of engineering solutions, and consideration of contemporary issues. Adequate thought is required to craft assignments that not only demonstrate course objectives that feed seamlessly into demonstrating the "hard" outcomes like design and use of modern tools, but especially to demonstrate "professional" outcomes such as ethics, consideration of contemporary issues, leadership, business practices, and asset management. (Welch, 2009b)

\section{Current actions}

The faculty are experimenting with Public Policy coverage in the two course environmental sequence (CENG 3371 and 4371) since much of environmental activity is grounded in past and present public policy. With the current level of Bloom's taxonomy for the new outcomes within the CE program criteria (leadership, business practices, public policy and administration, and asset management) at Explain (PO 9, Table 1) (ABET, 2011; ASCE, 2004) which could be covered by 2-3 lesson blocks rather than the current use of a 10 lesson block, the program is studying if the minimal coverage of leadership, business practices, and asset management within the senior design two-course sequence as listed in Section 3.3 of this 
chapter as well as if possible additional embedded indicators within sophomore and junior year courses will be satisfactory. The consideration of modules of professional outcomes throughout the curriculum allows the program to consider accreditation of its master's program as well. (Welch, 2009b; 2010a) Without it, any student wanting to graduate from an accredited program would need to complete the undergraduate program before starting the graduate program to ensure coverage of all of the outcomes. Requiring accomplishment of modules will also allow students without an accredited undergraduate degree to take the accredited graduate degree and complete modules for outcomes not covered within their previous undergraduate program. This methodology will allow modules to be moved between courses without affecting the overall course structure or focus, while providing the program flexibility to meet defined outcomes as the technical body of knowledge advances and faculty skills improve. Since many non-accredited degrees do not require a capstone experience, the senior design will be ideal to provide demonstrated accomplishment of

\begin{tabular}{|c|c|}
\hline Outcome & Course or Module \\
\hline \multicolumn{2}{|l|}{ Professional } \\
\hline Communication & $\begin{array}{l}\text { English I and II, paper and presentation in each graduate } \\
\text { course }\end{array}$ \\
\hline Public Policy & $\begin{array}{l}\text { Module in CENG } 4341 \text { Leadership, Public Policy, Business } \\
\text { Practices, and Asset Management } \\
\text { (moving to CENG } 3371 \text { Intro to Environmental Engineering) }\end{array}$ \\
\hline $\begin{array}{l}\text { Business and Public } \\
\text { Administration }\end{array}$ & $\begin{array}{l}\text { Module in CENG } 4341 \text { Leadership, Public Policy, Business } \\
\text { Practices, and Asset Management } \\
\text { (moving to CENG } 4315 \text { Senior Design II) }\end{array}$ \\
\hline Globalization & $\begin{array}{l}\text { Senior Design, Module in ENGR } 4109 \text { Senior Seminar } \\
\text { (to be completely covered in CENG } 4315 \text { senior design) }\end{array}$ \\
\hline Leadership & $\begin{array}{l}\text { Module CENG } 4341 \text { Leadership, Public Policy, Business } \\
\text { Practices, and Asset Management, CENG 4115/4315 } \\
\text { Senior Design (Moving completely to CENG 4115/4315 } \\
\text { Senior Design) }\end{array}$ \\
\hline Teamwork & $\begin{array}{l}\text { CENG 4115/4315 Senior Design, projects in senior level } \\
\text { design courses (CENG 4412, CENG 4351, CENG 4371, CENG } \\
\text { 4381, etc.) (remain the same) }\end{array}$ \\
\hline Attitudes & $\begin{array}{l}\text { Module in CENG } 4341 \text { Leadership, Public Policy, Business } \\
\text { Practices, and Asset Management, CENG 4115/4315 } \\
\text { Senior Design (Move completely to CENG 4115/4315 } \\
\text { Senior Design) }\end{array}$ \\
\hline Lifelong Learning & $\begin{array}{l}\text { Projects in senior level design courses (CENG 4412, CENG } \\
\text { 4351, CENG 4371, CENG 4381, etc.), CENG 4115/4315 } \\
\text { Senior Design (remain the same) }\end{array}$ \\
\hline $\begin{array}{l}\text { Professional and Ethical } \\
\text { Responsibility }\end{array}$ & $\begin{array}{l}\text { Module in CENG } 4341 \text { Leadership, Public Policy, Business } \\
\text { Practices, and Asset Management, CENG 4115/4315 } \\
\text { Senior Design (Move completely to CENG 4115/4315 } \\
\text { Senior Design) }\end{array}$ \\
\hline
\end{tabular}

Table 8. Professional outcome matrix versus course or module 
many outcomes with the insertion of individual assignments; thereby, decreasing the number of leveling courses and modules required by graduate students from non-ABET accredited undergraduate programs. Many of the outcomes currently not covered by nonABET accredited programs are the professional skills.

The initial work to develop the matrix of coverage of professional skill outcomes for graduate leveling is shown in Table 8 . The level of detail is whether a course or a module within a current course is required. As can be seen, the movement of condensed modules from CENG 4341 into the senior design experience would be efficient; especially with a decrease in technical lessons needing to be covered in the senior design with the maturing of other senior level design courses. However, there will be a need for students to complete individual assignments on each professional outcome prior to applying in a team setting to ensure each graduate can demonstrate each outcome.

Many programs experience problems within the design experience and the recent ABET visit noted that the coverage of seven $\mathrm{CE}$ sub-disciplines and the assessment process working toward coverage and assessment of all outcomes within the senior design was the best the PEV had seen in all of his numerous visits. The fact that the students must address demonstration of their skills for each outcome truly brings the entire process together and reinforces what skills they must have at the time of graduation. The comments have been reinforced by the engineering firms who have reviewed the senior design documents and provided comments on the design experience by the UT Tyler CE students. Increasing coverage of professional skills within the senior design will only strengthen the senior design since professional skills are critical during the design process and the profession has been active in demanding more professional skill development as evident with the additional outcomes generated from BOK I (ASCE, 2004) and the increased level of Bloom's for professional skills within BOK II. (ASCE, 2008)

\section{Conclusions/lessons learned}

The faculty team must decide the courses that should be able to provide an embedded indicator for each program outcome. However, this is usually not enough; each professor must also develop a plan before the semester starts as to which assignments within the course will contain an embedded indicator. If the plan is not fully developed prior to the start of the semester, the normal day-to-day activities may (usually will) inhibit quality development of embedded indicators or prevent collection of embedded indicators that leaves some program outcomes without adequate demonstration of accomplishment. This is especially true for some of the professional outcomes which appear harder to demonstrate than other outcomes.

Currently the UT Tyler Civil Engineering program has successfully implemented a single synergistic course CENG 4341 Leadership, Public Policy, Business Practices, and Asset Management which includes multiple modules to demonstrate many of the professional outcomes. The offering of this course along side of the senior design allows for the students to study the concepts using their senior design experience as a focus. The single course provided a solution to properly demonstrate multiple outcomes that do not naturally align with traditional technical courses. The experience has also enlightened the faculty to the possible use of modules to successfully level graduate students desiring an ABET accredited graduate degree without graduating from an ABET accredited undergraduate program. 
The current investigation to move accomplishment of the professional outcomes from CENG 4341 into the senior design would allow for the removal of CENG 4341 as the program investigates the affect of a possible mandated decrease in credit hours from 128 to 120. Additional embedded indicators for the professional outcomes in sophomore and junior level courses would be required to ensure multiple opportunities to apply skills and develop confidence before the senior design since one of the opportunities maybe deleted (CENG 4341). The senior design is a part of the solution and as shown above can assess more outcomes than just multi-disciplinary design alone.

The senior design is already being taught and each assignment is being assessed. Once developed, the evaluation rubric only needs to be modified each year to improve the balance of points between outcomes. Many faculty within the UT Tyler CE Program are now part of the senior design grading since the design usually includes all seven traditional subdisciplines of CE. Where better to demonstrate through the actions of the faculty as well as the design products of the students that professional skills are integral to a successful design. Since design products and construction of these designs is the heart of the globalization issue for engineers, the active demonstration of professional or global skills during the senior design will develop new engineers who are ready to meet the globalization challenges as firms adjust to a global perspective while completing day-to-day company missions, especially as companies move toward international markets to remain competitive. Professional skills are the globalization equalizer.

\section{References}

ABET. (2011). ABET General Criteria, In: ABET, 13 Jan 2011, Available from: $<$ http://www.abet.org/forms.shtml\#For_Engineering_Programs_Only>

ASCE Body of Knowledge Committee. (2004). Civil Engineering Body of Knowledge for the 21st Century: Preparing the Civil Engineer for the Future, ASCE, Reston, VA.

ASCE Curriculum Committee Report. (2007). Development of Civil Engineering Curricula Supporting the Body of Knowledge, ASCE, Reston, VA.

ASCE Body of Knowledge Committee. (2008). Civil Engineering Body of Knowledge for the 21st Century: Preparing the Civil Engineer for the Future, Second Edition, ASCE, 978078440965-7, Reston, VA.

Bloom, B., Englehart, M., Furst, E., Hill, W., \& Krathwohl, D., (1956). Taxonomy of Educational Objectives, the Classification of Educational Goals, Handbook I: Cognitive Domain, David McKay, NY, NY.

Brown, G. (2008). PM backs apprenticeships to boost UK in 'global skills race', In: Andrew Sparrow and Agencies, 13 March 2011, Available from:

<http://www.guardian.co.uk/politics/2008/jan/28/labour.uk>

CENG. (2009). Course Assessment Document for CENG 4341, Fall 2007 and 2008 and Spring 2009, University of Texas at Tyler.

Downey, G., Lucena, J., Moskal, B., Parkhurst, R., Bigley, T., Hays, C., Jesiak, B., Kely, L., Miller, J., Ruff, S., Lehr, J., \& Nihols-Belo, A., The Globally Competent Engineer: Working Effectively with People Who Define Problems Differently. Journal of Engineering Education, 95, 2, April 2006, pp.107-122, , 1069-4730. 
European Commission. (2011). Agenda for New Skills and Jobs, In: Employment, Social Affairs and Inclusion, 16 March 2011, Available from:

http:/ / ec.europa.eu/social/main.jsp?langId=en\&catId=958

Freidman, T. (2005). The World Is Flat, Farrar, Straus \& Giroux, 1069-4730, NY.

Fridley, K. (2010). How the Civil Engineering BOK2 is Being Implemented at the University of Alabama, Proceedings of the American Society of Engineering Education, Louisville, KY, June 2010.

Goinglobal. (2011). The New Global Skill Set, In: Hot Topics, 13 March 2011, Available from: <http://old.goinglobal.com/hot_topics/general_the_new_global_skill_set.asp>

International Monetary Fund (IMF) Staff. (2008). Globalization: A Brief Overview, In: International Monetary Fund, 13 March 2011, Available from:

<http://www.imf.org/external/np/exr/ib/2008/053008.htm>

Meyer, K. \& Bert, S. (2007). A Technique for Program-Wide Direct Assessment of Student Performance, Proceedings of the American Society of Engineering Education, , Honolulu, Hawaii, June 2007.

Peters-Behrens, D. Getting Ready, In: Transitions Abroad, 12 March 2011, Available from: <http://www.transitionsabroad.com/publications/workabroad/articles/gettingre ady.shtml>

Ressler, S. (2010). Assessing the Standards For Assessment: Is It Time To Update Criterion 3 ? Proceedings of the American Society of Engineering Education, Louisville, KY, June 2010.

Shuman, L., Besterfield-Sacre, M., \& McGourty, J., (2005). The ABET “Professional Skills". Can they taught? Can they be assessed? Journal of Engineering Education, 94, 1, pp. $41-55$, , 1069-4730.

The Steering Committee of the National Engineering Education Research Colloquies. (2006). The Research Agenda for the New Discipline of Engineering Education, Journal of Engineering Education, 95, 4, October 2006, pp.259-261, , 1069-4730.

University of Wisconsin-Parkside. (2011). Center for International Studies, In: International Studies Program, 13 March 2011. Available from:

<http://www.uwp.edu/departments/international.studies/program.cfm>

Welch, R., Estes, A., \& Winget, D., (2005). Assessment of Squishier Outcomes: Open-Ended Problem Solving Through Client-Based Projects. 2005 ABET Annual Meeting, San Diego, CA, October 2005.

Welch, R., (2009a). Surviving ABET Under the New Criteria - From the Eyes of New Chair in a New CE Department., Proceedings of the American Society of Engineering Education, Austin, TX, June 2009.

Welch, R., (2009b). Integrating Professional Topics and Engineering Constraints Across the Curriculum, Proceedings of the American Society of Engineering Education, Austin, TX, June 2009.

Welch, R. \& McGinnis, M. (2010). Assessment of ABET 3 a-k in an Open-ended Capstone? Proceedings of the American Society of Engineering Education, Louisville, KY, June 2010.

Welch, R., (2010a). Single Synergistic Course or Modules in Multiple Courses, Proceedings of the American Society of Engineering Education, Louisville, KY, June 2010. 
Welch, R. (2010b). CENG 4341 Course syllabus, In: UT Tyler web pages, 13 March 2011, Available from: <http://ce.uttyler.edu/Documents/CENG4341ABETsyl2008Jun.pdf >. Woodson, T. (1966). Introduction to Engineering Design, McGraw-Hill, New York. 


\title{
Impact of Globalization on Indian Technical Education System
}

\author{
Mahadevi. S. Banad and Mahadev. Talawar \\ Dept. of Electrical \& Electronics Engg. B.V.V.S.Polytechnic (Autonomous), \\ Bagalkot, Karnataka State, \\ India
}

\section{Introduction}

The internationalization of higher education can be linked to various internal and external changes in the international system. Externally, there have been changes in the labour market, which have resulted in calls for more knowledge and skilled workers, and workers with deeper understandings of languages, cultures and business methods all over the world. Education is becoming more invaluable to individuals. In today's environment, education provides individuals with a better chance of employment, which in turn leads to a better lifestyle, power and status. A global education should teach about issues that cross national boundaries, and interconnected systems on ecological, cultural, economical, political and technological grounds such as the Globalization program which draws upon expertise in many areas such as humanities, social science and environmental science. Globalization and technological advancements are delivering and increasing access to the world and subsequently subjects should reflect this global outlook.

It is a fact that the world is moving fast in technological developments and subsequently there is much advancement and reforms in teaching methodology and the contest of courses in developed countries. It is time in our country have to achieve at par that excellence in our teaching programs . According to the findings of one survey made public last year, none of our universities including the IIT's has appeared in ranking of first top 100 universities of the world. It is therefore, stands appropriate to think that if some of bright ranked foreign universities come to India, we will have their standard of excellence to compare with at home for our own growth and the development.

The students and the country can also accrue benefits from foreign universities in India. Not only the students and their parents will be partially relieved from their financial burden but there will be reduction in brain drain of the country. Our youth will get psychological satisfaction getting degrees of foreign university here itself and will able to contribute to serve the country enjoying the life on home-front thereafter.

Again we in our country are not so equipped now to fulfill the necessary requirement of admissions facility and infrastructure for some of the advanced post graduate technical and other professional courses. By encouraging setting up of foreign university in India, the country will get advantage of coming near to the world class faculty of excellence and various reforms of the methodology of the teaching and education prevalent threat. We will also be able to develop research culture in our institutions and the universities for which we lack in. 
In this technical era, people of India are going through a very crucial phase. Some defines it as a phase of development and others strictly believes it as a devaluation of Indian system. There is tremendous growth and changes in every field mainly in technical education. Technical education works as knowledge transmitters and new knowledge creators, sure these institutions are backbone of a country's future.

The $21^{\text {st }}$ centaury presents unique challenges for the technical education system. Technical education must be able to respond to rising student expectations and the demands of global competition. The quality of knowledge generated within technical education institutions, is increasing determining the nations global competitions. This posses a major responsibility on the institutions of technical education in countries like India. With abundance of human resources India is eminently equipped for growing itself as a global leader in the knowledge society. Development of any nation does not depend on the available resources but on effective utilization of these resources. Unless effective technical education is provided to the youth of the nation, the process of development cannot be accelerated. The globalization can prove to be an effective means of modifying the flawed education policy on the lines of those developed countries that have successfully transformed themselves to an economic power with the help of their technical education.

\section{Review of literature}

Nobel Laureates T.W.Schultz and Gary Becker in 1961 and 1963 respectively propounded the new economics of education. According to this, all investments in education, be private or public, were guided by profitability.

Globalization refers to the spread of new forms of non-territorial social activity (Ruggie, 1993; Scholte, 2000). To make term more clear, Globalization has been defined as the process of rapid integration of countries and happening through greater foreign trade and foreign investment. In essence, it refers to increased possibilities for action between and among people in situations irrespective of geographical considerations as per the definition of social theorists.

Ground Realities: Sadly, the Human Development Report of UNDP indicates that India had the largest national population of illiterates in the world. Thus, it may be recalled that it was Gopal Krihna Gokhale who advocated making primary education free and compulsory 94 years ago. Even the Article 45 of the Indian Constitution that promised for free and compulsory education within the first decade of our Independence, achieved very little, partly due its non-judicial character. However, the Education Commission further hoped that "all the areas of the country should be able to provide five years of good effective education to all the children by 1975-76 an seven years of such education by 1985-86". The simple calculations of free and compulsory education were never gone into though all realized that the total cost would be enormous. Obviously, the India's Education Commission (1964-66) under the leadership of D.S.Kothari and J.P.Naik as the Chairman and Member-Secretary that laid the foundation of post-Independent India's national education policy. Thus, the Commission had recommended that $6 \%$, as against $3 \%$, of the national income be allotted as government expenditure on education.

\section{History of globalization}

Socialization of people for improving business and financial activities across the globe can be referred as globalization. It is not a new phenomena as people kept searching new places and avenues to increase their business activities as evident by explorations of Vasco 
degama, Columbus and East India Company. Bitter experiences from East India Companies \& British rule makes Indian little bit cautious for adventures of globalization. This has been the root cause for delay in liberalization in India. they had committed previously by opting for isolation.

Globalization has been a historical process. During the Pre-World War I period of 1870 to 1914, there was rapid integration of the economies in terms of trade flows, movement of capital and migration of people. The growth of globalization was mainly led by the technological forces in the fields of transport and communication. Indeed there were no passports and visa requirements and very few non-tariff barriers and restrictions on fund flows. Globalization, process was slow between the First and the Second World War. After World War II, all the leading countries resolved not to repeat the mistakes they had committed previously by opting for isolation.

India is also following the global phenomenon. As part of globalisation, the economic reform packages were introduced in India in the beginning of 1991. These reform packages imposed a heavy compression on the public budgets on education sector, more specifically on higher education. This has trickled down to public expenditure on education in general, and higher education in particular.

\section{Some important facts about Indian education}

The Indian education is not new, some of the facts about Indian education are: Indian Ayurveda is the earliest school of medicine known to the world and 'charaka' is known as the father of Ayurveda. He developed this system some 2500 years back. Takshila was the first university of world established in 700 B.C. Indian Nalanda University, built in 4 AD, was considered to be the honor of ancient Indian system of education as it was one of the best Universities of its time in the subcontinent. Indian language Sanskrit is considered to be the mother of many modern languages of world. Similarly place value system was developed in India in 100 B.C. India was the country, which invented number system. Aryabhatta, the Indian scientist, invented digit zero. Trigonometry, algebra and calculus studies were originated in India.So India seems to be an education centre since ancient days.

\section{Indian technical education}

In India there were 2942 degree level engineering institutions approved by AICTE with an intake of about 10 lakh students. It is believed that there is an excess supply of unemployable engineers. According to one of study of NASSCOM about $25 \%$ of total graduates engineers passing out every year are employable in MNCs and rest of these have to undergo some kind of training to overcome their skill deficit. Some of the NITs have started finishing schools to bridge the skills gap of their students. In metro cities, private sectors companies have come forward to organize finishing schools for the students of the self financing engineering colleges in specific areas like VLSI Design, Embedded system, computer added SAP, Advance computing etc. of 3 to 6 months duration to make these students employable

\section{Challenges to technical education}

Globalization has resulted in many new challenges to the technical education system. Till recently technologies were mostly imported and the training needed for these technologies were generally carried abroad. Globalization has opened the economy to global players in 
the industry and service sectors. New products and services are being introduced continuously with improved quality and customer focus. The key input to the success of this new brand of industries and service units is a group of highly motivated and meticulously trained forces. The knowledge and technical skills of this work force have to be regularly updated. The engineer coming out of our institution should be capable of meeting the challenges of the modern industry. They should be up- to- date in their technical knowhow. They must have a deep sense of quality, work ethics and motivation and be conversant with the skills, interpersonal skills, team work skills,, self esteem, goal setting skills, leadership and creative thinking. Development of these skills are a part of curriculum in many foreign universities some of the challenges of the globalization are indicated below:

\subsection{Government plan}

Governments's plan expenditure on different sectors of education reveals that a meager allocation of $3.5 \%$ of the total GNP that there is a decline in allocation towards higher and technical education.

A good percentage of students who do get past $12^{\text {th }}$ grade cannot afford to go to institutions where professional degree programs are offered. This is because unlike most the developed world where on average expense on education do not exceed 25\% capita GNP in India that figure is a staggering $400 \%$.

\subsection{Traditional setup}

It is still our education system dominated by the traditional set up of rules, regulations and statutes that offer little scope for quick improvement in its present work-system and the required level of autonomy and flexibility.

\subsection{Curriculum}

The curriculum today is out of touch with the ground realities and of little practical import. The curriculum does not provide knowledge that can be utilized to enhance local resources through which employment could be generated in addition to improve the existing conditions.

\subsection{Industry - institute interaction}

The challenges of globalization need to be recognized by both industry and educational institutions without any further delay, otherwise India will have no foothold in the business world and its industry may become a victim of its own policies of liberalization and open market economy. For this both the industry and educational institutions put their shoulders to wheel and work toward the creation of India incorporated with capabilities of operating as a major player in the global arena. Partnership may be developed in one or more areas like faculty development, faculty exchange, curriculum development, resources support, institution of chairs, institutional evaluation, service to industry, adoption of institution, project assignment, testing and facilities, production -cum-training centre, seminar and conferences, continuing education, guest lectures, Rand D facilities etc. Other challenges are like International collaboration, Difficult to adapt new technology.

\subsection{Infrastructure facilities}

Infrastructure facilities, Restructuring of education system, Positive attitudes towards national integration, Research activities Updating knowledge, Consultancy, More Autonomy, Strengthening of multi institutional integration. The reposition of technical 
education in response to global force driving challenge in a knowledge based economy, In many developing countries, particularly in India technological change and globalization have exacerbated existing unemployment problems that have been due, in some measure, to poor economic performance.

\subsection{Skilled labour}

Many low-to medium-technology industries have been relocated in developing countries to benefit from cheaper labour, The combination of globalization and technological developments has enabled highly skilled technical personnel living in developing countries to provide service for industries in developed countries ,Globalization affected the world population in different and unequal ways. It has resulted in rapid economic benefits for some countries while causing acute social problems for other.

\subsection{World market}

Rapid technological change makes skills obsolete very quickly and demands higher levels of initiative and more frequent retraining. Newly emerging high technology jobs often require job seekers to have immediate 'plug-and-play' skills, cross-disciplinary knowledge, better communication and interpersonal skills, and the ability to work in teams. Other attributes such as motivation, creativity, self adjustment, commitment, attention to detail and a sense of responsibility are critical to success and must take equal priority to functional skills in Technical Education.

Globalization helped to grope new industries to compete in the world market, it also exposed the weakness in their economic fundamentals and resulted in financial crises, by reducing the value of their currencies, Globalization has increased economic growth in some countries, it has demanded heightened competitions Technical Education system is dynamic in nature, Technical Education is the component of education most directly concerned with the acquisition of the knowledge and skills required by workers in most manufacturing and service industries, It faces many challenges in responding to societal, technological and economic changes in the local and global environment, Technical education is widely recognized as an important part of the total education and training system.

\subsection{Restructuring of technical education}

The real challenge is how to reposition it in response to the global forces driving change in a knowledge-based economy, The era of rapid scientific and technological advancement that we live in has spawned a communications revolution that is pervading every region of the world and creating a global information society, The sudden economic contraction in the south-east Asian countries may also be a by-product of globalization. While globalization helped their new manufacturing industries to compete in the world market, it also exposed the weaknesses in their economic fundamentals and resulted in a financial crisis that drastically reduced the value of their currencies. The result was a ready pool of skilled personnel that entrepreneurs found cheaper than the industrial workforces in the developed countries.

Production systems based on new technologies that enable greater productivity and flexibility as well as workers with updated skills and more independent initiative are required if industries are to survive in this climate. Thus, with the demand for greater productivity, new technologies are radiating into almost every industrial sector, including the traditional labour-intensive industries. 


\subsection{Entrepreneurship training}

Entrepreneurship training is considered a valuable tool for inspiring motivation, creativity and innovation. In addition, entrepreneurial skills are expected to equip Technical Education graduates with the ability to generate employment opportunities through the creation of new businesses.Expectation of further Training of Technical Education graduates at their place of work or at a public or private institution.

In a rapidly evolving work environment, educational and vocational guidance and counseling are critical and must constitute an integral part of any Technical Education programme as they contribute to enhancing the relevance and effectiveness of training.

\subsection{Counseling}

Counseling is necessary to understand and appreciate the talents of students and trainees, and to help them explore career alternatives. Guidance and counseling must define career development as a systematic process during which individuals develop their vocational awareness, employability and maturity.

\section{SWOT analysis of Indian education system}

\subsection{Strength}

The Indian have made many contributions among those are Arybhatta, Sir, C.V. RAMANNA, H.J. BABHA, Sir, J.C. BOSE. Some of the strengths of Indian technical education system are: India has got very rich and learned education heritage. Very good primary education which provides a very strong base. Indian education system moulds the growing minds with huge amount of information and knowledge. Indian education system gives the greater exposure to the subject knowledge. Indians are rich in theoretical knowledge .India has abdunt strength of resources and man power(NASA, MAC).Cost of education is very low. Number of higher education institutions in India is more compare to developed countries. Indians are interceded in normal education and higher education.

\subsection{Weakness}

The weakness of Indian technical education system are: Lack of adequate up-gradation of curriculum. No benchmark and no common course content and no common exam procedure national wide. Lack of specialized courses or modular and rigid curriculum learning considered as one step process. Education is exam oriented. No fixed parameters. Lack of Industry -Institute interaction. Rigidity in curriculum. Lack of multidisciplinary courses. Role of teacher is confined to teaching alone. Lack of policy makers. Mind set of stakeholders. Lack in accepting immediate changes. Learning is job oriented

\subsection{Opportunities}

India has rich resources of human as well as physical. In India enough number of higher education institutions. Therefore, we can produce more and highly qualified students . Fulfilling students demands by providing enhanced quality of education. Producing enough number of technically skilled outputs. By making more Autonomy Curriculum should be made more realistic, practically biased and job oriented. Students will be regarded more as a customer.To provide highly technically skilled labour to the country 


\subsection{Threats}

Similarly the threats of Indian technical education system are :Lack of interest and interaction from the industry in developing and collaborating in the research field. Threat from within of deteriorating standards of education due to lack of benchmark in terms of quality of institutions. Loss of quality standards by technical institutions as more and more students opt for education abroad. Lack of team work. Attitude of the people who fail to work collectively on a common platform

The following are the few solutions to counter measure to overcome threats are: Update and relevant curricula to meet the global standards and demands. Establishing state of art institutions. More interaction and collaboration between institutions and industry at all levels. Encouraging research programmes in virgin areas with the support of industry. Encourage and establish institutes capable of providing consultancy and specialized service for facing and assignments for students.

\section{Methodologies to globalize the technical education system}

In order to avoid the scenario there are various possibilities to globalize the technical education . They are:

\subsection{Curriculum}

The Indian education authority must develop a data base on all categories of education regarding the number of educational institutions, their domestic and foreign elements, faculty strength, financial resources and quality and accreditations. Further market intelligence regarding the situations in other countries is sought through diplomatic attaches in the Indian embassies abroad. Existing reputed educational testing services will have to be modernized. Our reputed testing services such as CAT, GATE and other must be upgraded and modernized to complete with foreign testing services such as GRE, GMAT and TOFEL.

\subsection{Exchange programme}

Education particularly technical education has involved in many ways has been found upon, a great deal of international exchange programme in terms of students seeking to study overseas, staff transfers( on short-term exchange programme or by recruiting for academic positions on a global basis) and global sharing of knowledge, whether through conference on international accessible publications.

The traditional way for a students to gain experience of other cultures is to attend an exchange programme and spend, for example, one year studying abroad.

\subsection{Accreditation}

This is the context of rapidly changing scenario in which higher education institutions and quality assurance agencies functions. Globalization of higher education and the opportunities and risks which arises the out of the liberlazition to trade in higher education services challenges the academic community worldwide and call for new and imaginative strategies. In international quality assurance there is an urgent need for action in order to establishes a basis of thrust in quality of global higher education. With the unprecedented expansion in the type and number of higher education institutions, all over the world, the need for the students, institutions, employees, government and other for reliable information about the quality of institutions, courses and programmes become all the more important. 
The educational authorities must study the system of regulation and accreditation of educational institutions in foreign countries. In accreditation system and laws for foreign institutions must be developed taking into account the treatment given to them in their respective countries. So every institutions should come forward for the accreditation . Identification and propagation of best practices, networking of accredited institution, remedial measures for the removal of academic obsolescence and up-gradation of academic infrastructure are some the national board of the accreditation (NBA) post accreditation drives. It should be initiated and acted everyone fruitfully.

\subsection{Appraisal system}

Appraisal of teaching process has emerged in the changing perceptive of education; consumerism, cost effectiveness and teacher accountability are elements leading attention. It has been emphasized that the purpose of entire process is to improve the quality of technical education on the basis of feedback mechanism. Once the suggested evaluation process finds a place as an inbuilt mechanism in any technical institution, the quality will defiantly improve. Faculty education has long been considered week among the higher education degree programmes, one that lacks high standard and strong contacts with the field, unlike the professional higher education courses meant for doctors, engineers, lawyers, the professional education course for faculties often found to be not only short in duration, but also very limited in exposing faculty trainees to the practical realities of classroom teaching. In the present context of knowledge- intensive and information- driven society, it becomes even more important for faculties tom become facilitators of learning in diverse learning situations rather than merely perform ring teaching rolein a face-to face situation. It is noticed that both economic and social factors have been responsible for shaping and determining the quality of faculty education system in many countries. Additionally, the colonial legacy has also imposed certain rigid conditions, which has made many developing countries difficult to overhaul the faculty education system to suit the current socio-economic demands and challenges. So steps have to be taken to hold great promises for reforming faculty preparatory programmes and to change of mind set and attitude among faculty community.

\subsection{Infrastructure}

Improvement in the educational infrastructure must take priority. The following items need to be addressed if the infrastructure of import compete ting institutions has to be of international standards. University courses scheduled must be available on the internet; automated telephone course registration for every term must be available to students, payments of fees by credits card should be of a standard option, classrooms, libraries, dormitories and sport facilities should be of international standards. Off campus housing arrangements must be facilitated through the private sector for faculty, staff.

\subsection{Connectivity www for students to study abroad}

The world wide web represents a new concept in technology, the library on your desktop, the dictionary at your fingertips, the sound at your ear. Advancement in telecommunication and computer technologies will speed up national and international cooperation in both research and documentation. Educational researchers can take active part in design of online courses. The introduction of technology into the classroom is changing the nature of delivering education to students is gradually giving way to a new form of electronic literacy, more programs and education materials are made available in electronic form, teachers are preparing materials in electronic form; and students are generating papers, assignments and 
projects in electronic form". Video projection screens, books with storage device servers and $\mathrm{CD}$ ROMs as well as the emergence of on-line digital libraries are now replacing blackboards. Even exams and grades are gradually becoming available through electronic means and notebooks are starting to give way to laptops. Also, students can be examined through computer managed learning systems and do tutorial exercises on a computer rather than in a classroom conventional exam system changed to on line. Such developments in education portray that there has been a shift from industrialization to information-based societies. Subsequently, technology is foreseeing a change in the education environment towards a reliance on electronic sources to deliver material. With such changes and the emergence of video conferencing and the Internet, the barriers of distance are being broken down at a rapid rate, due to the key aspect of globalizations. Children and adults can now learn in a variety of ways and no longer have to be physically present in an education institution in order to learn, a definite advantage of flexible delivery systems.

\section{Impact of globalization}

The impact of globalization on technical education imply to many as a modification of the curriculum taught in our technical universities on the line of that being followed in foreign universities. It is to be crystal clear that there is no flaw in the curriculum being taught in our universities. Frequent analysis carried out by AICTE has shown that our curriculum is a global one and is on par with a highly placed university in a developed country. The flaw is then certainly in the process of delivering this technical education to the aspiring engineers. This implies that the RAW MATERIAL entering the process line of our universities is brilliant but the final product lack the quality and is not competent enough to sell in the global market. A change in this mentoring process is then is the need of the hour. Globalization of technical education is to be focused on improving the mentoring capabilities and the mentoring process of imparting this global curriculum. The mentors in India seem to lack of industry -institute partnership which is an important aspect of globalization Policy in India is to adopt. The industry in India seem to be more profit oriented rather than research oriented. Hence local industry-institute partnership might not be of great help to Indian technical education. Hence collaboration of Indian institutes with global or multinational companies involved in advanced research areas might provide the Indian engineers a chance to implement their knowledge in practical areas. This practical aspects of technical education might prove to be a great boost to the sloppy development process in India. The other impacts of globalization on technical education are:

\subsection{Labour}

Many low- to medium-technology industries have been relocated in developing countries to benefit from cheaper labour, The workers made redundant as a result have found themselves unqualified to work in jobs created in the high technology and service industries.Thus while globalization has stimulated the high technology and service industries, it has placed a heavy social welfare burden on governments in developed countries.The combination of globalization and technological developments has enabled highly skilled technical personnel living in developing countries to provide services for industries in developed countries.

\subsection{Employment}

In many developing countries, particularly in India, technological change and globalization have exacerbated existing unemployment problems that have been due, in some measure, to 
poor economic performance.Inefficient, labour-intensive industries that could not compete with transnational corporations have had to close down. These industries were unable to modernize as they could not afford the new technologies.

Due to lack of employment opportunities in the formal sector of the economy, individuals in many developing countries have resorted to the informal sector to subsist. Consequently, the informal sector is growing rapidly and currently represents, in some countries, more than 60 per cent of urban employment opportunities.

Another trend that has had a negative impact on industries in some developing countries has been the exodus of skilled people to countries where they are able to earn higher wages.

\subsection{Market economy}

Globalization has affected some countries in a process of transition towards a market economy by confronting them with the inefficiency of their industries and placing demands for new skills and trades. As a result, relative affluence and a degree of social transformation are evident among groups of urban youth while many older urban people and rural people in general suffer acute economic hardship and social exclusion. While globalization has increased economic growth in some countries, it has also demanded heightened competitiveness.The cost of introducing new equipment and tools, and retraining the teaching staff is often prohibitive.

\subsection{Communication and information}

Indeed, the new information and communication technologies are dramatically changing the way people in many parts of the world live, learn, work or think about work. This trend of globalization has, in combination with technological developments, affected the world population in different and unequal ways. It has resulted in rapid economic benefits for some countries while causing acute social problems for others. In the developed countries, there have been massive changes in the work content of most occupations as well as an overall diminution of work and employment opportunities in the industrial sector. Computer software developers and telephone service providers in developing countries are significantly less expensive than their counterparts in developed countries and are being employed in increasing numbers by transnational corporations that obtain their services while they live in their home countries.

\section{Positive implication of globalization on education}

The following are the few positive implication of globalization are : India is one of the leading supplier of the changing skilled manpower. Students are preparing themselves to face challenges before them in the global village. Education system getting expert facility and needed financial support from management. Technicians are accepting changing paradigm and are more securing facilities. Salaries are now more attractive than in the nineties. Students get selected by the companies through campus recruitment an year before the date of completion of their technical education. More emphasis on performance and not on number of years in the job. More flexibilities in timings and work from home arrangements are becoming common. Office automation has helped improving effeciency of employees . More and more recruitments are being made using job portals. Earlier ads were placed in the newspapers. Scientific and technological innovations have made life quite comfortable, fast and enjoyable. People are less worried for government jobs as MNC's and private or public sector are offering more lucrative jobs. Extension of internet facilities even to rural areas. 


\section{Negative implications of globalization on education}

Similarly, the negative implications are: Movement of skilled students from developing to developed countries. Easy availability of educational loan. Technically better equipped institution and their practical and flexible approach is also a future for attracting students. Commerlizations and corporate take over of education system. The first major concern is that globalization leads to a more iniquitous distribution of income among countries and within countries. The second fear is that globalization leads to loss of national sovereignty and that countries are finding it increasingly difficult to follow independent domestic policies. More inflow of money has aggravated deep rooted problem of corruption? Top colleges of different streams.

\section{Gains from globalization}

The gains from globalization can be analyzed in the context of the three types of channels of economic globalization identified earlier.

\subsection{Trade in goods and services}

According to the standard theory, international trade leads to allocation of resources that is consistent with comparative advantage. This results in specialization which enhances productivity. It is accepted that international trade, in general, is beneficial and that restrictive trade practices impede growth. That is the reason why many of the emerging economies, which originally depended on a growth model of import substitution, have moved over to a policy of outward orientation. However, in relation to trade in goods and services, there is one major concern. Emerging economies will reap the benefits of international trade only if they reach the full potential of their resource availability. This will probably require time. That is why international trade agreements make exceptions by allowing longer time to developing economies in terms of reduction in tariff and non-tariff barriers. "Special and differentiated treatment", as it is very often called has become an accepted principle.

\subsection{Movement of capital}

Capital flows across countries have played an important role in enhancing the production base. This was very much true in $19^{\text {th }}$ and $20^{\text {th }}$ centuries. Capital mobility enables the total savings of the world to be distributed among countries which have the highest investment potential. Under these circumstances, one country's growth is not constrained by its own domestic savings. The inflow of foreign capital has played a significant role in the development in the recent period of the East Asian countries. The current account deficit of some of these countries had exceeded 5 per cent of the GDP in most of the period when growth was rapid. Capital flows can take either the form of foreign direct investment or portfolio investment. For developing countries the preferred alternative is foreign direct investment. Portfolio investment does not directly lead to expansion of productive capacity. It may do so, however, at one step removed. Portfolio investment can be volatile particularly in times of loss of confidence. That is why countries want to put restrictions on portfolio investment. However, in an open system such restrictions cannot work easily.

\subsection{Financial flows}

The rapid development of the capital market has been one of the important features of the current process of globalization. While the growth in capital and foreign exchange markets 
have facilitated the transfer of resources across borders, the gross turnover in foreign exchange markets has been extremely large. It is estimated that the gross turnover is around \$ 1.5 trillion per day worldwide (Frankel, 2000). This is of the order of hundred times greater than the volume of trade in goods and services. Currency trade has become an end in itself. The expansion in foreign exchange markets and capital markets is a necessary pre-requisite for international transfer of capital. However, the volatility in the foreign exchange market and the ease with which funds can be withdrawn from countries have created often times panic situations. The most recent example of this was the East Asian crisis. Contagion of financial crises is a worrying phenomenon. When one country faces a crisis, it affects others. It is not as if financial crises are solely caused by foreign exchange traders. What the financial markets tend to do is to exaggerate weaknesses. Herd instinct is not uncommon in financial markets. When an economy becomes more open to capital and financial flows, there is even greater compulsion to ensure that factors relating to macro-economic stability are not ignored. This is a lesson all developing countries have to learn from East Asian crisis. As one commentator aptly said "The trigger was sentiment, but vulnerability was due to fundamentals".

\section{India's stance}

What should be India's attitude in this environment of growing globalization? At the outset it must be mentioned that opting out of globalization is not a viable choice. There are at present 149 members in the World Trade Organisation (WTO). Some 25 countries are waiting to join the WTO. China has recently been admitted as a member. What is needed is to evolve an appropriate framework to wrest maximum benefits out of international trade and investment. This framework should include (a) making explicit the list of demands that India would like to make on the multilateral trade system, and (b) steps that India should take to realize the full potential from globalization.

\section{Concerns and fears}

On the impact of globalization, there are two major concerns. These may be described as even fears. Under each major concern there are many related anxieties. The first major concern is that globalization leads to a more iniquitous distribution of income among countries and within countries. The second fear is that globalization leads to loss of national sovereignty and that countries are finding it increasingly difficult to follow independent domestic policies. These two issues have to be addressed both theoretically and empirically. The argument that globalization leads to inequality is based on the premise that since globalization emphasizes efficiency, gains will accrue to countries which are favourably endowed with natural and human resources. Advanced countries have had a head start over the other countries by at least three centuries. The technological base of these countries is not only wide but highly sophisticated. While trade benefits all countries, greater gains accrue to the industrially advanced countries. This is the reason why even in the present trade agreements, a case has been built up for special and differential treatment in relation to developing countries. By and large, this treatment provides for longer transition periods in relation to adjustment. However, there are two changes with respect to international trade which may work to the advantage of the developing countries. First, for a variety of reasons, the industrially advanced countries are vacating certain areas of production. These can be filled in by developing countries. A good example of this is what the East Asian 
countries did in the 1970s and 1980s. Second, international trade is no longer determined by the distribution of natural resources. With the advent of information technology, the role of human resources has emerged as more important. Specialized human skills will become the determining factor in the coming decades. Productive activities are becoming "knowledge intensive" rather than "resource intensive". While there is a divide between developing and the advanced countries even in this area - some people call it the digital divide - it is a gap which can be bridged. A globalized economy with increased specialization can lead to improved productivity and faster growth. What will be required is a balancing mechanism to ensure that the handicaps of the developing countries are overcome.

Apart from the possible iniquitous distribution of income among countries, it has also been argued that globalization leads to widening income gaps within the countries as well. This can happen both in the developed and developing economies. The argument is the same as was advanced in relation to iniquitous distribution among countries. Globalization may benefit even within a country those who have the skills and the technology. The higher growth rate achieved by an economy can be at the expense of declining incomes of people who may be rendered redundant. In this context, it has to be noted that while globalization may accelerate the process of technology substitution in developing economies, these countries even without globalization will face the problem associated with moving from lower to higher technology. If the growth rate of the economy accelerates sufficiently, then part of the resources can be diverted by the state to modernize and re-equip people who may be affected by the process of technology up gradation.

The second concern relates to the loss of autonomy in the pursuit of economic policies. In a highly integrated world economy, it is true that one country cannot pursue policies which are not in consonance with the worldwide trends. Capital and technology are fluid and they will move where the benefits are greater. As the nations come together whether it be in the political, social or economic arena, some sacrifice of sovereignty is inevitable. The constraints of a globalised economic system on the pursuit of domestic policies have to be recognised. However, it need not result in the abdication of domestic objectives.

Another fear associated with globalization is insecurity and volatility. When countries are inter-related strongly, a small spark can start a large conflagration. Panic and fear spread fast. The downside to globalization essentially emphasizes the need to create countervailing forces in the form of institutions and policies at the international level. Global governance cannot be pushed to the periphery, as integration gathers speed.

Empirical evidence on the impact of globalization on inequality is not very clear. The share in aggregate world exports and in world output of the developing countries has been increasing. In aggregate world exports, the share of developing countries increased from 20.6 per cent in 1988-90 to 29.9 per cent in 2000. Similarly the share in aggregate world output of developing countries has increased from 17.9 per cent in 1988-90 to 40.4 per cent in 2000. The growth rate of the developing countries both in terms of GDP and per capita GDP has been higher than those of the industrial countries. These growth rates have been in fact higher in the 1990s than in the 1980s. All these data do not indicate that the developing countries as a group have suffered in the process of globalization. In fact, there have been substantial gains. But within developing countries, Africa has not done well and some of the South Asian countries have done better only in the 1990s. While the growth rate in per capita income of the developing countries in the 1990s is nearly two times higher than that of industrialized countries, in absolute terms the gap in per capita income has widened. As for income distribution within the countries, it is difficult to judge whether globalization is 
the primary factor responsible for any deterioration in the distribution of income. We have had considerable controversies in our country on what happened to the poverty ratio in the second half of 1990s. Most analysts even for India would agree that the poverty ratio has declined in the 1990s. Differences may exist as to what rate at which this has fallen. Nevertheless, whether it is in India or any other country, it is very difficult to trace the changes in the distribution of income within the countries directly to globalization.

\section{Government policies}

On the contrary, there are no regulations today, because we don't have a law. We want to regulate these to ensure that quality institutions come in. They should have the freedom that they are entitled to under the national laws because we are changing the structure of our laws. They will have to go through an accreditation process and can teach what they want, in the manner they want and there will be no interference in those processes.Globalization is expected to have a positive influence on the volume, quality and spread of knowledge through increased interaction among the various states.

Today our educational system is strong enough but Central and state governments should change their roles within the education system, re-inventing themselves as facilitating and supervisory organizations. Teacher training, infrastructure and syllabuses need to be urgently upgraded. Industry should come forward to share experience with students and to offer more opportunities for live Projects.

The free market philosophy has already entered the educational world in a big way. Commercialization of education is the order of the day. Commercial institutions offering specialized education have come up everywhere. In view of globalization, many corporate universities, both foreign and Indian, are encroaching upon our government institutions.

Our Institutes like IIMS and IITS have produced world class professionals. These institutes imparts quality education as per industry expectations and give due importance to Institute Industry Interface. Under the new scenario, Government Private partnership is becoming important in Management Education.Now India is a transforming country. We are near to achieve status of developed nation.

The demand for higher education has been growing rapidly with comparatively faster growth in enrolment in higher educational institutions than the growth in number of higher educational institutions). The growth rates are doubled among the students enrolled in postgraduate and research, while the number of institutions for post-graduate and research studies has grown at a slower rate in 1990s than in 1980s.

Privatization of higher education has emerged in several forms and types in the recent decade in India. One, privatization within government higher education institutions take place in the form of introducing self-financing courses within government institutions; two, converting government-aided private institutions into private self financing institutions; three, allowing to expand self-financing private institutions with recognition and also without recognition, which may be termed as commercial private Commercial private higher education emerges from market forces and tied to economic and global forces.

We can divide institutions in to various types, like of the self-financing engineering colleges and management institutions are affiliated to the conventional universities In which, the course structure, design, curriculum, and the pattern of examination fall withinthe purview of the national or state pattern. On the other side, several of these self financing private institutions are also non-affiliating to any universities and cater to the demands of the corporate sector nationally and internationally. 
In an era characterized by the challenge of rapid technological change, globalization, economic uncertainty and diminishing resources, it is imperative that all stakeholders work together to develop legislation and policies, establish the institutional structures and redesign curricula to ensure that Technical Education caters adequately to the varied needs of all members of society to enter or re-enter the world of work.Indeed, the Declaration of UNESCO's Fifth International Conference on Adult Education concluded with the pledge to forge extended alliances to mobilize and share resources in order to make adult learning a joy, a tool, a right and a shared responsibility.

\section{Issues with globalization}

One of them is that the universities which will come will be of low standard and therefore there will be no useful advantage to encourage their setting up here. Also our one expert and experienced faculty is likely to migrate to those universities and will their by create further shortage of faculties in our institutions. Our standards will go down because we will loose good faculties from existing institutions.

It is also likely that the fees will be quite higher their. The students of low income group will not be able to afford to pursue studies in those institutions. They may not been ready to offer free ship to many poor students. The questions of provision of reservation to SC, ST and $\mathrm{OBC}$ students will also stand if not resolved amicably.

The big question is also raised whether the foreign universities can fulfill the aspiration of our country in terms of our culture, civilization and the requirement of the development of the rural India. Shall the foreign facilities adjust here to the tune and rhythm of our expectations? There is also a doubt that the foreign universities will pump out considerable amount of money to their countries leading ultimately the same problem of our wealth going to other country. We should concede that there are views both in favour and against the entry of the foreign universities. But the better counsel seems in favour that it will not be appropriate to reject that move outright till we are able to establish institutions to meet with the requirement needed for the world class department in science and technology along with the education.

What is needed is to proceed to gain substantial and sustainable advantage from foreign universities for the cause of our national development. Let us remember our Vedic philosophy that we should remain open to receive good thought coming to us from all directions. The following are the issues related to globalization.

\subsection{Commercialization}

As world economy has faltered, colleges and universities have been forced to adopt strategies for increasing revenues and decreasing cost. Students have traditionally attended universities for free or have been paid for attending a university. As an economic problem faced by all colleges and universities, the solutions to many problems seems amenable by an internet, virtual universities, non- accredited degrees, on line education, distance education. The strong growth of private and for profit institutions around the world has attracted a great deal of attention, in country after country. Government have admitted that they cannot provide places for all the qualified in their countries and this created legislation and policies which encourage private money flow into their countries for building new universities.

Education if self has become an international business. Due to the vast economic slash in many countries, many institutions have forced to generate their own fund for their operations resulting in new commerlization of engineering education because of the 
increased opportunities for profit delivery in transactional technical education . Many internationalization strategies and actions of universities now are market driven instead of motivated by intentions of co-operation and mutual developments.

\subsection{Implications for quality}

The quality standards of public and private universities operating in the competitive global education market place get eroded as a result of commerlization and lead to differentiation of educational supply. In a more demand-driven educational market, standards trend to adopt themselves to the demands of the customers. Evidence for this fear can be found in uncontrolled mushroom developments of virtual and non-virtual universities, increasingly operating via internet and offering degrees of non- accredited type without even any form of educational activity.

\subsection{Insecurity}

Globalization is threatening the conventional modes of technical education in a many ways. The fact is that the concept of globalization is heavily loaded with emotions and it has triggered the increasing insecurity in new global environment in which institutions have to operate, is perceived as destabilizing, subjecting institutions and professionals to economic competition, market dependency and various forms of dislocation. Many universities are left behind in the hard arena of international competition without much defense.

\subsection{Interdependence}

The most pervasive aspect of globalization is the increased reality and sense of interdependence. Interdependence means that changes in one part of the global technical education system affects institutions in other parts of the world. Though this creates opportunities to rise of the for-profit but is absolutely also generates important challenges and problems, at least in the field of quality.

\subsection{Harmonization}

Globalization means, harmonizing the educational system worldwide, but we can note contrary tendencies in harmonizing the present system. Increasing rigidity as countries seek to harmonize structure, e.g. language of the course, degree duration, learning frame works, curriculum, syllabus, course type etc. to permit mobility and recognition. Increasing flexibility with more emphasis on outcomes or in claiming substantial equivalence.

\section{Trends in engineering education today}

With the driving force of globalization of the engineering profession, mechanism have been developed for mutual recognition across national boundaries and borders. Several current trends in engineering education is towards mutual acceptance and substational equivalence. The following are the few important changes occurring worldwide.

Many countries are in the process of framing their structure of education towards worldwide accreditation of engineering programme. Refer fig 1

Reformation of engineering education, wide utilization of advanced technologies in education and harmonization of education pattern( like language, course length, syllabus, course xtructure etc.) Employer and industry involvement in engineering education Evaluation of distance education courses and virtual universities. 


\section{Action by India to meet the global demands}

The second set of measures that should form part of the action plan must relate to strengthening India's position in international trade. India has many strengths, which several developing countries lack. In that sense, India is different and is in a stronger position to gain from international trade and investment. India's rise to the top of the IT industry in the world is a reflection of the abundance of skilled manpower in our country. It is, therefore, in India's interest to ensure that there is a greater freedom of movement of skilled manpower. At the same time, we should attempt to take all efforts to ensure that we continue to remain a frontline country in the area of skilled manpower. India can attract greater foreign investment, if we can accelerate our growth with stability. Stability, in this context, means reasonable balance on the fiscal and external accounts. We must maintain a competitive environment domestically so that we can take full advantage of wider market access. We must make good use of the extended time given to developing countries to dismantle trade barriers. Wherever legislations are required to protect sectors like agriculture, they need to be enacted quickly

In fact, we had taken a long time to pass the Protection of Plant Varieties and Farmers' Rights Act. We must also be active in ensuring that our firms make effective use of the new patent rights. South Korea has been able to file in recent years as many as 5000 patent applications in the United States whereas in 1986, the country filed only 162. China has also been very active in this area. We need a truly active agency in India to encourage Indian firms to file patent applications. In effect, we must build the complementary institutions necessary for maximizing the benefits from international trade and investment.

Changes in the foreign trade and foreign investment policies have altered the environment in which Indian industries have to operate. The path of transition is, no doubt, difficult. A greater integration of the Indian economy with the rest of the world is unavoidable. It is important that Indian industry be forward looking and get organized to compete with the rest of the world at levels of tariff comparable to those of other developing countries. Obviously, the Indian Government should be alert to ensure that Indian industries are not the victims of unfair trade practices. The safeguards available in the WTO agreement must be fully utilized to protect the interests of Indian industries.

Indian industry has a right to demand that the macro economic policy environment should be conducive to rapid economic growth. The configuration of policy decisions in the recent period has been attempting to do that. It is, however, time for Indian industrial units to recognize that the challenges of the new century demand greater action at the enterprise level. They have to learn to swim in the tempestuous waters of competition and away from the protected waters of the swimming pools. India is no longer a country producing goods and services for the domestic market alone. Indian firms are becoming and have to become global players. At the minimum, they must be able to meet global competition. The search for identifying new competitive advantages must begin earnestly. India's ascendancy in Information Technology (IT) is only partly by design. However, it must be said to the credit of policy makers that once the potential in this area was discovered, the policy environment became strongly industry friendly.

Over a wide spectrum of activities, India's advantage, actual and that which can be realized in a short span of time must be drawn up. Of course, in a number of cases, it will require building plants on a global scale. But, this need not necessarily be so in all cases. In fact the advent of IT is modifying the industrial structure. The revolution in telecommunications 
and IT is simultaneously creating a huge single market economy, while making the parts smaller and more powerful. What we need today is a road map for the Indian industry. It must delineate the path different industries must take to achieve productivity and efficiency levels comparable to the best in the world.

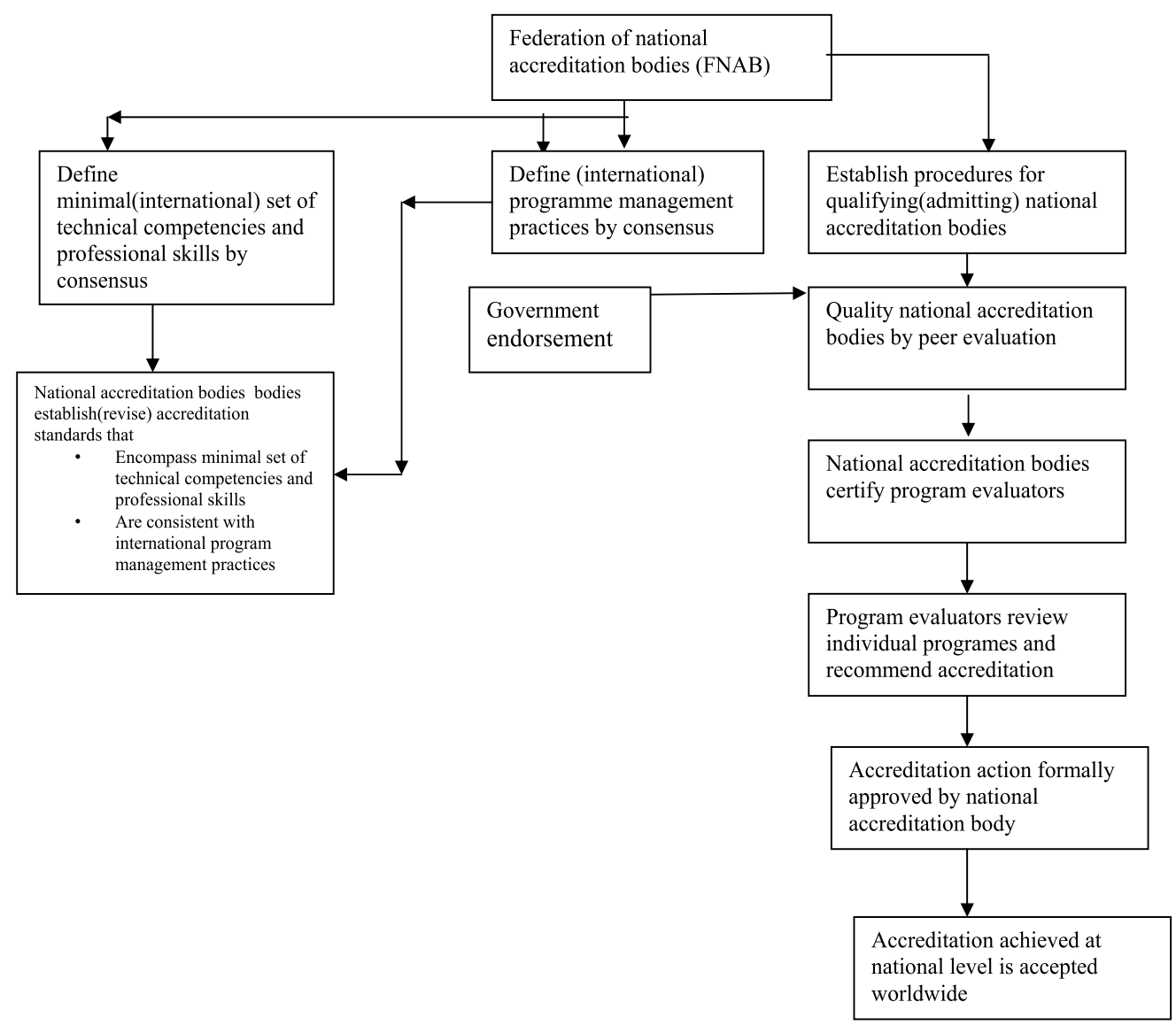

Fig. 1. A proposed model for worldwide accreditation of Engineering programmes

Globalization, in a fundamental sense, is not a new phenomenon. Its roots extend farther and deeper than the visible part of the plant. It is as old as history, starting with the great migrations of people across the great landmasses. Only recent developments in computer and communication technologies have accelerated the process of integration, with geographic distances becoming less of a factor. Is this 'end of geography' a boon or a bane? Borders have become porous and the sky is open. With modern technologies which do not recognize geography, it is not possible to hold back ideas either in the political, economic or cultural spheres. Each country must prepare itself to meet the new challenges so that it is not being bypassed by this huge wave of technological and institutional changes.

Nothing is an unmixed blessing. Globalization in its present form though spurred by far reaching technological changes is not a pure technological phenomenon. It has many dimensions including ideological. To deal with this phenomenon, we must understand the gains and losses, the benefits as well as dangers. To be forewarned, as the saying goes, is to 
be forearmed. But we should not throw the baby with bath water. We should also resist the temptation to blame globalization for all our failures. Most often, as the poet said, the fault is in ourselves.

Risks of an open economy are well known. We must not, nevertheless, miss the opportunities that the global system can offer. As an eminent critic put it, the world cannot marginalize India. But India, if it chooses, can marginalize itself. We must guard ourselves against this danger. More than many other developing countries, India is in a position to wrest significant gains from globalization. However, we must voice our concerns and in cooperation with other developing countries modify the international trading arrangements to take care of the special needs of such countries. At the same time, we must identify and strengthen our comparative advantages. It is this two-fold approach which will enable us to meet the challenges of globalization which may be the defining characteristic of the new millennium.

The key to India's growth lies in improving productivity and efficiency. This has to permeate all walks of our life. Contrary to the general impression, the natural resources of our country are not large. India accounts for 16.7 per cent of world's population whereas it has only 2.0 per cent of world's land area. While China's population is 30 per cent higher than that of India's, it has a land area which is three times that of India. In fact, from the point of view of long-range sustainability, the need for greater efficiency in the management of natural resources like land, water and minerals has become urgent. In a capital-scarce economy like ours, efficient utilization of our capacity becomes even more critical. For all of these things to happen, we need well-trained and highly skilled people. In the world of today, competition in any field is competition in knowledge. That is why we need to build institutions of excellence. I am, therefore, happy that the Ahmedabad Management Association, besides other functions, is also focusing on excellence in education. Increased productivity flowing from improved skills is the real answer to globalisation.

\subsection{Bench marking}

As on date universities like Stanford, Massachutes, and Haward are considered to be the best. Following their foot steps in terms of building of infrastructure, facilities, computerization and networking, library, technical manpower etc. in Indian universities will strengthen the hands of technical education and if it combines with a specific vision then it will be just like sugar in the milk.

\subsection{Multidisciplinary approach}

Technical education in its wide spectrum covers engineering which includes branches like electronics, computer, IT, electrical, mechanical, production, metallurgy etc.

Across the globe there is a change thought process in the era of software-netwaresimulation and modeling. Now there is changing trend that people with multidisciplinary knowledge are preferred in industries. This is because in most of the sunrise industries the knowledge base is now available on computers. Sooner or later this will be coming to India. So we must prepare ourselves in this direction to meet global competitiveness.

\subsection{National library}

Currently the scenario is such that each individual institute is subscribing separately to various national and international journals and they are not having any connectivity amongst them. This scatters in totality. If agencies like AICTE/UGC goes in agreement with such publishers and make these journals and other information relevant to research 
available on their national digital library then institute from any corner of the country can access the same. This will enhance the current knowledge base thereby the research.

\subsection{Academic reforms (credit system, autonomous status)}

In most of the countries industry plays the major role in deciding the curriculum. The industry goes by the inputs of technical manpower required by them. The industrial funding to the institutes has this as the basis. Thus a scientific curriculum based on the needs of the industry which is the customer of our product i.e technical manpower we produc e, and is derived by eminent technologists and which can be modified from time as per the technological changes and reforms in the industry is the need of the time to face global competition.

Credit system of assessment is globally accepted. In India exculuding IIT's, IISc other universities which can be counted on finger tips, rest of the universities are still following the percentage system of assessment. On a similar, scale it always becomes easier to rate our students internationally, so it is the need of the current time.

\subsection{Competent technical teachers}

Global standards suggests that the technical faculty becomes more competitive with introduction of roper promotions and performance appraisal schemes which are rationally based on the basis of industries like no. of papers published at national and international level in journals and conferences, number of patents in his name, technology transfer he has done, no. of Ph.D/M.Tech's he has produced, industrial consultancies he has done, research projects he has completed and his such other contributions in academics.

In an autonomous status the institute can think of appointing teachers on contrast basis, hire or manifest exchange programme of teachers with other reputed universities in the world, impart training to his teacher's in world's best universities so that the competency level goes up and the institute gets prepared to face global competition

\subsection{Industry institute partnership}

In the era of globalization Indian industry must work in the tandem with the academic institutes for its own benefits.

\subsection{Entrepreneurship development}

Creating one entrepreneur is equivalent to producing several technical people because he his the man who will be providing job opportunities to others. Industry and institute should jointly work together to transfer the technical know how and other essentials in this era. This will be a building up process towards creation of new research avenues and global competency.

\subsection{Women in development}

Women are now almost constituting $1 / 3^{\text {rd }}$ of the upcoming technical manpower. This has happened because of $33 \%$ reservation provided to them in technical education. They are fast coming out of discrimination they had to face earlier. Now it is a very common features that on shop floors of many industries are working shoulder to shoulder with them. With education and training they are now in close competition with men in non-traditional jobs, promotion, higher earning, and continuity of employment. 
Global observations reveals that amongst women self-employment is rising, with women launching a large share of new enterprises in Americas, Africa and Europe-despite discrimination, because of increase education, and largely in the service sector.

\subsection{E-learning}

Most of the forign universities are conducting online technical degree programme. They are having satellite campuses which offers variety of associate degree and diploma programmes like economic development programme etc.

\section{Foreign universities in India}

The following are the few foreign universities in India are: Virginia Polytechnic Institute and State University (Virginia Tech) .Georgia Institute of Technology (Georgia Tech). Schulich School of Business. Boston University Middlesex University and Duke University

There is one report that the world renowned universities like the Oxford, the Harwards , the Stanfords, the Karngi Melons and some other have already declared that they are alright were they are and they might not be able to maintain the same high standard of performance in other countries and they may probably loose their present reputation and the status established in the eyes of the world. Some of the other universities believe that to impart education is a noble cause and it should be an endeavor to propagate and spread education thought the length and breadth of the world.

They are ready to adjust to the norms and regulations of the countries where they go. They are also ready to invest for the cause of education and get back their invested money through collection of education fees and from research as well as consultancy activities. They will plan in a way that they become self-supported financially and can as well send part of the income back to their country from the profit which they earn. It seems they have vision and mission.

They are yet other universities whose would like to set of campus into other countries only with professional motive. They think that education is a trade. Plan, work and earn. The students who will not get admission in courses of their choice at home and crave for the degree of the foreign university will take opportunity to opt for admissions in these universities. These universities on the other hand will have to establish their own reputation of excellence to stand, earn and survive.

Needless to mention that such universities mentioned above will enter here once the legislation is operative and they wish to step in. It should not be out of place to mention here that there are some strong use coming from academic, politicians and the public against welcoming the foreign universities to our country. The foreign universities bill was approved by the union Cabinet in March this year (2010) and was introduced in the Lok Sabha on May 3, 2010. nThe bill, once passed, has the potential to create the same impact on India's higher education sector as the economic liberalisation and deregulation in the 90s had on India's industrial sector. The bill is unclear whether reservation of seats for OBC and SC/ST students would be an eligibility criterion for the foreign educational institutions to be notified as Foreign Education Providers (FEP).The FEPs would be treated as Indian private universities and allowed to set their own fee and would be exempt from reservations. Also, one of the concerns expressed in the monograph is the imposition of the condition that no repatriation of profits will be allowed might act as a deterrent for the foreign universities to enter India. Without a possibility of taking back its invested capital, a foreign institution might simply choose to not enter the Indian education sector. 


\section{Objectives of collaboration \& partnerships between Indian and foreign universities / institutions in the field of technical education, research and training}

1. To facilitate collaboration and partnerships between Indian and Foreign University / Institutions in the field of Technical education, Research and Training

2. To systematize the operation of Foreign Universities / Institutions providing training and other educational services, in India leading to award of Degree, Diploma, Post Graduate Diploma and Post Diploma Level in technical education on their own, under any mode of delivery system such as conventional / formal, non-formal and distance mode.

3. To systematize the operation of Foreign Universities / Institutions providing training and other educational services, in India leading to award of Degree, Diploma, Post Graduate Diploma and Post Diploma in technical education in collaboration with an Indian educational Institution, under any mode of delivery system such as conventional / formal, non-formal and distance mode.

4. To safeguard the interest of students' community in India and ensure uniform maintenance of Norms and Standards as prescribed by various Statutory Bodies.

5. To ensure accountability for all such educational activities by Foreign Universities / Institutions in India.

6. To safeguard against entry of non-accredited Universities / Institutions in the Country of origin to impart technical education in India.

7. To safeguard the nation's interest and take punitive measures, whenever necessary, against the erring Institutions, on case-to-case basis.

\subsection{Eligibility}

1. Foreign Universities / Institutions interested in imparting technical education on their o/. wn in India leading to award of Diploma and Post Diploma and Degrees including post graduate and doctoral programs.

2. Indian University / Institution which is already in existence and is duly approved by the Council, interested in imparting technical education leading to award of Degree, Diploma, Post Graduate Diploma and Post Diploma including post graduate and doctoral Programs of a Foreign University through collaborative / twining arrangements.

3. Offshore Campus of Indian AICTE approved Institutions offering Indian Degree. Any other educational activity carried out in India, in any manner by the Foreign University / Institutions

\section{Future scenario}

Education system should be framed in such way that their output should be face globalization challenges successfully.

Firstly, $80 \%$ of the new jobs coming in next decade of this century will be in companies that do not exits now secondly, $75 \%$ of the technology used earlier(about 10 years back) does not exists now. Thirdly, the world fund of knowledge doubles in every 2.5 years As a result of globalization the qualities expected of technical manpower will be the same thought the world. Institutions have to produce manpower not only for the local marred but also for the national and international market as well .So students should have skills of Good communication, thinking and ever learning, Team work, Positive attitudes and good behavior, Facing responsibilities, creativity, adoptability. 
In the present time there is a need for the technical universities to re-structure their curriculum of engineering courses to increase more credits for hands on practices, laboratories and industrial projects to ensure engineering graduates passing out have better skill sets which make them employable. IT companies are the major employers of engineering graduates in India. Before recession, USA was the main export destination for services of these companies, but these firms have now started looking for business in Frances, Germany Brazil and African countries and Indonesia also. The knowledge of one foreign language other than English would enhance the chances of employment of engineering students in companies having business in countries other than USA. It will serve a very useful purpose if universities make a provision in the curriculum regarding teaching of one foreign language other than English. The future engineering graduates would need to have some business acumen also. This necessities the need to teach some business skill also in classroom along with domain specific skills to engineering students to enhance their employability. Technical Education needs to strengthen basic cognitive learning to give students and trainees more flexibility to meet the changing requirements of the workplace

\section{Conclusion}

The purpose of globalization of Indian education is to make a major sources of earning foreign exchange ; to improve quality of Indian education and to spread Indian culture and value. Setting up units abroad will create awareness about Indian education, but it will not help us to earn a substational amount of foreign exchange because a major portion would be spent to run the institution. Hence looking at the purpose, of various options of globalization of Indian education, the most appropriate option would be attract the maximum possible number of foreign students. Globalization of higher education is to be promoted not only because it yields financial benefits, but also because of the academic, political and social advantages that accrue from the presence of international students on campuses. Technical institution must re-engineer their vision and mission to carryout multinational activities. The technical institutions must withstand the challenges of globalization. To meet this following steps to be followed.: All technical institutions must have autonomy for academic, administrative and financial; Partnership between industries and technical institutions should be encouraged and promoted; More effective means of information delivery must be used; Institutions should have freedom and motivation to generate additional financial resources through research, consultancy, continuing education etc; Technical institutions should be internationalized by developing linkages and partnership with -international agencies for the various programmes and services offered by the institution; Communication through satellite for continuing engineering education program will help a large number of country men in getting informed about the latest development taking place in the world. Globalization leads to challenges and threats also. The major concern is to deliver world class education with updated curriculum and practical exposure. This is possible only by attracting talented \& experienced persons in to academics. At present it is difficult to assess not only the nature and dimensions of globalization, but also what it means to the field of education. A few educational researchers have attempted to make connections between the several dimensions of globalization and the policies of education. 


\section{References}

[1] Metzer C, Berset J E, Zemsky R, Law S S and Innozzi M, Different Paths, Similar Pursuits- The Economic and Personal Potential of Vocational Training and Education in an International Context, Studies and Reports 12, University of St.Gallen, Switzerland, 2001.

[2] Law S S, Vocational Training and Education: The Lessons and Beyond- A Personal Perspective, ITE Paper No 4, Institute of Technical Education, Singapore, 2001.

[3] Law S S, A Journey Towards Organisational Excellence- The Singapore Experience, International Symposium on Quality Management and Quality Assurance in Colleges and Vocational Education, Esslingen, Germany, 2003.

[4] Stromquist, N. P., \& Monkman, K. (2000). Defining globalization and assessing its implications on knowledge and education. In Nelly P. Stromquist \& Karen Monkman (eds.), Globalization and education (pp. 3-26). Lanham, MA: Rowman \& Littlefield Publishers, Inc.

[5] Wu, R. T. Y. (2000). Trends in technological and vocational education in Taiwan, Republic of China. Workforce Education Forum, 27(1), 1-14. (ERIC Document Reproduction Service No. EJ 625 969).

[6] 'Higher Education: Free degrees to fly', Economist, February 26th-March 4th, 2005, pp63 65

[7] Survey: Higher Education, Economist, September 10th-16th, 2005, page 50 onwards

[8] Times Educational Supplement, 7 October 2005

[9] 'Simputer for Poor goes on sale', BBC News, Monday March 29, 2004, bbc.co.uk

[10] Solution lies in Private Initiatives, Hindustan Times 20 November 2005, New Delhi)

[11] A. Sheshbalaya, Yale Global online:www.yaleglobal.yale.edu)

[12] Ashutosh Sheshabalaya, 'Rising Elephant-the Growing Clash with India over whitecollar jobs and its Challenge to America and the World', Macmillan India, 2005

[13] Ramping up in India, Business World, 21 November 2005

[14] The other MIT', Business Week, 22-29August, 2005

[15] Long term Advantages for the Indian IT Sector, Business Today, 4 December 2005

[16] India Today International, 3 Oct 2005

[17] H. Wadhwa and Harpreet Khurana, ‘Beyond Cost Reduction: Risks \& Rewards of Services Sourcing', Columbia Business School

[18] India and the Knowledge Economy; Leveraging Strength and Opportunities', The World Bank, Report number 31267-IN, April 2005

[19] Editorial, Economic Times, 8 November 2005

[20] UGC and the tale of two promotions, Economic Times, 15 November 2005

[21] 'Regulating Higher Education' ( published in three parts), Indian Express, New Delhi Edition on July 14th, 15th and 16th, 2005- also posted online in www.indianexpres.com).

[23] India on Top in US Varsity enrolments, Hindustan Times, 8 November 2005

[24] India's Higher Education needs Policy, Hindustan Times, 28 November 2006

[25] Responding to globalization: india's answer Dr. C. Rangarajan Chairman, Economic Advisory Council to the Prime Minister New Delhi, 2006. 


\title{
How to Discover a New World Without Being in Danger of Wreck
}

\author{
Miguel González-Carbajal Pascual and Ludmila Martínez Leyva \\ Medical Sciences University: Dr. Joaquín Albarrán and Carlos J. Finlay \\ Cuba
}

\section{Introduction}

The fact that a serpent has been chosen as a component of medicine caduceus should not be surprising because, from his oldest ancestors, man has shown a strong tendency to idolize this species either by his cunning and wisdom or because of the intense vital impulse that is attributed to snakes. The world's oldest ritual, possibly due to an enigmatic cosmogonic influence, was centered on a snake. A professor at the University of Oslo, Sheila Coulson, found evidence of the cult when studying the origin of the San tribe living in a sparsely populated area of northwestern Botswana, Africa. The scientists' team got into a small cave where they found the simulation of a huge snake six feet long carved on a stone. It was a stone with a serpent figure with hundreds of indentations that could have only been made manually by man. Immediately, they decided to excavate beneath the rock searching for the equipment used to make incisions and found many stone tools with which the cuts were made. But most importantly, they found a piece that made up the snake, which should have fallen during the construction, 70 thousand years ago. The world's oldest ritual took place in Africa, (the first finding of this kind took place in Europe 30,000 years before) where a group of homeless and fearful men worshiped a stone boa. It seemed to move by stealth down the torch light due to sinuous anatomy and fissures that had been carved to worship it in some distant connection, knowing that knowledge and strength are attributed to this reptile (Gonzalez, I. 2007). If we stimulate our imagination a little bit, it would be conceivable that one of those men would have been the first to start the men diaspora to all latitudes of Earth from its cradle and source of an African common origin, which could make this fact the predecessor of what we call today Globalization. His name is unknown, unlike the others who followed him through history such as Alexander the Great, Marco Polo and Christopher Columbus as outstanding figures of this complex and fascinating feat in which humanity got in first, with tentative steps and then, with increasing enthusiasm. One of the motives seems to have been the need for communication, prompted by an innate curiosity that lies at the heart of the human species. It has been argued that early hominids got raised to the standing position, encouraged by the desire of discovering what was happening beyond weeds covering the wide savannahs.

If we stick to the Dictionary of the Royal Spanish Language Academy (DRAE in Spanish), we will see that communication has as first meaning: (From lat. communicāre) to share with others what someone has. (DRAE 2001, 22nd edition). However, history has stubbornly taught us that most of the time, when the communication between men takes place, what happens is 
exactly the opposite, that is, oneself is a participant of what someone else has. Sometimes more blatant than others, as soon as the man had a bit more than what was strictly necessary for survival, he became interested in plunder philosophy, an inspiring source of all conflicts. Not even the Great Admiral could elude that fate, and perhaps unintentionally in his overall relationship, addressed to the Catholic Monarchs, the references to the "gold" word count around two hundred times, while he only mentioned the name of the "Almighty" fourteen times. Thus, he revealed accidentally the closest motives that inspired his false devotion feat, which was permeated with a distinctive smell of sulphur, a smell of Devil's claw (Carpentier, A. 1979). When a mugger stops his victim in a dark way and blurts out: Your money or your life! he shows a specific message, very clear indeed.

The grueling route required not only human nature as the driving force, but it also needed science peremptorily so that the steps could go directly to conquer the coveted top of the planetary scale, a prerequisite that authenticates the Globalization concept; and humanity decided to cultivate it and make it progress vehemently. Jean Jacques Rousseau accurately identified man as a social being, and according to him, man was destined at finding a way of association that should defend and protect, against all common forces, the person and goods of each associate, and through which each person together with everyone else, should obey only himself and remain as free as before (Rousseau, 1988). It could be interesting to medicine professionals to find contact points between this idyllic association, that referred the remarkable French philosopher of the Enlightenment, specifically in regard to healthdisease process during humankind inevitable course through Globalization.

If we move a little inside the rough track of medieval thought, so constant in worshipping religious mysticism and liturgical rituals as well as in the proscription and insatiable persecution of witches, wizards, alchemists and freethinkers, we could feel the beneficial influence of the Renaissance breezes, which are impregnated with the freshness that only the relief from a too much heavy burden provides. We could also perceive the reason why is still celebrated the resounding displacement that took place when the man, in his own right, became the center of every interest. It was a historical portentous turning point that embraced society and its cultural values system. Science did not let the chance go, and in the twinkling of an eye, it soon provided the foundation for an unprecedented flowering that would induce an improvement of such great magnitude that indelibly removed contextual frameworks that humanity had in the west.

With these premises, it is not difficult to understand why, taking as a starting point science development since the seventeenth century, the information it produces turned into a normative knowledge pattern, to become almost exclusively the sole and legitimate representative of human wisdom, a phenomenon in which should not be overlooked the seal left by the French Revolution at the end of the next century. Modernity opened a new independent cognitive relationship, which was eventually consolidated. The "reign of reason" became the "reign of experimental science." Today, we can see how a huge portion of humanity assumes scientific thought legitimacy in order to create a predominant trend; over and above which, there are still alive with a particular frequency the magic, the occultism, the necromancy, the astrology, and many other reality approaches to which could be added pseudo-science, the danger of which lies in the fact that, unlike the others, it presents itself as a science.

Knowledge scientific character consists of the fact that, in this case, man deals consciously and in a planned way, with a reality area in order to investigate it and study it deeper, more systematically and accurately than the common man, and achieves to establish the accuracy 
of knowledge thus gained. It is then a specialized activity that becomes a profession in the person of the scientist (Rojas, 1996).

Other specific science qualities that allow its differentiation from everyday thinking and other knowledge forms are: Objectivity, Rationality, Systematicness, Generality, and Fallibility. Science is one of the few man-made systems which explicitly recognize its mistake possibility. The real capacity to overcome resides in this awareness of its limitations. If this work accomplishes to clarify some of the actions brought about by Globalization and the huge technological advances that go along with it, together with the Clinical Method and the doctor-patient relationship; contributes to establish a balanced role to be played by the Evidence Based Medicine powerful movement on the diagnosis and treatment of our patients; collaborates to restore the place that Biostatistics should occupy at these burning issues, and allows us to approach the answer to the question: "Is the association we found in the Globalization process similar to that proposed by Jean Jacques Rousseau?" Then we will consider fully well accomplished our most ambitious aspirations.

\section{Approach to the concept of globalization}

At the beginning of this epigraph, we feel compelled to clarify some points regarding the Globalization concept, a phenomenon difficult to explain, to which many authors have attributed a large number of definitions. We will try that the concept offered here can be comprehensive so that it can help as a reference for the aspects we will analyze. We will also seek to be concise enough so that it can have a proper accreditation.

The Dictionary of the Spanish Royal Academy records "Globalization" as the "tendency of markets and enterprises to increase themselves, reaching a global dimension which transcends national boundaries" (DRAE 2001, 22nd edition). According to this definition, it is a fundamentally economic process.

When people hear about Globalization, they think of a phenomenon born in our time. It seems that the world got globalized just a few years ago. The classics of Marxism, Marx and Engels, even when they did not use the term Globalization in vogue today, were able to see the process as a historical tendency of capitalist development. Globalization is the increasing integration into a sole world capitalist market. It is defended by neo-liberalism embodied in international organizations such as the WTO (World Trade Organization), the IMF (International Monetary Fund) and the WB (World Bank), and it is rejected by antiGlobalization groups (Moran, M. et al. 2008). In 1945, shortly before the end of World War II, the United Nations, still in process of constitution, carried out a financial conference in Bretton Woods, United States, where it is decided to create the International Monetary Fund and World Bank. In that moment, that superpower took control of international financial institutions, where it unflinchingly holds veto power (Castro, F. 2011). Soon after, in 1947, the WTO predecessor is signed, that is the General Agreement on Tariffs and Trade (GATT). In 1971, during Richard Nixon's presidency, United States suspended the dollar conversion into gold. Unlimited U.S. bills were printed with which this nation acquired large properties and wealth in the world, as they had a currency in constant and growing process of devaluation. In 40 years, its value was reduced to $2.5 \%$ from the previous one it had then (Castro, F. 2011). These data explain the rising hegemonic role, played by a nation in the development of Globalization. Understanding extra-economic dimensions of Globalization cover issues that affect all humankind worldwide, among which may be included: immigration, transportation, education, medicine and population health, cultural 
imperialism against multiculturalism, mass media, Internet, climate change, global economic crisis, food crisis and the real danger of a conflagration that could quickly reach international proportions.

\section{Internet: Vehicle or globalization purpose?}

Just because it is a tremendous informative building which has been self-configured, it becomes a leading cultural event, although it has been and is being so essentially chaotic. The prodigious ease with which we can now identify text, sound and pictures, keeping them in our own personal computer and modify them or share them with colleagues; opens up opportunities for scientific culture unsuspected until very recently, especially in the South. And in the specific case of researchers, they are strengthened with the distribution list by email, the access to many journals in all disciplines, the connection to databases and records with information (e.g. demographic and epidemiological), the access to academic institutions, the research centers, and webpages or individual blogs from eminent scientists (Silva, L. 2008). Historically, the most effective way to combat false or misguided information has been to provide genuine and accurate information, but the big challenge is to demarcate each other. It is necessary to insert that, although slow and laborious, the system of conventional scientific journals towards peer review, offers in principle a rigor guarantee that happens to be a good deed not negligible at all, and it is needed mostly while we live in this information flood that usually develops more rapidly than our own ability to rationally assimilate it (Silva, L. 2008). Literacy concept now includes not only words reading and writing, but also computer skills are essential, as well as mathematical, methodological, epidemiological and statistical knowledge. In the information age, the library role assumes a definitive function in "information literacy." The increasing production volume of information requires a growing space for its conservation. It also requires an almost instantaneous dissemination of information as a result of the so-called Globalization process or knowledge internationalization. Factors that have influenced the most the publications movement to new media are: the need for immediate distribution of information, the rising costs of printed editions and paper, contrasting with the accessibility and affordability of modern media. In this way we are, in the health field, with a high percentage of professionals who are only superficially related to the information world. It is considered that to have "information literacy" is " to know when and why you need information, where to find it, and how to evaluate it, use it and communicate it in an ethical way." We live in an increasingly competitive globalized environment, which is in short, a new economic context in which the best source to obtain a sustainable competitive advantage for an organization, region, or society is the continuous innovation and the knowledge that enables such innovation (Casate, R. 2007). Internet is here to stay, and it can be considered as a consequence of Globalization and at the same time, an important driving factor.

\section{Clinical method: Rising and declining. Globalization and technology effects}

\subsection{Background}

Many people tend to repeat that prostitution is the oldest of all trades; if we admit that the massage that is practiced on a swollen and sore area after a surprising bang, is one of the earliest and instinctive attempts to relieve pain and, therefore to exert medicine though 
rudimentary, let me have at least some misgivings about the first in the time of the trades mentioned. What no one will ever put into question is that since it was born, the medical profession was essentially benign, beneficial, and charitable; which aims to cure or relieve disease effects on people. At that time, and even many centuries later, concepts of disease prevention were not important at all, or they were simply not known; and it is remembered how surgeons and dentists, better classified as "tooth-takers", alternated their functions with barbers. The science of first physicians was limited to relationships with patients, and politicians were far from imagining the importance of health care and its promotional program designs, to acquire the development of future societies. Given the powerlessness to carry out many diagnoses and the lack of resources for effective treatment, doctors interacted with patients and their families and thus appeared the so called "bedside doctor" or "family doctor".

The truth is that medical practice only had, at the beginning, the interrogation, physical examination and urine, feces and other patient secretions visual exploration, in order to make their diagnoses. With the gradual introduction of scientific and technical advances in the identification of conditions that patients suffered, there were provided unexpected options to successfully complete a diagnosis process. The microscopy was introduced and urine revealed previously unknown secrets, when only visual examination was available to evaluate its characteristics. Blood, feces and other fluids were thoroughly analyzed with the lens amplification ability. Would it be then, when appeared an irresistible temptation for some medical practitioners to abandon the habit of examining carefully and sometimes even smell the urine and other revolting secretions, to instead indicate a microscopic examination of them, which, besides being more elegant, was a demonstration of scientific progress?

\subsection{The Scientific Method}

Along with all particular methods, there is another one called the scientific or experimental method, common to all sciences, whether applied or theoretical. There is no science without Scientific Method, because it is the research strategy, it is the one that has to do with the entire research cycle and not only to one of its individual parts. It is also independent from the subject or the phenomenon that is selected for analysis or study. The hallmark of science is the Scientific Method. This is a universal, unique, and common method to all sciences; it covers all research, and constitutes its strategy (Moreno cited by Nassif, 2010). There is considerable consensus concerning the fact that the scientific or experimental method was definitely stated by Claude Bernard in 1865, although it was applied some time before. It consists of the following steps or stages: formulation of the problem to be investigated; scientific hypothesis to be proven, design and implementation of experiments that need to be carried out, to verify whether the hypothesis was proven or not, review and re-checking, because no experimental science is checked just once since either chance or favorable bias may have intervened, so we must check and recheck, which is called reproducibility and consistency (Moreno cited by Nassif, 2010)

\subsection{The Clinical Method}

The Clinical Method can be summarized as the application of the Scientific Method by the healthcare doctor to the object of study: the health-disease process in humans. It is simply the Scientific Method applied to the work with patients. When a doctor treats a patient, he also applies the Scientific Method; the difference is that he is not dealing with a laboratory 
experiment with inanimate material or plants and animals, but humans. In this case the patient talks about his discomforts and the doctor gets the symptoms through the interrogation and the signs through physical examination. So, he gets the information needed to immediately establish the presumptive diagnosis hypotheses and checks through the contrast, which, most of the time, is performed by laboratory analysis or other tests called complementary tests. The steps were: formulation, information, hypothesis, contrast and verification. These organized steps or stages consist of the Clinical Method or the diagnosis process, as it is also known. Each time a clinician faces a patient diagnosis, he is carrying out an investigation and makes it through the Scientific Method common to all sciences (Moreno, M. 2001). Nowadays, treatment is included in the Clinical Method due to its close relationship since there is no diagnosis without treatment and it is necessary to have a diagnosis in order to indicate a therapeutic remedy. In addition, the Clinical Method ultimate goal is no other than the application of a treatment to heal or relieve the patient. (Rodríguez, L. 1999).

Scheme No. 1 illustrates the similarity of the Scientific Method and the Clinical Method stages.

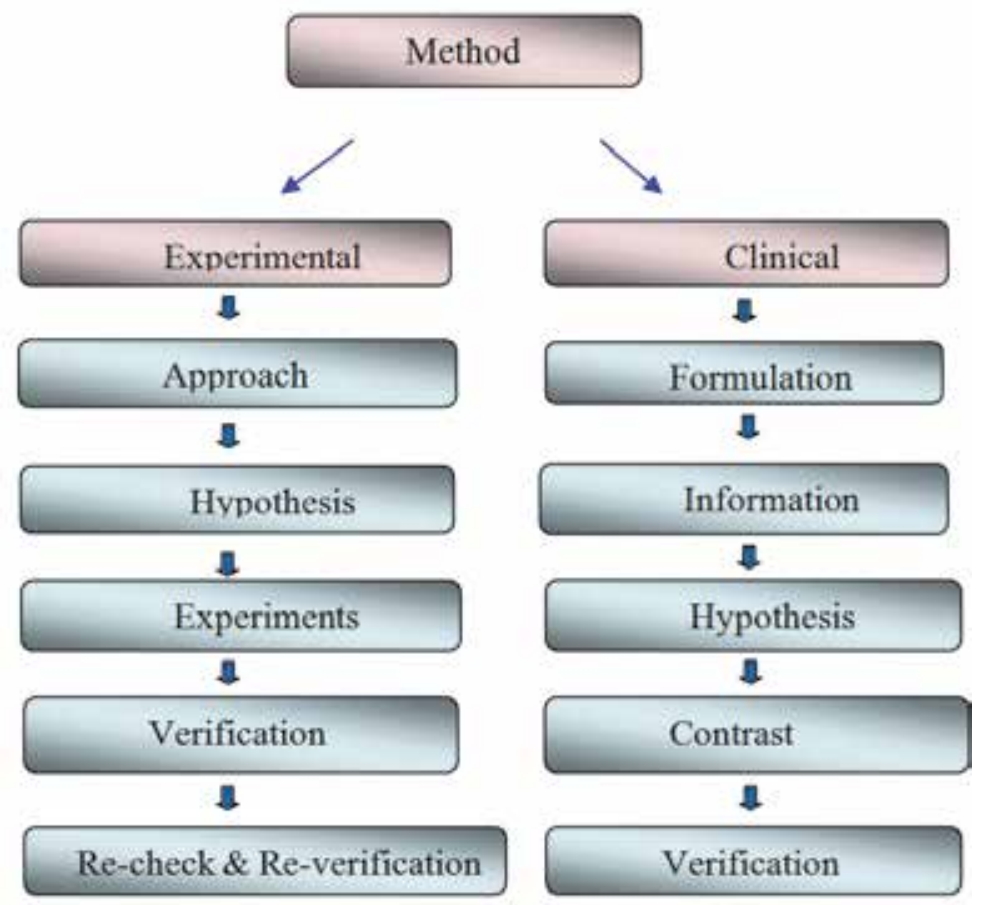

Scheme No.1

When breaking down this scheme can be seen, in regard to clinical methods, the way in which (Ilizástigui \& Rodríguez cited by Nasiff, 2010) each stage of the method depends on the previous one:

Formulation: the problem or problems of the patient. The reason why the patient consults the doctor is because of his health loss.

Information: The search for basic information. It refers specifically to the interrogatory and physical exam, which is equivalent to the clinical history. The physical examination should 
be complete regardless of the organ to which the subjective symptoms may suggest. Previous unsuspected findings in the physical examination have led to accurate diagnosis. Hypothesis: It is, in the Clinical Method, the diagnosis or presumptive diagnoses. Contrast: The presumptive clinical diagnosis is subjected to verification by scheduling additional laboratory tests, imaging, pathology and others. It is also essential to observe the patient's evolution as the results of the tests arrive.

Verification: Finally, there will be an accurate diagnosis that will allow the doctor to indicate some treatment or, what is crucial, the diagnosis hypotheses stated will be denied or new problems will be discovered. The latter will make obligatory to reassess the situation and restart the process.

In the stage of the hypothesis formulation, a procedure that consists of grouping patients' symptoms and signs into syndromes is applied, and thus a syndromic diagnosis can be formulated. Then, the doctor proceeds to examine carefully which diseases, according to the clinical manifestations, could explain the symptoms and signs that the patient presents at that moment. It is basically a rational scientific thought exercise, some call it "medical thinking", in which the clinician proceeds to analyze similarities and differences of diseases that could be responsible for the patient's syndrome or syndromes and are excluded one after the other, the ones that fail to adequately combine with the clinical features of a particular patient. Sometimes the doctor prefers only a clinical diagnosis; it is called like this because in its elaboration there have not been included data provided by complementary examinations. Some other times it is necessary to admit a second or third diagnostic possibility in the patient. All this process is called differential diagnosis and it can be richer and more productive while more clinical knowledge has the one who carries it out. The foundations upon which further examination will be selected to prescribe on each patient and its initial consecutive order depend on the clinical diagnosis, which is equivalent to the hypothesis.

The clinician has the advantage that in addition to symptoms and signs, he can study the sick person; he can also know everything about the patient's life. When delving into the socio-psychological study of the patient, the clinician's work takes on its true dimension of integration. The doctor-patient relationship is the most sensitive and humane aspect of medicine, and the first principle for a correct application of Clinical Method. If the doctor does not establish a positive and cordial human relationship with the patient, he has misspent his chance of succeeding. This type of relationship can not be replaced by the use of apparatus and analysis as modern as they can be, because its content is eminently human. Some doctors do not fully understand that the patients' satisfaction, their views on their caregivers' competence, and their final assessment on the health system efficiency are closely linked to the doctor-patient relationship. Today it is common to speak of good clinical practice. The first rule of good practice is to apply the Clinical Method excellently. There is no science without Scientific Method (Moreno cited by Nassif, 2010).

Urbanity or formal education, as it is nowadays usually called, plays a leading role in the fact that this relationship between patient and doctor, as well as with nurses and other health workers, can flow fruitfully. It is a massive discourtesy that an elderly person, which may be a famous writer, an economics or medicine professor, a skilled worker or a modest street sweeper can be automatically reduced to the status of "my folk", "grandfather" or "grandpa" just because he filled out a hospital admission slip, no matter the good intentions that could have been applied in one case the degrading, and in the other absurd and equally irreverent adjectives, as there is no blood link with the patient. Which right has that that assists in the plethora of his or her youth, to arrogate that inadmissible prerogative stuck to spruce up in a white coat or other health clothing? 
Clinic science takes the general, which is the disease, and combines it with the individual in a close particular dialectical unity that leads to the patient. That is why there are not two patients alike. A doctor attends a patient, not a disease.

The intelligent and rational use of diagnostic means that technology gives us does not create any problem if the hypothesis is put before the contrast, and not the other way around. The use of technology is part of the Clinical Method. Proceeding to the contrast stage without having a clinical hypothesis would indicate a complementary "set" -as it is often calledcarrying out a frantic divination race against scientific procedure. Additional tests exist to be prescribed by stages, gradually, and subjected to a previous formulation of a clinical hypothesis, as each one should be correlated with the initial hypothesis, the patient's evolution and the rest of the results that have been received. Understanding the Clinical Method value in medical practice and to fight for its proper application is the cornerstone of an excellent medical care (Ilizástegui cited by Nassif, 2010).

However, despite all its benefits and its convinced defenders agglutination capacity, many data indicate that the Clinical Method suffers, for decades, a continued deterioration in Cuba and worldwide. This global crisis is manifested by:

- Underestimation of the interrogation value and the physical examination as diagnostic tools.

- Excessive and irrational use of diagnostic technology.

- Deterioration of the doctor-patient relationship.

\subsubsection{Underestimation of the interrogation value and the physical examination as diagnostic tools}

Partly inspired by a "law" that although with degrading consequences is not less attractive, we refer to "comfiness law" or " least effort law ", a growing number of doctors have given up dialoguing with their patients and they perform a superficial physical exam or simply do not do it. Why bothering on getting out of the consulting room or staying bedside of the patient? Since the authors are active practitioners of the profession, we know that, in addition, not all patients present neatly and their illness severe nature -skin lesions, fever, sweats, productive cough, bruises, petechiae, foul breath, etc.- are factors that do not encourage to approach and touch them. To do so, doctors must deeply feel the vocation towards the profession they chose, and they should be convinced that the daily routine lies in the close coexistence with people suffering from diseases that have unpleasant physical manifestations.

Thinking of a diagnostic hypothesis has become a very laborious task, which according to them, should be supplemented by the reference to a barrage of complementary examinations, which with a sudden shot impact with pellets would work the miracle of exposing the patient diagnosis without the awkward situation of wasting time in a lengthy interview and a physical examination, and what represents an even greater burden for those minds: the ominous sacrifice of thinking, an essential condition for developing a diagnostic hypothesis. This volition is more pseudoscientific than misleading; since science recognizes its mistakes. Some doctors, driven by the growing fascination with the technological advances in the field of diagnostic and therapeutic alternatives that are available today, have assumed behavioral methods that, though wrong, have been incorporated to themselves with a pedestrian easiness. Delighted with an inexplicable spell, they forget that science and technology are products of the human brain that can not become their slave.

\subsubsection{Excessive and irrational use of diagnostic technology}

Prof. Miguel Angel Moreno, with his masterful teaching aptitude, gives us this eloquent example of what unfortunately is happening now in the field of clinical diagnosis when 
glossing Karl Marx when he said: "Men have become goods the subject of an almost religious worship; they, creators, have come to surrender to their creatures, the products of their heads have finally seized creators' own heads" (Marx, K. 1973). Similarly, "technology fetishism" has ignited feverishly many physicians' minds, according to Prof. Moreno (Moreno cited by Nassif, 2010), in order to make them sink into the delirious illusion of the fact that technology can provide solutions to the diagnosis uncertainty against the Clinical Method, and without the assistance of semiology, propaedeutic and rational thinking. Almost all imaging scans excepting ultrasound scanning cause human body exposure to radiation in varying amounts, from Roentgen rays to multi-cut helical tomography. There are other investigations, also invasive, in certain indispensable cases such as the endoscopic endoluminal exploration and many others. That is reason enough to justify the Clinical Method use in making decisions that will guide the explorations sequence when examining a patient.

In addition there are economic reasons that can not be underestimated. In many countries there are agreements between physicians and laboratories so that the former receive a bonus for each research they indicate and the patient must pay; of course, the more analysis indications the more profit for the medical professional that recommends it. Such a link has been woven between doctors and drug companies so that the higher the amount of drug prescriptions, the higher the amount of money going to those who prescribe those drugs, which also includes invitations and other perks at the expense of patients' pockets, without being able to obviate the adverse impact on the patient health due to the drugs unjustified prescription. It is possible that sometimes the patient can not afford the economic burden of multiple investigations, many unnecessary, and instead he can be more dissatisfied than grateful to the doctors, who are backwards to the Clinical Method and to the most basic ethics driven by their profitable greed. In other places, where a covering system through insurance is assumed, huge costs come into conflict with the limits that this brings. If a nation health system, as in Cuba, takes the free conducting of any investigations referred by physicians, even the most sophisticated and expensive, the wasting of resources resulting from this procedure is imperative to prioritize rationality recovery when indicating additional tests to patients with the aim of avoiding the risk of making it untenable.

\subsubsection{Deterioration of the doctor-patient relationship}

These mistaken trends have not made their way with impunity, but instead have led doctors to separate themselves from patients and reduce their personal contact with them. It is a bad practice that should be reversed immediately because, if continued, it would entail an irreparable void in medical practice, a discipline eminently social that does not admit being depersonalized as its very essence lies in physical, emotional and affective support that only the doctor is able to provide to a helpless and ill human being -that is beyond co-workers, friends and the closest family members no matter how close they can be. The patient and his family members, regardless of a correct diagnosis and appropriate treatment, require the doctor's presence, the security provided by their professionalism conviction, and the solidarity solely provided by the physician, when doing everything that depends on him in order to restore the patient's health. Medicine is the purest and most human of professions; those who choose it will constantly have opportunities to demonstrate their vocation. It is, in that moment, where the doctor must display his experience and expertise, because the patient's conceptions about his illness vary from one to another as well as the disease presentation; some clinical manifestations are so different that have to be studied and classified as forms of presentation of a particular disease. Each person is a universe in itself, and the minds dark labyrinths usually mask what is unknown to most people and the 
patient reveals only to his doctor. The doctor who forgets that his professional activity center is another human being might be in great troubles. Their success and failure depends largely on the capacity of individualizing each patient. Today it is tangible that, despite the importance of creating a successful doctor-patient relationship, this physical link crumbles rapidly. The removal of this affinity archetype, considered as part of a sterile liturgy or a superfluous ceremonial in the era of modern technology, is a task that does not require too much hard work, as it does with almost all demolition activities. This is part of the current clinical practice in many places, including our country.

\section{Clinical epidemiology, evidence-based medicine and Clinical Method. Incompatible or complementary?}

\subsection{Background}

Beginning with the medical clinic, and according to the author, an inexperienced nephrologist and renal tubule physiologist, David L. Sackett, becomes in 1962, when the missile crisis in Cuba occurred, in a reluctant field epidemiologist at the Public Health Service of the United States. He carried out cardiovascular and epidemiological studies, he learned epidemiology and biostatistics and began to reflect on the area in which new knowledge could be useful to decide to apply them to the clinic rather than population health problems. He did not know initially how to call this discipline until finally decided to borrow a term introduced by John Paul during 1930's decade, he called it clinical epidemiology (Sackett, D. et al. 1989 and Ramis, A. et al. 2005). It basically stated that the application of epidemiological principles and a few more on Biostatistics to beliefs, judgments and intuitions that comprise the art of medicine, could substantially improve the accuracy and efficiency of diagnosis, prognosis, treatment, continuous updating of knowledge and especially the ability to teach others how to do these things. A new School of Medicine at McMaster University gave Sackett, Tugwell and Haynes, the opportunity they craved (Ramis, A. et al. 2005), and that led, perhaps without even imagining it, to build the movement foundations, which later became known as Evidence Based Medicine.

As part of the most remote history of Evidence Based Medicine, there was a movement supported by France in the mid-nineteenth century, which defenders were Pierre C. Louis Alexander, Bichot and Magendie, enthusiastic promoters of the "Medicine d'Observation". They argued that in the clinical practice, doctors should not be solely based on personal experience and their assessments on the position to take towards certain disease, but these should be backed up on research results that will show effects quantitatively. It was clearly observed in the biomedical area, often conservative and attached to the authority, a healthy questioning spirit of those opinions and maneuvers that were based more on tradition than on deliberate reflection and rational synthesis. These fundamentals, proven by A. Louis with the implementation of experiments in which he used his numerical method, revealed the degree of ineffectiveness of some treatments that, at the time, were applied to heal some diseases. Thus, he contributed to the unnecessary therapies removal, and although there were those who described him as a "post-revolutionary skeptical ", his findings had a major impact in France, England and United States of America (Boucourt, L. 2001).

\subsection{Approaching an evidence-based medicine definition}

The term Evidence-Based Medicine emerged in 1992 and was officially mentioned for the first time in an article that can be classified as seminal, and appeared in the Journal 
American Medical Association (JAMA) magazine (Evidence-Based Medicine Working Group, 1992). To practice Evidence-Based Medicine "it is required the integration of best research evidence resulting from our clinical skills and our patients' individual values and preferences". This definition was made by one of the world's most prestigious teams in this field. It appears in a textbook published on the subject and has an Internet website that can be consulted (Strauss, S. et al. 2005). It has been pointed out that the definition is somewhat vague and general because ultimately, everyone might agree with it, but this may not be a defect but a virtue of any definition.

Another way, not essentially different, of approaching the Evidence-Based Medicine concept is the following: "... it is the conscious, explicit and judicious use of the best available evidence when making decisions about a particular patient's care. Evidence-Based Medicine practice means individual clinical expertise integration with the best external clinical evidence available that results from systematic research" (Sackett, D. et al. 1996).

\subsection{Some facts that characterize the present}

Certain facts are unanswerable: (Krabshuis, J. 2007)

- One is the explosive growth of medical information published and the corresponding need, by health professionals, to have this information available and in a way that allows it to be usable.

- $\quad$ The term Evidence-Based Medicine was used in 1996 only 181 times. The number grew to 6452 times in 2004.

- The number of randomized and controlled trials, compared to 1996, has doubled to 15,000 in 2004 .

- Traditional information sources such as text books are not as updated as they should be, and some of their recommendations have been discarded as not useful as a guide for decision making at the patient's bedside.

- A rift has been opened between what is known and what is done, that has been identified by doctors and patients.

The Medline database, which is the most important bibliographic database of the United States Medicine National Library, provides an example of the enormous volume of existing medical information. This entity comprises the fields of medicine, dentistry, veterinary science, health care systems and preclinical sciences. It contains citations and author summaries of dozens of thousands biomedical journals published in the United States and other countries. Its files contain more than 20 million references from the mid 60 's. Its coverage is worldwide and most records come from English language sources or have English abstracts (National Library of Medicine, n.d.).

Although the Evidence-Based Medicine background dates back to little more than two decades ago, its rapid growth has begun just recently. The $91 \%$ of the work on this subject, processed by Medline in last decade, correspond to the most recent 5 years. It can be admitted that such tests are among the strongest evidence and more vigorous research designs of a research scientific validity in this area of knowledge (Canedo, R. et al. 2003).

The Evidence-Based Medicine is a consequence of the necessity to not only answer but also provide a solution to the problems arising from the situation just described. It is therefore, a natural result of the need to create a new healthcare model capable of integrating solid and clinically useful results of investigations that take place in the health sector with daily clinical practice, in order to achieve high quality care supported on the latest developments in the areas of biomedicine, chemistry, technology, humanities, etc. (Broche, J. et al. 2003). 


\subsection{Classification of scientific evidence and degrees of recommendation}

It was necessary to design a system to classify the level of available evidences on a particular clinical problem according to its origin, because, as these come from various sources, the reliability degree was inevitably different.

In general, the levels proposed can be summarized as (Broche, J. et al. 2003):

Level I. The best evidence that certain treatment is effective in achieving a specific goal derives from a controlled clinical trial. This type of experiment, in its simplest design, compares the drug effect to a placebo, both administered in a way that neither the person supervising the experiment nor the patient knows which one receives the placebo and which one the medicine object of study (double blind). The allocation to each group, either of study or control, is done in a strictly random way. With this process, most of the biases are avoided.

To group a set of studies and analyze the results, it is necessary that they fulfill certain requirements related to homogeneity and other aspects. The result is a meta-analysis that, if done properly, can also be considered as evidence of level 1 (Broche, J. et al. 2003)

Level 2. Basically includes the controlled clinical trials that do not reach enough power to prove, unequivocally, the effectiveness of an intervention; because the results are located around the statistically significant borderline.

Level 3. Includes the controlled clinical trials where randomization is deficient or not enforced, reason why biases can be introduced in assigning patients to one of the study groups. The same occurs with cohort studies. Level 3 evidences should be approached with caution and, wherever possible, carefully analyzed, and should be subjected to consensus groups' approval as far as possible.

Level 4. Includes clinical trials where there is no control group and the results comparison is made with the same individuals before and after treatment. It also covers historical cohort studies. In all these studies may be present multiple biases.

Other evidences. All other types of studies such as case reports or case series, descriptive studies, as well as expert reports, among others, may be useful, but their level of evidence is low. However, sometimes they can be the only information available as it happens, for example, with rare cases or unexpected side effects.

There are other classifications of evidence levels that vary in non-essential aspects of the outlined ones.

In concordance with evidence levels, there have emerged degrees of recommendation as to the behavior to be followed in each clinical problem in an order so that they referred them as A, with maximum evidence, to the D. (Broche, J. et al. 2003)

However, there are strong indications that allow predicting a risk of Evidence Based Medicine wreck that should not be dismissed.

\subsection{Evidence-based medicine. "Denial, use or abuse?}

The Evidence-Based Medicine would be called to revolutionize medicine and to establish a new way to practice it from an integrated conception, where it is consciously unified the individual clinical experience acquired by the physician in his professional performance with the most relevant research outcomes recorded in the scientific and clinical literature (Broche, J. et al. 2003).

There is no room for relativism in medicine. The recommended treatments have real consequences, so we better make sure that they are effective, or at least not harmful. That is the purpose of Evidence-Based Medicine: to base our treatment decisions on the best available science, rather than the prevalence of opinions or experience. 
Some colleagues, however, not only abuse the term but also the extent of its projections. Dr. Bernadine Healy, former director of the Health National Institutes in the United States, in an editorial in the U.S. News and World Report in which she commented on the way EvidenceBased Medicine was going up; she labeled it as "micro-fascism." This way, she said, leads Evidence-Based Medicine directly to a tyranny of medical thought. The term "micro-fascism" is striking, while suggesting a totalitarian management of medical practice by the state so, due to such pronouncements, as expected, controversy aroused (Marchetti, P. et al. 2007).

We have reached a moment in which the abuse of Evidence-Based Medicine involves as much risk as its rejection. The evidence can be manipulated to make marginal benefits seem greater than they are. Even more worrying is that, because of necessity, therapeutic studies tend to focus on treatment for a disease in a homogenous population of middle-aged patients. Our patients are not homogeneous, nor have a single disease and few of them are middle-aged. Many of them are elderly with multiple medical problems which require various interventions. There is no reason to expect that they respond to treatment as ideally as research individuals (Marchetti, P. et al. 2007).

In our hospital, the authors have been witnessing a peculiar situation: a non-negligible proportion of doctors who rely on the Evidence-Based Medicine, sometimes with unusual fury, use the phrase to reinforce their own opinions and biases, which may be in some measure related to the extraordinary rising of the term and its relative novelty. Thus, many Evidence-Based Medicine invocations might not be based at all on the evidence. We are concerned, of course, with the fact that the phrase is being "whisked" to add weight to presumed experts views, or just the view of some specialists and residents. It is true that Evidence-Based Medicine underpins the development of guidelines. However, too often, guidelines are intended to be based on the evidence when they really reflect important biases of committee members, or at least consensus views that may not have unanimity in the conclave itself.

One of the problems with Evidence-Based Medicine is derived from the transferring of data into practice. The evidence is involved in our medical decisions, but we also have to use the evidence in the context of the patient's situation. We would like to believe that the use of best information available warrants per se decision making without biases, but that would be naive.

The way we make decisions involves data, but also involves assessing risks and benefits. Conclusions differ because data alone are not sufficient, and they require an analysis and interpretation that may not be equal, and may even have essential differences. We are in favor of developing the best analysis of the evidence without bias, as far as possible. We need good evidence, but we must always interpret it from an excellent clinical judgment (Marchetti, P. et al. 2007).

The Evidence-Based Medicine can not say the way we should treat patients individually. We have to use Evidence-Based Medicine as a welcoming tool in our process of making individual decisions. To expect more than that of Evidence-Based Medicine would endanger the judicious application of the Clinical Method, and consequently the doctor-patient relationship.

On the other hand, the ones who advocate in favor of Evidence-Based Medicine have the right to point out the dangers that holds to base treatment only on pathophysiological foundations (for example, inotropic agents for heart failure and antiarrhythmic drugs to treat ectopic ventricular beats), representing in this case the theory, not substantiated in practice by appropriate clinical trials. Theory that is not borne out in practice is invalid. But it is never convenient to be exaggerated; de-emphasizing basic science entails certain dangers that hinder 
setting it and the reading support aside. Doing so, would lead us to a formulae approach that would preclude preventing errors in patients who do not comply with certain algorithms.

\subsection{Danger of wrecking and moral breaking down}

"... Certain ugliness has its purpose in the very depths of eternal beauty." (Hugo, V. 1975)

There is no less important side of the problem because if pseudoscience is an acknowledged science enemy, fraud is equally abhorrent; both have a common platform that is deceit. That is why, while the powerful interests that increasingly dominate the health care might be offended, we must teach people to distinguish the evidence of propaganda and advertising. The Evidence-Based Medicine may suggest that some expensive and profitable drugs, devices and health care programs, are not as good as they seem, according to its reputation. It is expected that this do not cause sympathy for those who obtain profit, power or prestige of the situation.

Consequently, dominant interests face the temptation of manipulating the development of Evidence-Based Medicine, which entails the risk of eventually having a bad reputation, when discredited. The biotech and pharmaceutical companies have come under the mantle of Evidence-Based Medicine, to use it as one of its methods of distributing products, devices, programs and strategies for health and the publication of original clinical studies in world prestigious medical journals that are only the result of research sponsored by them. However, traders know they can not avoid evaluative resources already well settled among professionals, called upon prescribing their products, such as Evidence-Based Medicine principles and statistical evaluations. The management done based on statistical data in the advertising context is still poorly studied, and the scope given for deepening on its management is enormous. However, no alarming signs of manipulation are missing (Silva, L. 2008).

The magazine quality would support the medicine quality, which affects this way writing evidence-based guidelines for their interests. This procedure dynamics and other no less worrisome aspects closely linked to it are reported by David Sackett, universally known personality. He is considered one of the fathers of Evidence-Based Medicine. Oxman did something similar in a publication that turned to be obliged reference for those interested on the subject. The title of the article is quite eloquent: HARLOT, prostitute in English. It provides the following translation when breaking down its initials: how to achieve positive results without lying to overcome the truth (Sackett, D. et al. 2003).

Harlot promises to give drug companies and other clients the results they want. Your medicine may be totally ineffective, but Sackett and Oxman promise to produce positive results in clinical trials as long as the medicine is not much worse than taking a swig of distilled water three times. It is important to note that these results can not be achieved in low quality clinical trials. These authors, experts in the designing and analysis of trials, describe 13 methods for obtaining the desired results.

In other words, we witness a process characterized by a real danger of manipulation in the designing, implementation and analysis of research studies by the dominant interests in an attempt to increase the probability that results are favorable to them. This was an early envisioned peril, even before the authors of this work, by eminent scientists of international prestige to which would be difficult to credibly tick of being permeated of conflicting ideologies with the political and economic balance of their societies, due to their findings on the subject (Sackett, D. et al. 2003). 
In the Globalization era, the Evidence-Based Medicine commercial handling shows the seriousness that entails its vast dissemination. A significant number of authors have felt compelled to denounce this phenomenon that could be characterized by its ubiquity, rather than its eventuality. This has revealed certain procedures employed by pharmaceutical companies to achieve the expected results in their clinical trials (Journal PLOS Medicine, 2005) which include:

- $\quad$ To compare the drug to be promoted with other less effectively known or a placebo. The important thing for patients is not whether the drug is better than nothing, but if it is better than existing treatments.

- The company compares its product with lower doses of the competition medicine.

- One of the tricks lays in the question it seeks to answer (hypothesis) and the trial design.

- Multicenter studies to select the results in places where they have been favorable.

- To carry out studies with subgroups and select those with favorable results.

- To present results that may be more impressive such as the reduction of relative risk rather than absolute risk.

\section{More threats: The tyranny of statistical significance tests, peer review, debates in the "Science" commission and the power drunkenness}

It is widely disseminated the belief that inferential statistics, and particularly statistical significance tests, provide the bulk of objectivity that underpins scientifically the research findings. It is not definitive the objectivity provided by the statistical significance tests, and even by the confidence intervals, used not as a source of reflection, but as substitute statistical significance tests. The use of dichotomous rules takes actually nowhere; although not few people use them thinking that no additional reflection is needed, convinced that statistical significance tests are self-sufficient (Silva, L. 2008).

The Maastricht III Consensus meeting was held in 2005, in which guidelines were drawn to the therapeutic approach of Helicobacter pylori infection (Malfertheiner, P. et al. 2007). According to that meeting, the usefulness of treating dyspeptic patients not studied, based on a $1 \mathrm{~A}$ evidence level and an A recommendation degree, with the "test and treat" strategy, is based on a randomized controlled study carried out by Chiba in Canada with patients of primary health care (Chiba, $\mathrm{N}$. et al. 2002), as shown quoted in the consensus report. Providing such evidence level 1 and recommendation degree $\mathrm{A}$, to the use of the bacterium eradication therapy in patients with any kind of dyspepsia, which have not been studied, based on a single randomized and controlled trial. This would be methodologically reliable according to rules that were previously established; but this approach is contrary to the spirit of scientific thought, because such invitation entails restricting our valuation tools to pragmatism, as if the theory and general knowledge could be superfluous. Accepting therapy, exclusively taking as a starting point the fact that it successfully passed a clinical trial is a methodological error. First, because it opens the doors to the widespread practice of admitting or recommending a procedure, just because "meaning" was gotten. Does the recommendation to indicate appropriate eradication therapy to all patients with not studied dyspepsia have, despite the results of that work, a clinical and epidemiological justification? Is it that, despite that study findings, there are not expected adverse side effects, which include the increasing bacterial resistance and the dissolution of the normal gut flora caused by the use of two antibiotics in a very broad population that cast doubt upon that 
recommendation? Everyone knows that a general recommendation can not be a reasonable option to treat all dyspeptic infected patients with eradication therapy of Helicobacter pylori without even studying them. It simply involves the real danger of delaying the diagnosis of a benign or malignant disease, which can include extra-digestive location. At the same time, it is a strategy that involves treatment with two antibiotics and a proton pump inhibitor of thousands of patients unnecessarily, either because their dyspeptic symptoms respond to an organic cause not related to Helicobacter pylori, as stated above, or because these are functional dyspeptic patients that may not get any benefit from the infection eradication (González-Carbajal, M. and Martinez, L. 2008).

Moreover, that expert panel also recommends to treat with A degree, due to a $1 \mathrm{~A}$ evidence level, all patients with Helicobacter pylori positive functional dyspepsia, also a position without solid foundations (González-Carbajal, M. and Martinez, L. 2008). All the established steps can be followed to perform a productive clinical trial, but the advent of failure is inevitable, as it is deployed on a context of a theoretical and conceptual gap that would serve as a basis. It is essential to distinguish between statistical significance and clinical significance when it comes to analyzing results, and this is the one that should be priority, the statistical significance can be then insignificant (Silva, L. 2008)

Clinical trials are, as mentioned, the most efficient tool for refining knowledge, but it is not difficult to find other examples where statistically significant differences are justly scorned by the scientific community. The famous magazine Annals of Internal Medicine published, at the beginning of the XXI century, a review article (Astin, Harkness and Ernst, 2000). It examines research carried out towards the effectiveness of distance healing methods, among which are included resources as prayer, mental healing, therapeutic touch and spiritual healing. The review included only controlled clinical trials, as a guarantee of a minimum methodological quality. It is surprising that twenty-three experiments that meet these conditions have been found in literature, five of them referred specifically to the use of prayer as a healing method. To observe an illustration, seek the study by Harris et al. (Harris, W. et al. 1999), which attempts to show therapeutic benefits of intercessory prayers on patients from an intensive care unit, who did not know there were others praying for them. Despite having obtained statistical significance, that is, chance is discarded as an explanation according to the "official" rhetoric of classical inference; the fact is that there is no news that therapeutic services have been created based on anonymous prayers in any hospital in the world. This is because we all intimately know that it would be foolish not to qualify the statistical results using our culture, our prior information and common sense (Silva, L. 2008). Unfortunately the eradication of Helicobacter pylori infection as a treatment for not studied dyspepsia, and functional dyspepsia has not been received with the same degree of skepticism, though it stands on an equivalent pedestal.

The pitfalls to make science a more rational activity may actually be accented as a result of thoughtless acceptance of the verdict that provides statistical significance tests. The following confirmation is valid. The issue of "intercession by prayer" has attracted the attention of the Cochrane Collaboration, which in its recent review on the topic (Roberts, A. et al. 2003), surprisingly finds that "the evidence presented so far is interesting enough as to warrant further study." It is amazing that this organization, the greatest exponent and promoter of the so-called Evidence-Based Medicine, which has advocated for over twenty years the need to make decisions concerning health care grounded in sound scientific evidence, call for more research on a therapeutic procedure which only support comes from the application of a highly disputed resource: Statistical Significance Tests. The network of 
vertebrate misunderstandings can lead up to that point regarding this technique, which is able to provide absolutely undeserved guarantees. (Silva, L. 2008). Once again, the human intelligence product, its tool, daringly tries to subdue the rational thought that was its forge. The peer review itself, considered an important extension of the scientific process depends largely on how to deal with interest conflicts. Financial relations -such as employment, consultancies, stock ownership, honoraria, and expert reports- are interest conflicts more easily detected and most likely to undermine the journal, authors and the science selfcredibility. However, conflicts can occur for other reasons such as personal and academic competition. Participants in the peer review and the publication process should declare all relationships that could be considered as a potential interest conflict. Editors might well avoid selecting external reviewers with interest conflicts, for example, those working in the same department or institution as any of the authors. The referees, if decent, should disclose to editors any interest conflict that could affect their views on the manuscript, and they should refrain from evaluating manuscripts when these biased factors are present. Therefore, reviewers will be asked to explicitly set out whether or not these conflicts exist. To illustrate it, consider the following example. The author of the manuscript proposed for publication has just broken its link with an institution due to obvious conflict with the director, and it is given to the latter -who shamelessly declares no problem- the arbitration on the manuscript with full powers to veto it. Of course, the former employee, now turned into an ungrateful person and perhaps considered as an opponent by the sordid manager, shall suffer the punishment of seeing his article rejected with the most childish excuses-that automatically transmutes the very well inspired peer review evaluation system in a cheap parody, the basis of which is a dirty vendetta, that suits more to film scripts as The Godfather saga, than the ethical behavior of real scientists.

There will be people enough to discuss these issues and, as it is usual on scientific commissions' debates, encouraged by arrogance, they reveal that under the science thin film covering there are no differences with respect to an excited fan, and it overflows in primitive impulses, behaving like a football fan. This procedure is not completely useless if considered that, sometimes, who chairs the "scientific" committee is affected by an incurable disease that is characterized by suffering from a rabbit heart and newborn mare's legs.

Power provides certain non-negligible opportunities for mediocre people; one can be rough, brutal, and moody under its shade. These men abused their performance to, blinded by vanity, enjoy punishing viciously in the professional and academic order, beyond their guilt, personal enemies -or branded by them as such- that can take dissimilar identities, for example, the incautious son-in-law who, indifferently abandoned the gentleman's daughter, or who despite providing unrestricted support aroused professional jealousy -every privilege, as mean as it can be, bid for solitary fulguration without other light that could play down its carats, or another one with "opponent" requirements. Containment mechanisms of these behavioral patterns, which are legally established, may fail -to what they bet, blinded by the thirst of false compensation- either working or not; the cost in prestige of our presumptuous Guru apprentice will be inestimable. The power shown off, finally make them kneel to themselves, and produces some kind of grievous metamorphosis from which they can never be free; screws from Pandora's box got loosen and appear strange monsters. The village and tribal feeling that works as cradle to these dejected vanities must definitely disappear from science scenery; the apparently cryptic origin of these actions lies on the cavemen clan, strongly nailed on a science representative. Purity deserves respect, and must be praised. 


\section{An attempt to synthesize and some reflections}

The principle expressing that only a minority of decisions taken for a patient's diagnosis and treatment are substantiated through randomized clinical trials, involves a scientific rigor that aims to make the results of biomedical research available to the medical practice, in order to contribute with more science to medicine, based on literature review relevant strategies, meta-analysis, disease treatment guidelines, and most importantly, to educate doctors since they are studying medicine on statistical techniques that allow them to find their way and find the right individual diagnosis, and to apply appropriate treatment, which is an excellent solution to the problem of knowledge (Vidal, M. et al. 2005).

Classics manifest oppositely, defenders of the Clinical Method that assesses the patient as an individual entity, in which medical personal experience in decision making plays an important role due to the diagnosis uncertainty and appropriate treatment. This disjunction between the Clinical Method and the evidence, between experience and evidence is what has provoked many disagreements that make controversial the issue (Vidal, M. et al. 2005).

Does the Evidence-Based Medicine imply that deviation? We do not think so. It depends on the doctors themselves, their ethical principles and proper use of Clinical Method that in such a way is at odds with the challenge that represents the responsible and sensible adoption of Evidence-Based Medicine, which, as the scientific progress in general has come to stay and its irreversibility is unknown. Rather, we dare to ensure that the Clinical Method, the doctor-patient relationship, clinical epidemiology, Evidence-Based Medicine and more rigorous application of the research methodological principles are all important branches of one same tree, which complement each other.

Nowadays, the resolvent scope of medical science remains indeed very limited. Professional success in terms of sound judgment and acceptance does not rise linearly with theoretical and practical mastery of the performer. Psychological and emotional aspects involved in the doctor-patient relationship can hardly be prescribed and proper handling of this connection decisively influences the physician performance acceptance by the patient. The emotional and intuitive implication is inherent to professional action in this area. Individual, psychological, behavioral, cultural and social genetic development of each patient requires a specific and unique approach (Vidal, M. et al. 2005)

The following statements summarize the arguments just outlined, and to a greater or lesser extent, might be assumed that they are shared by major authors that have been devoted to the topic (Sackett, D. et al. 1996) (Vidal, M. et al. 2005) (Gordon, G. et al. 2004):

- A good doctor uses individual clinical expertise with the best available external evidence.

- Neither clinical experience nor available external evidence, separately, is sufficient.

- Without clinical experience, medical practice takes the risk of being tyrannized by external evidence.

- Excellent external evidence may be inapplicable to a particular patient.

- Without updated external evidence, clinical practice is in danger of being outdated at the expense of patients.

\section{Conclusions}

Globalization is irreversible, and its influences on medical science and the medicine practice are radical and deep, which does not imply that they should be taken at any price and with fundamentalist rage; that would only contribute to foster another threat more: to assume as 
true an innocent, sweetened, apathetic vision of the problem, impregnated with an unforgivable Panglossian, deluded, defenseless, and uncritical optimism. The Clinical Method, clinical epidemiology and its most refined contextual expression in the present, and the Evidence-Based Medicine are leafy branches that are part and parcel of what it is and should be a same tree: the Medical Sciences.

The way of science is fraught with danger. We have mentioned some such as pseudoscience, alienated use of statistical significance tests, the tendentious use peer review procedure, frivolity, comfiness, the personal behavior not consistent with scientific ethics during the debate on a scientific problem that pervades certain mentalities. They are vices which constitute a clear danger of sinking.

Some believe that the great difference in the greatness of a medical researcher currently resides, not in the depth of his pathophysiological knowledge, much less in the extent of his clinical skills. Today, as declared emphatically, the final characterization is given by the knowledge on research methodology and biostatistics that this professional has been able to hoard up. The mastery of the clinic and the study of diseases is, to these thinkers, an arid task if wanted but not hard, intricate, dignified by mathematics complexity and the axioms and theorems that provide sustenance to biostatistics science, which by the way, assisted by computer has been remarkably simplified in its applications when the machine performs arithmetic processes that were previously occupied by the biostatistician. Unquestionably, to successfully develop in the world of contemporary medical research is required to get in as deeply as possible in the study of research methodology and biostatistics; it is an important difference between some doctors and others, but not the principal. The truth is that there are other contrasts that leave a lasting impression among medical professionals, such as the one that stands between impersonal medical cares, dehumanized, rejecting the Clinical Method in the practice and the rational medicine that bases on it, and equally provides psychosocial care that patients and their families demand and highly need. We could name others, which does not constitute the most fearsome of the risks and are summarized below.

We can not lose sight of the fact that scientists are so exposed to material temptations as anyone. Subsidies, awards, jobs, invitations, fame, honors, rights coming from patents and monetary compensation are disputed. And these motivations may be equal to or greater than those of finding and disseminating new knowledge (Hauptman, R. 1999).

It is chilling to reflect upon the resistance capacity of a scientist under the perfidious influence of a social environment in which there are many privileges and perks for those who learn to submit their wills to spurious interests. The debasing seed will find welcoming refuge in the grooves given by the companies where the profit motive reigns omnipresent on all mechanisms that determine human activity; but there is no immune social system since depravity seductive figure goes beyond the purely financial dimension to adopt, as sinister Fantomas, the faces of other sinecures that cover the broad spectrum going from a managerial assistance, ministerial position, editorship on scientific journals, and educational category to any other comfortable prerogative, which at times is hard working, but the exquisite charm that power confers is enjoyable. In addition, it is almost always accompanied by the exemption of direct care activities, which astonishingly represents, for certain characters, a burdensome tiredness. When bribes are not succulent and there are not big favors like late-model cars or juicy cash bonuses, takes space voraciously the sailor greed to see more and more filled with cheap goods the duffel bag.

The truth is that the wreck of science, society as a whole, and of humanity itself, on which it has operated -while also starring it- the immeasurable process of Globalization, depends on 
a substantial disjunctive which is not other than the one that throbs and expands between mercenaries without morals or principles, and honest men who defend decency as part of their essential values, even though many others discard them. That is the cardinal difference between some doctors and scientists and others, among some men and others. At the same time it is the main danger on which, later or earlier, a doctor or scientist should make a decision, and when that time comes, he will be alone with his conscience.

The paths that lie ahead are impenetrable but can not be separated from this ethical duality. There is a way -perhaps the only one- to face this pressing problem of science and man. The task is peculiarly difficult if we take into account the concept of Globalization issued at the beginning of this article- there is no easy worthy task. It consists of challenging the powerful dominant forces at the international and national level to disseminate the values we believe at the cost of any sacrifice, to cultivate modesty, selflessness, solidarity, altruism, to report the fraud every time their hairy ears are seen, with the aim of achieving an equality and freedom order, and to be treated and treat others with the generosity they deserve as human beings, as we have the right to be properly treated, regardless of geographic area to which someone can belong to or the financial position they may have. This challenge requires never lying or violating ethical principles, and to act with courage, intelligence and realism, which will enable us to make tangible the longing to transform everything that needs to be transformed in the Globalization formidable process. Alonso Quijano is awake and the chevalier Bayard has a lot to do with us. Some will smile sardonically at the exposition of these views, without realizing that this is not a trivial utopia or a childish nonsense of improvised acquisition, let alone unleashing a furtive iconoclast vocation; on the contrary, it is the essence of the human condition from its most remote origins and the significance of its consequences. Remember Ariel (Shakespeare, W. 1948), to whom William Shakespeare, perhaps the most universal writer in the English language, idealized. Ariel is the greatness and the source of inspiration. He represents the tenacious struggle in pursuit of perfectibility. He gets turning human clay, sometimes miserable, into virtue; the beast that man carries inside into mercy. He is the eruption of the spirit forces. He embodies the man noblest aspirations synthesized in honest disinterest; he is a call to courage, bravery and the renouncing of temptation. He is the idol in the human enterprise. His irresistible force encourages the upward march of life. Thousand times mocked by opportunism and the lack of scruples of Caliban, condemned by perishable winners, bites the dust of defeat in many battles, but does not surrender. He knows no discouragement and he always runs glowing to justice demands. His enemies respect him and his example goes through and still catches his deniers. Many Ariels must rise from humanity, conscious leaders, champions of decorum, and apostles of dignity so that humanity cherished longest and most spread dream become a reality: Globalization of brotherhood. Globalization thus, will resemble the delicious partnership envisioned by Rousseau and we could conquer a new world better than this, despite all the dangers and risks. This way, next port will be not only a miserable place for arrivals, but a fugacious transit scale to the future. The complexity of the matter is summarized in a concise dilemma: wrecking or seizure of the world's second dawn.

\section{References}

Carpentier, A. (1979) El Arpa y la sombra. Capítulo II Pág. 99. Editorial Letras Cubanas. Ciudad de La Habana. Cuba.

González-Carbajal, M. y Martínez, L. (2008) Maastricht III y dispepsia. razones para una discrepancia. Revista Cubana de Medicina. Vol.47, No. 4. 
Harris, W.S. et al. (1999). A randomized, controlled trial of effects of remote, intercessory prayer on outcomes in patients admitted to the coronary care unit. Archives of Internal Medicine 159: 2273-2278

Hauptman, R. (1999). Research misconduct: why are definitions so elusive? Science and Engineering Ethics 5: 443-444 in Silva, L. (2008) La Investigación biomédica y sus laberintos. En defensa de la racionalidad para la ciencia del siglo XXI. Ediciones Díaz de Santos. Impreso en España. Cap IV.

González , I. (2007) Un Rito Giró la Manecilla de Europa a África. Orbe. Semanario Internacional Editado por Prensa Latina. Sección de Ciencia y Técnica. 30 de Diciembre al 5 de Enero de 2007. pp. 13

Hugo, V. (1975) Los Miserables. Tomo 2. Cossete Cap II. Dos retratos completados. Editorial de Arte y Literatura. La Habana, 1975. Pág. 140.

Microsoft Encarta® 2009. Microsoft Corporation 2008. Reservados todos los derechos.

Nassif, A. et al. (2010) Método Clínico, In: Práctica clínica, Editorial de Ciencias Médicas. pp 1628 ISBN 978-959-212-568-1. La Habana. Cuba

Real Academia Española: Diccionario de la Lengua Española. (2001) 22a edición. Madrid. En Microsoft Encarta@ 2009. Microsoft Corporation 2008. Reservados todos los derechos

Rodríguez, H. et al. (n.d) El Método clínico. Mesa Redonda. Video. Departamento de Divulgación y Docencia Ministerio de Salud Pública de Cuba.

Rojas, R. (1996) Guía para realizar investigaciones sociales. (Edición: 18a. Ed.)Plaza Valdés. México DF MX.

Rousseau, J. (1988) El contrato social o Principios de derecho político. Estudio preliminar y traducción de María José Villaverde. Madrid: Editorial Tecnos.

Shakespeare, W. (1948) Four Great Comedies. The tempest. Pocket Book, Inc. Edition. New York. pp 272-338.

Silva, C. (2008) La Investigación biomédica y sus laberintos. En defensa de la racionalidad para la ciencia del siglo XXI. Ediciones Díaz de Santos. Impreso en España.

\subsection{World Wide Web sites and other electronic sources}

Boucourt, L. (2001)Su excelencia: la medicina basada en evidencias. In: ACIMED [publicación periódica en línea]. 25.06.2005 Available from:

http://bvs.sld.cu/revistas/aci/vol11_5_03/aci07503.htm. Acceso: 15 Mayo del 2008

Broche, J. et al. (2003) Medicina basada en la evidencia: un reto para el médico contemporáneo. In: ACIMED. No 6. Vol 11. nov-dic. 15.10.2008. Available from : http://bvs.sld.cu/revistas/aci/vol11_6_03/aci02603.htm\#cargo.

Cañedo, R. et al. (2003) De la medicina popular a la medicina basada en evidencia: estado de la investigación científica en el campo de la medicina tradicional Contribuciones Cortas In: ACIMED, 11(5). 18.10.2008. Available from:

http://bvs.sld.cu/revistas/aci/vol11_5_03/aci07503.htm\#autor. Acceso: 18 de Octubre del 2008.

Casate, R. (2007) El cuadro de mando integral como herramienta para la gestión. In: La dirección estratégica en la sociedad del conocimiento. Parte I. ACIMED; 15(6). 13.01.2010. Available from: http://bvs.sld.cu/revistas/aci/vol15_6_07/aci02607.htm)

Chiba, N. et al. (2002) Treating Helicobacter pylori infection in primary care patients with uninvestigated dyspepsia: the Canadian adult dyspepsia empiric treatmentHelicobacter pylori positive (CADET-Hp) randomised controlled trial. In BMJ. 03.02.2011. Available from: http:// bmj.com.

Sackett, D. et al. (1996)Evidence Based Medicine: what it is and what it isn't. In: BMJ; 312:71-72 -13 January. 06 .02. 2011 Available from: 
http://bmj.com/cgi/content/full/312/7023/71.

Evidence-Based Medicine Working Group. (1992)Evidence-Based Medicine: a new approach to teaching the practice of medicine. In: JAMA; 268: 2420-5.

Gordon, G. et al. (2004) Evidence based medicine has come a long way. In: BMJ ;329:990991 .30.10.2010. Available from: doi:10.1136/bmj.329.7473.990.

Krabshuis, J. (2007)Evidence-Based Medicine - Why Did it Take the World by Storm. World Gastroenterology Organisation (WGO). In: Setting Global Standards in Education and Training.htm. 29.09.2008. Available from http://www.omge.org/?publication .

Malfertheiner, P. et al. (2007) Current concepts in the management of Helicobacter pylori infection. In:The Maastricht III Consensus Report. Published online 17 Jan. 25.01.2010. Available from: http://gut.bmj.com/cgi/content/abstract/gut.2006.101634v2..

Marchetti, P.et al. (2007) "Evidence-Based Medicine" disminish the physician's role? In: Medscape Students; 9(1). 15.10.2008. Available from: http:/ / www.medscape.com/viewarticle/549329?src=mp.

Medical Journals are an Extensión of the Marketing Arm of Pharmaceutical Companies . (2005) In: Revista PLOSMedicine Vol 2, No.5, May. 20.10.2008. Available from: http://medicine.plosjournals.org/per/serv/? request $=$ get.document\&doi=10.1371/journal.pmed.0020138.

Morán , M. and Flórez, D. (2008) La globalización en América Latina: Economía. 02.02.2011. Available from: http:/ / www.slideshare.net/guest284235/la-globalizacin-en-america-latina.

National Library of Medicine. PubMed Overview. 06.02.201. Available from: http://www.ncbi.nlm.nih.gov/entrez/query/static/overview.html

Ramis, A.et al. (2005) Origen e intencionalidad de la epidemiología clínica. In :Rev Cubana Salud Pública, vol.31, no.3, p.0-0. ISSN 0864-3466.

Sackett, D. et al (2003) AD. HARLOT plc: An amalgamation of the World's two oldest professions. In: BMJ 327: 1442-14445.

Strauss, S. et al. (2005) Evidence-based medicine: how to practice and teach EBM, 3rd ed. Edinburgh: Elsevier/Churchill Livingstone,. ISBN 0443074445. 17.10.2008. Available from : http://www.cebm.utoronto.ca/.

Vidal, M. et al. (2005) Medicina basada en la evidencia. Reflexiones sobre el tema. Revista Cubana Educ Med Super v.19 n.1 Ciudad de La Habana ene.-mar. . 15.10.2008. Available from: http://scielo.sld.cu/scielo.php?pid=s0864_21412005000100010\&script=sci_arttext\#cargo.

Vidal, M. et al. (2005) La enseñanza clínica. Reflexiones sobre el tema. In: Revista Educación Superior (En línea) 01.01.2011. Available from: http://bvs.sld.cu/revistas/ems/vol 19_2_05/ems 10205.htm. 


\title{
Sport in Asia: Globalization, Glocalization, Asianization
}

\author{
Peter Horton \\ James Cook University, Townsville \\ Australia
}

\section{Introduction}

Sport is now a truly global cultural institution, one that is no longer the preserve of occidental culture or dominated and organized by Western nations, the growing presence and power of non-occidental culture and individual nations now makes it a truly globalized product and commodity. The insatiable appetite for sport of the enormous Asian markets is redirecting the global flow of sport, with the wider Asia Pacific region now providing massive new audiences for televised sports as the economies of the region continue their growth.

This chapter will consider the process of sport's development in the Asian and the wider Asia Pacific context through the latter phases of the global sportization process (Maguire, 1999). As the locus of the centre of gravity of global geopolitical power is shifting to the Asia Pacific region away from the Euro-Atlantic region the hegemonic sports are now assuming a far more cosmopolitan character and are being reshaped by Asian influences. This has been witnessed in the major football leagues in Europe, particularly the English Premier League and is manifest in the Indian Premier League cricket competition, which has spectacularly changed the face of cricket world-wide through what could be called its 'Bollywoodization'(Rajadhyaskha, 2003). Perhaps this reflects 'advanced' sportization (Maguire, 1999) with the process going beyond the fifth global sportization phase in sport's second globalization with 'Asianization' becoming a major cultural element vying with the previously dominant cultural traditions of Westernization and Americanization? This notion will be discussed in this paper by looking at Asia's impact on the development of sport, through the three related lenses of: sportization; the global sports formation and, the global media-sport comple. Particular reference will be made to the region's engagement with the summer Olympic Games as hosts.

\subsection{The analysis}

This analysis will interrogate the relationship between globalization and Asian sport by analyzing three domains of the sports industry: the commodities - Asian performers and the staging of performances (events) in Asia; the Asian 'market' - both live and the vast television audiences and online users of sporting networks, and Asian 'money' - both from sponsors and in the purchase of sports clubs and in hosting high profile competitions or festivals. How each of these growing domains is impacting upon sport globally will be 
discussed. This analysis proposes the notion of an emerging Asian hegemony in global sport with not only the economic power shifting away from its North Atlantic (Occidental) epicentre, but also contend that the nature of the institution itself, specifically its heritage and ethos are being confronted by the pull of the geopolitical power that is consolidating in, and with Asia. The direction of the flows of globalization (Appadurai, 1990), particularly the spread of sport have through history been impacted upon by hegemonic power structures and the associated cultural diffusion of the dominant ideologies; and the effect continues today. Geopolitical, economic and of course, military power have steered the course of global flows and, as it is the very essence of history, axiomatically characterized the nature and the timing of the phases of both globalization as describe by Robertson (1992) and of Maguire's (1999) parallel model of sportization.

The explication of the global cultural system and the examination of globalization theory could be likened to the analysis of the Earth itself and all life-forms that live and have lived on it with the undertaking being so vast and complex. The discussion of globalization, as a seemingly unstoppable agent of the homogenization of global culture, initiated by imperialism and the associated diffusion of the dominant culture, religion, language and governance and now by global patterns of consumption and consumerism and a global economy, remains highly problematic. Similarly, the discussion of an 'Asian' impact, indeed of Asia per se, is itself open to debate for, as Philip Bowring so provocatively asked "What is Asia?" (Bowring, 1987) He points out that, “...Asia would have been no more than a geographic concept but for Europeans deciding they were somewhat different" (Ibid.). In strict geographically terms there is in fact no 'Asia' or 'Europe"; the land-mass that embraces 'Asia' actually extends from the Iberian Peninsula to that of Korea and includes the islands of Britain and Japan, indeed it should be referred to as Eurasia. In this discussion the simplistic and 'incorrect' use of the term in reference to a continental mass will not be assumed, nor will it solely favour Said's representation of Asia (the 'Orient' in his terms) as a Western cultural construct, the West's "Other" (Said, 2003). Asia has in reality no common identity and is more divergent geographically, ethnically and culturally than any other land-mass on Earth. Considering the current discussion, as dominant civilizations will always dictate how they are defined, perhaps, as the conglomerate-concept that is 'Asia' rises, the notion of Asia, as Bowring (1987) predicted, "will fade away." This may well be precipitated with the decline of Western economic, cultural and military predominance which is becoming a major dimension of the globalization process of the $21^{\text {st }}$ century.

Discussion of globalization invariably gathers around predictable binaries including, as suggested by Maguire's (1999) description of the "fault-lines regarding homogeneity/heterogeneity, monocausal/multicausal, unidimensional/multidimensional, unity/fragmentation (and) universalism/particularism." A typical example of such discussions is that developed by Tyler Cowen, who reflected that although the advance of globalization does not necessarily mean the absolute homogenization of global culture, it can and does result in the destruction of cultures, albeit "creatively"(Cowen, 2002). However, current globalization theories largely dispute this notion of a singular process with the generally accepted consensus being that globalization is the outcome of the interaction of two contradictory processes; a homogenizing process and another that generates increased levels of differentiation. Thus, as a social or cultural form, such as a sport, is globalized, a growing level of interconnectedness emerges between the sites of its 
diffusion. Although the levels of the contrasts diminish at the same time and either subtly or significantly, the number of varieties of the sport increases.

The figuration of sport involves a highly convoluted web of interdependencies involving individuals, sporting bodies and nations. Lim (2004) maintains that Maguire, though basing his conceptualization of sport on an Eliasian framework, has expanded the discussion wellbeyond the emergence of sport, characterizing it as a global phenomenon that embraces an increasing intertwining of nations, cultures and people, which, as she points out, "affects a diminishing contrast and increasing variations in social and sporting discourse". In expanding Elias's original concept of sportization with the embrace of the Robertson's 'minimal phase model' (Robertson, 1992), Maguire suggested that progressively a 'global sports formation' emerged, evolved and continues to do so. In the fourth (1920s-1960s) and fifth global (1960s-1990s) sportization phases, the role and impact of non-Western nations has become ever-increasingly significant. This process, Maguire states, first became evident when "...Non-Western nations began to beat their former colonial masters, especially the English...in a range of sports" (Maguire, 1999) and importantly, considering the theme of this paper:

Anglo/Euro and American control of global sport has also begun to wane off the playing field. The control of the international sports organizations, which had been gained during the fourth global sportization phase, which appropriately parallels Robertson's 'struggle for hegemony' phase, slowly and unevenly, began to slip out of the exclusive hands of the 'West' (Ibid.).

Initially, as Maguire points out the conduct of sport was still undertaken on the terms of the Western world, through the medium of Western sports however, as globalization moved on through its phase of 'uncertainty' (Robertson's phase V) characterized by growing numbers of varied global institutions and social and political movements; the global dynamics changed. Humankind, as Maguire (1999) states, became beset by "problems of multiculturality and polyethnicity" and global sport was a primary site and source of related tensions. By the end of the $20^{\text {th }}$ century it soon became apparent that, just as the geopolitical power structure of global affairs was shifting away from its Atlantic hub to the Asia Pacific, so too were aspects of the focus and control of global sport. The globalization of sport, as Lim (2004) maintained, revolves around "labour, knowledge and culture migration," all of which are central to the processes of: the commodification; the commercialization; the media penetration and, politicization of sport (Lim, 2004). The sum of the effect of these processes results in what Maguire calls a "global sports exchange" (Maguire, 1999) and a subsequent wider commingling of cultures, which precipitates a double-bind effect with an apparent level of a diminishing contrast between individuals, groups and nations and, simultaneously, the emergence of a wider variety of cultures and sub-cultures (Maguire, 1999).

A global consideration of such shifts and movements in the power base of sports, particularly those of the hegemonic sports, such as football, cricket, basketball, baseball, tennis, motor-sports, track and field athletics and swimming presents some contentious issues. Can we categorize their development under the banner of a single process such as Maguire's sportization despite the rejoinder that it supports the notion of 'increased varieties'? Caution is also implicit in the Hegelian concept of Aufhebung, that Markovits and Rensmann (2010) adopted in their discussion of global sports, politics and identities, which implies that a social movement is simultaneously preserving and changing a culture, in this case sports culture, yet eventually it advances or "transcends" (Ibid.). 
Markovits and Rensmann (2010), in their discussion of how sports have "reshaped" global politics and culture, consider the whole process to be "postindustrialization" or the representation of the "second globalization": And it is suggested in this analysis that in the second globalization the hub of the effect and the source of the flow are now in Asia.

\section{The emergence of an Asian hegemony of sport}

In Norbert Elias's first discussion of sportization, he outlined the development of English pastimes into codified sports and their subsequent global diffusion where they were exported as cultural icons of the British Empire. Elias used the notion of 'industrialization' in the conceptualization of the notion of sportization, in which he described the transformation of English leisure activities into a work-like structure (Elias, 1986). It is the latter phases of this expansion of Elias's concept that will provide the framework for this discussion. The quest for territory and resources by European nations ahead of and during the Industrial Revolution, especially by and most successfully the British, produced the epoch of colonialism. This period of expansionism precipitated, through invasion, settlement and, the creation of hegemony was an implicit conduit for the diffusion of the cultural artefacts of the European colonizers. The British Empire advanced through Asia, from the sub-continent to Southeast Asia and to the Far East. They also travelled south and settled the Antipodes. In the colonies of the Empire the British established a social and cultural hegemony that supported its military, political and economic rule. Sport and the cult of leisure and recreation were central to the hegemony of the British Empire. In the colonies and dominions of Britain sport proved to be so central that it acted, as Galtung (1982) said, "a carrier of deep culture and structure." Throughout the Imperial territories in Asia and the Antipodes the associated ideology of muscular Christianity and the cult of Athleticism were central elements of the educational philosophy established by the British and were enlisted to, "control the morals and minds of the 'native' in the interests of political stability, religious proselytism and ethnocentric moralism" (Mangan, 2002). Sport proved to be a unifying element of the cement that held the Empire together and, as Kirk-Green (1992) suggests, sport and the English language, are the most enduring aspects of the cultural imposition of the British. Today, in most of the ex-British imperial territories, sport remains as one of the most predominant social institutions and is still viable terrain upon which the allegiances, both past and present, are expressed. This very successful "Spiritual Export" (Mangan, 1992) is still a significant medium for 'communication' between the members of the British 'family' though the exchanges can at times become a little excessive!

Sport was so embedded in the texture of most British colonies in Asia that when the British along with the various missionaries left the colonies or were forcibly expelled (as in Singapore), sport and Christianity endured. Other colonizing forces and cultures took and used popular culture, including sport, as a central dimension of the soft power-cum-public diplomacy activity during their 'occupations'. Japan throughout used sport, physical education, fitness activity and military drills as means of enculturation, control and discipline in the wider communities and especially in schools during its imperial rule of Korea and Southern China from latter part of the 19th century to the late 1930s and of the territories they occupied during World War Two. Ironically, the US as the 'occupying force' of Japan after the war also used sport as part of its diplomatic armoury to remediate the 
social fabric of the previously tyrannical nation. Massive campaigns and sports programmes were also core to their activity in South Korea (Korea) after World War Two and during and after the hostility of the (still on-going) Korean War.

\subsection{The US and sport in Asia}

American missionaries in Asia in the late $19^{\text {th }}$ century, particularly those working under the mantle of the YMCA embraced the doctrine of muscular Christianity through the enculturation of the 'American' sports of basketball, volleyball and baseball in the programmes of their missions in South East and Eastern Asia during this period. Thus, American sports, were incidentally 'exported' from the USA as an element of its cultural imperialism linked to work of their missionary groups and their proselytization efforts. American sports became established in China, Japan and the Philippines, where glocalized (Robertson, 1995) forms/styles evolved, particularly volleyball in China, baseball in Japan and basketball in the Philippines. These games were enthusiastically promoted in Asia throughout the latter stages of the 'Take-off' phase of sportization and during the fourth phase of sportization (Maguire, 1999) - 1920s to the 1960s - particularly during the period of US 'occupation' in Japan, Taiwan and the Philippines following World War Two and later in Korea after the cessation of the Korean war in the 1950s.

These periods of military occupation and the attendant political, economic and social stewardship of the American forces established a platform for a wider 'Americanization' of popular culture in the region. Though, whether this adds support to the notion of American imperialism as being distinct from the dominant element of the globalization of and subsequent commercialization of sport is a question that remains unanswered. The soft power policies and public diplomacy engagements of the US in the region after World War Two and the Korean War, were very much part of the American response to the threats emanating from the Cold War. Their 'occupation' of Japan with the security pact (The US-Japan Security Treaty, 1951) and the massive aid programmes that supported the rebuilding of Japan's infrastructure, cities and identity were accompanied by a forceful promotion and diffusion of the 'American' sports of baseball, basketball, volleyball and ice hockey, which were also being promoted in other American spheres of influence globally including Europe and South America (Maguire, 1999). In 2010 the US still had a major military presence in Japan, having 85,000 troops and civilian staff accompanied by 43,000 dependents stationed in 85 bases throughout the country ("Field assumes command of U.S. Forces Japan", 2010).

Following the signing of the cease-fire in the Korean War in July 1953, the US military 'presence' on the Korean Peninsula and its sponsorship of South Korea's economic and industrial growth and the support of its drive to the democratization of its governance went on well into the 1990s (See, Woo-Cumings Meredith, 2003). This period represented a period of quasi-occupation by the Americans and they engaged in an extensive campaign of soft power diplomacy in which sport again figured significantly. Baseball, naturally, was a central element in this, even though ironically, as mentioned above, it had been originally introduced by the Japanese during their earlier occupation. The end of World War Two saw the end of Japan's rule in Korea as an imperial power with the subsequent power-vacuum being filled by the US in the guise of patron/protector of South Korea, which had been placed under America's aegis in post-World War Two peace treaty negotiations (See, Millett, 2005). The US led the Allied forces in the Korean War and remained to continue the 
development and renewal of infrastructure and the extensive re-urbanization programmes begun after the end of World War Two, which had become all the more necessary following the three harrowing years of the Korean War. In the subsequent six decades the new 'occupying' cultural forces had a ready and profitable context to diffuse its 'culture' including its sporting predilections. The major purveyors of this were the US troops over the 60 years of their deployment on the Korean Peninsula. At the height of the Korean War there were over 300,000 US military in Korea (Huang Zhi-Wei, 2009), whilst in 2010 there were still 28,500 based in Korea (US Department of State, 2010).

\section{Asia and the Olympic Games in the $20^{\text {th }}$ century}

At the time of the Tokyo Olympics, October 1964, Japan had already become the world's fifth largest economy following a decade of double digit growth. In 1964 Japan was inducted into the Organization for Economic Co-operation and Development (OECD) and was recognized as a GATT Article 9 nation (Cha, 2009). They began the bid for the 1964 Olympic Games in 1957 and were awarded it in May 1959, so the economic recovery and the reurbanization and infrastructure development programmes had not reached their peaks. Certainly Japan's march back to its status as a world power from what Reischauer and Craig (1978) call, the "dark valley" of their period of imperialist rule over Korea and the territories it occupied in China during the Second Sino-Japanese War, and for its role and conduct in World War Two was based on their single-minded industrious work ethic and the nation's all-absorbing quest to redefine itself following the war. To be once again accepted as a 'worthy' member of the international community, Japan had to be seen to have normalized. The Tokyo Olympics was the exemplar of Japan's 'normalization'. As a state which, undoubtedly, would be to the advantage of the USA, Japan, along with Korea and Taiwan, offering a buffer to Communist China and its allies. The Tokyo Olympics were the exemplar of Japan's 'normalization' and its bid and the associated re-urbanization and infrastructure development were enabled by massive support from the USA.

Thus, with the opening of the Tokyo Olympics Japan re-entered the international arena 19 years after it had surrendered in such horrendous circumstances. More importantly sport (the Olympics) gave the Japanese people an opportunity for redemption and a medium through which they were able to reframe the nation. Cha (2009), remarks that "the 1964 Games offered a way to write a new post-war narrative for Japan: Japan was no longer an aberrant actor in the international system but a peace-loving, affluent, and supportive member of the system." Despite these endeavours Japan is still regarded with a good deal of suspicion and mistrust by both Korea and China. Regarding the rebranding of Japan through the Tokyo Olympics, Tagsold (2009) suggests that despite the enthusiastic acclamation of Japan's restoration of national pride via Tokyo 1964, the effort was tainted. The Tokyo Olympic Games of 1964, he believes, was immersed in layers of political action and the "subtle politics" of revisionist conservative neo-nationalism, which was not apparent at the time. The attempts by the Japanese to cast their organization and promotion of the Tokyo Olympics as being apolitically motivated is seen by Tagsold (2009) as being problematic. In the engagement of 'subtle' politics it could be said that the US was complicit as it unquestionably served its own public diplomacy agenda during the Cold War, for, as Hunt (2006) points out, through the 1950s and 60s the US administrations avidly embraced international sporting engagement as an instrument of diplomacy. Typical of the sentiments 
expressed at this time of the Cold War came from Attorney General, Robert Kennedy (1964, cited in Hunt, 2009) who maintained that:

...Part of a nation's prestige in the cold war is won in the Olympic Games, ....In this day of international stalemates nations use the scoreboard of sports as a visible measuring stick to prove their superiority over the 'soft and decadent' democratic way of life.

The Seoul Olympics also featured as a central element of the public diplomacy activity of the US during its period of stewardship over Korea in the 1980s. Against all odds and frankly political logic, in 1981 Korea won the bidding contest to host the 1988 Summer Olympic Games. Observers of this period in Korean history have reflected that it is somewhat remarkable that Seoul was actually awarded the Olympics of 1988 so soon after the Kwangju uprising (See, Savada \& Shaw, 1990). In 1980 during, in what has been called "Korea's Tiananmen" (Scott-Stokes \& Lee Jai Eui, 2001) thousands of demonstrators were arrested, mercilessly beaten and over 200 people, some say thousands, including innocent bystanders including young girls and female office workers were killed as a student pro-democracy rally in Kwangju, in the province of Cholla, was savagely suppressed by Korean martial army troops (Kim, 2000). The actual Tiananmen Square massacre in 1989, essentially isolated China from the core of the Olympic community for 12 years until they won the bid to host the 2008 Olympics, whilst the Kwangju atrocity occurred just 15 months before Seoul was awarded the 1988 Games (Pound, 1994). Perhaps, the key for this apparent anomalous decision by the IOC and incidentally the gifting of the host-city role to Tokyo was the fact that both Japan and Korea were on each occasion "firmly under America's dominance" (Collins, 2008). The US, which at the time strode the global scene as the champion superpower of Western democracies, was also not without influence in Olympic circles.

Richard Pound, former vice president of the IOC illustrated the extent to which the US went in its support of Korea's Olympic efforts, and this support went far beyond the Olympic arena. In his discussion of the politics behind the bid for and the preparations and hosting of the Seoul Olympics he suggests that the US government demonstrated its arousal as to any potential threats to the Games by actually setting up "summit meetings between Reagan and Gorbachev" (Pound, 1994) to discuss the possible exigencies considering the catastrophic bombing of the Korean Airlines flight 858 by North Korean sponsored terrorists a year earlier (Cha, 2009). President Reagan also sanctioned the deployment of "significant elements of the Pacific fleet to the Sea of Japan immediately before and during the Games" (Pound, 1994). Pound alluded to the fact that despite the apparent contradictory support of the undemocratic regime of Chun Doo Hwan, the US government did "put enormous pressure on the South Koreans to speed up the process of democratization." He added that he believed, "...It is also fair to say that the administration was in high-level discussions with Chun Doo Hwan and his officials to press for progress in the liberalization of the existing regime."

The most renown of sporting arenas, the Summer Olympic Games, represented a very meaningful element of the US's patronage and 'support' during its post-war stewardship of Japan and Korea. The first two Summer Olympic Games to be held in Asia are oft described in terms of what the Olympic Games, Olympism and sport in general brought to the nations of Japan and Korea in their particular periods of regeneration, redefinition and remediation after traumatic epochs in their history. The associated Olympic legacies, both tangible and intangible, and the subsequent geopolitical advancements gained have been characterized as being direct consequences of the compliant, effective and efficient management of the festival itself. The honour was all theirs (Japan and Korea) so to speak, and both were seen to have emerged or re-emerged in the case of Japan, as worthy members of the global 
community of nations. It is a gross understatement to say that both benefited enormously from the opportunities presented by hosting the festival; for both, hosting the Olympic Games was a significant turning point in their history. Conversely, the concomitant direction and development of both these nations changed global geopolitics and global economics irrevocably. It must stated that as much as hosting an Olympic Games impacted upon Japan and Korea so too did the festivals of 1964 in Tokyo and Seoul in 1988 impact upon all future Olympic Games and many other mega-sports festivals. For Japan and Korea the Games represented very successful major incursions into the upper levels of elite global sport in sport's most prestigious and iconoclastic event, the Summer Olympic Games, and most significantly both impacted upon sport in such a way that it would change forever.

\subsection{Tokyo, Seoul, Beijing and the Olympic discourse}

The Tokyo Olympic Games set a new standard in terms of related infrastructure and urbanization spending. It was unquestionably meticulously organized and importantly it was also, up to that time in Olympic history the most profitable Olympic Games ever held (Zarnowski, 1984). Television broadcasts were beamed live around the world via satellite (the first such instance in Olympic history), and in many ways the Tokyo Olympics shifted the manner in which we reflected on the meaning of the Olympic Games. Prior to the Tokyo Olympics, the dominant discourse on the Games, was definitively that of the Western nations, which reflected Western political, economic and cultural domination globally (Close, P. et al., 2007), and this included elite sport and particularly the Olympic Games. Although a part of the Olympic establishment, Japan had to re-establish itself as a credible nation in regard to the Olympic community but even more importantly it had to demonstrate it was ready, once again, to assume its position as a world leader. Their whole Olympic effort as host nation emphatically validated the rejuvenated nation and importantly, as Sandra Collins maintains, they largely achieved this by presenting their propensity to modernize whilst simultaneously foregrounding their ancient cultural traditions by embracing, at all opportune 'media moments', symbols of their "distinctive culture" (Collins, 2008) in all aspects of the Games organization. The Japanese did in fact create a whole new way of handling the raft of Olympic administrative, organizational and particularly the political machinations an Olympic Games organically precipitates and this, recognizing the geopolitical situation of Japan at that time; was a daunting task. The process, characterized by Manheim (1990) as the "Japanese Experience", also precipitated a distinct discourse and, it is suggested, this is the most important and enduring intangible 'Olympic' legacy to emerge from the 1964 Olympics.

All aspects of the planning, preparation and the conduct of the Tokyo and as a consequence the two subsequent Asian Summer Olympic Games, Seoul in 1988 and Beijing in 2008, reflected this definitive Asian discourse, which Close et al (2007) maintain came from:

The Japanese experience of hosting the Games (which) was perceived in terms not just of the country's sporting agendas, aims and achievements per se, but also of its underlying social, political and economic (or political economy) and associated internal (or domestic) and external (or international, regional and global) agendas, aims and achievements.

For the two Asian Olympic hosts that were to follow Tokyo, the legacy of the validation of the Asian Olympic discourse bequeathed to them by the first Asian Olympic hosts provided both inspiration and a sense of justification when they faced their own Olympic challenges. For Korea the "Japanese Experience" was the ideal model upon which to base their plans for 
Seoul in 1988 (Manheim, 1990). This economically-predisposed, nation and culture confirming 'Asian' Olympic discourse appears now to be the current dominant form, for now all Olympic Games are driven, not only by the host nation's sporting agendas and aspirations, but also by their underlying social, cultural, environmental, economic and political motivations.

As China advanced to its regional leadership status and, it could be argued, to its position as a 'global' 'superpower', it passed three major milestones. The first two were; China's invitation to join the WTO in 2001 and, the selection of Beijing as the host city for the 2008 Olympics. The third was the realization of the planning, preparation and management of the Beijing Olympic Games itself. At the time, the successful management of the Beijing Olympics may have been regarded as marking the close of this particular chapter China's role in world history. However, before the nation could taste the fruits of the 'victory' the Global Financial Crisis (GFC) of 2008-9 intervened, shackling global economic growth and virtually bringing the developed world to its knees. Immediately a fourth epoch-marking milestone in China's history dramatically evolved. The confluence of the staging of the Beijing Olympics and the GFC acted to accelerate China's ascendance to global leadership. Indeed, as Timothy Garton Ash (2009) observed, the catastrophic global economic crisis had actually been "the catalyst" for China's real emergence as a world power. The nation's leaders and the people palpably assumed a level of confidence, fuelled by the nation's economic and political global leadership role during the crisis coupled to the global acclaim of the Beijing Olympics and, not least of all, the outstanding performances of their athletes. Both the acceptance and the granting of this acclaim, if supported by increasing levels of tolerance and a willingness to come to terms with the cultural differences that reside either side of the "fault lines between civilizations" that Huntington (1996) suggested would be the sites of future global political clashes, it may well prove to be the most important intangible legacy that emerged from the Beijing Olympics. It unquestionably facilitated the concretion of China's global integration and its assumption of a position as a world leader in this, the Asian century.

The question as to what extent China's hosting of the Beijing Olympic Games, which was undoubtedly a highly successful manifestation of its soft power diplomacy, has impacted upon its visceral sense and desire for further liberalization and political change remains unanswered. Leading up to and during the Games, as Cha contends, China was faced by "tremendous internal and external pressure" (Cha, 2009) from many groups trying to effect change in Chinese human rights policies, both domestically and with their international engagement in the Sudan and Burma. He maintains that despite a deafening level of protests and campaigns for the governments and athletes from various countries to boycott the Beijing Games, the Chinese were able to disperse the heat of the various protests by using "calibrated changes in policy" to facilitate the conduct of a "successful" Olympic Games. However, the policy changes and the micro-shifts in the human rights policies that were instituted ahead of the Beijing Olympics did, as Cha (2009) points out, "constitute change." Undoubtedly, just as the efforts to sanitize the air and water surrounding Beijing for the duration the Games (holding the 'Green Olympics' being one of China's primary stated ambitions) were patently overt and, amazingly expensive, public-relations exercises, they have actually spawned an apparent shift in environmental policies in China. In the 2011 Five Year Plan, China will be adding greenhouse gas emission goals to its domestic policies (World Resource Industries, 2009). The rhetoric surrounding the legacy to be left following the Beijing Olympics after aspiring to conduct the 'Green Olympics' would, it 
seems, have been, if not a definitive catalyst, certainly part of the thrust responsible for the laying-down of a realistic future environmental sustainability policy by China's national government.

However, from the dialogues surrounding the Beijing Olympic Games one wonders to what extent a national conscience has been stirred by more recent dysfunctional manifestations of polity and ideology identified in the management of human rights. China has still to reconcile some embedded issues, such as the annexation of Tibet, the treatment of Muslims in Xinjiang, their relations with Taiwan and, the inordinate economic divide between rural and urban Chinese (Kurlantzick, 2008). All have been portrayed as 'stumbling blocks' preventing an unimpeded advance to a world leadership position. Even in direct association with the Beijing Games, the mismanagement of the Olympic Flame Relay, the early tensions with the international media and the somewhat churlish security attitude in and around Olympic venues all gave traction to the critics' concerns as to China's sincerity in its espoused aspirations, which were heralded so loudly in their Olympic manifesto of "One World, One Dream" (See, BOCOG, 2008). This was a declaration that looked to the Beijing Olympics to achieve global harmony and, of course, their own central role in this process.

It cannot be said that China opened its doors entirely in 2008. Though perhaps as a consequence of the Beijing Olympics, and undoubtedly with the nation's positive (and admittedly very profitable) actions during the GFC of 2008-9, the people have opened their minds (and possibly their hearts) to the rest of the international community. A major and undeniably far more complex task for China will be to reconcile its own domestic human rights issues, including the massive dichotomy between urban and rural communities and the growing numbers of urban-poor, which Kurlantzick (2008) has so emphatically illustrated by pointing out that, "according to the World Bank, over 200 million Chinese earn less than US\$1.25 per day, a near-African wage, and today China's Gini coefficient, the standard measure of inequality, is far higher than that of India."

Using the Summer Olympics Games as a measure by which to judge, only the East Asian nations of Japan and Korea were, prior to the rise of China on its way to Olympic supremacy, could be considered to be called 'all-round' sporting nations with an entrenched sports culture and one that seeks and achieves international sporting success. Not unexpectedly Japan (Tokyo) and Korea (Seoul) achieved their greatest Olympic successes when they hosted the Games. In Tokyo Japan, winning 16 Gold medals, came $3^{\text {rd }}$, Korea in Seoul came $4^{\text {th }}$ with 12 Golds and the pinnacle of 'Asian' Olympic achievement was unquestionably China's performance at the Beijing Olympics in 2008. China's performance as host nation was outstanding and as a public relations exercise it was, as veteran journalist Kent Ninomoya (2008) commented the:

...net result is a public relations victory for China that will likely contribute to their already booming economic prosperity. The last impression billions of people around the world have about China is one of awe. Whether the perception matches the reality of China is irrelevant. Image is about perception and China won that battle.

The three Asian Summer Olympic Games in Tokyo, Seoul and Beijing and the two Winter Olympics, both held in Japan (Sapporo - 1972 and Nagano - 1998) all accelerated sport's development in Asia. In the 1990's and the first decade of the $21^{\text {st }}$ century the growing prosperity and the further penetration of elite sport by commercial and media interests had a symbiotic relation that saw both rapidly gain popularity and wealth. China's drive for global sporting success was epitomized by its quest for Olympic supremacy, which they 
resoundingly achieved in such a startling manner in 2008. The Beijing Games has been likened to an epoch marking moment in the history of sport. China's invitation to join the World Trade Organization (WTO) in 2001 marked its emergence as a global economic powerhouse, whilst gaining the hosting rights for 2008 Olympics is widely viewed as ranking, in terms of geopolitical significance, with China's admission to the WTO. (Fan Hong et al, 2005 \& Xu Xin, 2006)

\section{The acceleration of the sportization process}

The emerging geopolitical importance of the Asia Pacific region and the predicted shift of the centre of gravity of global geopolitical power, which are being largely driven inexorably by the Asian 'super-economies' of China, Japan and India, all of which ranked in the top four of the world's leading national GDPs (by purchasing-power-parity, PPP), even though the US remains number one (International Monetary Fund, 2010). However, as predicted in the Goldman Sachs Global Economic Report (2010), by 2030 China will be the world's leading economy in terms of both GDP and Equity Market Capitalization. The notion of the emergence of the Asia Pacific as a growing economic, strategic and political power of the nations was muted by Henry Kissinger in 2004. However, he pointed to the shift in the centre of gravity of global politics from the Atlantic to the Pacific with the theatre of influence revolving around Russia, India, China and Japan (Kissinger, 2004). Unlike DobbsHigginson, who delimited the Asia Pacific region in terms of the Western Pacific rim plus South Asia (Dobbs-Higginson, 1993), it is suggested that the US should be firmly situated at the eastern extremity of the Asia Pacific as a significant future global geopolitical stability will be defined by the dynamics that will emerge from the region. Thus, as the second globalization advances in the 'Asia Pacific' century China, as an emergent superpower, now assumes the centre-ground of the region, with the US in the (new) 'far east' and India along with the Arab states in the 'near west' the region will assert an increasing influence upon global political, economic, military and cultural dynamics.

Sport exemplifies the changing cultural dynamics that are emerging globally and it could be suggested that the most profound changes to sport during the fifth phase of sportization and beyond are derived from the intersection of sport, the media and the global cultural flows, in what Maguire (1999) refers to as the "Global Media-Sport Complex." Sports, the dominant globalized western forms of course, have long been seductive localized pastimes and spectator activities but once micro-technology and satellite television broadcasting developed and sporting broadcasts could be simultaneously thrust into homes, cafes and bars world-wide, they immediately became, along with news broadcasts, the most valuable of all media commodities.

Media sports, with their potential to attract vast audiences world-wide, axiomatically have the power to sell both related merchandise and most importantly advertising time and space. The global flow of mass-media, or the "mediascape" as described by Arjun Appadurai (1990), is not only the indexing medium of the capability of the electronic and print media to produce and disseminate "the images of the world created by these media" it is also the one of Appadurai's five 'scapes', that conveys the images that carry the concepts, beliefs, and values - the ideologies - and, is thus a central conduit for the "ideoscapes" that come, as Appadurai (1996) says, in the "form of chains, terms and images." The intersection and interconnection of these, along with the movement of capital (financescapes), the collision with technologies (technoscapes) and the migration of people (ethnoscapes) in a 
series of unpredictable and unplanned movements, is what creates the disjunctures that characterize the dynamics of globalization as described by Appadurai (1990). Despite the unpredictability of the resultant global flows, well into the $20^{\text {th }}$ century there existed a "unidirectional" tidal flow to globalization and as Maguire (1999) says the developments tended to move "from the West to the 'rest'." As Maguire points out, this added oxygen to the argument that the emanant cultural changes were seen to be having a homogenizing effect. Global culture, including sport, was seen to be 'Westernizing' largely under the influence of American popular culture. However, although globalization had the effect of raising the consciousness of the world as being a 'single place', there was simultaneously a glocalization process going on (Robertson, 2002) with an ever increasing number varieties of cultural products, including particular sports being formed in response to the demands of the local context. Even the most 'global' and comparatively simple of games, football, varies in terms of how it is played, its shape and the nature of the 'place' the game occupies culturally, socially, economically and even in terms of gender, class and race in the particular community. As sports were 'imposed' or adopted as a result of the effect of the global media-sport complex, they assumed characteristics that made them culturally relative to their 'local' context whilst retaining their universal characteristics; hence they emerged as glocalized forms.

\section{Asian commodities, the Asian market and Asian money}

As global geopolitical, economic and industrial powers shift so too does the market potential of the regions. Asia and its market, which potentially embraces over $60 \%$ of the world's population, including a rapidly increasing number with accessible discretionary income and a passion for sport, has become the major focus of the global sports industry. It would be timely to once again reflect upon what is actually implied when using the descriptor 'Asian' in reference to sport. In 2010, 45 nations took part in the Asian Games in Guangzhou, these nations came from the shores of the Mediterranean Sea (Lebanon) to those lying in the western reaches of the Pacific Ocean (Japan) and with Indonesia in the South and Mongolia in the North. Including Russia and Turkey, who are not categorized as 'Asian' nations, the population of 'Asia' is over 4 billion and represents approximately $66 \%$ of the World's population, of which 2.5 billion (approx.) reside in China and India. (CIA, World Fact Book, 2011)

Global sport is still, in the main, under the 'control' of Western-led international sports federations, administrators and corporate interests, however, the tide of the flow of the control of global sport is turning with the prime example being the shift in the power-base of world cricket, with the International Cricket Council moving out of Lord's Ground in London to Dubai in the UAE. As more Asian economies develop, matching the efforts of the four 'Tiger' economies of Asia (Hong Kong, Singapore, Taiwan and South Korea) and those of the resource-rich Middle East nations, sport will become a more accessible and affordable commodity and with this further shifts in the control of global sport will follow. The impact of the three engines of the sports industry of Asian: the commodities; the market, and the money is so profound that they have become irresistible to the producers of the sporting contests, the international sports federations, and the purveyors of the events, the global multi-media outlets; the following discussion of this sport-media complex will demonstrate how the impact of this interaction has the potential to effect the Asianization of global sport. 


\subsection{Asian athletes and events: units of production}

All athletes who train and compete in a sporting contest, whether amateur or professional, are producing and reproducing themselves in order to be part of the production of a contest, be it a game or an individual performance-event such as, a swimming race. A key, internal dialectical production/consumption aspect of competitive sport is that in the completion of this productive activity, they also consume themselves through: energy consumption; extending the corporeal limits of the body; fluid loss, and sometimes through bruising and injury. This aspect is central to sport and the production of a competitive event, be it a oneoff match or a two week long Olympic Games, which in themselves all become commodities which, at the elite level have tremendous commercial possibilities in the market-place. The growing preoccupation with media-sports throughout Asia thus opens up not only a market for sports products but also spaces for Asian athletes to profit from their efforts and the commodities they produce.

In this the third of Mangan's three phases of globalization: imperialism, nationalism and consumerism (Mangan, 2002), the global consumer market is demanding more and more sport and, more and more in terms of sating performances from the athletes as units of production. As the Asian market grows it ferociously consumes the television broadcasts of the top flight of media sports, whether from American Major League Baseball or National Basketball Association games, English Premier League football and, particularly on the subcontinent, limited-overs cricket. With the growth of such opportunities in the global market, sport has become a viable career-choice for young athletes, and in Asia, increasing numbers of talented young people are turning to sport as a career.

Ironically, in the People's Republic of China the Soviet-styled sports universities set up in the 1950s, as 'athlete factories' along with the many thousands (over 3000) of governmentrun sports' schools for students from Kindergarten to year 12 (Hays, 2008) are now geared to producing athletes for the professional sports' industry as well as state-athletes in the traditional Soviet manner. Thus, it can be seen, that under the influence of globalizing forces in this age of global consumerism the two domains of elite sport in China have now converged. An explicit example of what amounts to an exposition of the two systems of China's polity in action was the show-casing of Li Ning at the opening ceremony of the Beijing Olympic Games: state athlete at the age of 8, he became the world's leading male gymnast in the 1980s, being labelled the 'prince of gymnasts' after winning 6 of the 7 available individual Gold medals at the World Championships in 1982. In 1990 he founded his sports clothing and footwear company, which was the first Chinese-owned sports goods brand, which now commands over $10 \%$ of the domestic market: Li Ning's entrepreneurial activity and the exploitation of his status as a national hero has thus, in true neo-liberal style, made him a multi-millionaire (Mulvenney, 2008).

Governments, by definition, also engage in massive political and economic involvement with elite professional sport, as has been previously illustrated above, with the level of public spending involved with hosting an Olympic Games. Our gaze of the hosting of megasports festivals has largely been set at the themes of nationalism and the furtherance of the ideals of Olympism and, despite the current dominance of the Asian discourse on the Olympics, with its heavy emphasis upon underlying social, economic and geo-political aspirations of the hosting city (nation) and the preoccupation with the production of meaningful legacies, including those concerned with profitability and economic efficiency and effectiveness, they have not been heavily geared towards the commercial or the 
'business' dimensions. The acquisition of the hosting rights of mega-sports festivals, such as, the Football World Cup, the Rugby World Cup, the Cricket World Cup and all manner of tennis, golf and significantly motor-racing events has now primarily assumed 'commercial' motives as well as the wider politico-economic aspirations. A feature of Asia's growing sporting profile over the past two decades has been a trend towards the profiling of certain Asian cities as dedicated sport event venues, destinations that are exotic tourist destinations in the first instance and sporting event hosts in the second.

In November 2010 Singapore was voted the 'world's best sports city' at the International Sports Event Management (ISEM) Awards annual conference (6th International Sport Event Management Conference, 2011). But, what has this to do with their athletic potential as a nation? The event was organized by a private company the Informa Sport Group (ISG), thus it is very much a self-serving event and the attendees are interested in 'event management' including such conferences rather than 'sport' per se. Singapore is not known as a 'sporting' nation in terms of elite success on the world stage and, upon receiving the award the Singapore Sports Council's (SSC) director of sports business, David Voth affirmed this, in his response illustrated the way in which the government sees sport in Singapore, he said, "...Our strategy is simple - to position Singapore as the premier venue for international sports events...Winning this award is a firm validation of our strategy and efforts in leveraging on the resulting business opportunities" (Tay, 2010). At the ceremony, sporting success for Singapore in 2010 was characterized by the CEO of the SSC, Said Oon Jin Teik, with a list of the major events the nation hosted that year: the inaugural Youth Olympic Games; the Formula 1 SingTel Singapore Grand Prix and the Standard Chartered Bank Marathon. A core criteria upon which Singapore was judged to be the 'world's best sports city' was, not surprisingly, "the level of support and commitment made by a municipality in terms of funding and resource, legislation and planning as well as marketing and promotion" (Tay, 2010). Athletic excellence, sports participation and the notion of the 'contest' are all obfuscated by the commercial jargon as the description of the significance of the awards, as Tay (2010) suggests, indicates that:

An ISEM Award brings with it the status of global recognition as a current market leader, placing the winning company or individual firmly in the international sports event industry through extensive media coverage and professional recognition from industry peers and colleagues.

As concerning as this is, this is now the world of elite sport, it is the world of mediasport and mega-events and Asian 'hosts' are eagerly accruing a grand portfolio of prime international mega-events that purvey this notion of sport.

\subsection{The Asian market: Ready and waiting}

From the earliest phases of the sportization process to the first decade of the $21^{\text {st }}$ century professional sport (Western hegemonic sport that is, Sumo wrestling has been professional sport since the $14^{\text {th }}$ century [Khoon Choy Lee, 1995]) had been dominated "politically, economically, technologically (and) culturally... by the West" (Rowe, 2008). As we approached the end of the first decade of the $21^{\text {st }}$ century the previously established Western media-sports markets lost their potency and became, as Rowe and Gilmour (2010) suggested, "saturated". At this time the world's sporting gaze was firmly fixed on Beijing and China's preparation for the 2008 Olympic Games. Yet, as the Beijing Games opened an uninvited 'guest' arrived on the scene; the GFC of 2008-9. Despite the looming collapse of 
world's financial markets the Games continued, as is their want, China's athletes were supreme and the Beijing Olympic Games received global, albeit politely reserved, acclaim with matters of human rights and governance in China still remaining vexatious. However, needs must and the 'stumbling blocks' were obfuscated, subsumed by the horrors of the GFC. The initial salvos of the GFC were met in the main by the fiscal stimulation and the strength of China's massive capital reserves and their manipulation of their large exposure to US debt. Whilst for resource producing nations, particularly Australia, the on-going insatiable demands of China's manufacturing industry proved to be a saviour.

India's economic development and increasing levels of personal wealth and related levels of disposable income are still very unevenly distributed across its massive population. High levels of consumerism are being seen in expected sectors of the community; the urban upper middle classes, in particular the under- 25 year olds, who are avidly seeking a more cosmopolitan lifestyle. Major sports organizations that sell their product globally, such as, the EPL, the NBA and the US National Hockey League (ice hockey) are frustrated that they cannot develop any meaningful footholds in the Indian domestic television network. Even though ESPN Star successfully covered the FIFA World Cup in 2010 they have shied away from purchasing the rights to televise the EPL or UEFA Champions League ("2011 will be a challenging year for Indian sports Channel", 2011).

In a market research report of India's sport retailing industry, Mukharjee et al state that only $1 \%$ of the Indian population are actively engaged in sport (Mukharjee et al, 2010), and it is most disconcerting to deduce from Mukharjee et al's analysis that of the 770 million people below the age of 35 years in India only 50 million have access to organized games and sports facilities. This pales to insignificance when compared to the 480 million from the same age group in China. Perhaps the most disturbing of Mukharjee et al's data are those that expose the parlous state of school sport in India, it is indicated that only 50\% of Indian schools have sporting facilities and only 30 million of the 220 million school children and college students have access to physical education, sport and games in their curriculums (Mukharjee et al, 2010). Physical education and school sport in China are much more entrenched with most school and college students receiving daily physical activity programmes, though on-going adherence is problematic as is the case in developed nations.

Mukharjee et al (2010) rationalize this low figure by reflecting upon the Italian population (the Italian Trade Commission being joint sponsors of the research project) saying that $1 \%$ of the Indian population would equate to $30 \%$ of the Italian, which is a spurious comment, if the position was reverse and we were looking at the Italian population and had recorded that only $1 \%$ were engaged in regular physical activity it would precipitate a national inquiry. They have effectively othered themselves by reaffirming the stereotypical view of developing nations. The authors of the report should themselves have met this finding with outrage rather than with the platitudinous response they made. However, in terms of the current argument the only way to go from $1 \%$ is up and the point they should have made is that if the level of participation can rise even by $1 \%$ it would have a massive impact upon the overall sports economy of the nation. This would also have further stimulated the sports industry through the growth of discretionary spending in the upper and middle sectors of the population. Despite the fact that of all the Emerging Market Economies (EMEs) India's discretionary spending in 2010 was projected to be the lowest per capita spending amongst all EMEs at US\$690 (Euromonitor International, 2020). Ironically, the impact of these gargantuan markets is significant despite the fact that 
although China, along with India, are amongst the lowest per capita spending nations amongst the EMEs, yet in 2010 China simultaneously had the largest volume of consumer spending of all EMEs, accounting for $23.2 \%$ of the total spending in the major 25 EMEs. India, with the worst per capita spending, was placed $3{ }^{\text {rd }}$. Asia thus, occupies both ends of the spectrum of spending on consumer goods and services amongst the EMEs, as the United Arab Emirates (UAE) continued its position as having the highest per capita consumer expenditure of the EMEs at US\$22,728.

China's reported level of physical leisure activity in 2005 was $24.5 \%$ of the population of adults between 35 -74 years (Muntner et al., 2005), however, this figure was drawn from the combination of rural and urban figures with the urban component being only $7.9 \%$ and the rural 28.5\%. However, it is suggested that post-Beijing Olympic Games and with 5 subsequent years of urban drift in China these figures may well now be very different. By comparison $31 \%$ of US adults reported that they engage in regular leisure-time physical activity but disconcertingly approximately $40 \%$ of adults reported no leisure-time physical activity at all (National Center for Health Statistics, Chartbook on Trends in the Health of Americans, 2008). Evidently, in the US market there must be a quite small number, comparatively speaking, that have far more disposable income which they choose to delegate to sport, leisure, fitness and recreation in general, including, of course, incidental spending on the many direct linkages to other markets such as, travel, accommodation and the 'essentials' - electrical appliances (televisions) and cable fees.

As countries such as India, China and all other 'developing' nations in Asia advance, they will organically increase spending on sport: sectors of the population will gain more purchasing power; luxury items (as sport is viewed in many, if not most, developing nations) will become less exclusive to the wealthy and more widely accessible and governments, as their nations develop, will also be able to invest more in sport being less pre-occupied with the establishment of basic infrastructures such as, transport systems, roads, water and sanitation, health programmes and education systems. Perhaps this is most graphically illustrated in the case of the city-nation of Singapore. India will soon have much more than $1 \%$ actively engaged in sport and physical activity and active recreation particularly as the trend is already apparent that there is an increase in the percentage of affluent and educated middle-class young Indians with disposable incomes and ever-increasing levels of IT and media access. Soon India's 1\% will be swamped. Though the figures for active engagement in physical activity in the urban areas of China are very low at $7.9 \%$ these too will soon blow-out, for with life in the cities of China, particularly for the post-university age generation of young professionals, consumption, in all senses of the word, will increase as will the people's expectations and aspirations.

It has been estimated that China's sport's industry has a market potential of RMB2 trillion or approximately US\$303 billion (China Market Research Reports, 2010). Surprisingly, this still lags behind the US sports industry which in 2010 was estimated to be worth US\$414 Billion ("Sport Industry Overview", 2010). Prior to the Beijing Olympics the sports product market of the US (equipment, apparel, footwear and accessories) represented one-third of the global industry whilst Asia even with the gigantic populations of India, China and Indonesia, plus the highly buoyant sports markets of Japan and South Korea only commanded $25 \%$ of the global market. The disproportionate weighting can be rationalized simplistically by invoking the argument of developed against developing nations, however, it is perhaps 
more pertinent to consider the levels of participation in active leisure and sport against the sport industry activity of the nations involved.

The potential market for sports apparel, equipment and shoes in China and India is massive but for the most important stakeholders, the international media companies that deliver the product that links all aspects of the sports industry to the consumers the key for success will be a more comprehensive share of and access to the vast and immensely lucrative television audiences in India and China. Considering the potential size of the Asian sports media market, audiences there are really untapped and certainly nowhere near 'saturated'! The extent of India's sport spectatorship potential is indicated by the level of support for the Indian Premiership (cricket) League, which offers the 'Bollywood' form of Twenty/20 cricket. This competition is played by teams owned by franchisees and made up of top-class players from around the world that have been 'bought' by the franchises at auctions, reminiscent of thoroughbred horse sales. This highly TV-friendly truncated form of cricket is played at a frenetic pace over a mere three hours and is accompanied by live music between overs and incessant pyrotechnic displays after 'maximums' (sixes) are scored. It is not, however, just the new upwardly-mobile and increasingly affluent 20-30 year olds that are courted by this shortened form, for the game globally is very much the domain of working-class supporters and this is nowhere more so than on the sub-continent. Significantly, it attracts a sizeable female audience even in the more patriarchal societies of southern Asia.

China's potentially massive television audiences continue to be difficult for all the major football leagues of Europe to penetrate meaningfully. There has been an on-off relationship between the EPL and China's state controlled and private pay-TV outlets for the past two decades. The EPL sold the broadcasting rights to the pay-TV company Win TV (China) group but poor management, high fees and limited rural coverage resulted in them becoming bankrupt. China Central TV (CCTV) the national television provider has just a single sports channel CCTV-5 and carries some coverage of matches from various other European leagues such as, the German Bundesliga, and the Le Lega from Spain. Various cable networks do carry sport from overseas, but audiences are surprisingly modest compared with the population. CCTV 5 is the state-run all-sport channel and it covers all major domestic and international sporting events, such as the Olympic Games and the Football World Cup. It has been estimated that it carries $80 \%$ of all sport advertising on Chinese television and not surprisingly has the biggest viewing audiences, which prior to the Beijing Olympics was estimated to have been 100 million people per day (Jennings, R., 2006). It is presumed that this level has increased and would obviously have peaked for the Olympics. The biggest single day's audience for the Beijing Olympics (August, 2008) was 675 million, whilst the total audience for the whole period of the Games was 1.102 billion people or $80 \%$ of the country's entire mainland population (BOCOG, website, 2008). Such figures, even though they do represent, what must be viewed as a 'one-off' market response, do little to assuage the sense of frustration the major global media sports providers, such as the EPL feel, as they struggle to get a firm purchase on the Chinese markets.

\subsection{Asian money, Asian hegemony?}

The growing presence and potential of Asian athletes when mobilized has long been apparent in niche sports, such as table tennis, badminton and martial arts, though trends 
are beginning to emerge showing that Asian athletes are beginning to more consistently dominate traditional hegemonic sports such as, golf and cricket. In the ultimate arena of elite sporting endeavour, the summer Olympic Games, the three Asian hosts have not only, as previously mentioned, morphed the manner and scope of the preparation, organization and conduct of the festival and reconceptualised the discourse on the Games, their athletes and coaches performed magnificently. In this analysis discussion of China's market and investment potential it must always be remembered that China is still considered as a developing nation and economy, yet very importantly it is also currently the world's second largest economy and, as has been predicted for nearly a decade, it will soon be the largest (Goldman Sachs, 2003).

Over the past decade the growing penetration of global sport by Asian capital has become increasingly apparent. The direct investment in major sports clubs and in the quite literal sense, the 'purchasing' of major sports events in order to host them, which axiomaticaly provides the hosts with massive roll-on commercial opportunities from linked activities associated with inbound tourism opportunities. The economic development of cities such as, Singapore, Hong Kong, Shanghai, Dubai and Doha has allowed their governments (and rulers) to provide financial and political support to such projects by building the required sporting facilities, be they: race tracks for Formula 1 or horse racing; golf courses; football stadiums; indoor tennis stadiums; athletics tracks, and even cricket pitches along with necessary infrastructure for their hosting aspirations.

The hosting of major sports festivals such as, Olympic Games and the Football World Cup have historically been the preserve of nations with elite and long-standing heritages in the particular sport or movement (for example, Olympism and that of the Commonwealth or Asian Games). Though, the selection of the host city (nation?) for an Olympic Games is often, if not always, veiled in political intrigues. Recently a major shift in philosophy was apparent with the selection of Qatar as host for the 2022 World Cup. Qatar is ranked 90th in the FIFA world rankings list and 10th in the Asian rankings (FIFA, 2011) and with a population of 1.45 million and a modest land mass questions were obviously asked as to why they were awarded the 2022 World Cup. Conjecture will not be made here as to the possibility of any intrigue, however, football critics globally are still waging campaigns vilifying the decision, its motivation and the decision makers (Jennings, A., 2011). The shift in philosophy, as suggested above, is to do with both the desire and willingness on the part of the Qatari rulers to support the bid 'enthusiastically' using their not insignificant wealth and (still) absolute power to acquire both a market position and a high-status position in the hierarchy of world football. Recent economic data serves to illustrate the basis for the decision made by FIFA: Qatar's predicted percentage GDP growth for 2011 is $18.6 \%$; its per capita GDP for 2010 was US\$74,473 compared to the figure for the US was US\$47, 312 (Global Financial Magazine, 2011).

It goes without saying that the 'world game' has massive appeal throughout Asia and, as has been noted above, is a central feature of the potential the Asian market offers the global sports industry, it is also a very attractive 'target' for Asian investors at all levels; individual entrepreneurs and national government investment bodies from major Asian economies have in recent years made or have attempted to make ownership bids of some of the most prestigious football clubs in the world. In 2008 an Indian consortium, headed by poultry and poultry products producers, Venkateshwara Hatcheries Pvt. Ltd. or as they know globally 'Venky's', took over EPL club Blackburn Rovers, who were facing bankruptcy, for $£ 23$ 
million, in what must be viewed as a modest sum, for Blackburn Rovers that was established in 1875 and was a foundation member of the English Football League in 1888 has a tremendous tradition and following. Venky's, who are no doubt supporters of the game, view this move in clinical financial terms and unlike other acquisitions of football clubs is not driven by masculine sublimation. The company is run by Anuradha Desai, who succeeded her father BV Rao as chairperson and, from her initial comments, she appears to be parsimonious and committed to making the take-over profitable, though she admits, she does not expect miracles. Desai responded to questions regarding the purchase of new highprofile players, using a rather 'un-football' like expression saying that, the new administration does "not need to buy expensive players, we can always lease them." (The Economic Times -Times of India, 2010)

Other Asian business-houses and individuals have made incursions into, what is one of the most popular sporting competitions in the world and certainly one of the world's biggest earning football league. The ex-Prime Minister of Thailand Thaksin Sinawatra, who owned Manchester City for two years before selling it to the a member of the ruling family of the United Arab Emirates, Sheik Mansour bin Zayed Al Nahyan. Sheik Mansoor has since spent many millions of pounds in an attempt to unseat Manchester rivals, Manchester United, from the throne as the EPL's leading club. In 2009 Hong Kong businessman Yeung Ka Sing (Carsen Yeung as he is known in Europe) took over Birmingham City Football Club through the parent company of his various businesses, Birmingham International Holdings. Yeung, who previously owned a football club in Hong Kong, said he would like to break into the massive Chinese football market by signing "the best Chinese talent he can find" (Harris, 2010). Yeung's ambition to take China's best players to Birmingham City would definitely serve to promote Chinese football talent but, and perhaps more importantly in business terms, it would attract a host of Chinese supporters to Birmingham's cause and incidentally to the advertising of the ambush-marketing related to match-broadcasts, if and when their matches are ever broadcast in China.

Yeung's gambling interests are almost certainly driving his motivation for trying to break into the Chinese market. Gambling is a fundamental aspect of Chinese culture and sport provides it with a perfect medium and Yeung, described as an "obscure casino millionaire" (Chen, 2007), gained most of his wealth from shrewd investments in the stock market in Hong Kong and Macau, where he is part-owner of a chain of casinos. An indication of Carsen Yeung's cross-business interests and perhaps his motivation can be gleaned from an analysis of the major advertisements displayed on the computer generated pitch-side advertising hoardings during Birmingham City's home fixtures. For example, throughout Birmingham City's home match against city rivals West Bromwich Albion played on the 5th March, 2011, and broadcast live around the world, there were fifteen major advertisements that appeared in rotation throughout the match, seven of which were advertising gambling outlets while three others were for finance houses, including two banks and Yeung's own investment business.

In 2009 there was a series of, as of yet, unsubstantiated reports, in the British press suggesting that a Chinese consortium had made some initial moves to take over Manchester United. The club is arguably the highest profiled EPL club and the third biggest-earning football club in world football: In the 2009-10 season it earned €350 million (Deloitte, 2011). In December, 2009 it was reported that a "group of Far East billionaires" was engineering a takeover bid for Manchester United, "masterminded out of Beijing" (Ashton, 2009). However, no further reports have surface regarding this bid by 
the Chinese, though in 2010 it was reported that the China Investment Corporation (CIC) China's overseas investment corporation, was brokering a deal to support Chinese sport tycoon Kenny Huang's £300-350 million bid to buy Liverpool City FC (Power \& Evans, 2010). Though, again no response came from the club's owner. However, it would be no surprise that if in the future the Chinese, with the support of the CIC, were to make a successful bid for an EPL club.

An investment in such a high profile 'business' as an EPL club, particularly one that is as successful and profitable as Manchester United would represent not only 'good business' for $\mathrm{CIC}$, it would undoubtedly be a significant diplomatic coup for Chinese government. Manchester United has also been the target of the enormous wealth of the Qatari royal family who are looking at purchasing the English club in order to set up a direct confrontation with arch-rival, Sheik Mansour bin Zayed Al Nahyan of the United Arab Emirates' ruling family, who now owns Manchester City (Green, 2011). The frequency and size of such offers from the extremities, ideologically and geographically speaking, of the Asian money 'market' are indicative of the potential impact Asian 'money' will have on the world-game and consequently upon the future global sports industry per se. The sportrelated political power the Arab states hold was further demonstrated when on the 19th March, 2011 Mohamed Bin Hammam, the President of the Asia Football Federation announced his decision to run for the FIFA presidency at the annual congress in meeting of FIFA in Zurich on June 1st 2011. When he announced his bid he indicated that he wanted to challenge the current president, Sepp Blatter with the aim of bringing "transparency" to the leadership of FIFA (Scott, 2011). Leaving his reasons and their validity aside, his proposed announcement is indicative of an emerging shift of the locus of the hub of the power-base of world football, which mirrors the well-publicised move of the executive hub of cricket from its spiritual home, Lord's Ground in London to Dubai in the heart of the Middle East.

The move of cricket's headquarters to Dubai is another graphic illustration of the raw impact of the weight of Asian (mainly Indian) money in global sport. Taking the control of world cricket out of the hands and the home of its custodians the English Test cricket authorities along with the Marylebone Cricket Club and establishing its new base in Dubai was achieved without a whimper of protest. The move was both economically savvy and, in terms, of the new realpolitik of world cricket, was very pragmatic. As Raja (2005) noted the shift was, "a move reflecting the game's changing financial epicenter and one that is aimed at taking advantage of the tax-free status of the emirate." In moving to Dubai the ICC was able to save millions in tax, for being based in the UK meant it had to pay $30 \%$ of its revenue in tax. The geographical aspect of the relocation to Dubai also had economic implications as it embraced an implicit redirection of interest and emphasis, with 70c of every dollar made in world cricket being made in/from India (Linnell, 2008). Thus, the ICC's gaze is now very much towards the east from Dubai to the sub-continent.

The epitome of this change in attitude, if not the game's values, is the emergence of the IPL, and not just its Bollywood choreography, but the fundamental premiss upon which the annual league contests are based: These are 'performances' which could be categorized as 'sport-a-tainment'. Television rights are sold world-wide with the Sony/World Sport Group (Singapore) paying US $\$ 1.89$ billion for a 10 year contract to broadcast to the domestic Indian audience (Cricinfo, 2008). In 2008 India's biggest property developer the DLF Group paid US\$50 million for a three year deal to be the championship's title sponsor (Singh, 2009). In 2010 the IPL's overall value was estimated to be US\$4 billion (Gill, 2010). As the IPL is aligned with the Board of Cricket Control of India (BCCI) it will contribute at least US\$1.5 
billion over the next 5 to 10 competitions to the BCCI's coffers. Not surprisingly the IPL concept and its underlying motivation are avidly supported by the ICC. The BCCI, which as has been noted above, controls $70 \%$ of all cricket income globally is a major force on the Executive Board of the ICC and, with the Chief Executive Officer, Haroon Largat a South African of Indian heritage and the president Shawad Pawar, an ex-Minister of Defence from India, it also has considerable senior executive 'clout.' The ICC Executive Board has ten members and with four coming from the sub-continent (ICC, 2011) the region is also micropolitically very powerful. As Garry Linnell (2008) most adroitly remarked, when closing his reflection upon this shift in power in world cricket:

“...World cricket has a new master. And its new servants had better get used to it."

\section{Epilogue}

It is apparent that Western or Anglo-American sport, in all its guises and with a variety of underpinning motivations was a significant element of the cultural diffusion of imperialism through the actions and intentions of colonizers and missionaries. Indeed, it has been stated that sport and particularly the Olympic Games acted as a major accelerant in, what Robertson (1992) termed, the 'take-off' phase of globalization (1870 -1920). And a century before, from the middle of the eighteenth century sport and sporting leisure had been cast wide by British imperialism. In the colonies and territories of the British Empire the traditional English games were inculcated and taken-up and played to varying degrees by the local people. Cricket spread more widely than Rugby football and Association football on the sub-continent and whilst Rugby took root in parts of Australia, an invented Australian form dominated in the southern and western colonies (now states). Games, such as cricket, baseball and football, although played under the same rules globally, developed idiosyncratically or were creolized because of climate, ground conditions and social, cultural and ethnic configuration of those playing the game (Hannerz, 1992).

It has been demonstrated that now in the 'advanced' phases of the global sportization process the sport industry of Asia is now regarded as an emerging superpower: the impact of the three economic 'engines' of the Asian sports industry have rapidly accelerated the development of sport in Asia to such an extent that Asia is beginning to wrest the leadership, certainly on economic terms from the Euro-American hub, and it is evident that hegemonic sports are now assuming a far more cosmopolitan character and are even being reshaped by Asian influences. This emerging trend mirrors the already established shift of the locus of the centre of gravity of global geopolitical and economic power in general. This may well be a tangible reflection of the advent of 'advanced' sportization with the process continuing in sport's second globalization with Asianization becoming a major cultural element vying with the previously dominant cultural traditions of Westernization and Americanization. Though the Asianization of Western culture was always a reciprocal feature of imperial expansion and exploration, the process of the Asianization of Western popular culture accelerated after World War Two. Ironically, the growing wealth of Asian nations, particularly Japan, precipitated an increase in the process of Asianization of popular culture to "suit Asian tastes" (Befu, 2003) whilst at the same time retaining its EuroAmerican essence. Befu (2003) noted that this may well stem from the "common implicit yearning of Asians for Western culture." This definitively applies definitively to the growing engagement of the Asian market with sport, though now, as has been illustrated in this analysis, the geopolitical characteristics of the major stakeholders are changing. In this 
chapter it was proposed that there is an emerging Asian hegemony in global sport, which is a corollary of the shift of the global economic power away from its North Atlantic (Occidental) epicentre to Asia. However, this reconfiguration of the power-base of global sport is viewed as being problematic, and to an extent is considered with an element of trepidation, for if the ascendancy of 'economy' - the commodities, market and money - leads to the demise, even the diminution, of the effect of 'ecology' - its heritage, traditions and ethos, then there is a very real possibility that the meaning and essence of sport will be eroded beyond repair.

\section{References}

"2010 Report on China Sports Industry" 168Report- China Market Research Reports, 1, accessed 14/02/11, available at: www.168report.com/Report/DOC/Report0072.doc.

"2011 will be a challenging year for Indian sports Channel" MediaDir DTH News, January9th, 2011 (8 January 2011), Indiantelevision.com Team, accessed 18/02/11, available at: http://dthnews.mediadir.in/2011-will-be-a-challenging-year-forindian-sports-channel/.

$6^{\text {th }}$ International Sport Event Management Conference 2011 Webpage - "About ISG" accessed09/01/11, available at:

http://www.iirme.com/isem/generalinfo/about-isg.

Appadurai, A. (1990) "Disjuncture and difference in the global cultural economy" Theory, Culture \& Society, 7, 295-310. (1996). Modernity at Large: Cultural Dimensions of Globalization, University ofMinnesota Press \& Oxford University Press, India.

Ashton, N. (2009)"Debt-Laden Man United Are Ripe For Plucking", accessed 20/02/11, available at: http:/ / www.thegoalposts.com/showthread.php?p=955366

Befu, H. (2003)"Globalization Theory from the Bottom Up: Japan's Contribution" Japanese Studies, Vol. 23, no. 1, pp. 3-22.

BOCOG, (2008a) The Official Website of the Beijing Olympics, "One World One Dream" accessed 10/08/08, available at:

http:/ / en.beijing2008.cn/spirit/ beijing2008/graphic/n214068253.shtml (2008b)

"Olympic TV audience on rise in China" Games, accessed 22/08/08, available at:

http://en.beijing2008.cn/news/official/noc/oca/n214569915.shtml.

Bowring, P. (1987) “What Is "Asia"? Far Eastern Economic Review, Vol. 135, No. 7, February12, 1987, accessed, 19/01/11, available at:

http:/ / afe.easia.columbia.edu/geography/geo_whatis.htmlconomic,1-4.

Central Intelligence Agency (CIA) (2011), World Fact Book, accessed, 06/02/11, available at: 2011https://www.cia.gov/library/publications/the-worldfactbook/geos/xx.html

Cha, V. (2009) Beyond the Final Score: The Politics of Sport in Asia, New York: ColumbiaUniversity.

Chakraborty, A. \& Ganguly, S. "Blackburn bid underlines India's global ambition” Reuters online: Fri, Oct 29, 22:08, accessed 05/11/10, available at: http://in.mobile.reuters.com/article/topNews/idINIndia-52551820101029. 
China Market Research Report, (2010) “2010, Report on China Sports Industry”, pp.12.168report.com, 2010, accessed 15/02/11, available at: http:/ / www.168report.com/Report/report0072.html.

Close, P., Askew, D., \& Xin Xu. (2007) “The Olympic Games as a 'coming out party': Tokyo, Seoul, Beijing and the Asian Olympic discourse" in, Close, P. Askew, D., \& Xin Xu. (eds.)The Beijing Olympiad: The Political Economy of a Sporting Mega-Event, London: Routledge, pp. 121-144.

Collins, S. (2008) 'The Fragility of Asian National Identity in the Olympic Games', in,Monroe E. Price and D. Dayan, (eds.) Owning the Olympics: Narrative of the New China, University of Michigan Press, pp. 185-209.

Cowen, T. (2002) Creative Destruction: How Globalization is Changing the World, Princeton, NJ.:Princeton University Press.

Deloitte, (2011) The Untouchables: Football Money League, Sports Business Group, February 2011, 11, accessed 12/03/11, available at: http://www.deloitte.com/assets/DcomUnitedKingdom/Local\%20Assets/Documents/Industries/Sports \%20Business \%20 Group/USBG_DFML2011.pdf.

Dobbs-Higginson, M. S. (1993) Asia-Pacific: A View on its Role in the New World Order,Longman: Hong Kong.

Elias, N., 1986. "The Genesis of Sport as a Sociological Problem," in Quest for Excitement:Sport and Leisure in the Civilizing Process, (ed.) E. Dunning and N. Elias, Oxford: Blackwell, pp. 126-149.

Euromonitor International, "Spending power in emerging market economies grows rapidly"Euromonitor Global Market Research Blog, September 6, 2010, accessed 05/03/11, available at: http://blog.euromonitor.com/2010/09/spending-powerin- emerging-market-economies-grows-rapidly.html.

Fan Hong, Ping Wu \& Huan Xiong. (2005) "Beijing Ambitions: An Analysis of the ChineseElite Sports System and its Olympic Strategy for the 2008 Olympic Games" The International Journal of the History of Sport, 22, no. 4, 510-20.

"Field assumes command of U.S. Forces Japan" Stars and Stripes, 25 October, 2010, accessed 06/03/11, available at: http://www.stripes.com/news/pacific/japan/fieldassumes-command-of-u-s-forces-japan-1.122944?localLinksEnabled=false.

FIFA, (2011), FIFA/Coca Cola, World Rankings 2010, accessed 03/02/11, available at: http:/ / www.fifa.com/worldfootball/ranking/lastranking/gender=m/fullranking .html.

Galtung, J. (1982) "Sport as a carrier of deep culture and structure", Current Research on Peace and Violence, Finland.

Garton Ash, T. "China arrives as a world power today - and we should welcome it "The Guardian, Thursday 2 April 2009, accessed 6/04/09, available at: http:/ / www.guardian.co.uk/commentisfree/2009/apr/02/g20-china-worldpower-economy.

Gill, H. (2010) "Players eyeing big league" Friday, November 19, 2010, National News.com, Barbados, accessed, 15/03/11, available at: http:/ / www.nationnews.com/articles/view/ players-eyeing-big-league/ 
Giulianotti, Richard and Roland Robertson, (2004) “The Globalization of football: a study in the glocalization of 'serious life', The British Journal of Sociology, (2004)Vol. 55, Issue 4, pp. 545-568.

Goldman Sachs, (2003) Goldman Sachs Global Economics Website, Paper No: 99, "Dreaming With BRICs: The Path to 2050", 1 October 2003, accessed, 12/04/09, available at: http://wWorld War Two.goldmansachs.com/ideas/brics/book/99dreaming.pdf.

(2010) Global Economics Paper 204, 13, accessed 17/01/11, available at:

http://www.dasinvestment.com/fileadmin/images/pictures/0809_Global_Econ_ Paper_No_204_Final.pdf.

Green, A. (2011) "If Qatar really wants to buy Manchester United then $£ 1$.5bn is way over the odds" The Guardian, Friday 25 February 2011, accessed 25/02/11, available at: http://www.guardian.co.uk/football/blog/2011/feb/25/mancheste-united-qatarglazers.

Hannerz, U. (1992) Cultural Complexity: Studies in the Social Organization of Meaning, New York: Columbia University Press.

Harris, N. (2010). “Carson Yeung: 'I'll bring China's finest to Birmingham'” The Independent online, Friday, 16 April 2010, accessed, 25/02/11, available at:

http:/ / www.independent.co.uk/news/people/profiles/carson-yeung-ill-bringchinas-finest-to-birmingham-1946203.html.

Huang Zhi-Wei, “US Military Actions after World War II” Journal of International Relations, Focus on International Relations, October 22, 2009, accessed, 05/11/10, available at: http://www.focusire.com/archives/133.html.

Hunt, T. (2006) “American Sport Policy and the Cultural Cold War: The Lyndon B. Johnson Presidential Years" Journal of Sport History, Vol. 33, No. 3, Fall, 2006, 273-297.

Huntington, S. P. (1996) The Clash of Civilizations and the Remaking of World Order, Simon and Schuster: New York.

ICC, (2011) Official webpage, accessed 18/01/11, available at:

http:/ /icc-cricket.yahoo.net/index.php.

International Monetary Fund, (2010), accessed 17/01/11, available at: http://www.imf.org/external/pubs/ft/weo/2010/02/weodata/weorept.

Jennings, A. (2011) "Blatter wants Prince Who? to be new FIFA boss" Sunday, January 2, 2011, Transparency in Sport -website, accessed, 11/03/11, available at: http://www.transparencyinsport.org/Blatter_wants_Prince_Who_to_be_new_FIF A_boss/blatter_wants_prince_who_to_be_new_FIFA_boss.html.

Jennings, R. (2006) "The business of Chinese sports" Asian Times online - China Business, 13 May 2006, 5, accessed, 22.02/11, available at:

http://www.atimes.com/atimes/China_Business/HE13Cb05.html.

Kay, O. \& Ducker, J. (2009), "Chinese consortium believed to be lining up offer for Manchester United with Glazers standing firm" The Times, December 14, 2009, accessed 14/01/11, available at:

http://www.timesonline.co.uk/tol/sport/football/premier_league/manchester_u nited/article6955272.ece . 
Khoon Choy Lee, (1995) Japan: between Myth and Reality, Singapore: World Scientific Publishing Pte. Ltd.

Kim, Chung Keun. (2000) "Days and Nights on the Street" in, Scott-Stokes, H. and Lee Jai Eui, (eds.) (2000), pp. 3-18.

Kirk-Green, A. 'Badge of Office: Sport and His Excellency in the British Empire', in, Mangan, (ed.) The Cultural Bond: Sport, Empire, Society, (London: Frank Cass, 1992), pp. 178-9.

Kissinger, Henry A. "Centre of gravity shifting”, Khaleej Times Online, 2 November, 2004, accessed 10/01/09, available at:

http:/ / www.khaleejtimes.com/DisplayArticle.asp?xfile=data/opinion/2004/Nov ember/opinion_November2.xml\&section=opinion\&col.

Kurlantzick, J. (2008) “The Beijing 2008 Olympic Games: Not all of China is cheering” Posted: August 18, 2008, 3:30 PM by Daniel Goldbloom, accessed 20/04/2010, available at: http:/ / network.nationalpost.com/np/blogs/fullcomment/archive/2008/08/18/j oshua-kurlantzick-on-the-beijing-2008-olympic-games-not-all-of-china-ischeering.aspx.

Lim, Lai Kuan, (2004) The Development of Sport in Singapore: An Eliasian Analysis, unpublished $\mathrm{PhD}$ thesis, James Cook University.

Linnell, G. "India buys cricket's crown" The Daily Telegraph, February 02, 2008, accessed, 24/02/11, available at: http://www.dailytelegraph.com.au/sport/cricket/indiabuys-crickets-crown/story-e6frey50-1111115455498.

Maguire, J. (1999) Global Sport: Identities, Societies, Civilizations, Polity Press: Cambridge.

Mangan, J. A. (1992) 'Prologue: Britain's Chief Spiritual Export: Imperial Sport as Moral Metaphor, Political Symbol and Cultural Bond', in, Mangan, (ed.), The Cultural Bond: Sport, Empire, Society, London: Frank Cass, pp. 1-10.

Manheim, (1990), 'Rites of passage: the 1988 Seoul Olympics as public diplomacy', Western Political Quarterly, 43(2) June, pp. 279-95.

Markovits, Andrea, S. \& Rensmann, Lars. (2010) Gaming the World: how sports are reshaping global politics and culture. Princeton University Press: Princeton, NJ., 2

Matles, S. A. \& Shaw W. (eds.) South Korea: A Country Study. Washington: GPO for the Library of Congress, 1990, accessed, 09/04/2010, available at: http://countrystudies.us/south-korea/21.htm.

Millett, Allan R. The War for Korea, 1945-1950: A House Burning. Lawrence: Univ. Press of Kansas, 2005, pp. xviii - 348. ISBN 978-0-7006-1393-9.

Mukherjee A., Goswani, R., Goyal, T. M. \& Gupta, A. (2010) “Sports Retailing in India: Opportunities, Constraints and Way Forward" (Draft Paper) The Sports Retailing Industry In India Market Research 2010, Italian Trade Commission, 31.

Mulvenney, N. (2008) “Li Ning, "Prince of Gymnasts" and businessman" accessed 10/03/11, available at: http://www.reuters.com/article/2008/08/08/us-olympics-li-ningidUSSP4750620080808.

Muntner, P., Gu Donfeng, Wildman R. P., Chen Jichun, QanWenqi, Whelton P. K. \& He Jiang (2005). "Prevalence of Physical Activity Among Chinese Adults: Results From the International Collaborative Study of Cardiovascular Disease in Asia" American Journal of Public Health 5 September 2005, Vol 95, No. 9, fig. 1. (1631-1636.) (C) 2005 
American Public Health Association DOI: 10.2105/AJPH.2004.044743, accessed 16/02/11, available at:

http://ajph.aphapublications.org/cgi/content/full/95/9/1631\#F1.

National Center for Health Statistics. Chartbook on Trends in the Health of Americans. Health, United States, 2008. Hyattsville, MD: Public Health Service. 2008. Cited in, Weight Control Information Network, National Institute of Diabetes and Kidney Disease (NIDDK), accessed 16/02/11, available at:

http://www.win.niddk.nih.gov/statistics/index.htm.

Ninomoya, K. “China's Public Relations Success: China Turns PR Nightmare Into ImageVictory On Worldwide Stage" 25, August, 2008, accessed, 12/01/09, available at: http://www.suite101.com/content/chinas-public-relations-successa65801\#ixzz1BdWAXzVo.

Power, H. \& Evans, T. (2010) “Chinese Government backs sports tycoon Kenny Huang's bidfor Liverpool FC", The Times of London, in The Australian, Aug. 5, 2010, accessed, 10/01/11, available at: http://www.theaustralian.com.au/news/sport/chinesegovernment-backs-sports-tycoon-kenny-huangs-bid-for-liverpool-fc/storyfn63e0vj-1225901482464.

“Qatar Country Report" Global Finance Magazine - Qatar, 11/03/11, accessed, 11/03/11, available at: http://www.gfmag.com/gdp-data-country-reports/195-qatar-gdpcountry-report.html\#axzz1GFdOLwIb.

Rajadhyaskha, A. (2003) “The 'Bollywoodization' of the Indian Cinema: cultural nationalism in a global arena" Inter-Asian Cultural Studies, Vol. 4, No. 1 2003, pp. 25-39.

Raja M. (2005) “Cricket's home moves closer to the money" Asia Times Online, April 23, 2005, accessed, 08/12/08, available at:

http://www.atimes.com/atimes/South_Asia/GD23Df05.html.

Robertson, R. (1992) Globalization: social theory and global culture. Sage: London.

(1995) “Glocalization: Time-Space and Homogeneity-Heterogeneity' in, Featherstone, M., Lash, S. \& Robertson, R. (Eds.) Global Modernities, London: Sage,pp. 25-44.

(2002) 'Globality' in Smelser, N.J. \& P. B. Baites (eds.) International Encyclopaedia of the Social and Behavioural Sciences, Vol. 9, Oxford: Elsevier/Pergamon Press, p. 6254.

Rowe, D. (2008) “The East-West Balance in 21st Century Media Sport", in, Luo Qing, Wen Chunying, Liu Fenghai, Zhou Xuemei, Zhao Jingsong, Hu Rong, Liu Xing, Liu Pengzhe (eds.), Sports Globalization Communication, Asia Media Research Centre, Communication University of China: China, pp 14-27.

Rowe, D. \& Gilmour, C. (2010) "Sport, Media, and Consumption in Asia: A Merchandised Milieu" American Behavioral Scientist, May 7, 2010 vol. 53 no. 10, i., pp. 1530-1548.

Said, E. W. (2003) Orientalism, London: Penguin Books.

Scott, M. (2011) "Mohamed bin Hammam confirms intention to run for Fifa presidency",guardian.co.uk, Friday 18 March 2011 21.36 GMT, accessed 19/03/11, available at:http://www.guardian.co.uk/football/2011/mar/18/mohamed-binhammam-fifa-president .

Scott-Stokes, H. \& Lee Jai Eui, (eds.) (2000). The Kwangiu uprising: eyewitness press accounts of Korea's Tiananmen, Armonk, N.Y.: M.E. Sharpe. 
Sender, H. \& Hille, K. (2011) "CIC seeks more funds out of China reserves" Financial Times.com -China, January 16, 2011, accessed, 26/02/11, available at: http:/ / www.ft.com/cms/s/0/a657ba86-219a-11e0-9e3b-

00144feab49a.html\#axzz1F2eez8BZ

Shu-Ching, (Jean) Chen. (2007) "Macau Winnings Flow To Bid For U.K. Soccer Club" Forbes.com. - Faces in the News, 02/07/2007, accessed, 21/06/09, available at: http:/ / www.forbes.com/2007/07/02/yeung-birmingham-hk-face-marketscx_jc_0701autofacescan01.html.

Singh, K. P. (2009), Forbes.com. 03-11-09, accessed, 07/03/10, available at: http://www.forbes.com/lists/2009/10/billionaires-2009-richest-people_KushalPal-Singh_0UU7.html.

"Sony and World Sports Group bag IPL television rights", Cricinfo - staff January 14, 2008, accessed 24/02/11, available at:

http://www.espncricinfo.com/ipl/content/story/330881.html.

"Spending power in emerging market economies grows rapidly" - online report, September 6, 2010, accessed 19/02/11, available at:

http:/ / blog.euromonitor.com/2010/09/spending-power-in-emerging-marketeconomies-grows-rapidly.html.

"Sports Industry Overview", Plunkett Research Ltd., 2010, accessed, 14/02/11, available at: http://www.plunkettresearch.com/sports\%20recreation\%20leisure\%20market\%20research/ industry\%20statistics.

"Stiff clauses leave only 4 in race for IPL teams". The Economic Times - Times of India online, accessed 24/02/11, available at:

http:/ / economictimes.indiatimes.com/news/news-by-industry/et-cetera/Stiffclauses-leave-only-4-in-race-for-IPL-teams/articleshow/5648934.cms .

Tay, D. (2010) “Singapore named world's best sport city" online article, accessed 09/01/11, available at: http:/ / redsports.sg/2010/11/04/singapore-best-sport-city/.

The Financial Times -Times of India, "Venky's scores a coup with EPL buy" ET Bureau, October 29, 2010, accessed, 15/03/11, available at:

http:/ / articles.economictimes.indiatimes.com/2010-10-

29/news/27589546_1_blackburn-rovers-venky-s-venkateshwara-hatcheries The Times of India (2010). http:/ / economictimes.indiatimes.com/News/ ... The Times Of India. 26 April, 2010.

“The US-Japan Security Treaty, 1951" accessed 12/10/10, available at: http:/ / www.mofa.go.jp/region/n-america/us/q\&a/ref/1.html,

US Department of State, "Diplomacy in Action: Background Note: South Korea, US-Korean Relations." Accessed 04/11/10, available at:

http:/ / www.state.gov/r/pa/ei/bgn/2800.htm.

Woo-Cumings Meredith. (2003) "South Korean Anti-Americanism", JPRI Working Paper No. 93, July 2003, Japan Policy Research Institute (JPRI), University of San Francisco, Center for the Pacific Rim, accessed 31/10/10, available at:

http://www.jpri.org/publications/workingpapers/wp93.html.

World Resources Institute, 2009. 'Energy and Climate Policy Action in China' (Fact Sheet) accessed 25/09/09, available at:

http://pdf.wri.org/factsheets/factsheet_china_policy.pdf. 
Xu Xin, (2006) "Modernizing China in the Olympic Spotlight: China's National Identity and the 2008 Beijing Olympiad" The Sociology Review (2006), 104. (90-107).

Zarnowski, C. Frank "A Look at Olympic Costs" accessed, 07/04/2010, available at: http://www.la84foundation.org/SportsLibrary/JOH/JOHv1n1/JOHv1n1f.pdf. 


\section{Part 2}

Globalization and Human Being 



\title{
Simularizing Tradition and Foreign: Osmotic Production of Justice in the Milieu of Hong Kong Anti-Domestic Violence Law
}

\author{
Chiu Man-chung \\ Hong Kong Shue Yan University \\ P. R. China
}

\section{Introduction}

Between 2007 and 2009, the Legislative Council in Hong Kong had passed a series of amendments in relation to law controlling domestic violence. The two most controversial provisions include (1) introduction of court mandated counseling; and (2) extension of protection to Tongzhi' ${ }^{1}$ couples. In 'Politicizing Han Chinese Masculinities: A Plea for Court Mandated Counseling for Wife Abusers in Hong Kong', 2 and 'Contextualizing the Same-sex Erotic Relationship: Post-colonial Tongzhi and Transgender Political Discourse on Hong Kong and PRC Law of Marriage',3 I had argued that both court mandated counseling and legal recognition of Tongzhi couples have no inherent conflict with Han Chinese traditional culture and thus can work effectively in Hong Kong, a predominately Han Chinese society. However, two questions remain unanswered: (1) Is Han Chinese traditional culture still influential and relevant in 21 st century Hong Kong society? (2) Can the 2008 -- 2009 amendments produce justice? In this article, I adopt the Deleuzean perspective on time / history and Rawlsian theory of justice in responding to the questions. Also, I will refer to the theory of 'transcultural simularity' when examining how the foreign theories can engage smoothly with Hong Kong legal culture. I also hope the following discussion can shed light on the future development of legal device controlling domestic violence in Mainland China. Let us start with discussing the details of amendments.

\section{Hong Kong anti domestic violence law reform in 2008 and 2009}

Before 2008, a victim of domestic violence can apply for injunction orders under Domestic Violence Ordinance ${ }^{4}$, the court may, on the application of an abused party to the marriage, grant an injunction. The injunction can (1) restrain the other party from molesting the applicant and / or any child living with the applicant; and / or (2) exclude the other party

\footnotetext{
${ }^{1}$ In Chinese, 'TongZhi' includes two words - 'Tong' (同) means the 'same' and 'Zhi' (志) connotes 'beliefs (of anti-heterosexism)'; 'TongZhi' therefore signifies all people who share and stand up for the problematization of heterosexism. See Chiu, Man-chung (2001b).

${ }^{2}$ Chiu, Man-Chung (2001a).

${ }^{3}$ Chiu, Man-Chung (2001b).

${ }^{4}$ Cap 189, LHK.
} 
from the matrimonial home, or from a specified part of the matrimonial home, ${ }^{5}$ or from a specified area whether or not the matrimonial home is included in that area (like the applicant's place of work and her / his parent's apartment). In 2008, a series of amendments were introduced and one of the most important amendments is the introduction of court mandated counseling - in other words, after the amendment, the court can order the abuser to attend counseling programme (for example, anger management). And, in 2009, another significant amendment was passed, under which the Tongzhi couples can also apply for injunctions. ${ }^{6}$ Since Tongzhi couples do not enjoy the right to marriage, and the Ordinance no

${ }^{5}$ Matrimonial home means 'a home in which the parties to a marriage ordinarily reside together whether or not it is occupied at the same time by other persons.' (Section 2(1)) The order has no relation with the property rights. In other words, a cohabitant, who has no proprietary right, can also apply to exclude her/his partner, who is the owner of the place. Before the amendment introduced in 2008 and 2009, the orders which an abused party can apply included: ' 1 (a) a provision restraining that other party from molesting the applicant; (b) a provision restraining that other party from molesting any child living with the applicant; (c) a provision excluding that other party from the matrimonial home, or from a specified part of the matrimonial home, or from a specified area whether or not the matrimonial home is included in that area; (d) a provision requiring that other party to permit the applicant to enter and remain in the matrimonial home or in a specified part of the matrimonial home, whether or not any other relief is being sought in the proceedings.' After the amendments, the order available include '(a) a provision restraining the respondent from molesting the applicant; (b) a provision restraining the respondent from molesting any specified minor; (c) a provision prohibiting the respondent (i) (where the applicant has been molested by the respondent) from entering or remaining in - (A) the residence of the applicant; (B) a specified part of the residence of the applicant; or (C) a specified area whether or not the residence of the applicant is in that area, whether or not the residence is the common residence or matrimonial home of the applicant and the respondent; (ii) (where the specified minor has been molested by the respondent) from entering or remaining in - (A) the residence of the specified minor; (B) a specified part of the residence of the minor; or (C) a specified area whether or not the residence of the minor is in that area, whether or not the residence is the common residence of the minor and the respondent; (d) a provision requiring the respondent to permit - (i) (where the applicant resides with the respondent) the applicant to enter and remain in the common residence or matrimonial home of the applicant and the respondent or in a specified part of such common residence or matrimonial home; or (ii) (where the specified minor resides with the respondent) the minor to enter and remain in the common residence of the minor and the respondent or in a specified part of such common residence, whether or not any other relief is being sought in the proceedings. (1A) A court may in an injunction containing a provision mentioned in subsection (1)(a) or (b) include a provision requiring the respondent to participate in any programme, approved by the Director of Social Welfare, that is aimed at changing the attitude and behaviour that lead to the granting of such injunction.'

${ }^{6}$ Before the amendment introduced in 2008 and 2009, only parties to marriage and their children can apply for injunction order under the Ordinance. (Section 3) Under the amended Ordinance, the following person can apply for injunction: '(a) the applicant's father, mother, grandfather or grandmother (whether natural or adoptive); (b) the applicant's step-father, step-mother, stepgrandfather or step-grandmother; (c) the applicant's father-in-law or mother-in-law who is the natural parent, adoptive parent or step-parent of the applicant's spouse; (d) the applicant's grandfather-in-law or grandmother-in-law who is the natural grandparent, adoptive grandparent or step-grandparent of the applicant's spouse; (e) the applicant's son, daughter, grandson or granddaughter (whether natural or adoptive); (f) the applicant's step-son, step-daughter, step-grandson or step-granddaughter; (g) the applicant's son-in-law or daughter-in-law who is the spouse of the applicant's natural child, adoptive child or step-child; (h) the applicant's grandson-in-law or granddaughter-in-law who is the spouse of the applicant's natural grandchild, adoptive grandchild or step-grandchild; (i) the applicant's brother or sister (whether of full or half blood or by virtue of adoption); (j) the brother or sister (whether of full or 
longer only protects people within the familial relationship network, the Ordinance is retitled 'Domestic and Cohabitation Relationship Violence Ordinance.'

\section{Time is always out of joint: Is the past always with us?}

I support the amendments, not only because they can effectively control the wrongdoing, but also because they can effectively engage with Han Chinese traditional culture. However, in 2007, during a conference '21 st Century Sex and Gender in Greater China: A Roundtable', Professor Angela Wong of Chinese University of Hong Kong posed me a question: Is HanChinese tradition still relevant in Hong Kong nowadays? Why? I at that time put forward numerous pieces of evidence (for example: Chinese traditional medical practice and FengShui (風水) - Han Chinese traditional environmental science - are still widely referred today in Hong Kong) showing how important and vital Han Chinese tradition is in contemporary Hong Kong society. In the following section, adopting the Deleuzean philosophical paradigm, I will construct a more sophisticated philosophical framework in creating the relevance of traditional culture.

When the academics question the significance of Han Chinese traditional culture in contemporary Hong Kong Society, they assume that heritage is a contextual product and since Hong Kong today is obviously very different from Han Chinese traditional society, Han Chinese traditional culture is no longer applicable in current society. Underlying their argument is a linear model of time: time is a join up of numerous 'instants' -- it links or glues distinct moments of experience in fixed uni-direction, i.e. the model of 'past $\rightarrow$ present $\rightarrow$ future'. Deleuzean philosophy challenges this way of thinking: as Todd May elaborates, if time is made up of 'instants', then it should be divisible into different units (years, months, days, hours...), otherwise present cannot be grasped; but instant at the end is always indivisible, because 'however thinly we slice the instant of the Now [instants], we can always slice it thinner. ${ }^{\prime 7}$ In other words, present can never be caught as some academics want and assume.

The Deleuzean school argues that it is not the movement or moment which produces and derives time, but vice versa - time creates and invents movements, since time is a 'becoming' which is made up of 'durations'. 'Duration' is different from 'instant': the

half blood or by virtue of adoption) of the applicant's spouse; (k) the applicant's step-brother or stepsister; (l) the step-brother or step-sister of the applicant's spouse; (m) the applicant's uncle, aunt, nephew, niece or cousin (whether of full or half blood or by virtue of adoption); (n) the uncle, aunt, nephew, niece or cousin (whether of full or half blood or by virtue of adoption) of the applicant's spouse; or (o) the spouse of any person mentioned in paragraph (i), (j), (k), (l), (m) or (n). Whether a couple who have not married are qualified to apply injunction are determined with regard to the following criteria: (a) whether the parties are living together in the same household; (b) whether the parties share the tasks and duties of their daily lives; (c) whether there is stability and permanence in the relationship; (d) the arrangement of sharing of expenses or financial support, and the degree of financial dependence or interdependence, between the parties; (e) whether there is a sexual relationship between the parties; (f) whether the parties share the care and support of a specified minor; (g) the parties' reasons for living together, and the degree of mutual commitment to a shared life; (h) whether the parties conduct themselves towards friends, relatives or other persons as parties to a cohabitation relationship, and whether the parties are so treated by their friends and relatives or other persons.' (Section 3B)

${ }^{7}$ May, Todd (2005: 41). 
former, as it is constituted by mental activities (perception and memory), can be divided. Whenever 'duration' is divided, it changes, because how it is divided can be both a cause and effect of mental activities, which never stop and can never be forever consistent or totally predictable. Gilles Deleuze writes:

Duration divides up and does so constantly...but it does not divide up without changing in kind, it changes in kind in the process of dividing up: this is why it is a nonnumerical multiciplicty. ${ }^{8}$

Duration, being a product of mental activities, contains both continuity and differences. Cliff Stagoll gives the best illustration: '[m]ental states flow together as if parts of a melody, with previous notes lingering and future ones anticipated in the unity of a piece...To try and grasp this flow as a complete set of notes is pointless, because the music is always on the verge of ending and always altered by the addition of a new note. ${ }^{9}$ Deleuze also proposes that time / 'duration' progresses, not in a linear direction, but by continuously fissioning into past and present, ${ }^{10}$ because past needs to be there for present to pass into past. Put simply, past and present constitute themselves at the same duration.

...if the present can pass away, it is because, in some sense, it is already past or has a past element to it. In other words, every present must have a past aspect in order for it to pass away. ${ }^{11}$

When a present, together with a past, passes away, it becomes a past event for forthcoming present (ie. the new present / future). The difference between past and present, however, must exist; otherwise, the passing cannot occur. So what is the difference? Deleuze argues that past is virtuality, and present actuality, as we are experiencing it. Please note: it is not a dichotomy of past / virtuality vs. present / actuality; in fact, when present passes into past, past also engages (not mixes) with present at the same duration -- past actualizes and becomes part of the present.

The present and former present are not, therefore, like two successive instants on the line of time; rather, the present one necessarily contains an extra dimension in which it represents the former and also represents itself. ${ }^{12}$

History, a concept produced by past, as argued by Elizabeth Grosz, is thus still influential contemporaneously through 'its capacity to link to and thus to inform the present.' 13 When (part of) past actualizes, it is becoming the line of social force in a 'duration' and 'conditions all the experience that we have since actual experience is a composite of the virtual natural natures of perception and memory.'14 It does not mean present is only a reconstitution of history / past; in fact, the entirety of past and history always coexists with present. That is why Dean Tipps stresses that tradition is an integral part and product of modernity (present). $\cdot{ }^{15}$ Nonetheless, present, which is always together with past and history, can always be innovative and create new -- a (forthcoming) present must be absolutely new, since once

\footnotetext{
${ }^{8}$ Deleuze, Gilles (1991: 42).

${ }^{9}$ Sagoll, Cliff ‘Duration (Duree)' in Parr, Adrian (ed) (2005: 79).

${ }^{10}$ Bryant, Levi (2008: 114).

${ }^{11}$ Williams, James (2003: 94).

${ }^{12}$ Deleuze, Gilles (1994: 80).

${ }^{13}$ Grosz, Elizabeth (2005: 102).

${ }^{14}$ Due, Reidar (2007: 31).

${ }^{15} \mathrm{Fu}, \mathrm{Zi}$-tang (2008: 297)
} 
whenever a present passes into past, a new present (the forthcoming present) is created.16 Xing-jian $\mathrm{Hu}$ also proposes: the traditional legal system structures our current concept of justice. ${ }^{17}$

Time is, put simply, according to Deleuze, not only an objective and transcendental scale that exists outside human life, 18 but a circular and folding motion of duration (past $\leftarrow$ (falling into) present 1 => (forthcoming) present 2 (falling into) $\rightarrow$ past [+ present 1]). Deleuzean concept of duration sensitizes us to the multiple interpretations and constitutions of time, history, and memory.

Using this perspective, then Han Chinese traditional culture (past) in fact has never left us; it always exists with contemporary Hong Kong society (present), who is predominantly Han Chinese. The traditional culture could become the force of social control in our current society, but it does not forbid the current society from changing. In other words, whether the mechanism of court mandated counseling and acceptance of Tongzhi couple, originated from overseas jurisdiction, can engage with Han Chinese traditional culture and function in Hong Kong, a predominately Chinese society, must be considered in order to ensure or evaluate the effectiveness of the amendments.

Another problem is: although we have to take into account the Han Chinese traditional culture, another aim of reforming law is to maintain and produce justice. If harmony, as argued by some of academics and lawmakers, is the core value of Han Chinese traditional culture, ${ }^{19}$ then we have to understand, harmony may also be the contrary of justice -dispute, especially familial conflict, may be covered and ignored so as to maintain superficial peace of interpersonal relationship. In other words, the fact that the new provisions of Hong Kong anti domestic violence law can engage smoothly with traditional Han Chinese culture and function does not mean they can essentially bring just and fair consequences. So, are they just? And more importantly, what is justice?

\section{Imagine there will be no powerless: Can the reforms produce justice?}

In this section, I will investigate Han Chinese traditional cultural perspective on justice and examine if the newly introduced sections of law controlling domestic violence (ie. court mandated counseling and inclusion of same sex couples) is just. First, we have to define 'justice'.

In his groundbreaking monograph, A Theory of Justice, John Rawls argues that 'justice' starts with 'fairness', which means equal distribution of primary goods (i.e. rights, freedom, resources and self-respect) among multitude. ${ }^{20}$ And, even though inequality is always presumed, when it is accepted by the most marginalized / powerless in a society, it can become positive and productive under his theory. ${ }^{21}$

Drucilla Cornell, in The Imaginary Domain: Abortion, Pornography and Sexual Harassment, further substantiates Rawlsian theory of justice, and relates the theory with the Lacanian 'imaginary domain': According to Lacanian philosophy, imaginary relates to self projection

\footnotetext{
${ }^{16}$ Bryant, Levi (2008: 118).

${ }^{17}$ Quoted in Fu, Zi-tang (2008: 360). For more discussion in relation to $Y_{i} /$ justice, please see below.

${ }^{18}$ May, Todd (2005: 41).

${ }^{19}$ Chiu, Man-chung (2001a, 2001b).

${ }^{20}$ Rawls, John (1971: 62, 95); see also Jiang, Shan (2002: 31).

${ }^{21}$ Zhao, Dun-hua (1988: 151).
} 
/ introjection of (erotic) desire, which is vital in the re-construction of individual human subjectivity. In imaginary domain, one can fantasize oneself having indefinite and multiple identities. ${ }^{22}$ Prohibiting people from representing their desire in imaginary domain or imposing a particular socio-political-cultural model on others without mutual consent is a neglect and suppression of others' self-respect is simply a kind of subordination and dehumanization which is, according to Rawls and Cornell, unjust. ${ }^{23}$ They also agree that among all primary goods, self-respect is especially vital. ${ }^{24}$

Within the Rawlsian theory, there always exists a problem: if 'Veil of Ignorance' 25 can stop everyone from knowing and understanding exactly their respective and others' sociopolitical-cultural positions, how can people understand and feel the possible and unwilling discrimination, subordination and inequality faced and experienced by others and then willing to value and realize justice? The question can be answered by engaging the Lacanian concept of the imaginary domain with Rawlsian theory - as argued by Cornell, in the imaginary domain, a person is able to fantasize herself / himself becoming others, and feel how others feel in the contexts where they are situated. ${ }^{26}$

Applying the above principles in analysing the introduction of court mandated counselling and the inclusion of same sex couples in the sphere of protection, the first step is: we put ourselves into the shoes of victims of domestic violence and / or Tongzhi. Then we have to ask: are we (becoming the victims of domestic abuse and Tongzhi) the marginalized powerless in contemporary Hong Kong? Where the victims' rights to body and freedom and self-respect are neglected by the abusers when domestic violence happens, are they not oppressed and dehumanized? In Hong Kong, where the anti sexual orientation discrimination law and Tongzhi's rights to marry are absent, the Tongzhi's self-respect is peripherized. The recent reforms, which can provide increasing and effective legal protection, are of course welcomed and accepted by them and are thus just and fair.

\section{Engaging foreign concepts with Hong Kong culture: Where are the simularities?}

In order to transplant the Deleuzean perspective on time / history and Rawlsian theory of justice, philosophical products reproduced in Euro-American socio-political-social matrix, into Hong Kong, we need to develop a machine / a mechanism by which the import can carry out smoothly. ${ }^{27}$ The model of transcultural simularity, developed by Hsiao-hung Chang, can offer us with an efficient and functional paradigm to conduct effective transplantation.

Chang, in Fake Globalization, adopting Deleuzean theory of simulacrum, challenges the dichotomy of real / origin and fake / replica. Chang, in short, argues that an authentic original culture does not exist, and we can put the effort in locating the zones of possible

\footnotetext{
${ }^{22}$ Grosz, Elizabeth (2005: 73).

${ }^{23}$ Cornell , Drucilla (1995: 7-8).

${ }^{24} \mathrm{Hu}$, Shui-jun (2005: 9).

${ }^{25}$ According to John Rawls, in 'Original Position', people are covered by the 'Veil of Ignorance'; hence they only have the ordinary economic and political knowledge, they know nothing about 'real' social positions, resources under control and life plans of themselves and the others (Rawls, John 1993: 23).

${ }^{26}$ Cornell, Drucilla (2008: 136).

27 Any transplantation of law without being sensitive towards the possible conflict of cultures can lead to failure and / or postcolonial violence. That is why I argue that a very in-depth investigation of the cultural contexts need to be carried out before any transplantation of law. Chiu Man-chung (2010).
} 
similarities between cultures, i.e. simulacra. Chang goes on and advocates that dialogue between cultures can be viewed as the simularity between cultures - there are similarities, and simulations can occur between cultures.

Chang, in this context, produces the machine of transcultural similarity. ${ }^{28}$ According to Chang, the simularity is a virtual zone, where osmosis between cultures can be proactively conducted. In the mileau of the transcultural simularity, cultural concepts and related legal reform can be mutually infiltrated. ${ }^{29}$ How can the infiltration be carried out? The key, as I argued, is 'matching point' - we need to locate and create the points where transcultural simularity machine can function as the starting points of osmosis. ${ }^{30}$ We thus, in the context of anti domestic violence law, need to find out the matching points between the Deleuzean concept of time / Rawlsian theory of justice and Han Chinese traditional culture.

If we have to locate and construct the matching points, we have to understand how Han Chinese traditional culture engineers its perspectives on time / history and justice. Han Chinese traditional concept is a hybridity of different schools of thought, and we are going to put the focus on (Orthodox) Confucianism, (Orthodox) Daoism and Buddhism - which are considered as the mainstream of Han Chinese traditional culture. ${ }^{31}$

\subsection{Daoist and Confucian perspective on history: Medium of promotion?}

According to Lao $\mathrm{Zi}$, the philosopher believed to be the founder of (Orthodox) Daoism, Dao is the source and reference of everything, including nature and human society. ${ }^{32}$ Thus, Dao consumes the status of transcendental metaphysics.33 So, Dao is not only a philosophical perspective but also a cosmic force. Since Dao determines everything, action-less, i.e. 'letting things work to their perfection naturally', becomes one of the thematic principle of Lao Zi's ideology. ${ }^{34}$

(Orthodox) Confucianism, produced and advocated by Confucius and Mencius during Zhou (周) Dynasty (BC 1066 - BC 221), advocates the importance of Ren -- good being / benevolence, which is derived and considered as the most important guideline of Confucian interpersonal politics, since harmonious interpersonal relationship enjoys a very high status in Confucianism. ${ }^{35}$ Familial relationship is always the centre of Ren: Ren starts with filial piety and extends to other interhuman relationships. It is in this context where (Orthodox) Confucians formulate the famous five Constant Virtues (benevolence between father and son, righteousness between emperor and ministers, differences between husband and wife, hierarchy between elder and the young, fidelity between friends), the core of $L i$ (禮, social moral order), to engineer Ren's smooth operation. ${ }^{36}$ The principles formatted a highly hierarchical society, which stressed harmony, in imperial China.

\footnotetext{
${ }^{28}$ Chang, Hsiao-hung (2007: 20, 68, 73)

${ }^{29}$ Chiu, Man-chung (2008).

30 Chiu, Man-chung (2010).

${ }^{31}$ Chiu, Man-chung (2008).

${ }^{32}$ Wang, Ze-ying (2003: 98); Wang, Qing-jie (2004: 149).

${ }^{33} \mathrm{Ng}$, Yu-kwan (1998: 2).

${ }^{34}$ Koller, John (2002: 288).

${ }^{35}$ Please note that ren was not invented by Confucians, it is said to have existed before Confucius' ${ }^{\prime}$ time. However, it was Confucius who transformed it into a virtue achievable by man (i.e. human being), broadened it to become a comprehensive virtue covering all individual Confucian virtues, and finally elevated it to become the centre of his philosophy.' (Ling, D W 1995: 73).

${ }^{36}$ Tang, Kai-lin \& Zhang, Huai-cheng (2003: 76).
} 
Analyzing tradition and history from the perspective (Orthodox) Daoism and (Orthodox) Confucianism, philosophical historians always use the historic facts and issues as the tools or media to promote and market their philosophical ideals - for instance, Daoist would also praise Emperor Wen (漢文帝) of the West Han Dynasty (206 BC- 9 AD) as he adopted Daoist principle of action-less as his state policy: Book of Han writes: 'During his 23 year reign, there had been no further construction of palace, palace garden, vehicle and uniform...Emperor Wen also instructed that when he passed away...no royal burial chamber was allowed to be built.'37 (trans., 即位二十三年, 宮室、苑直、車騎、服禦無所增益……治霸陵, 皆瓦器, 不得以金、銀、銅

、錫為飾, 因其山, 不起㫩) Confucian academics appreciate those emperors who realized or recognized Ren during their reigns, for instance, Confucius himself always praised Emperor Yao (堯) - a legendary king - as he considered what Emperor Yao did establishes the highest standard of Ren: 'Great indeed was Yao as a sovereign! How majestic was he! It is only Heaven that is grand, and only Yao corresponded to it. How vast was his virtue! The people could find no name for it. How majestic was he in the works which he accomplished! How glorious in the elegant regulations which he instituted!'38 (trans., 大哉, 堯之為君也! 巍巍乎! 唯天為大, 唯堯則之。蕩蕩乎! 民無能名焉。巍巍乎! 其有成 功也; 焕乎, 其有文章!) When carefully examine the Daoist and Confucian perspectives on history, we will find that they are in fact taking historic fact (past) as the teaching examples for people in contemporary society (present). In other words, they are using the linear model of history, hence, it is impossible to have any simularity between Deleuzean perspective on time / history and Daoist / Confucian view on history - the latter cannot be the matching point for transplantation of philosophy.

\subsection{Buddhist perspective on time / history: Beyond past / present dichotomy}

One of the thematic principles of Buddhism is Karma, which indicates the mechanism by which what a human did and / or thought would determine her / his future action and / or status. ${ }^{39}$ It is not a kind of absolute destiny pre-determination, but a mechanism of choice and responsibility: one can choose her / his act / thought and would be held responsible for that. Karma, put simply, is the 'power by virtue of which cause is followed by effect.' 40 Daofa Song writes, for example, Emperor Wu Zhong (武宗) of Tang Dynasty (618 - 907 AD) decided to abolish Buddhism in AD 845, the incident is titled 'Hui Chang Buddhism Abandonment' (會昌滅佛). In AD 846, someone saw two deities, dressed in official uniform, came out from a tomb. The person asked why they came to human world, and the deities said: because Emperor Wu Zhong abandoned Buddhism, his life had been cut short and he would pass away very soon. Three days later, Emperor Wu Zhong died suddenly. ${ }^{41}$ The parable, which is extremely Buddhist-centric and aims at creating the sacredness of Buddhism, indicates that bad activities (leaving and abandoning Buddhism) will certainly bring bad consequences (early death) of a person; and even emperor cannot escape.

\footnotetext{
37 'Annals of Emperor Wen', Book of Han (http://www.guoxue.com/shibu/24shi/hansu/hsuml.htm 22 March 2011).

${ }^{38}$ Chapter 8, The Analects of Confucius (http://www.yellowbridge.com/onlinelit/analects08.php accessed 22 March 2011).

${ }^{39} \mathrm{Hu}$, Xiao-guang (1999: 9).

${ }^{40}$ Tom Sun (1998: 3).

${ }^{41}$ Song, Dao-fa (2009: 203).
} 
The interaction between human and the common sense world constitutes the Karmic seeds - bija, which are stored in alaya-vijnana, the storehouse-consciousness which is a timeless concept, determines the forthcoming interaction between human and the common sense world. ${ }^{42}$ Alaya-vijnana 'collects and stores the effects or bija of experience until they mature and give rise to new experiences.' ${ }^{43}$ As Karma is a non-stop accumulation and depletion, the production and attrition of bija never ends. Every decision and action of human subject influences the nature of bija production: When a particular set of bija becomes mature and consumed under a particular material environment, other bija and another context is manufactured. 44

Buddhist theory of Karma offers a philosophical perspective which describes how past (action / thought) and present (forthcoming action / thought) intermingle in detail, although it mainly aims at elaborating and reconstructing the interaction between human action / thought and the constitution of her / his subjectivity. Put simply, the concept goes beyond the binarism of past vs. present. Karma also offers a perspective explaining how past can be actualized in present via bija activities - Buddhism thus is able to offer another model in understanding how past can become the social control force in Han-Chinese traditional culture. This Buddhist mechanism, in short, is very similar to and can simulate interactively with Deleuzean concepts of time, i.e. fission of time into past and present and past folding with present. Buddhist Karma hence can be used as a matching platform for the successful and smooth transplantation of Deleuzean concept.

\subsection{Absence and presence of equality: Is there any justice in Han-Chinese culture?}

In contemporary Han Chinese language, justice is translated as $Y i$ (義). However, $Y i$, does not start with equality but harmony. 45 This is why Duan Lin says: in ancient China, there was no justice (which starts with equality), but $Y_{i}$ (that emphasizes harmony and appropriateness). ${ }^{46}$ In this section, I will investigate if Lin's statement is valid.

We can again start with (Orthodox) Daoism. (Orthodox) Daoists are generally believed that they will view $Y i$, as a human product, violates the principle of action-less and thus Dao. ${ }^{47} \mathrm{In}$ (Orthodox) Confucianism, Yi always assumes a vital role: 'The superior man considers $Y i$ as the most important.' 48 (trans., 君子義以為上) Both Confucius and Mencius advocate that $Y i$, a natural product of Ren and $L i$, i.e harmonious hierarchical interpersonal network, ${ }^{49}$ aims at

\footnotetext{
42 The mechanism will be further elaborated below.

${ }^{43}$ Koller, John (2002: 222).

${ }^{44}$ Yang, Wai-zhong (2007: 298-299).

${ }^{45} \mathrm{Hu}$, Shui-jun (2005: 12); Jiang, Shan (2002: 38).

${ }^{46}$ Lin, Duan (2007: 437).

${ }^{47}$ Wang, Ze-ying (2003: 23, 43). According to Lao Zi, the philosopher who is widely believed to be the founder of the school, Dao is the origin and reference of everything, including human, society and culture. Thus, Dao consumes the status of ultimate and transcendental metaphysics. For details, please see Wang, Ze-ying (2003: 98) and Wang, Qing-jie (2004: 149). However, Guu-ying Chen has another interpretation, he points out that, $L a o \mathrm{Zi}$ does not object $Y i$, provided that it is derived from Dao. Please see Chen, Guu-ying (2001).

${ }^{48}$ Chapter 17, The Analects of Confucius (http://www.ccnt.com.cn/wisdom/rujia/lunyu/lunyu3.htm accessed 22 March 2011).

${ }^{49}$ Book 2, Tso Commentary to Spring and Autumn Annals

(http://www.guoxue.com/jinbu/13jing/cqzz/cqzz_ml.htm accessed 22 March 2011); see also Zhu, Yi-ting (ed) (2005: 24). For the definition and discussion of Ren and Li, please see Chiu, Man-chung (2006).
} 
maintaining the operation of the hierarchical social structure.50 The two most important elements of $Y i$, in the discourse of Ren and Li, are Zhong (忠) and Shu (恕). Zhong, according to Confucius, is 'a matter of going on to establish other people because one seeks to establish oneself, and of bringing other people to perfection because one desires perfection for oneself'51 (trans., 已欲立而立人, 已欲達而達人), i.e. faithfulness; and Shu means ' $[\mathrm{w}] \mathrm{hat}$ you do not wish for yourself, do not do to others'52 (trans., 已所不欲, 勿施於人), i.e. forbearance. $Y i$, hence, in sum, signifies an extension of oneself to the others, ${ }^{53}$-- there is others in one self, and a self in the others: 54

People all have things that they will not bear. To extend this reaction to that which they will bear is benevolence. People all have things that they will not do. To extend this reaction to that which they will do is righteousness [i.e. Yi]. ${ }^{55}$ (trans., 人皆有所不忍, 達之於其所忍, 仁也; 人皆有所不為, 達之於其所為, 義也。)

Mencius further elaborates Confucius's perspective on $Y_{i}$; he takes $Y_{i}$ as the ultimate standard of human performance: ' $Y i$ is people's correct road.' 56 (trans., 義, 人之正路也); and connects $Y i$ with individual self-respect: 'There is nature's nobility and human nobility. Being benevolent, dutiful, loyal, and trustworthy; enjoying the good without tiring - these are nature's nobility. Dukes, ministers, and great men - these are human nobility.' 57 (trans., 有天爵者, 有人爵者。仁義忠信, 樂善不倦, 此天爵也; 公卿大夫, 此人爵也。古之人修其 天爵, 而人爵從之。今之人修其天爵, 以要人爵; 即得人爵, 而書其天爵, 則惑之甚者也, 終亦必亡而已矣。) What Mencius means is: self-respect is the result of self discipline and self practice; and it must be protected, preserved and emphasized by $Y i$ : 'Life is also something I want, and righteousness [i.e. Yi] is also something I want. If I cannot get both of them, I am one who will do without life and choose righteousness [i.e. Yi].' (trans., 生亦我所欲也, 義亦我所欲也; 二者不可得兼, 舍生而取義者也。)'58

Juxtaposing Rawlsian / Cornell's theory of justice and Han Chinese traditional cultural concept of $Y i$, we can locate the transcultural simularities, i.e. an effective transplantation platform, between two ideologies: both are using $Y_{i} /$ justice as the standard of human behaviour evaluation. The second matching point is self-respect: both Rawlsian / Cornell's theory and Mencius's perspective stress the nurture, protection and promotion of individual self-respect. Cornell's respect of individual desire also echoes with (Orthodox) Confucian concept of 'putting oneself into others' shoes': 'If you don't want others to impose their choice on you, should you not do the same to others?' Also, Cornell's interpretation of imaginary domain supplements Confucius's concept of Shu: only if one can imagine what

\footnotetext{
${ }^{50}$ Pan, Li-ping (2006: 45).

${ }^{51}$ Chapter 6, The Analects of Confucius (http://www.wfu.edu/ moran/zhexuejialu/Analects_PEM.html accessed 22 March 2011).

${ }^{52}$ Chapter 12, The Analects of Confucius (http://plato.stanford.edu/entries/confucius/ accessed 22 March 2011).

${ }^{53}$ Zhu Zi Zhu Zi's Explanation to Zhong Yong (中庸章句集注)

(http://www.millionbook.net/gd/z/zhuxi/000/001.htm accessed 22 March 2011).

${ }^{54}$ Wang, Qing-jie (2004: 246).

${ }^{55}$ Chapter 14, Mencius (http://faculty.vassar.edu/brvannor/mengzi.html accessed 22 March 2011).

${ }^{56}$ Chapter 4A, Mencius (http://www.tianyabook.com/gudian/mengzi.htm accessed 22 March 2011).

${ }^{57}$ Chapter 6A, Mencius (http://www.tianyabook.com/gudian/mengzi.htm accessed 22 March 2011).

${ }^{58}$ Chapter 6A, Mencius (http://fsrcenter.blogspot.com/2009/02/fish-and-bears-palm_14.html accessed 22 March 2011)
} 
may happen to others (for example, the marginalized powerless), s/he can understand and feel the vitality of respect and accepting (not simply tolerating) differences; this attitude and technique can certainly assist a person to avoid (unconsciously and / or unintentionally) imposing her / his agenda and value judgement on others within the interpersonal politics network.

The problem, however, is: $Y i$, which is developed in imperial China, is used to restrengthen and reconstruct the social hierarchy and hence inequality. In other words, equality, an essential element in producing Rawlsian / Cornell's theory, is not a factor in the formation of $Y i$ in Han-Chinese traditional culture. Again, it seems Buddhism can fill the gap.

According to Vasubandhu, a significant Buddhist philosopher, there are eight vijnana / consciousnesses: the five consciousnesses respond respectively to visual perception, auditory perception, olfactory perception, gustatory perception, tactile perception (the five senses), mano-vijnana (mind-consciousness), mana-vijnana (ego-consciousness) and alayavijnana. Samdhinirmocana-sutra states that the first five vijnana are indeed the consciousnesses of the senses which create the biological human body, and mano-vijnana is responsible for individual moral determination and connection between a person and the common sense world. ${ }^{59}$ Alaya-vijana, as mentioned above, which is the storehouse of bija, reproduces and sustains the other seven consciousnesses. ${ }^{60}$

The interaction among the performances of the eight vijnana is a loop of production and constitutes the (virtual) subjectivity of human. The interactive production of body and the world -- the Karma mechanism - continuously produces / consumes bija and maintains alayavijnana, as discussed above. Please note: Karma cannot totally predetermine what is going to happen in the forthcoming duration, as Karma always creates new bija, thus new and unpredictable interaction between human; and unforeseeable interaction human and common sense world are allowed and encouraged. According to this analysis, enactment of new law (for example: the amendment of anti domestic violence law and introduction of court mandated counseling) would 'perfume' (薰習), or affect, the nature of existing and forthcoming set of bija. Karma hence leads to one of the most important Buddhist ideologies, 'Dependant-arising thus Emptiness of Self Nature' (緣起性空). It describes the mental constitutive reception of every activity and phenomenon that can never be a fixed and universal essentiality, but a virtuality recreated and re-newed by the non-stop Karma machine and bija exercise (for example, consequences of perfume) under a milieu -- a forever changing set of connections between desire (needs and request of justice) and social force (for example, enactment of new law), which itself can be a (new) product of bija activity.

This line of argument devises and formulates another two important Buddhist principles: (1) 'Non-Insistence' (諸法無我) or 'Self-less-ness (Anātman)', 'self' in this context does not only mean ' $\mathrm{I}$ ', but over-insistence of any philosophical perspective; 61 and (2) 'Non-Permanence' (諸行無常): since human body and subjectivity cannot be preset and can be changed, due to the karma, bija exercise and perfume, there is no forever eternality and essentiality in common sense world. In other words, since the composition of bija goes on changing, it is impossible to have any monolithic and universal subjectivity / self; and if the common sense world, the related activities and phenomena are only and partly a psychological product, initiated by a set of bija and end up with the production of another cluster of bija, any metanarrative is only a virtuality.

\footnotetext{
${ }^{59}$ Powers, John (1995).

${ }^{60}$ Yang, Wai-zhong (2007: 288).

${ }^{61}$ Chan, Stephen (2005: 25).
} 
The two principles, 'Non-Insistence' and 'Non-Permanence', are part of the Buddhist 'Correct Law' (Prävaccana), i.e. the most important beliefs in Buddhist philosophy. ${ }^{62}$ It is therefore not surprising when Saakyamuni developed and advocated the theory of equality, since everything is not fixed, every identity / subjectivity is not fixed and monolithic, thus any kind of hierarchy cannot exist forever thus becomes meaningless:

Within my Dhamma, the 4 clans -- (1) priestly, (2) military and ruling, (3) farmers and traders, and (4) serfs... would all drop their original titles and are called 'Shih' students of Buddha. 63

Buddhist emphasis on equality becomes a platform for the exercise of transcultural simularity, and can be utilized as a matching point for the import and transplantation of Rawlsian / Cornell's conception of justice. ${ }^{64}$ Buddhist machines of Karma and perfume have also constructed a theoretical framework by which we can understand and investigate how new laws can change and re-new human and society. 65

\section{Conclusion: Implication for mainland Chinese legal development}

I always emphasize that it is not my intention to propose that 'Hong Kong Culture = traditional Han Chinese culture = Orthodox Confucianism + Orthodox Daoism + Buddhism': if a traditional cultural concept is a virtuality, and becoming, as argued by Deleuze, then an authentic original notion of culture simply does not exist. Please also note: even if transcultural simularity is proactively created and / or located, and transplantation can be carried out, whether the new concept / law can reach its scheduled and planned effect and outcome cannot be predicted or guaranteed - transcultural simularity only promises the possibility of successful transplantation; it cannot guarantee the effect and outcome. 66

However, one question remains: If Buddhism can be used as a philosophical paradigm for analyzing the effect and status of Han Chinese tradition in contemporary Hong Kong and producing justice, why do we still need to import the foreign support? Why don't we simply utilize the materials we already have? The answer is: In the case of interpreting and understanding tradition at present, Buddhist theories of Karma and bija are mainly used to understand how human subjectivity is reconstructed and problematized - in the example I quote above, the parable was used to demonstrate how Karma can work on a person: even when the Emperor, who was usually called 'Son of Heaven', had done something against Buddhism, he would be punished by his own decision and action - Buddhism has not frequently used the Karma machine to investigate how culture and tradition work contemporarily. We therefore need the Deleuzean perspective to sensitize Buddhist theory towards how it can be used in deterritorializing the connections between time and history. And, in relation to justice, as Guu-ying Chen sharply points out, there is a lack of critical perspective within Han Chinese traditional culture.67 In other words, there is no

\footnotetext{
${ }^{62}$ Quoted in Li Cun-shan (2009: 440).

63 Taisho Tripitaka Editorial Committee (1985) Vol. 22.

${ }^{64}$ However, I have to emphasize that there are a number of very discriminatory practices within Buddhism, for example: transgender are not allowed to practise fully Buddhism, and Buddhist nuns (bhilsuni) cannot enjoy same status with male monks (bhiksu). The practices nonetheless are now under serious challenges in Taiwan. Please see Shih Chao Hui (2002) and Yang, Hui-nan (2002).

65 For discussion on perfume and Buddhist jurisprudence, please see Chiu Man-chung (2007, 2009).

${ }^{66}$ Chiu, Man-chung (2010).

${ }^{67}$ Chen, Guu-ying (1988: 1).
} 
philosophical perspective that develops a strategy to challenge injustice. Since (Orthodox) Confucianism is developed in the discourse of harmony, where conflicts are devalued, how can they develop an effective strategy to challenge injustice?68 This viewpoint is especially loomed large due to the hegemony of harmony in the cultural construction of legal perspective - harmony is the prime principle and it never encourages people to use litigation to resolve conflicts. While Daoism stresses 'action-less' and Buddhism emphasizes equality, have they said anything on the motivation / intention of challenging inequality and producing justice? Transplanting Rawlsian / Cornell's theory of justice can certainly help connect Buddhist equality with the possible development of justice in Hong Kong.

In this article, I have developed a line of argument, according to which, when making new policy and enacting new law, the stakeholders have to take into account the Han Chinese traditional culture when considering if the law controlling domestic violence in Hong Kong should adopt court mandated counseling as a device to reform the behavior of the perpetrator and include Tongzhi couples as part of the protection targets: as I argued elsewhere, since (Orthodox) Confucianism puts so much effort on maintaining and reproducing interpersonal harmony in the context of social hierarchy -- - as Confucius said: 'For judging law suits I share the same position with others. What I insist upon is to make it impossible for all law suits to arise '69 (tran., 聽訟, 吾猶人也。必也使無訟乎!) -- courtmandated counseling can certainly help re-constructing the familial harmony as it avoids directly sentencing the abusers in jail, and thus can be well accepted and engaged with Hong Kong Han-Chinese traditional culture. Also, because (1) sexual orientation does not play any role in Confucian philosophy of harmony, (2) when Daoism advocates action-less and therefore would only object excessive and non-essential regulation of sexuality and sexual orientation, and (3) as one of the most important Buddhist principles is equality, Buddhism certainly rejects any proposition of not embracing Tongzhi in the orbit of protection; the revision of Hong Kong anti domestic violence law by which Tongzhi couples are now protected from domestic violence can, like the introduction of court-mandated counseling, will not be strongly resisted by Han-Chinese traditional cultural perspective. ${ }^{70}$

Putting the focus on the possible legal device controlling domestic violence in Mainland China - like Hong Kong, Mainland China is dominated by race of $\mathrm{Han}^{71}$-- we can find that besides two provisions in Mainland Chinese Criminal Law which prohibit people from abusing their marital partners, and one similar article under Marriage Law, ${ }^{72}$ there is an absence of law which particularly deals with domestic violence. Anti Domestic Violence Network, an organization under China Law Society, has together with a team of law and

\footnotetext{
${ }^{68}$ Chen, Ying-xun (2004: 215).

${ }^{69}$ Chapter 8, Great Learning (http://www.en84.com/article-4277-1.html accessed 22 March 2011).

${ }^{70}$ Chiu, Man-chung (2001a, 2001b).

71 According to the Consensus conducted in 2007, the population of Han in Mainland China is $1,182,950,000,90.56 \%$ of the total population.

${ }^{72}$ Art 260 of PRC Criminal Law (刑法); which writes that vicious abuse of family members amounts to a criminal offence, the offender may be subjected to $2-7$-year imprisonment. It is the so called 'offence of (domestic) maltreatment' (虐待罪). Art 182 of the PRC Marriage Law (婚姻法) also includes the same stipulation. 'Vicious' in this context means that the maltreatment (1) has an immoral intention; or (2) is conducted in a grave manner; or (3) continues for a long period of time; or (4) is imposed on a minor, elderly, pregnant woman. 'Maltreatment' refers to physical abuse and psychological abuse. It, therefore, seems that spousal abuse would not be considered as a vicious maltreatment. For details, please see Chiu, Man-Chung (2006).
} 
social science academics, drafted 'Law of the People's Republic of China on the Prevention and Punishment of Domestic Violence - A Draft Proposal' (hereafter 'Draft') in 2010. The Draft, like the Hong Kong law, suggests the issue of court orders in relation to nonmolestation (Art 36), exclusion (Art 54), and court mandated counseling (Art 22). But the Draft is more ambitious and aggressive as it does not only concern the legal status of victim shelter (Art 20), it also sets up the compulsory reporting system and makes the education institutions and medical service providers responsible (Art 31 and 32). Besides, the Draft also suggests a further emphasis on domestic violence related criminal offences (Part 3). When discussing the possibilities of implementing the Draft effectively and efficiently, and if it is accepted by the Government and National People's Congress, the academics argues that the local and indigenous experience produces a very strong foundation for successful exercise of the Draft (and possible future law) (page 8, the Draft). Nonetheless, the Draft does not offer a very clear definition of the local and indigenous experience - does it also mean the culture and tradition? If yes, then, like the dialogue between Hong Kong law and Han-Chinese traditional culture, how the Draft (and possible future law) can engage with the traditional culture must be investigated and examined carefully. The following questions hence must be answered: In Mainland China, will criminalization and compulsory reporting of domestic violence welcomed by the society and work effectively? In other words, will reporting domestic violence to police, either by the victims or other professionals (like medical practitioners), be taken as a further violation of social harmony (on top and above the damaged familial relationship), including neighbourhood and interpersonal relationship at work? Provided that Rawlsian / Cornell's justice is still new and is not yet fully engaged with Mainland (Han-)Chinese society, can the implementation of law, without the evaluation of a sophisticated perspective of justice, help to solve the problem of domestic violence and reveal the suppression of powerless? It seems, whether law can be an effective means to control domestic violence in Mainland China, still needs to be further explored and discussed.

\section{References}

\subsection{English}

Bryant, Levi (2008) Difference and Givenness: Deleuze's Transcendental Empiricism and the Ontology of Immanence United States of America: Northwestern University Press.

Chiu, Man-chung (2001a) 'Politicizing Han-Chinese Masculinities: A Plea for Court Mandated Counselling for Wife Abusers in Hong Kong' Feminist Legal Studies 1-25.

Chiu, Man-chung (2001b) 'Contextualizing the Same-sex Erotic Relationship: Post-colonial Tongzhi and Transgender Political Discourse on Hong Kong and PRC Law of Marriage' in Wintemute, Robert (ed) Legal Recognition of Same Sex Partnership: National Law, European Law and International Law London: Hart.

Chiu, Man-chung (2006) 'Negotiating Han-Chinese Legal Culture -- Postcolonial Gender Political Discourse on Hong Kong Small House Policy' 17 King's College Law Journal 45-70.

Chiu, Man-chung (2007) 'De / Sexing Law / Fa: Development of an lndigenous Theory of Sexuality Justice in Hong Kong' 37(3) Hong Kong Law Journal 775-803.

Chiu, Man-chung (2008) 'Harmonizing the Resistance, Resisting the Harmony: Development of an Indigenous Theory of Gender Justice in Hong Kong' (2008) 36(1) Asian Journal of Social Sciences 79-103. 
Chiu, Man-chung (2009) ‘Beyond colonialism: osmotic reconstruction of gender / sexual justice' 10(3) Inter-Asia Cultural Studies 399-421.

Chiu, Man-chung (2010) 'Going Beyond Globalization and Localization: Articulating a Theory of Justice in Han-Chinese Culture' 21 Law and Critique 93-110.

Cornell, Drucilla (1995) The Imaginary Domain London: Routledge.

Deleuze, Gilles (1991) Bergsonism New York: Zone Books.

Deleuze, Gilles (1994) Differences and Repetition New York: Columbia University Press.

Due, Reidar (2007) Deleuze Cambridge: Polity.

Grosz, Elizabeth (2005) Time Travels - Feminism, Nature, Power Durham: Duke University Press.

Ling, D W (1995) "Confucianism and English Common Law" 1(1) Journal of Chinese and Comparative Law 72-107.

May, Todd (2008) Gilles Deleuze: An Introduction Cambridge, UK: Cambridge University Press.

Parr, Adrian (ed) (2005) The Deleuze Dictionary United Kingdom: Columbia University Press.

Powers, John (trans.) (1995) Wisdoms of Buddha: Samdhinirmocana-sutra Berkeley: Dharma Publishing.

Rawls, John (1971) A Theory of Justice Cambridge MA: Harvard University Press.

Williams, James (2003) Gilles Deleuze's Difference and Repetition: A Critical Introduction and Guide Edinburgh: Edinburgh University Press.

\subsection{Chinese}

Chen, Guu-ying (陳鼓應) (2001) “The Renewal of the Taoist Tradition in Contemporary World" 37 Philosophical Forum 136-143.

Chiang, Hsiao-hung (張小虹) (2007) Fake Globalization (假全球化) Taiwan: Unitas (聯合文學).

Fang, Li-tian (方立天) (2008) Chinese Buddhist Culture (trans., 中國佛教文化) Hong Kong: Joint Publication.

Fu, Zi-tang (付子堂) (ed) (2008) Lectures on Jurisprudence (法理學講演錄) Vol. 3 Beijiing: Law Press.

Gong-Pi, Xiang (公丕祥) (2004) The Legal Modernization in China Beijing: China University of Political Science and Law.

Hu, Shui-jun (胡水君) (2005) Political Analysis of Law (trans., 法律的政治分析) Beijing: Peking University Press.

$\mathrm{Hu}$, Xiao-guang (胡曉光) (1999) 'Alaya-Vijnana: an Opinion (阿賴耶識芻議)' 4 Fa Yin (法音) 9.

Jiang, Shan (trans., 江山) (2002) Jurisprudence of InterpersonalIsomorphistic-structuralism (trans., 人際同構的法哲學) Bejing: China University of Political Science and Law.

Li Cun-shan (李存山) (2009) Study of Qi and Theory of Ren (trans., 氣論與仁學) Zhengzhou: ZhongZhouGuJi (中州古籍).

Lin, Dennis (2008) 'The Proscription of Online Male Queer Obscenity in Taiwan' in Yin-bin, Ning and Ho, Josephine (eds) Taking Pornography Seriously Jhongli, Taiwan: National Central University of Taiwan

Lin, Duan (林端) (2007) 'The Chinese traditional legal culture: Kadi justice or the Third Realm?' 6 Sino-western legal tradition (trans: 中西法律傳統) 425-453.

Lin, Wai-yi (trans., 林緯毅) (2004) The Engagement of Fai-ism and Confucianism (trans., 法儒兼容) Taipei: WenJin (文津). 
Shih, Chao Hui (釋昭慧) (2002) 'A personal explanation of a humanistic Buddhism practitioner (trans., 人間佛教行者的「現身說法」一從提倡動物權到提倡佛門女權) ' 173 Contemporary Monthly 62-71.

Song Dao-fa (宋道發) Research on Buddhist perspective on History (trans, 佛教史觀研究) Beijing: Religious Culture(trans., 宗教文化出版社).

Taisho Tripitaka Editorial Committee (trans. 大藏經刊行委員會) (1985) Vijnaptimatratasiddhisastra, Taisho Tripitaka (大正新修大藏經) Taipei: XinWenFeng (新文豊).

Wang, Ze-ying (trans., 王澤應) (2003) ZiRan Yu DaoDe Changsha: HuNan University Press.

Yang, Hui-nan (楊惠南) (2002) 'Tong Xin Fan Xing: Taiwan Buddhist Tongzhi Equal Rights Movement (trans., 童心梵行: 台灣佛教徒同志平權運動)' 173 Contemporary Monthly 30-51.

Yang, Wai-zhong (楊維中) (2007) A Research of the Nature of Mind of Chinese Buddhism (trans., 中國佛教心性論研究) Beijing: Religious Culture (宗教文化).

Zhao, Dun-hua (trans., 趙敦華) (1988) Rawls's Theory of Justice: a Comment (trans., 勞斯的正義論解說). Hong Kong: Joint Publication. 


\title{
The Impact of Globalization Determinants and the Health of the World's Population
}

\author{
Mario J. Azevedo and Barbara H. Johnson \\ School of Health Sciences, Jackson State University, Jackson, Mississippi, \\ USA
}

\section{Introduction}

Since the late 1970s, globalization has become a phenomenon that has elicited polarizing responses from scholars, politicians, activists, and the business community. Several scholars and activists, such as labor unions, see globalization as an anti-democratic movement that would weaken the nation-state in favor of the great powers. There is no doubt that globalization, no matter how it is defined, is here to stay, and is causing major changes on the globe. Given the rapid proliferation of advances in technology, communication, means of production, and transportation, globalization is a challenge to health and well-being worldwide.

On an international level, the average human lifespan is increasing primarily due to advances in medicine and technology. The trends are a reflection of increasing health care demands along with the technological advances needed to prevent, diagnose, and treat disease (IOM, 1997). Along with this increase in longevity comes the concern of finding commonalities in the treatment of health disparities for all people.

In a seminal work by Friedman (2005), it is posited that the connecting of knowledge into a global network will result in eradication of most of the healthcare translational barriers we face today. Since healthcare is a knowledge-driven profession, it is reasonable to presume that global healthcare will become more than just a buzzword.

This chapter looks at all aspects or components of globalization but focuses specifically on how the movement impacts the health of the people and the nations of the world. The authors propose to use the concept of health as a measuring stick of the claims made on behalf of globalization.

\subsection{Evolving perspectives on the globalization of health and analytical framework}

Although predicated on the premise that the global concept is new, it actually had its origins in the late 1800s. Religious foreign mission groups felt it was their spiritual calling to tend to the sick and afflicted in poor countries (Schroth \& Khawaja, 2007). The religious work of missions was closely linked to medical work. These missionaries believed that the services they provided were designed to reduce human misery and suffering, thereby elevating the status of God in the minds of people. Mission hospitals and mission doctors served as important points of entry of Western medicine into other countries, and were the hub of medical knowledge and practice.

Private healthcare facilities were established as part of the charitable mission. Even now, medical mission groups, such as Doctors without Borders and Heal the Nations, provide 
charitable medical care to the developing world. Subsequent innovations in healthcare have made it possible to bring patients from other countries into US hospitals for care that is not available in their home country. Specialists from US hospitals may also be utilized in countries that have no such physicians. For instance, Operation Smile, an international medical humanitarian organization, has a presence in over 50 countries (Magee, 2009). Their focus is surgical treatment of children with cleft lip and palate while providing the necessary medical training for local medical volunteers that will result in self-sufficiency for these communities. Often persons travel to the US to avoid delays in care due to long lines and waiting periods experienced in other countries that may have universal coverage.

Telemedicine is the exchanging of patient information through the Internet or cybertechnology. This ability allows healthcare professionals to communicate patient status regardless of distance (Goldbach \& West, 2010). Telehealth and teleconferencing have been used extensively for consulting with other professionals as well as reaching patients who live in rural or remote areas.

The most popular direction globalization has taken is in the area of medical tourism. This aspect involves patients choosing to leave one country for another in order to seek quality specialized care or major surgery at a reduced cost (Keckley \& Underwood, 2007; Goldbach \& West, 2010). Countries such as India, Singapore, and Thailand provide care such as cardiac surgery, joint replacements, and reconstructive surgery at significant differences in cost. For instance, in India, a person can have cardiac surgery for approximately $\$ 25,000$ less than the cost in the US. Along with the medical care provided, these locations offer a vacation-like atmosphere. Another feature that encourages the use of medical tourism is the availability of medications and technologies that may be experimental in some countries but readily available in others. Because of the cost differential, some private insurers also offer incentives to utilize medical tourism as a means of accessing health care services.

Although medical tourism has led to knowledge development on a worldwide scale, concerns remain as to quality and liability. However, despite these concerns, entities such as medical tourism have the potential to increase awareness of illness and disease processes. This knowledge could be empowering to developing countries.

Since the early 1990s, over 48 million people have been displaced due to the environmental crisis and its health related impact (Toole, 1995). HIV rates are increasing both in the US and abroad, infecting nearly 25 million people. Other diseases such as tuberculosis and cholera have developed into drug-resistant strains proven difficult to treat, thus increasing the disease transmission rates. It is predicted that by 2020 , heart disease will become the leading cause of disease an disability followed by depression and traffic accidents (Murray \& Lopez, 1996).

Poverty has been found to be a leading predictor of health disparities. More than 25 percent of the world's population lives in poverty. This economic burden results in decreased access to necessary and affordable healthcare. Public and private healthcare expenditures worldwide equal about 8 percent of the world's economic output (World Bank, 1993).

\subsection{Globalization defined}

Using the IDRC (Labonte, 2011) definition, "globalization, defined at its simplest, describes the constellation of processes by which nations, business and people are becoming more connected and interdependent across the globe through increased economic integration and communication exchange, cultural diffusions (especially of Western culture) and travel." This involves breaking barriers on flow of capital, goods and services, expected to lead to equality and liberty, infusion of new ideas, technologies and global economic growth. 
In their article, Globalization and Health: A Framework for Analysis of Action, Woodward et al. (2001) note that:

Economic globalization has been the fundamental force behind the overall process of globalization over the last two decades. It has been characterized both by a dramatic growth in the volume of cross-border flows and by major changes in their nature. International trade has grown at an accelerated pace-nearly 8.6 percent per year over the period 1990-1999-with the proportion accounted for by services increasing steadily, reaching nearly 19 percent in 1999. However, this transformation has largely by-passed low-income countries, most of which remain critically dependent on aid flows (Woodward et al., 2001).

It is important to note at the outset that a major question that scholars have been trying to answer is how to differentiate the terms "globalization" and "global health" while maintaining the interrelatedness, yet distinctness of the two concepts. In order not to confuse the reader, we plan to use this concept of globalization within the context of the meaning we ascribed to "health" and "global." Health is defined here as the World Health Organization (WHO) has defined it, that is, "complete physical, mental and social wellbeing and not merely the absence of disease or infirmity" (WHO, 1948). We plan to use "global" as defined by Bozorgmehr (2010).

Bozorgmehr (2010) defines global health as "public health," a distinct field, which focuses on people's health rather than on individual health, thus distinguishing itself from medical science or from an individual socio-behavioral science. Global does not mean international, as international may connote what is happening between as little as two nations. It does not mean a health issue that is local and spreads to the rest of the world geographically and it does not mean that which is happening everywhere. Global in this context, according to Bozorgmehr, means that which is 'supra-territorial' in the sense that it is not limited by geographic space, country, countries, or region. Thus, "global" impacts the social determinants of health from a holistic perspective. While globalization becomes a reconfiguration of social space, the term 'supra-territoriality' describes this evolving shift (Bozorgmehr, 2010).

Labonte (2011) is quick to point to the danger of focusing on the global economy as a natural, logical system when it is actually an outcome of political and economic interaction. As a counterpoint, it is also not productive to balance either the political or economic components. To do so, would diminish the impact of either or both.

Rennen and Martens (2003) have suggested a definition of globalization that is perhaps more acceptable, as it conveys all these dynamic ingredients. They define "Contemporary globalization as intensification of cross-national cultural, economic, political, social and technological interactions that lead to the establishment of transnational structures and the global integration of cultural, economic, environmental, political, and social process of global, supranational, national, regional, and local levels" (Rennen \& Martens, 2003).

\section{The interface between globalization and the social determinants of health}

The social determinants of health are the conditions in which people are born, grow, live, work and age, including the health system. These circumstances are shaped by the distribution of money, power and resources at global, national and local levels, which are themselves influenced by policy choices (WHO, 2003) The issue of social determinants of 
disease, and their interaction with health conditions is so significant that WHO established the Commission on Social Determinants of Health (CSDH), in 2005 "on the premise that action on SDH is the fairest and most effective way to improve health for all people and reduce inequities," which are "systematically associated with social advantage and/or disadvantage" (Labonte \& Schrecker, 2007).

As they give us their model on evaluating globalization impact on health, Huynen et al. (2005) focus on four determinants of health, namely, institutional, economic, socio-cultural, and environmental determinants. Each one of them interacts within itself and with one or more of the others determining to a major degree, beyond the impact of genetics, proximally and distally, the health outcomes of a nation or a people.

Institutional determinants consist of infrastructure, health policy, health-related policy, governance structure, political environment, system of law, regulation, all impacting on health services. The economic determinants, which are occupational structure, tax system, and markets, interact or determine the economic infrastructure, economic development and trade. The socio-cultural determinants include culture, such as religion, ideology, customs, population structure, size, and geographical distribution. In addition, knowledge, social organization, social security, insurance system, mobility communication, and social interactions, are socio-cultural determinants that have an impact on social environmental lifestyle. Finally, the environmental determinants refer to ecological setting, climate, ecosystem stability, goods and services, interacting with the physical environment such as food and water. All of these have an impact on social lifestyles and environmental conditions. These determinants are always present and may interact and necessarily impact population health and the services available and accessible for the maintenance of a sound public health system. Consequently, the establishment of a sound public health system entails constant surveillance of the determinants named above and their impact, as man tries to prolong life and improve its quality on earth.

\subsection{Trans-disciplinary approaches to globalization and global health}

Globality, therefore, "links people anywhere in the world but it does not follow that it connects people everywhere" (Bozorgmehr, 2010). Used this way, global health focuses on elements such as water, sanitation, environment, inequality, malnutrition, HIV, tuberculosis, malaria, mental illness, health policy, behavioral health, and maternal mortality, research, education, and practice, linked to the basic human health rights. As a trans-disciplinary field, global health brings to bear the perspectives from the natural and social sciences in order to explain and allow understanding of "the social relationships, biological processes and technologies that contribute to the improvement of health worldwide" (Bozorgmehr, 2010). Along with global health and the attempt to provide a framework for analysis, the determinants of health occupy a prominent role in any discussion. We proceed now to examine this issue as it relates to global public health.

Given that the nature of social determinants of health are many and consistently interact and impact health, no one discipline can unravel the total complexity of health and health care. As noted by Labonte and Schrecker:

Globalization comprises multiple, interacting policy dynamics or processes the effects of which may be difficult if not impossible to separate. Pathways from globalization to changes in social determinants of health are not always linear, do not operate in isolation from one another, and may involve multiple stages and feedback loops. 
Similarities exist with the task of analyzing causal links between environmental changes and human health which are complex because often they are indirect, displaced in space and time, and dependent on a number of modifying forces" (Labonte \& Schrecker, 2007).

It is reasonable to surmise that only a multi-disciplinary or trans-disciplinary approach to health and globalization can produce an objective body of knowledge.

According to Labonte \& Schrecker (2007), it is necessary to utilize a trans-disciplinary approach which consists of quantitative and qualitative methodologies using varied units of analysis. One mistake common to many globalization approaches is to portray the economy as the primary or sole measuring stick of the process itself, while relegating the impact of globalization on health to a secondary role.

As one analyzes the impact of globalization on health, the UNDP (1998) and many globalization experts, such as Labonte \&Torgerson (2005), warn the international community to keep in mind the following five principles. The first thing to consider is that the impact of globalization will be contingent upon the individual states' social and economic political traditions and "endowment." This aspect refers to a tradition of democracy, dictatorship, theocracy, patriarchy, or oligarchy, and impact of the level of development, the extent of the natural resources, and utilization of human capital.

Second, it is important to know which vehicles or processes are employed to foster and sustain globalization, which are usually "macroeconomic policies," encouraged and imposed primarily by the International Monetary Fund and the World Bank through the socalled Structural Adjustment Programs (SAPs) or Poverty Reduction Strategies. The World Trade Organization (WTO) has also presented insurmountable obstacles to the social programs of the developing world.

The third consideration is the status of vectors for globalization which are often a multiplicity of bilateral and multilateral agreements among the richer and the poorer nations, with the appearance that they are being signed to promote human rights, and protect the environment, and the rights of women and children. Even though desirable in specific cases, quite often the agreements are not properly enforceable. The fourth principle to hold in mind is "the ability of regional and local governments to have the national policies and resource allocations to provide equitable access to health promotion services, enhance generic community capacities, foster community engagement, or cope with the impact of increasing rapid urbanization" (Labonte, 2004).

\section{The great debate: Globalization and global health}

\subsection{Unfavorable globalization perspectives}

The flow of goods, capital, and services across borders now total $\$ 1.5$ trillion in currency transactions daily. This aspect makes it difficult for governments to control their exchange markets in an effort to stabilize currencies, manage their economies, and maintain fiscal autonomy (UNDP, 1999). There are binding rules and sanctions mainly emanating from the World Trade Organization established in 1994. As a result, globalization experts and others have noted that the imbalance between enforceable social and environmental obligations represents an area of implacable governance challenges that will continue to be for centuries the biggest governance challenge of the new millennium (Labonte, 1998; UNDP, 1998; Kickbush \& Buse, 2001). 
The size of transnational corporations, such as Mitsubishi in South Africa and Poland in 1997, quite often larger than the nations in which they operate, as measured through their gross domestic product (GDP), is choking many developing countries. One reason for this is that the CEOs of transnational business enterprises can dictate the terms of trade, influence policy, and stifle governments' ability to tax them, resulting in no discernible benefits for the population. Thus, "the ability of transnational corporations to organize production across borders, sometimes by using multiple tiers of sub-contractors, is an important contributor both to the emergence of genuinely global labor markets " (World Bank, 1995) and to "tax competing jurisdictions, as intra-firm transfer pricing enables corporations to shift profits to low-tax countries." Invariably, countries integrate into globalization by committing themselves to lower taxation and liberalization of imports and exports. However, the more powerful countries often find ways to refuse to accept or enforce the regulations, and proceed, for example, to subsidize their own agricultural enterprises.

Woodward et al. (2001) note that flows, even though they increased over the years, in 2000, remained 16 percent below their levels in 1991 and the total net of official development finance (including non-concessional loans, they add), declined further from "a peak of $\$ 60.9$ billion in 1991 to an estimated \$38.6 billion in 2000, an overall decline of 37 percent." In addition, critics point out that globalization has brought about socio-economic, environmental and health conditions that allow the easy spread of epidemics, which, in turn, directly or indirectly, have led to world economic "stagnation" and regional conflict. Hertz (2001), a critic of globalization, wrote:

In the Third World we see a race at the bottom: Multinationals pitting developing countries against each other to provide the most advantageous conditions for investment, with no regulation, no red tape, no unions, a blind eye turned to environmental degradation. It's good for profit, but bad for workers and local communities... Globalization may deliver liberty, but not fraternity or equality.

Woodward et al. (2001) stress the importance of appropriate representation by the developing countries and vulnerable populations as part of the international decision making that is vital to achieving globalization from a health perspective. Even though this approach seems more normative than evidence-based practice, it provides an excellent common-sense framework that very few individuals can argue against.

\subsection{The pro globalization argument}

The defenders of globalization argue that knowledge and technology through trade and investment help wipe out epidemics through more advanced surveillance systems, treatment and more effective prevention. In fact, the rapid and advance diffusion of information communication technologies (ICTs) is "frequently cited as an overwhelming positive aspect of contemporary globalization" (Chinkin, 2000; Harcourt, 2000). ICTs "enable more rapid scientific discovery, create virtual communities of support, increase knowledge of human rights, strengthen diasporic communities and create an international advocacy movement pushing to create new global governance structures to balance the predominance of market-driven initiatives" (Labonte et al., 2004).

On the spread of diseases, such as malaria from mosquitoes found on transcontinental planes, HIV/AIDS, tuberculosis, mad cow disease, and severe acute respiratory syndrome (SARS), through rapid movement of people from one part of the globe to another, the defenders of globalization note that the phenomenon of the last two decades "can improve access to the medicines, medical information, and training that can help treat or cure these 
diseases" (Levin Institute, 2011a). However, others argue that under the agreements of the World Organization for Animal Health, it is easier to stop the spread of certain diseases on the planet. The detractors of this argument note that often because of the costs involved, there is no consistent enforcement of the agreements across continents and among countries. The other major argument in favor of globalization is that it spurs economic growth through foreign investment, liberalization, and competition, both of which contribute to higher incomes, reduction of poverty, and better health care, leading to desirable change in the determinants of health (Levin Institute, 2011b).

\section{The true face of globalization and its impact on global health}

The globalization processes may have positive and negative health consequences on the population they are supposedly intended to help. These include increasing health care and education access, legislation designed to protect human and labor rights, restriction on exposure to hazardous drugs and products, such as tobacco, environmental waste, and environmental protection.

In fact, there has been evidence that globalization has resulted in higher tobacco consumption, notably in poorer countries (WHO, 2001) and higher alcoholic consumption, particularly among the young (Kuo et al., 2003). Normally, poorer countries have been able to provide services, such as education, health, and sanitation, through taxation and domestic subsidies. However, liberalization has meant the elimination or reduction of tariffs which, ultimately, are designed as a mechanism to reduce poverty and assist the poor. Experts point out that what has happened is that "global and regional trade agreements... are increasingly circumscribing the social and environmental regulatory options of national governments" (Labonte et al., 2004).

\subsection{Commercialization of commodities}

Liberalization may, indeed, result in price increase or price reduction, lower wages, or risks to the farmers. Lower prices may mean that the farmer will have to work more hours to be self-sustaining. Studies in Rwanda, Zambia, Kenya, Malawi, Sierra Leone, the Gambia, the Philippines, Guatemala, Papua New Guinea, and India found that globalization had mixed results, as a great effort was mounted to move from subsistence agriculture to agricultural commercialization. Even though, in some countries, the health results were promising, in others, such as Zambia that tried to move from subsistence corn production to commercialized corn output, the health conditions deteriorated more for children from commercialized than from subsistence households. These findings stress the need for gender analysis when the impact of globalization on household health is considered. What similar studies have done, says one commentator, is to make the point that "sweeping claims about globalization's benefits can safely be disregarded unless the claims clearly identify the relevant processes, and describe the pathways through which these processes are believed to affect the outcome of interest, health and health care."

Free trade as a part of globalization, even though it may have contributed to the provision of food to many countries, has also led to food insecurity in many, leading the International Covenant on Economic, Social and Cultural Rights to declare in 1966 that food security was a right of all peoples, which the World Food Summit endorsed that same year. Obviously, the protection of our ecosystem is paramount in the preservation and improvement of public health. Ecosystems provide us with the basic human needs like food, clean air, clean 
water, and clean soils and prevent the spread of diseases throught biological control. Finally, ecosystems provide us with medical and genetic resources, which are necessary to prevent or cure diseases. However, profitability goals often take precedence over ecosystem concerns.

\subsection{Globalization and economic consequences}

The impact of globalization on social services and employment has been detrimental to health and access to quality health care for most people of the world. Once a government eliminates tariffs, export taxes, and agricultural and industrial subsidies, as the World Trade Organization has mandated, supported by such major loan corporations and institutions as the World Bank, the International Monetary Fund, and the Paris Club, it also reduces its revenue. The resulting unemployment in "micro-enterprises," especially in the "informal sector," has increased exponentially during the last 20 years in developing countries. For example, in Latin America, unemployment increased by 50 percent during the 1990s, and, in Sub-Saharan Africa, North Africa, and Asia, by 74 percent, 43 percent, and 62 percent, respectively, even though overall GDP social services budgets remained the same (World Bank, 1995). In many cases, there may be a temporary economic growth but, almost always, economic sustainability is not maintained without further assistance through grants and loans by wealthier and technologically more advanced institutions and nations, continuing to maintain a state of dependence on donors.

Zambia is a good example of where liberalization policies led to unemployment and further poverty, as a result of the World Bank and International Monetary Fund loans during the 1980s, which encouraged this country to open its borders to cheap textile imports (Azevedo, 2003). Unable to compete, Zambia lost 30,000 jobs and 132 of 140 textile mills, resulting in a "40 percent loss of manufacturing jobs within eight years" (IDRC-CRDI, 2011: 5). This and the introduction of user-fees for school led to an increase in dropouts and illiteracy rates. The government was forced to eliminate the newly-imposed school fees and health care copayments and to re-introduce subsidies to agriculture and domestic industries.

Similar tragic examples happened in Kerala, India, which had a reasonable population health care, despite the country's low income. Domestic products gave preference to imported luxury goods. As a consequence, the local entrepreneurship was severely weakened, resulting in higher unemployment and a lowered tax base for the government for social programs, such as health care. Liberalization of coconut and rubber products, as dictated by the WTO, led to a drop in prices. Experts predicted that Kerala would also abandon its food subsidy, which would have tragic consequences for the nutrition of its people. The same consequences were observed in Mexico, Uruguay, Zimbabwe, Kenya, Cuba, Costa Rica, and the Philippines, where a noticeable decline in income and an increase in the rate of poverty and poor health, especially among the rural populations occurred, all seen by the World Bank and the International Monetary Fund, until a few years ago, as collateral damage for the greater good (UNDP, 1999).

Unfortunately, globalization has also fueled the external debt of many of the developing countries, decreasing, amidst rampant corruption and mismanagement, their ability to serve their own citizens. In 2009, for example, Africa's external debt, notwithstanding the new terms of "forgiveness," was $\$ 300$ billion, representing 16 percent of its export earnings. Asia's huge external debt represented close to 15 percent of its GDP, even though such countries as South Korea are able to absorb the debt burden. While South Korea's external 
debt in 2010 was $\$ 401$ billion, representing 42.8 percent of its GDP, Brazil, in Latin America, was struggling with an external debt of about \$211.4 million in the mid-2000s (WHO, 2011).

Several studies have also shown that liberalization has led to pollution and ecological damage, resource depletion, climate change, and increased fossil fuel emissions, due to required spending cuts, as illustrated by the Brazilian crisis of 1998. On a loan from the World Bank, Brazil had to cut its budget, including two-thirds of its environmental spending, which led to a collapse of a mapping project of its Amazon rainforest as a preliminary step to save its forests (Labonte \& Torgerson, 2003). Even though globalization can be beneficial under the right domestic policy circumstances and can be beneficial to health and health care, "Liberalization in capital accounts, which is urged to promote foreign direct investment (FDI), generally wreaks havoc for the poor in poorer nations" (Labonte \& Torgerson, 2003). The case of Nigeria, with the Exxon Oil Company, has become a classical example of how the environment can be destroyed and people's lives made worse along the pipeline and the oil extraction and transportation sites.

Berhman et al. (2000) studied the impact of globalization in 18 countries of Latin America between 1980 and 1998. They found imbalances in the distribution of incomes. Inequality increased in 13 cases out of the 18 countries. There was constant inequity in six countries. The worse impact came from international finance liberalization followed by domestic financial liberalization, and tax reform, while trade liberalization had no visible impact on inequalities. Interestingly, outsourcing, a major point of political contention this decade, was found to "weaken collective bargaining, minimum wages and safety at work" (WHO, 2001). One can counter-respond by noting that during the economic growth of the 1980s in Asia, for example, per capita incomes declined, and so it was in almost 70 countries that decade worldwide. As other studies have demonstrated, there is no definitive proof that globalization improved the world's overall economic growth. Cornia (2001) notes that the rate of per capita gross national product (GNP) growth decreased from 2.6 percent during 1960-1979 to 1.0 percent during the period between 1980 and 1998. During the 1990s, worldwide, the world economic growth was lower than that of the 1980s, declining by 1.0 percent, manifested into a slowdown in virtually all developing countries, most of which had accepted liberalization and economic globalization (Cornia, 2001).

Poverty in rural areas is not reduced when economic activity is concentrated in small urban sectors (Behrman et al., 2000). Sharp rises in inequality can also increase poverty, even though per capita income might grow. When inequality or disparities increase, overall growth is reduced, thus stagnating and frustrating the effort to reduce poverty for the majority of the people. Globalization, through an increase in women's labor force, is said to have had a negative impact on children's health. For example, it is noted that in East and Southeast Asia, up to 80 percent of the workforce in export-processing zones is female. In Bangladesh, garment factories rose from two in 1978 to 2,400 in 1995, when they employed 1.2 million workers, of whom 90 percent were women below the age of 25 years. The health consequence was that there was no equivalent adequate growth in childcare facilities or institutions, which resulted in increased children's injuries and malnutrition, notwithstanding the growth in household family income.

\subsection{Globalization, inequalities, and inequities}

When inequality or disparities increase, overall economic growth is reduced, thus stagnating and frustrating the effort to reduce poverty for the majority of the populace. Research has also shown that low growth leads to a rise in inequalities, as happened during 
the 1990s. In that decade, health care suffered from de-regulation and globalization in many countries, especially in Africa and the former Soviet Union, where "total stagnation followed or resulted in sharp regression in health."

Child mortality, a key indicator of overall health in developing countries, decreased slower in 1960-1998 than in previous years, despite many low-cost public health programs (Bach, 2007). Vaccination coverage increased from 25 percent to 70 percent in 1980 and at the end of the 1990s, due to improvements in the spread of knowledge about health, nutrition, and hygiene among parents. UNICEF noted a few years ago that, in countries that one could characterize as in transition in Europe, infant mortality rates were higher in 1994 than in 1990, while in Sub-Saharan Africa, in 1997, the mortality rate for children 5 years of age was higher than in 1990 (Bach, 2007).

Globalization has resulted in higher inequalities, both within and among nations. It is not clear, however, whether this alone has contributed to health deterioration or the prevailing health disparities (Labonte et al., 2004). Furthermore, in so far as poverty is concerned, which is usually higher in countries with high income disparities, "the greater the inequality, the harder it becomes for the economic growth presumed to follow trade liberalization actually to lift people out poverty."

Increased inequalities lead to less social cohesion, conflict, support for strong redistributive income, health and education policies, and lead to increased mortality rates due to homicide and suicide (Deaton, 2004). It has also become clearer that integration into the international economy or economic globalization usually does not result in people's ability to pay for the services they require but to an increase in payments to receive such services, thus negating any beneficial income that results in reduced poverty or poverty alleviation, noted by the International Monetary Fund and the World Bank as one of the ultimate aims of the Structural Adjustment Programs. Income growth and dispersal, says Cornia, "economic stability, the availability of health and other social services, and stress often dictate the degree of the international specialization of the economy, the availability and distribution of assets, its human capital and infrastructure, and the quality of its domestic policies" (Cornia, 2001).

\section{Globalization and health outcomes}

\subsection{Illness and disease management}

Huynen et al. (2005) note that governance for health purposes is done through policy pronouncements and enactments, but that, "globalization, has eroded the policy making authority of governments" and relegated it to partnerships between the state and private companies and to the International Monetary Fund and the World Bank, but, especially now, to the World Trade Organization, the reason why health and social services have declined in many of the developing countries. As a result of privatization and the "law of the market," we have reached a point where the primary issues focus on determining "whose health is most profitable." A study of private for-profit and of not-for-profit dialysis in the United States found that hemodialysis care in not-for-profit centers presented lower risks of death following treatment. In some cases, the provision of water was being privatized (Pang \& Guindon, 2004), which results in worse conditions for the poor.

A reduction in governmental spending has also been linked to deterioration of key indicators of child health, namely, infant mortality, child survival after birth, malnutrition, educational status, and access to such social determinants of health as food and social 
programs in countries such as Chile, Ghana, Peru, Zimbabwe, Philippines, South Korea, and Sri Lanka. In addition, the relationship between education and health must be seen as important. Studies have shown that adding a mother's education by one year to her life cuts childhood mortality by 8 percent--so vital are certain social services that the major corporations urge developing countries to stop subsidizing. Furthermore, data from over 100 countries collected during the 1960s and 1970s revealed that increasing adult literacy would increase life expectancy at birth by about 20 years, and reduce infant mortality by about 100-130 deaths per thousand live births (Pannenborg, 1995).

On the publicized Mexican and Thai financial crisis, World Bank studies showed a decline in income and job security. One consequence of this crisis was the forcing of children to drop out of school and engage in prostitution, which led to increased sexually transmitted diseases and infections, and employment of minors in hazardous factory conditions. Other sequelae included "acute malnutrition, severe brain damage, mental disorders, stress, increased overall domestic violence and a heightened death rate from cardiovascular disease." In fact, in some Eastern European countries, life expectancy fell by 2 to 6.6 years during 1989-1999 (World Bank, 1995).

Some noted scholars studying the harm caused directly or indirectly by globalization point to the fact that the rapid spread of HIV during the 1980s was in part fueled by the globalization efforts of the period. In other words, globalization was the precursor of the epidemic (Kunitz, 2007). AIDS, says Kunitz, "is a product of contemporary globalization because it erupted simultaneously with, and was exacerbated by, the economic crisis that engulfed many poor countries, especially in Africa, in the 1980s. That crisis had measurable demographic effects beyond those attributed to HIV and AIDS, and though they were not AIDS-related, they prepared fertile ground in which disease could take root" (Kunitz, 2007).

Okasha wrote convincingly that:

The global village allegedly created by globalization is not global after all. If we assume that 100 people are living on earth, 57 of them are Asians, 21 are Europeans, 8 are Africans, 6 are Americans; 48 are men and 52 are women; 30 are white and 70 are nonwhite; 30 are Christians and 70 are non-Christians. On the other hand, six people own 59 percent of the community wealth and they are all North Americans. Eighty live in poverty, 70 cannot read, 50 die in famine, 1 has a higher education and 1 has a computer. It is obvious that power and resources do not seem to follow the majority/minority pattern of the world population, i.e., globalization has failed until now to democratically represent the world it has claimed to globalize (Okasha, 2005).

It is important to note that the world is becoming more obese, and the proliferation of fast food restaurants is responsible for part of the problem. The World Health Organization (WHO) estimates that, by 2020, non-communicable diseases such as cancers, diabetes, obesity and cardiovascular diseases will represent two-thirds of the deaths on the globe, up from the present 40 percent (Pang and Guindon, 2004). Virtually un-regulated food imports have also been a cause for concern, as many agricultural products coming from developing countries in Latin America and Asia have caused severe salmonella and E. coli poisoning that at times has killed several Americans, while making others sick at other times. A key factor "has been the unprecedented increase in the global food trade, and its domination by large transnational companies that have developed global brand names and aggressive marketing strategies adopted to local situations," as are the Coca Cola, Pepsi, and Nestle brands in China [and McDonalds] (Pang and Guindon, 2004). 


\subsection{Cultural impact}

In fact, globalization, as it has been implemented to this very day, highlights several crises of different natures (Okasha, 2005). As noted by Okasha:

A leadership crisis exists where wealth is allowed to be concentrated in fewer and fewer hands so that the world's three richest individuals have assets exceeding the gross domestic product of the poorest 48 countries. A domestic crisis is apparent because 1.3 billion people live on incomes of less than $\$ 1 /$ day. An economic failure is seen in that 1.5 billion people have no access to clean water and 1 billion live in miserably substandard housing. There is also a spiritual crisis in which many people are so poor that they can only see God in the form of bread. Finally, a moral crisis is evident in which 40 thousand children die each day from malnutrition and disease.

\section{Globalization and the intellectual impact}

It must also be noted that the impact of trade-related aspects of intellectual property rights (TRIPs) imposed by the 1994 World Trade Agreement prevents easier access of the poor and under-represented populations to essential drugs due to high prices and legal and illegal restrictions. In general, the guidelines protect the rights of pharmaceutical companies for 20 years, while the latter can also restrict affordability and availability of generic drugs through subtle ways. In May 1999, the World Health Organization was asked by the World Health Assembly to monitor the health effects of international trade agreements. It is interesting that, while the large countries of Latin America and Asia have been able to exert pressure on the international pharmaceutical industry for it to produce several drugs locally, the African continent has succeeded only in forcing them to undertake local production that consists of "simple packaging or reformulation of products" (Van Der Velden, 1995: 318).

Last but not least, partly due to undemocratic politics, insecurity, and the impact of globalization, many countries, such as South Africa and India, are experiencing extensive "brain drain" of thousands of doctors and medical personnel every year. These health care professionals, lured by the lifestyle of the developed world, especially Great Britain, Canada, and the US, leave their country to practice or live abroad.

\section{Globalization and an equitable world}

As noted at the beginning of this chapter, globalization is here to stay even if it benefits just one set of nations of the world. However, that does not mean that it is fair, justifiable, and that its course cannot be altered. On thing remains clear: Most citizens of this world realize the injustices and are asking the major powers and corporations that benefit from the system to ensure that the planet is the ultimate winner, bringing an end or reduction to inequities or disparities, especially in health, the theme of this chapter, and provide the means, the knowledge, and the empowerment they need politically, economically, and environmentally to live better lives. This chapter has argued, and many others have done, that one of the most potent sticks through which to measure the objectives and the success of the phenomenon we have come to call globalization is the extent to which health and health care systems function for the extension of life expectancy and access to quality health care services.

One can argue that, in the final analysis, globalization and its acclaimed successes are interdependent on people's health. Health concerns and priorities dominate our lives and without it, life is almost meaningless, as it is for many who carry the burden of disease, 
especially when this condition can be easily alleviated, as is the case with many infectious and communicable diseases in the developing world. According to Okasha (2005):

The process [of globalization] has clearly both negative and positive results and is likely to create both losers and winners. Globalization has promised to grant the world instant communication, fast and efficient means of travel, a widened access to technology, cross-border cultural interaction and globalized approaches to environmental issues. However, it also entails deregulation of commerce and the creation of supernational political and economic bodies. As a result, the gap is widening between societies that "enjoy knowledge, technology and the ability to control events and others which are still backward, ignorant, frustrated, helpless and unable to follow progress and selfactualization" (Okasha, 2005).

\subsection{The public response}

It is encouraging, however, that the unfairness of the system has not gone unnoticed. Labonte \& Torgerson (2003) remind us that the WTO has actually been under fire from social and human rights activists, the United Nations, civil society, and non-governmental organizations (NGOs), and even from the European countries themselves, which created it at the Uruguay Round of Talks on the General Agreement on Tariffs and Trade (GATT). The WTO's "level playing field," with different rules and treatment, "is pushing many of these countries into deeper health-compromising poverty. Its negotiations to open public services to trade will hasten their privatization, with loss of access for the poor." In other words, the health needs for most inhabitants of this planet appear gloomy for the foreseeable future.

\subsection{Looking toward solutions}

What is the solution? The intent of our chapter was not to give solutions to the problems of globalization but to provide an overview of what the phenomenon and its system have done to the health of many people of the world, currently reflected in the existing health disparities or inequities that have prevented them from enjoying access to quality health "care, life saving knowledge, reasonable income, clean air, clean water, sanitation, land, and gainful employment." In order to reap the benefits of globalization, say many experts, "we need novel approaches to international cooperation that place national self-interest in the context of global mutual interest to promote international cooperation and goodwill" (Frenk and Gomez-Dantes, 2000; Pang \& Guindon, 2004).

\section{Conclusion}

For scholars and students interested in globalization and health, the preceding discussion pointed out the areas that need more research to make health care more affordable, open the eyes of world leaders to the misery their people live in every day, and put in place policies that are both enlightening and empowering. First, the study has made it clear that there is a need for a trans-disciplinary approach to the study of globalization and its impact on health, given that both globalization and health affect all aspects of people's lives and development programs. It is clear, therefore, that no one discipline alone can adequately deal with the complexity of globalization.

Second, our study demonstrates, we think, that those engaged in shaping people's lives through globalization must know that, while they attempt to make their own lives better, 
health and people's decent living standards must be one of their priorities, if not the priority. In addition, we maintain that globalizing leaders must understand that the planet resources are finite, that they exist for the benefit of all mankind, and that they should not, therefore, be used solely as the privilege of the wealthy few, the powerful, and the unscrupulous, always keeping in mind that prolonging people's lives on earth, in a dignified way, is a noble goal, expected of those who are the stewards of our fate. Issues of inequities or disparities, impact of household income on the family and health outcomes, self-sustainability in a globalizing world, socio-environmental impact on life expectancy, child mortality, the role of globalization and violence in the developing world, drug use and alcohol consumption and globalization, technology and impact in rural areas must be of constant concern for those in leadership position.. For example, how wise is it for a man in the village to own an expensive cell phone, paying a monthly bill, but struggling to have one decent meal a day?

Third, we might say that, even though we cannot move the clock of globalization back, we can correct its course. In terms of development and health, each country's internal conditions and resources ought to be dealt with as unique cases using inclusive and fair multilateral regulatory agreements that respect each nation's both its geographic and its social space. Cornia is clear in telling the readers that:

Premature, rapid and unconditional globalization in these countries could be expected to immediately generate considerable costs in efficiency and social affairs that would worsen growth performance and health outcomes and erode the necessary political support for opening up to the world economy. Particularly for these countries, a gradual and selective integration into the world economy, linked to the removal of the major asymmetries of global markets and to the creation of new democratic institutions of global governance is highly preferable to instant globalization (Cornia, 2001).

Finally, family household income and distribution for social programs such as health and education are determined by globalization activities and regulations. Studies have shown that, under poverty conditions, when women control the household income, children's health is better or remains acceptable. Even if globalization provides a higher income to women, the studies claim, it means that they have less time to spend with their children and family. It is also important to know that a single determinant affects many others, while all health is affected by environmental "pathways" related to such elements as water, land, forests, biodiversity loss, pollution, and "the loss of ecosystem services such as the sequestration of carbon by forests."

If globalization is properly managed, it can advance the state of the health system and people's health but only if the domestic markets are competitive, regulatory institutions strong, asset concentration moderate, access to public health widespread, if social safety nets are in place, and rules of access to global markets are non-exclusionary. Only then, "can globalization reduce opportunistic behavior, operate economies of scale, reward efforts and entrepreneurship, improve employment opportunities, raise earnings, and reduce the price of consumer goods." Regrettably, none of these indicators have been common in most of the developing countries that joined the globalization wave, at least none in Africa, Latin America, and most of Asia. In fact, studies conducted during the 1950s through the 1990s have resulted in disturbing findings on the impact of globalization, especially in the developing world. For example, while inequalities are said to have increased in 48 out of 73 countries, income concentration has remained in 16 of them, including Bangladesh and India. Inequality was universal in countries of the former Soviet Union, almost universal in 
Latin America, and common in member countries of the Organization for Economic COOperation and Development (OECD), and in Asia, South-East Asia, and East Asia (WHO, 2011).

Labonte \& Torgerson (2003) recommend several prescriptions designed to alleviate the disease burden that has been exacerbated by the process of globalization, and they include:

- Instituting special and differential trade agreement exemptions for developing countries until domestic development can sustain globalizing requirements

- Banning patenting of life forms, exempt patent protection legislation for poor countries indefinitely

- $\quad$ Reversing the burden of proof in health and environmental protection cases argued under GATT Article XX (b) and under SPS

- Imposing fines tied to gross domestic product rather than trade sanctions as penalties, "since trade sanctions invariably hurt poor countries more than wealthy ones"

- Instituting a "Tobin tax" on currency exchange

- Relaxing liberalization requirements in agriculture, and

- Negotiating "an overarching and enforceable rule in all trade agreements to the effect that, when there is any conflict, multilateral environmental agreements and human rights agreements (including the right to health) shall trump trade agreements."

One cannot overemphasize the responsibility of any government, and more so in the developing world, to slow the nefarious tide of globalization. It is obvious to any observer that not a private company, corporation, or insurance scheme organization can affect the health of a people and their healthcare system nationally and internationally. If one is in agreement with the United Nations that health care is a right of every human being rather than a privilege of a few and that epidemiological occurrences that affect a community rather than isolated individuals are turning into global rather than local problems, "only an organization such as the state can muster the resources" that can ensure and monitor fairness and equity in the provision of healthcare services, mobilize the international community for assistance, provide most of the needed resources, and set the research agenda for the study of the ecosystem and its impact on people's health, while enlisting private health care enterprises and NGOs to assist in the process (Azevedo, 2003). Thus, allowing private corporations, loan institutions such as the IMF and the World Bank, and financial underwriters and Western nations' accountants to issue a series of ultimata to leaders of the developing world requesting that they "roll-back tax-supported state services and mandated benefits - in effect to disband public service, deregulate labor, and lower their tax bills" (Azevedo, 2003), before they would invest their financial resources, is insensitive and ought to be resisted at all cost.

The preceding discussion has centered on how directly and indirectly globalization, through its liberalization, de-regulation, and unhindered across-the-border flow of financial capital and goods, can impact adversely the social determinants of the disease burden, especially in developing countries that have no political and international power or clout to fight the mega-corporations, the superpowers, and the will to resist the cultural baggage and its influence on malnutrition, drug use, alcoholism, sex and violence, and the lure of its lifestyle and sedentary habits, which are now clearly recognized as leading to such ill health as obesity, diabetes, several types of cancers, and cardiovascular disease.

In other words, the claim that globalization has brought the people of the planet closer, embracing the same human values and aspirations, "with the traditional boundaries separating individuals and societies gradually and increasingly" receding, has not been 
realized. The differences between and among societies have tended to increase over the past decades despite improvement in communication and transportation, technology, and efforts at creating global guidelines of conduct politically, economically, and scientifically. Mental illnesses, for example, a part of public health, have increased rather than decreased over the past two decades, “.... and poverty and mental disorders feed into each other, one leading to another in a vicious circle that has to be broken by either the eradication of poverty or adequate intervention with patients with mental disorders or preferably both."

In sum, while globalization has meant ill health and other risks, it also constitutes an opportunity for human kind to work together and assist those who cannot help themselves to lead productive and meaningful lives. Two well known critics of globalization remind their readers that "globalization is an ideology that suggests distribution through market is the best way. The challenge is to find arrangements whereby the production and distribution of international goods such as primary health care and public health provision may be managed within a multilateral system" (Barnet and Whiteside, 2002).

Despite the increasing concerns related to the globalization of health, there remains a divergent path between the global health issues and current systems to address the incongruence. The achievement of globalization" must be recognized as more an ideal attainment. The political will toward this goal must be tackled by broad alliances of health workers and those who serve the public good. As noted earlier, globalization has been viewed as an anti-democratic movement that would weaken the nation-state in favor of the great powers. Multinational corporations intent on seizing hegemonic control over the world both economically and culturally have aggravated the disparities between rich and poor. The so-called pro-globalization camp views the expanding phenomenon as spurring global competition that benefits all consumers and provides opportunities for states to work together and generate goods that will reduce hunger and poverty and create greater international cooperation. The facts analyzed in this chapter appear to dispute the claim.

\section{References}

Azevedo, M. (2003). Health and Economic Development in Africa." In African Economic Development, Nnadozie, E. (ed.), (pp. 181-205). Academic Press: San Francisco.

Bach, S. (2007). Globalization and Health. Bulletin of WHO, 85(11): 897-899:

Barnet, T, \& Whitesite, A. (2002). AIDS in the Twentieth-First Century: Disease and Globalization. Palgrave: New York.

Behrman J, Birdsall N, Sze'kely M. (2000). Economic Reform and Wage Differentials in Latin America. Washington, DC, Inter-American Development Bank.

Bozorgmehr, K. (2010). Rethinking the 'global' in Global Health: A dialectic approach. Globalization and Health (6) 1-19. Available from: http://www.globalizationandhealth.com/content/6/1/19

Chen, L. , Evans T., \& Wirth, M. (2002). Philanthropy and Global Health Equity. In Critical Issues in Global Health, C. Koop, C. Pearson , \& Schwarz, M. (Eds.) (pp. 430-439. San Francisco, CA: Jossey-Bass.

Chinkin, C. (2000). Gender and Globalization. UN Chronicle, 37(2).

Cornia, G. (2001). Globalization and Health: Results and Options, Bulletin of the World Health Organization, 79 9): 834-841.

Deaton, A. (2004). Health in an Age of Globalization. Brookings Trade Forum. 83-130.

Frenk, J. and Gomez-Dantes (2002). "Globalization and the Challenges to Health Systems." Health Affairs, 21(3), 160-165. 
Friedman, T. (2005). The World Is Flat: A Brief History of the Twenty-First Century. Farrar, Straus. \& Giroux Publishers: New York.

Goldbach, A. \& West Jr., D. (2010). Medical Tourism: A New Venue of Healthcare. The Journal of Global Business Issues, 4(2), 43-53.

Harcourt, W. (2000). Communicable Disease, Gender and Equity in Health. Available from: http://wwwhsph.harvard.edu/Organizations/healthnet/Hupapers/gender/harti gan.html.

Hertz, N. (2001). Why we must stay silent no longer." The Observer, April 8.

Hofrichter, Richard (2003) (ed.). Health and Social Justice: Politics, Ideology, and Inequity in the Distribution of Disease. San Francisco, CA: Jossey-Bass.

Huynen, M., Martens, P., Hilderink, H. (2005). "The Health Impacts of Globalization: A Conceptual Framework." Globalization and Health, 1-14.

Institute of Medicine [IOM], Board on International Health, (1997). America's Vital Interest in Global Health: Protecting Our People, Enhancing Our Economy, and Advancing Our International Interests. National Academy Press: Washington, DC. Available from: http://www.nap.edu/catalog/5717.html

Keckley, P. \& Underwood, H. (2007). Medical Tourism: Consumers in Search of Value. Deloitte Center for Health Solutions. Washington, DC.

Kickbush, I. and Buse K. (2001). Global Influences and Global Responses: International Health at the Turn of the Twenty-first Century. In Merson, M., Black, R., and Mills A. (eds.) (2001). International Public Health: Diseases, Programs, Systems, and Policies. Gaithesburg, MA: Aspen Publishers Inc.

Kuo, M., Heeb J., Gmel G., \& Rehm, J. (2003). “Does Price matter? The Effect of Decreased

Price on Spirits Consumption in Switzerland." Alcohol: Clinical and Experimental Research, 27, $720-725$.

Kunitz, S. (2007). The Health of Population: General Theories and Particular Realities. Oxford University Press: London.

Labonte, R. (1998). Healthy Public Policy and the World Trade Organization: A Proposal for an International Health Presence in Future World Trade/Investment Talks. Health Promotion International, 13(3), 245-256.

Labonte, R. (2011). Globalization, Health and Development: The Right Prescription?, pp. 1-11. Available from: http:/ / www.idrc.ca/en/ev-67832-201-1-DO_TOPIC.html,

Labonte, R., Schrecker, T., Sanders, D., and Meeus, W. (2004). Fatal Indifference: The G8, Africa and Global Health. University of Cape Town Press: Lansdowne, South Africa.

Labonte, R. \& Schrecker, T. (2007). Globalization and Social Determinants of Health: Introduction and Methodological Background (Part 1 of 3)." Globalization and Health, 3:5. Available http://www.globalizationandhealth.com/content/3/1/5.

Labonte, R., \& Torgerson, R. (2003). Frameworks for analyzing the links between Globalization and Health. World Health Organization: Geneva.

Labonte, R. \& Torgerson, R (2005). “Interrogating Globalization, Health and Development: towards a Comprehensive Framework for Research, Policy and Political Action." Critical Public Health, 15(2), 157-179.

Levin Institute (2011a). Globalization 101. IMF+World Bank. State University of New York.

Levin Institute (2011b). New analysis: Globalization of the food Supply: Mad Cow Disease and International Trade, IMF+World Bank, State University of New York.

Magee, B. (2009) Operation Smile, In: Management of Cleft Lip and Palate in the Developing World, M. Mars, D. Sell \& A. Habel, eds. John Wiley \& Sons Ltd: Chichester, UK. 
Murray, C., \& Lopez, A. (1996). Global Burden of Disease and Injury, Vol. 1. Harvard University Press, Boston.

Okasha, A. (2005). Globalization and Mental Health: A WPA Perspective. Journal of the World Psychiatry Association, 4(1), 1-2.

Pannenborg, O. (1995). "An Economic and Financial Look at Health in Low and MiddleIncome Countries." In Health Matters: Public Health in North-South Perspective, K. Velden, K. Jeroen, J. van Ginnegen, V. Foppe de Walle, \& J. Wijnen, pp. 43-62. Royal Tropical Institute Amsterdam.

Pang, T. \& Guindon, G. (2004). “Globalization and Risks to Health.” EMBO Reports, 5, S1, S11-S16.

Rennen W. \& Martens P (2003). The globalisation timeline. IntegratedAssessment, 4, 137-144.

Schrecker, T. \& Labonte, R. (2007). What's Politics Got to do with it? Health, the G8 and the Global Economy. In Kawachi, I. \& Wamala S. (eds). 2007. Globalization and Health. Oxford University Press: Oxford.

Schroth, L., Khawaja, R. (2007). Globalization of Healthcare. Frontiers of Heath Services Management, 24(2), 19-30.

Toole, M. (1995). Mass Population Displacement-A Global Public Health Challenge. Infectious Disease Clinics of North America, 9(2), 353-366.

United Nations Development Program [UNDP]. (1999). Globalization with a Human Face. Human Development Report. Available from: http://hdr.undp.org/en/reports/global/hdr1999/

United Nations Development Program [UNDP] (1998). Consumption For Human Development. Human Development Report. Available from: http://hdr.undp.org/en/reports/global/hdr1998/

Woodward, D., Drager, N., Beaglehole, R., \& Lipson, D. (2001). Globalization and Health: A Framework for Analysis and Action. Bulletin of the World Health Organization, 79: 875-881.

World Bank. 1993. World Development Report 1993: Investing in Health. Oxford University Press, New York.

World Bank (1995). For Better Health in Africa: Lessons from Experience. World Bank, Washington, D.C.

World Health Organization (1948). Preamble to the Constitution of the World Health Organization as adopted by the International Health Conference, New York, 19 June - 22 July 1946; signed on 22 July 1946 by the representatives of 61 States (Official Records of the World Health Organization, no. 2, p. 100) and entered into force on 7 April 1948.

World Health Organization [WHO] (2001). Bulletin of the World Health Organization, World Health Organization [WHO] (2003). Bulletin of the World Health Organization, World Health Organization [WHO] (2011). Bulletin of the World Health Organization, 


\title{
Ups and Downs of Ethnic Identity in the Era of Globalization (Focusing on the Middle East Region)
}

\author{
Akbar Valadbigi and Shahab Ghobadi \\ Islamic Azad University, Sanandaj Branch, Kurdistan,
}

Iran

\section{Introduction}

In the 1990s, the phenomenon of globalization appeared one of the most controversial topics of the closing years of the $20^{\text {th }}$ century in the social sciences and yet it has maintained this status in the second decade of the 21st century. Globalization has been approached with various perspectives, each one in its turn has strived to define it and suggest its possible challenges to, amongst others, politics, culture, economy, national states, identity, and ethnicities.

Cultural particularism, however, is supposed to be a process formed by globalization; such casual relationship, therefore, takes place when globalization hardens the process of identity-making in our era through changing the traditional conditions of identity-making and undermining the traditional compounds and sources of identity. This predicament, in its turn, can make grounds for most of the existing cultural particularisms. Speaking about the extensive growth of ethnicalism in the light of globalization, that is the spread of ethnic identities within the national boundaries and the Third World countries in general, and across the countries of the Middle East in particular, and challenging national identity are not of a defendable nature neither theoretically nor practically.

It is dominantly agreed upon that resisting challenges of globalization has occurred mainly in the guise of national identities in the context of national states, rather than the growth of ethnic identities against national identity. (Ahmadi, 2003)

Thanks to the developments of industries in the second decade of the 20th century, people observed a dramatic change in their surroundings which Marshal McLuhan has suggested it as promising of the formation of the "global village", that is known for us as " globalization". Globalization transcends cultural, social, political, and economic borders and then paves the ways for the appearance of a new world order in the peripheral regions (e.g., the Middle East countries). The events have taken place in the recent decades in the Middle East indicate that the nations of this region are suffering from various internal and external crises; whatever the causes of these crises be, most of them have their origins in identity issues and conflicts.

The relatively rapid political changes of this region taking place in forms of revolution, coup d'états, unrests (e.g., the recent popular movements in the northern African countries), maintenance of the authoritarian political cultures, and lack of progress in democracy and civil society reveal that the peoples of the Middle East, and even their 
elites, have not acquired a certain definition of themselves and their surroundings, such a definition which can be applied as a firm basis for arranging individual and collective identities.

It is allegedly believed that the transnational forces and developments are the vital elements in posing the ups and downs of identity across the Middle East. It has had always a direct relationship with the importance of the international system, at one hand, and decreased economic and managerial potentials of the Middle East countries, at the other hand. (Ghahremanpoor, 2002)

Exploring the relationship between globalization and identity in the Middle East is of great importance, since the crisis of identity in this region hasn't been always the side-product of globalization; the political elites of the Middle East, however, have had a noticeable part in regulating the relationship between the internal and external events. Due to the weakness of social forces, therefore, these elites have been regarded as the most influential social forces in manipulating ethnic and identity challenges. (Zakeryan, 2003)

Unique the region may be, but its exceptional status is tested in its inability to manage the challenges posed by globalization. As Hinnebusch notes, Middle East responses to globalization should be seen as 'a function of a changing interaction between the systemic (inter-state) and state (domestic) levels'. At this level, the region faces seemingly insurmountable challenges. In other words, it is in the exploration of the interaction between the inter-state and domestic levels that we understand better the nature of state responses to globalization. (Ehteshami, 2007)

Among the hypotheses intended to be dealt with in this paper is the implication of a mental and cultural approach by the elites of the Middle East to the phenomenon of globalization; making effort to transfer this approach to social and individual levels, therefore, is argued to be the main cause of enduring identity problems in the region. There is no doubt that the discourse of globalization has added to the layers of identity; the citizens of this region accordingly have encountered a great deal of crisis and failure in their search to adopt these new layers, so it is natural that they resist against this trend.

At the other hand, however, according to the essentialists, identity is an essential element, then a force like globalization cannot make any crisis in which. One of our main approaches in this paper is addressing the different thought orientations in relation with the positions of globalization and its subsequent effects on issues as diverse as political and cultural affairs which enclose, among others, ethnicity and identity.

Some like Zbigniew Brzezinski argue that we will notice the formation of next to 400 new political units in the future, which revolve around ethnicity and different sects. Nevertheless, he articulates that the realization of the ethnic and sectarian fundamentalisms is inevitable, he also predicts that in the future, the world would be a forum for the political exchanges of ethnicities and political sects. Others such as Fukuyama suggest that certain values of sectarian fundamentalism will not be the background of future exchanges, rather some different aspects of power will make grounds for these essential exchanges at the international level. (Fukuyama, 2000)

Among the positive consequences of globalization what follows are noteworthy: increasing collaborations, interaction, exchange, balance, tolerance, regenerating human awareness, and promoting the meditational potentials of national identities. From the other hand, there are the negative consequences of this process, which contribute to undermining national identity. Increased structural conflicts and identity dichotomy, cultural assimilation, and promoting decentralist tendencies are some examples of these consequences. 
Over the last 30 years, most of the Middle East countries have been engaged in some sort of war and unrest; it is why the process of globalization and its subsequent challenges in this region have always had a crucial value in the political and cultural studies conducted on this region. For example, three major approaches of the international geopolitics regard globalization through different points of view; first, the neo-liberal approach observes that the international markets create balance between the interests of all nations, and then decrease the possible challenges of identity. Second, the neo-real approach holds that government is the core of the international system while it underestimates the issues surrounding ethnicity and identity. And the third one, the neo-Marxist approach suggests that globalization is a new version of colonialism which not only increases vulnerability and interdependency of the developing world, but also widens the existing gaps between the rich and poor countries. This approach, therefore, warns about the domination of identity and ethnic crises across the multi-cultural and multi-ethnic context of the Middle East.

A probable reason why globalization faces so many pitfalls in the Middle East, as one of the world's challenging regions, is that it has failed to keep pace with the global economic race which in turn results from the current socio-political conflicts including the identity and ethnic crises and challenges which make obstacle in this region's path to achieve development.

The present paper attempts to evaluate the process of globalization as well as ethnic identity in the context of the Middle East while taking a critical sociological perspective; in doing so, it will take advantages of the attitudes of the protagonists and antagonists of globalization and ethnic identity, then, the internal and external forces that leverage these matters will be discussed in a parallel manner.

This introduction is followed by the section of definitions. In this section, we are going to provide the definitions of those essential terms applied afterwards. Following this part, several controversial and influential questions, which have weight in the geopolitical debates of the region, will appear to continue our discussion. Subsequent to these questions, our broad, yet flexible, theoretical perspective in relation with globalization and the identity and ethnic issues of the Middle East will be explained. We hold the opinion that the strength of our paper lies in its simultaneous addressing both the positive and negative consequences of globalization as a double-edged sword and their possible impacts on identity issues in general and ethnic identity in particular. After this section, however, the fears and hopes of this discussion will be presented while we shortly look at the mechanisms and challenges imposed by globalization to ethnic identity in the region. The conclusion of our debates will come afterwards. The paper's recommendations for developing the possibilities of solving the current structural conflicts flaming in the region will terminate the discussion. These recommendations seem to be what the civilized democracy-based strivings of the contemporary elites of the Middle East share.

\section{Key questions}

This paper poses several questions, which revolve around the process of globalization as well as its ensuing impacts on identity, especially ethnic identity, in the region under study. From now on, we take a double approach, and then discuss both the positive and negative consequences that globalization has brought for ethnic identity; yet we think it does not suffice and go on to explore the fears and hopes of this dominant process for ethnic identity in the Middle East. 
The questions of this chapter are arranged as follows:

- Have the compounds of globalization penetrated the ethnic culture of the Middle East countries?

- How have the diverse ethnicities of this region reacted to the wave of globalization? Has globalization spurred the region's identity crises?

- What are the impacts of globalization on ethnicity in general and ethnic identity in particular? Do these impacts trigger ethnicalism or make it weaker against the greater identities, nationality and national or regional identities, for instance?

- Can we argue that the cultural diversities in the era of globalization, which are laden with technological achievements, maintain along with the national identities?

- Can the globalization of culture influence the progress of cohesive cultural identities or it results in undermining the ethnic, racial, and local linkages?

- Finally, does globalization generally threaten the unity of the multi-ethnic countries and how is the influence of this process on the ethnicities of a given cohesive country?

\section{Concepts}

\subsection{Identity}

In the social sciences, identity is a general concept that is free of a certain space and time. The correlation between identity and culture is the main cause of this limitation, and the diversity of the current societies is due to this fact. (Eyvazi, 2002)

In our era, due to the growth and spread of the communication technologies, different identities have been challenged, as across the modern communication spaces (e.g., the Internet), the special and temporal boundaries are transcended easier. The very question that rises here is that "What is the relationship between information and communication technologies and cultural achievements (ethnic identities, for instance) and can we suppose it as an independent variable? With respect to the artificial separations among the peoples which have appeared in form of limited geographical boundaries called "nation-states", it seems that the similarities and differences among the influential civilizations of the world have their roots in the culture and history of these civilizations, as a result, they are not the vintages of the fake and imposed distinctions of the colonial powers.( Wallerstein, 1997)

\subsection{Ethnicity}

Ethnicity refers to a sometimes rather complex combination of racial, cultural, and historical characteristics by which human groups are sometimes divided into separate, and probably hostile, political families.

Ethnicity rises the whole socio-political question of national identity, which is why ethnic politics are often at their most virulent and important in Third World and other countries whose geographical definition owes, often, far more to European empire-builders than to any ethnic hegemoneity. It was precisely such problems, which led to conflict in Yugoslavia and the former Soviet Union in the early 1990s once the power of communism, which had maintained artificial boundaries, collapsed. (Robertson, 2004)

Ethnicity, however, is a term used to refer to the insights and methods of cultural interactions, which differentiates a certain community from the others. (Suizi, 2000) The common feature and function of all the ethnic communities has been development and 
diversity at the level of human social cooperation. The sense of having a shared ethnicity by now has been a major core for individuals' identity-seeking. (Held, 2003)

Not only do ethnic phenomena differ in practical terms with each other, but also they are contradictory. At one hand, we are facing a losing respect, and at the other hand, however, we notice the rise of the new ethnicities, the decline of the older ones, and the mobile cultural developments happening for these ethnicities. (Fukuyama, 2000)

In the turn of the 21st century, we observed a widespread split among ethnicities and mobility in ethnic identity-seeking across the Middle East. The literature is abundant with samples of multiple identities, which not only include the peoples, but also other different classifications such as gender, region, religion, and class. (Ahmadi, 2003)

\subsection{Ethnic Identity}

Ethnic identity is composed of some objective and subjective cultural, social, and political components that realize in a certain humane group (Burton, 2001) which distinguish it from other counterpart groups, as identity should be consistent with the reality of that given group. Castles writes that ethnicity, as the source of identity, is becoming paler, not against the ethnicities, rather against nation and gender (2001). However, the concept of ethnic identity, in spite of its vanishing nature, reveals a series of imposed limitations on the roles one can apply for, and the parts that are eligible for making exchanges with.

\subsection{International system}

Through its global aspects, the international system relates all the societies in form of a global social order. This can be simply considered as a "single global unit". (Giddens, 2002)

International system has been formed once the western societies experienced their extensive development that partly coincides with the seventeenth century, but at our era, the existence of an ever-connected system is amidst the compounds influencing people's life more than ever. (Wallerstein, 1997)

\subsection{The Middle East}

The Middle East is a term of European, chiefly British origin, with a wide and rather inexact scope. Its maximum definition comprises the countries along the southern and eastern coastlines of the Mediterranean Sea, from Morocco to Turkey, plus Sudan, the countries of the Arabian Peninsula, Jordan, Iraq, and Iran. (Robertson, 2004)

In this paper, the term "the Middle East", has got a functional dimension in its broader meaning. The borders of the new countries characterize this region, and albeit they have share features, they are believed to be of basic socio-economic systems.

The end of the Cold War was thought to offer some hope for a more peaceful future in the region, and some progress was indeed made, but the region's internal sources of conflict proved sufficiently enduring for the Middle East to remain the world's principal source of insecurity. (Robertson, 2004) Putting these threats aside, still this region has had so much of rapid social, political, and cultural changes that have turned to a crucial opportunity for socio-political studies. Although this region has kept its various strategic significances, yet it should be regarded as a less-developed region. The deep-rooted decays which have afflicted this region for centuries, at one hand, and the recent revolutionary movements across the region for reviving the socio-political life, at the other hand, have situated this region at the core of the international debates. 


\subsection{Globalization}

Globalization has proved to be one of the hardest concepts to define, however, in the literature, numerous definitions have been suggested to the term" globalization", among which we just point to those that cover the presented subjects of our paper.

Globalization- the ongoing process of greater interdependence among countries and their citizens- is complex and multi-faceted. Many of the problems the critics of globalization point to are real. Some of them relate to economics. Others relate to non-economic, but no less important, aspects of life. And while some of the problems do stem from the process of global integration, others do not. (Fischer, 2003)

Giddens, in his turn, tries to define the term as follow: " I would have no hesitation...in saying that globalization, as we are experiencing it, is in many aspects not only new, but also revolutionary... Globalization is political, technological, and cultural, as well as economic. (Ehteshami, 2007)

Others assert that globalization is mobility and transformation at the scale of human organizing (Held, 2003). Naderpoor defines the term as an ever-increasing coordination for solving the problems of human society. (2003) Still some consider globalization interchangeable with globalization of the international economy. In other words, globalization equals with Americanization of the international economy.(Miz, 2006)

Globalization, as a process, is assumed the continuation of the experiences of modernism. The developments that were made in thought and techniques in the preceding century joined hands with the extension of the communication systems as well as trying different economic systems and gave rise to this idea that globalization will determine the fate of every society; the cultural dimension of this fate is characterized by accepting the modern values (i.e., the American and European values), its political dimension consists of the formation of the national states(liberal-democratic ones), and its economic dimension requires the acceptation of market economy. Finally Martin et al (2006) have pointed out that, "To speak freely of globalization tends to show that, due to the expanded (economic, financial, informational, human) inflows, we are aiming at an integrated world, and that this evolution is new and unavoidable."

\section{Theoretical framework and approaches}

Every researcher of geopolitics and the socio-political issues takes a different approach to regional studies. Among the common approaches in regional studies, however, we adopt the theory of systems for our paper. First, we think it better to present a short definition for the terms region, region divisions, and the significance of regional studies.

\subsection{Region}

In strategic literature, region compromises several countries, which due to their shared geographical linkages or common interests are related to each other. Cantori and Spiegel observe region as containing several countries that are geographically close to each other while having interconnected foreign policies. (1970) Patrick Morgan (1972) suggests that region is a set of countries with some shared features (e.g., culture and political institutes).

\subsection{Region's divisions}

Regions have been divided in numerous different manners. A famous classification made of regions, for examples, suggests that the world is dividable into three categories: 
- Central regions: The regions that are characterized with political stability, developed economy, and capability in intervening in the affairs of other regions( Europe and North America, for example);

- Middle regions: Regions with characteristics like close relationship with their central counterparts and rapid shift toward political stability and economic development (central Europe, East Asia, and Latin America, for example); and

- Sub-regions: The regions that are encountering political conflicts, developing economy, and widespread identity challenges (Balkan, south Asia, and the Middle East, for example).

\subsection{Significance of regional studies}

It was believed for a while that the regional and national studies have lost their importance for the benefit of the continental and international studies; however, the recent developments and democracy-seeking movements of the Middle East which took place in search of more democracy and justice, proved that the regional studies, at least for the crisisstricken region of the Middle East, have still maintained their strategic importance.

Establishment of the regional studies seems to be the result of the following cases:

- Regions are supposed to be an important aspect of the international politics. Since the end of the Cold War, however, the importance of regional relationships has grown and in light of that, nowadays we notice more regional conflicts and collaborations. (Morgan, 1972; Ja'afari, 2009)

- Regional systems will take a great part in the controversies of the future (for example, Persian Gulf Cooperation Council has taken the first steps in establishing a collective security system in the region). (Lake and Morgan, 1997)

- Making grounds for promoting regional collaborations: The recent initiatives made for inter-regional dialogues (for example, the dialogues held between Arabs and the Europeans or Europe talks with North Africa). The significance of such provisions has doubled in recent years in shaping the developments of the Middle East. (Spiegel, 1970)

\subsection{Regional studies in the theory of systems' point of view}

Cantori and Spiegel propose three different systems: global system (the dominant system); subordinate system (regional); and internal system (nation-states). According to them, the regional systems are located between the global and internal systems. Moreover, each subordinate system consists of several interactive neighboring countries that have common cultural, social, historical, ethnical, and lingual characteristics. They add that the sentiments of assimilation and identity are sometimes triggered by the interventions from the side of external countries. Thompson (1996) identifies the following features for the subordinate systems: a) the presence of common historical, social, cultural, and lingual backgrounds for convergence; and b) active mutual interdependence among the members that provides the necessary sensitivity for the appearance of convergence among them.

In the process of formation of a given regional system, one can mention the following variables:

a. Geographical status: with characteristics like borders and weather(e.g., the Mediterranean system).( Morgan, 1997; Ja'afari, 2009) 
b. Different political, ideological, and security factors.

c. Historical, cultural, lingual, ethnic, religious, and racial connections; the oil-producer countries of the Middle East, for example, are extremely dependent on each other in oil production and its pricing.

During the 20 $20^{\text {th }}$ century, the world experienced, among others, two major phenomena: globalization and regionalism. An approach believes that globalization and regionalism are contradictory, because globalization removes the conventional borders. (Morgan, 1997; Ziegler, 2000) Another approach suggests, however, that these two phenomena bolster each other and accordingly, the efforts of this region's countries to get out of this deadlock and walking into the way of development are intellectual and rational. (Buzan, 2003)

The different approaches to globalization have their own followers in the intellectual circles, and with respect to the emphasis that cultural approaches put on cultural particularism against universal generalism of globalization, it has drawn the attentions of the protagonists of cultural particularism and ethnic identities. (Golmohammadi, 2002)

Regarding the attitudes of European researchers and some supporters of the flourishing and development of ethnic identity toward this cultural approach, there are some disagreements. Some researchers believe that the core of discussions on globalization in the Middle East is often the resistance of this region to this process (Ahmadi, 2003) which has showed itself mainly in the form of growing national identities within the national states instead of growing ethnic identities against national identity. As Mohamed El-Shibiny puts it:" There is real fear of globalization in this part of the world, and it is seen as a threatening force in many quarters." (Ehteshami, 2007)

In addition to make distinction between the current terms in this field, we should present different theoretical approaches to globalization and the way they are going to challenge ethnicity and ethnic groups in the Middle East. The following is a quadruplet classification of the common theoretical approaches regarding the interactions between globalization and ethnicity or ethnic identity:

a. World system approach, which is based on the famous division of the world into center, periphery, and quasi-periphery. (Tomlinson, 2003);

b. World culture approach, which emphasizes the globalization of culture and predominance of culture on economics and politics. (Featherstone, 1990);

c. World comprehensive approach, which persists on the growing international awareness and its effects on society, government, and international security. (Robertson, 1992); and

d. World capitalism approach, which assumes the dominant international forces in the structure of a universal capitalism. (Ross and Trachte, 1990)

The ways the abovementioned approaches and their views about the consequences of globalization on ethnicity and identity have been interpreted are very variable, that is, from one hand, some interpretations have emphasized the necessity of creating a single universal identity and from the other hand, some others have focused on the resistance of identity against the international culture which rises under the influence of globalization. Throughout the whole paper, we have taken these approaches and continue our discussion with our thought line being consistent with either. It is also worth to mention that issues like ethnicity and identity have a salient position in the theoretical considerations of globalization, and the ethnicities of the Middle East and their related issues are no exception. 


\section{Exploring the mechanisms of globalization in relation with ethnic identity in the Middle East}

It is reasonable to suggest that the process of globalization and the ways in which it affects different spheres of social life in a peripheral region like the Middle East, serve as a doubleedged sword. To put it differently, the present paper at one level specifies a pessimistic approach to this process according to which, globalization is understood as an imposed project. At the other, we clarify a positive approach to the very process based on that globalization is a generalized project, then the paper explores either positive and negative consequences of this project on ethnic identity.

Taking globalization as a historical trend and a conceptual evolution, which brings changes in perceptions, beliefs, thoughts, and tastes of people with its range covering culture and identity, one can pose this question: "Can globalization be applied as an alternative for local identities, and is this process in productive interaction with these identities?

The way we are going to answer this question leads us to illustrate a clear spectrum on one end of which globalization is strongly believed to result in subverting all kinds of local identity, especially ethnic identities. On the other end of the spectrum, however, we are provided with this assumption that globalization generates ethnic differences and increases identity-seeking strivings. In hope of identifying the positive constructive impacts of globalization on cultural identities in general and ethnic identities in particular, we classify them into the below cases:

- Accelerating social mobility, knowledge achievements, increased communications, mutual cultural understanding, embracing plural cultural identities, promoting cultural regionalism, and cultural plurality(Robertson, 1992);

- Directing the international public opinion through communicational networks, launching dialogue among different ideas, cultivating common human values, directing cultural identities to acquire higher tolerance in considering others' opinions(Huntington, 1995), increasing the range of thought tolerance as a prerequisite in the cultural interactions of local identities, and considering inter-civilization mechanisms;

- Increasing diversity-seeking cultural identities and making them to accept criticism with more tolerance, creating contacts between the continental sub-cultures and the international culture, accepting human inter-mind values, promoting human selfawareness, and emphasizing the transnational and ethnic identities;

- Developing values like humanism, thinking universally, joining to the international thought community, and laying the dogmatic racial ethnic and racial prejudices away.

At the other hand, although the national borders and identities are becoming weaker under the influence of globalization, the cultural identities, which are dependent upon locality and localism, will gain more value. (Ardalan, 2000)

If the former theorists considered globalization to be the cause of ethnic groups' integration, their recent counterparts suggest this process to be the cause of rising awareness among the ethnic groups, an element which has provided them with ability to resist to national and international identities. (Maghsoodi, 2000) This approach proposes the ever-increasing trend of ethnic crises and cultural identity-seeking across the multiethnic regions (the Middle East, for instance). (Fukuyama, 2000) Increased levels of 
exchange have been credited as the cause of expanding cultural awareness and ultimately ethnic movements. (Castles, 2001)

Through emphasizing this role and the influences on governments' one-sided efforts in culture assimilation, theorists like Conner, Park, and Castles argue that cultural penetration, hegemony and assimilation, imposing unequal cultural relations, and premium value in cultural exchanges through communications are more influential in generation ethnic challenges and crises than convergence and homogeneity. (2000)

\section{Threats imposed by globalization to the perspective of ethnic identity}

Our second approach promises decreased ethnic conflicts. It has emphasized on the decreasing trend of ethnic conflicts by borrowing the ideas of Tunis and Girts and through evaluating the positive role of cultural and communicational developments in national-state building, establishing convergence, national unity, accelerating the flow of development, and creating a universal culture. (Maghsoodi, 2001)

The rationale behind this approach lies in the fact that the older identities, however, are declining in the process of globalization, and the newer identities, which form the universal culture are getting dominance. Tomlinson is one of the most celebrated holders of this approach. According to him, similar to a flood, globalization is destroying the cultural diversity of the world, declining the local identities, and demolishing the distinctions of the local cultures that form our identity. (2004)

By the dominance of the paradigm of reconstruction in the social sciences, the major approach in theory-making in the field of ethnic identity had been borrowed from the conceptions of Marx and Webber. That approach, however, had been arranged in a manner in which the process of social change had run from traditional to modern, simple to complex, and particularism to generalism. (Castles, 2001) In such context, therefore, ethnic issues are assumed as belonging to particularism or pre-modern, which are being evaded by the process of reconstruction. Therefore, if they get power again, their results will be as incomplete as those of reconstruction. Then, it is why the theorists do not consider them important. (Maghsoodi, 2001) The traditional theories about development and ethnic identity insist on this point that the economic and industrial backgrounds, lack of national investment, and lack of national coherent markets have made grounds for the maintenance of regional and local markets to continue their limited exchanges among their ethnicities. (Shayegan, 2000) To sum up our discussion about the key positive impacts of globalization on ethnic identity movements, the below items are noteworthy:

- Through the development of ethnic movements and fulfilling three approaches: declining the sovereignty of the central government; difficulties of suppressing ethnic identities by the government; and, intensifying ethnic sensitivities due to the subsequent opportunities of globalization (Shult, 2003);

- The grounds for identity-making are transformed during reconstruction (Giddens, 2002). So, the more the tradition gets paler, the more the individuals try to adopt creative lifestyles and succumb to the traditional tools of identity-making to get rid of the crises of identity. It is why, then, that these individuals are easily absorbed by the movements that promise reconstruction and renewal of such spaces through which their opposition strategies to globalization. The local identity movements, as a result, find an appropriate opportunity to appear, among which the ethnic movements are more noticeable. (Golmohammadi, 2002) 
- Inability of the national states, especially those of the Middle East, in establishing security and order, increasing the level of transnational forces and the international institutes, and the shift of the international community from political identity to cultural identity are some examples of the elements, which have strengthened ethnic identity movements in the region. (Ghavam, 2004)

- The era of globalization coincides with the weakening role of national identities both at national and international level. It is the vintage of elements such as transnational companies and international groups that are the source of increasing ethnic awareness and ethnic conflicts. (Mawlaee, 2000) At the other hand, through the following patterns, globalization has undermined ethnic identities: collapsing local identities in the light of the international systems, international capitalism, powerful government supports of the local states and reinforcing them. (Castles, 2001)

\section{Ethnic evolutions in the light of globalization's consequences to ethnic identity}

In terms of the consequences of globalization to ethnicities in the multi-ethnic region of the Middle East, the appearance of major evolutions is common. The most noticeable evolutions in this regard being:

- Establishment of the virtual ethnic communities: ethnic communities have formed over time, while the virtual ones are the product of communication era. They divide such communities into centralized ethnic communities, scattered ethnic communities, and virtual ethnic communities. They stress that, however, the term "virtual" should not be understood as an approximate incomplete community, rather they are alive and active which defend their rights through appropriate pressure groups.

- Undermining the nation-states: due to inability in establishing order and security, economic welfare, and socio-political development in the Third World countries, the international community seeks to replace maximal governments with minimal ones, and then to reinforce ethnic identity-seeking movements.

- Reinforcing ethnic identity-seeking: based on the cultural features(language, religion, and historical traditions, for example) and under the influence of the shared experiences of injustice, exclusion, and ethnic identity-seeking, globalization has directly reinforced ethnic identity-seeking.

\section{The Middle East and the historical challenges to identity}

Theorists like Marx, Bernard, Small, and Park believe that conflict and tension is a positive non-conflicting function. They also argue that conflict not only results in group coherence, but also in generating group identity. (Coser, 1959) The Middle East is a region has been more than other points engaged in different conflicts during its history. Out of the occurred 150 conflicts of the recent conflicts in the world, some 30 cases have been more or less related to this part of the globe. (Ja'afari, 2009)

The origins of identity crisis, and particularly ethnic identity crisis, in most of the states of this region gradually developed and appeared as a primitive version of nationalism with two apparent dimensions: first, the rise of ethnic identity and second, growing tendencies toward autonomy. (Ja'afari, 2009) 
In the preceding century, the Middle East encountered an era fraught with ups and downs and underdevelopment; in this situation, the region had no choice except for embracing modernity as a tool for getting out of that destructive status. Most of the region's states, in the new situation, failed to establish their native structures and patterns. Being dependent on oil economy and world capitalism, at the other hand, added to the dilemma and vanished the opportunities of this region in developing their native mechanisms. Still this correlation has diffused to other areas (identity, for example). (Ja'afari, 2009)

\section{The continuation of identity crisis in the Middle East in the era of globalization}

In the literature, the term "globalization" has been understood in a sense with its economic dimension more salient (Wallerstein, 1997) and has continued to be so under the influences of neo-liberal policies of Reagan a Thatcher. With the collapse of the former Soviet Union, this situation developed and since the late 1990s, we have noticed its widespread sociocultural outcomes.

Throughout the Middle East, the generic identities (e.g., ethnicity, language, and culture) have prevailed over other forms of identity. (Ghahremanpoor, 2002) Lack of harmony between ethnic and lingual borders with national borders of the countries of this region, at the other hand, has exacerbated this situation. Some conflicts resulting from having a onesided definition of identity, among others, being: the Arab-Israel War of 1967, Egypt's interventions in Iran-Iraq War, and Iraq's invasion of Kuwait in 1990.

The globalization of culture requires free stream of information, ideas, and the knowledge, which allows subjectivity and objectivity to grow while encompassing every aspect of life. The importance of reconsidering ethnicity and ethnic identity in this era in the context of the Middle East lies in the fact that these characteristics are some useful instruments for reacting against globalization. (Giddens, 2002)

In most of the capitalist countries, sub-national identities are presently defined according to the political affairs of day (Robertson, 1992), gender (Buzan, 2003), or political reform (Wallerstein, 1997). Across the Middle East countries or even in the Third World, in contrast, ethnic identities are defined in terms of race, territory, and language and are always characterized with a hue of massacre, chaos, and bloody clashes. (Ghavam, 2004)

In this sense, no matter we understand globalization whether as the collapse of governments, sovereignty, or even world order which is based on the scattered local, individual, ethnic, and global identities(Buzan, 2003; Wallerstein, 1997), this problem remains that the identity borders of the Third World seem unprecedentedly bloody(Giddens, 1991) and asks for reconsidering nationalism, sub-nationalism, and ethnic identity. The recent unrests, which occurred in North Africa and still are flaming, can testify our claim.

\section{Conclusions}

Globalization serves as a double-edged sword for ethnic identities and movements; in shortrun, it entails the promotion of ethnic movements and identities, however, in long run, in the absence of some pivotal elements (e.g., government support, international potentials, rich written heritage, and non-monopoly in a certain country), the culture of these ethnic identities will collapse.

In the era of globalization, our globe tends to experience a new phase of evolutions which are essentially different with what has been experienced by now. There is no doubt that in 
this situation, no country will be exempt from the outcomes globalization brings about. At this time, the governments of the Middle East cannot, without considering the world's economy, culture, and politics' requirements, make their decisions independently. In the light of globalization, the governments will be restricted in taking independent measures and establishing wayward policies, therefore, their control over the current of products and information will reduce. (Suizi, 2000)

Globalization has resulted in encouraging identity-seeking demands across the multi-ethnic regions. If such demands are not responded with intellectuality, one can consider them as some effective levers that can threaten central governments and draw on decreased authority and increased identity crises. If these crises are recognized, as a result, we can use them as appropriate potentials. (Shult, 2003)

However, finding a democratic solution for the issue of ethnicities in the Middle East is amongst the major paradigms of internal policies, and the international community has always called for such solution. Exclusion, murder, or cultural exploitation of the minorities cannot decrease from the predicament; the aggressive military reactions of internal groups in this region are the aftermath of power monopoly, military governments' iron fist policy, and lack of sufficient grounds for the rise of civil society. When masses, ethnicities, and minorities are deprived from their legitimate rights (individual and collective freedom for requesting political, social, and cultural rights, for example), what they will find is clenched fists, then it is why interaction and participation are replaced by de-empowerment, decentralization, and the current historic vengeances.

It stands to reason that globalization undermines national states and encourages ethnic identity-seeking; nevertheless, the final solution for this problem is through recognizing the identities and making decisions based on collective participation. Having easier access to the mass media, respecting human rights, and the dominance of democratic discourses have cheered demands for ethnic identity.

In the face of the taken efforts for establishing regional and world cultures in the Middle East, still ethnic identity tensions and conflicts exist in this region and continue to be. It is the efficiency of the ethnicities that promises their survival in the future. (Fukuyama, 2000) Globalization of the economy and growing dependency of this region on oil has increased its vulnerability and this, at last, has led to increasing tendencies toward authoritarianism across the region. (Suizi, 2000) The interventions from the superpowers in the internal affairs of this region which sometimes has taken place in form of military invasions have deepened the roots of the existing conflicts. The declined economic power of these countries (Suizi, 2000) and their failures in international politics (Wallerstein, 1997) over the last two decades are two evidence for this claim.

Fukuyama (2000) and Huntington (2002) argue that in the globalization age, ethnic identities will preserve their authenticity and keep on living, while due to the rise of necessities in the world, new identities will emerge unavoidably. Currently, the threatening ambiguities and challenges of identity-seeking are sill potent across this region. With respect to the spread of communication systems, however, the world is expected to be well-aware of the grievous situation the nations and ethnicities of the Middle East are suffering from.

\section{Recommendations}

For the purpose of our discussion, here we want to review the necessity and inevitability of globalization and pervasive mechanisms of ethnic identity-seeking. Resisting to these 
trends, however, seems to be impossible. If we accept this supposition that the world tends to go toward democratic systems, the local collective identities are expected to co-exist with more harmony with the macro collective identities, as they are not in severe clash with each other, and it is the dominance of a given identity on others that cannot be tolerated.

From the other hand, globalization has created a competitive space in the Middle East that allows those communities which are more flexible, pluralist, tolerant, and respectful to the rights of other nations to join the new world order with less inconvenience.

What continues our discussion is a series of recommendations, which seem to us to be of great applicability in resolving the current pandemic tensions and challenges that have plagued this region:

- Recognizing the right of ethnicities in using their mother tongue and culture;

- Engaging the ethnic minorities in the collective communications and management;

- Avoiding dissuasive actions in relationships with local elites;

- Identifying, enriching, and promoting social capital;

- Reforming the structures of socio-cultural systems;

- Reforming education systems by considering cultural diversities;

- Allowing diverse ethnicities to take part in macro-level social planning; and

- Cultivating the rules of competition, opportunity-making, promoting public culture, and providing free political spaces.

Minorities and ethnicities of the Middle East, then, have no option but making grounds for cultural self-awareness as a prerequisite of human self-awareness. They should be also encouraged, from one hand, to promote their self-esteem, confidence, and readiness to react to the challenges imposed by globalization, and develop their cultural identity, from the other hand, in the plural democratic context of the world culture.

\section{Acknowledgments}

The authors wish to express their deepest thanks to Profs. Aleksandar Lazinica and Niksa Mandic who sincerely supported us from the beginning to finish and helped us in bringing this paper to press. Grateful acknowledgments also go to Dr. Adel Fatemi, Research Deputy of Islamic Azad University, Sanandaj Branch, for his supports and encouragements throughout the project. And last, but not least, as a meagre token of our love and gratitude, we dedicate this paper to our dear "Avin".

\section{References}

Ahmadi, Hamid.(2003). Ethnicity and ethnicalism in Iran. Tehran: Ney Press.

A.Lake, David and Patrick Morgan. (1997). Regional orders building security in a new world. Pennsylvania: The Pennsylvania State University Press.

Ardalan, Asa'ad. (2000). The phenomenon of globalization and cultural rights. Quarterly of Foreign Policy(4).

Burton, Rolan. (2001). Political ethnology. Translated into Persian by Naser Fakoohi. Tehran: Ney Press.

Buzan, Barry, and Ole Waever. (2003). Regions and Powers: The Structure of International Security. Cambridge: Cambridge University Press. 
Cantori, Louis. J. and Steven Spiegel. (1970). The international politics of regions: A comparative approach. Los Angeles: University of California Press.

Castles, Stephen. (2000). Ethnicity and globalization. London: SAGE Publication.

Castles, Immanuel. (2001). Information era, economy, society and culture, and power and identity. Translated into Persian by Hassan Chavoushyan. Tehran: Tarhe No.

Conner, Walker.(1994). Ethno-nationalism: the quest for understanding. Princeton: Princeton University Press.

Coser, Lewis. (1956). The function of social conflict. New York: The Free Press.

Duerty, James. And Robert Falter Graph. (1993). Contradictory theories in international relations. Tehran: Ghoomes Publication. P. 296.

Ehteshami, Anoushiravan. (2007). Globalization and geopolitics in the Middle East: Old games, new rules. London: Routledge.

Eyvazi, M. Rahim. ( 2002). Globalization and ethnic identities. National Studies Quarterly. $\operatorname{Vol}(10)$.

Featherstone, M. (1990). Global culture: nationalism, globalization, and identity. London: SAGE Publication

Fischer, Stanley.(2003). Globalization and its challenges. Ely Lecture presented at the American Economic Association meetings in Washington, DC on January 32003

Fukuyama, Francis. (2000). The end of order. Translated into Persian by Abbas Tavasoli. Tehran: Iranian Society Press. P. 105.

Ghahremanpoor, Rahman. (2002). The Antecedence of national identity in the Middle East (from the collapse of Ottoman Empire to the oil crisis of the 1970s). The Quarterly of the Middle East Studies (30) P.40.

Ghavam, Seyed Abdel Ali.(2004). Globalization and the third World. First Edition. Tehran: The Foreign Affairs Ministry Publication.

Giddens, Anthony. (1991). The consequences of modernity. Cambridge: Polity Press.

Giddens, Anthony. (2002). Runaway World: How Globalization is Shaping our Lives .London: Profile Books.

Golmohammadi, Ahmad.( 2002). Globalization, Culture, and Identity. First Edition. Tehran: Ney Press.

Held, David. (2003). Globalization and its opponents. Translated into Persian by M. Karbasian. Tehran: Cultural-Scientific Publication.

Hirts, P. and G. Thompson(1996). Globalization in question: The international and possibilities of governance. Cambridge: Polity Press.

Huntington, Samuel. (1995). The theory of civilizations' encounter. Translated into Persian by M. Amiran. Tehran: The Office of Political studies, The Foreign Affairs Ministry.

Imanuel, Wallerstein. (1997). The capitalist world economy. Cambridge.

Ja'afari Valdani, Asghar. (2009). Challenges and conflicts of the Middle East. Tehran: Research Center for Strategic Studies.

Maghsoodi, Mojtaba. ( 2000). Culture, communications, and ethnic developments. Tehran: The Quarterly of National Studies (2).

Maghsoodi, Mojtaba. ( 2001). Ethnic developments in Iran. Tehran: Institute of National Studies.

Martin, Dominique, and Jean-Luc Metzger and Philippe Pierre. (2006). Sociology of globalization. International Sociology. July Vol21(4).p. 499-521. 
Mawlaee, Ayat. (2000). Human rights and national sovereignty. Journal of EconomicPolitical information (155-6). P. 125.

Miz, Marya. (2006). The war without border, the new colonialization of the world. Translated into Persian by Nahid Ja'afarpoor.

Morgan, Patrick, M. (1972). Theories and approaches to international politics. California: Consensus Publishers, Inc.

Naderpoor. 2003. Globalization :fears and hopes. First edition. Tehran: Hadithe Emrooz Publication.

Robertson, R. (1992). Globalization: social theory and global culture. London: SAGE Publication.

Robertson, David. (2004). The Routledge dictionary of politics. London: Routledge.

Ross, R. and K. Trachte (1990). Global capitalism: The New Leviathan. Albany State University of New York Press.

Shayegan, Daryush.(2000). The new fascination: the patched identity and fluid thought. Translated into Persian by Fatemeh Valyani. Tehran: Foroozan Press.

Shult, Yan Art.(2003). A subtle look at globalization. Translated by Maso'd Karbasyan into Persian. Tehran: Scientific-Cultural Press.

Suizi, Paul. (2000). More or less about globalization. Tayehaye-Eghtesad Vol(74). PP 80-82.

Tomlinson, John. (2003). Globalization and culture. Translated into Persian by Mohsen Hakimi. Tehran: The Center for Cultural Research, International Center of Civilizations' Dialogue.

Zakeryan, Mehdi. (2003). Human rights in the Middle East. Tehran: The Center for Academic and strategic Studies of the Middle East. P. 15.

Ziegler, David. (2000). War, peace, and international politics. New York: Longman. 


\title{
Fostering a "Monozukuri (Manufacturing)" Organization Suitable for the $21^{\text {st }}$ Century Digital Economy
}

\author{
Toshiko Asai ${ }^{1}$, Hidehiko Hayashi ${ }^{2}$ and Akinori Minazuki ${ }^{3}$ \\ ${ }^{1}$ Information Workshop, co. \\ ${ }^{2}$ Dep. of Technology and Information Education, Naruto University of Education \\ ${ }^{3}$ Center for Information and Technology and System, Kushiro Public University
}

Japan

\section{Introduction}

The origins of Japanese "Monozukuri" (literally "making things") can be traced back to the history of Kyoto. For about 1,000 years, starting with the relocation of the capital from Tokyo in the year 749, Kyoto was the seat of government and the heart of Japanese culture, and became the birthplace of many industries. In the midst of this long history, even now, in the 21st century, Kyoto is the focus of attention from both inside and outside of Japan as a region where traditional industries that are representative of Japan coexist with industries at the cutting edge of the era. Many of the world's leading companies have established bases of operation in Kyoto, supported by advanced "Monozukuri" technologies.

Kyoto's industries have brought color to people's lives in all four seasons, for example through kimonos and various other crafts, as well as traditional foods. The "Monozukuri" industries of tradition and culture developed along with the community while forming social "division of labor" structure, functioning as the platform that gave rise to Japan's modern industry during the $20^{\text {th }}$ century.
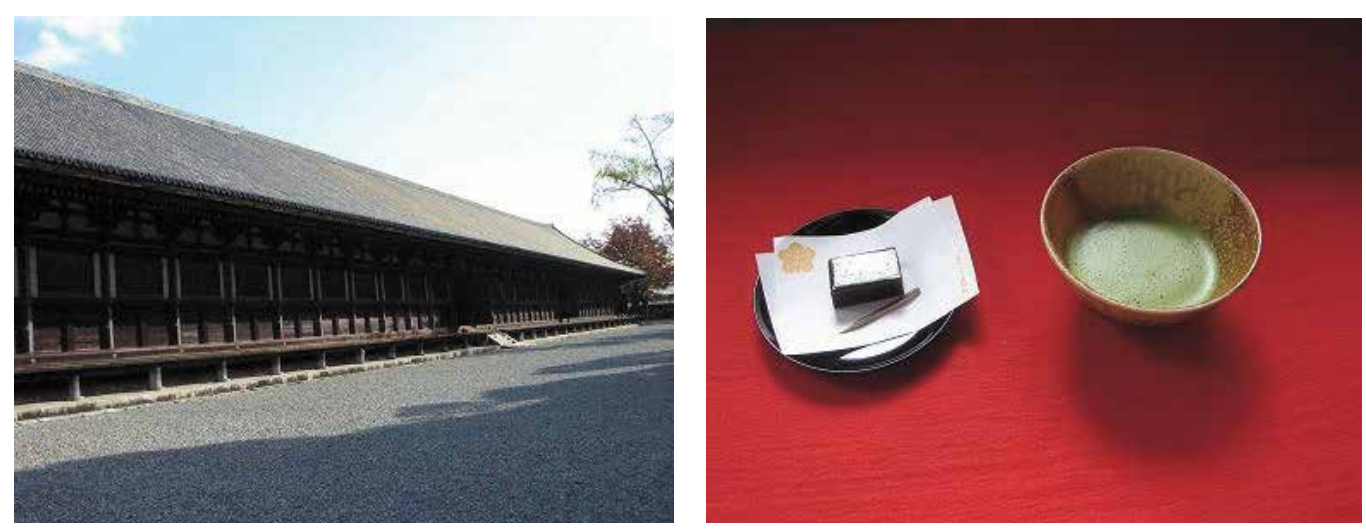

Fig. 1. Temple (Sanjusangen-do) and Sado(Ohara-Sanzenin) - Traditional Craftsmanship 
Until the capital of Japan was relocated to Tokyo, Kyoto was called "Heian-kyo," and for about 1,000 years, it demonstrated continuity in Monozukuri even in the midst of war and great fires. It is important to think about what factors were behind this strength of continuity. One important factor was the history of Monozukuri, which fostered an original awareness of beauty that combined a different culture with natural laws, and a culture of craftsmanship that was passed on continuously across countless generations. These analog factors offer extremely important hints for modern men seeking out spiritual richness even now, in the $21^{\text {st }}$ century, when lives are lived on a more digital social platform.

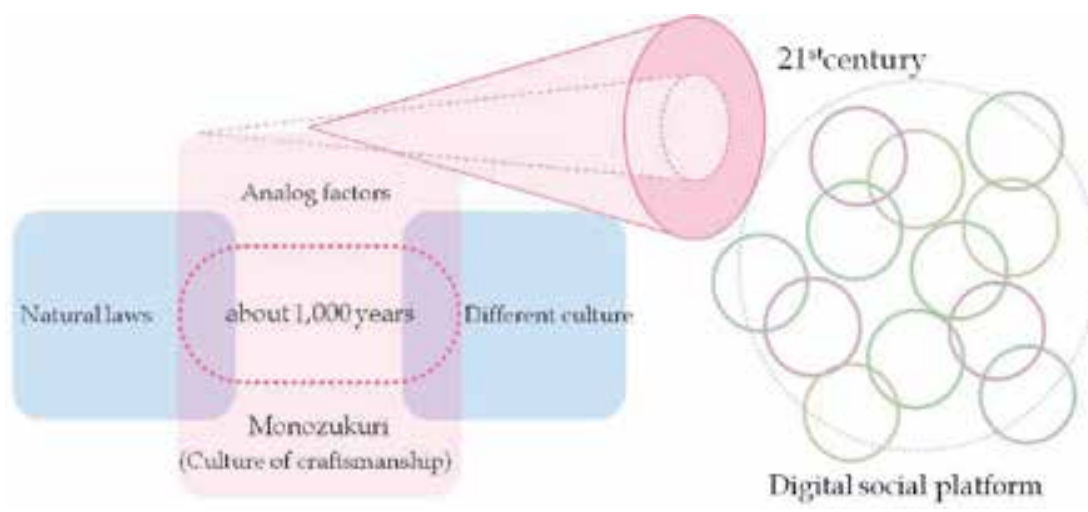

Fig. 2. $21^{\text {st }}$ century, digital social platform

\section{Japanese technology}

The relocation of the capital from Kyoto to Tokyo, in what was called the Meiji Restoration, marked the beginning of modernization in Japan. At that time, railway, steamships, telegraphs, and other new technologies were purchased from the west, and then modified in a Japanese style. It is said that the strength of the Japanese manufacturing industry is in process innovation. In order to achieve its mission of creating more efficient, less expensive, higher quality products based on sciences and technologies born in the west, Japan made improvements and developed applications, and the innovations that arose through these processes were held in very high esteem in countries around the world.
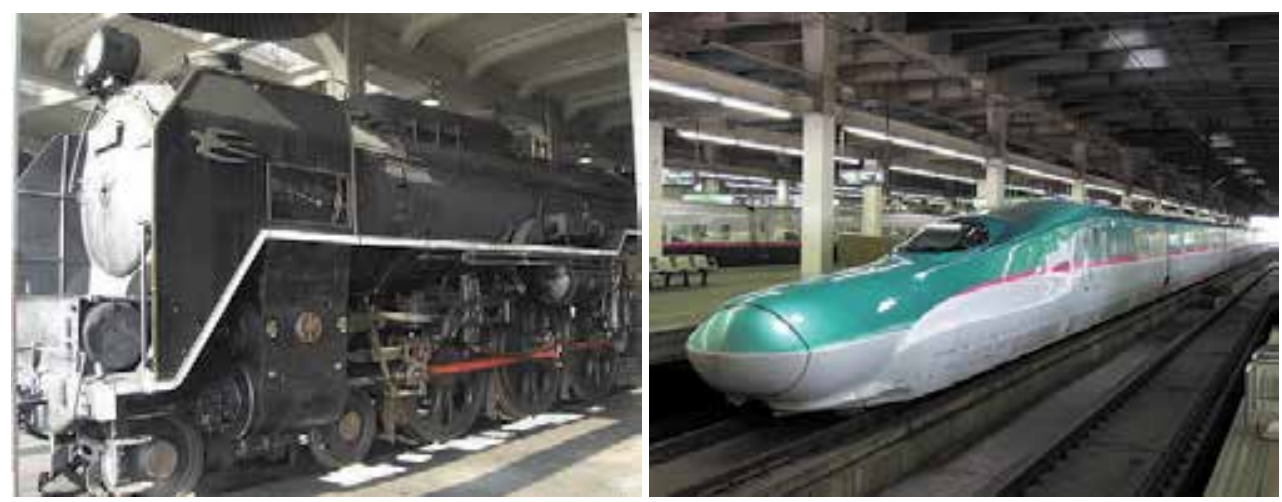

Fig. 3. Steam Locomotives and the Bullet Train (Hayabusa2011) 

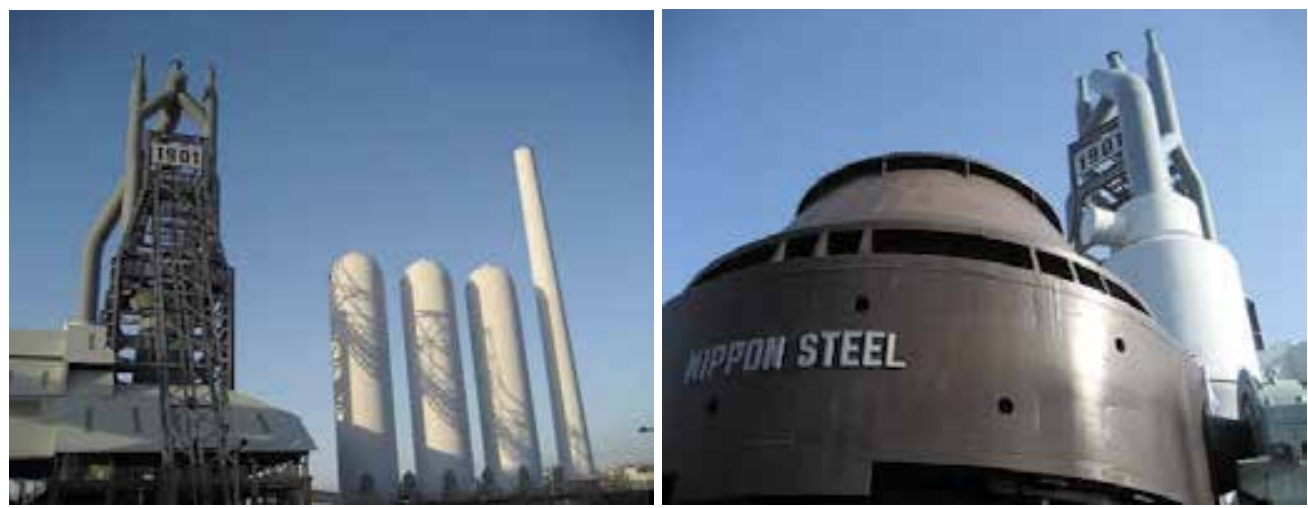

Fig. 4. 1901: Nippon Steel Yahata Works

The Meiji Restoration and the birth of modern Japan that followed were embodied by a catch phrase that could be translated as "National prosperity and a strong military"; in other words, the goal was to form a nation-state through the expansion of domestic production and the creation of military power. Based on this approach, the Meiji government built on the attempts at modernization in gun manufacturing initiated by the Bakufu government, established as an extension of the steel manufacturing and civil engineering technologies, and put railroads in place. Then, by establishing army and navy arsenals to introduce the latest military technologies, the government pushed forward in building platform technology industries introduced from European countries. In this way, Japan came through the Sino-Japanese War and the Russo-Japanese War to enter the ranks of the world's industrial states.

There has been an emphasis on the fact that Japan's sciences and technologies have been learned from the west since the Meiji Era, and there is a deeply rooted belief that Japan's society as a whole is an "imitation" or "borrowed" from the west. This has created a social environment in which it is difficult for Japanese people to assert with confidence that Japan has created its own original sciences and technologies. Monozukuri in Japan did not begin with the modernization seen in the Meiji Era; there was a foundation of Monozukuri that formed the base upon which that modernization and the advanced western technologies of that era could be assimilated, understood, and put into practice. This is origin of Kyoto's spirit of Monozukuri.

One of the reasons for Japan's successful modernization through rapid industrialization following the Meiji Restoration was that for around 1,000 years, mainly in Kyoto, people in all levels of society, particularly during the Edo period, had a high level of knowledge, and the literacy rate was also very high. In addition, the Japanese as a people had a strong interest in new technologies, an ability to absorb those technologies, and a desire to make things with their own hands.

In other words, it would have been impossible for Japan to achieve modernization of its domestic industries simply by introducing the sciences and technologies that were the fruits of modern civilization in the west. Japan, located in the easternmost part of Asia, was able to achieve a rapid penetration of modern technologies after the Meiji period that other countries in Asia failed to do, and to demonstrate substantial industrial and economic development after the 2nd World War as well. This achievement cannot be explained without the hypothesis that Japan already had outstanding social and technological 
structures and systems even from before the Meiji period that acted as a platform for modernization. During the era before modern industrialization, for a period of more than 1,000 years, from the birth of Monozukuri centered in Kyoto to the Edo period, Japan's social systems and the foundations of Monozukuri played the role of an adhesive that enabled fundamentally different modern technologies to take root in Japan, and at the same time played an important role in promoting the understanding and acceptance of these technologies in Japanese society. In order to investigate the roots of the international competitive superiority of Japan's Monozukuri, we just reevaluate and reconfirm Japan's social climate, foundations, systems, and traditional technologies and techniques, from the perspective of creativity.

These foundations have been cultivated gradually up to today, though their forms have changed. Even today, Japan is capable of a creative Monozukuri that can respond to new requirements from the market or from the era in general.

\section{Kyocera in Kyoto}

The traditional technologies and techniques that live even today in modern advanced industrial fields are an important element in the formation of the creative and international superiority of Japan's Monozukuri. Based on this awareness, if we look closely at the cutting-edge industries and Monozukuri in our modern society, we will find that in a variety of industries and markets, Japan's traditional technologies and techniques, as well as traditional approaches based on original Japanese social climate and climate conditions, have all come into play. Here, we will describe one important case. In the field of ceramics technologies, it is easy to see that countless technologies and techniques cultivated through Japan's traditional industries are used in recent cutting-edge technology fields. The strong heat resistance and light weight of silicon nitride are used to increase engine response. The photo below is a cross-section of the engine from a Japanese sports car, the Nissan GTR. Using a new forming method developed by Kyocera in Kyoto that demonstrates outstanding precision and productivity, Nissan developed and manufactured a ceramic turbo charger rotor for its sports car engines. The development of this component brought about an innovation that enabled Japanese sports cars to compete with some of the top manufacturers in the world, including Porsche in Germany. Kyocera's outstanding technologies contributed to a $36 \%$ increase in response and a $34 \%$ improvement (reduction) in the moment of inertia.
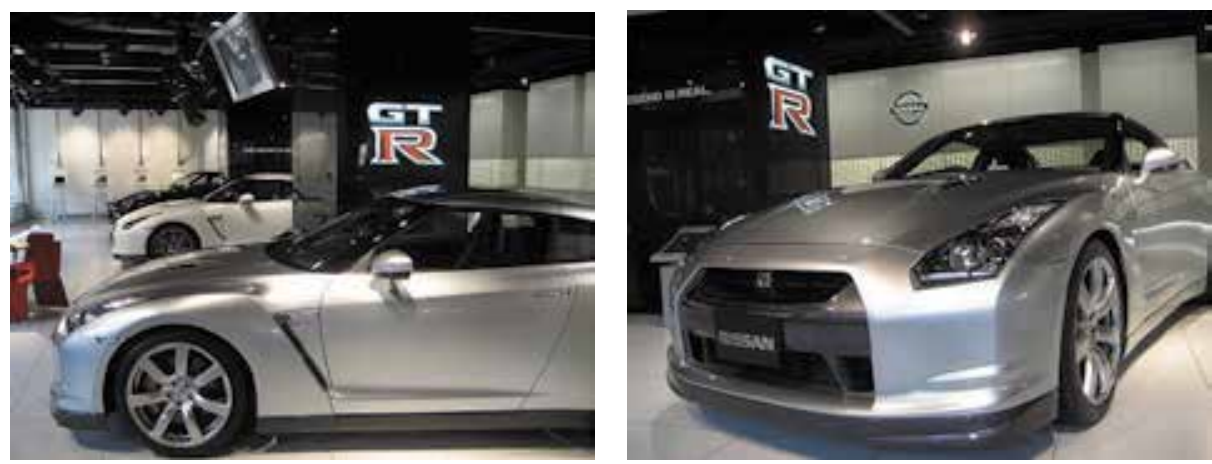

Fig. 5. NISSAN GTR body-Premium Super Sport Car 

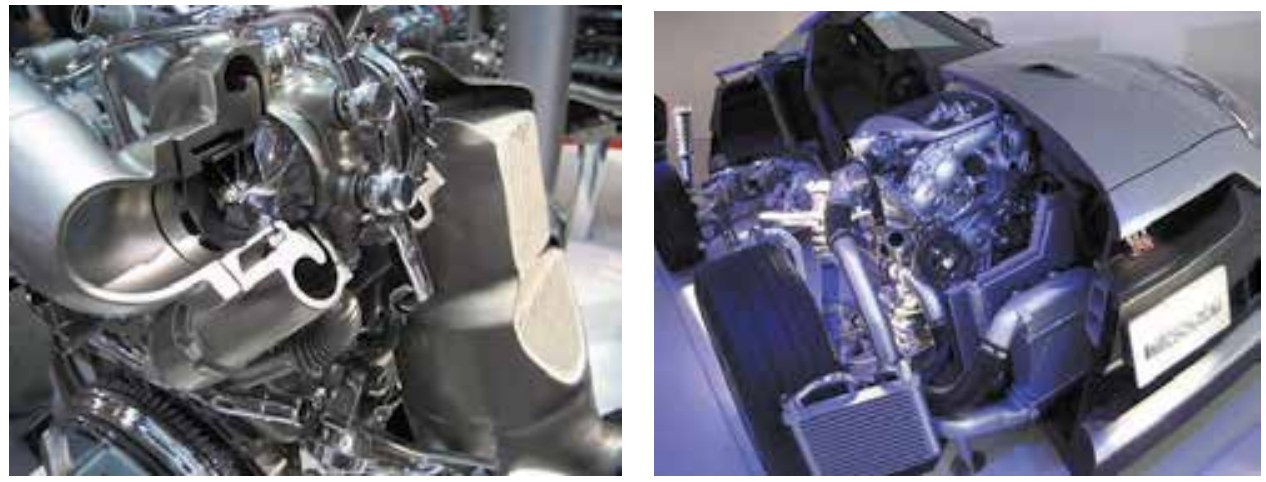

Fig. 6. Kyocera Ceramic Turbo Fin in the NISSAN GTR engine

Kyocera has other ceramic ECU technologies that are closely related to the application of IT in automobiles. ECU modules using multi-layered ceramic substrates required advanced mounting technologies. Development was achieved using Kyocera's extensive experience and data based on an unparalleled knowledge of the unique characteristics of these multilayered ceramic substrates. Automotive components also require a high degree of reliability. Kyocera's automotive materials are developed based on diverse forms and technologies accumulated over many years; they have an outstanding track record of automotive applications, and have contributed to the increased export of Japanese automobiles overseas. Kyocera is involved in a wide range of fields, from solar power generation systems and substrate materials, components, and devices to integrated systems, and has contributed to the development of everyday social infrastructures, mostly related to the automotive field, based on communication technologies.

In this way, Kyocera's Monozukuri has accumulated many forms and places an emphasis on the relationship with the surrounding circumstances. Each type of Monozukuri has a different definition depending on the form and circumstances, and companies are the shared embodiment of Monozukuri.

\section{4. "Form," learning + obedience - breakdown - breakaway}

Regarding "Form," if the basic form has not been mastered, then subsequent changes cannot be expected. The training of manpower for handling form requires "circumstances," and the structures involved here involve knowledge that is the result of accumulated human experience and learning. Knowledge is an important asset that is obtained through a long process of trial and error, and which is communicated through the medium of "circumstances" in a specific "form." The "form" of a company contains formless elements such as corporate culture and tradition. If knowledge is a "form" that is acquired by humans through a long history, then in the beginning, then in the beginning, it is essential to learn the initial "form," and Japanese people have practices this for about 1,000 years. Form changes through "learning + obedience - breakdown - breakaway." In other words, form is similar to the teachings of "obedience - breakdown - breakaway," which can be found in the traditional Japanese martial arts and "Sado," the art of tea. "Form" is learned even before the process of "obedience - breakdown - breakaway," so it is important to begin one's studies from this process of "learning + obedience - breakdown - breakaway." The Meiji Restoration, which was the embodiment of Japanese modernization 100 years ago, was not 
an imitation of the west, but learning from it. The 20 year period from the introduction of IT and the Internet into Japan during the latter half of the $20^{\text {th }}$ century was a period of "learning + obedience - breakdown - breakaway."

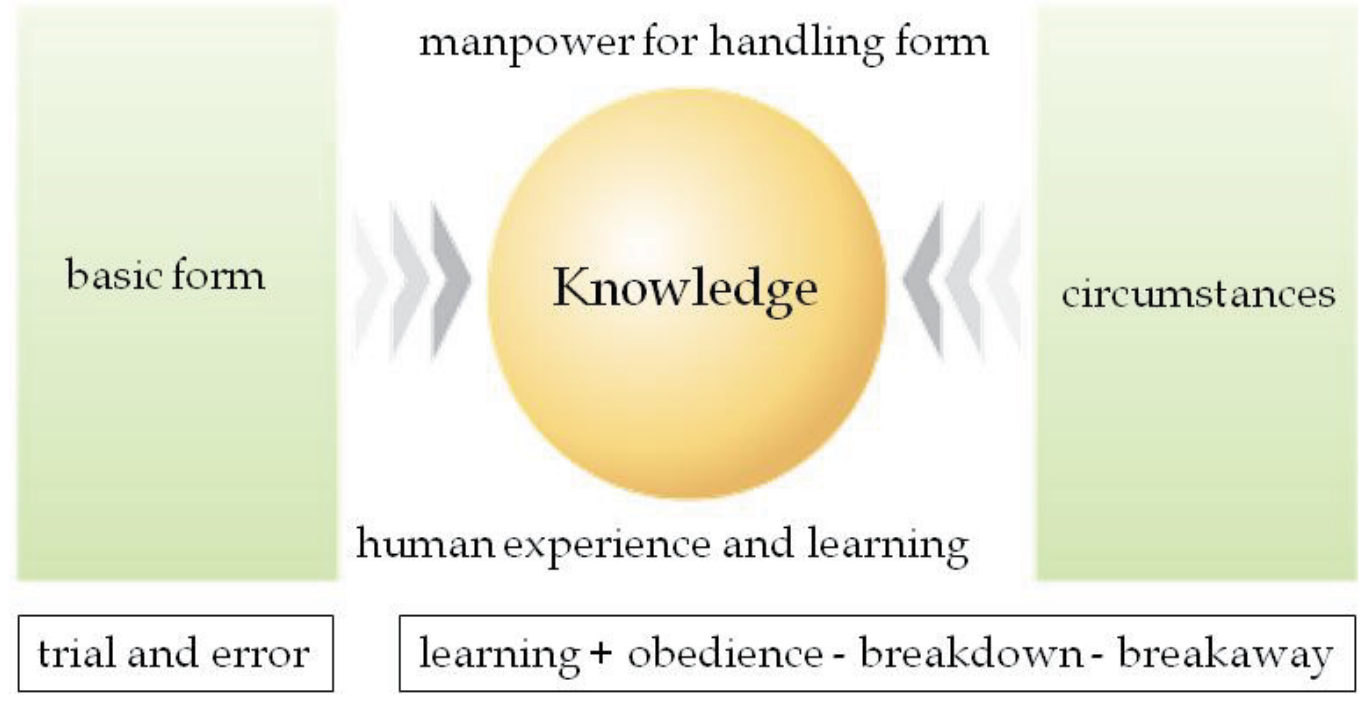

Fig. 7. Knowledge is a "form"

The concept of "obedience - breakdown - breakaway" was born from Higashiyama Culture (the era of the Shogun Ashikaga Yoshimasa); it rippled outward from Noh theater (the actor Kanami) to the art of tea, and from there was adopted by masters of the martial arts. This spirit was also passed on from the Edo era to the modern day in Japan through the apprenticeship system in Monozukuri. Following is a summary of the description of "obedience - breakdown - breakaway" as found in the journals of Yamanoue Soji, on the art of tea:

15-30 years of age: The period of obedience. The student follows the teacher's instructions, and focuses on the practice of being obedient to these teachings.

30-40 years of age: The first stage of "breakdown." The student begins to find his own approach, accounting for about $50 \%$ of the whole.

40-50 years of age: The second stage of "breakdown." The student strives to apply new and creative approaches (using methods that may be completely at odds with the teacher's).

50-60 years of age: The final stage of "breakdown." The student carefully studies and reexamines the master's works, and prepares for the next stage; that of "breakaway."

70 years of age: The stage of "breakaway" is a result not only of spiritual effort, but of an inborn talent; this stage only occurs rarely, when the student has reached the level of the master, who himself has achieved breakaway.

In the case of traditional Japanese Monozukuri, the most fundamental items are thoroughly learned during the "obedience" stage of "obedience - breakdown - breakaway," but the truly important thing is not simply to learn from the teacher, but to be obedient to the process of feeling, thinking, and learning for oneself. Right now, Monozukuri in the backdrop of Japanese IT is in this "obedience" stage. 
"Circumstances" are required to change "form," and these circumstances could be thought of as transcending time and space. In terms of "transcending time," we can "interact" with Christ by reading the bible, and similarly interact with Socrates or Buddha through their teachings. Today, one example of "transcending space" is that through the Internet and ICT (information and telecommunication technologies), we can interact with and learn from people anywhere in the world. In this sense, circumstances transcend both time and space.

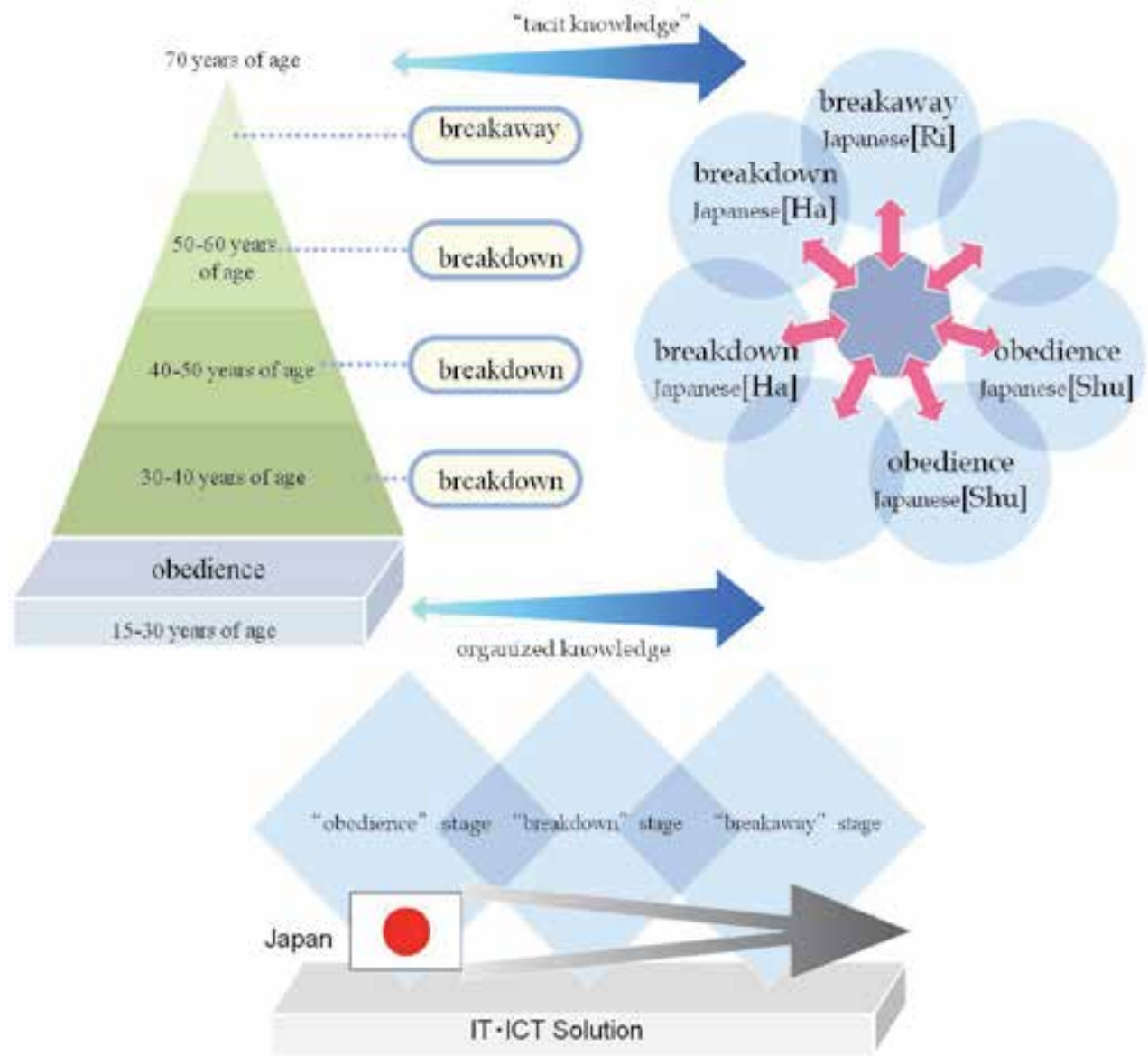

Fig. 8. Obedience - breakdown - breakaway

Human capabilities are based on our capacity to take "tacit knowledge" and express it as "organized knowledge." Knowledge is expressed and shared to become organized knowledge, and this in turn become the practical knowledge of companies. As long as knowledge exists only on an individual level, it is not shared. The cultivation of tacit knowledge is related to both an internal and a cultural aspect, so it is necessary to develop original learning curriculums that are suited to the climate and characteristics of each country and its people. In other words, if knowledge does not become organized knowledge, then individual tacit knowledge cannot become the assets of an organization. In a company, it is important to provide the circumstances in which individual tacit knowledge can be expressed and shared in order to become organized knowledge. Even if those 
"circumstances" do not have a formal structure, in Japan, one can see cases in which meetings take place at drinking establishments every day after work, where colleagues gather to exchange opinions. In the west, meetings after $5 \mathrm{pm}$ would no doubt be criticized. In order for "forms" to improve, there must be circumstances that allow those forms to compete and mutually develop. Forms change by competing in these circumstances. Meetings at drinking establishments promote common understanding through mutual exchanges of information, and through the generation of a psychological energy, they promote collaborative work with other persons and other companies. They also promote learning for the future. In this way, through a process of improving output, these informal meetings act as the circumstances that can be expected to further assist in mutual exchanges of information.

\section{5. "Group" common body of practice}

The term "company" is used now, but the common bodies that have practiced Monozukuri in Japan for the past 1,000 years share the same concept as that espoused by Wenger, the Swiss knife manufacturer. This common body of practice is a group of people who share an interest in a given theme, related problems, enthusiasm, and other factors, and deepen their knowledge and skills in that field through continual mutual interactions.

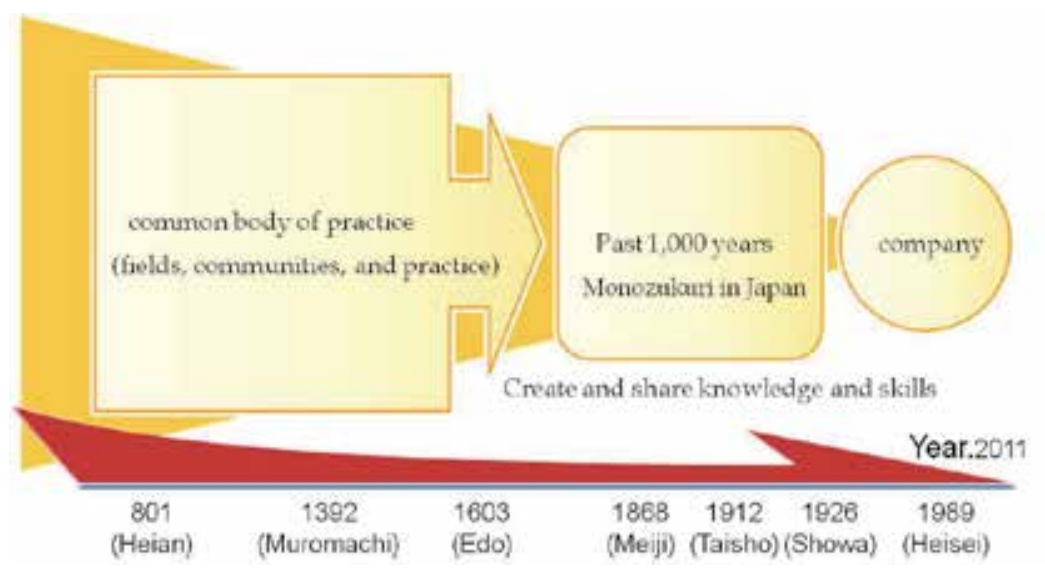

Fig. 9. Common body of practice

The common bodies of practice create and share knowledge and skills, and as a result the design of learning in those common bodies of practice defines levels of participation; for example, participation (or lack thereof) in the common body, creative action, and interactions or collaborations with parties outside of the common body. The common body of practice also has component elements: fields, communities, and practice. The most notable of these is "fields"; as in the case of specialized fields, there are common characteristics such as: Creating a common platform among the members to create a sense of unity; securing a promise from the members and other related parties regarding the community's goals and values, and justifying the community; and inducing contributions and participation from the members, leading in learning, and giving meaning to action. Thinking about it in this way, compared to "circumstances," the "common body of practice" is a more specific concept, and can be thought of as a connotation of circumstances. The 
common body of practice is a concept that further narrows down the focus on learning and knowledge sharing. Particularly given the approach of being obedient to and evolving "form," it is important to use the knowledge of the common body of practice more effectively. The knowledge base in traditional Kyoto crafts provides important hints regarding the synergistic effects of Japanese Monozukuri. In the orthodox participation in the common body of practice by others as seen in Monozukuri (e.g., in traditional crafts), skills are acquired simultaneously with participation in the common body that possesses those skills. It is necessary to deepen the degree of participation on those common bodies, and to increase involvement. First of all, participation in the common body is a process of learning, and at the same time, it promotes the construction of identity as a member of that body. In this way, the framework of orthodox participation by others can be seen as a kind of trinity: an acquisition of knowledge and skills; participation in the common body; and the construction of an identity as a component member. Each of these three elements affects the other, creating a synergistic effect. If the acquisition of form transcends simply learning skills and knowledge, then this is the result of the synergistic effect. The acquisition of "form" could thus be seen as a result of participating in the common body, and learning the history that is incidental to those skills and knowledge, the learner's own approaches and beliefs with regard to his or her skills, and the overall skills that are supported by these other elements. Automakers such as Honda and Toyota are participating in this type of common body of practice.

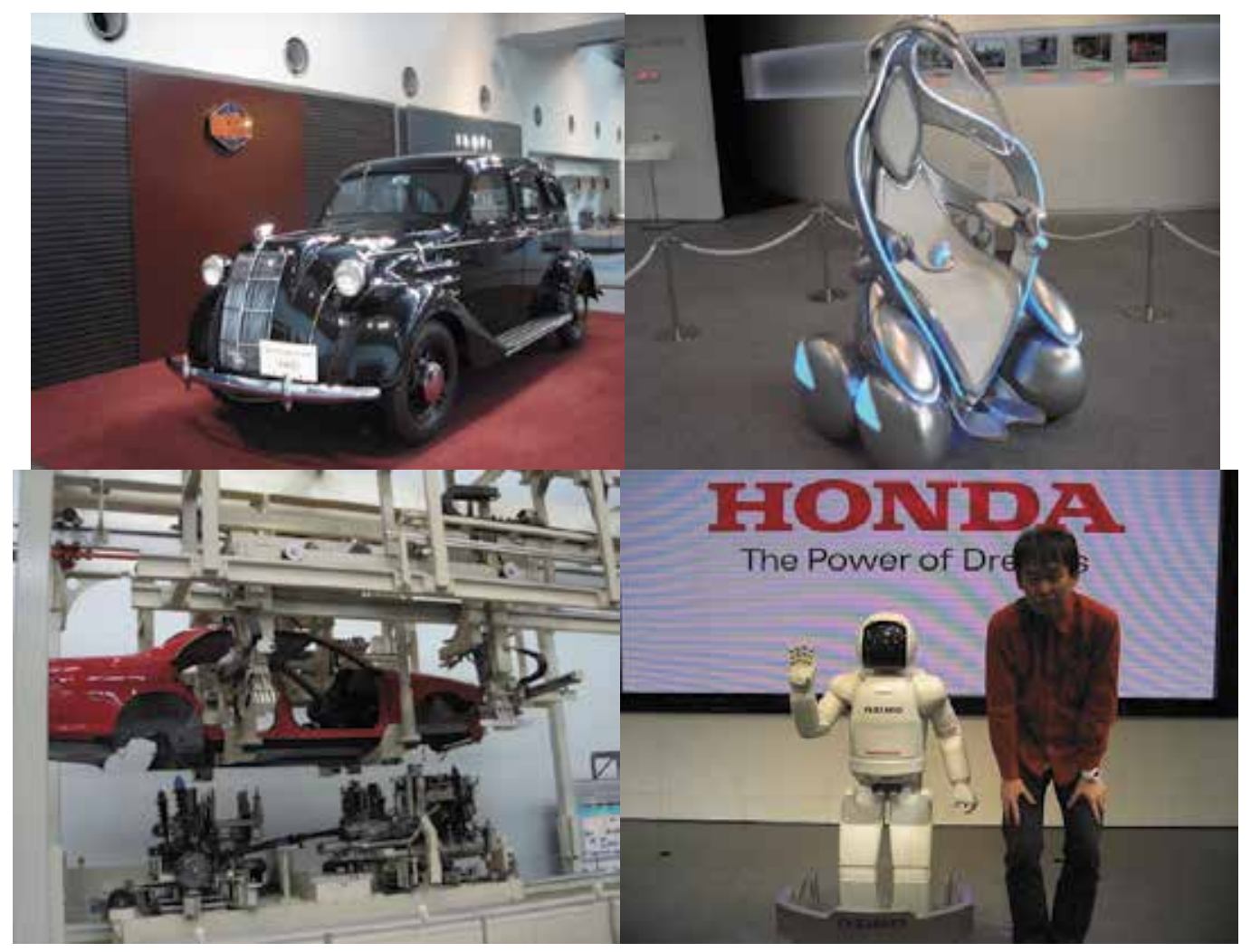

Fig. 10. Car and Robotics (TOYOTA Type-AA, i-unit, product-robot and Ashimo) 


\section{Knowledge creation}

Japanese companies have succeeded thanks to the skills and technologies of organized knowledge creation in the company as a whole, based on participation in the common body of practice which forms small organizational frameworks. Organizational knowledge creation refers to the capacity of the organization as a whole to create new knowledge, spread it out across the entire organization, and give it concrete form as a product, service, or operating system.

Japanese traditional Monozukuri is carried out in the context of "transmission." In the midst of this transmission, only the best information, which has endured the tests of time, is selected. In western Monozukuri in recent years, however, the mainstream approach is the dialectic method, involving debates in a dialog format. In the world of the dialectic method, sound arguments sometimes lose to sophistry, and in order to rectify this, Socrates's student Plato introduced the theory of ideas. In the field of natural sciences, the dialectic method functions correctly because ideas are embodied in the subject nature itself, but in the fields of social sciences or human sciences, if the dialectic method is applied without discussing the ideas, then a mistaken conclusion may result. This is because in corporate management, the corporate philosophy is considered important. In order to form a rich pool of tacit knowledge, it is necessary to circulate both the world of transmission and the world of the dialectic method.

In the case of Japanese technologies, which are good at imitation and good at creating, the speed of catching up is important. The speed of catching up is not limited only the Japanese manufacturing industry after the war, since 1945; as indicated by the Great Buddha of Nara and the manufacture of guns, when Japanese come in contact with advanced civilization and culture, they are able to evaluate them honestly and incorporate them with a great determination. What was the secret that made this incredible speed of catching up possible? States simply, Japan already had the groundwork - the potential capability 0 to accept and absorb new technologies. For example, in the case of firearms, Japan had already accumulated advanced metal processing technologies, even before guns arrived in the country.

When examining Japan's speed of catching up from the perspective of this process of "obedience - breakdown - breakaway," for example, in the front lines of technologies possessed by the world's artisans, for generations, the work always involved participation in a common body of practice (a group). In that context, when one person mastered a new skill, the others all imitated it. During the teaching process, rather than having the teacher do all the work, the student was set free in the workplace and told to pick up on skills independently: "Rather than learning, just get used to it," or "watch and steal what you see." In other words, the learning process was a process of thorough imitation.

Even in the case of the arts in Kyoto, the concept of "obedience - breakdown - breakaway" has been around for many generations. First of all, the students learned the old traditional approaches, being thoroughly obedience to them. Then, once the students had sufficiently mastered the basic skills, they would gradually break down the old traditions, eventually breaking away from what they had learned, establishing completely original methods, in the form of a new "school."

Japanese people have thus adopted a stance that thorough imitation means learning, and have a history in which the adoption of this stance is a major premise behind demonstrating true creativity. In our modern world, this has come to be misunderstood - imitation is seen 
as a lack of creativity - but this is only because the people who say this do not clearly understand the distinction of "breakdown" and "breakaway" in the process of "obedience breakdown - breakaway." When "form" is established and recognized by people, after a time, people forget who it was that created the form in question, and it permeates through the culture. Still, the nature of that form as a model never disappears. People look up to that model, imitate it and learn from it, and practice so that they can make that form a part of their being. But this is more than just a simple imitation. Zeami Motokiyo, a Japanese actor, playwright, and drama theorist who lived in the 15th century, taught students to "learn well from the teacher and imitate him." Once the student has transcended that stage of learning, however, the goal is to transcend imitation: "Reach a level that is not imitation; if you become that thing, then there is no desire to imitate." The poet Matsuo Basho said of this process, "Enter that rank, and then leave it," and Kawakami Fuhaku of the Edosenke school named this process "obedience - breakdown - breakaway [Shu-ha-ri]." If we look back to our original theme, the students of Noh theater begin by using this form as a model, practicing and training while following the teacher; later, they will separate themselves from that form, eventually reaching a state where they are able to form their own style, based on their own free performance. This process of assimilating form was dubbed [Shu-ha-ri]; this "form learning" then became the pattern for practical education in the context of Japanese culture. In the backdrop of obedience - breakdown - breakaway [Shu-ha-ri], "Form" has many characteristics, including functionality, rationality, stability, continuity, and an artistic character. In the context of Japanese Monozukuri, form has the nature of a model and a standard, and has a dramatic effect on social and economic structures as the foundations of modern IT.

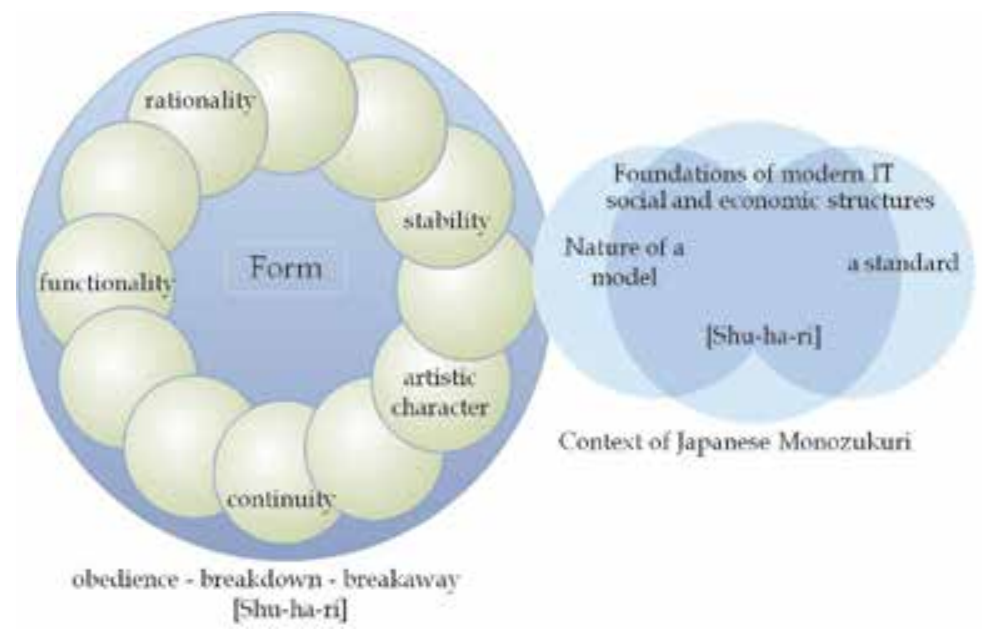

Fig. 11. Shu-ha-ri

\section{Modern Monozukuri -software design}

In modern Japan, the Internet and other information technologies were introduced from the west about 15 years ago, and have developed at a rapid pace. Both common bodies of practice and ICT are involved in fostering Monozukuri organizations that are suited to the digital economics of the $21^{\text {st }}$ century. For people studying modern Monozukuri (software 
design) in a school or a workplace, it is valuable to learn from examples of failure in order to resolve a variety of problems. Our goal will be to achieve more creative design by building a database of various failure examples, and present resolution measures to the organization.

\section{ICT solutions}

The first decade of the 21st century has passed. During this period, the key word of "economy" has undergone a transformation throughout the world. Over these first ten years, in the foreground of global economics and management, computer networks are now being used proactively. Information and knowledge obtained through these networks are creating new values and generating wealth in the world economy and indicating the need for ICT in economic strategies. In order to remain competitive in the current global market, ICT frameworks are imperatives as the era has arrived where we now need ICT to obtain new values and wealth. This way, ICT is becoming requisite in global environment and human resource to create the ICT is required. In Japan, in 2003, the subject of "Information" became compulsory, as one of the changes in educational policy for secondary education. This policy is one of the new cornerstones of human resource development, and Japan implemented the policy with the foresight to establish an on-coming ICT-supported knowledge-based society, of which, ICT was indispensable. As a system possessing the full adaptation of the organizational characteristics of Japanese cultural and traditional manufacturing, "monozukuri", human computing instruction system is important. In this field, it is necessary to incorporate so-called humanistic elements to understand human being, like creating elaborate traditional craftwork. Elaboration in monozukuri (manufacturing) has always been of the most significant for many Japanese products. By adapting ICT to these traditional concepts, the utmost of the elaboration is being asked for. To achieve the utmost in elaboration, the development of human resources is unarguably vital. Schools and business enterprises are now seeking to develop human resource capable of designing and developing integral products based on Japanese tradition.

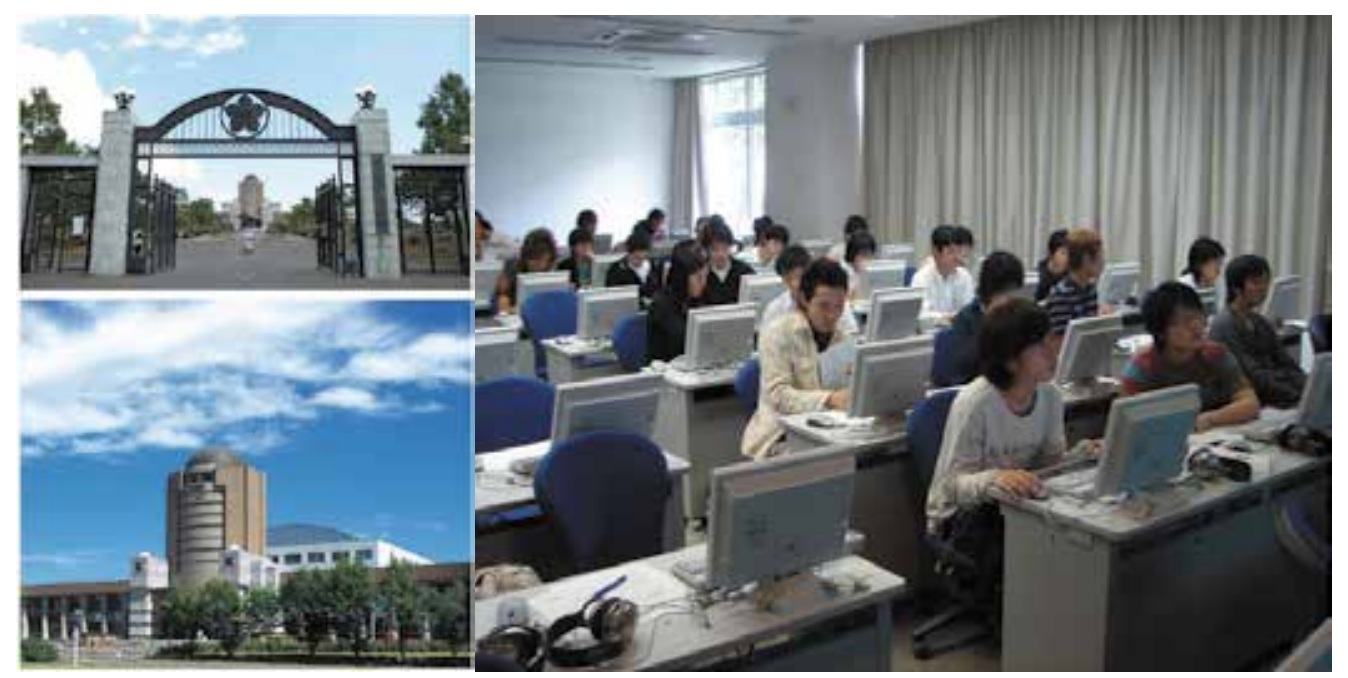

Fig. 12. Study of Computing Science in University(Kushiro Public University) 
This integration is truly an epoch-making idea for many multilateral issues and requires organizational communication to elaborately and seamlessly affix surfaces. Business enterprises attempting epoch-making ideas for the introduction of new strategies or problem solving procedures are making investments with futuristic perspectives, by foreseeing prospective changes expected to happen in mid-to-long terms, instead of making investment with traditional perspectives of thinking what to do for its products or management from analysis of its current situations. An example of this can be clearly seen with the development and introduction of a new IC card boarding system for Highway, railways and airlines in Japan. In adding a new service to a traditional service structure, and foreseeing profits in the future, a large investment was required for the development of ICT. This is genuinely a digital economic strategy.

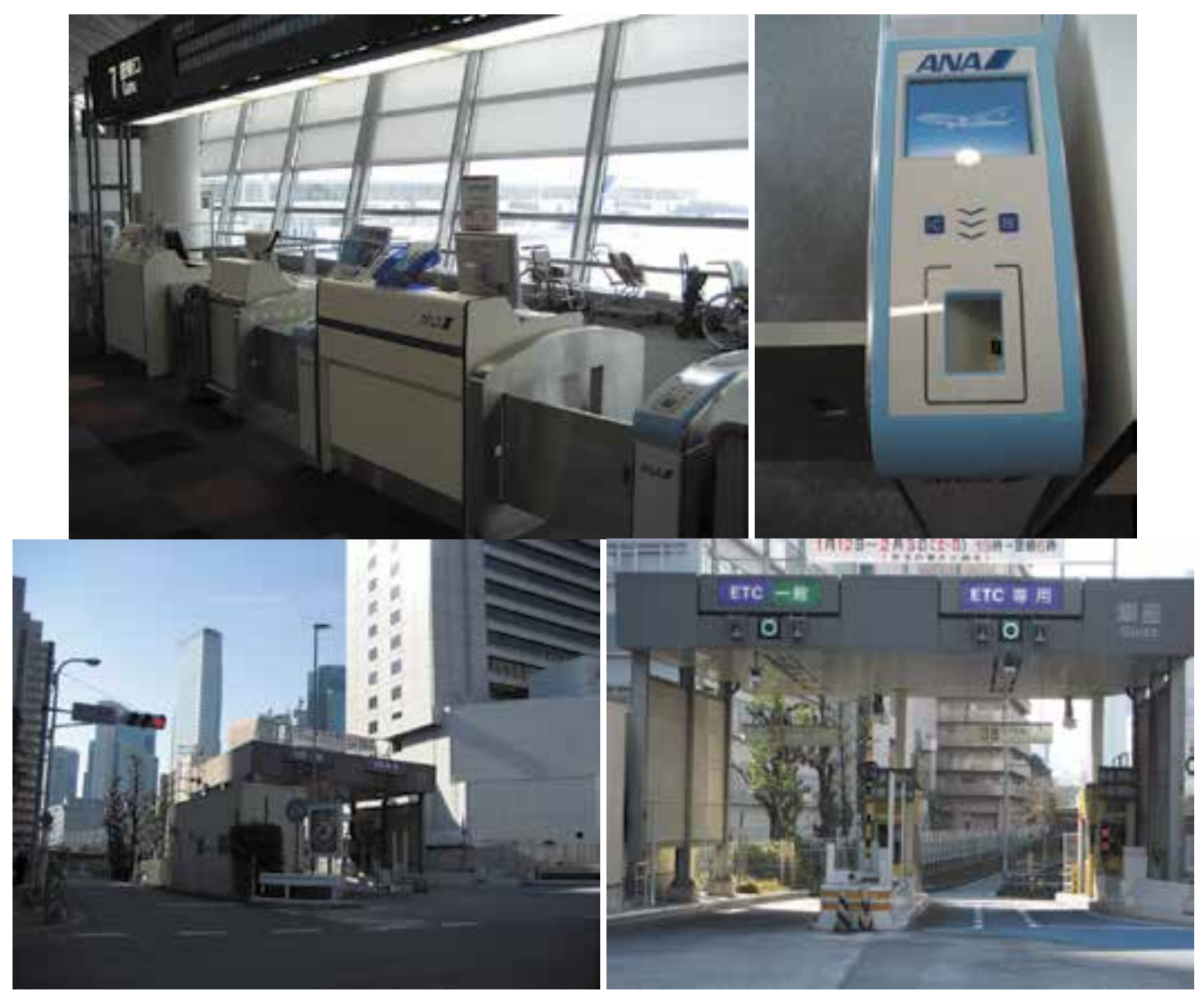

Fig. 13. IC card boarding system(Airport Check-in and Highway payment system: ETC)

\section{Young people education for digital economy strategies}

In traditional economic strategies, it was believed that one could remain dominant for the long term. However, in the present world, a company's competitiveness in any given market is extremely short. For this reason, companies place importance on the generation of as many new ideas as possible; ideas such as those for services to generate profits or create values, and companies foster human resource to create these values. 
In a knowledge-based society, a digital economy cannot be realized just by introducing computers to old structures. At least for the realization of the digital economy, organizations to materialize epoch-making ideas and success of information education to support new ideas are inevitable as premises.

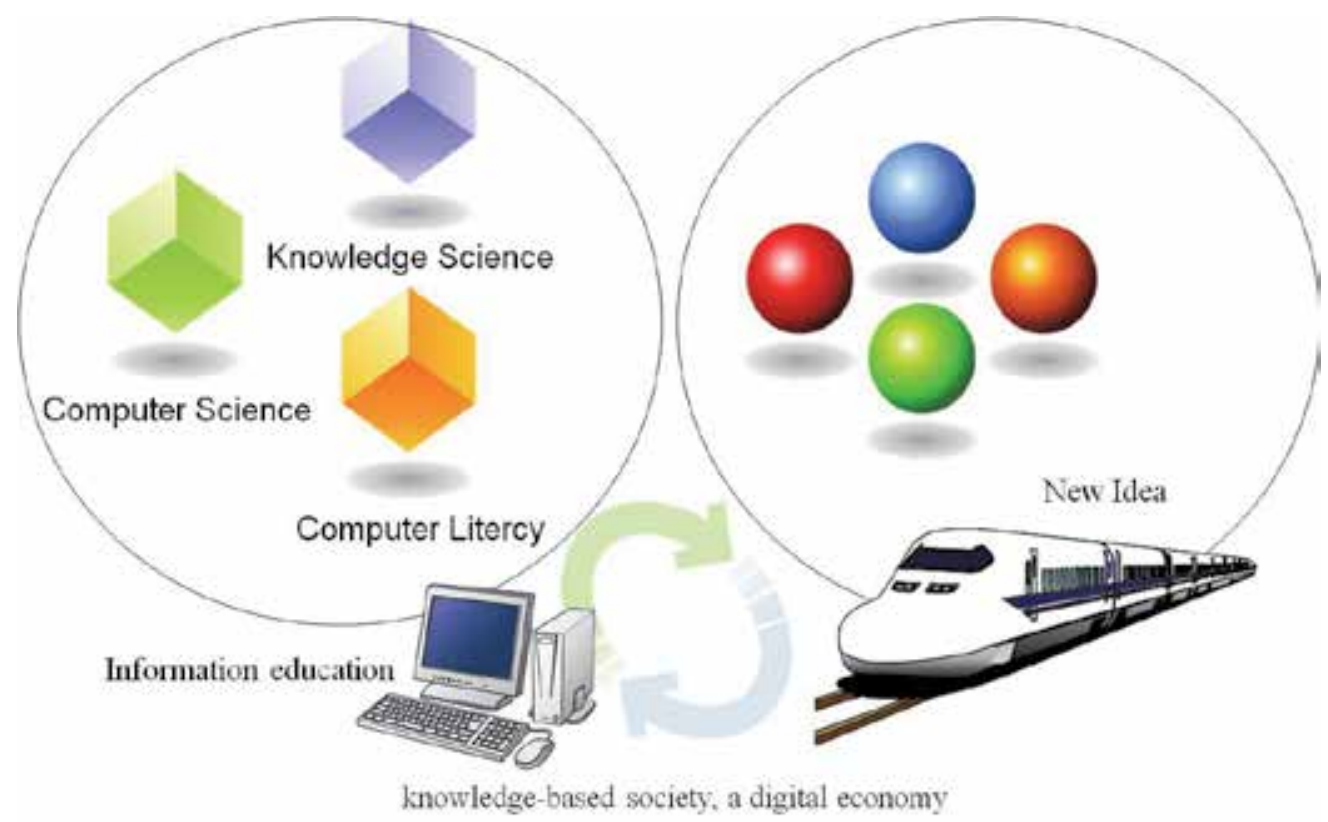

Fig. 14. Knowledge-based society Supported by epoch-making

Social science departments at universities in Japan have begun to admit the difficulty in solving issues in global competitions solely through the economic and management theoretical system called the old economy. Universities are now actively providing education to create digital economic business models with an emphasis on ICT. Recently, even in other fields, new value creations through the addition of ICT to traditional structures and systems has been sought and developed. It can be considered that whether or not to success in introduction of IT is leading actual economy in Japan. Since there are complex and multilateral issues regarding the direction to which the international society is heading, the necessity to create epoch-making values through the utilization of ICT is of extreme importance. After a decade in the new century and going through necessary revisions, high schools have also moved toward fostering human resources with the ability to create values by utilizing ICT through the introduction of "Society and information" and "Information science", and aim to create knowledge-based societies being asked for. The following section illustrates two examples of the fostering of human resources for a knowledge-based society.

\section{Education1}

The first example presents the education of human resources for the purpose of leading a knowledge-based society. The title of the research is Programming Through the Transferring of Skills to Non-Computer Science Majors from a research called establishment 
of creative programming class environment and practices. For information education at universities, the introduction of standard curriculum for information-related departments is being discussed mainly for students with a Computer Science major. For non-CS majors, such as those majoring in the social sciences or teacher training, the introduction of standard information curriculum is not being discussed. From a global perspective, as issues for programming classes for students with non-CS majors, the followings can be included: the necessity for specific class structure while taking less background knowledge, interest, or eagerness of non-CS major students than CS major students or consideration for practical class development within limited time frame. This research proposes a methodology for the programming of classes for non-CS major students, and indicates its effectiveness through the comparison of results obtained from actual practices of the method over the past 3 years with those from earlier studies. The programming class is one of the few practical training classes for non-CS majors, and presents an opportunity for the students to experience and practice system establishment (monozukuri (manufacturing)).

In support of the classes, from the last school year, post-process related files created by students over the previous 2 years, including system source code, and class and Readme files, can be accessed on an exclusive server for the programming class. With this system, failed source code Tips for the past 2 years can be viewed and executed so that students can trace programming to date. Failed source code Tips which cannot be executed are offered together with Readme files attached filled with the know-how of the previous students.

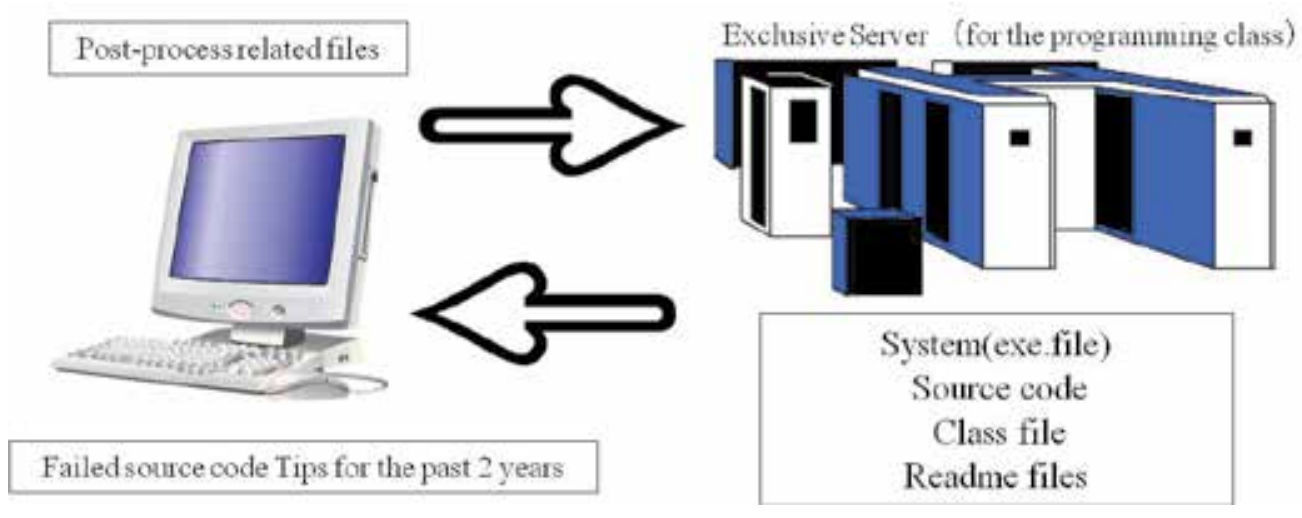

Fig. 15. Failed source code Tips view system

Preceding process and post-process are 2 divisions of the software development process, with the line which divides the two not clearly visible. In these two processes, knowledge spiral phenomena are anticipated when writing programs. In dividing the process in two, we considered that learning support methods for students would be different for the two processes. In other words, the learning of "precise sample codes for the description of classes" will be the preceding process, while the utilization of failed source codes of students in the past will be the post-process.

This division is related to characteristics of programming classes and also similar to the transferring methods for Japanese monozukuri (manufacturing) technologies.

This problem solving through education means that a high percentage of software development in Japan is being outsourced not only to western countries but also to Asian countries and that human resources to promote monozukuri (manufacturing) are not being 
fostered in Japan. However, when actually practicing an educational method proposed in this research by commanding Java or C\# language, it can be expected that even non-CS major students can obtain conception ability and achieve skilled monozukuri (manufacturing).

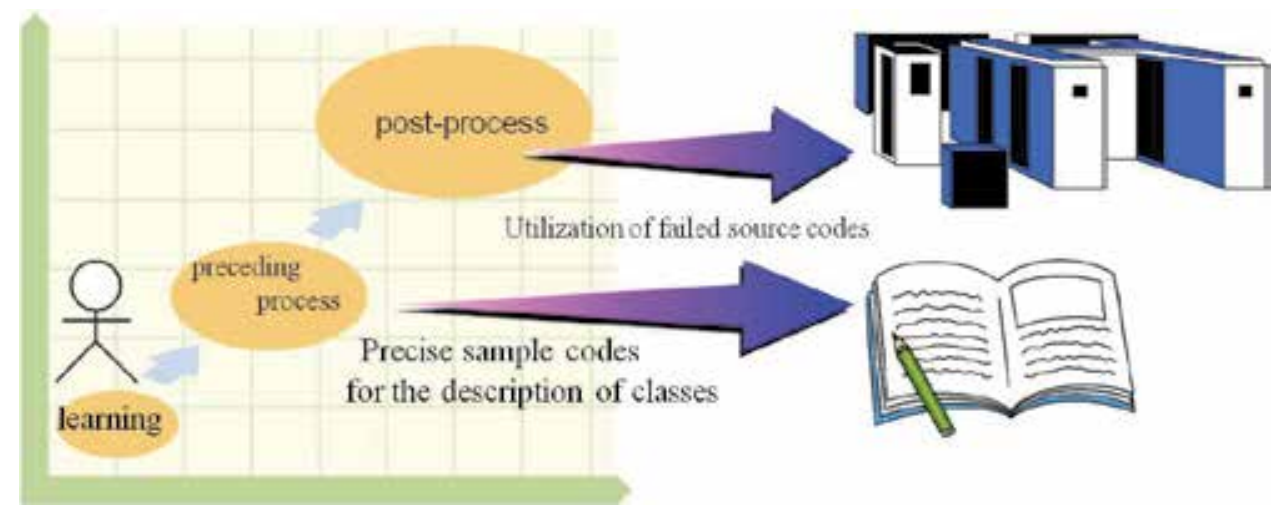

Fig. 16. Post-process and preceding process
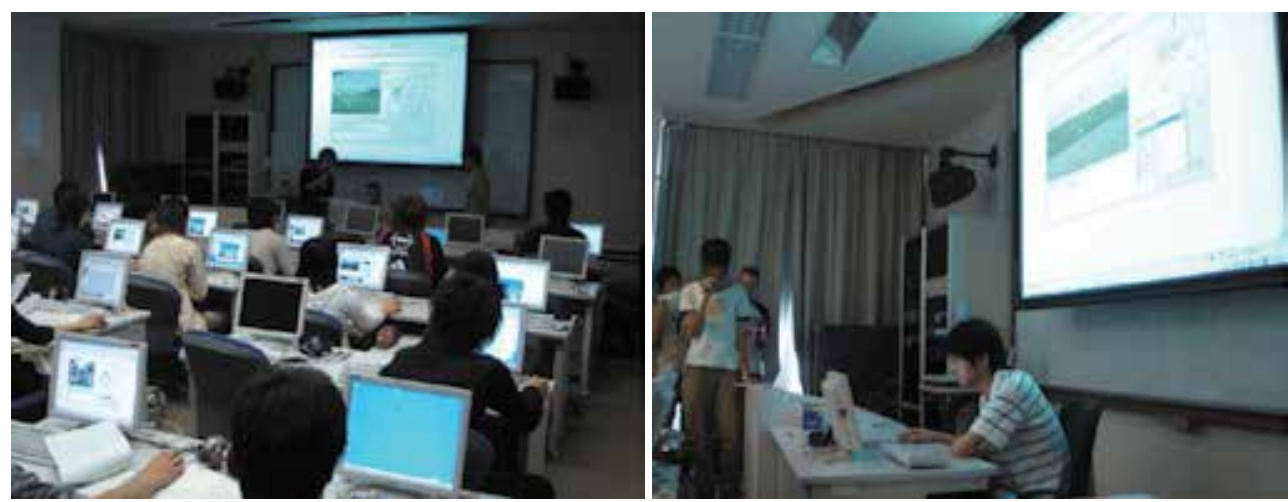

Fig. 17. Class(Final Presentation) of non-CS major students

\section{Education2}

The second example is the establishment of a class environment through the utilization of SECI model theory with a method by clarifying weak points (WP) in learning. In this research, by focusing attention on the weak points (WP) of students in programming classes, we established a learning support environment and system to overcome those weak points (Anti Weak Point). Effective lecturing and a positive learning environment were realized by having students identifying their weak points (WP) by themselves to overcome them on 3 levels: as an individual, as a group, and as an organization.

Lectures on programming consist from 2 parts: teachers explaining the grammars of programming to students, and students learning these grammars. As can be seen in text examples published in the world, including Japan and western countries, a systematic understanding of these grammars consists of sections, including an overview of the program development environment, the kinds of variables, and the control statement. 


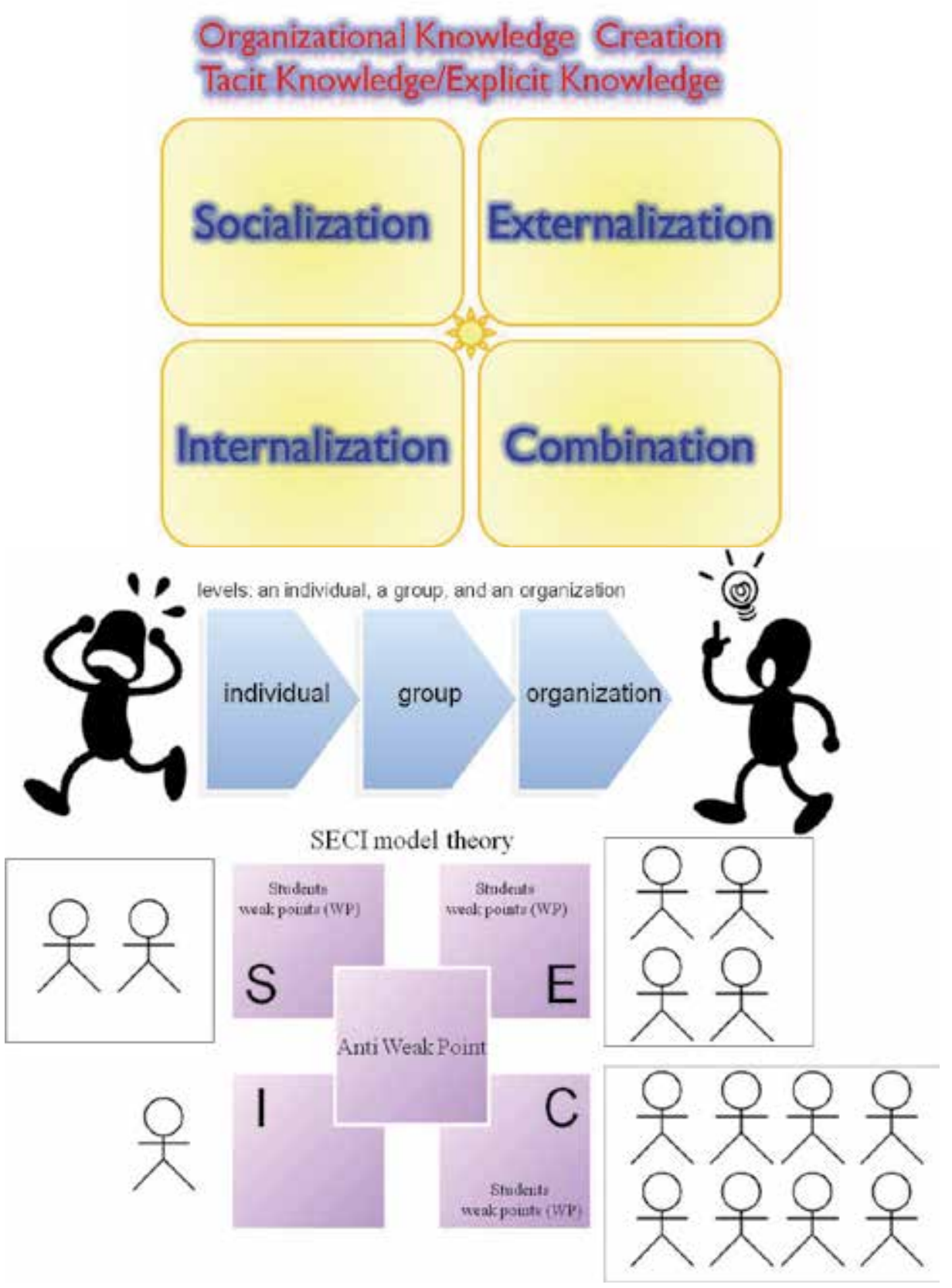

Fig. 18. SECI model theory with a method by clarifying weak points (WP) in learning

Without consecutively "combining" knowledge obtained in preceding sections with that to be obtained in sections to come, and "internalizing" the obtained knowledge as one's own, students cannot truly understand and apply the programming skills. In other words, understanding obtained from lectures should become each individual student's internalized knowledge. In understanding the contents of each section of lectures, each individual 
student's capability varies in their extraction of meta-knowledge. Additionally, each student's knowledge is delivered from the lecture as explicit knowledge, and while some students are able to "combine" the explicit knowledge of each section of the lectures and obtain true knowledge, or tacit knowledge, others are only able to obtain explicit knowledge. Without being able to combine the various fragments of learning obtained from each lectures for tacit knowledge, students cannot write programs. Knowledge can be considered combinations of explicit knowledge obtained from lectures. While some students can combine the explicit knowledge from each lecture by themselves, others need groups or organizations for peer teaching to "socialize" and "combine" the explicit knowledge. In this research, we focused on the latter group of students, formulating a hypothesis, testing the hypothesis and studying the results.

In this research, we hypothesized that knowledge can be obtained by converting explicit knowledge to tacit knowledge. Based on this assumption, we supported the attainment of tacit knowledge to support programming ideas or creation as an organization.

The explicit knowledge obtained from lectures includes many weak points (WP) for students. Traditionally, group learning and quizzes have been used to solve these weak points of students but outcomes were not satisfactory. For instance, since questions in quizzes are fragmented parts of explicit knowledge from lectures and cannot be comprehensive, students cannot obtain the epoch-making knowledge (tacit knowledge) needed to write a program. Therefore, as a method to support the attainment of tacit knowledge, we clarified the students' weak points (WP) and had the students discuss the essential parts of the explicit knowledge in groups and an organization.

In the process to lead from descriptions of lectures to student understanding, knowledge is delivered from the instructor to students as explicit knowledge, which will then be converted to tacit knowledge. Students who cannot combine the explicit knowledge from each lecture by themselves often feel difficulties in understanding. In this research, we distributed record cards so that students could freely document their weak points (WP). We called these cards Weak Point Cards (WPC), and at the end of each lecture in the first and second half of the course, students were given approximately 5 minutes to write their weak points in the following manner: a maximum 150 Japanese characters divided into 5 points (no more than 30 characters for each point within 1 minute), leaving each comment short like a whisper. Writing WPC briefly can be used effectively as a metaphor to promote conversion of knowledge when communicating each student's murmuring of distress in learning at a later date. To actively promote understanding of descriptions and discussions in groups or organizations with the metaphors, we set a rule not to write their weak points in detail. Using the writing of WPCs as a starting point for the "socialization" of each student's tacit knowledge, by exchanging each other's WPC, students could often obtain ad-hoc opportunities to communicate with other students outside the classroom.

The explicit knowledge provided from instructors in lectures is merely understanding at one point. To promote socialization and the externalization of tacit knowledge among students, we had students write WPC at the end of each lecture of the course (a total of 12 lectures). For the "conceptualization" of weak points (WP), group participation is needed. Consequently, we divided students into groups of 4 to discuss and conceptualize their weak points for presentation. After presentation, groups are disbanded. In the second half of the course (classes 7-12), new groups of 4 members are created to further develop a system to overcome weak points (WP). 

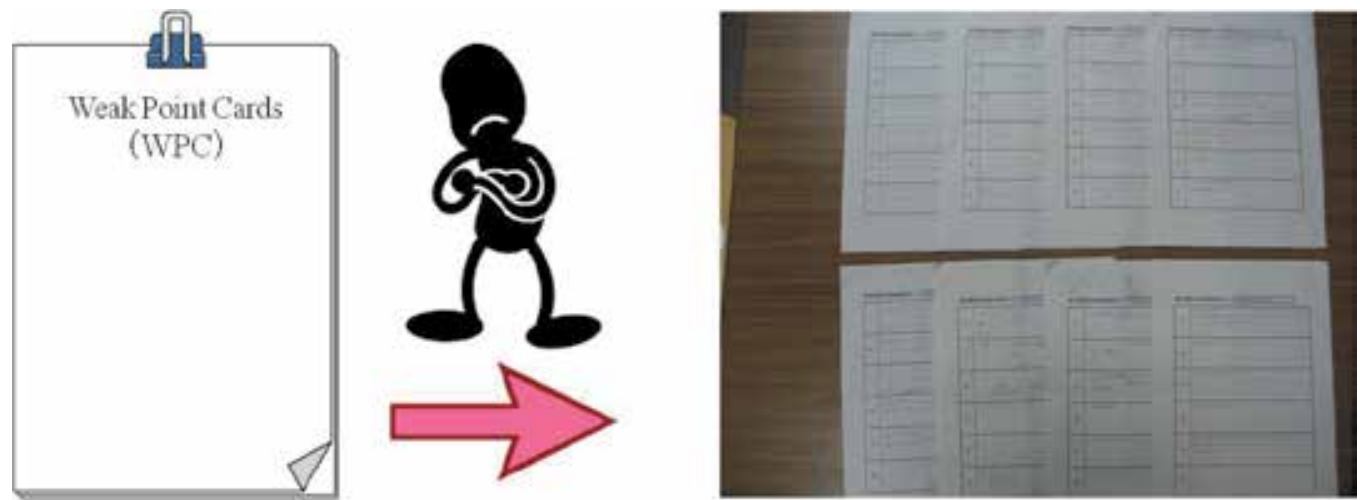

150 Japanese characters divided into 5 points

(no more than 30 characters for each point within 1 minute)

Fig. 19. Weak Point Cards

In writing WPCs as a method to find and record weak points (WP), as described previously, each student's weak points (WP) for each lecture are clarified as points for homework or review. However, to further utilize WPC, without socialization and externalization of tacit knowledge and exchanging WPC with others, new tacit knowledge cannot be obtained.

After every lecture, within limited number of characters, weak points (WP) of students were listed as "a whisper" on the WPCs. Examples of such whispers include: "2nd lecture; for sample codes and practice exercises, locations to designate local variables torture me (29 characters)" or " 5 th lecture; conditional branching processing of list contents. No, No, No (18 characters)".

By distributing WPC twice, once each for the first half and the second half of the course in order to supplement the argument in Figures, tacit knowledge can be obtained. The 1st attainment of tacit knowledge from WPC is as follows: In the middle of the course (in the 5 th or the 6th class), WPCs are collected and groups of 4 students are created by randomly drawing cards. By exchanging WPCs with others and using metaphors for weak points (WP) to allow for a free discussion, students will obtain as much tacit knowledge as possible.

Utilizing WPCs in the latter part of the course (the 11th or the 12th class), an organization (in the beginning, an assembly like a group) to develop a learning support system to overcome weak points (WP), promotes the combination and externalization of knowledge obtained from WPC. As a general rule, groups of 4 members should be different for the first group in the first half of the course and the second group for the second half of the course. The new group of 4 persons will decide support targets to overcome the weak points (WP). To decide the groups, the instructor randomly picks a number of WPCs (the total number of WPCs divided by 4 equals the number of cards chosen). The first student chosen by the instructor will pick the 2nd member by looking at the back of their cards, each card with different pictures on it. This process continues until the last of the 4 members is picked in this manner. Pictures on the back of the cards used for the second half of the course are to maximize the chance of choosing different members for the first and second half of the course. When all of the members of a group are chosen, the 4 members will externalize and combine their WPCs to review and plan learning support measures to conquer their weak points (WP). Then, prior to their presentation, using Visual Studio ASP .NET C\#, a system 
development tool, students decide the name of their system, and create a flow chart and an image of their system to be developed by using a designer function of the development tool. Approximately four weeks later, after making any necessary adjustments after their presentation, students complete the assignment of developing a learning support system to overcome weak points (WP) for learning programming.

While WPCs were used to write down the weak points (WP) of each student, they were also used to convert the tacit knowledge of weak points (WP) to explicit knowledge, and help students obtain new tacit knowledge. Each WPC of 4 group members helped to clarify weak points (WP), review conceptual design to support overcoming the weak points, and obtain tacit knowledge which will be a structure for the learning support system. The conquering of weak points (Anti Weak Point System; AWPS) is to notice one's weak points (WP) and to support to create knowledge for learning support (Creativity Support System; CSS) to help students understand. For this reason, we named the system "CSS on the AWPS". With this system, while sharing one's weak points (WP) with others, and undergoing discussions in an organization and actual programming process, each student is able to obtain operational knowledge (new tacit knowledge) while overcoming his or her weak points (WP) in programming. Practicing with WPCs and actual system development process assists in the identification and clarification of weak points (WP) and tacit knowledge through creative planning and development, mainly brought about through the externalization and combination phases of explicit knowledge.

For the weak points (WP) of individual students in the first half of the course, (as described in I , II, III, and IV), WPCs are utilized to write down each student's weak points in order to "socialize" the individual knowledge with a group. In the group, knowledge is "externalized" and "combined" to clearly "conceptualize" the whispered metaphors of the weak points (WP). In this process, each metaphor from the WPC triggers a topic for group discussion; a discussion starting from the socialization of knowledge by 2 or more members freely talking as individuals. Later, in the 5th or 6th lecture, discussions continue within the group as an "externalization" of knowledge. In the 11th or 12th lecture, discussions continue in new groups of 4 members in order to combine knowledge as an organization consisted of groups. Through this method, from our observations, it became obvious that relationships are formed for mutual learning. In this process of mutual learning, metaphors of weak points (WP) on WPCs are sometimes easily solved through the sharing of knowledge with others. In this combining of knowledge, weak points (WP) are found for "socialization", extracted for "externalization", and then "combined". The weak points are then converted into practical knowledge of programming (as internalized knowledge). The transition from WPC input to conceptualization of weak points (WP) to a development of learning support system clearly indicates that by organizing students, operational knowledge is created.

Though these 4 processes are based on our research practices in a programming course, this is similar to one of the theories for the creation of organizational knowledge. In this theory, II and III of Figure, a transition period can be described as follows: (II) "a learning period through dialogues and actions" and "a period of knowledge spiral and changing of its contents". In this period, conceptual knowledge can be obtained from the externalization of weak points (WP) on WPCs. In III and IV, through the organization of students, systematic knowledge is obtained by combining knowledge, and operational knowledge is obtained for the planning and development of learning support measures to overcome weak points (WP). 
These illustrate a starting point for a SECI theory of socializing tacit knowledge to make it into explicit knowledge of weak points (WP) for discussion. It is necessary to set an opportunity for socialization and externalization in order to transform tacit knowledge to explicit knowledge by combining WPCs with others. In the first half of the course, WPCs are utilized to emphasize the socialization and externalization of weak points (WP) in shifting focus from the individual to the group as shown in Figure

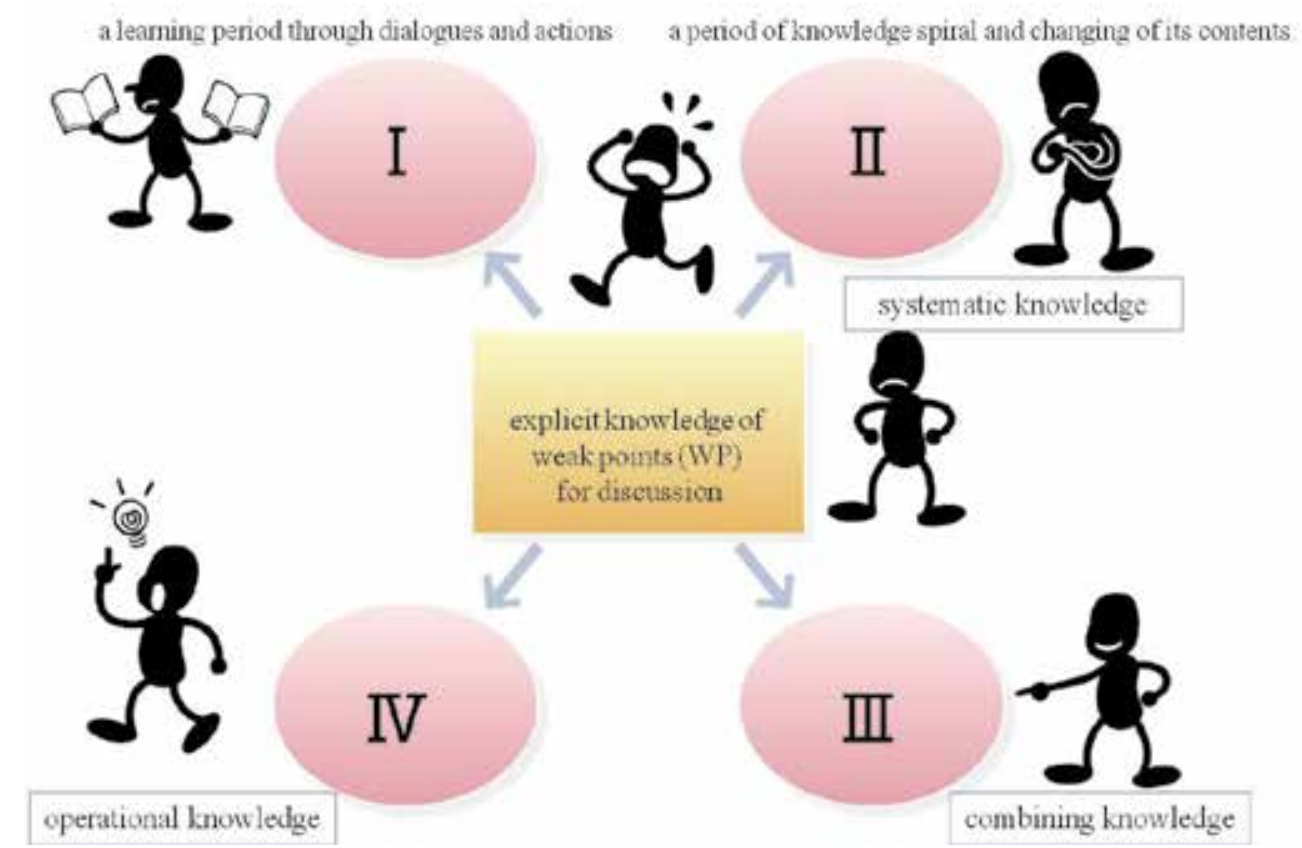

Fig. 20. Metaphors of weak points (WP) on WPCs

In the second half of the course, the WPCs from a wide range of students are utilized in the Combination and Internalization phases in order to combine explicit knowledge in an organization. Through Combination and Internalization, the conceptualization of weak points (WP) is promoted, and by investigating learning support measures, system design drawings were created. In the planning and development of AWPS, as for the shift from the group to the organization, since members are adjusted so that students can obtain operational knowledge of weak points (WP) of individuals by SECI theory, in the second half of the course, WPCs were utilized to obtain operational knowledge (tacit knowledge) from the organizational spiral as follows: the WPC allowed for the progression from sympathetic knowledge to conceptual knowledge, and then to systematic knowledge. As a result, AWPS was completed through phases of creating organizational knowledge. While learning with feedback involves the application of one's results to improve upon them, with AWPS, by reviewing the weak points (WP) of prior students, and by understanding potential drawbacks, students can make adjustments for the acquisition of skills to exert programming language. In this way, AWPS can provide feed-forward type learning control support. For use in the coming school year, in order to provide a feed-forward type learning support system with emphasis on prior course preparation by students to provide weak points (WP) and problem solving support beforehand, AWPSs will be gathered at the 
interface. In this way, AWPS developed by students this year can be utilized by students in subsequent years.
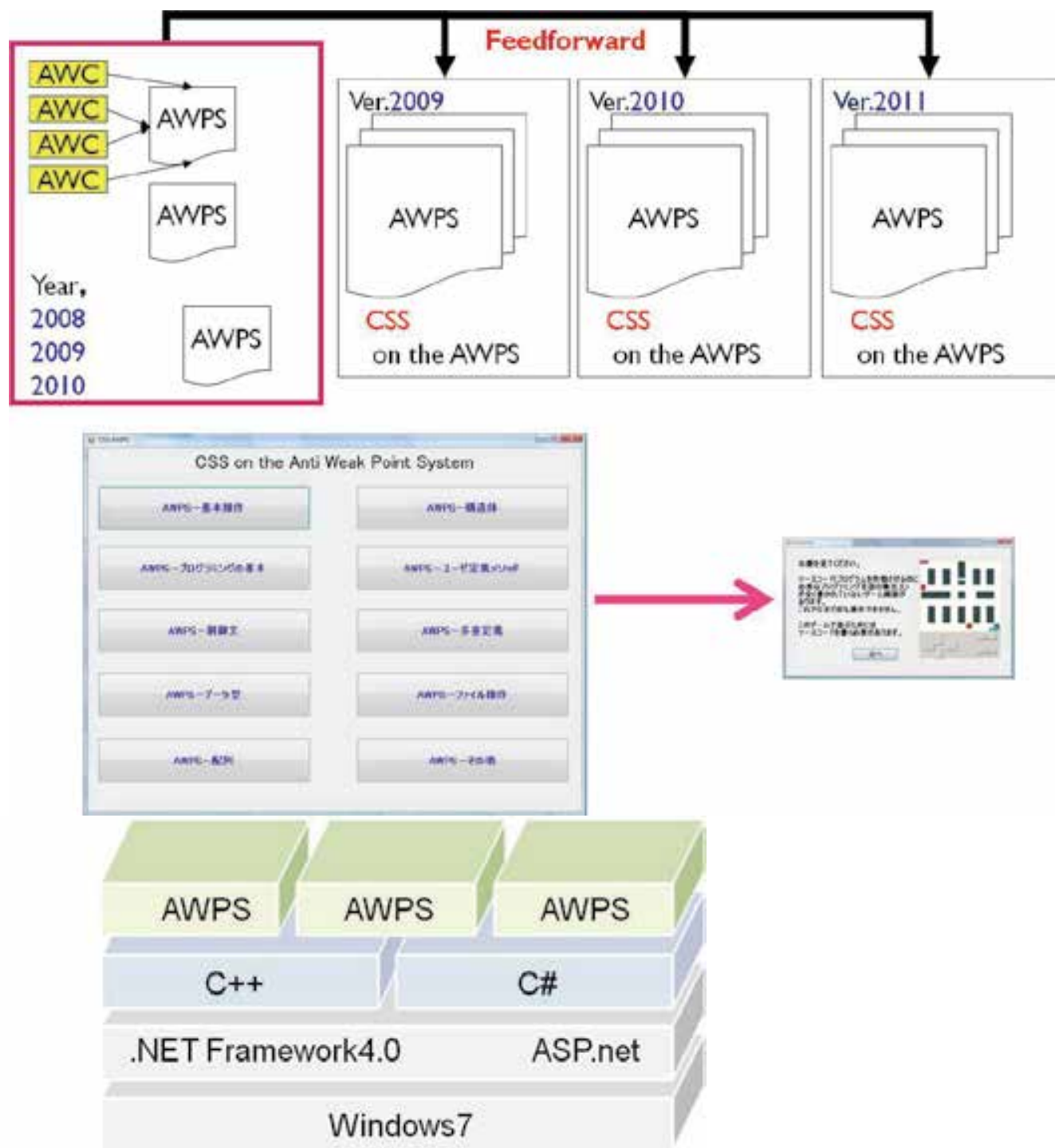

Fig. 21. AWPS system Window

For learning support to overcome weak points (WP), each student needs to combine the tacit knowledge of each class and convert the knowledge. This research showed that as a method to acquire knowledge, SECI theory in knowledge management is effective. In order to overcome weak points (WP) through an organizational knowledge spiral, this research indicated that by dividing the utilization of WPCs between the first and second half of the course, individual tacit knowledge steadily shifted to fit the SECI model. Though SECI theory is widely known, there are no reports of properly fitting the theory into corporate or educational learning environments. 
Fostering a "Monozukuri (Manufacturing)"

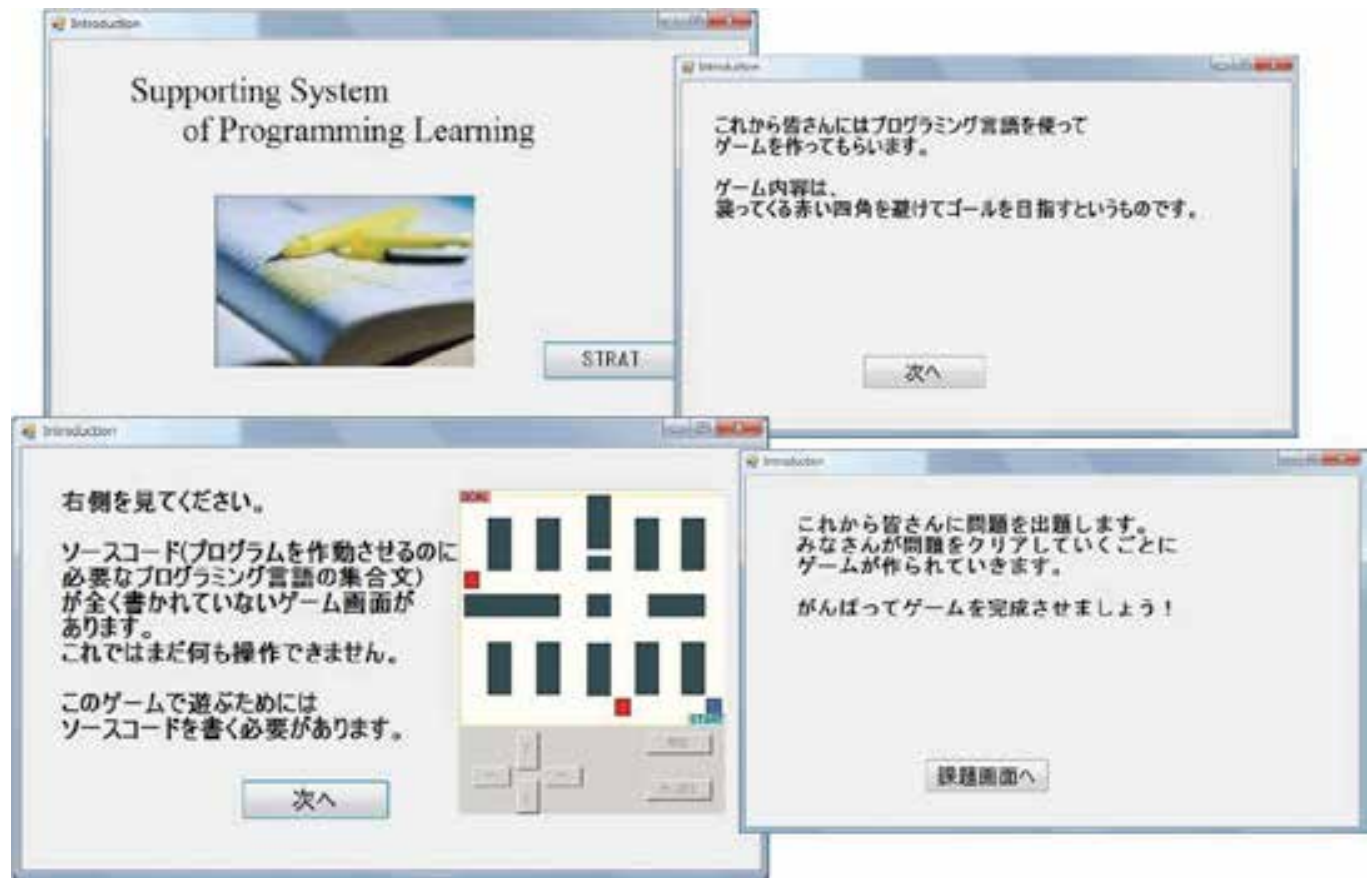

Fig. 22. AWPS contents(example)

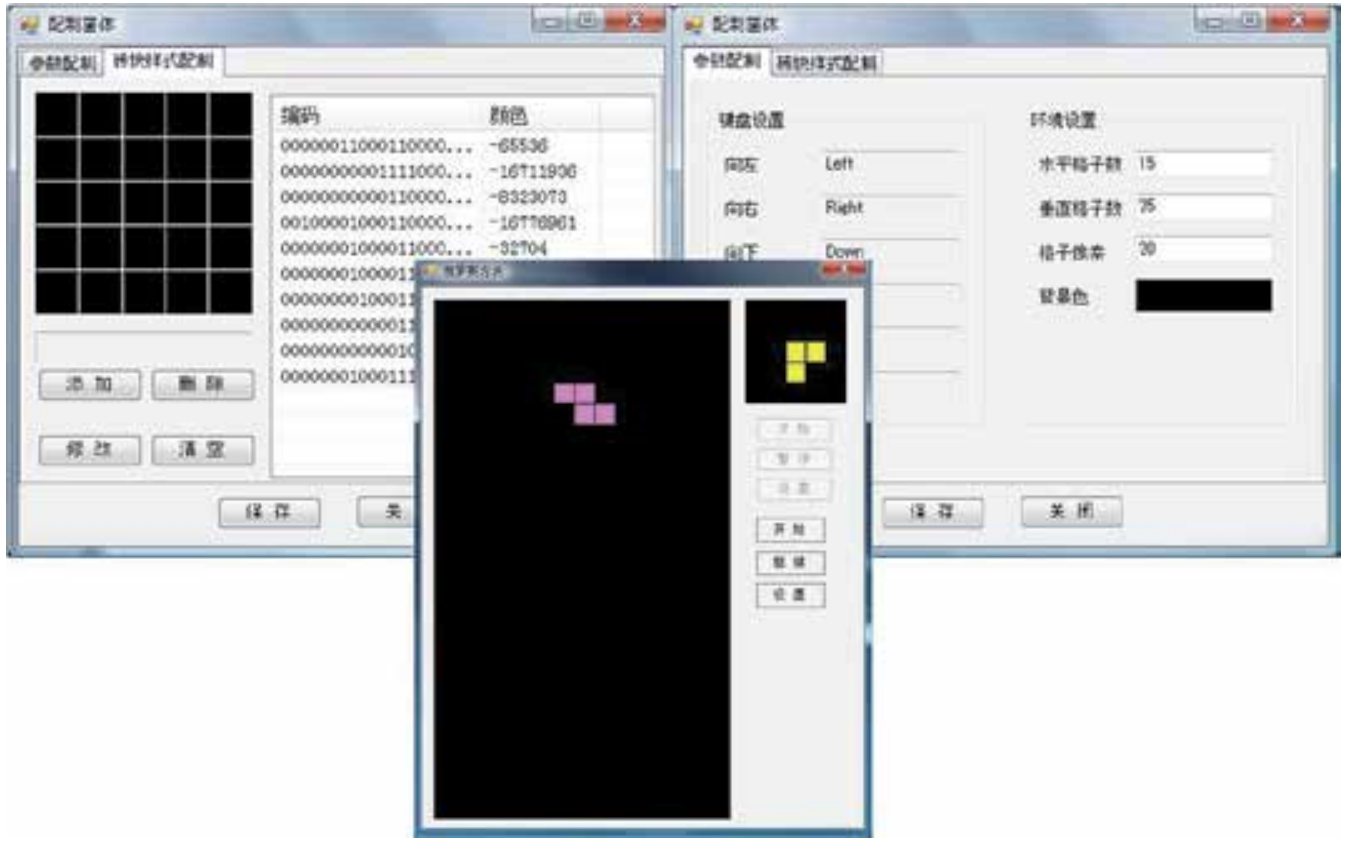

Fig. 23. AWPS contents(example2)

The procedure of whispering of weak points on WPCs after each class quite effectively fit into the S-E process. In the second half of the course, WPC metaphors effectively activated 
the knowledge spiral during the C-I process. As a result, we concluded that our shuffling of members two times during the course, group knowledge was effectively converted to operational knowledge (internalization) as organizational knowledge. In the planning and development of the system, students derived (converted) knowledge to solve their weak points (WP), and systemized the knowledge to overcome weak points (WP) with the tacit knowledge for the learning support of others. Having students from subsequent years utilize the system, the creation of a knowledge bank to conquer weak points (WP) in programming learning can be utilized for a long time.

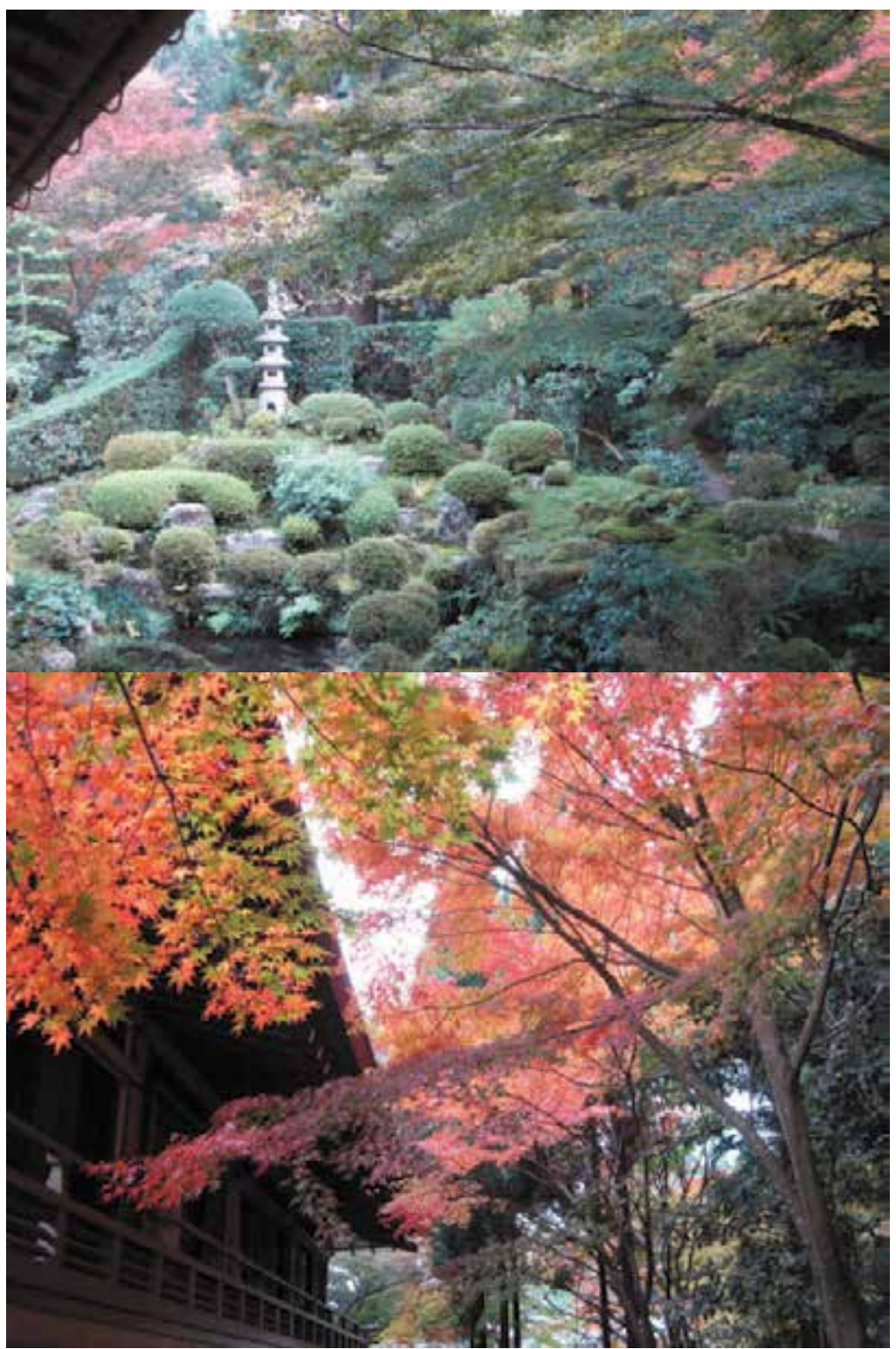

Fig. 24. The Sanzenin in Autumn (The leaves change color.) 
Basically, educational and corporate organizations must play their respective roles, and must work together to promote activities related to the following items:

1. Maintain and pass on traditional technologies and skills, and foster the individuals who will be responsible for the next generation of traditional and cultural Monozukuri industries

2. Leverage traditional materials, technologies, and craftsmanship, and combine these with IT and other advanced technologies, to promote a new form of Monozukuri that is adapted to the changes in the times.

\section{Conclusion}

The traditional and cultural Monozukuri industries of Kyoto maintain and pass on traditional technologies and skills, while developing as industries that create lifestyle cultures that embody those traditions. At the same time, these industries promote a new form of Monozukuri that adapts to the changes in the times by combining traditional technologies with advanced technologies. In this way, they are expected to play a major role in achieving a richer cultural society. Furthermore, traditional and cultural Monozukuri industries will continue to be a target of admiration for people around the world, and this will contribute dramatically to increasing the appeal of Kyoto in the context of international society.

\section{References}

Asai, T.; Hayashi, H., Minazuki, A. \& Kunifuji, S. (2006). Creative Transfer of Tradition and Next-generation Innovation Tradirional Japanese Culture, Journal of Japan Creativity Society, Vol.10, pp. 37-50, ISSN 1349-2454

Nonaka, I. \& David, J. T. (2001). Managing Industrial Knowledge: Creation, Transfer and Utilization, Sage Publications Ltd, ISBN 978-0761954989

Nonaka, I. \& Johny, J. (1996). Relentless: Japanese Way of Marketing, ButterworthHeinemann Ltd, ISBN 978-0750632089

Nonaka, I. (2005). Knowledge Management (Critical Perspectives on Business and Management), Routledge, ISBN 978-0415340298

George, V., K.; Nonaka, I. \& Nishiguchi, T. (2000). Knowledge Creation: A Source of Value, Palgrave Macmillan, ISBN 978-0312229740

Nonaka, I.; Charles, M. S., Florian, K. (2007). International Marketing in the Network Economy: A Knowledge-Based Approach, Palgrave Macmillan, ISBN 9780230515703

Nonaka, I., Nishiguchi, T. (2001). Knowledge Emergence: Social, Technical, and Evolutionary Dimensions of Knowledge Creation, Oxford Univ Pr on Demand, ISBN 978-0195130638

Nonaka, I. (2008). The Knowledge-Creating Company (Harvard Business Review Classics), Harvard Business School Pr, ISBN

Takeuchi, H. \& Nonaka, I. (2004). Hitotsubashi on Knowledge Management, Wiley, ISBN 978-1422179741 
Georg, V., K.; Ichijo, K. \& Nonaka, I. (2000). Enabling Knowledge Creation: How to Unlock the Mystery of Tacit Knowledge and Release the Power of Innovation, Oxford Univ Pr, ISBN 978-0195126167

Meinolf, D., Ariane, B., Antal, J., C. \& Nonaka, I. (2003). Handbook of Organizational Learning and Knowledge, Oxford Univ Pr, ISBN 978-0198295822

Nonaka, I. \& Takeuchi, H. (1995). The Knowledge-Creating Company: How Japanese Companies Create the Dynamics of Innovation, Oxford Univ Pr, ISBN 9780195092691

Nonaka, I. , Hirata, T. \& Toyama, R. (2008). Managing Flow - A Process Theory of the Knowledge-Based Firm, Palgrave Macmillan, ISBN 978-0230553767

Ichijo, K. \& Nonaka, I. (2006). Knowledge Creation And Management: New Challenges for Managers, Oxford Univ Pr, ISBN 978-0195159622 


\title{
Globalization and Global Public Goods
}

\author{
Bernur Açıkgöz Ersoy \\ Celal Bayar University \\ Turkey
}

\section{Introduction}

Everyday, the importance of global public goods (GPGs) is increasing in the globalization process. GPGs are public goods with benefits or costs (peace, crime, terrorism, disease etc.) that extend across countries and regions, across rich and poor population groups, and even across generations. GPGs comprehensively cover global issues such as peace and security, health, global warming, market efficiency, global financial stability, human rights, knowledge etc.

GPGs affect many aspects of our lives. Many GPGs have existed outside of human intervention, such as the oceans, the ozone layer, and the atmosphere. As globalization has advanced other GPGs have come to our attention, and this has increased the capacity of cross-border influences, both in a positive and negative manner. However, the concept of GPGs is new and an agreed-upon definition is unfortunately missing. As a result, it is a priority to define and structure the growing phenomenon of GPGs.

The growing force of GPGs has shown that policy decisions involving the public have been extremely positive in response to the challenges they pose (Gardiner, R. \& Le Goulven K., 2001b). C.P. Kindleberger first mentioned GPGs in his article on "International Public Goods without International Government" in 1986, although, GPGs did not achieve prominence until a publication by the United Nations Development Programme (UNDP) in 1999. I. Kaul uses the term GPG to mean a public good which is non-rival and non-excludable throughout the whole world, as opposed to a public good which exists in just one national area. Knowledge is a canonical example of a GPG for him. The term GPG has also become associated with the concept of a common heritage of mankind in some academic literature.

Nowadays, many crises threaten the globalization process of the world, including global conflicts, global warming, international financial stability, and growing poverty. With the globalization process, peace and security are also conceived as GPGs. During recent wars, millions of people died, and the costs incurred by the global community contained military costs, refugee costs, economic costs, instability costs, and international peace operations (Yllmaz, 2010). At the beginning of the 21st century, technological accomplishments have also given rise to fresh and unique patterns of communication, cooperation and mobilization, and discoveries in the fields of medicine and science allow the potential to make it possible for humans to lead longer, more productive and healthier lives. These benefits have been accompanied, on the other hand, by a parallel rise in threats to human security, ranging from 
international terrorism and global climate change, to increased poverty and the spread of new diseases, often resulting in the explosion of conflict (Smith, 2006).

In a minimal way, GPGs for health contain the control of diseases and epidemic surveillance, disease eradication, disease research, and pollution emissions. It can be further enlarged to cover poverty reduction and disaster relief, expertise in development and technical assistance in health (Sandler \& Arce, 2002).

The first objective of this study is to scrutinize the concept of GPGs and to show some concrete examples, and to suggest some solutions for solving the GPGs' problems. The second purpose of the study is to provide a contribution to the discussion of GPGs' theory, which is still at the development stage.

This chapter is organized as follows: The first part presents a literature review and the definition as well as the classification of GPGs. The second part examines in more detail, peace and security, and health GPGs. The final part resumes arguments on suggestions for solutions regarding GPGs.

\section{Literature review}

A growing literature stresses the raising awareness that the benefits or harm of some public policies, programs, and services extend beyond the boundaries of independent nation-states (for more details, see Stiglitz (1995); Sandler (1997); Kaul et al. (1999); Kaul et al. (2003)). For example, Jayaraman \& Kanbur (1999), Cook \& Sachs (1999), Ferroni (2000) investigate the role of foreign aid in the provision of GPGs while Stansfield et al. (2002) suggest that the development assistance community should become more clearly concerned with identifying different strategies for the prioritization and financing of GPGs. According to Ferguson (2004) and Lal (2004), stability needs the provision of GPGs in the form of a stable world monetary order, clear and enforced rules regarding international trade and finance, and the defence against state failure and rogue states. Kaul \& Conceicao (2006) highlight globalization and increasing porosity of national borders which have been key driving forces that have led to growing interdependence and interlocking of the public domains and therefore, public policy concerns - of countries, governments, private businesses, civil society, and people at large. Levaggi (2009) discusses optimal conditions for GPGs in his study, while Kammas \& Philippopoulos (2010) provide a quantitative assessment of the welfare cost of tax competition or, equivalently, the welfare benefit of international tax policy cooperation. The GPG concept has also been proposed to address a possible poor match between global problems and institutions to handle them (Fidler, 1998; Cornes \& Sandler, 1996; Sandler 1997; Chen et al. 1999).

Regarding peace and security, Mendez (1999) denotes peace as a state of relations among people and nations that everyone dreams to protect. He discusses the importance of UN peacekeeping forces in providing the GPG of peace and claims that a system of collective security, in contrast to a balance or concert of powers or predominance, is best suited to provide peace, exactly because it reflects the security management structure that exists at the national level. Moller (2004) concludes that there are therefore numerous ways of preventing, managing and resolving violent conflicts, all with a view to reducing the public evil represented by war, and thereby promoting peace as a GPG. Kocks (2005) sums up significant UN internal reform processes connected to their use and offers policy 
suggestions for a more integrated and innovative financing approach to UN peace operations as GPGs. Mitchener \& Weidenmier (2005) and Ferguson \& Schularick (2006) stress the resulting GPGs generated by military intervention and the declared willingness to use military force under certain conditions (Coyne \& Ryan, 2008). Similarly, Collier (2008) infers that properly timed foreign military interventions can generate global stability through the prevention of military coups.

On the other hand, regarding health, Sandler (1998) implements new concepts from the theory of public goods to point out why progress has been made with regards to some global and regional public goods but not with respect to others. Bradley (2001) stresses a crucial feature of preventing cross-border transmission of communicable diseases: the benefits of global control efforts will be greatest for countries that have already reduced disease prevalence rates within their borders to relatively low levels. Sandler \& Arce (2002) identify the need for international cooperation in some areas regarding the provision of such health-promoting activities. Smith et al. (2003a) discuss health issues as a GPG in their comprehensive book. Smith et al. (2004a) consider the implementation of the GPG concept regarding communicable disease control. Smith et al. (2004b) investigate the effect of the recent patent system regarding genomics knowledge of different economic powers. Wildasin (2008) highlights health care, health promotion and education regarding the GPG concept. Szlezak et al., (2010) define the global health system as the constellation of actors "whose initial aim is to promote, restore or maintain health", and "the persistent and linked sets of rules, that prescribe behavioral roles, constrain activity, and form expectations" among them.

\section{Definition and classifications of GPGs}

Globalization means broadened access to knowledge, communications, trade, and together with these, new possibilities for human development. This unheard-of mutual connection and mutual dependence among human societies also presents recently shared risks. (Stansfield et al., 2002). Many problems related to globalization involve the provision of GPGs. For instance, when environmentalists ask for the easing of pollution pressures on the atmosphere, they are asking that a GPG as a social choice should not be over-used (Desai, 2003).

The term "global public good" has rapidly become an often used term in policy circles. Other terms that are also used to express this comprehensive concept are "international public goods" or "global common goods" or "global collective goods". While there is a fast growing literature on the globalization implications for public policy, not much consideration has been paid to the concept of GPGs. The main issue is to explain what criteria should be used to identify a GPG but for this, first the concept of public good should be defined.

Samuelson (1954) described a public good as follows :

"...[goods] which all enjoy in common in the sense that each individual's consumption of such a good leads to no subtractions from any other individual's consumption of that good..."

Another definition of a public good, states that public goods are "commodities for which the cost of extending the service to an additional person is zero and for which it is impossible or too costly to exclude individuals who do not pay for the good from 
enjoying" (Nordhaus, 2005; Stiglitz, 2000). In other words, a public good is a good that is non-rival and non-excludable. These are two important properties of a traditional public good. We use the word "non-rivalry" which means that consumption of the good by one individual does not diminish obtainability of the good for consumption by others, and non-excludability that no one can be excluded from using the good (Cornes \& Sandler, 1996). Examples are air or moonlight, security, or global positioning systems. If both requirements are completely satisfied, a public good is said to be pure (Kocks, 2005). Public goods provide "consumption externalities" as well: when public goods are being consumed by people, benefits or harms are provided to others (Atkinson \& Stiglitz, 1980; Varian, 1992). It is also the occasion that many private goods show some degree of externalities. Smoking, a seemingly private activity, is now known to harm the health of others (second-hand smoke), giving rise to a series of public policy responses to curb this negative side effect (WHO, 2002).

For traditional public goods, three main questions have to be answered (Heal, 1999). The first one concerns the amount of provision, the second the question of financing it, and the third, linked to the free-rider problem, the access to information by the state to answer these questions. For privately produced public goods, another question can be asked. Given a desirable target level of production, how do we reach it, and how is this target production to be apportioned among all the potential producers? For instance, regarding greenhouse gas emissions, the important questions are which countries should cut back emissions, and by how much? Similarly, within the country, which sectors should cut back emissions? Of course, it is also possible to ask these questions within organizations and firms.

The second way of looking at a public good problem is from a public bad, whose negative utility nobody can be excluded. Due to their two crucial properties, pure public goods are subject to free-riding and hence correspond to a case of market failure creating a rationale for their public provision (for more details, see Morrissey et al., 2002). The market will not supply public goods or will supply too little. Once in the public domain, their sufficient provision is limited by collective action problems such as the prisoner's dilemma. Because of the free-rider problem and the prisoner's dilemma, public goods are generally undersupplied.

\begin{tabular}{c|c|c|}
\multicolumn{1}{c}{ Excludable } & \multicolumn{1}{c|}{ Non-excludable } \\
\cline { 2 - 3 } Rivalrous & $\begin{array}{c}\text { Private goods } \\
\text { food, clothing, cars }\end{array}$ & $\begin{array}{c}\text { Common pool goods } \\
\text { fish stocks, coal, national health serv. }\end{array}$ \\
\cline { 2 - 3 } $\begin{array}{c}\text { Non- } \\
\text { rivalrous }\end{array}$ & $\begin{array}{c}\text { Club goods } \\
\text { swimming pool or golf clubs, } \\
\text { cinemas, private parks, satellite tv }\end{array}$ & $\begin{array}{c}\text { Public goods } \\
\text { diplomacy, air, national defense }\end{array}$ \\
\cline { 2 - 3 } & &
\end{tabular}

Table 1. Private, club, common and public goods

Source: Shaw, 2004.

Table 1 and figure 1 show that the theory distinguishes between different kinds of goods, in terms of their two fundamental characteristics: rivalry and excludability (Shaw, 2004). But this distinction is not really certain. For instance, lighthouses were before seen as a public good but it is now realized that they are not (Shaw, 2004). 


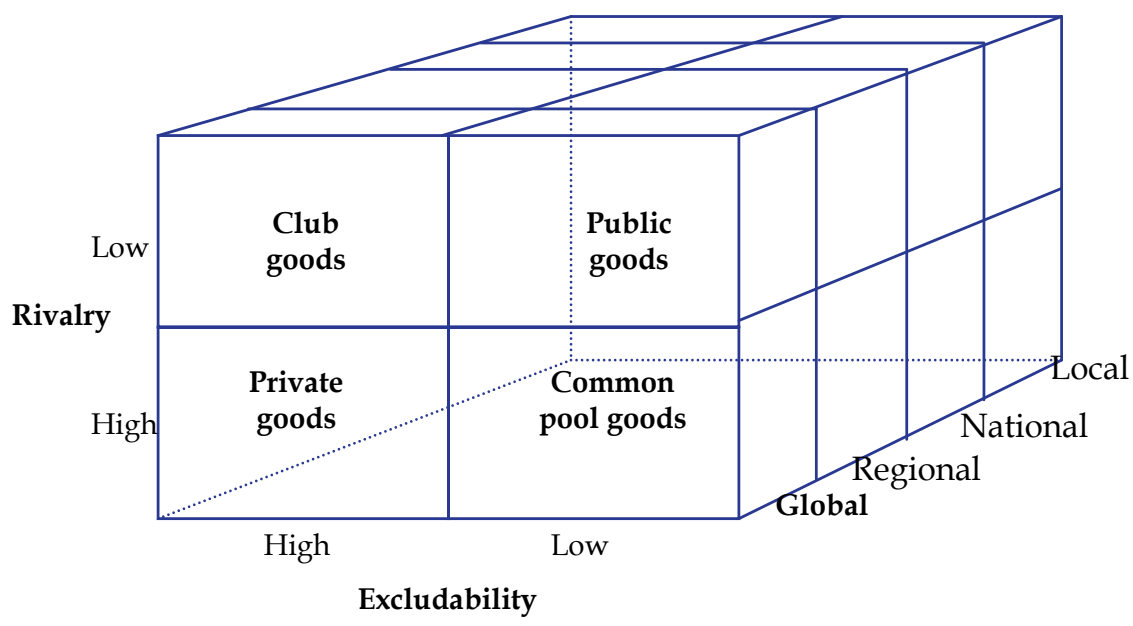

Fig. 1. Private, club, common and public goods

Source: Smith, 2004.

In reality, just few goods are purely public. They are mostly mixed public and private, also known as impure public goods, and these goods only partially satisfy the requirements of nonexcludability and non-rivalry (Kocks, 2005). Common pool goods and club goods are two apparent samples of impure public goods that can take their origin from relaxing one of the two technical criteria of a pure public good while holding the other constant (WHO, 2002).

A common pool good generally is rivalrous but non-excludable. The common goods problem is known as the tragedy of the commons. This is a dilemma that appears in situations in which a large number of actors driven by their self-interest might harm a shared limited resource while being conscious that this is not in their long run interests (Hardin, 1968).

On the other hand, a club good is excludable but non rivalrous. For example, once a golf club is set up, allowing an extra member to use it does not cost anything further. People can be easily excluded from using the facilities (Shaw, 2004).

A private good is the opposite of a public good. Private goods are excludable and rivalrous. For example, a cup of coffee is a private good, and the coffee's owner can exclude other users from using it, and when it has been used, it cannot be consumed again.

On the contrary of private goods, there is no so much qualitatively difference between GPGs and other public goods (Nordhaus, 2005). Examples of GPGs include information, environmental sustainability, disease prevention, political, economic and social stability, and transportation networks, and international communication. As these examples point out, GPGs can be both tangible (e.g., infrastructure or the environment) and intangible (e.g., social, economic or political stability).

The concept of GPGs is not as understandably defined as one would wish. While there is general consensus regarding what is at risk and what is being discussed, the nuances of writers differ. Many of the differences are basically semantic, and should be dispelled at the outset. Some questions should be asked regarding each of the three words it includes. The first question is "does 'global' have to mean that the benefits are entirely global?" While the answer is yes in a broad sense, the answer is no in a narrow sense. In this point of view, when the risk of contracting the disease is removed, the benefit can be available to all. The 
second question is "what is the exact meaning of 'public' in the context of public goods?" In this context there are benefits that are not private in nature, and public benefits do not hint that every member of the public practically derives a measurable benefit. Finally, the third question is related to the word 'good'. In this respect, a public good is a benefit that is useful to the public. So to get rid of a public bad (disutility) is itself a public good. For instance, a disease or pollution can be a public bad (Morrissey et al., 2002).

Like pure public goods, GPGs are characterized by the nature of non-rivalry and nonexcludability. From the other point of view, GPGs have the additional spatial characteristic of extending (Kaul et al., 1999). This means GPGs are public goods that do not "obey" national borders, and some of them are naturally global (Kaul et. al., 2003). In other words, GPGs are goods of this kind whose benefits cross borders and are global in scope (Smith et al., 2003b).

Many of the previous national borders have been taken away or released in recent decades. Generally, market integration has been the strengths of it, and enhanced transportation and communication technologies made it easer. These new facilities assisted networking opportunities for civil life as well (Kaul, 2010), but national boundaries still have an important role. In fact, the "Westphalian Peace Treaties" in (1648) laid down the principles of inviolable national borders. These peace treaties turned into the founding principles of the world order, and countries still largely accept and abide it. For an extended period of time, it was common for politicians to insist on absolute policy making sovereignty, using national borders as a shield behind which they followed specific policies that sometimes violated the most fundamental human rights (Kaul, 2010).

In the case of GPGs, if states explain their national self-interest from a purely national standpoint and pursue it powerfully, international negotiations tend to collapse. International cooperation has to be willing and has to be useful to all concerned groups. Delayed inaction on global challenges mostly increases cost compared to immediate corrective action based on mutually beneficial international negotiations regarding underprovided GPGs. The best way of seeking national self-interests is by way of international cooperation based on equitably win-win strategies (Kaul, 2010).

As it was mentioned before in the context of figure 1, public goods can be local, national, regional or global. If a public good has influence upon one geographic region or one nation, it would be a regional public good or national public good. A GPG should cover more than one group of countries. GPGs' benefit must also reach both an extensive spectrum of countries and an extensive spectrum of the global population. Intergenerational spillovers should be counted in the general definition of a GPG as well. GPGs satisfy the needs of present generations without putting into question the needs of future generations (Kaul et al., 1999).

On the other hand, there are three basic weaknesses in the common plans for providing GPGs. The jurisdictional gap is the first weaknesses of GPGs, i.e., the conflict between a globalized world and national, separate units of policy-making. There is no clear strategy for linked national policy aims with international diplomacy. The second one is the participation gap. This gap includes voiceless and marginal groups, in spite of the spread of democracy. The third one is the incentive gap. Nowadays, international cooperation is broader in scope. Initially, it concerned between-country and at-the-border issues, i.e., international traffic rules, now it is about behind-the-border issues. As a consequence, the implementation of international agreements becomes even more important. However, the operational follow-up to these agreements relies solely on the aid mechanism. Many other useful policy options are neglected, despite the fact that they could make cooperation a privileged strategy for both developing and developed countries (Kaul et al., 1999). 
We can define public goods in many several ways, e.g., referring to consumption, the scale of their impact, production, provision, and political properties. One can also see concrete examples of every type of GPGs for better understanding of the concept from tables 2 to 6 .

\begin{tabular}{|c|c|c|c|}
\hline $\begin{array}{c}\text { Local public } \\
\text { goods: }\end{array}$ & $\begin{array}{c}\text { National public } \\
\text { goods: }\end{array}$ & Regional public goods: & GPGs: \\
\hline $\begin{array}{c}\text { Street signs or } \\
\text { Street safety }\end{array}$ & $\begin{array}{c}\text { National electoral } \\
\text { system }\end{array}$ & $\begin{array}{c}\text { Early-warning systems } \\
\text { for tsunamis }\end{array}$ & $\bullet$ Global warming \\
\hline Law and order & $\begin{array}{c}\text { National health } \\
\text { system }\end{array}$ & $\begin{array}{c}\text { The management of } \\
\text { river basins }\end{array}$ & $\bullet$ Peace and security \\
\hline
\end{tabular}

Table 2. The scale of impact of public goods

Source: Kaul, 2010.

While local public goods benefit mainly people living in a particular community, national public goods may serve pure national purposes or form the building blocks of GPGs. Similarly, while regional public goods have positive effects on some countries within a geographical region, GPGs influence people globally.

\begin{tabular}{|c|c|c|c|}
\hline Pure GPGs* & Impure GPGs** & De facto GPGs*** & $\begin{array}{c}\text { GPGs with } \\
\text { restricted access }\end{array}$ \\
\hline $\begin{array}{l}\bullet \text { Financial and } \\
\text { economic stability }\end{array}$ & - The atmosphere & $\begin{array}{l}\bullet \text { International } \\
\text { communication and } \\
\text { transport networks }\end{array}$ & $\begin{array}{l}\text { Patented } \\
\text { knowledge }\end{array}$ \\
\hline $\begin{array}{l}\text { Peace and } \\
\text { security }\end{array}$ & $\downarrow$ The ozone layer & - Respect for human rights & $\begin{array}{c}\text { The World Wide } \\
\text { Web }\end{array}$ \\
\hline • Moonlight & - Fresh air & $\begin{array}{l}\text { Multilateral trade } \\
\text { agreements }\end{array}$ & $\begin{array}{c}\text { International } \\
\text { markets }\end{array}$ \\
\hline $\begin{array}{l}\text { Communicable } \\
\text { diseases control }\end{array}$ & & $\begin{array}{l}\text { Respect for national } \\
\text { sovereignty }\end{array}$ & \\
\hline $\begin{array}{l}\text { The warming } \\
\text { rays of the sun }\end{array}$ & & $\begin{array}{l}\text { Globalization of policy } \\
\text { approaches }\end{array}$ & \\
\hline \multicolumn{4}{|l|}{ The oceans } \\
\hline \multicolumn{4}{|l|}{$\begin{array}{l}\text { Integrated } \\
\text { markets }\end{array}$} \\
\hline & $\begin{array}{l}\text { Non-rival, but } \\
\text { excludable: }\end{array}$ & $\begin{array}{l}\text { A global gene pool to } \\
\text { promote biodiversity } \\
\text { preservation: }\end{array}$ & \\
\hline & $\begin{array}{l}\text { Knowledge-related } \\
\text { goods, e.g., inventions }\end{array}$ & $\begin{array}{l}\text { Medical, financial and } \\
\text { other technologies }\end{array}$ & \\
\hline \multicolumn{4}{|c|}{$\begin{array}{l}\text { * Pure GPGs are non-excludable and non-rival. } \\
\text { re either non-excludable or non-rival. Non-excludable or difficult to } \\
\text { exclude, but rival. }\end{array}$} \\
\hline
\end{tabular}

Table 3. The consumption properties of GPGs

Source: Kaul, 2010. 
Peace and security is one of the important examples of pure GPGs. It is non-excludable and non-rival. If well provided, everyone can benefit from them. On the other hand, an example of an impure public good is clean, fresh air. It is basically non-excludable, but from a certain level on, rival in consumption (Bieckmann, 2010).

\begin{tabular}{|c|c|c|c|}
\hline 1.Natural GPGs: & 2.Human-made GPGs: & 3.Best-shot goods: & 4.Summation goods: \\
\hline $\begin{array}{l}\text { The sunlight and } \\
\text { the moonlight }\end{array}$ & $\begin{array}{l}\text { Global norms, } \\
\text { standards, rules and } \\
\text { policy regime }\end{array}$ & $\begin{array}{l}\text { Inventions and } \\
\text { discoveries }\end{array}$ & $\begin{array}{l}\text { Mitigation of climate } \\
\text { change }\end{array}$ \\
\hline - The atmosphere & $\begin{array}{l}\text { Global infrastructure } \\
\text { and communication } \\
\text { networks }\end{array}$ & $\begin{array}{l}\text { Destruction of an } \\
\text { asteroid moving } \\
\text { towards the earth }\end{array}$ & - Financial stability \\
\hline • The oceans & $\begin{array}{c}\text { Global knowledge } \\
\text { networks }\end{array}$ & & \\
\hline $\begin{array}{c}\text { 5.Weak-link } \\
\text { summation goods: }\end{array}$ & 6.Club goods: & 7.Final GPGs: & 8.Intermediate GPGs: \\
\hline $\begin{array}{l}\text { Polioplus or } \\
\text { malaria eradication }\end{array}$ & $\begin{array}{c}\text { - Security provision by } \\
\text { NATO }\end{array}$ & $\begin{array}{l}\text { Controlled } \\
\text { communicable } \\
\text { diseases }\end{array}$ & $\begin{array}{c}\text { Pharmaceutical } \\
\text { knowledge }\end{array}$ \\
\hline $\begin{array}{l}\text { Civil aviation } \\
\text { safety - airport } \\
\text { security screening }\end{array}$ & $\begin{array}{l}\text { Airport lounges for } \\
\text { select groups of frequent } \\
\text { flyers }\end{array}$ & $\begin{array}{l}\text { - Financial stability } \\
\qquad \text { Peace }\end{array}$ & $\begin{array}{l}\text { International } \\
\text { agreement on banking } \\
\text { regulation }\end{array}$ \\
\hline
\end{tabular}

Table 4. The production properties of GPGs (The origins of public goods)

Source: Kaul, 2010.

GPGs can distinguish eight types regarding the origins of public goods. Natural GPGs have existed with regard to history outside of human intervention, such as the atmosphere or ozone layer. Another type, i.e., Club goods, stay between public and private goods with the characteristic of being excludable in consumption, and the optimal size of the club is mostly larger than one person.

\begin{tabular}{|c|c|}
\hline Typically consensual GPGs: & Frequently contested GPGs: \\
\hline$\bullet$ Communication \& transport networks & $\bullet$ Globalizing norms about gender equity \\
\hline$\bullet$ Globalizing views about what ought to be \\
public and what private
\end{tabular}

Table 5. The political properties of GPGs

Source: Kaul, 2010.

There is no absolute consensus on every GPG. While the right to basic education or abolition of slavery is the consensual GPGs, the multilateral trade regime or gender equity are the examples of contested GPGs. 


\begin{tabular}{|c|c|c|c|}
\hline Underprovided GPGs & Overused GPGs & Absent GPGs & Well-provided GPGs \\
\hline$\bullet$ Peace and security & $\bullet$ The ozone layer & $\begin{array}{c}\text { An international } \\
\text { migration regime }\end{array}$ & $\begin{array}{c}\text { Communication and } \\
\text { transport networks }\end{array}$ \\
\hline$\bullet$ Health and health care & $\begin{array}{c}\text { The } \\
\text { atmosphere }\end{array}$ & $\begin{array}{c}\text { A knowledge and } \\
\text { technology } \\
\text { framework }\end{array}$ & The World Wide Web \\
\hline Financial stability & $\begin{array}{c}\downarrow \text { Straddling fish } \\
\text { stocks }\end{array}$ & & $\begin{array}{c}\text { The universalization of } \\
\text { human rights norms }\end{array}$ \\
\hline $\begin{array}{c}\text { Environmental } \\
\text { sustainability }\end{array}$ & & & $\bullet$ Globalizing markets \\
\hline $\begin{array}{c}\text { Norms and standards } \\
\text { for traded goods }\end{array}$ & & & \\
\hline
\end{tabular}

Table 6. The current provision status of GPGs

Source: Kaul, 2010.

GPGs are usually underprovided. The reason lies in their publicness which generates collective action problems (for more details, see Kaul et al., 1999). An underused GPG exists, but some actors, countries, or people are unable to consume it, either in full or in part while an underprovided good does not exist or is not fully or adequately provided (Conceição, 2003).

\begin{tabular}{|c|c|c|c|}
\hline Class and type of global good & $\begin{array}{c}\text { Benefits } \\
\text { Non excludable }\end{array}$ & Non rival & $\begin{array}{c}\text { Nature of provision or } \\
\text { use problem }\end{array}$ \\
\hline 1. Natural global commons & & & \\
\hline Ozone layer & Yes & No & Overuse \\
\hline Atmosphere (climate) & Yes & No & Overuse \\
\hline $\begin{array}{c}\text { 2. Human-made global commons } \\
\text { Universal norms and principles }\end{array}$ & Partly & Yes & Underuse (repression) \\
\hline Knowledge & Partly & Yes & Underuse \\
\hline Internet (infrastructure) & Partly & Yes & Underuse \\
\hline 3. Global conditions & & & Underprovision \\
\hline Peace & Yes & Yes & Underprovision \\
\hline Health & Yes & Yes & Underprovision \\
\hline Financial stability & Partly & Yes & Underion \\
\hline Free trade & Partly & Yes & Underprovision \\
\hline Freedom from poverty & No & No & Underprovision \\
\hline Environmental Sustainability & Yes & Yes & Underprovision \\
\hline Equity and justice & Partly & Yes & Underprovision \\
\hline
\end{tabular}

Table 7. Global concerns as GPGs: A selective typology

Source: Kaul et al., 1999.

One can see provision or use problems of GPGs from table 7. GPGs have been also defined as goods that are methodically underprovided by private market forces and for which such underprovision has significant international externality effects (Blackden, 2009). 


\section{Peace and security GPGs}

As we mentioned before, peace and security is itself understood as a GPG and supporting activities of peace and security are defined as promoting this GPG (Yilmaz, 2010). Even in the work of Adam Smith, security is accepted as a pure public good at the national level. This is also true at the global level, (for more details, see Hamburg \& Holl, 1999; Mendez, 1999). Mendez (1999) declares that, unlike defense, peace fulfils substantive public goods criteria. In fact, defense may also have nationally or globally negative externalities. Moreover, Hamburg \& Holl (1999) mention "just peace" as the true public good. Specific conflicts may have only regional effects in the short term. But preventing fatal conflict has worldwide externalities because it acts on any probable source of violence, whilst potentially protects anyone from cruelty and death (Mendez, 1999). A person's security mainly depends on the lottery of where they were born. But we have passed into a period of transnational terrorism where even rich governments cannot provide the level of security that their citizens enjoyed (Addison, 2004).

Peace unarguably provides public goods' criteria from both a substantive (welfare) and formal perspective as a GPG. When one country or countries are at peace, no person can be excluded from profit by its benefits that are extended themselves to all people at the regional, national and international level. Peace is indivisible and non-rivalrous as well. Indeed, individuals and groups can also profit from these benefits without taking away the ability for others to realize the returns on peace. Hereby they have equal access to peace and are able to receive the rewards of peace equally (Smith, 2006). So everyone everywhere can enjoy the profits of peace, the enjoyment of one not detracting from that of another (Mendez, 1992). For instance, peace in Cyprus enhances peace in Turkey, Greece and the Mediterranean, and it helps peace in the world and the overall peace process. While the private profits are the strongest, a regional peace thus has positive externalities that give it public goods' properties (Mendez, 1995).

Galtung (1975) distinguishes between "positive" and "negative peace". While positive peace signifies an absence of not only direct violence, but also "structural violence", negative peace generally means a simple absence of "direct violence" (e.g., war) (Moller, 2004).

Without peace, people cannot enjoy the comforts of their life. It is a prior condition for the pursuit of happiness and welfare (Mendez, 1999). Without peace and security, countries are constantly considered as being in some way breaking off from the global economy as well. It seriously affects themselves, and also the stability of their neighbors, and global security more generally. The many points that link to the global economy include financial flows involved in the stealing and plundering of national properties and the following transmission of offshore money, the flow of illegally produced and internationally traded minerals and narcotics, flows of people as warriors, refugees, and human resource, and the use of technologies of global information and communications for organizing war economies (Addison, 2004). From this point of view, achieving peace should be a top priority within international forums (Smith, 2006).

The difficulty of providing peace as a GPG, however, lies in the quickly changing nature of the international environment, and also global crises, because of the processes of globalization. A rise of spillover effects of the present time conflicts, such as massive amounts of flows of refugees, a rise in the number of diasporic groups, and the resulting poverty and loss of infrastructure in regions affected by conflicts can act as catalysts, provoking new violence to erupt out of the suffering and inequality caused by war (Smith, 2006). 
One can see the knowledge summary of peace and security GPGs from table 8.

Indicators:

- Ratio of people with secure land tenure,

- Ratio below minimum level of dietary consumption,

- Democratic elections etc.

\section{Knowledge:}

- The Human Development Report (UNDP),

- UN Security Council,

- Regional institutions etc.

\section{Management:}

- UN Security Council, Human Rights Commission,

- UNHCR - refugee council,

- International Court of Justice,

- Convention on the Elimination of Discrimination Against Women,

- Convention of the Rights of the Child,

- The International Criminal Court etc.

\section{Participation:}

- UN Security Council,

- Human rights campaigners,

- Humanitarian groups,

- Food, medical and development charities etc.

\section{Finance:}

- Enhancing ODA (Official Development Assistance),

- Reorientation of defense expenditures towards long-term security provision and peace building,

- Application of regulatory tools, for instance The International Convention on the Suppression of the Financing of Terrorism provides a legal method of prosecuting those responsible for raising funds for terrorist activities,

- Global tax.

Table 8. Policy Options for Peace and Security GPGs

Source: Gardiner \& Le Goulven, 2001b.

\section{Health GPGs}

There are some important relations between health GPGs and other GPGs. Health GPGs will benefit from other GPGs, e.g., pollution control, education, while health betterments have positive effects on educational performance, productivity and economic performance (Smith \& Woodward, 2003). 
Health has a clear role regarding externalities given that health is probably an important dimension for the benefits of other GPGs and other sectors. For instance, reductions in $\mathrm{CO} 2$ emissions help slow down global warming. None of the countries can be excluded from benefiting from this, and from which all countries will benefit without detriment to others. Following the same reasoning, the eradication of infectious diseases of global scope, e.g. polioplus or smallpox or HIV (human immunodeficiency virus) / AIDS (acquired immune deficiency syndrome) provides a benefit from which no country is excluded, and each country can benefit without preventing another from doing so (Smith et. el., 2003a). Health improvements may also have positive effects on productivity, education and economic growth (Smith \& Woodward, 2003).

Smith et al. (2003a) mention that the GPG concept may possibly be most functional when applied to two aspects of health. These are research and development (R\&D) and communicable disease control. Health R\&D certainly has GPG aspects, and there is not sufficent of it in areas that would profit low income countries. With regard to history, the public and the "not-for profit sectors" have carried out research resulting in new drugs and treatments, but the private for-profit sector now plays an important role. The important thing is to encourage private sector companies to get involved with research benefiting low-income countries and poor people. Indeed, $90 \%$ of global R\&D spending in health is targeted at diseases affecting just $10 \%$ of the world's population (Smith \& MacKellar, 2007).

Regarding the second aspects of health, the GPG outlook assists collective action in the field of epidemic disease control when reduction in disease pervasiveness in one country has also a benefit for other countries. For example, the eradication of highly transmissible diseases around the world, like polioplus, SARS, HIV, West Nile Virus, avian influenza etc. is important for every country.

Control of infectious diseases innately includes cross-border matters due to the fact that migrant workers characteristically create routes for the spread of disease. This is true for the most important epidemic now hitting Africa - HIV/AIDS. This also applies for more traditional and destroying diseases such as malaria. Important migratory populations in East Africa, West Africa, Southern Africa, South-East Asia, and the Middle East are a reason that national health systems are overwhelmed by demands from non-nationals. A problem is that cross-country financial or administrative arrangements do not often correspond to the health needs of migratory populations. Basic research on diseases frequent to a particular region, e.g., onchocerciasis, also known as river blindness and Robles' Disease in West Africa, raises matters of regional cooperation, due to the lack of ability and incentive for any single country to bear the costs of effective R\&D on its own.

To show the importance of international actors for health GPGs, Rotary International has been helpful in both the financing and the implementation of polioplus eradication. Rotary and its partners are about eradicating this tenacious disease, after 20 years of much effort. The leadership of WHO and Rotary have elicited wide cooperation among developing countries, bilateral donors, multilateral agencies, non-governmental organizations and foundations (Stansfield et. al., 2002).

One can find knowledge summary of Health GPGs from table 9. 


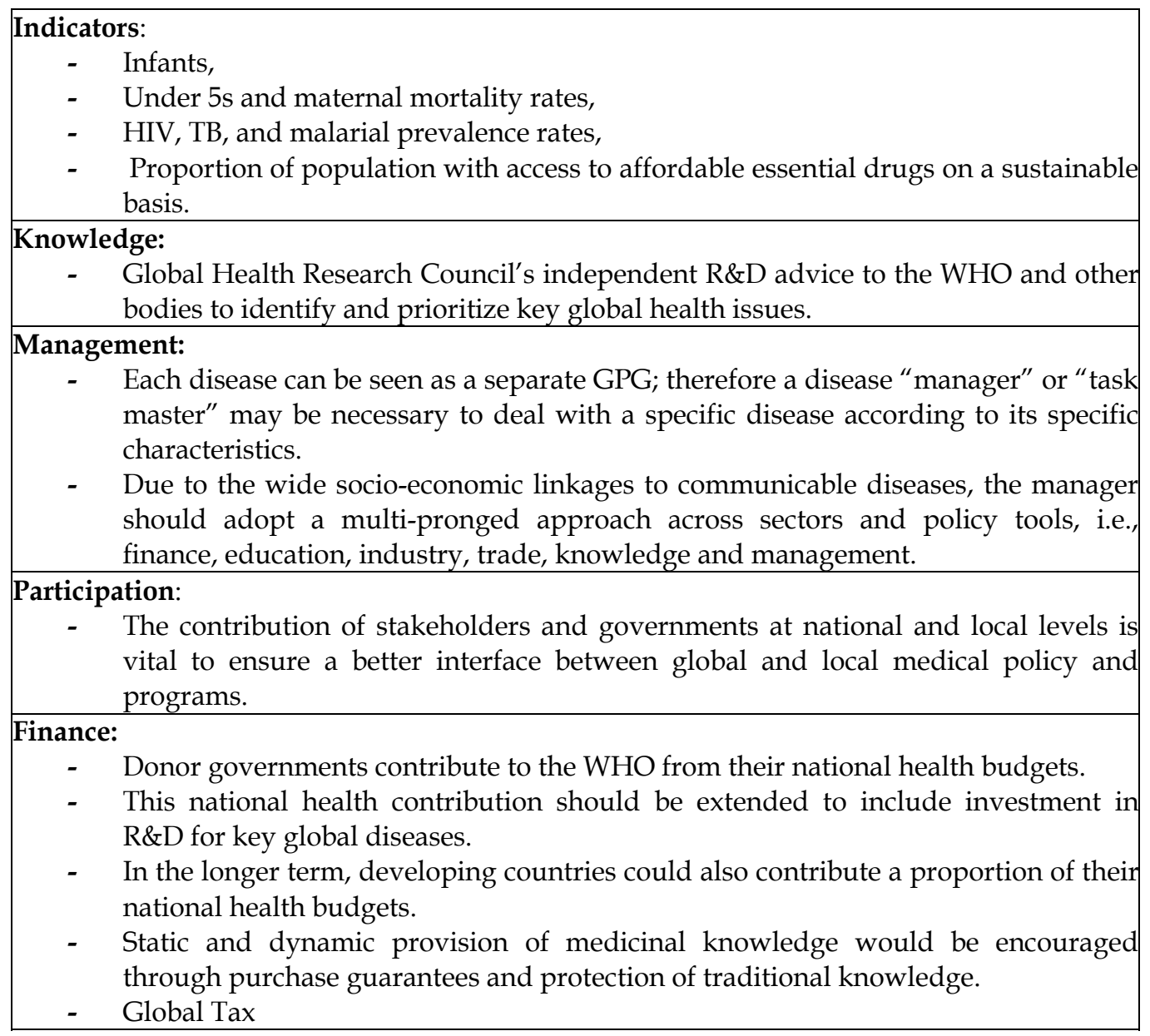

Table 9. Policy Options for Health GPG

Source: Gardiner \& Le Goulven, 2001b.

\section{Conclusion and suggestions}

With the acceleration of globalization, the number of public goods increases and expands, creating an effect on both regional and international levels, sometimes even when they have characteristics of semi-public goods, club goods etc. (Mutlu, 2006). The GPGs lens is intended to shed new light on how globalization could be better managed in the mutual interest of all (Kaul et. al., 2003).

Communities have generally been willing to spend money on national public goods but they should be equally willing to pay for GPGs that serve common interests, be they shared or not. Moreover, we should be prepared to finance such goods (systems of environmental controls, the destruction of nuclear weapons, the control of transmittable diseases, the avoidance of ethnic conflicts or refugee flows) through innovative mechanisms based on the principles of mutuality and collective responsibility, principles that go beyond the concept of ODA (Speth, 1999). In this sense, global tax proposals can be considered, although they are not new, and several plans have already been discussed in academic circles and think- 
tanks for decades. Maybe, a global tax on banks in all over the world could be a solution for poverty, climate change or other kinds of global problems as the IMF suggests and some celebrities also support, e.g., Robin Hood Tax.

Similarly, as national policy-makers are probably not taking into account the well-being of foreign citizens in preparing their own policies concerning public goods, GPGs need some form of global coordination. The reason is the existence of international spillover effects; however, confidence on national provision fails to meet global requirements efficiently or fairly (Blackden, 2009). Globalization has led to an interconnection of national public domains. Nowadays national level public policy requires more and more to be complemented by international collaboration operation efforts in order for GPGs to be accessible to local communities (Kaul et. al, 2003).

The term "shared global priorities" has gained refreshed momentum after the recent food, fuel, and financial crises, which, by the side persistent conflict, state fragility, HIV/ AIDS, and emerging global health problems (avian flu, swine flu), have brought into sharper focus the need for global responses, and suitable global mechanisms, to tackle these challenges (Blackden, 2009). Using a GPGs' approach should not be a means of "repackaging" international preferences. This approach emphasizes the crucial requirement for global collective action and recommends fundamental principles by which the global public can provide and manage more effectively these important global preferences (Gardiner \& Le Goulven, 2001a).

The general characteristics of common property resources cause several problems: Open access, free riders, anonymity, extreme poverty, and a lack of hope, and the larger the population, the larger the problem. These characteristics create problems because it is difficult to keep people away from taking advantage of an open resource. Similarly, you can take all the benefits from the common resources as a free rider, and you probably will not be caught. On the other hand, if you are hungry today, you cannot save some of the sources for tomorrow or for the next generations.

There are three types of control for GPGs. Hardin showed first two solutions. The first one said that resources can be privatized (grant ownership), and the second one, that government can control and use enforcement. Elinor Ostrom (for more details, see Ostrom, 1990; Ostrom et al., 1994) felt that Hardin was too pessimistic, and they suggested a third one, which is collective action like community pressure or control. They believe that if members have a sense of community, there will be less anonymity and greater peer pressure to obey. Similarly, rules are more likely to work if those who are affected can participate in making them. The best is if monitoring is undertaken by community members themselves and not by external authorities. A graduated system of punishments works also very well. Without any of them, there will be a "tragedy of the commons".

After all these issues, although there is a large development gap between developing and developed countries, for the long-term solution, the important suggestion should be related to the topic of education. People have to understand for instance, what radio activity is, why it is dangerous, what measure they can take. Similarly, people have to be aware of diseases like AIDS, to protect themselves from it, or they have to see environmental problems without warning from anyone else, or they have to become sensitive regarding birth control. These subjects are as important as learning mathematics lessons for elementary school students. If we can give correct education at the elementary school level, people will be more rational, more aware of their world when they mature, and they can act rationally, which means of course not just being part of a consuming community, but aware of their 
planet, their future and other people and animals, and they also act for this, about the environment, protect themselves from diseases, being aware of human rights etc. So, in the short term, international institutions can take the responsibility but in the long-term, with a rational education system, people could start to largely solve all the global problems locally. By this process, reward can be used for the correct behavior, and complementary punishment systems can also be applied for wrong actions.

First, educated and rational people can show their preferences to their governments, and finally, we can reduce pollution, control epidemic diseases and prevent the tragedy of the commons with the consensus of all nations. As mentioned before, rational education systems should expand to both developed and developing countries. For this, international cooperation support is vital.

If we ask how we can provide this rational education system, international cooperation could arrange the general framework of the education system, and the global tax would be useful for financing it. This subject should be investigated in any future research.

\section{References}

Addison, T. (2004). The Global Economy, Conflict Prevention, and Post-Conflict Recovery. World Institute for Development Economics Research (WIDER), Helsinki, (United Nations University) DESA Paper, ADDISON, First Draft (8.11.04).doc.

Atkinson, A \& Stilitz, J. (1980). Lectures in Public Economics, New York: McGraw Hill Publishing Co.

Bieckmann, F. (Eds). (2010). Collective Self-interest, Global Public Goods and Responsible Sovereignty, The Broker, issue 20/21 July.

Blackden C.M. (2009). Gender Equality and Global Public Goods: Some Reflections on Shared Priorities, OECD DAC Network on Gender Equality (GENDERNET).

Bradley, D. (2001). The Biological and Epidemiological Basis of Global Public Goods for Health, Paper prepared for Working Group 2 of the Commission on Macroeconomics and Health.

Chen, L ; Evans, T. \& Cash, R. (1999). Health as a Global Public Good. In: Global Public Goods: International Co-operation in the 21st Century, Kaul, I; Grunberg, I \& Stern, M (Ed.). New York: Oxford University Press.

Collier, P. (2008). The Bottom Billion: Why the Poorest Countries are Failing and What can be Done About It, Oxford: Oxford University Press.

Conceição, P. (2003). Assessing the Provision Status of Global Public Goods, In: Providing Global Public Goods: Managing Globalization. (Eds.) Kaul, I; Conceicao, P; Le Goulven, K. \& Mendoza, R., New York: Oxford University Press.

Cook, L. D. \& Sachs J. (1999). Regional Public Goods in International Assistance, In: Global Public Goods: International Co-operation in the 21st Century, Kaul, I; Grunberg, I \& Stern, M (Ed.). New York: Oxford University Press.

Cornes, R. \& Sandler T. (1996). The Theory of Externalities, Public Goods, and Club Goods. 2nd Edition. Cambridge: Cambridge University Press.

Coyne, C.J. \& Ryan, M.E. (2008). Foreign Intervention and Global Public Bads, Mimeo. http:/ / econ.as.nyu.edu/docs/IO/9831/Coyne.pdf.

Desai, M. (2003). Public Goods: A Historical Perspective, In: Providing Global Public Goods: Managing Globalization. (Eds.) Kaul, I; Conceicao, P; Le Goulven, K. \& Mendoza, R., New York: Oxford University Press. 
Ferguson, N. \& Schularick M.. (2006). The Empire Effect: The Determinants of Country Risk in the First Age of Globalization, 1880-1913. Journal of Economic History 66(2), pp. 283-312.

Ferguson, N. (2004). Colossus: The Price of America's Empire. New York: The Penguin Press.

Ferroni, M. (2000). Reforming Foreign Aid: The Role of International Public Goods. OED Working Paper Series, No 4. The World Bank.

Fidler, D. (1998). Legal issues associated with antimicrobial drug resistance. Emerging Infectious Diseases 4: pp. 169-77.

Galtung, J. (1975). Violence, Peace, and Peace Research, In: Peace: Research, Education, Action. Essays in Peace Research, Vol. I (Copenhagen: Christian Ejlers Forlag,), pp. 109-134.

Gardiner, R. \& Le Goulven K. (2001b). Global Public Goods, Briefing Paper, Towards Earth Summit 2002 Economic Briefing No. 3, Heinrich Boell Foundation, Germany.

Gardiner, R. \& Le Goulven, K. (2001a). Sustaining Our Global Public Goods. Economic Briefing No.3. UNED Forum project "Towards Earth Summit 2002".

Hamburg D. A. \& Holl J.E. (1999). Preventing Deadly Conflict from Global Housekeeping to Neighbourhood Watch (Peace and Security), In: Global Public Goods: International Co-operation in the 21st Century, Kaul, I; Grunberg, I \& Stern, M (Ed.). New York: Oxford University Press.

Hardin, G. (1968). The Tragedy of the Commons, Science, Vol. 162, No. 3859, pp. 1243-1248.

Heal, G. (1999). New Strategies for the Provision of Global Public Goods: Learning From International Environmental Challenges, In: Global Public Goods: International Cooperation in the 21st Century, Kaul, I; Grunberg, I \& Stern, M (Ed.). New York: Oxford University Press, pp. 220-39.

Jayaraman, R. \& Kanbur R. (1999). International Public Goods and the Case for Foreign Aid, In: Global Public Goods: International Co-operation in the 21st Century, Kaul, I; Grunberg, I \& Stern, M (Ed.). New York: Oxford University Press, pp. 418-435.

Kammas, P. \& Philippopoulos, A. (2010). The Role of International Public Goods in Tax Cooperation, CESifo Economic Studies. Oxford University Press. Volume: 56.2.

Kaul I; Grunberg I. \& Stern M.A. (1999). Global Public Goods: International Cooperation in the 21st Century. New York: Oxford University Press.

Kaul, I. \& Conceicao P. (2006). The New Public Finance: Responding to Global Challenges, New York: Oxford University Press.

Kaul, I. (2010). What is a Global Public Good, The Broker special report, issue 20/21 July 2010, http://www.search4dev.nl/document/181021

Kaul, I.; Grunberg I. \& Stern M. A. (Ed.). (1999). Global Public Goods: International Co-operation in the 21st Century, New York: Oxford University Press, pp. 436-449.

Kaul, I; Conceicao, P; Le Goulven, K. \& Mendoza, R. (2003). Providing Global Public Goods: Managing Globalization. New York: Oxford University Press.

Kindleberger, C. P. (1986). International Public Goods without International Government The American Economic Review, Vol. 76, No. 1. pp. 1-13.

Kocks, A. (2005). The Financing of UN Peace Operations - An Analysis from a Global Public Good Perspective, INEF Report, Institut für Entwicklung und Frieden der Universität Duisburg-Essen / Campus Duisburg, Heft 77.

Lal, D. (2004). In Praise of Empires: Globalization and Order. New York: Palgrave Macmillian. 
Levaggi, R. (2009). From Local to Global Public Goods: How Should Externalites be Represented? Discussion Paper No. 0903. Dipartimento di Scienze Economiche, Universita degli Studi di Brescia, Italy.

Mendez, R. P. (1992). International Public Finance: A New Perspective on Global Relations, New York: Oxford University Press.

Mendez, R. P. (1995). The Provision and Financing of Universal Public Goods, In: Desai, M. \& Redfern P. (Ed.). Global Governance: Ethics and Economics of the World Order, London: Pinter Publishers, pp. 39-59.

Mendez, R. P. (1999). Peace as a Global Public Good, In: Global Public Goods: International Cooperation in the 21st Century, Kaul, I; Grunberg, I \& Stern, M (Ed.). New York: Oxford University Press, pp. 382-416.

Mitchener, K.J. \& Weidenmier M.. (2005). Empire, Public Goods, and the Roosevelt Corollary, The Journal of Economic History 65(3): pp. 658-692.

Moller, B. (2004). Peace as a Global Public Good Research Center on Development and International Relations (DIR), Development Research Series Working Paper, No. 127, Aalborg University, Denmark.

Morrissey, O. D.W. te Velde \& A. Hewitt (2002). Defining International Public Goods: Conceptual Issues, In: International Public Goods: Incentives, Measurement and Financing, Ferroni M.\& Mody A. (Eds.), The Hague: Kluwer Academic.

Mutlu, A. (2006). Küresel Kamusal Mallar Bağlamında Sağlık Hizmetleri ve Çevre Kirlenmesi: Üretim, Finansman ve Yönetim Sorunları, Journal of Maliye, 150, Turkey.

Nordhaus, D.W. (2005). Life after Kyoto: Alternative Approaches to Global Warming Policies, mimeo.

Ostrom, E. (1990). Governing the Commons: The Evolution of Institutions for Collective Action. Cambridge: Cambridge University Press.

Ostrom, E.; Gardner, R. \& Walker, J. (1994). Rules, Games, and Common Pool Resources. Ann Arbor: University of Mishigan Press.

Samuelson, P. A. (1954). The Pure Theory of Public Expenditure. Review of Economics and Statistics 36 (4), pp. 387-389.

Sandler, T (1998), Global and Regional Public goods: A Prognosis for Collective Action. Fiscal Studies , 19, pp. 221-247.

Sandler, T. \& Arce, D. (2002). A Conceptual Framework for Understanding Global and Transnational Public Goods for Health. Fiscal Studies 23, pp. 195-222.

Sandler, T. (1997). Global Challenges: An Approach to Environmental, Political and Economic Problems. Cambridge: Cambridge University Press: chapter 5.

Shaw, D. J. (2004). Intervention A New Theory of Government Action, Johannesburg, South Africa. http://www.scribd.com/doc/92576/Intervention-A-Theory-ofgovernment-Action.

Smith RD \& Woodward .(2003). Global public goods for health: Use and limitations, Smith, RD, Beaglehole R, Woodward D \& Drager N.( a) Global Public Goods for Health: a health economic and public health perspective. Oxford: Oxford University Press.

Smith, J. (2006). Financing the Delivery of Global Peace through an L20? Considerations for an initial L20 meeting on financing Global Public Goods, L20 Financing Global Public Goods Conference, February 26 - 27th. 
Smith, R. (2004). Public Goods \& Health, Health Economics Lecture notes (lecture 20) Autumn 04/05.

Smith, RD, \& Mackellar L. (2007). Global public goods and the global health agenda: problems, priorities and potential, In: Globalization and Health 2007, 3:9 doi:10.1186/1744-8603-3-9.

Smith, RD, Beagehole R, Woodward D \& Drager N (2003b). Global public goods for health: from theory to policy. In: Global Public Goods for Health: a health economic and public health perspective. Volume chapter 14. Edited by: Smith RD, Beaglehole R, Woodward D, Drager N. Oxford: Oxford University Press.

Smith, RD, Beaglehole R, Woodward D \& Drager N.(2003a) Global Public Goods for Health: a health economic and public health perspective. Oxford: Oxford University Press.

Smith, RD; Thorsteinsdóttir H; Daar A; Gold R \& Singer P. (2004b). Genomics knowledge and equity: a global public good's perspective of the patent system. Bulletin of the World Health Organization, 82(5): pp. 385-389.

Smith, RD; Woodward D; Acharya A.; Beaglehole R \& Drager N. (2004a) Communicable Disease Control: A 'Global Public Good' Perspective. Health Policy and Planning, 19(5): pp. 272-279.

Speth, J.G. (1999). The Plight of the Poor: The United States Must Increase Development Aid, Foreign Affairs, May/June, pp.13.

Stansfield, SK; Harper, M; Lamb, G. \& Lob-Levyt J. (2002). Innovative Financing of International Public Goods for Health. Committee for Macroeconomics and Health Working Paper No. WG2:22 Geneva: World Health Organization.

Stiglitz, J.E. (1995). The Theory of International Public Goods and the Architecture of International Organizations. In: United Nations Background Paper 7. New York, United Nations, Department for Economic and Social Information and Policy Analysis.

Stiglitz, J.E.. (2000). Economics of the Public Sector, Third edition. W.W. Norton and Company, New York.

Szlezak, N. A.; Bloom B. R.; Jamison D.T.; Keusch G.T.; Michaud C.M., Moon S. \& Clark W.C. (2010). "The Global Health System: Actors, Norms, and Expectations in Transition." PLOS Medicine 7(1):e1000183.

Towards Earth Summit (2002). Sustaining Our Global Public Goods, Economic Briefing No. 3 Available from http://www.earthsummit2002.org/es/issues/GPG/gpg.pdf

Varian, H. (1992). Microeconomic analysis. New York: W.W. Norton and Company.

WHO (2002). Global Public Goods for Health, The Report of Group 2 of the Commission on Macroeconomics and Health, ISBN 924159010 6, Switzerland.

Wildasin, D. (2008). Public Finance in an Era of Global Demographic Change: Fertility Busts, Migration Booms, and Public Policy, Working Papers 2008-02, University of Kentucky, Institute for Federalism and Intergovernmental Relations

Yılmaz, B. E. (2010). Peace and Security: Provision and Financing Mechanisms As A Global Public Goods, Anadolu University Journal of Social Sciences, 10/1. 


\title{
Building Sustainable Capacity for Disease Diagnosis in Sub-Saharan Africa: Case Studies of Cooperation in Diagnostic Pathology
}

\author{
Renato Mariani-Costantini et al.* \\ Department of Oncology and Experimental Medicine, "G.d'Annunzio" University, and \\ Aging Research Center (CeSI), G.d'Annunzio" University Foundation, Chieti,
} Italy

\section{Introduction}

One of the most important outcomes of globalization's complex and debated processes is the possibility of promoting and upgrading services in geographically remote areas. Globalization yields the easiest means of transportation and communication, which makes networking a relatively simple process. Moreover, innovative sound technologies, such as tele-consultation, provide these networks with a solid base for continuation and further buildup. These possibilities apply to the field of Medicine in general, and Pathology in particular. These new opportunities are very promising in regard to the endeavor of building sustainable capacities for disease diagnosis in sub-Saharan Africa.

\footnotetext{
* Khalid Dafaallah Awadelkarim 1 , Massimo Barberis ${ }^{2}$, Claudio Clemente 3 , Pasquale De Blasio ${ }^{4}$, Mario Di Gioacchino ${ }^{5}$, Agostino Faravelli' ${ }^{6}$, Marco Forni ${ }^{7}$, Piergiovanni Grigolato ${ }^{8}$, Lorenzo Leoncini ${ }^{3}$, Karin Schuerfeld ${ }^{9}$, Ahmed Abdalla Mohamedani11 ${ }^{11}$, Giuseppe Lattanzio ${ }^{12}$,

Sandra Rosini ${ }^{12}$ and Vincenzo Stracca Pansa ${ }^{13}$

1 Department of Molecular Biology, National Cancer Institute (NCI-UG), University of Gezira, Wad Medani, Sudan, 2 Department of Pathology, European Institute of Oncology, Milan, Italy,

3 Department of Pathology and Cytopathology Division, S. Pio X Hospital, Milano, Italy,

4 President of the European, Middle-Eastern and African Society of Biopreservation and Biobanking (ESBB) and of BioRep SrL, Milan, Italy,

5 Department of Medicine and Science of Aging, "G.d'Annunzio" University, and Aging Research Center (CeSI), G.d'Annunzio" University Foundation, Chieti, Italy,

6 Università degli Studi di Milano - Bicocca, Milan, Italy,

7 Molecular Biotechnology Center - University of Turin, Turin, Italy,

8 Department of Pathology, School of Medicine, University of Brescia, Italy,

9 Department of Pathology, Montevarchi USL8, Italy,

10 Department of Oncology and Experimental Medicine, "G.d'Annunzio" University, and Aging Research Center (CeSI), G.d'Annunzio" University Foundation, Chieti, Italy,

11 Department of Pathology, Faculty of Medicine, University of Gezira, Wad Medani, Sudan,

12 Servizio di Anatomia e Istologia Patologica e Citopatologia Diagnostica, Ospedale CLINICIZZATO - SS.

ANNUNZIATA, Chieti, Italy,

13 Associazione Patologi Oltre Frontiera, c/o Anatomia Patologica Ospedale Venezia Campo SS. Giovanni e Paolo, Venice, Italy.
} 
In this chapter we describe cases of cooperation in the field of diagnostic pathology in subSaharan Africa that exemplify benefits from globalization. In these regards we believe that networking of sub-Saharan African institutions with biomedical centers and associations of pathologists in developed countries could significantly improve the current situation in many sub-Saharan African countries. However, to gain maximum benefits from globalization-related activities (networking/tele-consultation, etc.), there is a fundamental need for strongly committed contexts both in sub-Saharan African countries and in developed countries.

Pathology plays a pivotal role in diagnosis, staging and management of disease. The lack of adequate pathology services undermines the ability to rationally address health care needs and patient treatment based on evidence-based knowledge (Gray \& Carter 1997; Greene et al. 2002; Benediktsson et al. 2007). However, pathology is often perceived as a peripheral and ancillary biomedical specialty, which, under the pressure of limited resources, may be sacrificed to the benefit of needs regarded as more urgent (Awadelkarim et al. 2010b). Such wrong perception may account for the scarcity of pathology services in sub-Saharan Africa and for the fact that such services, when provided, are often below acceptable standards (Hutt \& Spencer 1982; Gray \& Carter 1997; Awadelkarim et al. 2010b).

The extreme shortage of pathologists and laboratory technicians in sub-Saharan Africa is a major issue (Gray \& Carter 1997; Awadelkarim et al. 2010b): for example, in 2007 Uganda had 18 pathologists for a population of 28 millions, Tanzania 15 for 38 millions, Sudan 51 for 40 millions (Benediktsson et al. 2007; Awadelkarim et al. 2010b). Emigration further compounds this problem: in fact, the necessity of training abroad, the awareness of the difficulties in applying newly-acquired skills back home, and the experience of the Western job market leads to a "brain-drain" from developing to developed countries (Garrett 2007). This depletes the human resources and the dissemination of knowledge.

Major challenges that need to be faced to improve pathology in sub-Saharan Africa include the geographic distances, which require logistic systems for sending appropriately annotated specimens from peripheral hospitals to centralized laboratories; the high temperatures (often above $45^{\circ} \mathrm{C}$ ) which result in the difficult use of paraffin wax, stains, and chemicals; the generally inadequate access to electricity services, with consequent frequent and extended outages; the dust and very poor maintenance, that compromise equipment and samples; the absence or inadequacy of standard operative procedures (Vacca 1985; Dafallah et al. 2005; IMF Survey online 2008 ; Bancroft \& Gamble 2008).

The implementation of new pathology activities in Africa must find a strong local commitment and should rely on strategies that combine economical sustainability in time with realistic compromises between costly "gold standard techniques" and less expensive alternatives, that could be more suitable to the environmental, infrastructural and personnel limitations. A cost-effective approach is mandatory in limited resource contexts and research should be oriented to develop innovative and less expensive diagnostic methods. To exemplify the feasibility of such approach it is worth to cite the article entitled "The poor man's cell block," a contribution from New Zealand describing a simple method to obtain a cell block (i.e., an inclusion for histology based on cell samples) that links the easy and widespread use of fine needle aspiration cytology to the power of detailed histological visualization (Leung \& Bedard 1993; Mayall \& Darlington 2010). The method is interesting also because it substitutes formalin with iso-propyl alcohol in fixation. Formalin is safe only in presence of adequate and perfectly efficient aspiration devices, generally not available in pathology laboratories operating in contexts with limited resources. The use of alternative fixatives is a reasonable and cost-effective alternative to expensive aspiration hoods, which need regular servicing and substitution, and proper disposal of costly filter units. 
The expertise required for African pathologists must comprise infectious diseases, including not only major global diseases such as malaria, AIDS and tuberculosis, but also neglected endemic tropical diseases, one of the key areas of health concern for Africa, as these diseases, in principle preventable and treatable, result in life-long physical pain and social stigma when overlooked (Muela Ribera et al. 2009). However, while this "traditional" infectious focus of African pathology remains very important, the need for expert cancer pathologists is rapidly growing, in parallel with the increasing incidence of cancer in Africa. According to the African-Oxford Consortium and World Health Organization, 15 million new cases of cancer worldwide are projected by 2020, and $70 \%$ of these will be in developing countries (Lingwood et al. 2008), with special problems in Africa (Morris 2003; Awadelkarim et al. 2010a).

\section{Neglected tropical diseases}

The World Health Organization (WHO) is currently focusing on 17 neglected tropical diseases (http://www.who.int/neglected_diseases/diseases/en/): Buruli ulcer, Chagas disease (American trypanosomiasis), cysticercosis, dengue/dengue haemorrhagic fever, dracunculiasis (guinea-worm disease), echinococcosis, fascioliasis, African trypanosomiasis, leishmaniasis, leprosy, lymphatic filariasis, onchocerciasis, rabies, schistosomiasis, soil transmitted helminthiasis, trachoma and yaws. These diseases, to which children are most vulnerable, affect an estimated one billion people, primarily among the poor populations in Africa, and are mostly attributable to well-known environmental factors, notably unsafe water, poor housing and poor sanitation (Stein et al. 2007). Programs aimed at controlling or eliminating these endemic diseases have come together in the Neglected Tropical Disease Coalition, which provides a unique opportunity for collaborative advocacy activities in industrialized countries while member organizations also explore coordination or integration of disease treatment and prevention in endemic countries (http://www.neglectedtropicaldiseases.org/about.html).

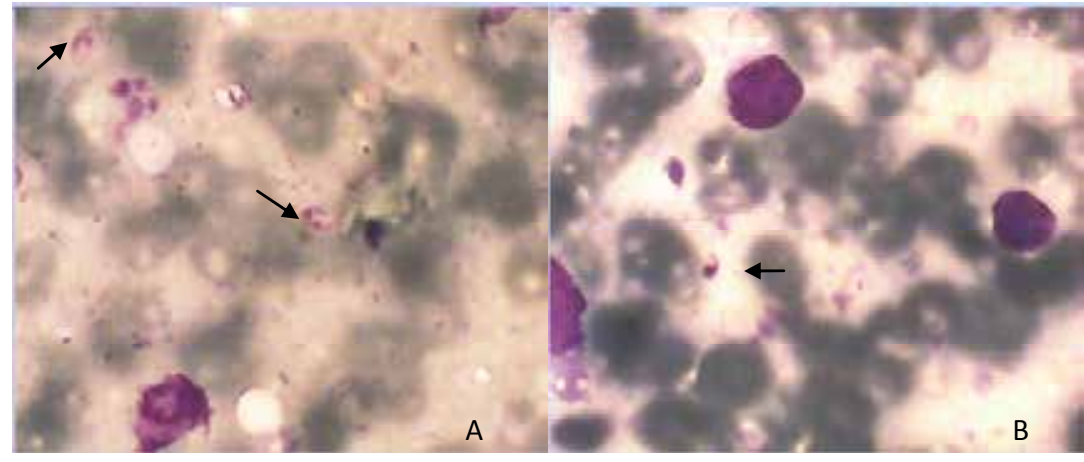

Fig. 1. Lymph node puncture stained with Giemsa. Leishman-Donovan bodies are seen (arrows). Case history: 17 years-old boy complaining of fever, fatigability and loss of weight. Clinical examination revealed a febrile anaemic patient with splenomegaly and enlarged cervical, axillary and groin lymph nodes. Differential diagnosis included acute leukemia, infectious mononucleosis and kala-azar. Fine needle aspiration was performed on one of the cervical lymph nodes. Cytology showed bloody background with mainly lymphocytes and few extracellular Leishman-Donovan bodies. Diagnosis of kala-azar (visceral leishmaniasis) was made. 
Endemic tropical diseases are tied to specific geographic and environmental conditions and carriers do not travel easily. Therefore these diseases are not perceived as a threat to developed societies and are neglected in most western pathology training programs. This results in a global lack of diagnostic capabilities, which negatively reflects on African health and on necessary finalized research. Thus, there is a need to introduce endemic diseases in the pathology training programs of developed countries. This could be done by networking with clinical centers and Universities in sub-Saharan Africa, and it could contribute to the global development of pathology training. Figures 1-4 exemplify educational cases of neglected tropical diseases from the files of the Pathology Department of Gezira University, Wad Medani, Sudan.

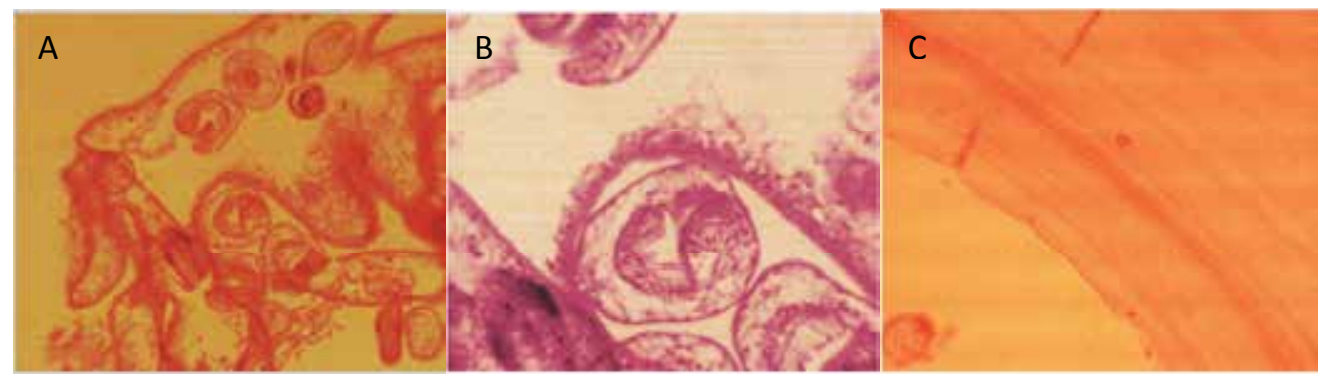

Fig. 2. Breast hydatid cyst. Case history: housewife aged 35 years, who complained of a right breast lump increasing gradually in size for the last two years, with mild pain. Local examination revealed a $5 \mathrm{~cm}$ cystic lump, which was totally excised. Macroscopically, the lesion consisted in a $5.5 \mathrm{~cm}$ diameter fibro-fatty tissue mass containing a thick-walled $4.3 \mathrm{~cm}$ cyst. Microscopic examination shows a cyst containing scolices of Echinoccocus granulosus and a thick laminated (brood) capsule, features typical of hydatid cyst (A \& B: scolices and inner membrane, C: laminated capsule, H\&E stain).

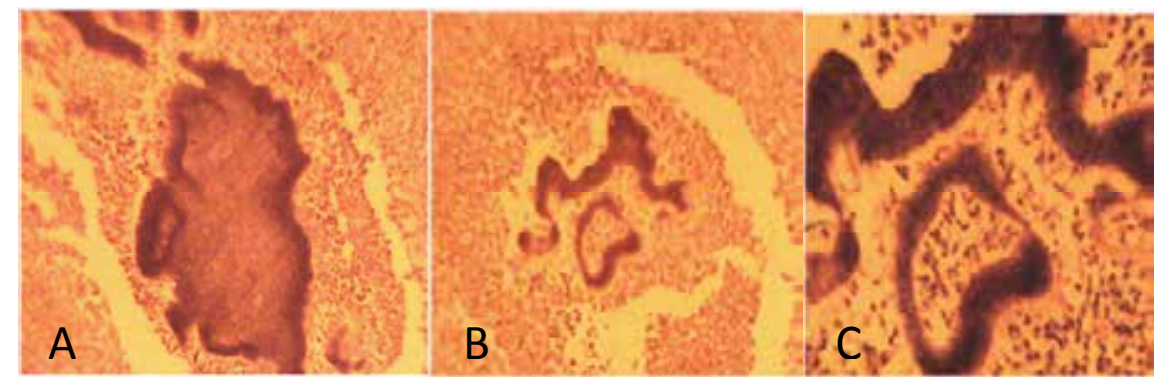

Fig. 3. Yellow Madura. Case history: 17 years-old female complaining of right leg swelling present for 5 years, with recent discharge of pus containing yellowish material, but no significant pain. Clinical examination showed right leg swelling, mainly around the ankle joint and involving the heel. Operated under general anaethesia using tourniquet, it was found that the lesion involved the tendons, being very close to bone. Macroscopic examination showed a $7.0 \mathrm{~cm}$ diameter irregular fibro-fatty tissue mass containing pus with yellowish granules. Microscopic analysis shows chronic inflammation and fibrosis, with foci of micro-abscesses containing structure-less fungal elements. These features are consistent with yellow Madura (A, B \& C, sections from left leg lesion, H\&E stain). 


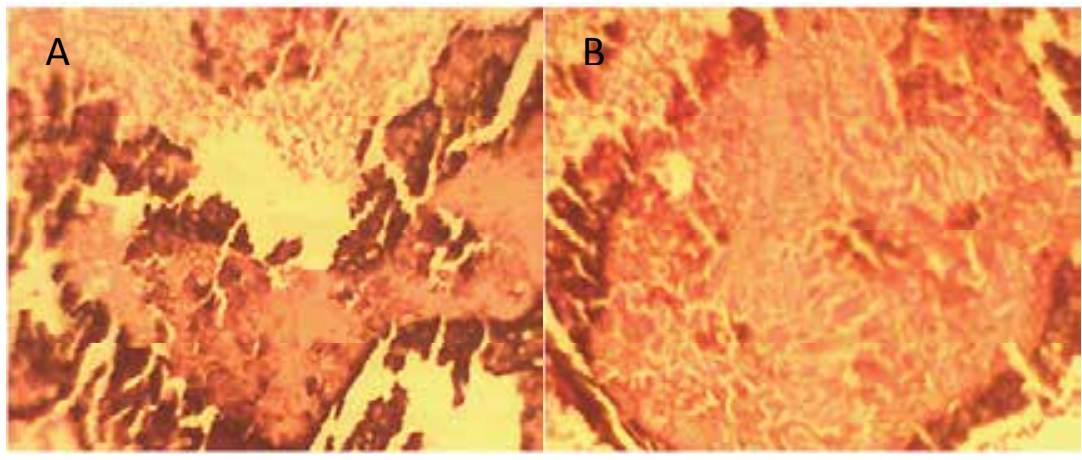

Fig. 4. Grains of black Madura. Case history: 29-years old man complaining of a painless foot swelling for the last 2.5 years, with no documented history of trauma or injury. Examination showed a well-circumscribed, partially mobile, non-tender $3.5 \mathrm{~cm}$ swelling in the sole of the left foot, with normal-appearing overlying skin and no discharging sinuses. The lesion was excised under general anesthesia. Differential clinical diagnosis included fibroma, giant cell tumor or Madura. Macroscopic examination showed a $4.0 \mathrm{~cm}$ wellencapsulated, firm mass. Sectioning revealed whitish tissue studded with necrotic areas containing small black granules. Microscopic examination showed chronic inflammation with granulomas surrounding dark-brown fungal elements. The features were consistent with Madurella mycetomi (black madura) infection. (A \& B, views of sections from mass, H\&E stain).

\subsection{A North-South intervention against a neglected tropical disease: Buruli ulcer in Benin}

An enigmatic infectious disease, Buruli ulcer (children leprosy), is the subject of a model North-South pathology intervention in Benin, within the framework of the WHO Buruli ulcer program. Buruli ulcer is a highly destructive necrotizing skin disease, usually with insidious painless onset, which occurs in tropical and subtropical areas of West Africa and South-East Australia, with increasing geographical spread (Zavattaro et al. 2010). More than $50 \%$ of the patients are below 15 years age. The disease is caused by Mycobacterium ulcerans (Connor et al. 1976), an opportunistic pathogen that grows at low temperature $\left(30\right.$ to $\left.35^{\circ} \mathrm{C}\right)$ in a rarefied oxygen ambience and produces pathologic effects through a plasmid-encoded macrolide toxin (mycolactone). The lesions involve primarily the deep dermis and the subcutaneous tissue, manifesting under various clinical forms, the most dramatic being large ulcerations that may reach the bone (Leigheb et al. 2008) (Figures 5, 6).

The classic treatment of Buruli ulcer relies on bi-antibiotic therapy (streptomycine/rifampicine), followed by surgical excision of the necrotic tissues and skin graft (Nienhuis et al. 2010). Hyperbaric oxygen therapy (Figure 6), even if not able to prevent germ growth, is an important adjuvant. It protects against over-infections after excision of necrotic tissues, it stimulates neo-vascularization with improvement of grafting, and it accelerates wound healing, reducing the risk of hypertrophic scars, which result in permanent deformities and loss of joint functions. 
'Oxygen for Life' is an ongoing project in Benin involving an Italian team lead by the Service of Anatomic Pathology and Cytopathology of the S. Pio X Clinic of Milan and other Italian Institutions, supported by important and stable private donations, in connection with the WHO's Buruli ulcer program (http://www.who.int/buruli/en/). This initiative currently provides expertise in pathologic diagnosis and medical/surgical treatment of Buruli ulcer, as well as the provision and maintenance of a multi-place hyperbaric oxygen chamber at the Centre de Dépistage et de Traitement de l'Ulcère de Buruli in Alladà, Benin, a facility unique in Africa (Figures 7). This program resulted in a significant improvement of clinical end points and quality of life for Buruli ulcer patients in Benin.

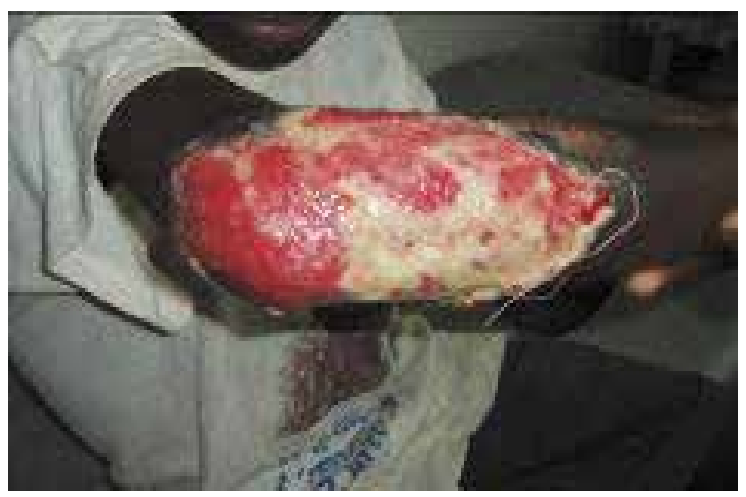

Fig. 5. Buruli ulcer before treatment.

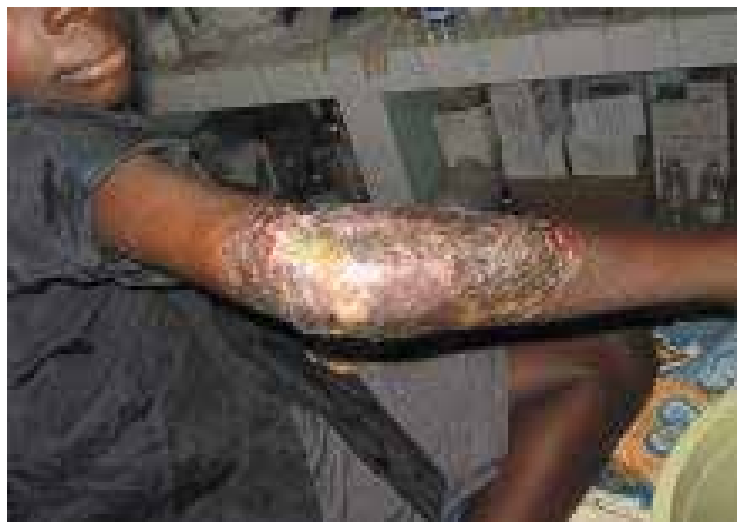

Fig. 6. The same case after combined antibiotic and hyperbaric oxygen treatment. 
The project involves multiple areas of expertise, including a specialized engineer responsible for the maintenance of the oxygen chamber already in place, and for the installation of a second one. A histopathology lab was also implemented ex novo, combined with a telepathology connection, which upgrades the diagnostic capabilities of the African team, as discussed further on. Meanwhile, a research project was started with the aim of understanding the natural history of $M$. ulcerans, with special regard to its possible diffusion from animal reservoirs.

Transmission modes are still uncertain, but epidemiological evidences indicate that interhuman contagion is rare. Rather than pointing to a single, specific vector, the available data suggest a key role for environmental factors, with a possible natural reservoir of the pathogen in aquatic insects, particularly of the Naucoridae and Belostomatidae families (Portaels et al. 1999). To verify this hypothesis, zoological samples collected in the endemic areas of Alladà and Lalo in Benin were analyzed with sensitive molecular techniques (polymerase chain reaction, PCR) for microbial DNA. More than 2,500 samples of aquatic insects (mosquitoes, coleoptera, larval Odonata, water-scorpions, etc.), as well as amphibians (frogs and tadpoles), mollusks, fish, shellfish, algae and samples of spring water, slime, and Akponé (Zé) water plants, were tested in cooperation with the Microbiology Laboratory of the University of Sassari, Italy. Only a few insects of the family Naucoridae gave positive results.

The "Oxygen for Life" project is contributing to the formation of a team of African pathologists, physicians and surgeons specialized in Buruli ulcer, and is bringing this forgotten disease to international attention, stimulating also specific research. It provides an illuminating example of globalization in the fight against neglected endemic tropical diseases in Africa.

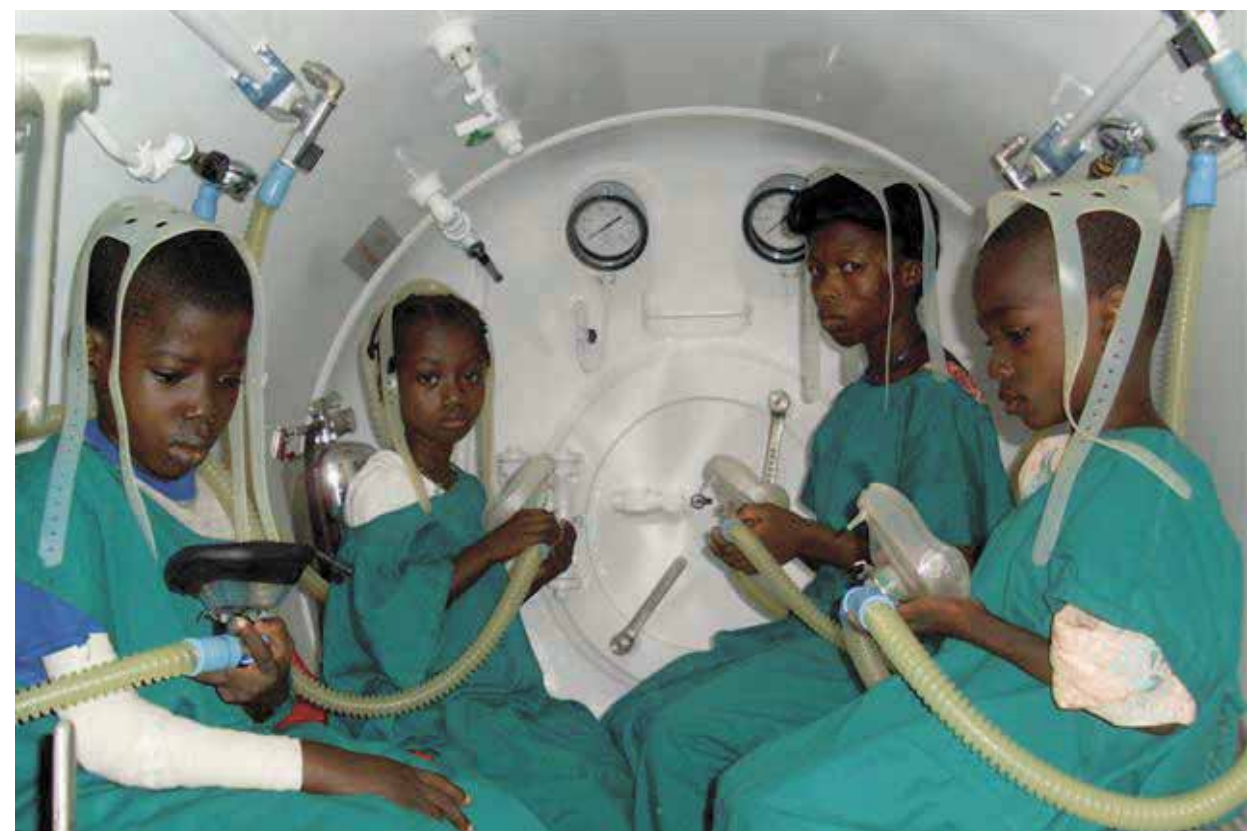

Fig. 7. The four place hyperbaric oxygen chamber functioning at the Centre de Dépistage et de Traitement de l'Ulcère de Buruli (CDTUB) in Alladà, Benin. 


\section{Need of pathology for the development of African oncology}

African governments and development agencies have thus far focused their attention on communicable diseases, and maternal and child mortality (World Health Organization 2004; Lingwood et al. 2008). However, these older health problems coexist now with new ones, in particular HIV/AIDS and cancer, which are closely connected and rapidly progressing. The importance of infections as a major cancer risk factor in Africa is clearly evidenced by the fact that as many as $36 \%$ of the cancer cases in the African continent are infection-related, which is double the world average (Parkin et al. 2008).

The WHO forecasts a dramatic increase of incidence of cancer in Africa in the next decades and the necessity to implement efficient oncology services. However, accurate cancer data are difficult to obtain because registries cover only $11 \%$ of the African population (Porter 2008), and the quality of information is poor because of the severe shortcomings in pathologic diagnosis (Parkin et al. 2003; Parkin 2006; Awadelkarim et al. 2010a; Awadelkarim et al. 2010b). Mortality statistics for cancer are also inadequate; since 1995, only three African countries (Mauritius, Egypt, and South Africa) contributed to the cancer mortality database. However, even in South Africa, death registrations for cancer are estimated to be incomplete (Parkin et al. 2003). Nonetheless, about 650,000 new cases of cancer were estimated to have occurred in Africa in 2002, 530,000 of which in sub-Saharan countries (Ferlay et al. 2004). Interestingly, cancer incidence and mortality seem to have risen before the spread of the current HIV/AIDS epidemics (Bulatao 2006).

As mentioned earlier, while cancer treatments must be adapted to fit local health conditions with cost-effective protocols, any treatment must be based on sound histological diagnosis (Greene et al. 2002), but this is largely unfeasible due to the dramatic shortage of histopathology and cytopathology services.

\subsection{Carcinoma of the uterine cervix: Need of novel pathology-based approaches to prevention}

The lack of pathology services is felt particularly in the area of cancer prevention in women, as exemplified by carcinoma of the uterine cervix. With an estimated incidence of 30-40 per $10^{5}$ females, carcinoma of the uterine cervix is the most common cancer of women in subSaharan Africa (Parkin et al. 2008). It is well known that the agents responsible for this cancer are human papilloma viruses (HPVs) (zur Hausen 2009) and that this cancer can be effectively cured when treated at early stages, as it mostly occurs in the developed world. However, in Africa the vast majority of the affected patients seen in hospitals have advanced to incurable disease at stages III or IV (Hamad 2006; Sitas et al. 2008). Another problem linked to this cancer in Africa is that HIV/AIDS represents a risk factor for persistent infection with cancer-related HPVs (Palefsky 2009; Singh et al. 2009).

The primary approach for cervical cancer in developed countries is prevention by organized population screening. In sub-Saharan Africa, the lack of infrastructures, trained personnel and funds make large-scale cytology screening programs unfeasible. Presently, diagnosis and treatment of cervical cancer are possible only in few organized centers, mainly in capital cities. Nonetheless, recent technological developments in cervical cancer screening could open a window of new opportunity for sub-Saharan African countries. In fact, in countries with established cytology prevention programs, HPV DNA testing is becoming the most attractive option for primary screening (Meijer et al. 2009) and there is a tendency to recur to it as the sole screening modality, with cytology reserved for triage of HPV-positive women. 
Furthermore, the new molecular tests allow to detect not only HPV DNA, but also the fulllength E6-E7 transcripts of the high-risk viruses that are associated with lesions which could progress to cancer (Cuzick et al. 2008; Zappacosta \& Rosini 2008). Therefore, established cytology-based programs are gradually moving towards a greater use of HPV DNA testing to improve efficacy and safely lengthen screening intervals. The higher sensitivity of HPV DNA testing compared to cytology argues strongly for using HPV DNA testing as the primary screening test in newly implemented programs in Africa.

In low resource settings, an interesting method that could be used for screening is visual uterine cervix inspection with acetic acid (Cuzick et al. 2008; Sankaranarayanan et al. 2008). This inexpensive method can be carried out using modest equipment and widely available consumables, without laboratory infrastructures. The sensitivity in the detection of highgrade precursor lesions and invasive cervical cancer has varied from 49 to $96 \%$ and the specificity from 49 to $98 \%$, being significantly lower in human immunodeficiency virus (HIV)-positive women, but the possibility to use HPV-DNA test to detect high risk viruses could complement this test (Cuzick et al. 2008). This would reduce reliance on cytology, too expensive and difficult to implement in Africa for lack of facilities and trained personnel (Cuzick et al. 2008).

Regardless of the tests used, screening must be linked to treatment to ensure program effectiveness. An option is a "screen and treat" algorithm, in which any suspicious lesion is referred for cryotherapy or loop electrosurgical excision, safe, effective and inexpensive outpatient methods used for treatment of cervical pre-cancer (Cuzick et al. 2008). After initial screening by HPV DNA testing of all women, those resulting HPV-negative could be recalled after 5-10 years; while those resulting HPV-positive could be visually-inspected, followed by immediate treatment. In women negative by visual inspection, the screening process could be repeated after 12-24 months. This approach could be combined with a mother-daughter approach for preventive vaccination. The HPV vaccine, now largely used in developed countries, is far from being available in Africa, due to costs and other social and organizational factors; however, it could be an effective tool to reduce health inequality for African women (Pollack \& Tsu 2005; Tsu \& Pollack 2005). In the aforementioned combined approach, daughters could be vaccinated while mothers are screened or treated.

\subsection{Development of diagnostic capabilities in cancer pathology through North-South cooperation: St. Mary's Hospital Lacor in Gulu, Uganda, and the Association Patologi Oltre Frontiera}

In Uganda, as in other sub-Saharan African countries, cancer appears to be steadily more important as a cause of disease and mortality (Table 1). As expected, the most prevalent cancers are associated with viruses, such as the human papilloma virus (carcinoma of the uterine cervix), EBV and HIV (lymphoma), HIV/AIDS and KS-associated Herpes virus/Human Herpes virus 8 “KSHV/HHV-8” (Kaposi sarcoma) (Table 2).

The Uganda Health Sector Strategic Plan III 2010/11-2014/15 acknowledges that "noncommunicable diseases and their risk factors are increasing in low income countries including Uganda." Already in 2006, the Ministry of Health established a program for the prevention and control of non-communicable diseases and, in collaboration with stakeholders, initiated the process of conducting a baseline study, yet to be completed, on risk factors and magnitude of such diseases. Major challenges in the control of chronic diseases in Uganda are the lack of local data, the inadequate capacity of the health system to address them, and the high cost of medicines and supplies. 
Uganda has four medical schools; the oldest of these is Makarere University in Kampala, where in 1958 Denis Burkitt first reported on the lymphoma later entitled to his name (Burkitt 1958).

\begin{tabular}{llll}
\hline Uganda & Male & Female & Both sexes \\
\hline Population (thousands) & 15849 & 15807 & 31656 \\
\hline Number of new cancer cases (thousands) & 11,8 & 15,3 & 27,1 \\
\hline Age-standardised rate $(\mathrm{W})$ & 156,9 & 186,8 & 171,9 \\
\hline Risk of getting cancer before age $75(\%)$ & 16,4 & 19 & 17,8 \\
\hline Number of cancer deaths (thousands) & 9,9 & 11,4 & 21,3 \\
\hline Age-standardized rate $(W)$ & 135 & 143 & 139,3 \\
\hline Risk of dying from cancer before age 75 (\%) & 14,1 & 15,5 & 14,8 \\
\hline
\end{tabular}

Source GLOBOCAN 2008 (IARC), Section of Cancer Information (8/8/2010)

Table 1. Cancer in Uganda

\begin{tabular}{llll}
\hline Uganda & Male & Female & Both sexes \\
\hline 1 & Kaposi sarcoma & Cervix uteri & Kaposi sarcoma \\
\hline 2 & Prostate & Kaposi sarcoma & Cervix uteri \\
\hline 3 & Oesophagus & Breast & Breast \\
\hline 4 & $\begin{array}{l}\text { Non-Hodgkin } \\
\text { lymphoma }\end{array}$ & $\begin{array}{l}\text { Non-Hodgkin } \\
\text { lymphoma }\end{array}$ & $\begin{array}{l}\text { Non-Hodgkin } \\
\text { lymphoma }\end{array}$ \\
\hline 5 & Liver & Stomach & Prostate \\
\hline
\end{tabular}

Source GLOBOCAN 2008 (IARC), Section of Cancer Information (8/8/2010)

Table 2. Five most frequent cancers in Uganda

The Uganda Cancer Institute was established at Mulago Hospital in 1967 as the teaching hospital of Makarere University. The other government Medical Schools are Mbarara University of Science \& Technology (since 1989) and Gulu University (since 2001), while Kampala International University (since 2001) is a private institution. However, it is possible to obtain a Master in Pathology only at Makarere. Cytopathological or histopathological diagnosis is essential for cancer treatment, and this is especially important for a country with limited resources such as Uganda, as it helps to avoid unnecessary and unhelpful therapies, therefore enabling a better use of resources.

St. Mary's Lacor Hospital, located about $6 \mathrm{~km}$ west of Gulu in North Uganda (Figure 8), is a private, non-profit, catholic-based institution founded in 1959 by the Combonian Missionaries and since then it has had a steady and continuous development. Lacor is one of the 21 government-designated national sentinel surveillance sites for monitoring trends of $\mathrm{HIV} / \mathrm{AIDS}$ epidemic in Uganda. It is registered with the National Board for Non- 
Governmental Organizations, it is accredited to the Uganda Catholic Medical Bureau and it provides all the major components of the Uganda Minimum Health Care Package, offering inpatient, outpatient and community-based services. It has adequate facilities and infrastructures, constant availability of electricity and water, and a well-trained staff of about 580 people (of which 35 MDs and 200 nurses). It includes a 470-bed hospital, 3 peripheral health centers (Opit, Amuru and Pabbo), and a teaching site with a Nurse Training School, a School of Laboratory Assistants and other training programs. It serves also as a teaching site for the Gulu University Medical School. The hospital receives patients from the Gulu District, other parts of North Uganda and South Sudan, serving on average 600 inpatients plus their attendants, and 500 outpatients daily.

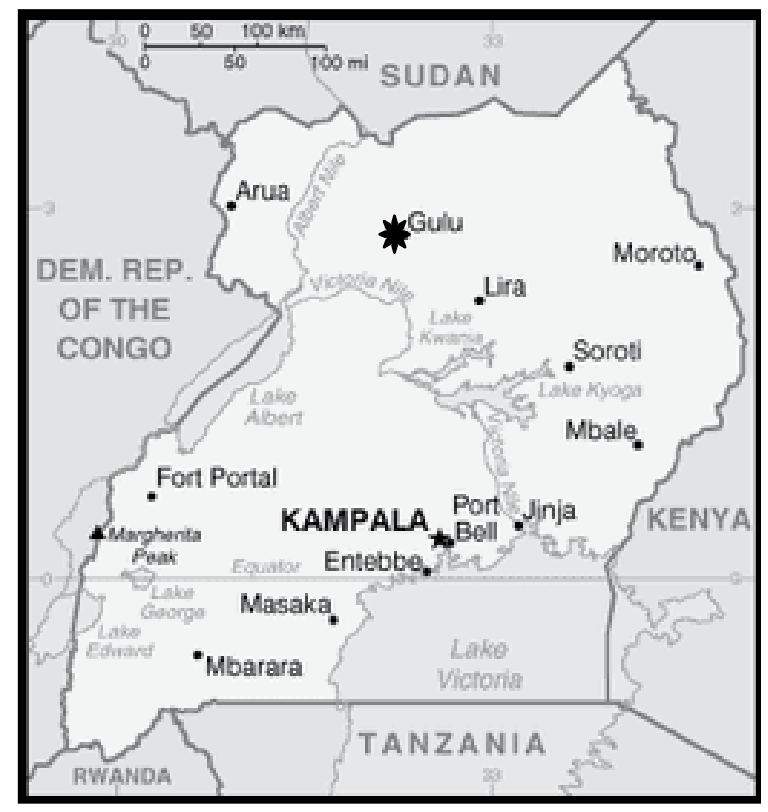

Fig. 8. St. Mary's Hospital Lacor is located near Gulu in North Uganda. Gulu is indicated by star.

At Lacor, before 2008 the histopathological specimens sampled by surgeons (about 1600 /year) were processed manually in a small histopathology laboratory by a technologist and the stained slides were sent to the Pathology Department of Mulago University in Kampala, which sent back the diagnostic reports by FAX. It took more than a month to get a diagnosis. The turnaround time and accuracy of pathological diagnosis was unsatisfactory, with profound impact on patient management and ultimate outcome. Patients were often lost to treatment before diagnosis. Lack of accurate diagnosis also impaired research projects.

These problems prompted the hospital direction to contact the Italian NGO Associazione Patologi Oltre Frontiera (Pathologists Beyond Borders, APOF), a non-governmental association of Italian pathologists founded in 1999 with the aim of realizing projects for developing pathological anatomy and cancer diagnostics in the South of the world. Based on its experience in creating pathology services in developing countries, APOF was charged with the task of establishing a histopathological diagnostic service at Lacor Hospital. 
The project was launched in July 2008 thanks to a grant for laboratory equipment from the Province of Bolzano, Italy, and it aims to create a functioning pathology service inside the hospital compound, staffed with a local pathologist. The Italian Ministry of Foreign Affairs provided up to 2010 contracts for pathologists who stayed for at least 4 months, while volunteer pathologists who stay a month have travel expenses and accommodation paid by Lacor Hospital. Since the beginnings, the diagnostic service has been secured by the continuous presence of volunteer pathologists, with two local technologists. This is going to continue until the local medical officer designated to become staff pathologist will have completed training. The laboratory can perform not only basic stains as H\&E, but also PAS, Giemsa, Ziehl-Neelsen and Papanicolau for vaginal smears and cytology. Basic immunostainig is also possible. The microscope has a digital camera and is linked to a computer for the acquisition of images. A second computer has software for basic data collection and writing/printing reports. The laboratory is "twinned" with specialized centers in Italy, mainly the Pathology Department at the University of Siena, and can get "on line" help.

Since 2008 the number of histopathology and cytology exams has been steadily increasing (2008: 254 for cytology, 1280 for histology; 2009: 453 for cytology, 1575 for histology; 2010: 1052 for cytology, 1930 for histology) and data from the pediatric ward show improved diagnosis of childhood tumors, dependent on the introduction of a limited panel of immunohistochemical stains for lymphoproliferative diseases and for the discrimination of hematological malignancies versus other neoplastic or even non-neoplastic diseases.

Integral part of the APOF program at Lacor is to raise the awareness of the medical and nursing staff of the new service and of its diagnostic and scientific possibilities. The presence of a functioning Pathology Laboratory enables the Lacor Hospital to participate in scientific studies such as EMBLEM (Epidemiology of Burkitt Lymphoma in East African Children or Minors, http://clinicaltrials.gov/ct2/show/NCT01196520) and the INCTR study on Burkitt lymphoma (http://inctr-news.wikidot.com/inctr0306).

This is important, as Burkitt lymphoma is one of the frequent childhood cancers in Uganda. Both studies enroll patients who benefit in many ways, for instance in terms of free treatment and support extended to their families. The establishment of a Pathology Service also allowed Lacor Hospital to start a screening program for cervical cancer, directed to women attending the antenatal and AIDS outpatient clinics, critical because cervical cancer is one of the tumors developing in AIDS (Bellan et al. 2003; Parham et al. 2006). The prevalence of HIV infection in adults in Uganda is about $6.7 \%$, and about $57 \%$ of all adults living with HIV are women; thus it is of the highest importance that these women are screened to prevent cervical cancer, a concept clearly stated in the Uganda Health Sector Strategic Plan III 2010/11-2014/15. Screening can only be successful when diagnosis is made in a short time, as delays often result in loss of the patient to follow up.

\section{Situation analysis of pathology training and services in Sudan}

Sudan provides an example for the challenges that face the development of pathology in sub-Saharan Africa. Historically, pathology services began with the Wellcome Tropical Research Laboratories in 1903, followed by the Stack Medical Research Laboratories, established by the British General Governor, Sir Lee Stack. This is now the National Health Laboratory of Sudan. It was the only laboratory providing histopathology services for Sudan until 1978, and reports were sent by telegraph to all the Sudanese states. Gradually 
some regional histopathology laboratories were established, the first of them built by the University of Gezira in 1978, as reviewed by Awadelkarim and co-authors (Awadelkarim et al. 2010b).

Currently, all histopathology services in Sudan are sustained by only 51 pathologists, 40 (78.4\%) of whom working mostly in Khartoum. Three pathologists $(5.9 \%)$ service the Northern States, two (3.9\%) Western Sudan, two (3.9\%) the western part of Central Sudan, two $(3.9 \%)$ Eastern Sudan and three $(5.9 \%)$ Gezira State, the most populated area of Central Sudan, servicing about four million people $(10 \%$ of the total population of Sudan, spread across 26,075 $\mathrm{km}^{2}$ ). Pathology services are also provided by private laboratories in Khartoum and in few other main towns, e.g., Wad Medani in Gezira State.

Up until 1980, most pathologists were trained in Western countries, mainly in the UK. This important training opportunity was unfortunately interrupted for political and economic reasons. Currently, there are only two postgraduate clinical pathology programs for medical officers in Sudan, one at the University of Khartoum (since 1980), and the other at the University of Gezira (since 1993). Both are four-year MD programs.

During 2009, there were 40 clinical pathology students enrolled at the University of Khartoum and 12 at the University of Gezira. In both programs, the first two years comprise Part 1, with theoretical general teaching in the four major branches of pathology (i.e., chemical pathology, microbiology, parasitology and entomology), hematology and blood transfusion, and histopathology and cytopathology. Students also rotate periodically in major laboratories. In the second two years (Part 2), students choose two subjects, which they study in detail, with regular seminar and journal club attendance. The main training in Part 2 is practical work in recognized laboratories under the supervision of experienced pathologists. A research project is required from each student. About $50 \%$ of the students take histopathology as their major subject. This four-year course leads to specialist registration in the Sudan Medical Council register.

Most of the graduates prefer to work in the capital, Khartoum. The Federal Ministry of Health has an agreement with Malaysia, where about 40 candidates are trained to MSc level in hematology, histopathology, and microbiology. Candidates undergo a minimum of threemonth performance assessment by two consultants when they return to Sudan before specialist registration. In Sudan there are 19 faculties of medical laboratory sciences. The programs are generally of four years; they include a three-year general course in medical laboratory technology and basic medical sciences, followed by a fourth year for specialization in one of the above mentioned four major branches of pathology, leading to registration as a technologist in the Sudan Health Profession Council register.

Laboratory technicians and technologists mostly practice independently, with no supervision from a pathology-specialized MD, except in histopathology and cytopathology. According to the Sudanese Ministry of Higher Education and Scientific Research (http://www.mohe.gov.sd/content/statistics.htm), the Sudanese medical laboratory schools had 4,505 undergraduate students in 2007-2008. In the same year, 837 medical candidates graduated in medical laboratory technology. Thus, an effort towards formation in pathology and medical technology is currently being made.

It is difficult to obtain data on the number of pathology specimens examined in Sudan, due to the fragmented nature of the services. A rough estimation ranges from 30 to 40 thousand specimens per year. Many laboratories use semiautomatic tissue processors and produce formalin-fixed paraffin-embedded blocks and routine sections stained with hematoxilyn and eosin. A few laboratories add some special stains, like PAS, Alcian Blue, reticulin and Van 
Gieson, especially for liver, kidney, and gastrointestinal biopsies. Immunohistochemistry services are provided by three laboratories and cytogenetic studies by one laboratory, all located in Khartoum, the capital city of Sudan.

However, almost all the pathology laboratories operating in Sudan have no written standard operative procedures covering quality control and quality assurance policies, and no strict measures against biologic risk for technologists and pathologists. Frequently the specimens are received unfixed, often being supplied in saline, and sometimes in absolute alcohol or in full-strength formalin, with obvious tissue alterations. The ratio of fixative to specimen size is frequently inadequate, with resulting poor fixation, particularly in central parts. Disposable jars are not used (to reduce costs), being replaced with any type of available container, mostly glass jars, with obvious handling risks. Reagents are imported mainly from low-cost factories, which may not always ensure quality standards. Precise personal and clinical data are often lacking, making clinicopathologic correlations and compilation of databases or registries difficult, if not impossible. This highly deficient referral system has been previously described by Dafaallah et al. (Dafallah et al. 2005).

The maintenance of equipment, especially tissue processors, poses problems, mainly because of unstable power supply, inexperienced maintenance personnel, and difficulty in getting the correct replacement parts. The process from surgical sample to pathologic diagnosis requires several steps to be performed with the aid of instruments that are most often inadequately maintained or out of order.

These problems clearly have deleterious effects on the quality of preparations and on the accuracy of diagnosis. At times, the combined effect of unavoidable and apparently trivial deviations from standard procedures or good practice makes it very difficult to recognize which step should be modified to improve the quality of the microscopic preparations which, in turn impinges on the ability to make an accurate diagnosis. Indeed the lack of ancillary techniques makes it mandatory to have very good microscopic preparations in order to facilitate diagnoses made solely on morphologic grounds. Hence, the limited availability of maintenance services and spare parts for instruments is a major problem. The bulk of the above-mentioned problems are exacerbated by the limited budgets constantly allotted to pathology departments.

These problems cannot be individually addressed. Government investments are needed to support backbone projects for the development of pathology departments. The first step could be consolidation of the existing resources and diagnostic activities in centralized laboratories, which would allow better training and costs optimization. This is the philosophy underlying the establishment of the National Cancer Institute of Sudan at the University of Gezira in Wad Medani.

\subsection{The National Cancer Institute (NCl-UG), University of Gezira, Wad Medani, Sudan}

The National Cancer Institute, University of Gezira (NCI-UG), is a special center established in 1994 by the University of Gezira (UG) in Wad Medani, Sudan. UG is a communityoriented university established in 1975, with a main objective of rural development. UG is located in the center of Sudan in Gezira state, the most densely populated state, which harbors the Blue Nile-irrigated Gezira Scheme. NCI-UG was established to meet the community's needs in the fields of Oncology, Nuclear Medicine, Medical Imaging and Molecular Biology, integrating activities of research, service and training.

The uniqueness of the approach of NCI-UG in implementing these complementary functions made the institute's environment quite satisfactory in providing medical services, 
good quality research, and training programs (Dessein et al. 1999; Mohamed-Ali et al. 1999; Abel et al. 2000; Pascal et al. 2000; Henri et al. 2002; Chevillard et al. 2003; Dessein et al. 2004; Alsheikh et al. 2006; Awadelkarim et al. 2007; Abuidris et al. 2008a; Abuidris et al. 2008b; Abuidris et al. 2008c; Awadelkarim et al. 2008; Dessein et al. 2009; Faggad et al. 2009a; Faggad et al. 2009b; Rahoud et al. 2009; Tofanelli et al. 2009; Awadelkarim et al. 2010a; Awadelkarim et al. 2010b; Elgaili et al. 2010; Elwali et al. 2010; Ali et al. 2011; Awadelkarim et al. 2011).

Its Nuclear Medicine, Oncology, Molecular Biology, Medical Physics and Engineering, Diagnostic Imaging and Medical Laboratories Departments make NCI-UG the only cancer institute outside the capital Khartoum (Figure 9). The growing number of the new cancer patients seen at NCI-UG during 2005-2008 is shown in Tables 3-5. The current status of knowledge on tumor patterns and risk factors in Sudan was comprehensibly reviewed by Awadelkarim and co-authors (Awadelkarim et al. 2010a).

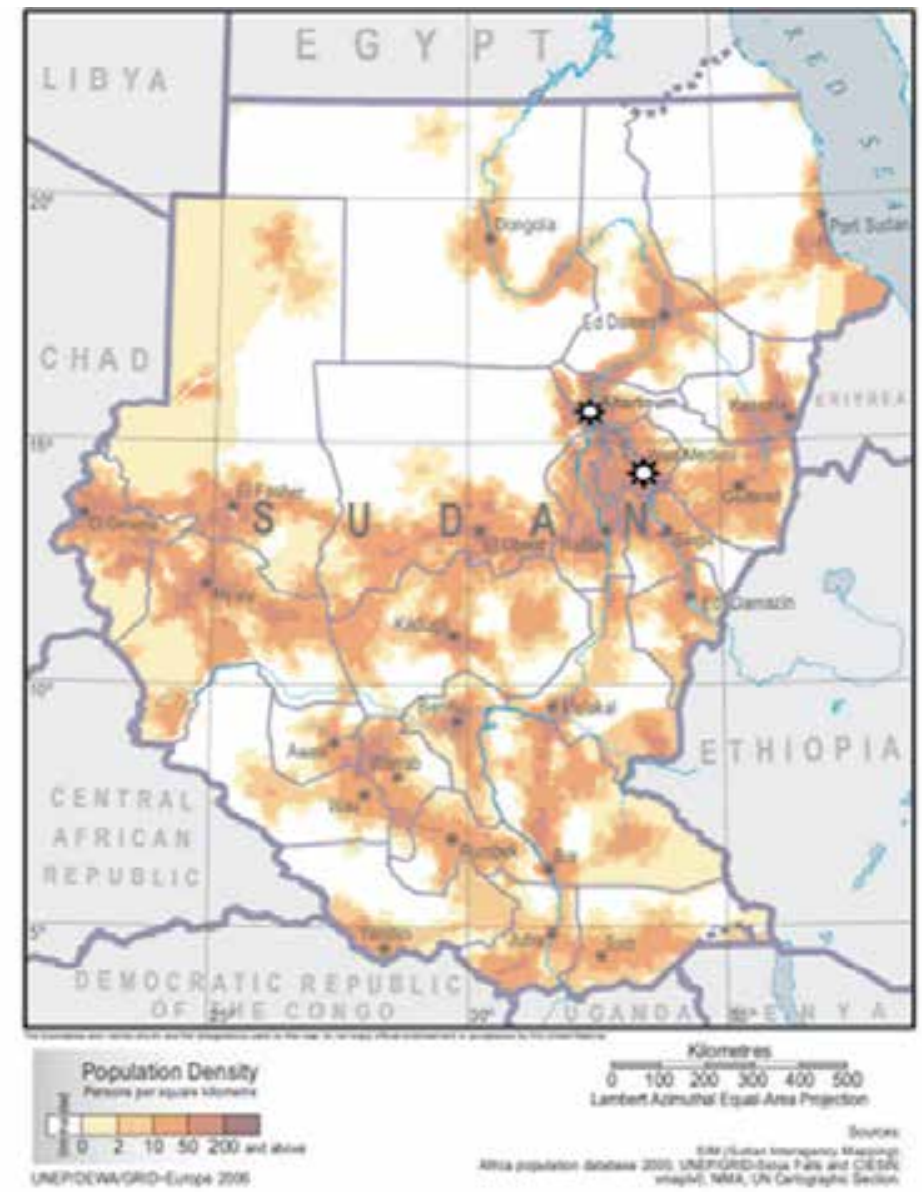

Fig. 9. Distribution of the population in Sudan. The stars indicate the only two cancer institutions, the Radiation and Isotope Center (RICK), and the National Cancer Institute of the University of Gezira (NCI-UG). 


\begin{tabular}{llll}
\hline Year & Male, $\mathrm{n}(\%)$ & Female, $\mathrm{n}(\%)$ & Total, $\mathrm{n}(\%)$ \\
\hline 2005 & $270(44.2)$ & $341(55.8)$ & $611(100)$ \\
\hline 2006 & $347(45.1)$ & $423(54.9)$ & $770(100)$ \\
\hline 2007 & $351(44.7)$ & $435(55.3)$ & $786(100)$ \\
\hline 2008 & $416(46.1)$ & $487(53.9)$ & $903(100)$ \\
\hline 2009 & $513(43.8)$ & $659(56.2)$ & $1172(100)$ \\
\hline Average \pm SD & $379 \pm 91$ & $469 \pm 118$ & $848 \pm 209$ \\
\hline
\end{tabular}

Table 3. Total number of patients diagnosed with cancer from 2005 to 2009 (Awadelkarim et al. 2010b).

The activities carried out at NCI-UG are mainly related to the diagnosis, management, and prevention of cancer, the use of radioisotopes in medical diagnosis, cancer research, and the training of doctors, scientists and technologists. To successfully achieve these objectives, NCI-UG establishes national and international collaborations with relevant Institutions. Efforts to interact and to solve problems related to pathology services at NCI-UG are ongoing; they include external collaborations with Italy, France, and UK. Currently, bilateral visits with Italian collaborators are regularly taking place.

NCI-UG, with the support of the International Agency for Research on Cancer (IARC), established in 2006 the Gezira Cancer Registry, the first population-based cancer registry in the country. The Gezira Cancer Registry, located at the NCI-UG in Wad Medani, the capital city of Gezira State, covers only Gezira State (Central Sudan, 26,075 km²), serving about four million people (10\% of the total Sudanese population). Most recently, in 2009, the Sudanese Federal Ministry of Health also established a population-based cancer registry named "Sudan Cancer Registry" (Awadelkarim et al. 2010a).

The collaboration between NCI-UG and the Curie Institute, Paris, France is supported and financed by the Sudanese Government, the French Embassy in Khartoum, and the Fondation Pierre-Gilles de Gennes pour la Recherche in the fields of oncology (i.e. pediatric oncology, breast cancer) and tropical diseases (i.e. schistosomiasis and malaria). The main goals are training and research. Similar activities in pediatric oncology and breast cancer are being conducted in collaboration with the National Cancer Institute, Milan, Italy. Furthermore, cervical cancer screening activities are ongoing in collaboration with the European School of Oncology, Milan, Italy. Notably, the collaboration between the "G. d'Annunzio" University Foundation of Chieti, Italy and NCI-UG is within the framework of activities developed by CeSI as special consultant of ECOSOC of the United Nations. Bilateral exchanges are supported by “G. d'Annunzio" University Funds for Mobility of Researchers and Internationalization outside the European Union and by the NCI-UG.

The lack of precise and timely laboratory-based cancer diagnosis remains a central problem at NCI-UG. As previously mentioned, in Sudan there is no pathology infrastructure which can guarantee the quality of the samples collected, processed and stored, and the clinical or biological data associated. These factors are the main reasons for the poor diagnosis of cancer and the ensuing scarce information on cancer patterns. Thus, as a consequence of the long-lasting scientific partnership between NCI-UG and CeSI Institutions, a specific project to update surgical pathology in Wad Medani was funded by a private foundation, the CariChieti Foundation of Chieti, Italy. This intervention integrates traditional educational goals with training periods of young MDs 
in the field of diagnostic pathology and the use of telepathology for cases consultation, in order to upgrade the diagnostic capabilities, as requested by the developing and increasing activity of the oncology clinic. Expertise is needed especially for pediatric oncology, and for breast and cervical cancer diagnosis. The partnership for pathology training is based on mutual respect and on the agreement to fully integrate the trained personnel in the pathology infrastructure developed at NCI-UG.

\begin{tabular}{|c|c|c|c|c|c|c|c|c|}
\hline \multirow[b]{2}{*}{ Rank } & \multicolumn{2}{|l|}{2005} & \multicolumn{2}{|l|}{2006} & \multicolumn{2}{|l|}{2007} & \multicolumn{2}{|l|}{2008} \\
\hline & Cancer type & $\mathrm{n}(\%)$ & Cancer type & $\mathrm{n}(\%)$ & Cancer type & $\mathrm{n}(\%)$ & Cancer type & $\mathrm{n}(\%)$ \\
\hline 1 & Prostate & $27(10)$ & Prostate & $53(15.3)$ & Prostate & $64(18.2)$ & Prostate & $96(23.1)$ \\
\hline 2 & NHL & $23(8.5)$ & NHL & $35(10.1)$ & NHL & $21(6)$ & Liver & $32(7.7)$ \\
\hline 3 & Colorectal & $19(7)$ & Bladder & $21(6.1)$ & Nasopharynx & $17(4.8)$ & Nasopharynx & $26(6.3)$ \\
\hline 4 & Nasopharynx & $18(6.7)$ & $\begin{array}{l}\text { Unknown } \\
\text { primary }\end{array}$ & $19(5.5)$ & CML & $17(4.8)$ & NHL & $26(6.3)$ \\
\hline 5 & ALL & $12(4.4)$ & Skin & $16(4.6)$ & Colorectal & $15(4.3)$ & Colorectal & $20(4.8)$ \\
\hline 6 & $\begin{array}{l}\text { Hodgkin's } \\
\text { disease }\end{array}$ & $12(4.4)$ & Liver & $15(4.3)$ & CLL & $14(4)$ & Esophagus & $19(4.4)$ \\
\hline 7 & Liver & $12(4.4)$ & ALL & $15(4.3)$ & Larynx & $12(3.4)$ & Stomach & $14(3.4)$ \\
\hline 8 & Esophagus & $10(3.7)$ & Nasopharynx & $12(3.5)$ & Liver & $11(3.1)$ & Bladder & $13(3.1)$ \\
\hline 9 & Hypopharynx & $9(3.3)$ & Esophagus & $11(3.2)$ & Bladder & $11(3.1)$ & Lung & $13(3.1)$ \\
\hline 10 & $\begin{array}{l}\text { Unknown } \\
\text { primary }\end{array}$ & $9(3.3)$ & $\begin{array}{l}\text { Hodgkin's } \\
\text { disease }\end{array}$ & $10(2.9)$ & Oral & $10(2.8)$ & CLL & $12(2.9)$ \\
\hline Sub lis & t Total & $151(55.9)$ & & 207 (59.7) & & $192(54.7)$ & & $271(65.1)$ \\
\hline Total & nale cancer & $270(100)$ & & $347(100)$ & & $351(100)$ & & $416(100)$ \\
\hline
\end{tabular}

Table 4. The most common ten cancers in males diagnosed at NCI-UG during the period from 2005 to 2008 (Awadelkarim et al. 2010b).

\begin{tabular}{|c|c|c|c|c|c|c|c|c|}
\hline & 2005 & & 2006 & & 2007 & & 2008 & \\
\hline Rank & Cancer type & n (\%) & Cancer type & $\mathrm{n}(\%)$ & Cancer type & $\mathrm{n}(\%)$ & Cancer type & $\mathrm{n}(\%)$ \\
\hline 1 & Breast & $105(30.8)$ & Breast & $163(38.5)$ & Breast & 147 (32.5) & Breast & $195(40)$ \\
\hline 2 & Cervix & $27(7.9)$ & Cervix & $50(11.8)$ & Cervix & $38(8.4)$ & Ovary & $41(8.4)$ \\
\hline 3 & Ovary & $26(7.6)$ & Ovary & $29(6.9)$ & Ovary & $31(6.8)$ & Cervix & $35(7.2)$ \\
\hline 4 & Esophagus & $24(7)$ & Esophagus & $18(4.3)$ & Esophagus & $25(5.5)$ & Esophagus & $28(5.7)$ \\
\hline 5 & Colorectal & $14(4.1)$ & Uterus & $13(3.1)$ & NHL & $22(4.9)$ & Uterus & $26(5.3)$ \\
\hline 6 & NHL & $10(2.9)$ & NHL & $12(2.8)$ & Uterus & $13(2.9)$ & Colorectal & $17(3.5)$ \\
\hline 7 & CML & $10(2.9)$ & $\begin{array}{l}\text { Unknown } \\
\text { primary }\end{array}$ & $11(2.6)$ & Colorectal & $12(2.6)$ & Bladder & $15(3.1)$ \\
\hline 8 & Hypopharynx & $9(2.6)$ & AML & $9(2.1)$ & Hypopharynx & $12(2.6)$ & AML & $14(2.9)$ \\
\hline 9 & Nasopharynx & $9(2.6)$ & CML & $8(1.9)$ & Nasopharynx & $11(2.4)$ & CML & $13(2.7)$ \\
\hline 10 & Liver & $9(2.6)$ & Nasopharynx & $7(1.7)$ & Liver & $10(2.2)$ & $\begin{array}{l}\text { Unknown } \\
\text { primary }\end{array}$ & $11(2.3)$ \\
\hline \multicolumn{2}{|c|}{ Sub list Total } & $243(71.3)$ & & $320(75.7)$ & & $321(70.9)$ & & 395 (81.1) \\
\hline \multicolumn{2}{|c|}{$\begin{array}{l}\text { Total } \\
\text { cancers }\end{array}$} & 341 (100) & & $423(100)$ & & 435 (100) & & 487 (100) \\
\hline
\end{tabular}

Abbreviations: ALL, acute lymphoblastic leukemia; NHL, non-Hodgkin's lymphoma; CML, chronic myelogenous leukemia; CLL, chronic lymphocytic leukemia.

Table 5. The most common ten cancers in females diagnosed at NCI-UG during the period from 2005 to 2008 (Awadelkarim et al. 2010b). 


\section{New technologies for North-South collaboration: Telepathology}

The advent of digital photography opened a new era in diagnostic pathology allowing easy sharing of single microscopic photographic images, and this resulted in the rapid development of "static" telepathology (Figure 10) (Guzman \& Judkins 2009). In the mid 1990s scanners capable of scanning whole microscopic slides were introduced, and dynamic high resolution images by first generation slide scanners became available around 2000. This prompted the development of "dynamic telepathology": in fact, with whole slide imaging (WSI) the restraints of "static telepathology" were overcome and transfer of diagnostic capability became a reality (Figure 11).

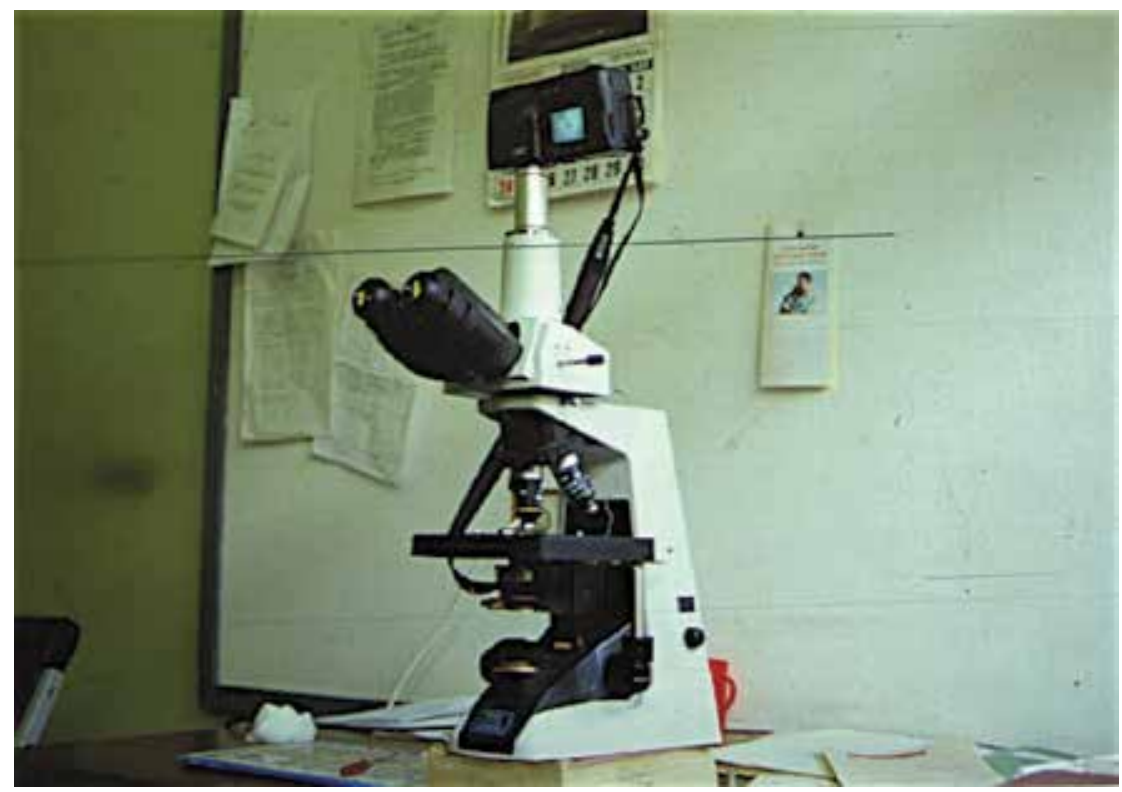

Fig. 10. The basic instrumentation for static telepathology is simple and inexpensive: a trilocular microscope coupled with a digital camera and a web connection.

This new technology may help in dealing with the dramatic shortage of pathologists and trained technicians in sub-Saharan Africa in front of the forecasted increase of incidence of cancer in Africa. The Associazione Patologi oltre Frontiera (APOF) developed pilot projects in Zambia and Madagascar to test "on the field" the impact of the new technological developments, utilizing both static and dynamic telepathology. Depending on local conditions, teleconsultation and distant quality assessment of local diagnostic activity are used where the number of local pathologists is adequate, while distant diagnosis is necessary where local pathologists are scarce or absent. Based on field experience, the following steps are essential:

1. Careful choice of hospitals with high-speed internet connections, especially in upload (ADSL or optical fibers are suitable for WSI). Peripheral hospitals far from cities are generally unsuitable, as they would need a satellite link, too expensive for a single small center.

2. Local availability of at least two laboratory-certified technicians (even personnel with high school degree or nurse formation may be involved). 
3. Training of local technicians to Pap test evaluation. After about six months of intensive teaching, technicians are generally able to prepare and stain standard cytological preparations, such as Pap smears. Similar training of local technicians can be done for histological techniques (fixation, embedding, cutting, staining and mounting histological slides). Training generally requires the on-site presence of expert technicians that supervise availability and correct use of the instrumentation and reagents.

When slides are ready they are scanned (WSI) and transferred to the server. The on duty telepathologist studies the case and signs out the diagnosis. Gross sampling can be performed by technicians (if no pathologist is locally present) with online supervision, pending availability of adequate macro-connections. Macroscopical description, microscopical evaluation and final diagnosis are loaded in the program with other available patient data and the final report is signed out.

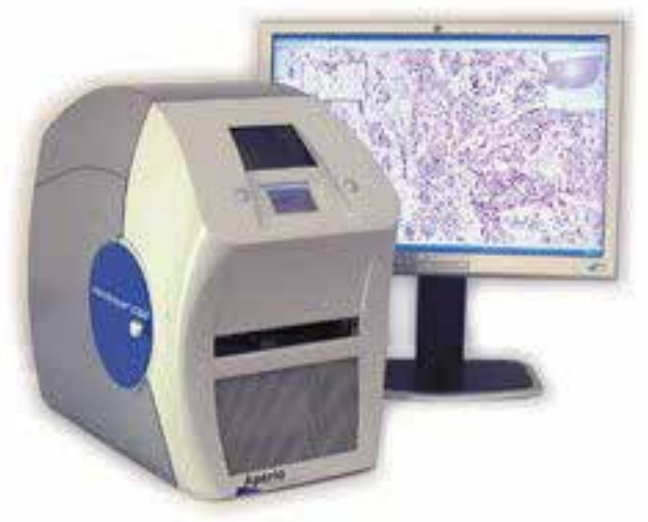

Fig. 11. For dynamic telepathology a slide scanner and a fast web connection with a server are mandatory. Costs are high but diagnostic and educational potentials are huge.

\section{Conclusion: Searching versus planning}

Passive participation in programs originating abroad generally does not work. Presently there is no consensus on how to help developing countries, and it is debated whether large centrally coordinated efforts are needed, or more simple solutions guided by innovative people "on the ground" (Easterly 2006; Benediktsson et al. 2007). This debate is complex, and should be familiar to pathologists who would like to get professionally involved in health care in developing countries or who simply want to understand the problems (Benediktsson et al. 2007; Hassan 2007b). However, the two diverse approaches are complementary, rather than alternative.

It has been pointed out that huge amounts of money were spent by international agencies in ambitious and elaborated development plans that had limited results. To counteract this risk, it is necessary to have a continuous feed-back of the results obtained, and the flexibility and ability necessary to find new approaches and establish new goals, that might be quite different from those originally planned (Easterly 2006). A practical approach, with direct involvement of the local population and attention to suggestions coming from local experts acting with open mind and creativity, is always necessary (Easterly 2006). Actually the 
original "searchers" are the local inhabitants, and some of their original approaches could be endorsed by actors coming from abroad (Easterly 2006). Thus, the identification of local partners with accountability is crucial for every project of intervention in pathology, as such partners could provide not only help, but also innovative solutions on their own.

Clearly, a volunteer approach from abroad cannot meet the need for diagnostic capability in sub-Saharan Africa. The development and strengthening of local skills remains crucial for improving local diagnostic performances.

Indeed, the development of pathology in sub-Saharan Africa reflects the complex spectrum of the educational, cultural, political and economic challenges that must be addressed to build basic biomedical capabilities in the developing world (Gray \& Carter 1997; Hassan 2007a). In this regard, the pathologists, academic institutions, and health centers from the developed countries of the North are called to provide help.

\section{Acknowledgments}

This chapter is based on the contributions presented at a combined meeting of the Italian Society of Anatomic Pathology (SIAPEC) and the "Associazione Patologi Oltre Frontiera" addressing cooperation with sub-Saharan African countries, that took place at the Aging Research Center (Ce.S.I.), G. d'Annunzio University Foundation, on November 3, 2010.

CeS.I. wishes to acknowledge the support of the "Fondazione Cassa di Risparmio della Provincia di Chieti" for the development of cooperation in Pathology with the Sudan.

\section{References}

Abel, L., et al. (2000). "[Genetic predisposition to bilharziasis in humans: research methods and application to the study of Schistosoma mansoni infection]." J Soc Biol 194(1): 15-8.

Abuidris, D. O., et al. (2008a). "Childhood cancer in Sudan: 1999-2007." Trop Doct 38(4): 20810.

Abuidris, D. O., et al. (2008b). "Histopathological patterns of nasopharyngeal carcinoma in Sudan." Saudi Med J 29(7): 962-5.

Abuidris, D. O., et al. (2008c). "Wilms tumour in Sudan." Pediatr Blood Cancer 50(6): 1135-7.

Ali, A. A., et al. (2011). "Clinical presentation and outcome of retinoblastoma among children treated at the National Cancer Institute (NCI) in Gezira, Sudan: A single institution experience." Ophthalmic Genet 32(2): 122-5.

Alsheikh, A. A., et al. (2006). Gezira Guidelines for Management of Breast Cancer. Wad Medani, Institute of Nuclear Medicine, Molecular Biology \& Oncology "Now, the National Cancer Institute (NC-UG)", University of Gezira, Wad Medani, Sudan: 140 .

Awadelkarim, K. D., et al. (2007). "BRCA1 and BRCA2 status in a Central Sudanese series of breast cancer patients: interactions with genetic, ethnic and reproductive factors." Breast Cancer Res Treat 102(2): 189-99.

Awadelkarim, K. D., et al. (2011). "Basal-like phenotype in a breast carcinoma case series from Sudan: prevalence and clinical/pathological correlations." Patholog Res Int 2011: 806831. 
Awadelkarim, K. D., et al. (2008). "Pathological, clinical and prognostic characteristics of breast cancer in Central Sudan versus Northern Italy: implications for breast cancer in Africa." Histopathology 52(4): 445-56.

Awadelkarim, K. D., et al. (2010a). "Cancer in the Sudan: An overview of the current status of knowledge on tumor patterns and risk factors." Sci Total Environ (DOI: 10.1016/j.scitotenv.2010.09.010).

Awadelkarim, K. D., et al. (2010b). "Role of pathology in sub-Saharan Africa: An example from Sudan." Pathology and Laboratory Medicine International 2: 49-57.

Bancroft, J. D. and M. Gamble ( 2008). Theory and practice of histological techniques. London, UK, Churchill Livingstone.

Bellan, C., et al. (2003). "Pathologic aspects of AIDS malignancies." Oncogene 22(42): 6639-45.

Benediktsson, H., et al. (2007). "Pathology services in developing countries: a challenge." Arch Pathol Lab Med 131(11): 1636-9.

Bulatao, R. A., Ed. (2006). Population and mortality after AIDS. Diseases and Mortality in Sub-Saharan Africa. Washington DC, The World Bank.

Burkitt, D. (1958). "A sarcoma involving the jaws in African children." Br J Surg 46(197): 21823.

Chevillard, C., et al. (2003). "IFN-gamma polymorphisms (IFN-gamma +2109 and IFNgamma +3810) are associated with severe hepatic fibrosis in human hepatic schistosomiasis (Schistosoma mansoni)." J Immunol 171(10): 5596-601.

Connor, D. H., et al., Eds. (1976). Infection by Mycobacterium ulcerans. Pathology of Tropical and Extraordinary Diseases. Washington, DC, Armed Forces Institute of Pathology.

Cuzick, J., et al. (2008). "Overview of human papillomavirus-based and other novel options for cervical cancer screening in developed and developing countries." Vaccine 26 Suppl 10: K29-41.

Dafallah, S. E., et al. (2005). " Analysis of documents used in referral system in Wad Medani, Sudan." Saudi Med J 1(26): 148-150.

Dessein, A., et al. (2009). "Variants of CTGF are associated with hepatic fibrosis in Chinese, Sudanese, and Brazilians infected with schistosomes." J Exp Med 206(11): 2321-8.

Dessein, A., et al. (2004). "Interleukin-13 in the skin and interferon-gamma in the liver are key players in immune protection in human schistosomiasis." Immunol Rev 201: 180-90.

Dessein, A. J., et al. (1999). "Severe hepatic fibrosis in Schistosoma mansoni infection is controlled by a major locus that is closely linked to the interferon-gamma receptor gene." Am J Hum Genet 65(3): 709-21.

Easterly, W. (2006). The White Man's Burden: Why the West Efforts to Aid the Rest have done so Much Ill and so Little Good. New York, NY, Penguin Group.

Elgaili, E. M., et al. (2010). "Breast cancer burden in central Sudan." Int J Womens Health 2: 77-82.

Elwali, N. E., et al. (2010). "Environment and immune-mediated diseases in Sub-Saharan Africa." Sci Total Environ (DOI: 10.1016/j.scitotenv.2010.08.044). 
Faggad, A., et al. (2009a). "Prognostic significance of Dicer expression in ovarian cancer-link to global microRNA changes and oestrogen receptor expression." J Pathol 220(3): 382-91.

Faggad, A., et al. (2009b). "Expression of multidrug resistance-associated protein 1 in invasive ovarian carcinoma: implication for prognosis." Histopathology 54(6): 65766.

Ferlay, J., et al. (2004). GLOBOCAN 2002: Cancer Incidence, Mortality and Prevalence Worldwide. Lyon, IARC Press. IARC Cancer Base No. 5. version 2.0.

Garrett, L. (2007). "The challenge of global health." Foreign Affairs(86): 1-17.

Gray, I. P. and J. Y. Carter (1997). "An evaluation of clinical laboratory services in subSaharan Africa. Ex africa semper aliquid novi?" Clin Chim Acta 267(1): 103-28.

Greene, F. L., et al. (2002). AJCC Cancer Staging Manual 6th edition. USA, Springer-Verlag.

Guzman, M. and A. R. Judkins (2009). "Digital pathology: a tool for 21st century neuropathology." Brain Pathol 19(2): 305-16.

Hamad, H. M. (2006). "Cancer initiatives in Sudan." Ann Oncol 17 Suppl 8: viii32-viii36.

Hassan, M. H. (2007a). "Building capacity in the life sciences in the developing world." Cell 131(3): 433-6.

Hassan, M. H. (2007b). "A new dawn for science in Africa." Science 316(5833): 1813.

Henri, S., et al. (2002). "Cytokine regulation of periportal fibrosis in humans infected with Schistosoma mansoni: IFN-gamma is associated with protection against fibrosis and TNF-alpha with aggravation of disease." J Immunol 169(2): 929-36.

Hutt, M. S. and H. Spencer (1982). "Histopathology services for developing countries." Br Med J (Clin Res Ed) 285(6351): 1327-9.

IMF Survey online (2008). "Africa's Power Supply Crisis: Unraveling the Paradoxes AFRICA'S ENERGY SHORTAGE-." IMFSurvey Magazine: Countries \& Regions.

Leigheb, G., et al. (2008). "Ultrasonography for the monitoring of subcutaneous damage in Mycobacterium ulcerans infection (Buruli ulcer)." Ultrasound Med Biol 34(10): 1554-63.

Leung, S. W. and Y. C. Bedard (1993). "Simple miniblock technique for cytology." Mod Pathol 6(5): 630-2.

Lingwood, R. J., et al. (2008). "The challenge of cancer control in Africa." Nat Rev Cancer 8(5): 398-403.

Mayall, F. and A. Darlington (2010). "The Poor Man's Cell Block." J Clin Pathol 63(9): 837-8.

Meijer, C. J., et al. (2009). "Guidelines for human papillomavirus DNA test requirements for primary cervical cancer screening in women 30 years and older." Int J Cancer 124(3): 516-20.

Mohamed-Ali, Q., et al. (1999). "Susceptibility to periportal (Symmers) fibrosis in human schistosoma mansoni infections: evidence that intensity and duration of infection, gender, and inherited factors are critical in disease progression." J Infect Dis 180(4): 1298-306.

Morris, K. (2003). "Cancer? In Africa?" Lancet Oncol 4(1): 5.

Muela Ribera, J., et al. (2009). "A word of caution against the stigma trend in neglected tropical disease research and control." PLoS Negl Trop Dis 3(10): e445. 
Nienhuis, W. A., et al. (2010). "Antimicrobial treatment for early, limited Mycobacterium ulcerans infection: a randomised controlled trial." Lancet 375(9715): 664-72.

Palefsky, J. (2009). "Human papillomavirus-related disease in people with HIV." Curr Opin HIV AIDS 4(1): 52-6.

Parham, G. P., et al. (2006). "Prevalence and predictors of squamous intraepithelial lesions of the cervix in HIV-infected women in Lusaka, Zambia." Gynecol Oncol 103(3): 101722.

Parkin, D. M. (2006). "The evolution of the population-based cancer registry." Nat Rev Cancer 6(8): 603-12.

Parkin, D. M., et al. (2003). Cancer in Africa: Epidemiology and prevention. Lyon, IARC Press.

Parkin, D. M., et al. (2008). "Part I: Cancer in Indigenous Africans--burden, distribution, and trends." Lancet Oncol 9(7): 683-92.

Pascal, M., et al. (2000). "Hyaluronate levels and markers of oxidative stress in the serum of Sudanese subjects at risk of infection with Schistosoma mansoni." Trans R Soc Trop Med Hyg 94(1): 66-70.

Pollack, A. E. and V. D. Tsu (2005). "Preventing cervical cancer in low-resource settings: building a case for the possible." Int J Gynaecol Obstet 89 Suppl 2: S1-3.

Portaels, F., et al. (1999). "Insects in the transmission of Mycobacterium ulcerans infection." Lancet 353(9157): 986.

Porter, P. (2008). "'Westernizing" women's risks? Breast cancer in lower-income countries." N Engl J Med 358(3): 213-6.

Rahoud, S. A., et al. (2009). "Factors controlling the effect of praziquantel on liver fibrosis in Schistosoma mansoni-infected patients." FEMS Immunol Med Microbiol 58(1): 10612.

Sankaranarayanan, R., et al. (2008). "Human papillomavirus infection and cervical cancer prevention in India, Bangladesh, Sri Lanka and Nepal." Vaccine 26 Suppl 12: M4352.

Singh, D. K., et al. (2009). "Human Papillomavirus Infection and Cervical Cytology in HIVInfected and HIV-Uninfected Rwandan Women." J Infect Dis.

Sitas, F., et al. (2008). "Part II: Cancer in Indigenous Africans--causes and control." Lancet Oncol 9(8): 786-95.

Stein, C., et al. (2007). "The Global Burden of Disease assessments--WHO is responsible?" PLoS Negl Trop Dis 1(3): e161.

Tofanelli, S., et al. (2009). "J1-M267 Y lineage marks climate-driven pre-historical human displacements." Eur J Hum Genet 17(11): 1520-4.

Tsu, V. D. and A. E. Pollack (2005). "Preventing cervical cancer in low-resource settings: how far have we come and what does the future hold?" Int J Gynaecol Obstet 89 Suppl 2: S55-9.

Vacca, L. L. (1985). Laboratory manual of histochemistry. New York, Raven Press.

World Health Organization (2004). The World Health Report 2004, Changing History. Geneva, WHO. 
Zappacosta, R. and S. Rosini (2008). "Cervical cancer screening: from molecular basis to diagnostic practice, going through new technologies." Technol Cancer Res Treat 7(3): 161-74.

Zavattaro, E., et al. (2010). "Serum cytokine profile during Mycobacterium ulcerans infection (Buruli ulcer)." Int J Dermatol 49(11): 1297-302.

zur Hausen, H. (2009). "Papillomaviruses in the causation of human cancers - a brief historical account." Virology 384(2): 260-5. 


\section{Part 3}

Globalization and Space 



\title{
Globalization in the Brazilian Amazon Region: Conflicting Answers from "Quilombo" Communities
}

\author{
Florent Kohler et al. ${ }^{*}$ \\ University of Tours, CREDA
}

France

\section{Introduction}

Globalization is a process that encompasses the accelerated and simultaneous circulation of ideas, goods, and human beings (Appadurai, 1996). In an Amazonian context, this chapter aims at analyzing the impacts of particular land status ownership on the resilience and flexibility of traditional communities facing globalization (Kramer et al, 2009).

The Amazon has been part of the global market since the 16 $6^{\text {th }}$ century: from the drogas do Sertão, through the rubber boom, to Brazil nuts (Bertholletia excelsa) and açaí (Euterpe oleracea), the global demand for Amazonian products has played a crucial role in the phases of human population of this rich basin (Bunker, 1985). Mark Harris (2006), following Moran and Parker, characterizes the "cabocla" populations by their ecological adaptations as well as their economic versatility.

During the 1990s and 2000s, a great number of "traditional" and/or indigenous communities were granted land rights in Brazil. Innovative legal statuses were created, either for the sake of environmental protection or as a function of the peculiar special social status of some social groups, mainly indigenous people and remnants of escaped slave communities (i.e. remnant quilombola communities). At the core of these rights is the recognition of a "special relationship" between these traditional communities and their territories. Due to the acknowledgement of this particular link, almost $30 \%$ of the Legal Amazon is officially under the responsibility of traditional communities. ${ }^{1}$

However, traditional communities are now facing contradictory pressures induced by Brazilian public policies and globalization. On the one hand, they were granted land under

\footnotetext{
* Ludivine Eloy², François-Michel Le Tourneau'3, Claire Couly", Stéphanie Nasuti³, Dorothée Serges ${ }^{5}$, Sophie Caillon ${ }^{6}$, Guillaume Marchand ${ }^{1}$ and Anna Greissing ${ }^{3}$.

1 University of Tours, CREDA, France,

2 University of Montpellier III, UMR 5281 ART-Dev, France; University of Brasilia, CDS, Brazil,

3 CNRS, CREDA, France,

4 French Research Institute for the Development and the French National Natural History Museum, France,

5 CREDA, France,

6 CNRS, CEFE, France.

${ }^{1}$ Indigenous Lands cover $20 \%$ of the extension of the Legal Amazon, while Extractive Reserves (RESEX) and Sustainable Development Reserves (RDS) cover 4.84\%, and Quilombola lands cover 1.6\% (Ricardo and Rolla, 2009).
} 
the assumption that they would maintain their traditional way of life, with low impact on the ecosystems (Diegues, 1996). On the other hand, they are more and more connected to global markets and information technology, and have access to a greater mobility. They face the challenge of improving their living conditions by developing their economic activities. Globalization in this sense should not be understood as a single threat. Isolated forest communities have acquired the chance to access better rural living conditions. But traditional communities are confronted by a "double bind" situation: economic development and the extension of contemporary ecological ideology.

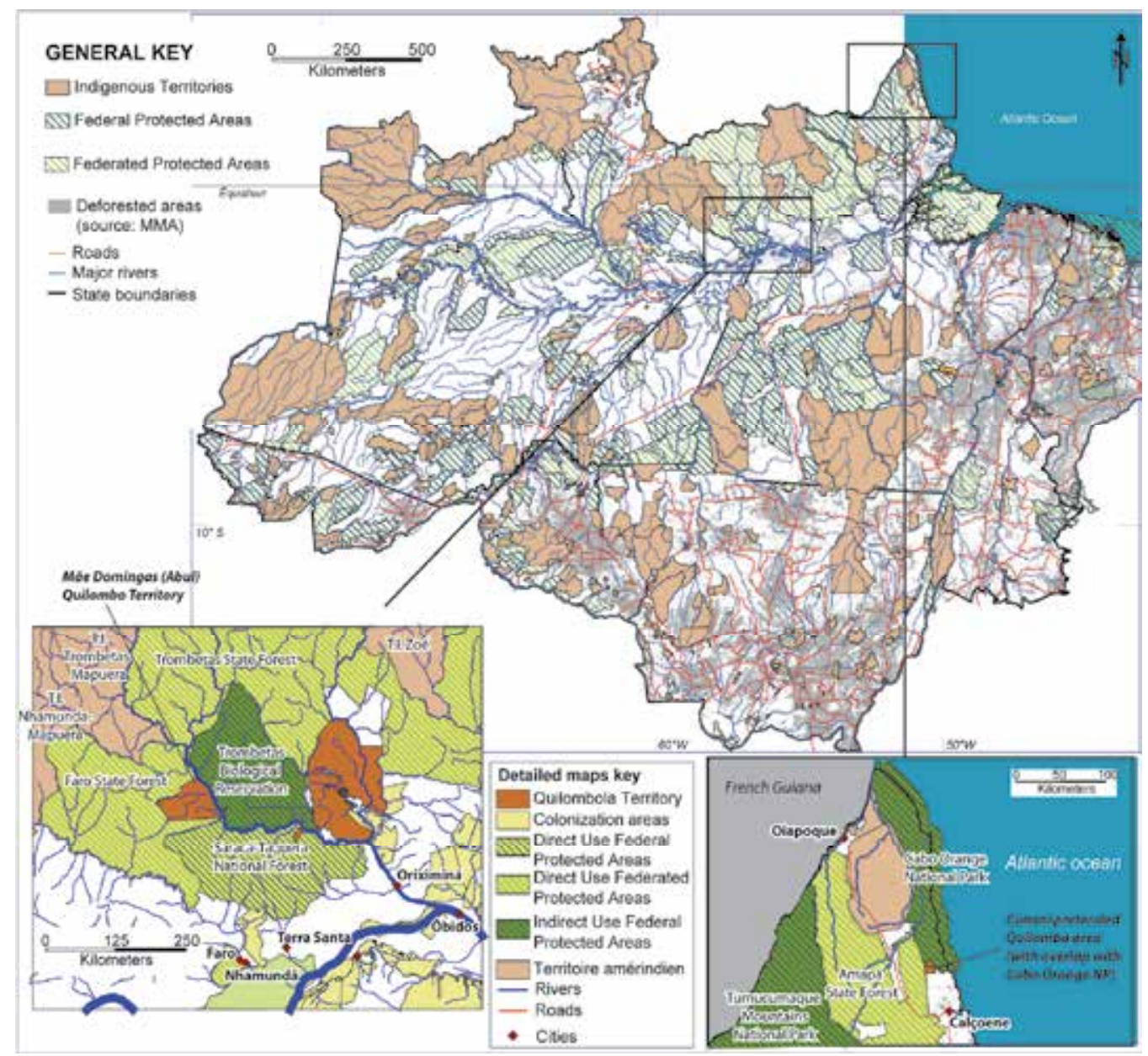

Fig. 1. Localization of the areas considered. Map by F.-M. Le Tourneau

Our work focuses mainly on the status of Quilombola, which we approach on the basis of two case studies in the Brazilian Amazon: one (the village of Cunani) in the Amapá state and the other one (the village of Abuí) in the Pará state. They experience contrasting demographic trends. The Cunani population, still waiting for its legal recognition, is decreasing. The village of Abuí, however, is included within a recognized quilombola land, its leaders are involved in the famous quilombola movement of the Rio Trombetas, and its 
population is increasing. While unveiling the current land-use situation, we investigate the benefits and consequences of two emerging commercial activities - ranching and açaí extraction. We study how the acquisition of land rights facilitates adaptation to the new economic context of the Amazon region.

\section{Globalization and the access to land rights: The ethnic strategy}

In "The Production of Locality" (1995: 213), Appadurai points to, among the effects of globalization, "the growing disjuncture between territory, subjectivity, and collective social movements". At the same time, the author underlines "the steady increase in the efforts of the modern nation-state to define all neighbourhoods under the sign of its forms of allegiance and affiliation".

In this context, indigenous or traditional populations occupy a special place. They are defined by the International Labour Organization (convention \#169, 1989) as having special ties with the territory they occupy, this territory being the guarantee and motor of their social (re)production.

Brazil was innovative in recognizing, in addition to ethnic categories (Amerindians and Quilombolas), another category, that of "traditional populations," defined not only by their activities and means of existence, but also by the transmission of their knowledge and practices from generation to generation (Barretto Filho, 2006). A number of the inhabitants of Amazonia can lay claim to one or another of these statuses, which differ in their degree of land rights: undivided joint ownership for the Quilombolas, usufruct for the Amerindians, and usage concessions for traditional populations. In order to be recognized as part of one or another of these groups, rural Amazonian communities need to adopt a universal dialectic of ethnicity and tradition.

The creation of quilombola territories is a response to a convergence between the global movement recognizing cultural diversity as being linked to biological diversity (UNESCO 2003), and the local movement of access to land. These two movements are mediated by the intervention of the Brazilian state, which imposes its structures and hierarchies in the creation of differentiated territories, for either nature conservation or cultural patrimonialization (Véran, 2002).

\subsection{The splendor and misery of Cunani}

The community of Cunani was formed over two periods. The first, that of the FrancoBrazilian Dispute $(1770$ - 1900), created an area frequented by French and Brazilian traders, while the main part of the population was composed of fugitive slaves. The latter, initially settling upriver, went on to colonize downstream as well. This period culminated with the proclamation of the short-lived "Republic of Cunani" (1882 - 1885), supported by the French, and ended in 1900 with the resolution of the Dispute in favor of Brazil. Then began a neo-Brazilian migration of people originally from the "islands" (south from Amapá and north-east from Pará). The two populations continued to intermingle, with the colonists returning upstream along the Cunani River.

Up until 1970, the inhabitants of Cunani benefited from a relative prosperity, though suffering the economic risks tied to the exploitation of Amazonian products: fur trade, fish, manatee oil, non-wood forest products, and logistical support for the garimpos of the region. Governor Janari, in the 1950s, began a politics of education that bore fruit. 
But the opening of BR156 linking Macapá to Oiapoque at the beginning of the 1970s changed all this: Calçoene, $50 \mathrm{~km}$ from Cunani, became the new economic centre of the region, leaving the enclaved communities to the side. A process of migration followed, due to the presence in town of commodities (health, education). The creation of the National Park of Cape Orange, in 1980, aggravated the situation, by restricting access to the Cunani River. With the increasing enforcement of environmental laws, the inhabitants of Cunani saw a continuously receding future. Finally, the route between Calçoene and Cunani, finished in 1987, is passable only part of the year, and at high transportation costs. The Amazonian "black gold" açaí, came too late for the possible creation of an Extractive Reserve (RESEX) bordering the Park. The projects of the Park management team concerning the community were quickly oriented toward equitable tourism, but the project never amounted to anything.

It was then that INCRA (National Institute for Colonization and Agrarian Reform, a branch of the Ministry of Agrarian Development charged with putting in place the process of surveying, demarcation, and land registry) intervened in the conflict between the community in outright decline and IBAMA (Brazilian Institute for the Environment and Renewable Resources). This intervention is part of a longstanding tradition of rivalry between the two federal organizations. In the struggle the community was waging for its survival and its remaining in place, the quilombola statute offered the advantage of a definitive land title. But the conversion of the inhabitants of Cunani into Quilombolas was not an easy thing: the local history was marked more by the Franco-Brazilian Dispute and by immigration from Pará than by the Quilombolas. As the oral traditions do not go back more than three generations, the identifying elements relative to belonging to Quilombolas are relatively recent contributions, contemporary with the community mobilization around this question.

It is thus that in the same phrase an informant could state that to be Quilombola "is to have black skin, like me," and then add "My grandfather wasn't black, he was like me." This paradoxical affirmation recurs in the context of quilombola claims (see also Boyer, 2002: 169).

Through the intervention of the INCRA, the identification and demarcation of the quilombola territory of Cunani was pushed through in 2004, though without passing the step of ratification because the anthropological study was - and still is - missing. The ICMBio (Chico Mendes Institute for Biodiversity, now in charge of National Parks and Protected Areas) also requested a study, not on the real character or the quilombola ascendance, but questioning the 36,000 ha (22,000 of which are in the Park) attributed to this community in decline.

These risks split the movement, some of whom (residing in Calçoene) wanted to invest in tourism by promoting the quilombola identity, while others, more pragmatic, wanted to start a cooperative with the aim of commercializing açaí. Faced with an uncertain future, migration to Calçoene went on, to the point that the school at Cunani went from 12 students in 2007 to only 5 three years later.

\subsection{Abuí, a quilombola community in the Trombetas valley}

During the pre-Columbian period, the valley of the Trombetas river was occupied by various Amerindian groups (Porró, 2008). At the beginning of the 17th century, Europeans occupied the Amazon valley, establishing cacao plantations and cattle ranches in the region of Óbidos, Santarém, and Belém. Following this period, African slaves were imported from the Gulf of Guinea. But the number of slaves escaping rapidly multiplied, and the fugitives organized themselves into communities along the branches of the Amazon. As punitive expeditions increased, the groups of fugitives spread out, going back up the main branch of the Trombetas river, seeking a sure refuge upstream from main rapids where navigation was particularly difficult. 
Increasingly, the interdiction of slave trafficking (1850) and the various laws improving the condition of the slaves, and finally the abolition of slavery (1888), led to the displacement of the fugitive slave communities, which nonetheless traded freely with the towns of the region. The Quilombolas abandoned the territories upstream from the Amerindian populations and increasingly resettled the middle course of the Trombetas (Coudreau, 1900).

The peace between the Quilombolas and Brazilian society did not, however, bring them land security. Starting in 1920, the families of merchants increasingly appropriated the lands along the middle of the Trombetas to control the areas of Brazil nuts trees (Castanhais) and practice cattle ranching on the river banks. The merchants used the widespread system of aviamento, wherein the collectors who gathered Brazil nuts on a merchant's land were obligated to deliver all of their production to him, and to get their provisions from his storehouse (Geffray, 1995). This system of patronage disappeared little by little during the 1960s and 70s, when the trade in Brazil nuts slowed.

The population of Abuí grew from the 1960s on, but settlement continued to be relatively isolated until the 1980s. After this period, the land situation in the Trombetas region was redefined many times. The first changes were linked to the installation in 1976 of a mining complex to extract bauxite from the right bank of the river. Shortly thereafter, as an ecological counterbalance to the mine, the federal government set up two protected areas, in 1979 and 1989, on either side of the river, which led to the expropriation of the land of the local communities. It was the merchants, however, being the official owners of the land, who were compensated, while the numerous inhabitants were evicted, sometimes quite violently (Nasuti, 2005). The inhabitants were thus forced to relocate to other villages in the valley, such as Abuí, which saw a major increase in its population.

The environmental measures of this period were even less in harmony with the presence of local populations (Barretto Filho, 2006), which led to the emergence of social movements fighting for the rights of local populations. Thus, in reaction to the evictions, after 1982 the inhabitants of Abuí were strongly mobilized under the guidance of a priest, Father Patrício, who came with the Rural Workers Union to inform the inhabitants of their rights and incite them to organize as an independent community. Thanks to their participation in the gatherings of the "black roots" (raizes negras), the inhabitants of the Trombetas valley found their identity and created an association in 1989 (Associação das Comunidades Remanescentes de Quilombos do Município de Oriximiná - ARQMO). Their territorial demands were expressed in ever more clear terms at the beginning of the 1990s.

In 1995, the community of Boa Vista, the first in the continuum of black communities in the Trombetas valley, was the first quilombola land to be recognized under this statute in Brazil, opening the way for other communities in the region. Thus, among the interstices of protected areas, Indigenous Lands, and the mining complex, five quilombola territories have since been demarcated, comprising 22 communities over an area of approximately 362,000 ha. It was in this way that the land statute of the Abuí community, and its four neighbours ${ }^{2}$, was stabilized in 2003, thanks to the granting of a land title for the quilombola territory “Mãe Domingas” (61 211,96 ha).

\section{Globalization and market access: Economic strategies and their impact on forms of development}

Populations that depend on extractive activities adapt continuously to the conditions of the market. They reconfigure themselves very quickly in the face of a changing socio-economic

${ }^{2}$ The communities of Paraná do Abuí, Tapagem, Sagrado Coração, and Mãe Cué. 
environment. Diversification of revenues is thus vital, when the object of public politics is to support the empowerment of local populations through aid to development. Public authorities, unfortunately, is discontinuous (Greissing et al., 2008), and depends largely on global orientations targeting sometimes environmental conservation, sometimes the fight against poverty. The object of this second section is to describe the relationship between economic choices and forms of development, this relationship having an indirect impact on environmental conservation (Kramer et al., 2009). For access to joint ownership of land does not mean an end to problems of subsistence. Even in extractive reserves, demarcated as a function of economic projects, the inhabitants often have to turn to unforeseen alternatives (as, for instance, cattle in the PAE Chico Mendes - Pantoja et al, 2009). And while the quilombola statute allows people to benefit from certain advantages in terms of cultural funding and access to education, it does not offer, in itself, a means of subsistence, at least for those who live far from tourist itineraries. The Quilombolas thus need to strengthen institutional alliances and commercial partnerships in order to stabilize their access to commodities and services.

\subsection{Açaí, an expanding global market in Cunani}

Among the plant species exploited by the villagers of Cunani, açaí is without doubt that which has gained most in economic value over the last few years. Açaí in effect is the perfect example of a local product that has become the target of a globalized market, avid for new and "ecological" products (Brondizio, 2002, 2008).

Although it has always been the object of local and seasonal consumption, this resource is now exploited for commercial ends by almost all families. Harvesting of açaí takes place from February to May/June. The harvest is often done with the help of brothers and sisters, children or nephews gone to live in Calçoene. The quantity gathered varies greatly according to the family: from 200 to $1500 \mathrm{~kg} /$ day on average according to the workforce, density, and distance to the açaí palms. The revenues tied to açaí corresponds to a large part of their annual household income (this revenue may complement the salaries of teachers, nurse aids, or watchmen, or even retirees and welfare recipients). However, the harvest is very irregular because of the heavy rains that fall during this time of year (the rainy season runs from January to June).

As opposed to other local produce, and in particular to manioc flour whose sale is strictly limited by the high cost of transport to take it to town, the problem of transporting sacks of açaí poses no problem. The buyers, coming from Calçoene or Macapá, go to the entrance of the village to load the produce. This in large part explains the importance of the commercialization of the fruit of this species in relation to other product. The açaí is then resold in Calçoene for up to $3.5 \mathrm{R} \$ / \mathrm{kg}$, and even more in Macapá. Paradoxically, the number of trucks loaded with açaí between February and May make the route impracticable for the rest of the year, contributing to the rise in the cost of transporting people as well as other product.

There is no management, properly speaking, of "wild" açaís, also called "natives": the villagers can use the wild stocks without really appropriating them for themselves, whence the fact that the gathering areas vary yearly ("Não tem açaízal fixo"). They are considered to be open access to all the members of the village, as well as people originally from Cunani living in town. These wild açaís are found in family fields, on the banks of the river, or in the igapós situated in Terra firme forests, without there being any quotas for gathering imposed. On the other hand, the occasional but repeated harvesting of the wild açaís by people outside the community is denounced by the locals. Certain among them know how 
to take advantage of this fad for the "black gold" by renting their açaís or demanding a tax on each $50 \mathrm{~kg}$ sack taken (a practice called matança).

Apart from the "wild" açaís, there are also "cultivated" açaís (according to local terminology): these include açaís not planted but the object of special management (manejado) as well as planted açaís: the palms that are too big or old are cut down to give more space to the productive açaís. But there are also açaís directly planted in swidden fields. This cultural practice aimed at the plantation of açaí on a large scale - more than 5000 açaí trees planted around the vila - is very recent (five years) and its appearance coincides with the strong economic value of this species in the region. In both cases, the açaí plantations are no longer considered to be of open access: the other inhabitants can only gather fruit there on the condition that they are authorized by the owners of the plants.

But the inhabitants who remain in Cunani, held by family loyalty towards their family in Calçoene, cannot pretend to have exclusive rights to the collection of açaí. What is more, the dependence of the inhabitants vis-à-vis the intermediaries and buyers engenders a loss of control over the açaís in the future perimeter of the quilombola territory. These "buyers" purchase the sacks sold by the inhabitants, and profit from illegal exploitation of the palms in the region by importing cheap labor from town. Thus, because of lack of regulation, certain inhabitants of Calçoene with access to means of transport, whether or not they have family ties with the local population, can with little expense obtain a large part of the production.

The practice of one of the principal families of the village, which consists of recruiting outsiders to harvest its açaís, illustrates the difficulty the community is faced with to unify in order to create a cooperative. With no collective organization, the greater value given to a particular hierarchy results in an individual appropriation of resources (the populations of açaís) and a certain concentration of wealth, even without the existence of private property, just as in Abuí with the introduction of cattle ranching. In this case, the recognition of collective quilombola land does not seem to be sufficient to avoid this socio-economic differentiation.

\subsection{Brazil nuts and introduction of cattle ranching in Abuí}

The principal economic activity of Abuí is the collection of Brazil nuts. This is an important activity for not only is it the principal source of income for the community (or at least it was until very recently), but it is also a source of local identity since the Quilombolas of the Trombetas River have been used as the labour source for the collection of Brazil nuts since the end of the 19th century.

This activity, which requires long stays in the forest, as well as a familiarity with the territory and the forest itself, carries a strong element of identity (the sharing of knowledge, a feeling of belonging). Collection is a seasonal activity, done after the nuts have fallen until all the areas of collection have been exhausted. Commercialization can occur in the field, with itinerant traders criss-crossing the area during the collecting season, or in town. The second solution is more interesting from a financial perspective, but it presupposes the ability to command transport to Oriximiná $(250 \mathrm{~km})$, something not everyone can do. Since 1998, a cooperative begun by the ARQMO has tried to play the role of intermediary by gathering the production of its associates and then transporting the nuts to be sold in town, but its somewhat chaotic management and the ties that continue to unite certain merchants and families of Quilombolas have led to this initiative remaining somewhat marginal. However, the production of the Brazil nuts from Abuí has not yet found its place in 
alternative circuits (fair trade, green, sustainable) because the cooperative has not succeeded in renewing its commercial partners. Thus, the Quilombolas of Trombetas have not found the means to convince their buyers of the value of the ethical/sustainable mode of their collection in order to obtain a higher sales price.

The Brazil nut groves are "communal", which means that there is not a right of preemption of an "owner" over such or such an area. The first comer can thus collect wherever he sees fit. In Amazonia, such a system is less frequent than the system of colocação, which holds for the collection of latex from rubber trees (Hevea brasiliensis), and in which a family is entitled to the collection of a demarcated area. But this system is not as open as it appears since there are secret collection zones known to a single family that one avoids showing to others.

A better organization of production, or the possibility of adding to the value by an initial processing in the field, would probably be an important factor to intensify exploitation, which is currently in decline. Cattle ranching is now the fastest growing alternative. Even there are not more than 100 head of cattle in Abuí, the phenomenon is particularly recent and rapid, the village having passed from one to thirteen ranchers since 1995. The introduction of monetary revenue, tied to the rise in salaried functions (teachers, health agents, school boat drivers, etc.) with external economic activities (salaried work around the Trombetas mine) or with social benefits (rural retirees, etc.), gives to some the possibility of investing small amounts of capital. Instead of risking it in Brazil nuts, a seasonal activity of uncertain return because of the oscillations in price, families prefer to invest in raising animals, where the return is guaranteed and which allows for savings until they have enough head of cattle to finance a large purchase (boat, motor, etc.). In addition, the practice of share breeding 3 by the two principal ranchers of Abuí shows that the chain of production is controlled by the political and commercial elite located in Oriximiná. The outlets for ranching are thus guaranteed through these political connections, which grant access to the municipal slaughterhouse.

But another phenomenon should be underscored here. The recognition of the quilombola territory Mãe Domingas was made in the context of an alliance between the people of the forest and the environmental movements. In this context, collection activities such as that of Brazil nuts were favoured, and ranching, which is considered as a vector of deforestation, was very marginal and little practiced. Once their territory was recognized, the Quilombolas of Abuí found themselves in a situation of land security, and it is possible that this new context favoured the increase in ranching. In effect, the alliance with the environmental movements became less indispensable to them, since the territory was now guaranteed, which may have led them to give in to a certain economic realism, encouraging a more profitable activity to the detriment of that which offered less financial security. One might thus put in parallel the marked weakening of the cooperative of the ARQMO, which barely functions, and the increase in the number of ranchers.

\section{Migration routes and urbanization}

The profound integration of the urban and rural worlds in Amazonia, which leads one to talk of "rural cities and urban forests" (Padoch et al, 2008), corresponds to a very old tradition

\footnotetext{
${ }^{3}$ Arrangement in which a big rancher, having productive capital and generally living in town, places his cattle in several small ranchers' fields, who, in exchange for half of the production, plant and maintain the pasture (Cochet et al., 2010).
} 
of multi-sited households. Previously arising from socialization needs (feasts of the saints) and the commercialization of extractive and agricultural products, these multiple residences today are motivated, among other things, by access to care, education for children, and paid employment.

Thus, with globalization, the traditional populations of Amazonia make up increasingly diverse and extended socio-spatial networks (Granchamp, 2001; Padoch et al., 2008). This mobility is accompanied by the transformation in types of residency, the dispersion and fragmentation of social groups, and the hybridization of knowledge and identity, but also the reconfiguration of use and rights to resources (Alexiades, 2009; McSweeney and Jokisch, 2007; Eloy and Le Tourneau, 2009). The impact of this rural-urban mobility on resource management and the socio-demographic behaviour of the Quilombolas depends on land tenure issues but also on the nature of social and commercial networks established with the town, which are nested in a particular economic and political context. In addition, means of transport play a key role in these recompositions, the high cost of which can only be deemed worthwhile if individuals maintain strong ties with the community from whence they come. In this light, the two villages studied present strongly contrasting profiles.

\subsection{The decline of Cunani, an irreversible phenomenon?}

In the 1930s, a large landowner from Belém brought employees from Marajó and Vigia to work in his agricultural lands located at the mouth of the Cunani River. The population naturally increased, with a mixture of inhabitants from upstream and downstream, until it reached approximately 300 people. At that time, the settlement pattern was dispersed (retiros), with main houses located near swidden fields.

The construction of a public school led to families relocating to Vila Cunani around 1940/45. The village began to become more lively, notably during the religious festivals of Santa Maria in August, and São Benedito in December. However, the school stopped at the primary level, and the children could not pursue their education past the fourth year. Some of them were taken in by a godfather or godmother (compadre or comadre) in the main towns of the State of Pará (Belém, Vigia). A first generation of migrants was thus formed outside of Cunani but came back to marry, set up house, and raised on average eight children. These movements were periodic - most often for several months - and were organized around economic opportunities: an initial migrant calling others to the towns of Calçoene, Macapa, Belém, Oiapoque, and Cayenne, in order to work there in carpentry, gold mining, agriculture, and warehouse work. Then, during the 1980s, in order to be able to educate their children, the families moved definitively to Calçoene, which had become a regional economic centre since the opening of BR156.

As a consequence, families started to sell their "retiros" to buy land and have a house built in Calçoene, while keeping a house in Vila Cunani in case of an eventual return. Cunani has seen its population fall, going from 250 in 1970 to 26 in 2010, 16 of whom are more than 40 years old. The majority of children are raised in Calçoene (nearly 9000 inhabitants), then in Macapa and/or Belém for now, as they say, "Cunani is outdated". Except for the period of gathering açaí, when the inhabitants of Calçoene come to help their families, and fishing or hunting during the vacations, the younger generations (15 - 25 years old) refuse to stay in this town in decline, with neither running water, electricity, or internet access. 
According to our interviews, four inhabitants of Cunani also frequent two other villages, Lourenço and Vila União. These are not quilombola communities, but rather places of leisure and religious festivals. But most displacements focus on Calçoene, followed by Macapa and then Oiapoque.

Calçoene fulfills a number of possible functions (economic, social, services) and brings together visits of relatives (the equivalent of Oriximiná for Abuí). Macapá (the capital of Amapá) is essentially visited for family and not for economic reasons, similar to how Manaus is visited by people from Abuí (see below). Trips to Oiapoque, exclusively tied to IBAMA/ICMBIO, are made by men and concern community interests.

Figure 2 shows the dispersion of the kinship network of people from Cunani, living in Cunani, or having migrated to Calçoene fewer than 30 years ago. It shows that the families are dispersed exclusively among the towns, since no village appears in the network, which confirms the process of a rural exodus on a regional scale. The network confirms the preponderance of Calçoene in the social organization of Cunani. The residents of Cunani have most of their relatives in this town and in Macapa. Individuals having their families the most dispersed (3A, 5A, and 8C, at the centre of the network) are inhabitants of Cunani. These are among the oldest families of Cunani, who are looking to diversify their activities (trainings at IBAMA, plantations of açaí), which explains their dispersion. On the other hand, it seems that the inhabitants of Calçoene, living on commerce, social benefits, and agriculture, have no need to disperse in this way to develop their activities. The area of dispersion for women is smaller than that for men, though more qualitative, both as to length and frequency.

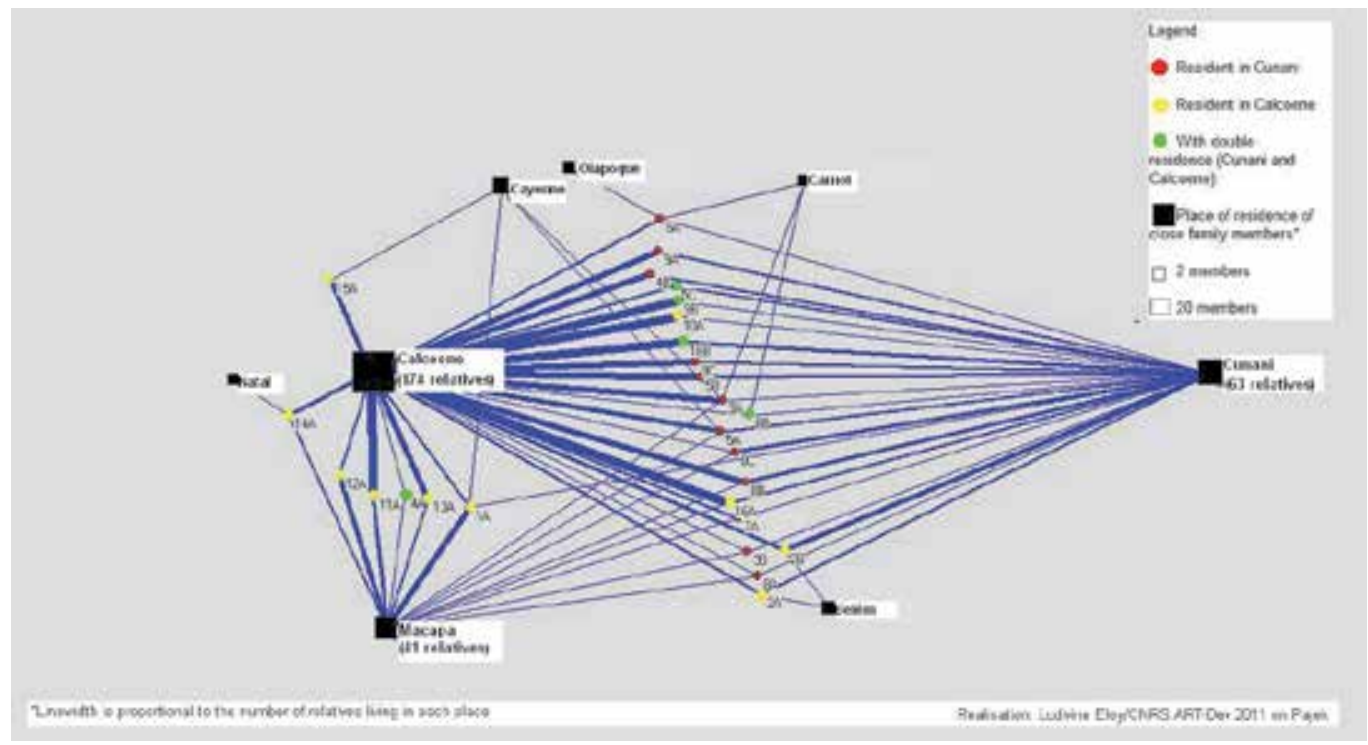

Fig. 2. Spatial dispersion of the kinship network of the inhabitants of Cunani and migrants from Cunani recently moved to Calçoene ( 29 surveys) ${ }^{4}$

\footnotetext{
${ }^{4}$ Considered as relatives in this graphic: father, mother, brothers and sisters, children, step-brothers and adopted children included, as well as current spouses.
} 
Thus, following the analysis of Domenach and Picouet (1987), thinking about the reversibility of migrations - and its corollary, irreversibility - allows us to highlight the importance of networks. The myth of return remains present in many discourses, as much for the affective ties as for the quality of life in the village. Once they have left, however, no family has returned to Cunani - with the exception of one person who had a serious accident - and the pensions of the retirees does not allow the migrants as frequent return visits as they might wish for. The oldest inhabitants would rather finish their days close to their children, in the hospital at Calçoene. Such a choice shows the increasing rootedness of the inhabitants of Cunani in the neighboring town of Calçoene. The analysis by network shows that the geographic mobility towards Calçoene may also constitute a step before that towards Macapa, where the university is a strategic asset for the younger generations.

Is the quilombola statute, on its way to recognition, a possible means of reversing this tendency? The funds released by the Secretary for Minorities, and given to the Quilombolas in the State of Amapá, can no longer be invested in local education, due to the lack of students. The teacher, who is also the president of the village association, has therefore proposed the building of a new community center, in the shape of an indigenous long house, or Maloca, thus hoping to give some prestige to the village; such an option, which shows the difficulty of characterizing culturally the Quilombolas of Brazil, would without doubt be the last major investment for the community.

\subsection{Abuí: A successful integration within global dynamics?}

Faced with the devaluing of extractive products and the rise in monetary needs, the Quilombolas of Abuí need to find new activities. A modification of the spaces frequented by members of the community can thus also be seen, tied to new social functions.

The study of the frequency and reasons for mobility reveal two principal modes of circulation outside the village. The short distance visits to the surrounding villages arise from "tradition" motivated by religious festivals, sporting events, and occasional visits to relatives. Displacement towards the towns deal above all with economic activities. These essentially concern Oriximiná: throughout the history of extractive activities in the region, the town has been a place of exchange and sale of extractive products for manufactured ones. But the frequency of displacements to Oriximiná seems to have increased these past few years, as the acquisition of a community boat as well as individual motorboats allow people to travel the $250 \mathrm{~km}$ of river in a single day, in contrast to many days in a pirogue. In $71 \%$ of the cases, people from Abuí say they go there at least once a month. This increase in the frequency of travelling to town is motivated by the growth of social benefits (accessible in town) since the Lula government (2003) as well as opportunities for salaried work. These are essentially jobs for women: the majority of young women from Abuí take their chances as house workers while pursuing their studies in Oriximiná, whereas the young children stay with their grandparents in Abuí. This growing interaction with Oriximina is thus expressed in the construction of multi-sited residential systems (or multi-sited households) between town and forest ${ }^{5}$.

\footnotetext{
${ }^{5}$ The residential system is an articulated group of places of residence for the members of an extended family (Le Bris, 1986\}.
} 
On the other hand, Porto Trombetas, located halfway between Abuí and Oriximiná, is much less frequented: most visits occur fewer than four times a year. Porto Trombetas essentially fulfils a function of access to health services. It is in effect a town built in the 1970s for skilled workers from the mining industry, and which had no role in the extractive economy. Visiting Porto Trombetas and the settling of families in nearby quilombola villages (such as Boa Vista) are strictly regulated and limited to avoid urbanization along the river in proximity to the mines (Nasuti, 2005). Faced with protests from the quilombola communities, the mining industry made the hospital at Porto Trombetas accessible in case of emergency, which explains such unusual displacements to this town. Porto Trombetas is also a destination for temporary work, but as opposed to Oriximiná, it is essentially work for men, tied to the mines. The regional towns, further away, such as Óbidos, Santarém, and Manaus, are less often cited, since they are visited only occasionally. Manaus is cited only as a place to visit relatives, who have left Abuí for good to work there.

Thus, the effects of recent urbanization in Abuí reflect in the extension of kinship networks in regional towns. Figure 3 shows that Abuí is where the majority of relatives reunite. The family network also links Abuí to other quilombola villages in the region (Tapagem, Sagrado Coração, Boa Vista, Erepecu), which reveals, as opposed to Cunani, the anchoring of this social structure in the rural setting. However, most of the people surveyed are situated between these three poles (Abuí, Oriximiná, and Manaus), which means they have close relatives in the two towns, notably Oriximiná, where they have older relatives as well as some younger ones (secondary school students, house workers). It can thus be said that most of the inhabitants of Abuí belong to multi-sited residential systems that link

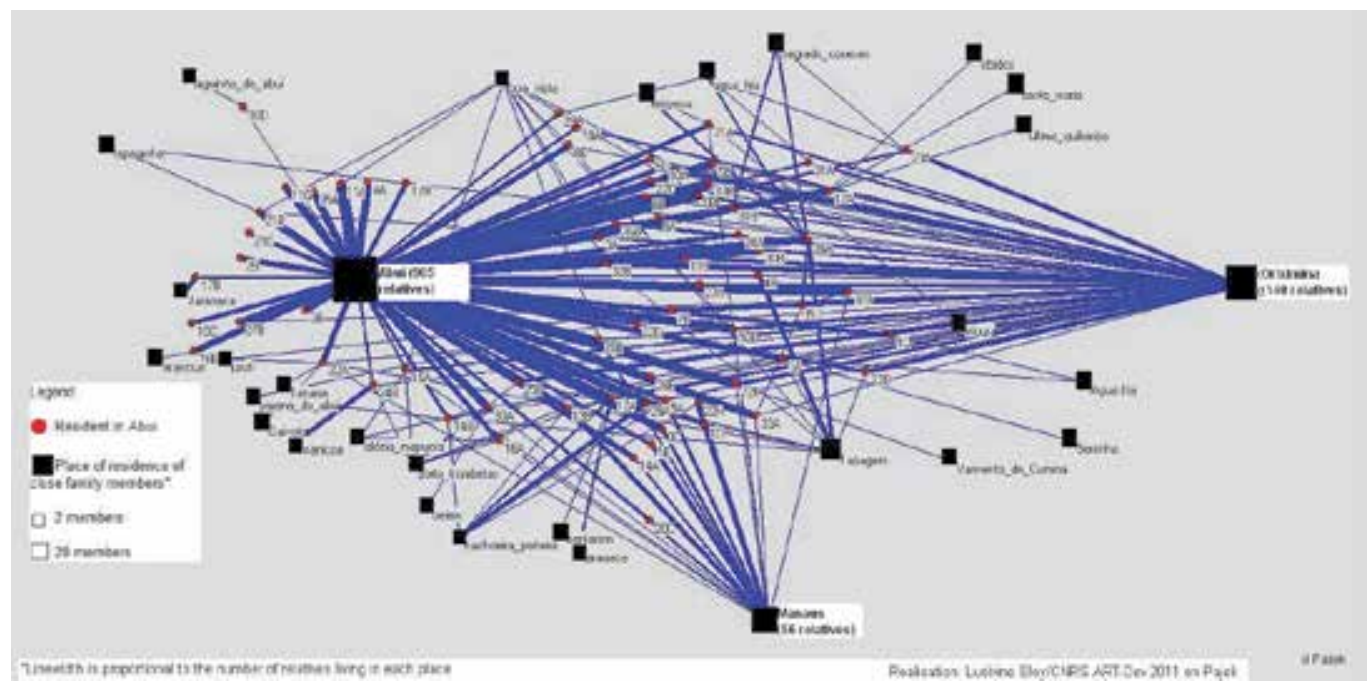

Fig. 3. Spatial dispersion of the kinship network for the inhabitants of Abuí

(76 surveys)

the legalized quilombola territory with regional towns offering economic alternatives to the crisis of extractivism. Instead of engaging in a process of rural exodus, the people of Abuí seek out available resources in different spaces by intensifying their movements into the towns. The polarized movements to towns are thus superimposed on the "traditional" movements between the other quilombola villages without replacing them. 


\section{Conclusion}

The two quilombola communities studied are confronted with the contradictory effects of globalization: while they are subject to increasing environmental restrictions because of the proximity to and juxtaposition with conservation areas, they are increasingly integrated within a globalized market and a formal education system. In this way, our research brings into evidence the increasing disjunction between territory and identity produced by globalization (Appadurai, 1995). In effect, as with other traditional populations in Amazonia (Eloy and Lasmar, in press; Moreira, 2003 ; Padoch et al., 2008), there is a growing gap between, on the one hand, a demarcated territory, associated with a specific identity, and on the other, the socio-economic reality anchored in towns and articulated around individual strategies. These manifestations of globalization are expressed in a change in the use of resources but also in the extension of family networks in the regional towns. However, the function and form of these networks differ between the two communities.

In Cunani, after the construction of the BR and the creation of the National Park, the decade from 1980 - 90 was marked by migratory circulation and dual residency between Cunani and Calçoene. With the restrictions imposed by the IBAMA on river transport, most of the inhabitants opted for a definitive migration to Calçoene, as individual transport by road became too onerous. The perspective of the creation of a quilombola community at Cunani was not enough to halt the rural exodus. In addition, the local production of açaí, being seasonal, was not enough to keep the new generations in place. In this context, swidden cultivation is increasingly replaced by plantations of açaí requiring less labour, confirming a process of deagrarisation already observed in other communities in Amapá (PinedoVasquez and Padoch, 2009). At present, the periodic and seasonal movements that link Cunani to Calçoene are motivated essentially by festive events and the production/commercialization of açaí. The social and commercial network of Cunani is thus centred around Calçoene and other regional towns.

In contrast, in Abuí, because of the devaluing of extractive products, land tenure security functions as a resource to free up new revenues that are complementary to or even dependent on urban resources (e.g. share breeding, social benefits, and paid employment). Despite the distance that separates Abuí from Oriximiná $(250 \mathrm{~km})$, the inhabitants have constructed multi-sited households between town and forest that rely on intensive river transport. The improvement in the level of livelihoods and the collective organization of river transport has been an essential factor in these socio-demographic adaptations. The mobility thus constitutes a "circulatory resource" (Cortes, pers. comm.) for the rural populations of Amazonia.

In both cases, the emergence of productive values brings with it the individual appropriation of resources (açaí plantations and pasture lands) and a certain concentration of wealth in the hands of a few families, and this even without private property. Thus, the recognition of collective quilombola lands would not be enough to halt the tendency towards socio-economic differentiation. The introduction of ranching in the quilombola villages of Trombetas, driven by the urban political elite through share breeding, indicates that land is not a privileged factor in the concentration of capital (Cochet et al., 2010).

Nevertheless, we cannot affirm that the land tenure security accorded to the Quilombolas of Trombetas explains and justifies in itself the introduction of cattle ranching. The fact that 
the quilombola lands are not under conservation restrictions leaves the owners free to exploit the resources as they see fit. And yet the introduction of ranching is also explained by the privileged relation that two families from Abuí have with a rancher from Oriximiná, which has allowed them to bring the initial productive capital (cattle). It is this type of network that the other community studied, Cunani, was not able to consolidate.

Thus, while the proximity to roads is known to be the principal factor determining the expansion of cattle ranching (Chomitz et al., 2007; Scouvart and Lambin, 2006), in this case the community that began this activity is precisely the one which is not connected to the road network and is furthest away from town. It seems therefore that the impact of globalization on land use of traditional populations is not uniquely determined by geographic factors (remoteness, land rights), but also depends on the access to mobility and the socio-cultural networks that these populations construct with different agents of development in Amazonia (urban political elites, businesses, NGOs).

\section{Acknowledgements}

Our study, financed by the French Agence Nationale de la Recherche, is part of USART program (Uses and transmission of territorial knowledge in traditional Amazonian context). Our fieldwork period was July and August 2010. We are grateful to all the farmers from Cunani and Abuí for their patience and kindness. Thanks to Kevin Frey for his accurate and rapid translation of this text.

\section{References}

Alexiades M. N., 2009, Mobility and migration in indigenous Amazonia: contemporary ethnoecological perspectives, New York, Oxford,Berghahn.

Appadurai A., 1995, «The Production of Locality », in FARDON Richard, Counterworks Managing the Diversity of knowledge, New York, Routledge : 204-225.

Appadurai A., 1996, Modernity at Large: Cultural Dimensions of Globalization, Chicago, University of Minnesota Press.

Barretto filho H. T., 2006, "Populações tradicionais: introdução à crítica da ecologia política de uma noção", In: Sociedades Caboclas Amazônicas: Modernidade e Invisibilidade. C. Adams, R.S.S. Murrieta, and W.A. Neves (eds.). São Paulo, Ana Blume : 109-144.

Boyer V., 2002, «Quilombolas et évangélistes: une incompatibilité identitaire ? Réflexions à partir d'une étude de cas en Amazonie brésilienne », Journal de la Société des Américanistes, $88: 159-178$.

Brondizio, E.S., et al., 2002, The urban market of Açaí fruit (Euterpeoleracea Mart.) and rural land use change: Ethnographic insights into the role of price and land tenure constraining agricultural choices in the Amazon estuary. Urban ecosystems 6 (1/2): 67-98.

Brondizio, E. S. 2006. Landscapes of the past, footprints of the future: historical ecology and the analysis of land use change in the Amazon. In W. Balée and C. Erikson (eds.) Time and Complexity in Historical Ecology: Studies in the Neotropical Lowlands. New York, Columbia University Press: 365-405.

Brondizio, E. S. 2008.The Amazonian Caboclo and the Açaí palm: forest farmers in the global market. New York Botanical Garden Press, New York, New York, USA. 
Bunker, S., 1985, Underdeveloping the Amazon. Extraction, unequal exchange, and the failure of the modern state, Chicago, University Of Chicago Press.

Chomitz K. M., Buys P., De Luca G., Thomas T. S., Wertz-Kanounnikoff S., 2007, At Loggerheads?Agricultural Expansion, Poverty Reduction, and Environment in the Tropical Forests.Washington: The World Bank.

Cochet, H., Leonard, E., Tallet, B., 2010, «Le métayage d'élevage au Mexique. Colonisations foncières et dynamiques d'une institution agraire dans l'histoire contemporaine ", Annales de géographie 6 (676) : 617-638.

Coudreau, H.,1900,Voyage au Trombetas. 7 août 1899-25 novembre 1899, Paris, A. Lahure.

Diegues, A. C., 1996, O Mito moderno da Natureza intocada, São Paulo, Editora Hucitec NUPAUB/USP.

Domenach, H., Picouet, M. 1987. «Le caractère de réversibilité dans l'étude de la migration », Population, 3: 469-484.

Eloy L., 2008, «Diversité alimentaire et urbanisation. Le rôle des mobilités circulaires des Amérindiens dans le Nord-Ouest Amazonien». Anthropology of food,vol. S4, p. http://aof.revues.org/document2882.html

Eloy L.,Le tourneau F. M., 2009, «L'urbanisation provoque-t-elle la déforestation en Amazonie ? Innovations territoriales et agricoles dans le nord-ouest Amazonien (Brésil)». Annales de géographie (Paris), vol. 118, $\mathrm{n}^{\circ} 667$ : 204-227. search.ebscohost.com/login.aspx?direct=true\&db=fcs\&AN=21936449\&amp;lang=f r\&site $=$ ehost-live

Geffray, C., 1995,Chroniques de la servitude en Amazonie brésilienne. Essai sur l'exploitation paternaliste. Paris, Editions Karthala.

Granchamp F. L., 2001,Urbanisation, stratégies familiales et multipolarité rurale-urbaine: la transamazonienne à l'ouest d'Altamira (Pará, Brésil). Thèse de doctorat. Paris: EHESS, Centre de Recherche sur le Brésil Contemporain, 386 p.

Greissing A., Kohler F., Le Tourneau F.M., Picanço J.R.A, 2008, «Iratapuru et la noix du Brésil: une expérience de durabilité en Amazonie brésilienne», Cybergeo, Environment, Nature, Landscape, Article 432, http:/ / cybergeo.revues.org/ 20763

Harris M., 2006, "Presente ambivalente: uma maneira amazônica de estar no tempo", in: Sociedades Caboclas Amazônicas: Modernidade e Invisibilidade. C. Adams, R.S.S. Murrieta, and W.A. Neves (eds.). São Paulo, Ana Blume: 81-108.

Kramer D. B., G. Urquhart, K. Schmitt, 2009, Globalization and the connection of remote communities: A review of household effects and their biodiversity implications, Ecological Economics 68 (2009) 2897-2909.

Lebris E., 1986, «Synthèse des travaux sur la mobilité interne et externe dans le Sud-Est Togo».In E. Le Bris, G. Pontié, A. Quesnel, J. Gregory, M. T.Duquette-Ahado and K. Vignikin (eds.), Migrations togolaises: bilan et perspectives. Lomé: Université du Bénin. Unité de Recherche Démographique (TGO) : 255-282.

Mcsweeney K., Jokisch B., 2007, «Beyond Rainforests: Urbanisation and Emigration among Lowland Indigenous Societies in Latin America ». Bulletin of Latin American Research, vol. 26, $\mathrm{n}^{\circ} 2: 159-180$.

Moreira E. L. (2003). «Amazônia em movimento: Redes e Percursos de Desenvolvimento dos Índios Ye'kuana, Roraima». Cadernos de Campo (USP),vol. 11. 
Nasuti S. (2005). Infrastructures industrielles et communautés: stratégies territoriales. Vallée de Trombetas, Etat du Pará - Brésil, Master. Paris: Université Sorbonne NouvelleParis III, IHEAL.

Padoch, C., E. Brondizio, S. Costa, M. Pinedo-vasquez, R. R. Sears, and A. Siqueira, 2008, Urban forest and rural cities: multi-sited households, consumption patterns, and forest resources in Amazonia. Ecology and Society 13(2): 2. [online] URL: http://www.ecologyandsociety.org/vol13/iss2/art2/)

Pantoja, M. C; Costa, E.; Postigo, A., 2009, “A presença do gado em Reservas Extrativistas: algumas reflexões". Caderno Pós Ciências Sociais. v.6 n.12 jul/dez, São Luis/MA: UFMA.

Pinedo-Vasquez M., Padoch C., 2009, «Urban and rural and in-between: Multi-sited households, mobility and resource management in the Amazon floodplain», In M. ALEXIADES (ed.), Mobility and migration in indigenous Amazonia. Oxford, Berghahn books : 86-96.

Porró, A., 2008,"Notas sobre o antigo povomaento indígena do Alto Trombetas e Mapuera",Boletim do Museo Paraense Emílio Goeldi, vol.3 n³, p.387-397.

Ricardo, F., rolla, A. 2009. Amazonia brasileira. Sao Paulo: InsitutoSocioambiental.

Scouvart M., Lambin E. F., 2006, «Approche systémique des causes de la déforestation en Amazonie brésilienne. Syndromes, synergies et rétroaction», Espace Géographique, vol. $35, \mathrm{n}^{\circ} 3: 241-254$.

UNESCO, 2003, Cultural Diversity and Biodiversity for Sustainable Development: a jointly convened UNESCO and UNEP high-level Roundtable held on 3 September 2002 in Johannesburg, South Africa during the World Summit on Sustainable Development: http://unesdoc.unesco.org/images/0013/001322/132262e.pdf

Veran J.-F., 2002, «Quilombos: des 'lieux de mémoire' bien vivants », Cahiers du Brésil Contemporain $n^{\circ} 49-50: 87-96$. 


\title{
The European Model of Agricultural Policy in the Global Context
}

\author{
Věra Bečvářová \\ Mendel University in Brno \\ Czech Republic
}

\section{Introduction}

The most noticeable processes affecting development of world economics as well as individual segments these days are without question the globalization processes. They are connected with a number of quality changes in the society as the mutual dependency of individual subjects of internal as well as international relations that go beyond the limits of the systems and rules originally formed by national states. Although we encounter this term usually in connection with establishment and ever-growing influence of transnational corporations, world chains and networks, the globalization processes themselves relate not just to economic but also to political, social and cultural changes in the society. They interfere in the already existing relations and form a qualitatively new social environment due to their positive as well as adverse effects.

These changes quite logically prove also under the development conditions of the current agriculture and the agricultural sector as a whole in its horizontal as well as vertical context. They overcome the formerly typical relative closeness of basic agriculture. They affect the whole segment of economics connected with production, processing, distribution and realization of agricultural products and services related thereto. They change the size, rules as well as criteria of forming the supply and demand relationships on agrarian markets, namely in whole verticals that these days frequently take the form of global networks.

The environment of agrarian markets is changing and new priorities are assigned the criteria of competitiveness and demands on their provision. Contemporary agriculture is far from being an enclosed autonomous system; not only due to the acceptance of its role in the sustainable development of society, but exactly due to the changes in the position of agriculture as a fundamental part of agribusiness within the global economy. However, it is this "production" function where the specialization of primary agricultural production into sectors is quickly overcome. Agribusiness shaping processes are typical of the inclusion of companies in many sectors that more or less participate in the production, processing and distribution of foodstuffs into a self-contained system. In this process, the influence of finalizing segments (processing and distribution) during the shaping of demand for raw products grows and affects the allocation and the level of utilization of production factors, which fact is also reflected in the potential development of individual regions with much broader economic, social and political consequences. 
Given that agribusiness development, this among other things, extends the spectrum of uses of agricultural products, increasingly affects the overall conditions for agricultural development in the current model. It becomes a factor influenced criteria and price competition from producers in world markets over the regional context. The quantity as well as the quality standards in relation to market price and their effects pertain not only to the producers or processors of agricultural products respectively and consumers but the whole (and not just the rural) population (Swinnen et al., 2008). The need for interdisciplinary solutions when selecting strategies of agricultural development has been objectively growing, reflecting the broad cross-conditionality of the changing market environment.

Also the concept of a balanced European model of multi-function agriculture and its implementation under the European Union (hereinafter referred to as CAP) for as many as 27 current member states, which differ in terms of their bases, reach as well as productivity, is ever more frequently confronted with new challenges arising from accelerated globalization processes. In the current model, the importance of the agricultural production role is growing in terms of meeting its function within development of the rural area as well as the society as a whole. Under the current conditions, the success or the failure of solutions within the production sphere is ever more markedly reflected by all dimensions (economic, ecological, technological as well as human and social) of regional development, that is, not just under the European conditions.

Evaluation of the general economic settings for the contemporary agrarian sector have detected the unprecedented implications which have determinate the fruitfulness of agricultural enterprises at the expanding markets. In practice, the acceptances of the consumer (demand-driven) concept in the CAP as well as the shift of focus to the finalizing segments of the processing and distribution of foodstuffs ever more significantly form a new and harder competitive environment of both food processing companies and agricultural companies. Although the above-mentioned development tendencies might be tempting to a simplified conclusion that under the current circumstances, there is no reason anymore to support the production dimension of agriculture, it is a paradox that in this very context of liberalized market, the issues of strategic nature connected with the role and integral objective of this sector in the modern society are becoming ever more important. The target solution does have a long-term nature but the dynamics of changes in the environment as combined with the specific aspects of agricultural production makes it necessary to select a complex approach from the very beginning of the solution including the permanent reflection of the effects of reform steps realization at the production as well as nonproduction level.

\section{Agriculture as a part of the wide economy segment}

Even if we take into consideration other than production functions and, to a certain extent, the specific position of agricultural enterprises in the food industry, future agricultural development is undisputedly connected to effective business activities. Which means not only the problem of productivity factors (land, labour, capital, management level) on a scale beyond the prior narrow definition of agriculture as a crucial/specific food production branch, but also the question of involving the primary production segment in the overall food production complex - agribusiness. A traditional farmer as a manufacturer of primary materials for food (and more frequently, non-food) production is ever more being put under 
pressure from world competitors of the ever-expanding food market and, therefore, loses the formerly decisive influence on food production conditions and possibilities in a particular region.

\subsection{Agribusiness concept - some theoretical implications}

The theoretical-methodological approach to dealing with the economy of agri-food production, including both production, agricultural product processing and trade, is based upon the classic Davis-Goldberg concept (Davis \& Goldberg, 1994), where "agribusiness" is characterized as a complex of activities concerning the production, storage, processing, distribution and selling of agricultural commodities and products.

For a more up-to-date approach reflecting the situation at the turn of millennium we can use the definition according to Sonka and Hudson (Sonka \& Hudson, 1999), which apart from the above-mentioned structure emphasizes the role of research and pre-production stages (the influence of genetic and biological research in particular and their practical application) and the growing role of the food catering industry in the consumption segment. According to this definition the world agribusiness involves about $50 \%$ working population, makes use of $50 \%$ of the worlds assets and presents more than $50 \%$ of consumer spendings.

It is obvious from analyses of the shaping of world agribusiness and its characteristics in the environment of the European region that a crucial change typical for the present-day stage of agriculture within the whole complex of business fields participating in food production, is the change in character of agrarian and food markets. In general, this development stage can be described by the following characteristics:

- $\quad$ supply of an agricultural product is formed by the evaluation of mutual interactions of supply and demand and their relations in the whole agribusiness chain, where the final demand has the decisive effect on the quantity and structure of production and quantities in time and space,

- a number of firms and organizations interfere in the flow of food and agricultural products, frequently of no agricultural character, global chains, private businesses and public subjects which participate in the identification and determination of particular requirements of consumers and consumer segments,

- consumers concentrate on value (quality at low prices) and on food assortment; demand for food of high added value grows - products such as thermally processed, preserved, frozen and dehydrated products; stores offering those sorts of food have become market leaders, play a key role in retail and determine the trade model in particular agro-food chains,

- the consumer protection criteria strengthened with respect to the quality of food concerning health-care, food safety, bio terrorism, and identification of original food source,

- integration of the world food industry proceeds, the effect of inner market protection by trade regulations diminishes in many countries, agrarian markets are being liberalised,

- corporate consolidation progresses in all segments of the food chain, firms benefiting from enlargement; checking and co-ordination of consequent activities intensifies, ecommerce and forwarders contracts act in close relations, etc.,

- competition becomes a struggle of the whole commodity verticals in the particular segment of the food market. 
Those imply - the demand actually becomes a major relation, determining the quantity and quality of agricultural products as well as the price/cost parameters on the market. It significantly affects the whole system of production, processing and distribution of agricultural products. This brings new challenges in the decision-making of agricultural producers as far as structure and production parameters and it more often causes clashes with government limits, regulations and limitations of the historically structured agrarian policy based on the regulating supply-oriented approach of agricultural production.

When the supply-driven approach prevailed, it mostly meant decisions based on production effectiveness parameters. From those were derived further key factors of product management (observing production, costs, profit, maximum sales and winning customers) based on which future business strategies were formulated.

Basically, the same parameters are still included in the commonly preferred intensifying of the consumer-side aspect, which is mostly presented as domination of demandorientation of the agri-food market. However, the demand-driven approach is far more challenging: should each segment of a vertical, including farmers, become effective. A certain form of presence in the vertical is essential, access to information and the ability to utilise acquired information for permanent evaluation of the market situation, the ability to anticipate demand in considerable detail and, if possible, supply has to be reflected immediately.

The dominant position of more concentrated food-processing businesses, retailers and the catering sector on the market enables advantages arising from that position in the selection of suppliers to be used, dictating commodity prices. At the same time, it increases competition in the horizontal plane of primary production and weakens the regulating effect and given limits of agrarian policy (as far as the structure and range of agricultural production in the particular region). These non-agricultural businesses of pre-production and consequent agribusiness stages completely change the whole character of the agricultural sector as well as production capabilities in the regional aspect, and influence, directly or indirectly, markets within the whole verticals by their trade policies.

If we briefly summarize the basic changes concerning the transformation from supplydriven models of traditional agriculture to the concept of modern agriculture focusing on demand-driven types of market relations, we indirectly get to the definition of agriculture as a part of agribusiness (more details, Bečvářová, 2005). In this context, among the crucial factors evaluating achievements of agricultural enterprises, new items significantly appearitems of the knowledge economy.

Comparisons of the characteristics of both models, i.e. traditional and new concept of agriculture, have resulted in the following changes in particular areas, see Table 1 (refer to Boehlje et al, 2001).

Even though some of the characteristics call for a more profound contextual explanation, far from all of them conform to official papers and concepts within the present European model, and the reality must be accepted that agricultural development is increasingly determined by the development of other business fields and sectors, not only within the national economy, but also in the international context, which considerably changes both the competitiveness criteria as well as the potential for further development of agricultural enterprises. 


\begin{tabular}{|c|c|c|}
\hline Characteristics & $\begin{array}{c}\text { Traditional concept } \\
\text { Supply-determined model }\end{array}$ & $\begin{array}{c}\text { New concept } \\
\text { Demand-determined model }\end{array}$ \\
\hline Agriculture position & Agriculture is agricultural production & $\begin{array}{l}\text { Agriculture is a part of food final } \\
\text { production }\end{array}$ \\
\hline Output character & Commodity as a final product & Commodity as a raw material \\
\hline Production structure & $\begin{array}{l}\text { Structure of production under natural } \\
\text { conditions }\end{array}$ & $\begin{array}{l}\text { Demanded plants/animal } \\
\text { products }\end{array}$ \\
\hline Determining production factor & Production facilities, land, capital & Customers demands \\
\hline Competitive advantage & Land quality, technology, buildings & $\begin{array}{l}\text { People, knowledge, strategy, } \\
\text { organization }\end{array}$ \\
\hline Production strategy & $\begin{array}{l}\text { Universal structure based on } \\
\text { availability of production factors and } \\
\text { inputs }\end{array}$ & $\begin{array}{l}\text { Specialised in particular/ } \\
\text { demanded raw material }\end{array}$ \\
\hline Assets & Own assets & Assets control \\
\hline Success determiner & Capital in finance and in kind & Knowledge, information \\
\hline Labour force & LF is a part of costs and investment & $\begin{array}{l}\text { LF is an investment and part of } \\
\text { costs }\end{array}$ \\
\hline Type of trade & Sells product, offers service & Sells service, offers product \\
\hline Market characteristics & $\begin{array}{l}\text { Impersonal relationships/ } \\
\text { open markets }\end{array}$ & Personal relationships - contracted \\
\hline Supplier/customer relations & Mainly adverse & Correct, friendly \\
\hline Input purchase & Bulk quantities, various suppliers & Mainly from one source \\
\hline Own input production & Strong tendency & Purchased \\
\hline Approach to product price & Pressure on high prices & Low costs preferred \\
\hline Crucial risks & Market failure (price) & Loss of relationships \\
\hline Position in system & Independence & Interaction with partners \\
\hline Business characteristics & Stability & Change, flexibility \\
\hline Crucial knowledge & Technical & Economic, communication \\
\hline Agriculture approach & Traditional, experiential based & $\begin{array}{l}\text { Learning and knowledge base, } \\
\text { innovative }\end{array}$ \\
\hline Approach to natural sources & Exploitation, usage & Usage, protection \\
\hline Production philosophy & Production, waste liquidation & Production, waste recycling \\
\hline
\end{tabular}

Table 1. Supply and demand-determined concepts of agriculture, main characteristics

\subsection{Competitiveness of present- day agricultural enterprises}

It follows that the effectiveness of agricultural enterprises is no longer primarily connected to the traditional territorial location of agricultural production as far as farmland quality and other agro-environmental conditions, according to former concepts of intensive and extensive economic systems. The influence of firms' individual capabilities of being responsive to free market challenges with considerable territorial and commodity differentiation is evident.

If we generally consider the competitiveness of a particular economy system as its ability, in a competitive environment, to achieve results appropriate to the objectives of the system 
and its dynamics, this definition implies that it is necessary for the competitiveness assessment to set not only given objectives and criteria enabling the level of their fulfilment to be quantified, but also define factors which determine and affect its fulfilment. At the present stage of agricultural development we can choose between a minimum of two approaches to assessing the competitiveness of agricultural enterprises, namely the horizontal and vertical levels.

The methodically more developed and so far more frequently method used is the competitiveness analysis based on a horizontal approach to the assessment of agricultural enterprises. In this approach, the commodity structure and its cost parameters confronted with the market price level, i.e. terms of supply related to criteria, factors and conditions for development of the financial and economic competitiveness of an enterprise, enable us to immediately assess the potential competitiveness level of the enterprise and the essential context of its development, using mainly the method of inter-company comparison within the agricultural branch of business.

In order to define the range of key factors which have an effect on conditions necessary for meeting the objectives of the given economic system and the position of an agricultural enterprise with respect to its "productive" function within present-day agribusiness, it seems more appropriate to use another distinction level. Competitiveness is assessed in terms of acceptability of the available structure and the production parameters for the market, therefore in the broader context of involvement of an agricultural enterprise in food production systems.

Examination of the economic effectiveness of the food industry as a whole is then derived from the dynamic concept of competitive advantage. It is measured not only by the economic results of a relatively independent subject in a particular agricultural market relevant for the specific assessment stage of the original primary material within commodity chains, but mainly by conditions and mutual relations among subjects participating in the development, production, processing and distribution of food within the whole process. This does not mean only a solitary evaluation of the development and results of suppliers and customers as independent subjects resp. representatives of relatively separate business areas of isolated markets, without considering interactions with other players. It further deals with the economic context resulting from the mutual conditionality of supplier/customer relationships based on the succession of all activities, beginning with primary material acquisition and ending in the sale of the final product -food- to end users. It always comprises a number of activities adding value to the final product in the process of production, storage, adjustment and distribution.

Competitiveness starts to be observed not only in the view of a company as part of a particular stage of the commodity flow, but also with respect to the efficiency of the whole system. It reflects the situation and examines causes why chains of mutually co-operating businesses (at both horizontal and vertical levels) more frequently succeed on the market, compared to individual retailers within a specific commodity chain. As a result of globalisation processes, relevant markets have enlarged considerably for most agricultural commodities. Therefore, we can expect changes in regional market definitions (even today often not respecting national borders and limitations) and also further changes and restrictions of political regulation instruments of agricultural production, distorting the competitiveness conditions of enterprises in a larger form than the national agricultural marketplace. This means that the success of particular subjects on the market in the whole verticals is still (but not only) conditioned by the achievement of a competitive labour 
productivity level and material inputs, which in agriculture is usually connected with necessary growth in agricultural production intensity (Fig. 1).

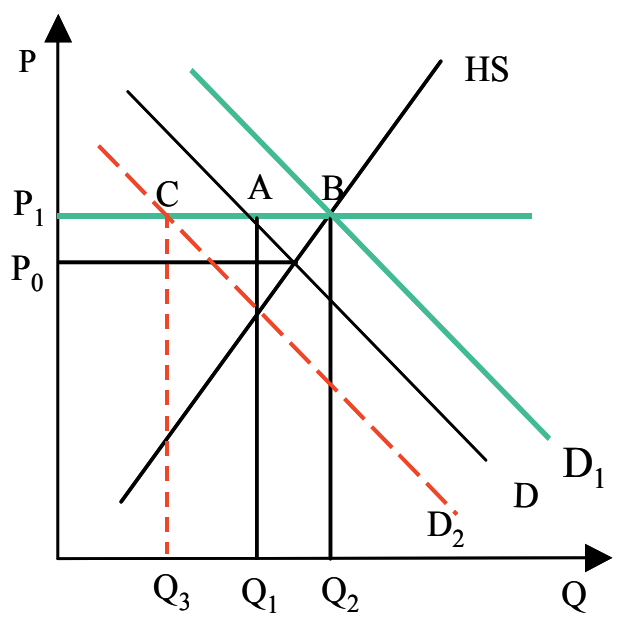

Legend:

$\mathrm{P}_{0} \quad$ commodity world price

$\mathrm{P}_{1} \quad$ subsidized commodity price WS $+D P$

HS domestic supply of the raw material on the market

D domestic demand for the raw material on the market

$\mathrm{D}_{1} \quad$ demand in state intervention purchase

$\mathrm{D}_{2} \quad$ domestic supply in case efficient substitutes are available

Fig. 1. Impact of subsidized price on changes in structure of commodity demand on the domestic market

Supply HS reacting to the high (subsidized) price $\mathrm{P}_{1}$ would require, in the balance point $\mathrm{B}$, sales of quantity $Q_{2}$, which is higher than domestic demand $Q_{1}$ (point $A$ ), which has to be sorted out by other economic instruments (limits, intervention purchase). In order to maintain the price, a customer begins to prefer such products of a lower price and purchases lower and lower quantities of the "expensive" commodity; in the given example, quantity falls to $\mathrm{Q}_{3}$ while supply is at the $\mathrm{D}_{2}$ level.

The figure contexts are supported by the results of former EU countries development. Reduction of subsidized agricultural products and the implementation of new instruments such as direct supports to the recipient bring higher economic differentiation in the corporate sphere. Production effectiveness falls to producers accustomed to using formerly higher support mainly for their own purposes e.g. for maintaining their market position. Reduced subsidies did not put at risk such subjects which invested financial resources in modernization and due to realised structural changes and subsequent innovations achieved higher effectiveness of production factors.

To increase the competitiveness of producers, in an environment where the situation in the market is increasingly affected by customers, is first of all a problem of lower costs of agricultural products on offer, products capable of accepting price requirements and capable of finding a place in certain consequent markets.

Businesses having a comparative advantage are those which have not underestimated technological development, modern management processes, and methods of strategic and 
tactical utilisation of market research, focusing on long-term cooperation relationships with core customers on the domestic as well as European and world market respectively.

Since relevant markets are expanding, tendencies to maintain high (subsidized) prices, as a consequence, handicap producers (supply side). Food-processing firms (demand side) prefer producers and markets offering agricultural commodities at lower prices. Therefore, in the long run, the volume of realised quantities of "more expensive" commodities decreases. The tendency to prefer "less expensive", therefore, cheaper offers for agricultural commodities brings the opportunity to enter the market, even for producers who have already determined the appropriate production structure and utilize technologies enable them to reduce unit costs at high intensity and, at the same time, contract selling outlets.

The process of expanding the agrarian market without significant barriers brings about many changes that positively influence the development of the particular segment of economy.

In general, conclusions of theoretical works, analyses and studies related to this issue (e.g. Ahn, 2002; Boehlje, 2002; Connor, 2003; Goldberg, 1998; Kinsey, 2003) can be generalized in the following fields of arguments:

- $\quad$ expansion to bigger markets supports the differentiation of products and causes regional transfers of production capacities and the growth of production with the most efficient entities and thereby accelerates specialization and the related possibilities to achieve savings from large-scale production; at the same time, the potential and recoverability of utilized innovations increase;

- increased competition on larger markets supports and accelerates better allocation of production factors towards (the most) efficient activities and entities; this fact also creates better starting points for the increase of competitive strength on the world market;

- larger common market and increasing competition require but also facilitate faster technical and scientific development, the development of new products, processes, technologies and procedures through common (internationally linked) research and its application in practice in all national economic systems connected to this market.

If we define the competitiveness of a certain economic system as the ability to achieve results corresponding to the aims of the system and the dynamics thereof in a competitive environment, it is clear that a prerequisite for achieving unbiased aims, including the selection of criteria for the evaluation of the extent to which they were achieved, is the knowledge of the range of factors determining their fulfilment.

To assess the competitiveness of agricultural enterprises, we may choose at least two approaches related to the definition of the level of the economic system, the qualities (i.e. competitiveness) and behaviour of which should be assessed, which fact is related to the choice of the level of differentiation and examination criteria.

From the perspective of method and methodology, we may choose an approach based on

1. inter-company comparison at the horizontal level of the particular stage of production or processing of the final product,

2. prerequisites for participation in the creation of added value in the final product, i.e. from the perspective of successful participation of a company in the appropriate stage of the foodstuff vertical.

Option (1): The analysis of competitiveness at the level of the differentiation of agricultural enterprises is used more often and its methodology is more elaborated. In this case, it is 
especially the structure of commodities and its costs parameters confronted with the level of market prices, i.e. demand conditions, related to the criteria, factors and conditions of the development of the financial and economic efficiency of an enterprise that allow them to directly assess the level of competitiveness of a company and a significant context of its development, especially through inter-company comparison at the horizontal level within the agricultural sector.

Option (2): To define the range of crucial factors influencing conditions for fulfilling the aims of the particular economic system and the position of an agricultural enterprise from the perspective of its "production" function in the current conditions of agribusiness, it is also necessary to examine the competitiveness of the agricultural enterprise from the perspective of the acceptability of the structure and achieved economic parameters of production on the part of the market in a broader context, especially from the perspective of real vertical participation in the appropriate foodstuff production system.

Within this approach, it is necessary to consider the fact that the relevant market is constantly expanding with the majority of agricultural commodities. The relativity of assessment and the predictability of changes in the definition of regional markets (they currently often exceed national frontiers) is also related to this issue.

\section{European agriculture and the policy of its support}

The environment of agrarian markets is changing, Europe's position at these markets is changing, and new priorities are assigned the criteria of competitiveness and demands on their provision. Agricultural producers should answer the new economic environment. The main motives for changes of traditional agriculture and its support for more active position in a process of integration in the agribusiness market place could be characterised as follows:

- globalisation of world markets that generally affect growth performance positively by allowing an expansion of markets (considerable market permits the specialisation of country in industries, that have scale economies, raising productivity; increasing the potential market size also raises the prospective returns to a successful innovation), by increasing outside competition (open market main lead to improving the allocation of resources towards more productive activities) and allows more rapid diffusion of new products, processes and research output;

- increasing value added: producers start to focus on dealing with technological innovation and product specialisation include downstream activities and attempt to form producer alliances and value-added cooperatives to capture some of the margin from further processing by increasing functionality through product features or service and by lowering cost for specific set of products and service features carrying out standards by first processors and customers that support their better position as a more demanding producer at the competitive market;

- efficiency improving and risk treatment: cost reduction by (1) more accurate use of inputs and systematic measurement on yield and profitability demanded product (i.e. structure related to demand) based upon the precision farming and soil cultivation technology utilisation at the farm level, (2) coordinating influence of the market include transaction costs restrictions through participation in vertical integration and/or the substitution of market transaction by contracts; 
- competency of people to understand new trends, expect and embrace change, identifying and defining strategy for agricultural and agribusiness firms; bring the results of quantitative and qualitative analysis to bear on concrete decisions and recommendations to capture the qualitative as well as the quantitative dimensions of the concrete problem and come up with adequate solution.

Also the concept of a balanced European model of agriculture and its implementation under the European Union for as many as 27 current member states, which differ in terms of their bases, reach as well as productivity, is ever more frequently confronted with new challenges arising from accelerated globalization processes. The different development of the scope of the agrarian sector and changes of its structure in the stage of transformation of economies of the "European Ten" in the 1990s as well as the differences in the focus of their agrarian policies including the differentiated level of support of the agrarian sector, modify in particular the allocation effect and benefits of the expanding market. In their context, they may even interfere in the production and out-of-production relations of agriculture and complicate fulfilment of the segment's multi-functional role within development of whole European regions.

\subsection{Basic characteristics}

In the current period, the situation in the EU may be documented by comparison of the share of employees in agriculture as well as the share the gross value added (GVA) of the segment in the gross domestic product (GDP) in individual member states in the following figure (2008).
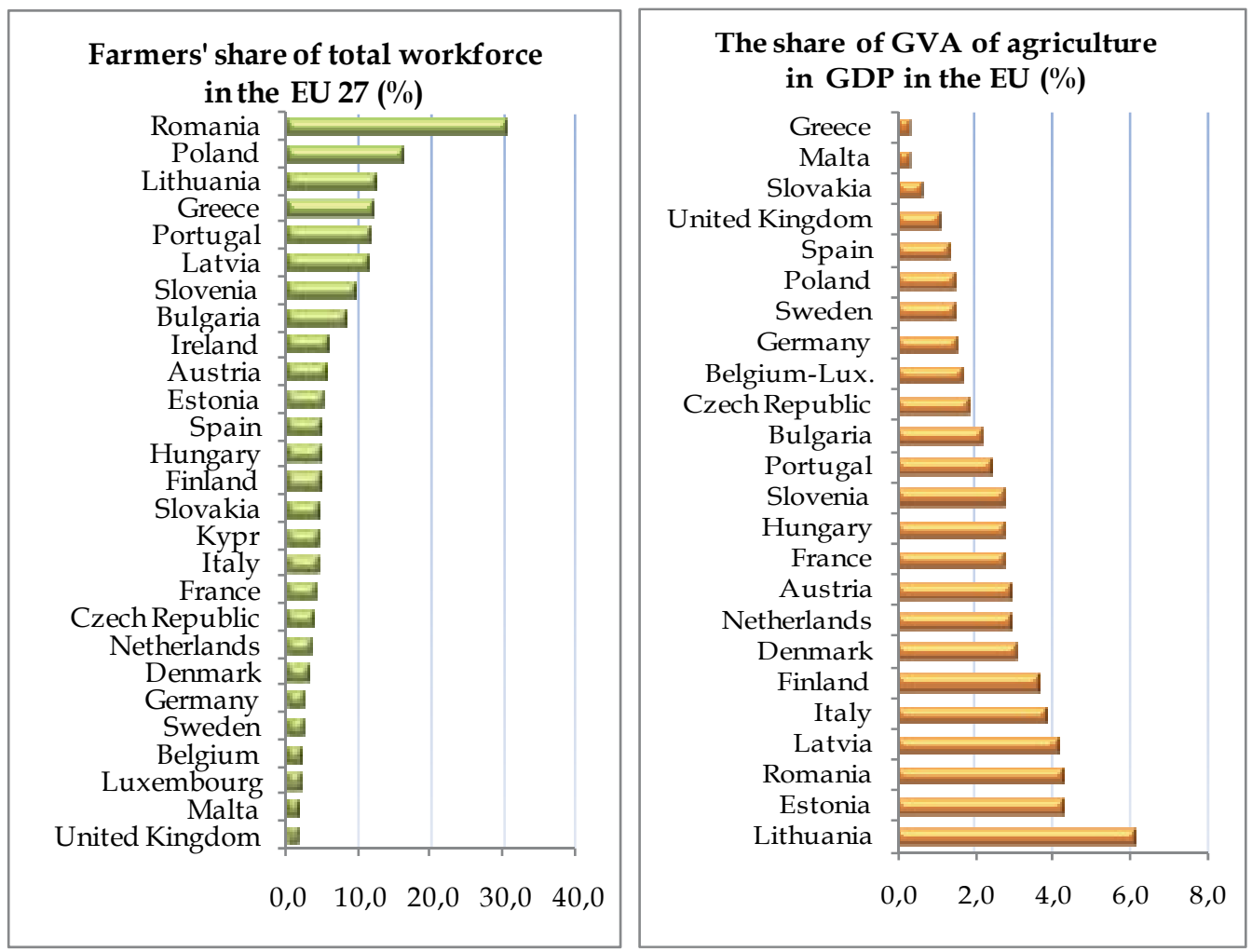

Fig. 2. Comparison of the place of agriculture in the economy of the EU member states 
The development of basic (agricultural) industry as well as the subsequent activities is the decisive preconditions of development of the territory. It is necessary for effective management of natural resources and also as a platform of economic diversification in rural areas of the EU. These represent $87 \%$ of the territory of EU-27, where more than half of its population lives, which is another serious argument for complex understanding of the task as well as the benefit of agriculture and the agrarian sector.

Hence in terms of the economic approach, the importance may not be estimated only on the basis of a direct interest in the outcome of economy. It applies to the overall relations including the benefits for employment in rural areas, namely including the developed and transition economies. The said scale of countries within both indicators confirms not only the diverse position of agriculture in the individual member states, but also its effectiveness and contribution in the differential levels of the economy. This applies to the structure, the production focus and overall conception of the policy affecting agricultural development.

It is clear that the problem is not just the said indices. It is much broader and more complex. The concerned matter is the development of scope and final production of the segment, i.e. the effects of the production aspect development as well as the effectiveness of making use of the production factors. In this context, the view is far from being unambiguous. The decrease of the relative indices in relation to the new members' agriculture sector was usually accompanied by a permanent reduction of the size of the segment.

The fact that the issue of production effectiveness and added value growth (with a suitably selected intensity and technology as a way of reducing the unit production costs) may be solved while optimally using the production factors, is proved by comparison of the level of final agricultural production and gross added value (GVA) realization per 1 hectare (ha) of agricultural land in the countries of the EU 25 in the following Figure 3 (sources: EUROSTAT, DG AGRI EC).

From the summary, in which the member states are specified in the order according to the standard of the end agricultural production (agricultural output) per 1 hectare of registered land and which at the same time also specifies the amount of gross added value, one may identify (in addition to the order) both countries with high intensity of using the land and the special structure of production and countries that are more markedly focused on animal production with a corresponding focus of the plant production structure. In terms of the overall position of the EU in the competition of global markets, the clue is the result from assessment of output of countries of the most important producers of European commodities, in particular Germany, France and Italy The relatively very good rank of the south-European countries with production different in terms of commodities focused in particular on export of fresh (tropical) fruits and vegetables is also interesting.

Application of this criterion brings along not just the issue of the Common agricultural policy (CAP) application and comparability of conditions in the old and new countries, but also of the ability of individual countries to make use of their own sources and production factors within the current development intentions. We can see that significant regional and structural differences are still hidden behind aggregated data about average economic performance of the agrarian sector of the EU and that different approach and priorities for solutions to individual issues can be chosen, provided that the issues have been identified and assessed in an objective manner. 


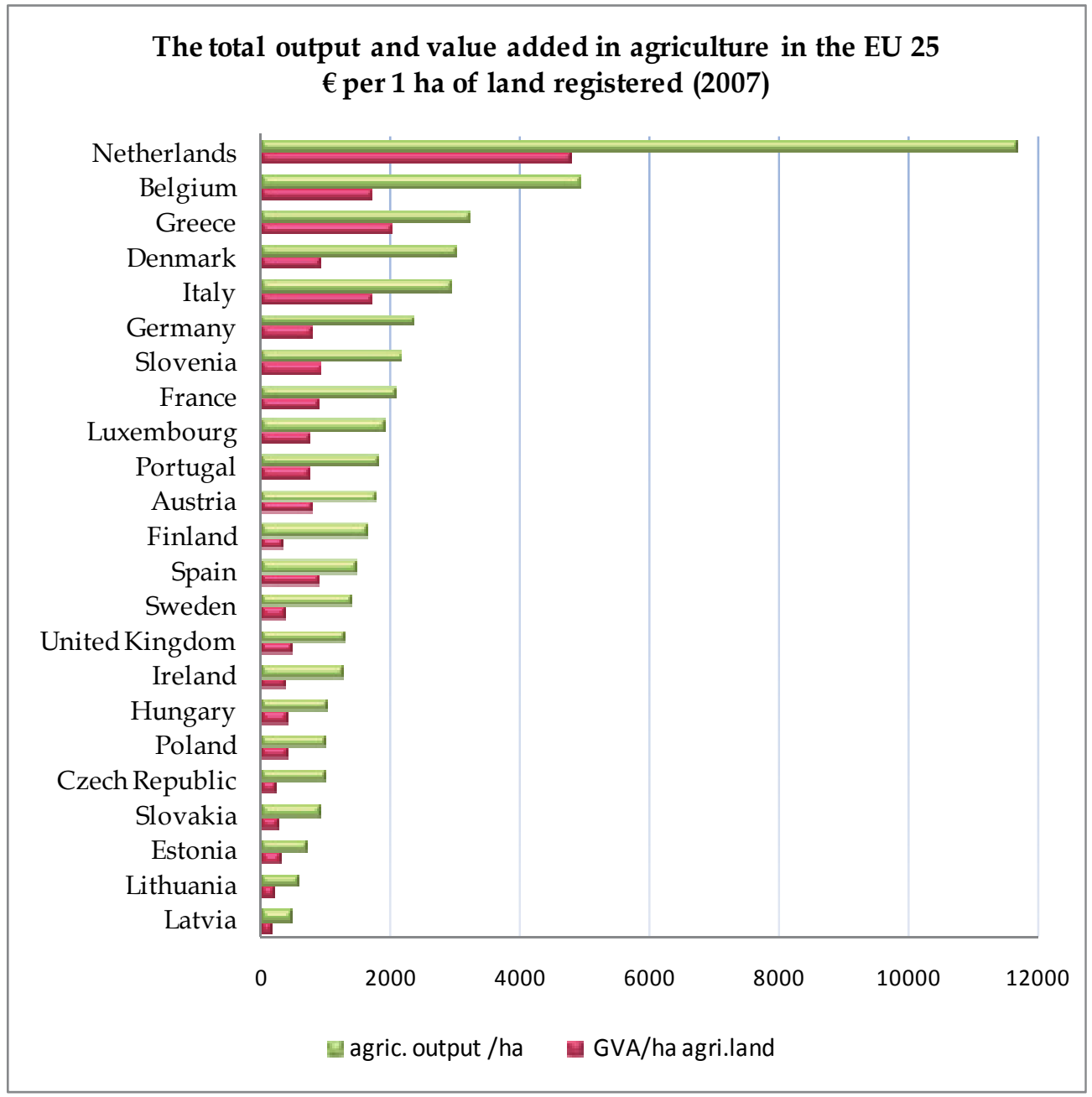

Fig. 3. Comparison of the place of agriculture in the EU member states

\subsection{Policy of support for the European Union agriculture}

Agriculture as a sector comes under those where the support/regulation policies exist for a long time. The last decades, however, has witnessed considerable changes in this sector across most developed countries in relation to their agricultural policies. The reconsideration of the role of government intervention in the sector has prompted by a number of pressures globalization of agricultural and food markets including changes in the international trade policy, regional integration initiatives, budgetary considerations, and (bio) technological changes.

On the basis of analyses of individual development stages and the manner, in which this sector has been legislatively and economically regulated, it is possible to document in the history of the EU Common Agricultural Policy (CAP) the radical development of the European agrarian sector in general in the second half of the twentieth century and how the community policy of the European Community (EC) reacted to this development. 


\subsubsection{Initial model and economic context of changes in the CAP}

The first CAP EC conception created in the course of sixties of the last century (those days adequately to the economic situation and defined objectives) were based on the principle of market prices support, common organization of the market of decisive commodities including implementation of import barriers for goods from third countries. In consideration of the fact that selection of specific economic tools is to a considerable extent connected with the level of economic development of the concerned country as under the conditions of high-level economic development, the prevailing solution is represented by forms of direct support of income while the support of market prices is typical for economies on the lower level of development, it is clear that originally, the preferred model was the one with low transaction costs. When we start from the presumption that in the concerned community policy, one applied an absolutely identical combination of tools in relation to the concerned sector in all countries, then the options of support of agricultural entities' income were derived from two groups of measures.

The particular problems of agriculture which resulted from the social structure based on family farm, the fundamental necessity to have stable supply, market instability which arose from weather conditions and the inelasticity of demand for certain products established a lot of questions in connection with the shaping of CAP at its inclusion into general European common market at the beginning of the 1950s.

In spite of some contradiction inherent in the objectives from the economic theory point of view, e.g. an increasing of agricultural earnings could come either from increased productivity, which in practice require permits the specialization of enterprises and regions, that have economies of scale and disregard of structural problems in the member countries, or from higher product prices, which disregard (the consumer interest with negative influence on commodity market functions), relatively high price level of outputs attracts more inputs into agriculture and makes new technologies more attractive and profitable and objectively have been stimulating for technical change in agriculture under the CAP.

In connection with overall evaluation of that policy the following consequences are evident:

- price certainty on the domestic market has increased agricultural production in the EU,

- because high prices foster increased input use in agriculture, endogenous technological chance has speed up,

- although there are no indications of important economies of scale in agriculture, this play a role in upstream and downstream industries; increased input use leads therefore to positive effect on productivity because of the scale effect (endogenous growth effect),

- $\quad$ structural policies for agriculture largely remained national policies within CAP; that for each country it is profitable to speed up technological change, because the price effects are often limited,

- $\quad$ in recent years a link has been made between EU expenditures on structural policy and market and price policy; this link has increased subsidies on investments and restructuring use in agriculture, which might be very productive.

In reviewing the origin and early goals of the CAP (e.g. Harvey, 1997) one of the imaginative aspects of the policy was that its designer visualized it as an integrated policy combining market and commercial policy with structural and partly social policies. In practice too much emphasis was placed on price support and market regulation. On the 
central level, it concerned in particular creation and use of the European Agricultural Guidance and Guarantee Fund (EAGGF), which was originally preferentially focused on support of the market and price policy (the guarantee section accounted approx. to $80 \%$ of the whole central expenditure) and only the remaining finances (the guidance section) were used to co-finance projects connected with support of structural agricultural changes in individual member states.

It follows from this fact that originally, in addition to the centrally-defined price support, a considerable portion of measures connected with the more considerable structural changes in agriculture including direct support of further growth of competitiveness of Europe's agriculture was dependent in particular on the standard of internal economy in the concerned member state. Hence it was the standard of the overall output from the concerned economy that determined the basis, the level and the option of income redistribution for support of sectors on such level of wealth (limit of utility options), which the concerned member state created and was able to distribute within the given CAP rules for the benefit of its agriculture.

Therefore at the times of its foundation until the sixties of the last century, the common structural policy for agriculture of states of the then European Community de facto was not a part of the initial CAP conception.

The first structural measures are related to the "Mansholt's Plan" dated 1968. From the overall radical proposal, which seriously justified the necessity of changes determining the sector competitiveness as early as at those times and pointed out the decisive role of the structural policy in relation to the future development of this sector in Europe, only partial measures were implements in the end. In 1972, one proceeded to support investments in the agriculture, early retirement and retraining and reinforcement of the orientation financing sections with support of social-economic aspects. The issue of balancing regional disparities in income of farmers farming under worse natural conditions was implemented in the CAP system in 1975 concerning the support of "less favored areas" (LFA). Since 1978, also the agricultural specifics of members states of southern Europe (Mediterranean regions) have been reflected, which has resulted into programs to support development in particular in Italy, southern France, Greece and recently also in Malta and Cyprus.

\subsubsection{Forming the first and the second pillars within the CAP reforms}

With the growing effectiveness of the EU agriculture, even the originally decisive reasons that had resulted in preferring the tools of price support in CAP ceased to exist. On the contrary, high prices and guarantees provided to farmers by means of these supports, further stimulated growth of production considerably exceeding the absorption capacities of the European agrarian market, namely under conditions of price-unfavorable ability of competitiveness on world markets. Moreover, the high protection level kept many enterprises in operation, which would have discontinued under a price regime with lover and more fluctuating (market) prices. The existing of CAP market and price policy was a type of "insurance" for agricultural producers that the technological improvements which lead to output increases do not depress too much of their income. Due to the effort to maintain relatively high prices paid to European farmers, the strenuousness of balancing the export conditions under the conditions of falling world prices was in the same time rising. Other tools with strong market deformation effects had to be applied (in particular volume 
quota, export subventions), which further increased financial demands on the policy conceived in this way.

The period of crucial reforms of the original conception of the common agricultural policy was initiated at the beginning of the nineties of the twentieth century. In 1992, the first important CAP reform (Mac Sharry's one) was adopted, which considerably reduced the support of agriculture on the basis of high market prices and which was to a considerable extent replaced with a commodity-focused compensation payment and which was focused on other directions as well as forms of income support in agriculture. In the same time, the issue of structural changes was reintroduced.

The European model of multifunctional agriculture started to be pursued much more considerably, in particular following the Austria's accession to the EU. The model respects not only the specifics of European agriculture in terms of greater demands on the methods of agricultural production in a densely populated European area but in particular its benefits in terms of production of positive externalities and public goods in the form of landscape cultural condition maintenance, its population, protection of natural resources and rural social development.

This approach was accepted also by the next reform prepared within the Berlin Convention in 1999 as a part of measures aimed at growth of effectiveness of the European Communities activity known as Agenda 2000.

Preconditions for further minimization of market deformations were created. A new CAP element was implemented, the so-called national envelopes, which allowed individual member states to support the conception of structural development by commodity selection, when national support would be provided according to national criteria up to the amount of the set limits.

The common policy of rural development, environmental protection and multi-function role of the European agriculture was adopted officially. In this context, the second CAP Pillar is created that is focused on support of structural changes and the rural development policy.

In 2003, the European Commission decided to adopt an offensive approach to negotiations about the agricultural chapter in WTO and it used its mandate granted by the Council in order to prepare the Mid-Term CAP Review. In addition to the CAP review, a motion was presented of a relatively crucial other reform steps and to reinforce the flexibility for member states when applying the future CAP.

The above-mentioned decisions in relation to the agricultural policy meant a reduction of agrarian expenditure as in 2004; EU was expanded by 10 new members while the agrarian policy costs had to be solved only within the budget stabilized in this manner. The decisive principles of the CAP reform based on the Mid-Term Review (the Fishler's reform) may be summed up by means of the following spheres:

- $\quad$ separating direct payment from the production ("decoupling") when henceforth, a farmer was to receive one support amounting to the sum of individual direct payments in the reference period, this payment being transferable, demisable and saleable,

- meeting environmental protection and foodstuff safety standards as a precondition for provision of direct payments,

- $\quad$ applying modulation, which means that by direct payments reduction, resources will be generated to reinforce rural development support, 
- implementing the tool of financial discipline that will allow, in the event of a threating overstepping of the EU agrarian expenditure limit, a lump-sum reduction of the direct payments expenditure,

- $\quad$ extending the range of rural development programs by measures aimed at reaching the standards of environmental protection, foodstuff safety and animal welfare, improved quality of agricultural products, associating of producers and partial adjustment of existing conditions of the current rural development titles,

- implementing the support of energetic crop growing,

- reducing the intervention prices of diary product and other market measures that are supposed to ensure a better position of EU during WTO negotiations,

- $\quad$ the option of simplifying the CAP administration system for member states as well as for farmers (it depends on selection of the system by the member state).

In general, it created a wider space for selection of measures supporting growth of agricultural competitiveness in individual member states in the international context. In the same time, it reinforced the support of rural development to the prejudice of market measures (growth of the second CAP pillar) and increasing safety of foodstuffs on the EU market.

In terms of the overall conception of the European agrarian policy, the next step in the changing philosophy of the basic support for agricultural businesses (which was supposed to lead to a more consequential separation of the support of agricultural business from the specific production structure and volume of secured production on the basis of uniform direct payments), proved to be a key one (Westcott \& Young, 2005). The development concerned both the very agriculture and the agrarian sector and its economic position and changes of the social environment itself and the selection of adequate regulation tools corresponding to the environmental development and changes of situation.

\subsubsection{Complex solution of agricultural and rural support}

The idea of a complex solution of further development of the agrarian sector including the necessary reinforcement of criteria of environmental and landscape protection and participation in the overall rural development became topical at the times when the EU, within WTO negotiations, became more open to business exchange and thereby to the pressure of competitive production from world markets. It meant new challenges for the further strategy of the European agriculture, to which EU reacted by restricting the support in the Pillar I and the growing importance of measures within the CAP Pillar II.

The common interest in support of agriculture in its production as well as non-production context as a vehicle of rural development became a part of the EU strategy and subsequently the Rural Development Programs (RDP) of the 27 EU member states.

It was reflected also in the EC regulation 1698/2005 on establishment of the European Agricultural Fund for Rural Development (EAFRD), which became valid as of January 2007. Strategic priorities were defined within 4 axis, for which also the minimum limits for distribution of finances were laid down.

- AXIS 1 is focused on support of competitiveness of the agriculture, agrarian and forestry sector (a minimum of $10 \%$ ).

- $\quad$ AXIS 2 is focused on creation of background for improvement of the environment and landscape (a minimum of $25 \%$ ). 
- AXIS 3 is aimed at support of quality of live in rural regions, by its approach, it oversteps agricultural issues and it is related to diversification of rural activities (a minimum of $10 \%)$.

- $\quad$ AXIS 4 - LEADER (a minimum of $5 \%$, $2.5 \%$ for new countries, a measure based on local development strategies within micro-regions)

The comparison of strategies of agricultural and rural development support may to a certain extent contribution to development of a notion of how distinct the differentiation is in today's approaches to the agrarian sector in individual EU countries within the "uniform" CAP framework. Different approaches to fulfillment of the philosophy of agricultural support as a key factor of this development are suggested by the very general international comparisons of the Rural Development Programs in individual 27 EU member states and by the conception of their reflecting into the presumed use of EAFRD finances within its individual axes in the period 2007-2013.

Within the ongoing reforms of this policy, however, there has been ever wider space opening for decision-making (but also responsibility) of individual member states when specifically fulfilling the general principles of the new CAP model.

Within the rules and limits defined in the Community level there is an opportunity to decide on the solution of specific problems in agriculture in individual countries. At the sometime these findings can be an opportunity to consider to what extent the individual member states are able to take over the existing rules and use conditions imposed by directives of the Community. To what extent are able to actively assess the situation of the world agrarian markets and adequately respond to the development of the economic environment in broader international contexts. It concerns also production effectiveness and the ability to withstand the wider competition on the common EU market also in relation to third countries.

\subsection{The European Union as a producer of agricultural commodities}

\section{Some methodical comments to the overall approach}

Analyses of the European agriculture development, its comparison with world production development as well as more detailed analyses allowing assessment of development of the production of the most important commodities that profile the group of old and new member states, which had been executed before preparation of this section of the study, offer quite extensive factual material.

On the whole, the results of analyses are arranged so that they

- allow a more complex view of the development and changes in the position of agriculture in the EU as one of the most important segments of agrarian markets under globalization in the context of world production of selected commodities,

- assessing the development of production of selected commodities within the Communities as a whole, in the group of countries of the original EU 15 and the newly acceded countries of EU 10 before and after 2004,

- $\quad$ assessing the development of production of selected commodities in the selected EU member states focused on the most important producers, drawing attention to the states with the most striking change of development.

The analyses, in which are used in particular the data of EUROSTAT, FAO and DG AGRI EK for the period 1993 - 2007 (Bečvářová et al., 2009), were focused on 8 main commodities representing more than $80 \%$ of the whole agricultural production of today's EU. 
Out of the plant production, the results of assessment of the development in production of wheat, potatoes, sugar beet and rape are evaluated.

Out of the animal production, the analyses were devoted to the development of production of cows' milk, beef, pork and chicken meat.

In consideration of the fact that with most of them, the production and their scope was more or less affected also by regulatory effects within the common organization of EU markets, market rules, the comparisons of development in time are assessed for EU 25, i.e. without the last new members, Romania and Bulgaria.

In terms of the overall as well as commodity development of the European agriculture in the world as well as common market context for the monitored period, the following can be mentioned as the most important:

\subsubsection{The European Union in comparison with other regions of the world}

The EU agriculture production growth pace is generally slower (cp. Witzke et al., 2008). The share in the world production has mainly decreased. The development is differentiated in terms of commodities, with more significant effects of the size and structure of animal production in the European countries.

As concerns plant commodities, the position of the EU remains roughly at the same with an approximately $20 \%$ share in the ever-growing world wheat production. More significant in relation to the world is production of rape, which provides more than one third of the world production of this commodity The overall increase of the world production reflects in particular the growing production in this region.

On the contrary, the European production of roots has been decreasing on the whole, which is reflected in a significant decrease of EU shares in the world production. As concerns sugar beet, a decrease was recorded from $51 \%$ to $45 \%$ of the world production, in relation to potatoes, the decrease is much more striking, from $31 \%$ to $18 \%$.

As concerns all animal commodities, the share of the EU in the world production has been decreasing too, the accompanying characteristics being the following: due to a stagnation in the volume of milk production in the EU, the position of European producers is getting worse as concerns their share in the growing volume of world milk production, which has been declining from the original $31 \%$ to today's $25 \%$.

Nevertheless, the declining production of beef is even more significant. In this connection, the share is not only reduced from the original $15 \%$ to today's less than $12 \%$, but the volume of production decreases too (from 9.5 million tons to 7.9 million tons).

No significant aspect of a growing (even though differentially in individual EU countries) production of monogastric animals was recorded.

The world production of pork growing by almost one third, the share of EU decreases (with a slight growth of production) from the original $26 \%$ to the current $18.4 \%$ of the world production.

The relatively significant increase in the production of chicken meat in the European countries (the production having doubled in the EU 10 states) was not reflected by an increase of the share either. On the contrary, in the monitored period, this commodity also experienced a decrease of the EU 25 share in the world production from the original $16 \%$ to the current $11 \%$.

\subsubsection{Development within the EU common internal market}

Developments of agricultural production in the framework of the EU common agrarian market are manifested quite differently. In general, there are differences in the development 
of agricultural production in the original and the new member states; a significant decrease was experienced by the production of EU 10, i.e. in the group of new member states, namely in relation to both animal and plant commodities, except for rape and chicken meat. Although the most significant decrease in the production of new EU 10 states was experienced as early as in the first half of the nineties and then during the pre-accession period, this decrease has generally not stopped even after joining the EU.

As concerns structure of the plant production, an important decrease seems to be the overall decrease in production of both of the most important roots (potatoes and sugar beet) in the new EU 10. In this group of countries, the production of potatoes decreased to $40 \%$ of the initial state, in Poland and the CZ even to a third of the original size of 1993. The decrease in the sugar beet production in the EU 10 meant a decrease to $70 \%$ of the initial volume; in the CR, it is even a decrease to $60 \%$ of the production of 1993.

On the contrary, the most important producers of the original member states EU 15 have generally retained their original scope of production of the said commodities and they even slightly increase the overall volume of production of wheat (France, Germany, Great Britain), sugar beet (France, Germany) as well as potatoes (France, Belgium, the Netherlands).

The actually provable growth of production in the group of EU 10 states applies only to the rape, namely as of the end of the millennium and then after accession to the EU. Within this competition, it is a positive fact that the rape production is increased also within Czech agriculture even though in relation to this commodity, an accelerated production of the neighbouring Poland has been breaking through. Nevertheless, a significant increase in the production is experienced also by the largest producers of the original EU 15 states, in particular in France, which almost tripled its volume of the original production; almost double the production volume has been registered by Germany and Great Britain in the monitored period.

The developments of the production of animal commodities are much more complicated. The volume of production has been gradually decreasing in the group of the original as well as the new members' states, i.e. in EU 15 as well as in EU 10. In particular the milk production and the beef production connected with beef-raising represent one of the most important problems not only in relation to production in terms of interconnection and making use of feeding crops of the plant production but also in terms of benefits of positive external agricultural effects in relation to making use of permanent grassland and meeting the multi-functional role in the development of rural areas.

Also in this case, the more significant decrease in milk production is evident in the EU 10 states and this decrease did not stop even after 2004. In comparison with other countries of the European 10, the production decrease in the Czech Republic was the most striking just in relation to this commodity. Although the specific problem of the CR in relation to milk production decrease dates back to the 1990s, upon two significant reductions of production $(1994,1997)$ in reaction to the reduced demand upon simultaneous opening of the market with milk and dairy products with a negative effect on numbers of the livestock, this is not a typical course of action in other countries, for example like Poland the support for beef-breeding stabilization was generally not reflected in a decreased production. The other most important European producers like France, Germany and the Netherlands also manage to keep approximately the same standard in the volume of production for the whole period. 
A similar development in the structure of the member states applies also to the beef production. Also in this case, the most important position is occupied by France, followed by Germany. Nevertheless, an important position in beef-raising is occupied by other countries like Italy, Spain and both countries of the British Isles - Great Britain and Ireland.

On the other hand, the development of production with the most important pork producers proves its permanent growth, namely both in Germany and in particular in Spain, which together with Poland has a significant share in the worldwide agribusiness networks of this commodity. However, the development in the $\mathrm{CZ}$ is the opposite. From the point of view of the Czech Republic, it is another one of the commodities that have experienced a decrease in the order of magnitude to almost a half of the initial production volume in the monitored period. Also in this case, a serious problem is posed in particular by the development since 2004.

A more significant acceleration of production in the EU 10 states is experienced by chicken meat. Just like with pork, however, the world production is much more affected by nonEuropean producers and firms of global agribusiness networks. According to the volume of chicken meat production in individual members' states of the EU in 2007, the most important position is retained by Great Britain, followed by Spain, Poland and France. Having performed a more detailed analysis of the development, however, one has to point out also the changes in the last period, for example significantly bigger growth of the chicken meat production for example in Poland and Germany in comparison to the stagnation of this production in the CR after its accession to the common market.

\subsubsection{The price environment on the EU common market}

Although the differences in production developments among member states of the EU were specified, it is undisputed that the dynamics of the concrete country agricultural sector development are influenced by a wide range of reasons, from the availability of technical factors shaping economic level of agriculture and then bringing the comparative advantages of both the level and productivity of labour and material inputs, the productivity of natural resources in biological and technical quality of products, to improving the position of foreign trade in agricultural and food commodities, two basic and common factors determining development of contemporary agriculture were specified.

1. change in the nature of a competitive environment where increasingly promoting the processes of globalization, which is reflected in the formation of markets and agribusiness development in the pricing environment, thereby also changing not only the position of producers in commodity verticals, but also the criteria of horizontal competition in the context of global markets just at the level of primary production,

2. the impact of common and national policies in shaping the parameters of local economic environment of agriculture creating the conditions of production and manufacturers' competitiveness; in the case of the EU CAP and its reforms - including addressing the consequences of modifications of the original model and to implement the different institutional conditions for the old and new Member States, restraining conditions for horizontal competition in the context of common EU agrarian markets at the level of primary production,

As shown by studies, both of the above range of factors closely relates, but their consequences can interact asynchronously. 
The different levels of agricultural commodity prices, formerly relative to relevant national markets, now pertaining to the regional markets of "unified" common market of the EU, are influenced by both of the above factors.

A difference in prices of agricultural products undoubtedly contributes to the different levels of production sources for the agricultural sector, therefore, the authors approached to examine price trends of agricultural producers as one of the possible effects of differential changes in the amount of new EU member states agriculture.

The change of strategy, meaning a retreat from the CAP price support as the original concept of Pillar I, and the gradual transfer of funds and direct payments to Pillar 2, which responds to environmental changes and demands control interventions in a globalizing market, in effect, enhances the role of prices. It starts to play an active role in the growing European market competition itself not only in the role of the social scale / exchange-value of agricultural products, but then contrariwise, as a solution in the future strategic arrangements dealing with the structural dimension of agriculture in (old and new) member states.

In general, results of the price development analysis within the EU common market and an evaluation of the findings from the development of production - economic context lead in these findings and conclusions:

1. price environment in terms of agriculture the EU is coming together, which is an undeniable manifestation of the formation of a wider European agricultural market;

- to form a single market and price comparable conditions during the whole period (without any significant deformation) occurred mainly in commodities that are not subject to direct regulation or other interference in the CAP (poultry - poultry meat, pigs - pork, rape),

- a negative impact on the formation of the European market, by contrast, historically shaped by the consequences of compensation payments for previously supported commodity prices (cereals, beef, milk) since the nineties of the twentieth century in the old member states, allowing to accept a lower level of producer prices and strengthen the competitive position of these producers even today,

2. generally is converging with the price levels of agricultural producers in the original and new Member States of the EU

- typical expression was more pronounced increase in the price levels of commodities in the new member countries, at all, even the much-produced by phased, crop commodities (particularly sugar beet, but also potatoes) and livestock (especially cow's milk), to this process and contribute significantly to the ongoing reform of the original CAP since 1992, of reducing the CPV agricultural products (instruments of direct control of the price support and stabilization),

3. growth and decline in price levels in both groups of member countries during the period significantly longer responds to the development of the world market, the commodities of plant and animal origin (world grain stocks, guidance and support for non-food uses, the situation on world commodity exchanges),

4. the influence of the demand-side downstream markets, position and size of production, but also the price of the commodity is increasingly derived from the competitive strategies of commodity verticals and networks (different manifestations in the individual member countries, an example of root crops, milk, pigs, poultry) 
- highlights the importance of guaranteeing the processors at a lower producer prices of domestic raw materials and greater use of products in successive stages of finalization of the commodity chain, to enhance the competitive position in the market (decisive cost producers of sugar beet and potatoes),

- downward pressure on prices of basic raw materials results in links advanced technological equipment and optimize the processor as a prerequisite for the price competitiveness of producers in the emerging markets of a more finalized product profile,

- quality is becoming a priority, innovation, precision manufacturing systems and technology to increase the intensity of production materials in compliance with qualitative parameters and thereby optimize the unit cost of production, which appears as a major trend in policy decision-making producers (especially Germany, Denmark, Netherlands, Spain).

\section{Conclusions}

A change in the CAP strategy, gradually implemented by means of steps of individual reforms as early as since the nineties of the twentieth century up to the solutions generally meant a withdrawal from the agriculture support on the basis of supporting prices of agricultural commodities as well as reactions to acceleration of globalization processes radically changing also the position of farmers.

The development has confirmed that in a whole range of connected markets, demand has been really establishing itself. It reacts to the development of world stock; it determines the conditions of offer on markets of most agrarian commodities much more flexibly than the agrarian policy measures ever can.

This in the same time changes the essence and further reinforces the risk of producers facing the market strength of purchasers under conditions of imperfect transfer of demand conditions in the market sequence from the consumer to the basic industry. These days, the transformation of demand for products with agricultural nature and in particular the possibility and the ability of its structural fulfilment in general define the space for producers of agricultural raw materials and in its effects also the economic dimension of agricultural production in the concerned region.

Nevertheless, this change requires also a new approach to the regulating interventions and supporting measures in the agrarian sector. Another dimension in the multi-function approach to its role was gained by the European agriculture in connection with emphasizing its role within the rural development. In the same time, there is a space opening for a wider participation of member countries in creation of agriculture support conceptions according to the specifics and priorities of the individual member states.

A change of the overall strategy and selection of CAP tools is typical by the growth of the share of transfers/subsidies requiring income distribution. Nevertheless, this generally increases the dependence of farmer and rural support on expenditure of tax payers. In the current stage, this applies in particular to allocation of support and use of the gradually balancing direct "decoupled" payments in compensation of lower income of the sector within the whole EU 27.

The difference within the level of direct payments in agriculture of new member states, provided that they equal the original EU 15 only in 2013, is one of the problems directly 
concerning the comparability of conditions and possibilities of development of the new members' agriculture as a modern sector capable of competition within the common market. The growth of commodity price levels was stronger in the new member countries, at all, even significantly limited by-produced, commodity.

Price developments in the two groups of countries have significantly responds to developments in the world market, the impact of the demand side of markets has increased; position and size of production, but also the price of the commodity are increasingly deducted from the competitive strategies of commodity verticals and networks. The risk connected with the realistic option of creating preconditions of producer competitiveness on the common market is increasing, namely in horizontal as well as vertical relations of a modern sector. Concentration and mainly the monopsonous, respectively oligopsonous position of food-processing firms, retailers and the catering industry in the market boosts their dominant positions in the selective process for suppliers, including the bargaining position for primary material suppliers and (often acting against the agriculture policy concept) begins to appear as a crucial factor, when deciding about the structure and range of agricultural production in a particular region. The food sector of the EU has recently been evaluated as one of those where significantly speedy concentration as well as structural changes is going on, both in the processing stages and food trade. This sort of business activity sharply contrasts with the frequently traditional behaviour of agricultural producers and their efforts to stick to a protected and relatively unchanging market. On the other hand, the pre-production stages and access to discoveries of science and research increasingly determine the chances of meeting quality and price requirements for agricultural products. This problem becomes serious in particular under the conditions of the emerging financial crisis accompanies with a pressure of connected processing and trading elements on further reduction of food consumer prices.

At the same time, however, it is necessary to take into consideration that other manifestations are connected with this process, in particular:

- decrease of effectiveness of regulating interventions and policies designed on the principles of market protection and isolation of specific market segments in individual segments or sectors,

- growing market force of decisive entities on the world market, in the concerned sector in particular the finalizing stages of agribusiness, types of supranational organizations and networks making use of various forms of connection determining the structure and development of the global markets.

Just when applying the current model, in consideration of the selected tools (subsidies with a relatively high proportion of transaction costs), it is necessary to objectively consider the level, the effectiveness and the benefits of such allocated resources in general as well as in terms of the possibility of developing business entities in typically productive regions of the state territory.

The effectiveness of subsidy allocation mainly depending on income redistribution at the level of member states as well as the Community, namely both as concerns direct payments and on the basis of selection of individual axis priorities, is conditioned by a systemconnected agrarian and structural policy. In countries of the original EU 15, it has its history, experiences as well as strategy of support and regulation reflecting the current as well as the 
future trends of the sector development in the global world. It has proved the positives and risks of steps taken to support specific regions. New member states are only acquiring such experiences.

Therefore the ability to meet the philosophy of complexity and mutual dependence of agricultural and rural development measures, which is systematically interconnected with the choice of priorities, seems to be strategically crucial also for the success of the next stages of reforms steps within the common European policy and its implementation under specific conditions of individual member states.

A certain level of independence in decision-making of individual member states in the current state should therefore make use of the current (and no doubt also time-limited) means in particular in order to create preconditions for development of modern production meeting the requirements of healthy foodstuff production while meeting parameters of natural resources protection so that in its complex effect, it contributes to the development of modern agriculture as one of the decisive vehicles of rural regions development and limits the dependency of the sector as well as the rural regions on subsidies in rather a longterm horizon.

The evaluation of price environment, and comparison of price levels development for each commodity in selected member countries, leads to the conclusion that the price environment in terms of broader EU agriculture market consolidates; there is a convergence level of agricultural producer prices in the old and new Member States.

The issue of causal connections related to the development of European agriculture, in particular in terms of development of the old and new member states is nevertheless more complex than the analysis of the current development in the production and price context of the size of agriculture.

To a substantial extent, it is connected with the problem of strategy and compliance with general rules of the CAP including the formation and fulfilment of the segment development concepts in individual EU member states. In this context, agriculture is understood as a decisive factor of environmental formation, shaping the landscape in rural areas as well as the provider of public domains.

The policy of rural area development support became a part of the CAP strategy also for the period until and after 2013 as in addition to the permanent objective of growing competitiveness of the agrarian sector and innovation support. It involves in particular the protection of nature and the landscape, by means of supporting the care for the landscape (including the common financing of rural area development measures), increased living standard in rural areas and support of economic diversification by means of measures focused on the agrarian sector and other concerned entities in rural areas.

The development of basic industry as well as the subsequent activities is hence one of the decisive preconditions of developing and making use of the territory. It is necessary for effective management of natural resources and also as a platform of economic diversification in rural areas of the EU.

Growing importance and a new dimension in the global context is experienced also by the factor of food certainty. In the context of the current model, it is becoming one of the key factors of national safety, in terms of securing access to a sufficient volume of food of necessary quality and nutritional value as well as in terms of the growing risk of national and international crises. 


\section{Acknowledgment}

The study was prepared within the research plan of the MENDELU MSM 6215648904 Czech Economy in Integration and Globalization Processes and Development of the Agricultural Sector and Services Sector under the New Conditions of the Integrated European Market, as a part of solving the Topical Specialization 04 "Development Trends in Agribusiness, Formation of Segmented Markets within Commodity Chains and Food Networks in the Process of Integration and Globalization and Change of Agricultural Policy".

\section{References}

Ahn, S. (2002). Competition, innovation and productivity growth: A Review of Theory and Evidence, OECD ED Working Papers No 317

Anderson, K., Swinnen, J. (2008). Distortions to agricultural incentives in Eastern Europe and Central Asia, World Bank, ISBN 978-0-8213-7420-7, Washington D.C.

Bečvářová, V., Vinohradský, K., Zdráhal, I (2009). Czech agriculture and the development of price environment in the EU common market Folia Universitatis agriculturae et silviculturae Mendelianae Brunensis II/11 ISBN 978-80-7375-368-9, 101 pp.

Boehlje, M. D. Hofing, , S. L. Schroeder R. C. (1999). Farming in the 21st century. Staff Paper No. 99-9, Department of Agricultural Economics, Purdue University, USA

Boehlje, M.D., Akridge, J.T., Kalaitzandonakes, N.G. (2002). Preparing for Success in the Agribusiness Marketplace. Journal of Agribusiness, 20 (1)

Connor, J.M. (2003): The Changing Structure of Global Food Markets: Dimensions, Effects in Policy Implication. In Changing Dimension of the Food Economy, The Hague

Davis, J.H., Goldberg, R.A. (1994). A Concept of Agribusiness. University of Arkansas, Montana State University, 6th edition

Goldberg, R.A (1998). Why the International Agribusiness Management? In Global Agribusiness for the future, Boston, IAMA

Harvey, D. R (1997). Extensions and Political analysis of the Common Agricultural Policy, CAB International, mimeofeaph, $23 \mathrm{pp}$.

Kinsey, J. (2003). Emerging Trends in the New Economy: Consumer, Firms and Science. In Changing Dimension of the Food Economy, 9 pp, The Hague,

Sonka, S, T., Hudson, M.A. (1999) Why Agribusiness Anyway? Agribusiness, An International Journal. pp. 305-314

Swinnen, J., Rozelle, S., Xiang, T., Vandemoortele, T. (2008). A Theory of Standards-Driven Rural Development, LICOS Discussion Papers K. U. Leuven

Westcott, P. C., Young, C. E. (2005). Influence of Decoupled Farm Programs on Agricultural Production, Working Paper USDA ERS, $17 \mathrm{pp}$.

Witzke, H., Noleppa, S., Schwarz, G (2008). Global agricultural market trends and their impacts on European Union agriculture. HU, Berlin WP Nr. 84

\subsection{Internet sources}

Czech Statistical Office [online] on <http://www.czso.cz/>

European Commision DG-AGRI [online] on <http://ec.europa.eu/agriculture/ 
Eurostat [online]: on internet http:/ / epp.eurostat.ec.europa.eu/portal/

Food and agriculture organization of the United Nations (FAO) [online]: on <http://www.fao.org/corp/statistics/en/ 


\title{
Future of Heritage - A Condition for Space Integrity
}

\author{
Lemja Chabbouh Akšamija \\ University in Sarajevo, Faculty of Architecture, Sarajevo, \\ Bosnia and Herzegovina
}

\section{Introduction}

"My ideal, however is not to erase national characteristics in the manner leading towards intellectually uniform humanity. To the contrary, long live the variety of all forms and colors on our dear planet Earth. Beautiful is the existence of many races and peoples, multitude of languages, different mentalities and worldviews. If I feel the hostility and irreconcilable intolerance towards wars, conquering and annexations, it is caused by many reasons but mostly because of the fact that many organic, highly individual and sumptuous achievements of human civilization had been victim of those dark forces. I'm the opponent of "grands simplificateurs" and a fan of quality, original skill and uniqueness". Herman Hesse, a part of his address while being awarded the Nobel Prize for Literature in $1946 .{ }^{1}$

Globalization, traditional values, rural architectural heritage, active protection of rural architectural heritage, integral active space protection, cultural landscape, cultural tourism, typology of rural architecture, methodology for identification and preservation of architectural heritage, identification and preservation of authenticity of rural architectural heritage, cultural landscape, ethno villages, methodology of the protection of integral rural spaces.

Researches, which tackle or deeply intrude into tradition and the traditional within architectural heritage, only under superficial assessment, may create conflict with globalization in the widest sense. The changes of the general picture of the world happening on the architectural plan, which will certainly stop to manifest in such intensity in the times to come, are, on one side, the result of "exhibitionism" to which the investors are ready, and the result of the economic momentum that is actually passing by which marked its existence with unique facilities of universal characteristics, with no stylish and traditional characteristics, with extraordinary technological performances.

\footnotetext{
1 "Doch ist mein Ideal keineswegs eine Verwischung der nationalen Charaktere zugunsten einer geistig uniformierten Gesamtmenschheit. O nein, es lebe die Mannigfaltigkeit, die Differenzierung und Stufung auf unserer lieben Erde! Herrlich ist es, dass es viele Rassen und Völker gibt, viele Sprachen, viele Spielarten der Mentalität und Weltanschaungen. Wenn ich ein Hasser und unversöhnlicher Gegner der Kriege, der Eroberungen und Annexionen bin, so bin ich es unter andrem auch aus dem Grunde, weil diesen finstern Mächten so viel an geschichtlich Gewordenem, hoch Individualisiertem, reich Differenziertem an menschlicher Kultur zum Opfer fällt. Ich bin ein Feind der "grands simplificateurs" und ein Liebhaber der Qualität, des Durchgeformten, Unnachahmlichen." Worte zum Bankett anlässlich der Nobel-Feier (1946), (1987). Gesammelte Schriften, Bd. 7, Betrachtungen/Briefe/ Rundbriefe/Tagebuchblätter, pp. (454), Suhrkamp Verlag, Frankfurt am Main.
} 

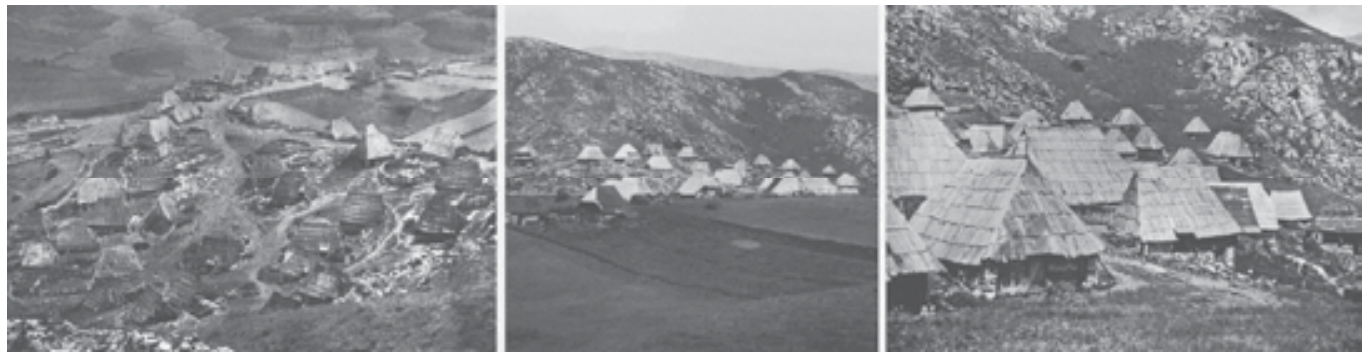

Fig. 1. Traditional Bjelasnica villages ${ }^{2}$

Speaking about global transformations that are omnipresent in physical, but also in spiritual sense, it is absolutely not to neglect the speed they have been happening. It is about every day, big changes being the consequence of the flow of information speed, thus, isn't it logical that, just through technological achievements that will be manifested rightly in architecture, this huge combining wave becomes the most visible and the most dramatic.

The expression of superiority towards invisible, adhesion, static forces has always been a symbol of strength and knowledge. Hasn't it been even in middle ages that secret brotherhoods had been established by those knowing the secrets of masonry and through them, the secrets of human existence? Respect of wisdom and preservation of accepted knowledge were given only to the privileged. It seems that nothing has been changed ever. The powers of those who knew to direct a vertical from the ground to the sky and who were able to maintain this vertical in static stability with no regards to the nature influences, were extremely appreciated. Thus, we may not resent the very process of rapid exchange of information, technological development having the goal of supporting human welfare and to technology which is progressing by itself because of the world capital which is directed to its development, for negative consequences of global development. We will easily state that globalization has the most negative influence to identity.

Today, there is no a priori respectable relation towards knowledge, probably because of the fact that levels of knowledge are reduced to the levels of information and the access to data basis.

Speaking about the globalization from the aspect of architecture, we are facing with very difficult task of estimating and clear expressing the fact whether it is about good or bad position of the architecture in global trends. Hadn't it been existing in the Roman Empire the global approach to architecture on the whole territory of big empire, but the goal was certainly clear, and in such manner the identification code of unique state was created Rome. Even later, when the universal style -modern was treated as the common attitude towards the architecture, there again, the message existed wanting to express modern and technological values present in twenties and thirties years of the past century.

What is especially warring in this historic moment is the fact that no matter to the information flow, technological values and all advantages of the communication systems, planetary idea, common denominator and global attitude are not recognized any more. Grandiose works became purpose in themselves. Ambience in which they are created is inferior in relation to contemporary interventions; there is no dialogue between the new and the traditional. Urban codes are no any more expressed in the space. Impressive Calatrava

2 Chabbouh-Akšamija, L. (2009). The Authenticity of the Rural Architecture as a Prerequisite for Active Protection; The Pilot Project Bjelašnica Village Ledići, Sarajevo. 
Bridge in Venice is the intervention which is evidently valuable and sensible towards the city but it imposes a simple question:"... is there enough space in Venice for two or more such bridges"? In the city in which the bridges and houses live unique story and create inseparable structure? It is strange that towards architectural value it behaves conceptual, that after the fact that the "form follows fiction" 3 where the ambience value is not relevant, it comes the moment when the mutual relation between facilities and ambience enter into conflict and compete between them. Accepting globalization as the result of time in which we live and analyzing correlation relation of facilities and their consumers in which sociological aspect dominates over esthetic one, in which the state of conflict is accepted as the expression of contemporary man spirit, the ethic component is neglected. It would contribute to harmonization between ambience and new projected part.

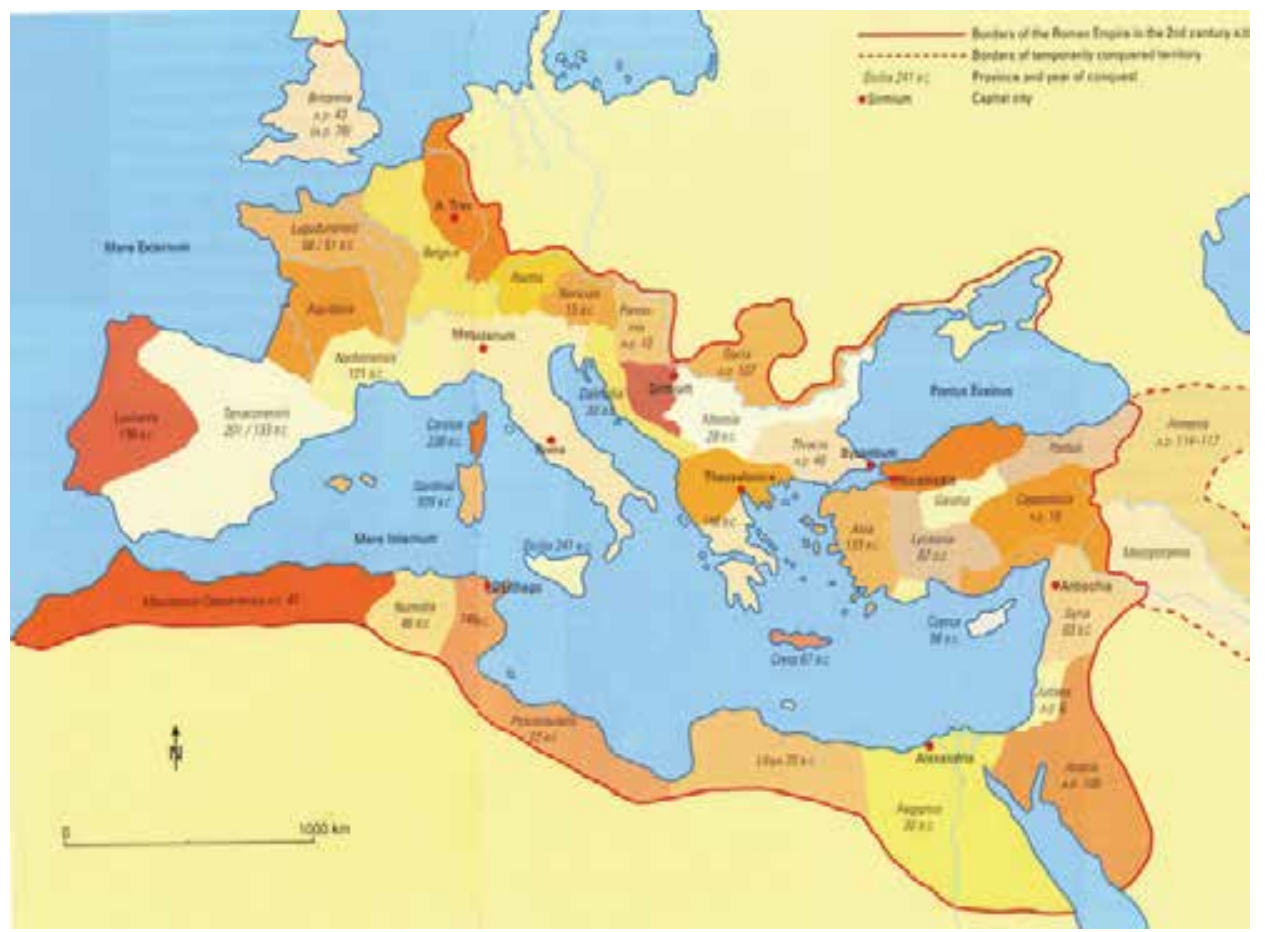

Fig. 2. Boarders of the Roman empire in 2nd century A.D.

There is no field in human life that so directly influences the performance of living functions and flows such as architecture. I would say that it deals with the designing creation of the life wrapping material. Such hypothesis will logically bring us to the conclusion that the care on wrapping is reduced to appealing design, treating trends and being under big influence of fashion which is, observed from the aspect of visual culture, a global appearance.

It is not that I try to find the justification for the condition we are in, but it seems to me that the situation is not thus warring and that it is the period having its natural flow which is just passing by.

${ }^{3}$ Tschumi, B. (1976-1981). Manhattan Transcripts - collection of drawings and collages. 
I think that this phase may be treated as the phase of fascination and absolute impression by technology, and the respond to it is in absolute pacification and return to tradition. If we try objectively to valorize the actual condition on the global level in traditional manner and with determined criterions, we will enter into the trap that could be foreseen. Thus, we will valorize architecture as the piece of art. Is there, in such case, any possibility to objectively valorize a piece of art? Naturally, there is no possibility and naturally, the emotional deflection being unquestioned is the goal of the creator. The only things in which we may thoroughly follow the valorization are the parameters that are placed in accordance to definition of sustainability. It often seems to me that sustainability in phenomenology sense is placed so well in order to be the alibi for numerous failures that contemporary architecture in global surrounding represents today. Of course, it is about the economic theory entering into frameworks of sustainability sociologic, economic and ecologic aspects not treating those parameters which should be the most important for a valuable creation. It is not spoken about form, its measure, volume, proportion, materialization and details, neither about the function and traditional values.

I will conclude that globalization has extremely positive influences to architecture but universal, as the expression of uneducated and superficial approach, is the most perishable for it.

Given the acceptance that architectural interventions may be classified in relation to ambience to harmonized, contrasted and anarchic, it would not be difficult to conclude that the harmonized ones are rarer and rarer and that arrogance and superficiality in approach the most often, the trial of contrast turns into anarchy.

The process of globalization as the general and terrifying rapid process contains some other processes which by awkward interpretation in our surrounding reduce development as the positive category to destruction of tradition. Often, trials of stopping destruction of ambience and traditional values produce the reaction as it is a trial of stopping life. My modest judgment on globalization in general will stop on the statement that we, as the humanity, are caught by unexpectedly rapid flow of information, that we are not ready and without the attitude about the entity and integrity of space for which formation we need much more time than the speed of the information flow offers.

I will return to sustainability in which wing numerous negative manifestations of technological superiority find shelter. Analyzing social aspect, we won't be wrong if we focus to traditional values. Such angle will significantly change the aspect of ecology which will become inseparable part in treating the space. It is direct reflection of the ethic attitude of contemporary architect towards universal values of cultural and natural landscape.

It seems that we are in crucial period of the economic crises which will again result with global transformations in architecture.

The time of the architects "stars" has just passed by because there are no investors being ready to finance their spectacular ideas, and as the human needs to satisfy the existence issues with no matter to crisis may not be stopped, the time of the architecture for a human is coming again. In such case, respecting the continuity in deliberation and shaping of space, we have to turn beck to the origin and remind ourselves to solutions offered long before through the forms created inside individual civilization circles. In previous period, people got used to think globally and to search for universal answers to very specific and closely problematic issues, so we may expect global attitudes further more but this time based upon tradition and identity of local solutions. In this respect, my thesis that protection of architectural heritage is not only for the purpose of reminding to traditional values but also 
to serve as the inspiration for contemporary architecture and it may only have the sense if people at all do care about their own identity. Contrary to the universal in architecture there are identity, integrity, continuity and context. These four parameters define uniqueness and traditional values of ambience and each individual facility within it. It gives a possibility to the smallest local culture to express its characteristics.

In trying to find solutions for the unspoken questions, I stopped to traditional rural architecture of the mountainous areas, recognizing in it multi layer universality, with no matter to visible traditional values, on which, in any case, we have to insist. As we live in times of compromises in ideas and conflicts in realization, bringing such architecture into the context of contemporary urbanism, we may not reaffirm its values a priori. Still, if we stick to defining continuity in architecture, and make general bio-climate approach of traditional builders reversible through individual elements, then we will reveal, in this traditional architecture, completely new values. With risk to be subject to Romanism, and absolutely conscious of the fact that the greatest price to globalization was paid by small nations who didn't have neither strength nor money to fight against it in their efforts to preserve identity, today, perhaps, they have the greatest chance to find themselves in reaffirming their tradition through cheap and already tested architecture.

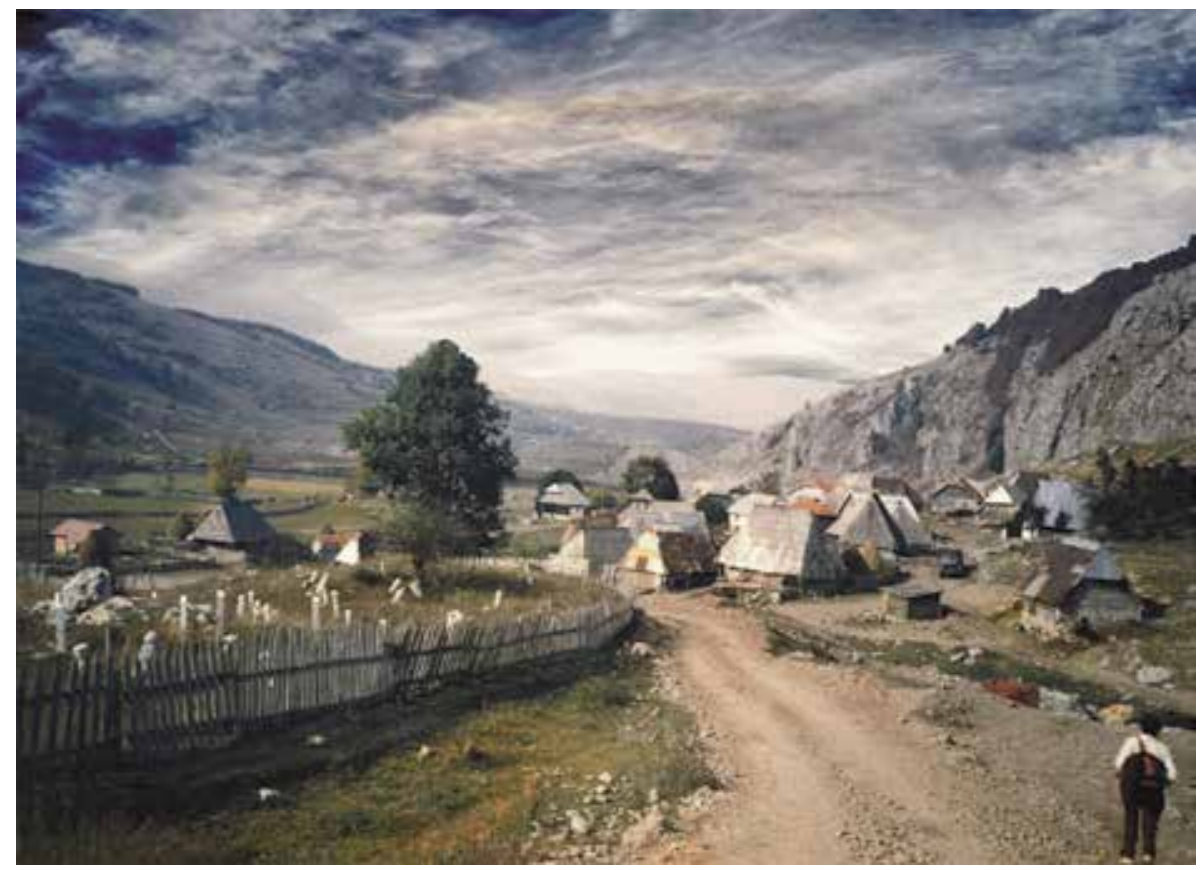

Fig. 3. Traditional Bjelasnica village ${ }^{4}$

\subsection{Background and goals}

However logical is the sequence of quoted facts on crisis, reaffirmation of traditional values and final resurrection of the space identity, it is hard to believe that the things may go this

${ }^{4}$ Chabbouh-Akšamija, L. (2009). The Authenticity of the Rural Architecture as a Prerequisite for Active Protection; The Pilot Project Bjelašnica Village Ledići, Sarajevo. 
way. Namely, to recognize traditional values in architecture, to undertake research of archetype form and to define the line of originality, in order to come to modern solutions that will stay in spirit of tradition, represent probably the greatest skill and privilege of the most sensible creators. Understanding the sense of invention has been always a part of my life attitude. For ones, its meaning is: to reveal something completely new, not seen before, while for the others, it is the revelation of the old and perhaps forgotten, but valuable.

It comes, from all perceived facts, that the protection of rural heritage value imposes itself as cultural, economic and social task of the first priority which should be one of the basic sociological, expert and scientific contents of action. Naturally, one should not stop to provision of material conditions for the protection of those values, but their survival in greatest measure should be connected to correct use with needed bigger engagement of all interested factors. The principle of such an approach to heritage is defined as an active protection, which, as the first element of procedure, points out the protection, but as the basic mean of directed projection insists on regular utilization of heritage.

Special interest should be directed towards rural ensembles, because it is about the spaces along which protection of architectural value of heritage, we protect also the ambience values of the landscape, meaning the natural heritage. In the time of the actual global warming and the lack of drinking and clean water, these elements get big importance in ecological sense. Whenever speaking about rural architectural heritage, we are facing with symbiotic juncture of the human and natural actions. Monuments unities should be a subject of special care in order to preserve their integrity, assure their recovery and arrangement, and through adaptation, to point out their values and adapt them to modern needs. Conservatory and restoration works on them should be performed in accordance to principles quoted in previous parts of the work. A term integral protection offers extraordinary advantages when talking about protection and the use of wider space in which the protection of ambience values is not under question and in those spaces where individual value of facilities is lower, so, by the concept of integral protection we give the importance to the whole agglomerations which value is exactly in the characteristics of unity. ${ }^{5}$

Finally, through all this analysis, we come to the question of authenticity which procedure of determination and the method of protection we try to identify by this work.

By putting numerous questions in trying to define "the right" and correct approach to heritage in contemporary life, we may not always come to solution. Responding to this question, we will try to develop the spirit of what was the content of the question. We may, with fear before the task, say that each of these questions is historical, fateful. It is historical, because it names the important in architecture, it names when and how the architecture may save and protect itself from the touch of the modern, sophistic mind having the reasonable explanation for all.

Cognition that the key task of the work is to question the essence from what has been questioned, explains that by questioning we will come to the source of what we want to think. Thus, it is about walkthrough into foundation, into pre-form, into the paradigm of the topic, being in this case the authenticity of the space in general.

The goal is certainly to turn back to originality and authenticity in the measure that such procedure will not disturb modern needs, but will use all forgotten knowledge that is

\footnotetext{
${ }^{5}$ This attitude stems from the European Charter of Architectural Heritage, adopted by the Committee of Ministers of the Council of Europe on 26.9.1975., and Resolution (76) 28, on 14.4. 1976., concerning the adaptation of laws and regulations to the requirements of integrated conservation of architectural heritage.
} 
repressed by the arrogant modern man relying on technology and contemporary achievements in the extent in which the connection with seminal creator of time and space, nature, is broken. In this respect, bio-climate experiences overtaken from ancestors, the feeling of harmony between the natural and the constructed landscape and the use of traditional materials may greatly improve the quality of life today.

With focus to only one sequence of heritage, no matter how minor it is in general and overall world heritage, I will offer solutions that may significantly contribute to the general attitude that vernacularism and bio-climate of traditional facility along with ambience harmony, represent permanent value of constructed space. Sustainability and ecological awareness are the factors that lift to the higher level the quality of traditional facilities. Harmony that exists in such unison with natural surrounding is the greatest value that the constructor and the creator of space may expect. In aesthetic sense, harmony and unison with nature, adjustment of volume, materialization and proportions are the elements we estimate as highly valuable but from the point of view of the user such facilities are primarily functional, according to human measure, unpretentious and thus pretty.

\subsection{Methods of research}

The work applied original methods for the research and determination of authenticity having the goal to point out the importance of consciousness in relation to authenticity and originality of architectural forms in certain space in order to prevent the creation of false pictures on traditional values, and, in the same time, to provide clear cognition of those traditional values whose detection enables the placement of the framework for new projects and contemporary interpretation in accordance to the original ambience. During the process of research and documentation the method De Angelis d Ossat was used. Using quoted De Angelis method, specific methodological procedure was made in five phases, each one adjusted to specific needs of rural unities, devastated stone facilities and natural values.

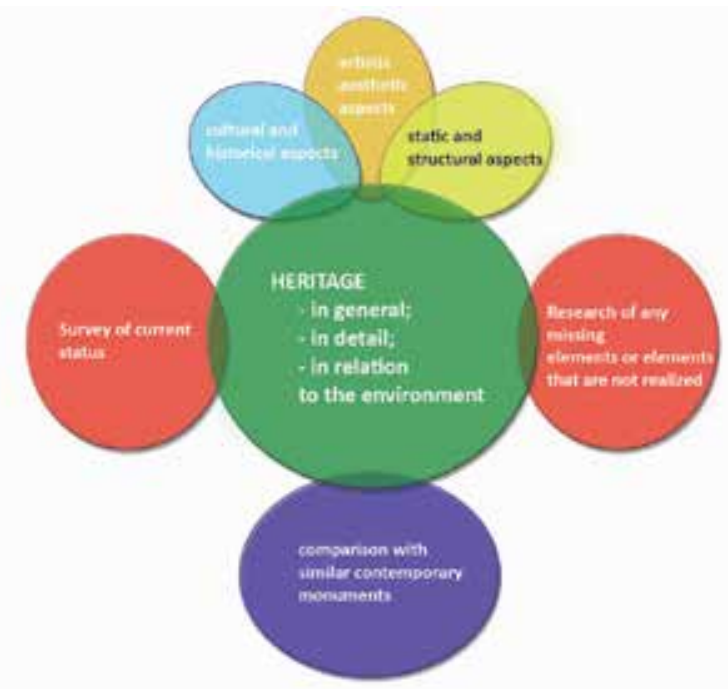

Fig. 4. Methodological approach De Anglis D’Ossat from 1974 - modified by author 6

${ }^{6}$ Translation from the original: V. Sanković-Simčić, 2009. 


\section{The First Phase:}

DETERMINATION OF AUTHENTICITY (original situation)

- Research of historical data

Original situation of the location;

- Verification of original situation

Scientific analysis of the space transformation;

- Determination of authentic traditional values

Establishing limit of the cognition on traditional values about authenticity.

The Second Phase:

IDENTIFICATION AND TECHNICAL DOCUMENTATION (Status quo)

- $\quad$ Research on the ground

Status quo on the ground and the creation of photo data base;

- Identification and location on the ground

The look of the facility and control of basic graphic elaborates, including changes on the facility;

- Graphic documentation and technical drawings

1. Charts on the site as the mean for introduction and understanding of the facility or unities

2. Technical shooting and measuring Me.1:100, 1:200; 1:50; 1:20 (for details)

3. Architectural projects Me.1:100, 1:200; 1:50

4. Projects on Constructions and Details Me. 1:20.

The Third Phase:

COMPARATIVE HISTORICAL ANALYSIS OF THERURAL OBJECTST AND STRUCTRES (from the first and second phase)

- Historical iconocraphy;

- Comparative analysis of the same or similar buildings or complexes - similarities and differences

- Analysis of objects or complexes

- Historical evolution of structure

- Analysis of the materials within the time frame

- Constructive-restauration hypothesis about the possible interventions on the buildings or complex;

- Analysis of structure with characteristics details

- Analysis of the walls (structural)Analysis of different walls to set a hypothesis about construction of the facility and determine the authenticity

The Fourth Phase:

\section{ANALYSIS OF FORMS AND LEVEL OF DEGRADATION, PLAN OF DEGRADATION STRUCTURE}

- Analysis and plan of the main structural undertaking on the facility or on the ensemble;

- Identification of problems;

- Identification through graphic documentation (situation, basis, sections, façade);

- Plan of degradation on facades;

- Graphic study and analysis of the basic pathologic degradation in co-relation to different materials and mutual relations;

- Identification of the problem determined by the form of degradation;

- Identification of degradation on the external look of the facility or ensemble; 
Structural plan of the forms degradation:

Analysis of possible dislocation,

Analysis of structural displacement staggered on the wall surface,

Analysis of structural displacement inside facility,

Reading of pressure and of its influence on the example of the facility openings,

Cracks and fractures on inside wall surfaces, analysis for interpretation on mechanical characteristics of the building,

Plan and analysis of the principle surface pathologic degradation caused by different materials,

Plan and analysis of degradation of the composition values of the complex,

Plan evidence and removal of elements or facilities in disharmony with ambience;

- Analysis of degradation

Such type of analysis, used only for the facilities of exceptional importance, where, in the process of restoration, it is necessary to substitute lacking parts, certainly defines all used materials, but is rarely used because of high costs being result of the complex and specific process;

Prior to analysis:

- Activities related to collection of samples and their testing;

- On the basis of collected materials, selection is made with the work plan;

a. Testing of samples:

- $\quad$ Resistance of materials;

Laboratory testing:

- Mechanical testing of samples and explanation connected to mobile samples (blocks or quadrant)

- Testing in site

- Mechanical testing used by Marttineti platti 7

- Module-metric verification using probe instruments

- Thermo-graphics as a general indicator for detection of holes or other types of non continuous damages in hardly accessible zones;

b. Chemical-physical characteristics of material

Laboratory testing:

- Chemical analysis

- Mineralogical analysis

- Weight and volume of materials

- Conductivity of materials

- Testing in site

- $\quad$ Testing of sediments.

The Fifth Phase:

\section{SCIENTIFIC RESEARCH}

Criterions for valorization and selected interventions;

Scientific elaborate of the protection of facility or ensemble;

Interventions: Project of structural conservation;

7 (1988). Indagine sulle strutture murarie del tempio cosiddeto di Romolo del Foro Romano: Prove non distruttive con Martinetti platti e analisi numeriche; pp. 16 (ISMES publ./1st sperimentale modelli e structure (Bergamo), No 237). Rossi P.P, Bergamo 
- Intervention on structural consolidation with project details;

- Intervention of protective restoration on facades;

- Project on architectural interventions;

- Project on urbanism interventions (at ensemble complexes).

This is a methodological procedure which flow is recommended as a methodology of the work in specific conditions of ambience valuable unities that have significant number of mutually similar facilities originating from merely same period and have similar stylish characteristics. Specific point of this work is the fact that the methodology is integral part of scientific research and a part of scientific contribution.

\section{Research}

\subsection{Determination of the originality line}

All previous classifications quoted through literature related to some of geographic, geomorphological, climate, ethno-religious, sociologic, demographic, historical and spatial characteristics that, as common denominator, connect or differentiate rural agglomerations. We often meet with the term Dinaric type of village which further on leads to South Dinaric and North Dinaric type. Those two types differ in their materialization because the South type is materialized in stone while the North one is characterized by wooden construction. Analyzing literature, it is noted that by now nobody has tried to identify Dinaric type with the way of Illyrian tribes disposition who populated these spaces of the Balkan Peninsula. Namely, these tribes, moving along Black see river basin from Asia, populated our territories and completed their movements in narrow path of the way to Poland. Following and marking this path, it is possible to draw the chart of village agglomerations who, as the roof cover, have maintain by today shingle, stone dray wall having the function of retaining wall for the house leveling, and wooden piles covered with mud and fold on quill at the wall construction of the house. Analyzing precious findings of the archeologist Borivoj Čović, who in the excavation of fort Pod near Bugojno found a house for which it may be stated that had the same elements. ${ }^{8}$ Cović mostly dealt with the Central Bosnia region and

8 Čović, B. (1983). Central Bosnia cultural group, In: Bronze age, Prehistory of Yugoslav countries IV, pp. (433-457), Sarajevo.

Čović, B. (1959). Trial Excavation on fort "Pod" near Bugojno, Archeological Review 1, Archeological Association of Yugoslavia, Belgrade, pp. (47-49); Čović, B. (1961). Pod Bugojno - prehistoric fort, Archeological Review 3, Archeological Association of Yugoslavia, Belgrade, pp. (51-52); Čović, B. (1963). Pod Bugojno - prehistoric fort, Archeological Review 5, Archeological Association Yugoslavia, Belgrade, pp. (3033); Ćović, B. (1964). Pod Bugojno - prehistoric fort of early and late Bronze Age, Archeological review 6, Archeological Association of Yugoslavia, Belgrade, pp. (23-24); Čović, Borivoj. (1965). Pod Bugojno prehistoric fort of early and late Bronze Age, Archeological review 7, Archeological Association of Yugoslavia, Belgrade, pp. (55-57); Čović, B. (1966). Pod Bugojno - prehistoric fort of early and late Bronze Age, Archeological review 8, Archeological Association Yugoslavia, Belgrade, pp. (23-27); Čović, B. (1967). Pod near Bugojno - fort from Bronze and Iron Age, Archeological Review 9, Archeological Association of Yugoslavia, Belgrade, pp. (27-28); Čović, B. (1968). Pod, Bugojno - prehistoric fort of Bronze and Iron Age, Archeological review 10, Archeological Association Yugoslavia, Belgrade, pp. (25-26); Čović, B. (1968). Pod, Bugojno - prehistoric fort, Archeological review 14, Archeological Association of Yugoslavia, Belgrade, 1972, pp. (39-40); Čović, B. (1968). Pod near Bugojno - prehistoric fort, Archeological review 16, Archeological Association Yugoslavia, Belgrade, 1974, pp. (54-55); Čović, B. (1983). Central Bosnia Cultural Group, In: Bronze Age, Prehistory of Yugoslav countries IV, pp. (433-457), Sarajevo;Čović, B. (1987). Central Bosnia Group, In: Iron Age, Prehistory of Yugoslav countries V, pp. (481-530), Sarajevo; Čović, B. (1991). Pod 
concluded that complex and technologically advanced facilities from the late Bronze age appeared rarely in the Sarajevo valley, so, without reliable archeological findings on the forts localities on the Bjelašnica mountain it is difficult to state whether it is about early Bronze or Iron age. In order not to speculate on real traces and remaining of this culture in this accented space, comparative method tried to bring some hypothetic conclusions. A part of B. Čović description may be quoted:

“.. In good manner stratified material from Pod, along with material from other numerous fort settlements, provided a defining of Central Bosnia cultural unity of late Bronze Age. This unity, stretching around the upper and middle the Vrbas river flow (to Jajce) and the Bosnia river (to Zenica, this unity didn't include the Sarajevo valley), understood the independent cultural-ethnic community with clear characteristics of material and spiritual culture. Settlements of forts type located near bigger complexes of arable land and high level of housing architecture ${ }^{9}$ are characteristic for this community. Parallel to described settlements and characterization of housing architecture of forts type ${ }^{10}$, where population dealt with agriculture as the elementary activity, there are settlements of city type in mountainous regions and people dealing with cattle breeding. Contrary to settlements of city type located along the rivers with orthogonal and paved structure of streets, the settlements of forts type originated in mountainous regions are characterized by radial structure of streets. There is dilemma whether it is directed to different tribes whose approach regarding shaping was different, but it is positive that the primary activity of these compared city settlements differed approved by the selection of settlement location. Probably, the shape of street structure, population activities and manner of life are causally connected to climate.

Dealing with the phenomenon of architecture constructed by ordinary man, the architecture which by its form unpretentiously follows the function and construction supported by available knowledge and materials, that is with the appropriateness of the process of the space shaping, with no stylish characteristics ${ }^{11}$ as visual determinants, it is concluded that here we talk about the group of facilities which, through long period of adopted form existence, represent timeless value. ${ }^{12}$ It is not odd that this type of architectural shaping kept so long the elements which, since their creation by now, have changed very little and only when it was conditioned by climate change or certain social circumstances that significantly altered culture of life. Certainly, it is about archetype of the village house that may be considered as the universal value of the first model which born plenty of modifications but

near Bugojno, Publisher National Museum of Bosnia and Herzegovina, Sarajevo; Decision from the Commission to protect national monuments, Official Gazette BiH, No. 75, (2008).

${ }_{9}$ Čović, B. (1983). Central Bosnia Cultural Group, pp. (433-434), Sarajevo.

10 Čović, B. (1983). Central Bosnia Cultural Group, pp. (437-439), Sarajevo.

Scientific work of Academician B. Čović had important influence to the process of conclusion bringing in this Doctoral Thesis. Available data that were presented provided the removal of limits in examining originality and authenticity of archetype forms of the facilities constructed in this area, under which it is important to stress that the term form, we often use in defining traditional values, represents only one segment that we consider relevant for determining originality and authenticity.

11 Here we consider recognized and classified aesthetic values and physical characteristics of construction. It means - stylish characteristics = classified forms of construction.

12 Under the term timeless value we understand characterization of those facilities that we recognize as the one and unique in corresponding time frame which have existed and which will exist as a product of the human work within the framework of adopted forms. 
always with the same bearers of the massage and the same common denominator (foundation, wall, roof...). For this research, based upon the searching for the authenticity of individual form of the facility, its proportion and materialization, and also for the authenticity of the unity, whether it is about the parts of the rural settlements or entire rural agglomerations, it is extremely important to find the archetype traditional value that would be a starting point for further development. In this analysis, it may be referred towards the integral heritage because the selection of theme clearly indicates that there is inseparable connection between natural ambience and those created by men's activities. In mountainous regions, each village has its characteristics. It is mostly connected for the position (location) of the village, for strong influences of the migration movements of population which are, on other side, directly connected to socio-political influences within certain historical periods. When analytically consider individual facilities, it is noted that the height of the window parapet was dimensioned according to the maximal height of the snow cover while the orientation of the windows was directed to the mildest wind and not to strongest insulation. The position of shingle placement is contrary to the wind direction. The facilities are regularly of rectangular rarely of quadratic form, but almost always with two sides exists on opposite sides, for the reason of snow, so that while entering the house it is not necessary to go around the whole house. The inclination mounts from 50 to 60 degrees because such spaces do not keep the snow. The houses are mostly located on steep terrains with the basement space, storehouse, serving as food storage or as a stable for small livestock. In such case, livestock through wooden attic construction warm by their own heat the upper floor thus participating in heating the upper rooms during the winter. Stables, as agricultural facilities, have the same concept of construction as the houses but only the under roof space is used for hay storage and this way hay is easily distributed before the livestock during the winters. Such facilities never have basement neither warehouse. This description with given conclusions that are presented in short review, refers to "The Nara Document on Authenticity", Conference on Authenticity in Relation to the World Heritage Convention, Nara, Japan, November 6, 1994.13 This document, from item 9 to item 13, treats problems of values and authenticity. Item 13 of the same document elaborates the things that may create authenticity:" Depending on the nature of the cultural heritage, in which we place its cultural context, its development through times, assessment on authenticity may be connected to great number of information. The aspects of information may include form and design, material and substances, use and functions, tradition and techniques, positions and locations, spirit and feelings, and other internal and external factors. The use of such sources provides the elaboration of specific artistic, historic, social and scientific dimensions of cultural heritage being examined.14 The speed of devastation of entire village agglomerations during the last twenty years, with special accent to the war and the post war periods when the massive degradation of these ambience ensembles happened, is merely non countable. There are many reasons for this and they primarily should be in the sphere

\footnotetext{
${ }^{13}$ Nara conference on authenticity in relation to the World Heritage Convention: Nara, Japan = Japon: 1-6 November $=$ November $1994:$ proceedings $=$ compte-rendu $=$ Conference de Nara sur l'authenticite dans le cadre de la Convention du Patrimonie Mondial / edited by = redacteur Knut Einar Larsen with an Editorial Group consisting of $=$ avec un comite de redaction compose par Jukka Jokilehto... [etc.]. Paris: UNESCO World Heritage Centre = Centre du Patrimoine Mundial [etc.] , 1995

The Nara document on authenticity, 1994; whc.unesco.org/archive/nara94.htm; www.international.icomos.org/naradoc_eng.ht
} 
of sociology interest and the subject of their analysis. The task of he architects- protectors in this sense is, before complete ruination of these facilities, to record the referent examples thus permanently preserving authentic model of village house and village way of life. Ethics obliges us to consistency in documenting that may provide the faithful reconstruction or contemporary construction with reminiscences to traditional values of space. This approach is the least what the protection services may undertake considering the high level of degradation and the facilities which constructive potentials are such that the conservatory and restoration procedures are hard to be applied.

Looking from the opposite side, such approach to studying the authentic, village, mountain house and wider space it was located in, in the same time opens much wider fields of research, from ethnologic, over archeological to historic revelations of very origin of peoples who lived and who live on this territory, constructing not only original houses for living, but also today highly categorized monuments of culture, medieval tombstones, their eternal stone houses with inscriptions and massages of universal value. Out from historic analysis of population who lived on the territory of Bjelašnica and slopes of Treskavica it is concluded that that the first founded material traces about the life and permanent living of people belong to Illyrians. Resident houses created inside or outside the forts in typology sense belong to animal husbandry mountain house today, and a spiral of human stay on this spaces, long over 2000 years, brings to actual form of the house, thus putting a logic question upon the what paradigm of today's mountain house should be, that is, how it looked, what from and in what manner the village house from this region was built.

Previously made analysis offered three basic elements promising coming to the adequate solution. Those are, mostly, materials, measure, then proportion. Talking bout materials, essentially, it is about local and unprocessed materials found in the site, just on the location the facility is built on. It in the same time separates city from village architecture, because the city house is equipped by craftsmen by prefabricates, such as "ćeremit" for roof cover, non baked bricks in combination with wood for the house walls, carved stone for the foundations and similar. However, in the village, it is said for the hewn shingles ("šimpla" or "kaplama") as a roof coverage, about complete wooden construction of the truss and the walls, which, as an alternative, may have stone walls from the foundation to the roof, and in such case, not without reason, the facilities are semi-sunken using the natural terrain slope in order to get sufficient height in the very facility. About the measure it may be talked from two aspects, primarily as

- spatial relation of the facility and surrounding, in which the facility is mounting to maximal:

Basement + ground floor + roof with protruding rooms, and from another side

- $\quad$ volume of the very facility and relation of its elements.

The house volume has rectangular forms of the basis, with storages placed transversally in relation to the house in one half to one third of the ground floor surface, seldom placed longwise, in what case they are in two parts. The roof is in majority cases, as already quoted, under the slope of 50 to 60 degrees. The roof surface is, by its volume and monochrome material, dominant on the whole facility.

Regarding the proportion, the facility almost always has harmonious and mutually corresponding relation of different elements such as the cuboids of the ground floor and the roof pyramid. The mutual relation is in majority cases is $1: 2,5 / 3$ on behalf of the roof. It is difficult to recognize distinction between:

- the form as the product of heritage and tradition incorporated into all cultural values, and 
- the form as the result of the cultural conditions of the civil community which construct it and "technological" knowledge and possibilities of the national builders.

Authenticity, treated in this manner and reaffirmed through the Venice Charter, appears as an important factor in qualifying values. Understanding originality plays the basic role in all scientific researches of the cultural heritage, in conservation and restoration plans, and especially in the process of recording and listing that are used for the World Heritage List and other inventory lists of cultural heritage. Keeping to the basic postulates of the Nara documents on the authenticity, it is considered that the essential part is to define authenticity ${ }^{15^{*}} 44$ in order to maintain it in further processes of protection. In this regards, two segments important for authenticity were defined:

- determination of authenticity, and

- preservation of authenticity.

\subsection{Determination of authenticity}

As stated that authenticity of the facility or the ensemble a key for preservation and further use of the object and ambience unities, the procedure of determining authenticity and the procedure of the preservation of authenticity are extremely important for what is defined as an active protection. Elaborating these two procedures, the contribution of this scientific work may be also defined as well as its original hypothesis being confirmed through these conclusions.

Through process which led to authenticity as phenomenon category ${ }^{16}$, the procedure was established which could represent a part of methodology for determining authenticity. The first phase is documentation and recording of selected space. Using documentation from all available sources understanding old photographs, old notes, historical data, archeological data, etc., the data base was created which served as the starting point for further research. Using documentation and comparing similar cases, by method of common denominator, it is possible to determine archetype value of the form that could be treated as authentic form on selected space. Upon research-documentation phase, the work on the ground follows. By shooting and recording traditionally valuable facilities, constructive details and materialization of the facility would be determined. By taking samples in site, the starting point would be made for the final definition of authentic materials, and systematization of constructive details will give synthesis conclusions related to the use of materials for the sake of the creation of authentic forms. By checking the structure of facility and analyzing

\footnotetext{
15 "Authenticity represents a collection of important historic determined characteristics; from the original to the actual condition, appeared as the result of different transformations happened during the times".

International conference on Conservation Krakow, 2000, Available from:

$<$ www.terport.hu/download.php?ctag=download\&docID=4583>; The Charter of Krakow 2000 www.triestecontemporanea.it/pag5-e.htm.

16 Phenomenology is a philosophy method trying to create conditions for objective research of topics that are commonly considered subjective. It means, phenomenology deals with experiences and their structure such as explained by Edmund Husserl: Intellectually or scientifically judge on the things means to direct yourself towards the things themselves, that is from talking and opinion to turn beck to the very thing, test them in their self-givens and to remove all prejudices strange to them. In this particular case, authenticity as phenomenon category appears as a product of the path by which, starting from the phenomenon of pure intentional aspects of consciousness, we want to understand their immanent essence as the essence of the very things.
} 
materials, it is possible to determine the age and authenticity from the aspect of materialization. Taken samples on the ground through chemical processing and analysis of materials, may offer correct data on the age of embedded materials, which is specially related to facilities whose aesthetic and constructive value may not be valorized through the form. Besides, it will provide the correct use of materials, at substituting of the missing on the facility, in the process of conservatory and restoration undertakings, not jeopardizing authenticity. The process of determining originality and authenticity is continued through a comparative method where unknown and missing elements are being compared with known and similar (the factors of resembling represent the same geo-morphologic and climate conditions, the same period of appearance, the same socio-political and anthropological surrounding...) thus, the method of common denominators brings the needed conclusions. It was stated, through previous researches, that there are few parameters that are being valorized in the segment of authenticity. These are form, materialization and function. It is noted that the differentiation of two categories, form and materialization, helps to perceive the existing facility from the two aspects. The first category does not exclude the second and vice versa, but neither does it a priori accept. Here, the third category appears being the content or the function of facility. This category comes out from the first two but is not directly conditioned by them. It may be original or secondary or even tertial one.

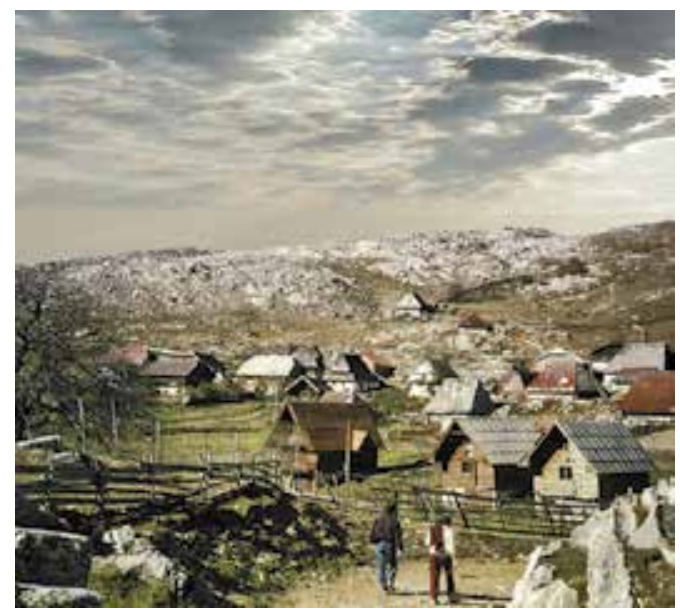

Fig. 5. Traditional Bjelasnica village ${ }^{17}$

- $\quad$ Analytic phase

a. documentation;

b. historical facts,

c. archeological findings.

- $\quad$ Research on the ground (Research of status quo)

a. recording

b. shooting

c. taking of samples

\footnotetext{
${ }^{17}$ Chabbouh-Akšamija, L. (2009). The Authenticity of the Rural Architecture as a Prerequisite for Active Protection; The Pilot Project Bjelašnica Village Ledići, Sarajevo.
} 

d. determination of types
e. valorization
f. method of common denominators as the sublimation of the researched.
- $\quad$ Synthesis work (directions for future work)
a. determination and defining of archetype form
b. determination and defining of the used materials,
c. determination of the facility function.

\subsection{Preservation of authenticity}

“... Those are precious witnesses of the past that will be preserved because of its' historical and mostly sentimental value; finally, also because some of them bear in themselves plastic virtue embodying the highest intensity level of human ingenuity. They are the part of patrimony of mankind and the people responsible for their preservation must do everything they can to transfer this noble heritage to future centuries" ${ }^{18}$

Le Corbusier

Upon determining all defined elements that create authenticity, there is a complex process of preservation of authenticity. Often, extremely valuable unities disappear or are devastated because of neglect and the lack of consciousness about their value, but also, because wrong or bad planning of local community. This is why it is important to start the process of protection by inventory and valorization of the status quo. Parallel, through legislation, the ambience should be protected in the actual form and it is necessary to proscribe the rules for protection, maintenance and utilization. It is possible, through valorization, to define explicitly the fund of the facilities with traditional values separating those that jeopardize ambience of space. Often, the facilities making selected ambience unity are in the ownership of different private owners, thus, it is illusory to expect that the existing facilities being in disharmony with the ambience are removed or re-designed voluntary. The role of local community must be directed to bringing decision on paying adequate charges for not obeying certain measures brought in order to protect ambience unity and to bring the owners into position to voluntary re-design their facilities. It should also provide for new facilities being constructed to respect the brought rules and to be in ambience sense incorporated into the space. Naturally, romantics' concept of reconstruction, promoted by Le Corbusier 46, being for its own sake, became irrelevant in time especially when talking about village architecture. Using of reconstructed space and its proper repurpose, if necessary, revitalizes the ambience. The aspect of active protection gives to this approach full foundation being in accordance to modern economic and tourist tendencies. Through active protection and its application, prosperity and real application of today's popular sintagma "sustainable development"19 will be provided. The term sustainable

${ }^{18}$ Le Corbusier. (1998). Le Couvent Sainte Marie de La Tourette / The Monestery of Sainte... / Athen Charter, Paragraph 60, Arhitektonski fakultet, Belgrade.

${ }^{19}$ UN Documents Gathering a Body of Global Agreements; Report of the World Commission on Environment and Development: Our Common Future Transmitted to the General Assembly as an Annex to document A/42/427 - Development and International Co-operation: Environment;

Sustainable development is the compatibility of nature, society and economy, that it is development that meets the needs of today, and that does not prejudice the ability of future generations to meet their own needs. In short, the concept of sustainable development is a new development paradigm, a new strategy and philosophy of social development. 
development deserves attention firstly because of the fact that all future planning has the support in theory postulates and international documents dealing with this topic. It is interesting that, when speaking about sustainable development, we mostly refer to environmental protection, although the UN documents on sustainable development deals with the protection of architectural heritage so, the General Assembly of UNESCO in its Universal Declaration on Cultural Diversities20, in the organization of Committee for Education, Science and Culture, treats the cultural heritage in the following aspects:

- cultural heritage as the source of creativity

- cultural goods and services: the goods of unique sort

- cultural policy as the catalyst of creativity.

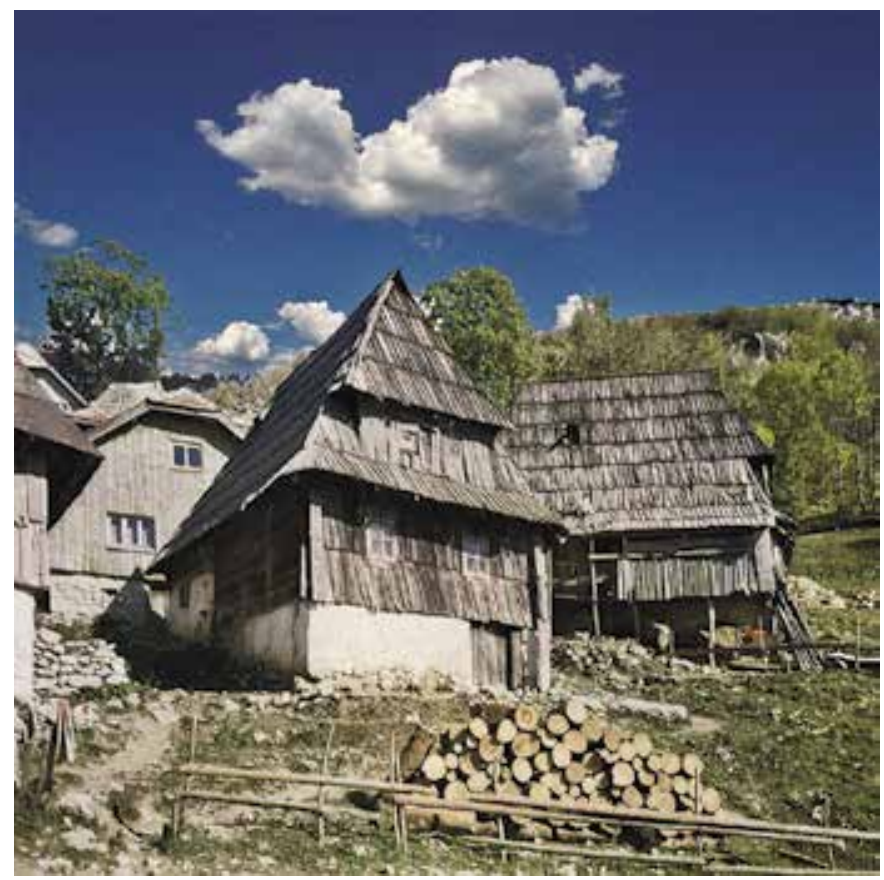

Fig. 6. Traditional Bjelasnica house - “čardak među rogovima" 21

In the part describing the cultural heritage as the source of creativity, it is pointed out that the root of cultural tradition is in creation and that the tree blossoms in the contact with other cultures. Out from this reason, heritage in all its forms has to be preserved, stressed and handed over to future generations as the record of human experience and aspiration, in order to support creativity in all its diversities and to inspire the real dialogue between the

www.wiserearth.org/resource/view/.../section/gallery

20 UN Documents: Gathering a Body of Global Agreements; Universal Declaration on Cultural Diversity, Available from: <www.un-documents.net/udcd.htm>; Statement of UNESCO Director-General; Resolution of UNESCO General Conference; Universal Declaration on Cultural Diversity; Cultural Diversity and Creativity; - Cultural heritage as the wellspring ofcreativity; - Cultural goods and services: commodities of a unique kind; - Cultural policies as catalysts of creativity. unesdoc.unesco.org. ${ }^{21}$ Chabbouh-Akšamija, L. (2009). The Authenticity of the Rural Architecture as a Prerequisite for Active Protection; The Pilot Project Bjelašnica Village Ledići, Sarajevo. 
cultures. ${ }^{22}$ It all is a contribution to the hypothesis on the preservation of authenticity which is a precondition for protection, and especially active protection which will, by giving directions for the correct use of integrated heritage, provide the lasting and the renewed life of traditional values of rural architecture and its overall landscape. ${ }^{23}$

\subsection{Originality, authenticity, autochthony and identity 2.4.1 Phenomenology of original}

While discussing about traditional values, it is inevitable to discuss the notion of originality in the context of defining authenticity of the rural architecture today. Originality within the framework of this work is considered as the realization of the results of the natural growth of ideas emanated to conscious human activities (homo faber) that were directed to satisfying existential needs for quality settlement and life of an individual or a group in certain time period on the rural territory along with the use of locally available materials while constructing shelters. This process does not examine the origin of the very need for the creation of shelter, because this need appeared as a result of certain historic flows and technical-technological stadium of society development, as the answer to characteristic motive of geographic and natural conditions of space. Through research and determination of the originality limits, it is possible to determine the starting point of creativity, but, the conscious about the very beginning is unknown to its creator because it is about spontaneous creation happening for its own sake, and essentially, it represents only possible answer to the condition in which the national builder was found in so that even his final effect was not completely visible. It was created continuously in time and space as a unique and valuable contribution, by the mediation of national builder characterized by creational spirit for satisfying his existential needs. The value of such human activity may be characterized as duly and with purpose, but still, even personal (in the sense of the authorship) in relation to his creator. Definition of vernacular architecture is recognized here which represents the essential status of rural heritage. It is known from the history that the influence of such form of originality was continuous and coherent relation between the act and its' surrounding, integral, intuitively recognizable, and in intelligent and unobtrusive manner inwrought into natural landscape. Analysis of actual conditions of rural heritage brought us before the clear picture about non-existing, or mildly said, merely perishing of traditional values of the rural architecture on Bjelašnica. The appearance of preserved traditional values or originals in the context of integral values of traditional rural landscape is multi-layer and manifests itself in few forms. The first and generally present element in the scope of integral rural heritage is the natural landscape. Its presence in integral rural heritage is ultimate, although the focus of protection is mostly placed on constructed heritage. It is caused by the fact that this element is stable geographic category, which definition, providing it is determined as natural value, remains as a constant, except the actions to its ecological aspect. Not always the most dominant, but the most durable and the most stable parameter in the scope of integral heritage, natural landscape remains authentic and original in the original sense until it is exposed to modern interventions that produce its

\footnotetext{
22 UN Documents: Gathering a Body of Global Agreements - Universal Declaration on Cultural Diversity: Identity, diversity and pluralism; Cultural heritage as a source of creativity, Article 7; www.undocuments.net/udcd.htm.

${ }^{23}$ UN Documents Gathering a Body of Global Agreements; Universal Declaration on Cultural Diversity; Article 7.
} 
degradation. Danger for degradation of natural ambience represents non balanced use of natural resources ${ }^{24}$ at which the anatomization to renewable and non-renewable resources, understands that the use of renewable resources provides the existence in space, while the use of non-renewable resources permanently degrade natural ambience. This non desecrated space, defined as natural landscape in the integral value of rural heritage, and also individually observed values, although in semantic sense experienced and aesthetically valorized, is the essential bearer of the massage of original, traditional value. Aspects of observation of originality and the originals may be from philosophy, over ethnographic to this protective. Still, they all agree in one, that is, originality, along with origin ${ }^{25}$, authenticity 26 and autochthony ${ }^{27 *} 130$, represent categories which for very long have not been status categories but the processes having two direction of movements. The value of these categories, in which, the level of society consciousness may be considered as the main characteristic of their conditions and status, remains constant providing no changes in the level of consciousness about them. Given the changes of the level of consciousness, depending on its growth or fall, its value in society proportionally grows or falls. All these categories represent the starting point of our existence and original traditional values and all meanings contained inside them, get or loose its value through time. It is not unusual when stating that there is forgotten knowledge, forgotten skills and by this forgotten tradition. Isn't it successive loosing of identity which in this existence leads towards deletion of memory and to globalization in all its most negative aspects?

\subsubsection{Four parameters of traditional value of heritage}

Speaking of originality, talking about heritage, we divide time to the period to massive industrialization and the time after it. We may with certainty state that massive industrialization destroyed crafts and made disappeared some previous knowledge and skills. New technologies brought practical and pragmatic, simple solutions, that replaced manufacture production of goods, but also construction. As the result, we meet the interventions on traditional facilities made in same materials, mounted in corresponding places but processed in modern manner, with no feelings and understanding for the original

\footnotetext{
${ }^{24}$ Hadrović, A. (2008). Bioclimatic Architecture on the Search of the Way to Paradise. Acta Arhitectonika et Urbanistica, Arhitektonski Fakultet u Sarajevu, Sarajevo, pp. (7-13).

${ }_{25}$ Under the term originality in the sense of geographic origin, we understand certain actions of man inside certain region, in certain place or, in extreme cases, in wider space, in maximally long time period which may be perceived as the most distant spot in relation to present time, along with evident use of composition-constructive possibilities and materials in order to satisfy the needs for defining own shelters.

${ }^{26}$ Under the term authenticity in the sense of valorization of engineering-construction characteristics of facilities in the times of their appearance, morphologic details, composition, characteristics and origin (in the sense of location) used materials.... We understand activity (construction; organization of the place of human existence), and appearance (constructed and designed forms), in maximally long time period that may be materially recorded in relation to the time of observation. Appearance as the integral part of authenticity we observe in immanent duality as spatial-event phenomenon (place) and shaped form (art effect).

27 Autochthony is considered as extraordinary value of defined heritage which creates a collection of material and non material goods which define identity of observed element being placed in that defined space. This phenomenon, so as authenticity, is bound to the place while the originality does not have to represent the observation of the heritage in site, but it is discussed about its origin.
} 
work techniques, thus, the general picture is not adequate to authentic and original condition. It is great difference in relation to originality of material and non material heritage. Material heritage, such as art effect, may be protected in its original form or devastated by negligence and numerous, other causes of devastation. Each intervention on material heritage with a goal to preserve its authenticity, by incorrect approach in its unity or in its detail, may become the main reason for the loss of its authenticity. A term phenomenology 28 of original is chosen consciously wanting to give the importance and specific features to the sphere of originality which phenomenology binds to itself. May, then, the original be considered as a phenomenon? If, under phenomenon we understand peculiarity, exceptionality and rarity, then the answer to this question is positive. It seems that time we live in, consumers' society which does not accept exceptionality and peculiarity as virtues, brings the original and originality in question. There are few reasons for this, but economic aspect and speed of living are decisive while stating this hypothetic presumption. Turning beck to the concrete example of traditional, rural architecture on Bjelašnica, out from concrete conditions, it may be seen that the truth about originality and original without adequate status and that, while estimating their traditional values, it has already lost the battle with contemporary architecture. In any case, village heritage is considered original, and all changes happened inside it during the use and time passing, that did not jeopardize its authenticity, are considered as a part of their originality. Still, analyzing development of commercialization of these places, it will be stated that the appearance of tourism (here, it has not been transformed into cultural tourism) brings to certain articulation between traditional, rural heritage and the users of tourism offer. This all significantly influence jeopardizing of authenticity and originality, because in this articulation, pseudo models of traditional heritage, successfully replace real models which were replaced because of their frazzle or had been so reconstructed to lose their authenticity and originality. Now, all is being returned to the beginning of a discussion about originality (not only about originality, but also about authenticity, autochthony) where we stated that the society conscious about them is just the thing which directly influences their valorization. Thus, the users, consumes, have no general conscious on the original value, not

28 Phenomenology is philosophic science about phenomenon of world and life. The task of phenomenology is to determine, understand and make out phenomenon. It is preoccupied by phenomenon only, that is, by what is shown; its basic task is to place itself with understanding towards what is shown, to watch it and to try to explain it thoroughly, with no evaluation.

Phenomenon, Greek, (fainomai - we appear) according to definition: rare (exceptional) appearance (i.e. in nature); something famous; unusual case, miracle, rarity, exception.

Unfortunately, originality inherited by phenomenology of material culture is considered by the many people to be behind us, our needs and our time. Tradition, as originality, seems to be spent and useless. The things being of interest for actual creators of daily-political eventuality, including urban culture, come out from desire to suppress tradition and traditional and from wrongly understanding of the globalization of the rural. In fact, instead of originality, with new sensibilities, the new form appears: it is insisted on uniformity and on transfer of architectural experiences from cities into rural surroundings. See: Lancey,A.R.: Dictionary of Philosophy; Kruzak, - Croatian Leskovac, 2006

Phenomenology of original reveals the right sense of traditional rural: it is not unity of nature in ontological form but eternally changeable product of endless reflection defined by the need of homo sapiens to satisfy and provide shelter with available materials within the framework of traditional, rural forms; thus, original, rural architecture is transformed into phenomenon, into the content of this situation and becomes self-understandable horizon of the subject fact as it appears in natural attitude. 
even knowledge to recognize the original from the copy. It brings to the conclusion that heritage lost, if ever had in these places, a status of the subject in the story about values of space and indicates that determination and preservation of authenticity, along with the strategy of implementation of this valorization through public announcements, would contribute to better understanding and the acceptance of originality, authenticity, autochthony as real and nonreplicable traditional values with the aim of repeated finding and real understanding of the own identity. Especially when talking about rural, traditional heritage, it may be stated that it is timeless picture of Bosnia, unchanged through centuries and thus valuable and precious.

It, instead of the wars and divisions, must be coherent force that could gather groups of peoples around its own identity.

\subsubsection{Time and space in the function of heritage determination}

Given objectifying of actual rural heritage on Bjelašnica, through quoted four categories, approaching heritage through two dimensions that reflect stratification of the place the heritage was constructed in, time and space, it will be confirmed that the protection of traditional values has absolute sense. Originality of heritage, treated by this part of Thesis, sounds a bit absurd taking into consideration the term heritage ${ }^{29}$ which meaning incorporates originality as well. Still, concrete form of rural heritage on Bjelašnica, leaves under question the elements of authenticity and originality, not because there were some changes on the facilities, but because the original facilities completely disappeared or are in the phase of bed physical preservation. Objective condition of heritage leads towards the initial hypothesis of the work in which the authenticity (including the originality) is a precondition for heritage protection. Its stratified meaning structured through spirituality of authenticity, originality and autochthony, its physical determination created by empiric knowledge, inosculate in final appearance. Absence of any of quoted categories makes heritage desecrated for such dimension. Philosophers were, abstracting material component, talking about the relation of being and time. Para-phrasing, the facility may be treated as the being, that is its position in time today, it may be considered as the being with two faces, one turned to the past and the other towards the future. Those are two faces which, Borhoevski 30 , look to the past and into future, but will never be "face to face". They are in Heidegger sense existential/hermeneutic. They have not been given or have been given; they cannot pass because they are not anything substantial. Still, unfortunately, they are, substantial, and scientists occupied by reconstruction and protection of heritage, may not literally accept philosophic understanding of originality because it understand originality of spirit which is imperishable being not material. It is not limited by anything; it is an idea and a thought, free in time and space...

It is however necessary to mention Hegel words as the introduction of his work Phenomenology of Spirit:

"We do not know destiny, European destiny of spirit, but also the World one. We do not know any more to name God without entering fear and suspicion in it with no reason; we

\footnotetext{
${ }^{29}$ According to definition: proves from the past, such as historic locations, buildings and unchanged natural environment considered as collective heritage of today's society; Collins English Dictionary Complete and Unabridged $6^{\text {th }}$ Edition 2003; William Collins \& Co. Ltd, 1979, 1986 Harper Collins Publishers 1991, 1994, 1998, 2000, 2003.

${ }^{30}$ Jorge Luis Borges, Argentina poet, essayist and novel writer.
} 
do not know to stop discharging an arrow which will, one day, fly towards somebody else seen as an enemy. If this idea, related to undermining of all values, would become a world's destiny, then, this unique human project reflected through the human appearance on Earth would really fail. We would bring into question the idea of evolution and the possibilities of the world and history. Along with this project I asked myself: Who am I? Where I would like to go? How can I get to know the thing about which there is no knowledge; how can I come to the cognition of social psychology? "31. These questions are key one if we want to talk about authenticity and originality. These are questions to which architectural heritage offers the answers. It helps in revealing the authenticity of spirit through the authenticity of the material, and, by determining authenticity and originality, to witness about the subject of research being the object and idea connected to its authenticity and originality.

\subsubsection{Identity}

Within the term of authenticity and originality, spiritual and material categories are contained. Terms autochthony and origin, there are the determinants of place and time of appearance, being existential determinants of facility, while the term identity 32 we find the idea on origination, location and time. Only this parameter demands the analysis of the relation between the two dimensions that are in correlation, space and time. It was noted that the sense of identity, within the context of this scientific branch, may define otherwise in relation to general acceptance of identity as a determinant for heritage. Namely, it is necessary to turn beck again to complex philosophic discussion placing time dimension in relation to identity. In general, and according to mathematics theory, identity understands the sameness or the identical in comparison to two or more individual elements in the same comparative line. Still, talking on identical, or about the recognition of the same characteristics (trying to bring theory in the level of heritage), there is a question whether it is about the fact that the material value appears in certain time, then lasts and exists in each following period thus passing through time and space. Or may be the time factor is not relevant, thus, material values appear in one time, they last through the space, with no time as the factor? It is about two theories, a theory on endurance or stability or the theory on per-durance or per-stability.

We are interested in this relation of argumentations because it directly reflects the relation towards facilities accented by this work. Namely, if we apply so called Endurance theory33 to selected examples, then we may say that traditional, rural architecture stays through time and space reflecting in any moment its past characteristics of form and function from this time sequence. If we apply Perdurance theory, then it should be stated that traditional, rural architecture, from the time of its appearance, exists in the space, with no time characteristics, maintaining original characteristics only as the proof of the time of appearance. ${ }^{34}$ In actual

\footnotetext{
${ }^{31}$ Hegel, G.W.F. (1987). Phenomenology of Spirit, Introduction, pp.(17), Naprijed, Zagreb.

${ }^{32}$ According to definition: feeling of selfness providing equality and continuity in person during time:

Synonyms: individuality, personality, exceptionality, uniqueness; (2009). Random House Dictionary,

Random House Inc.

${ }^{33}$ McKinnon, N. (2002). The Endurance/Perdurance Distinction. The Australasian Journal of Philosophy, 80:3, pp. (288-306); Merricks, T. (1999). Persistence, Parts and Presentism, Nous, No. 33, pp. 421-438; Hawley, K. (2001). How thing persist, Oxford University Press, Oxford; Sider, T. Four-dimensionalism: An Ontology of Persistence in Time, Oxford University Press, Oxford; Lewis, D. (1986). On the plurality of worlds, Basil Blackwell, Oxford

${ }^{34}$ Perdurance: theoreticians, such as places Quine, reject the attitude characteristic for the time of our natural communications. This attitude treats existing things of persistence and changes through time,
} 
discussions between supporters and theoreticians of these two directions ${ }^{35}$, the theory of perdurance has less and less supporters. It may be stated with certainty how the previous conclusion that traditional, rural heritage so as all material creations last through time and in each moment of its existence in space suffer from certain changes, today reflects the picture of all changes produced by passing of time in the same space. Heritage thus accepts the both dimensions equally, and the process of lasting exists as the basic parameter for its valorization. In this regards, going beck to the topic of originality, it may be stated that, when talking about rural, vernacular heritage, originality (thus authenticity as well) may be treated as a process of the changes on the facility, as long as the integrity of the facility is not damaged in widest sense. Even the process of violation of the physical integrity of the facility, as a consequence of the time passing, characterized as the aging of the facility, may (must be) treated as the originality of appeared changes. Contemporary interventions certainly are not to be accepted as originality but maintaining the facility in the spirit of time, appropriate to the unity of ambience, is a part of heritage for future. It has to be stressed that because of such situations, it is very important to determine the limits of authenticity and preserve it on the facility along with the respect of successive changes that meanwhile happened. At rural heritage, such cases where the visible changes appeared during the facility life time are very few, but at some monuments of higher classification value, it is the case. It is considered that the traditional values on the facility must be "readable" independently from the harmony of approach (styles) or specific materials. As by now, through certain theories or original conclusions, a status and reflection of these theories on all individual elements of integral heritage was tested, we will turn a bit to heritage that was already discussed in this work. It was previously concluded that natural heritage in the context of rural, integral heritage represents a factor of stability and consistency. Namely, it is rear the case that interventions in the past changed or jeopardized natural heritage. Such interventions are connected only to recent past and present time, treated as devastation and regulated through legislation and wider social actions. Concrete example of the Bjelašnica location by now hasn't had a transformation of natural heritage which would bring into question the originality or authenticity. Today, it is often the case. Such examples are noted on the places of quarry, at accented infrastructural network, which leave permanent changes on natural heritage as consequence. Originality and authenticity of archeological findings classified as sacral spaces, representing mostly necropolis of medieval tombstones, old Muslim graveyards with "nišan" (specific tombstone) and old orthodox cemeteries with crosses, were partly damaged by demolition and destroying but the biggest

but does not accept time, only space. Thus, the existing facilities rapidly differ from events or processes which enlarge its activities through time. One of the manners to describe position, when the perdurance theoretician is in question, will affirm that this theory negate the existence of different ontologic categories of existing things or materials.

Quine writes: “.. physical facilities, designed in four-dimensions in space and time, are not to be differed from events, or, in the concrete sense of this notion, from the process. Each is composed from simple content, but, heterogeneous characteristics of the parts of space and time is gerrymandered..." Quine,W.V.O. (1960). Word and Object, pp. (171), Mass: MIT Press, Cambridge; Zimmerman, D. Persistence and Presentism, Philosophical Papers, 25:22, Rhodes University, 1996, pp. (115-126).

35 David Kellogg Lewis (28.09.1941-14.10.2001) - American philosopher, John Jamieson Carswell (born 192) - Australian philosopher, William Van Orman Quine (25.07.1908-25.12.2000) - American philosopher, Alfred North Whitehead (15.02.1861-30.10.1947) - English mathematician and philosopher, Orlando Patterson (born in 1940) - American historian and sociologist of cultures. 
problem is dislocation of individual tombstones and moving and mounting of the "nišan" elements into the foundations and bearing walls of the facilities. Shifting from authentic location automatically brings into question the originality of these sacral spaces. Sometimes, it was done to protect these monuments but sometimes they represented obstacle for "development" of the space, or because of new spatial usable value. Anyhow, in this case, originality, needing a parameter of location determinant in site, may not be identified with authenticity because under this, we understand the condition of monument in the sense of its constancy and it doesn't have to take into consideration location originality, that is, autochthony. At the end of this discussion it is considered that, with no regard to distinction between these terms being almost versions (terms originality, authenticity, autochthony), they all together give determinants necessary for protection and renewal of heritage, corresponding mutually along with permanent correlation with time and space as dimensions always relevant for heritage.

\subsection{Rural heritage as bio-climate architecture}

When spatially framework for defining heritage was determined, mostly rural one, then the source for supplying construction materials was determined respectively. The principle of processing and installation of materials are reduced to primitive processing with formally simple constructive frames and essentially highly sophisticated and transferred to objective bio-climate and geo-morphological conditions of the climate in which it is constructed. In this sense, authenticity of materialization will be defined through geographic framework we are obliged to place, because, mutations of the same form happen just in the context of geographic framework with different materialization. We stress, that we do not refer towards archetype for which it was stated that it had dealt with authentic pre-form only, but to the authenticity and autochthony of forms and traditional values in the context of space. So, regionalization of territory, defined by different geo-morphologic and bio-climate structure, follows certain diffusion of characteristic materials in the specific typology of heritage. According to methodology proposed by Dr. Dušan Vuksanović36, applying method of bio-climate parameter analysis based upon previous identification and grouping of characteristic parameters, may be divided to:

- Bio-climate parameters - influences including conditions, reasons and motives

- Bio-climate parameters - answers including consequences and interventions.

Given the acceptance of such division to parameters of influence and answers to them, then, the sphere of interest is the answer/answers of national builders to conditions and influences of natural surrounding. Results of this research would then be focused to correlation relation of man and nature through creation of certain architectural solution as the answer to certain natural factors. Accented functionalism makes rural traditional

\footnotetext{
36 "Bio-climate parameters - influences made from factors of climate in certain location: climate, ground, relief, waters, vegetation. Bio-climate parameters - answers composed from architectural answers on the level of settlements and on the level of houses: selection of location, orientation, adjustment to topography, organization of space, materials and construction and finally typology of house and settlement". Vuksanović, D. (2005). Traditional Architecture as paradigm, Traditional Architecture of Monenegro, University Montenegro.

Faculty for Civil Engineering, Monograph, Podgorica, Retrieved from: $<$ www.montenegrina.net/pages/pages1/arhitektura/tradicionalna_arhitektura_kao_paradigma_d_vuksanovic.htm>
} 
architecture extremely bio-climate. Rural architectural heritage, as the expression of bioclimate architecture, is absolutely adjusted to climate on which was constructed shown through the heritage of the Bjelašnica mountain.

\subsubsection{Harmony of relations between rural and natural heritage - view from distance}

In semantic analysis ${ }^{37}$ of the space observation, the first to be noticed is the harmonious relation of natural landscape and constructed rural heritage. It is visible that measure and proportion in the relation of elements in rural heritage are harmonious and that ergonometric metrics used while dimensioning facilities, corresponds to natural and harmonious relation inside landscape of differentiated natural and architectural heritage. Analyzing further on the position of facilities in relation to terrain, it may be stated that the settlements were constructed regularly in the places where bio-climate influences were extremely positive. It is noted that the factors of insulation, winds circulation, water streams, sources of drinkable waters, vicinity of arable land...directly influenced the selection of location for the construction of settlement. This phenomenon is noted at transformation of rural settlements during the times, while enlarging, where obtained relation of space was maintained so that the stretching of settlement was directed regularly following the location of the first houses. In such way, mountainous, dense settlements were created and amphitheater position conditioned careful preservation of fertile land so the facilities were placed one behind the other while the plane was kept for processing. It was often that, because of specific features of terrain, the fertile land was not inside the village space thus bringing to the conclusion that while selecting location for the village construction along arable land or position that would satisfy bio-climate conditions, by existentially clear preference, the other solution was selected.

\subsubsection{Harmony of the relation between rural and natural surrounding - view of the proximity}

Observing position of traditional, rural settlement in relation to natural landscape from proximity, harmonious relation between materials used for construction and elements that were materialized with surrounding, will be noticed. It is exclusively about natural materials found in site so the facility interpolation into surrounding is clear. Besides already noticed values of measure and proportions, materialization contributes to specific mimicry of individual facilities and then rural, traditional settlements into natural surrounding. Installation of materials and their processing are part of knowledge about nature of materials and their characteristics. Constructive frames created for the sake of certain sustainable forms, being the answer to natural conditions of space the facility was constructed, are part of traditional knowledge or, as already stated, of intuitive knowledge.

\subsection{Facility details in relation to bio-climate parameters}

Analyzing contour of rural, traditional mountain house, multifaceted forms of each single element were found. The most often and almost ultimate premise of each housing facility in

\footnotetext{
${ }^{37}$ According to broader definition, semantic (the word originates from Greek semantikos or "important meaning" extracted from sema, sign) is a science examining meaning. It gathers perception, identification and interpretation of signs of certain disorder and serves as a synonym for symptoms. Common modern term for studying non verbal communication is harmonious relation of natural landscape and constructed rural heritage.
} 
traditional Bjelašnica villages is to be constructed on slope terrain. This, in multiplied manner, simplifies construction because the terrain is leveled by construction and not by digging considering difficulties at digging stone terrain; this way provides the space for small cattle breeding and their presence during winter time warms the space above storage.

Semi-floor being a floor from one part and from the other ground floor, having been built depending on geographic framework and geo-morphological characteristics from wood or stone, and later from "dizma", has unusually low height conditioned by impossibility of quality isolation of walls. Slope roof surface offers possibilities of bigger space volume for inside use but also as the answer to natural influences cause by precipitation and big number of snowy day annually. Wide eaves, sloped deeply towards the ground, serves as the windshield and shelter from snow.

It will be concluded that all quoted elements were in good manner adapted in the sense of the answer in relation to bio-climate parameters placed before rural heritage as conditions.

\subsection{Empiric and tradition checked through contemporary methodological approaches}

Observation of rural unities of the Bjelašnica Mountain leads to the thought that national builder had infallible, by experience obtained skills which resulted in form and in house construction. Talking about heritage, form and construction belong to traditional values of facility. What is indisputable, and may be considered as superstructure of the firstly mentioned fact that, final result, authentic village house and entire ensemble unity of village, reaches the level of mind message. It is what message?

Overall harmony with natural surrounding is in question. Neither element is in conflict with natural parameters. It is wise decision of national builder not to fight and jar with nature because they are in advance lost battles. To the contrary, harmony and unison in selection of materials and form led to the fitting in correlation of elements with entire house, the entire house with whole ambience and ambience with natural surrounding, so as of all quoted elements with each other and with all natural parameters. Such network of correlations speaks about the conscious need for adjusting not confronting. It is not about the conscious which led to formal harmony, out from purely formal reasons, but about existential need for survival, for lasting in these selected spaces and for searching the best manner for harmonizing needs and reality of existing in hard living conditions. Each of individual elements that may be recognized on the facility, if anatomized to constructive elements, is the bearer of the message about technical possibilities and real, sustainable values. Starting from the foundations which are only stone force supporting walls, adjusted to stone structure of ground being hard to dig and cut but solid enough to bear wall construction. Thus, all these facilities look like broke out from terrain without artificial horizontals of ground with terrain lines reflected in contour and not contrary.

Wall cover (mostly stone) by its mass, $50 \mathrm{~cm}$ thickness on average, with two sided masonry and lime mortar improving the solidness of wall, is the best thermal isolator in inconvenient time conditions. The size of wall openings is adjusted to technical possibilities thus no opening overpasses width that a $5 \mathrm{~cm}$ thick board may not bridge. In the same time, small dimension of windows disables loss of heat energy during winters, and heating from outside during summers. Parapet of the window is never lower than average height of snow thus the windows on different house sides are from different heights depending on the position of the facility in the village, or differing from village to village conditioned by micro-climate parameters. Generally looking, the windows on Bjelašnica are rarely open towards South because of strongest wind coming from there. Roof construction is slope, covered with shingle 
wrought one for another thus making monolith coverage from inside supported by horns with struts. This construction behaves spatially as harness series of linear grids so each frame of horn and struts represents single bearer and mutually they are connected by irregularly nailed boards from inside and with shingle from outside. Because of strong winds, very few facilities have chimney. The smoke from the house goes out through under-roof space ("badža"). Construction between floors is placed into the stone wall transversally and the beams interlocked to 2/3 with wedge-shaped strips placed into grooves thus increasing firmness and tension of the whole ceiling construction which behave as a board.
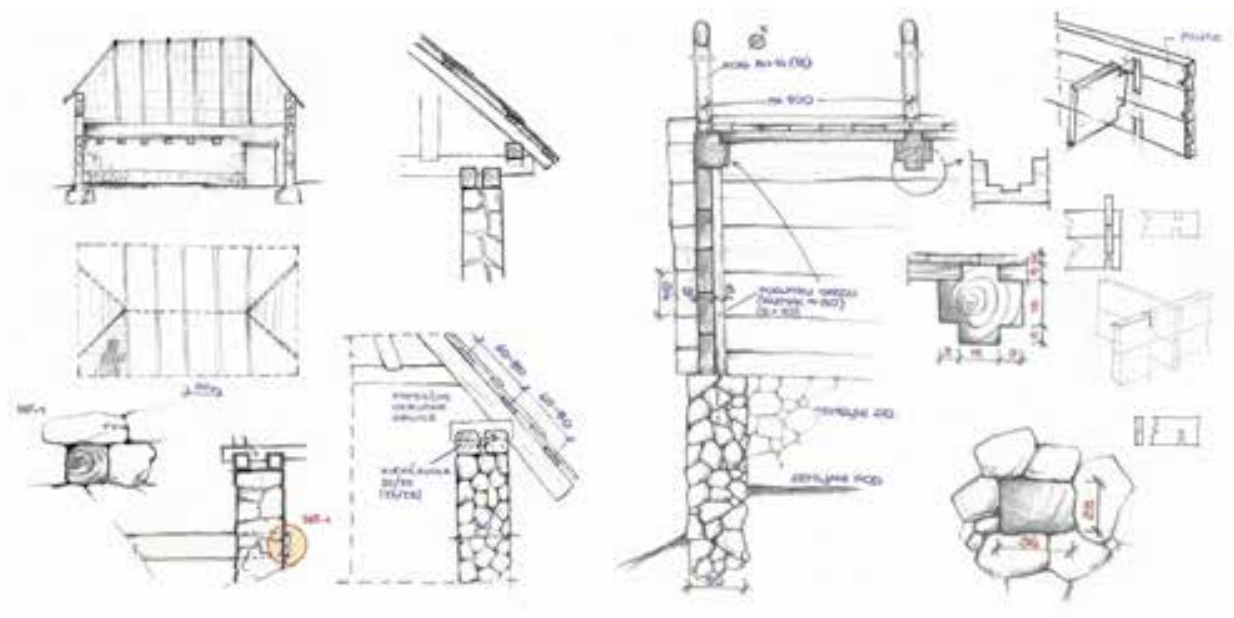

Fig. 7. Drawings of roof structures 38

The review of elements speaks in the favor of thoughtfulness of each detail and further researches would bring to the conclusion that from constructive aspect there is no better solution within the context of using traditional materials for these purposes.

Actual position of constructors provides, thanking to technology, to overcome obstacles, but often, there are consequences of these mistakes that appeared by bad application of that technology. Sometimes it looks that technological domain is its own purpose. So we again turn beck to historic facilities which in previous text ${ }^{39 *} 153$ were named architecture of vanity, so it seems that such phenomenon in architecture appear in cyclic and after them, each time, there is new time for cognitions.

\subsection{Ecologic aspects of materialization of rural heritage facilities}

Context of bio-climate architecture may be considered in solid relation with already defined integral heritage or with integral values of space. Stating that rural heritage is bio-climate architecture, it was also stated there is unbreakable connection between constructed heritage and natural surrounding understanding natural heritage and even the connection between sacral spaces inside integral heritage and its overall surrounding. With this harmonious solution of space, it was not considered about ecology but today these mutual relations of quoted elements of integral heritage represent ideal in ecological sense.

${ }^{38}$ Chabbouh-Akšamija, L. (2009). The Authenticity of the Rural Architecture as a Prerequisite for Active Protection; The Pilot Project Bjelašnica Village Ledići, Sarajevo. 
On the Bjelašnica Mountain, the eruption of new constructions in its central part brought to significant ecologic disharmony as a product of casual disrespect of basic ecological presumption regarding the use of traditional materials and volumes adjusted to such ambience. Here, the feasibility and need for traditional rural construction is recognized. To the contrary, actual modern construction, use of new materials, with questionable ecological value, and above all, big volumes radiating energy thus by its heat radiation danger microclimate of the location, brings to statement of how new builders rapidly destroy natural values of ambience. It will be concluded that manifested bio-climate value of rural heritage may be characterized through three elements of reunion:

- Synergy, as mutual and synchronized action of bio-climate parameters of influences and answers which contribute to the creation of ecologic ethics and where each parameter is inseparable, integral part of another one.

- Synaesthetic which, by perception of space, confirms that the sensible feelings of individually perceived elements of integral heritage, is much lower from the feelings of totally perceived space. Thus is an element of reunion which activates memory, experience, space and time for its evaluation incorporating form and structure of heritage so as aesthetic values of landscape.

- Synchronization, no matter to our preferences, heritage may not been considered as unique entity in space; it has to be estimated as inter-action of all factors in bio-climate process so that bio-climate parameters of influence may be considered relevant for the shaping of parameters of answers. But, given disharmony in shaping the parameters of answers, they would probably be responsible for changes of parameters of reasons. This is never the case with architectural solution of traditional rural heritage, but this parameter is important for the evaluation of its value in relation to contemporary architecture at these spaces. Ecologic aspect is considered as on of the most important attitudes while valorizing heritage, but it is also the most important factor while creating the concept of the use of space and sustainability of its concept of use.
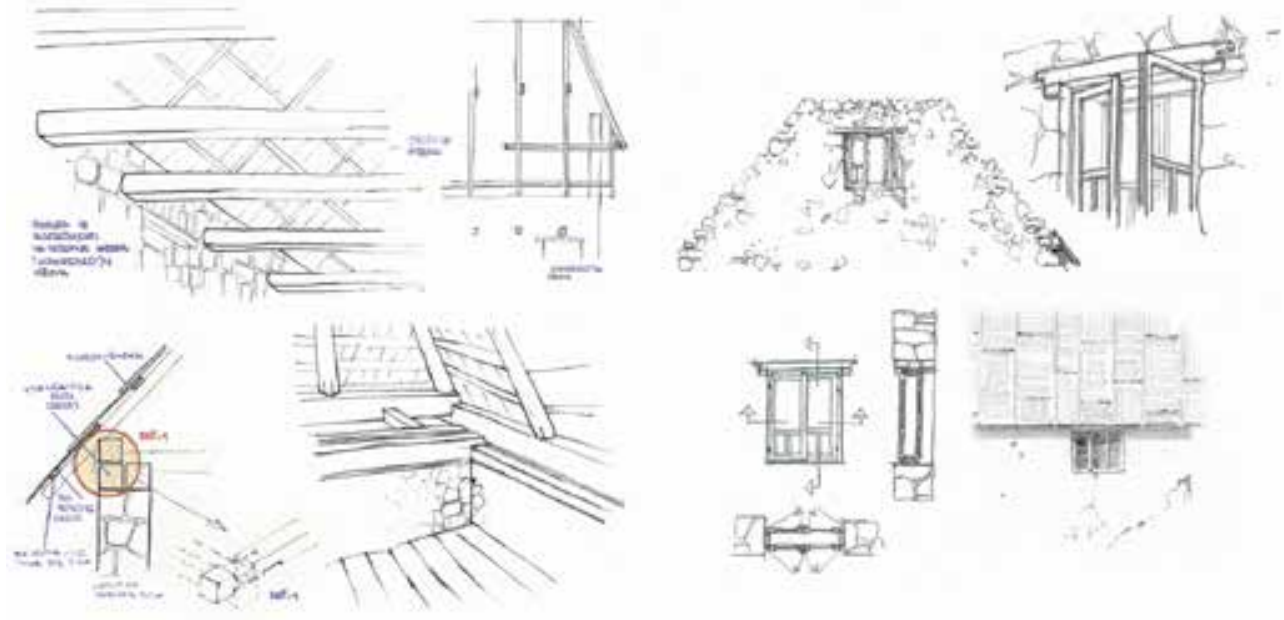

Fig. 8. Drawings of structural details ${ }^{40}$

\footnotetext{
${ }^{40}$ Chabbouh-Akšamija, L. (2009). The Authenticity of the Rural Architecture as a Prerequisite for Active Protection; The Pilot Project Bjelašnica Village Ledići, Sarajevo.
} 


\subsection{Causality}

It was already stated that on the Bjelašnica space, one type of house is mostly seen which is materialized in different materials depending on geographic framework and under which geo-morphologic characteristic it was created. Dispersion of "Dinaric" semi floor house ${ }^{41}$ speaks about causal connection ${ }^{42}$ between location and type of construction but also about similar constructions on different locations. "Typical natural conditions result (principally) with typical answers and differences in answer are the results of differences in social conditions (historical circumstances, cultural influences...) ${ }^{43}$.

Analyzing this similarity we come to an archetype form of the house and its origin and traditional architecture, or, we turn beck to placing boundary of originality as the constant value and technique of construction that have been developed and substituted through times. Reasons of this "unity in differences" are in unique contents of integrated housing and economic needs in rural surroundings so as in uniqueness of architectural philosophy: approaches, concepts of space and procedures in construction which no matter to differences (caused by differences in natural and social conditions) express more common elements in the sphere of establishment/construction of space. ${ }^{44}$

\subsection{Sensibility of peoples' builders for compatibility of integral heritage}

Although stated that on the Bjelašnica territory a type of semi floor house is perceived, this model varies from village to village not only in materialization but in plenty of variants stating that peoples' builders relied on their founded cognition about construction, using manual processing of materials (significantly contributing do diversity because there is no possibility of copying) and with unmistakable feeling for space and context, created values with expressed personality and recognizable features. ${ }^{45}$ In the Chapter related to the Ledići village, it will be explained on concrete examples. "Functional concept, construction, shaping of unity and details, or, all phases in construction procedure of peoples' builders, from the selection of location and position of house on the terrain up to details of eaves and openings, are subject to severe logics and functional demands. Through long-lasting process of improvement and selection, certain patterns that are used in creation of architecture were formed resulting with simple and practical solutions (as it couldn't be otherwise) and corresponding aesthetic. ${ }^{46}$

${ }^{41}$ Dinaric semi-floor house represents a term we consider more appropriate from the term "Dinaric log cabin" not considering this wooden variant of this type a priori older nor more important. This term in better way explains characteristics of facility giving possibilities of more clear definition with additional adjectives of stone, wooden...

42 One of the main legality in nature is causality, and we don't see causality from independence and connectivity. Causality presumes relation between accidental variable which is the reason and an accidental variable being the consequence.

43 Vuksanović, D. (1998). Traditional Architecture of Montenegro and bio-climate, Monograph, Fund Andrejević, Belgrade, Retrieved from

$<$ www.montenegrina.net/pages/pages1/arhitektura/tradicionalna_arhitektura-

_kao_paradigma_d_vuksanovic.htm>

${ }^{44}$ Krainer, A. Equality in Variety - A Review of Bioclimatic Growth of Buildings on Yugoslav Territory, Proceedings in Variety of Fifth International PLEA Conference - PLEA'86, Pecs, 1986.

${ }^{45}$ Bobić, M. (1994). Ecotechnologic aspects of architecture, pp. (79-89), De re Aedificatoria - Architecture and Technology, Belgrade.

${ }^{46}$ Vuksanović, D. (2005). Traditional Architecture as paradigm, Traditional Architecture of Monenegro, University Montenegro. 
Concluding this discussion, it may be concluded that, in the process of active protection of rural integral values of space, aspect of shaping, materialization and construction must be multiply analyzed in order to maintain traditional values of that space. This analysis has the goal to direct new construction with its conclusions giving all relevant parameters necessary for its correct direction.

\subsection{Cultural heritage as the source of creativity}

Despite definition of creativity understanding complex mental process, including creation of new ideas, notions and problems' solutions, this phenomenon may be regarded as the engagement on the creation of new connecting lines between existing ideas and notions. In this regards, not neglecting traditional values expressed through authentic forms and functions, through new approaches to existing values, keeping the spirit of traditional space, exceptional, contemporary creations could be realized. It is certain that this, almost empiric, methodological approach of contemporary interventions within traditional space is the heaviest possible task. Assumptions that one may relay on the sensibility of an architect, may not be decisive for bringing decision on giving absolute freedom while creating new facility. There are two dangers. One stating that because of ignorance there are actions in space with facility of contemporary expression, with measure, proportion and materialization that could degrade overall ambience. The second is that contemporary facility appears in the form of replica imitating traditional form but represents false document about the time in which it appeared in the expression that could not be treated as creative. Thus, it is necessary to place the framework, sufficiently solid not to leave dilemma on traditional values incorporated into new facility regarding the context of integrity, but flexible enough to leave space for creative action. Preservation of integrated values of space depends on definition of directions for construction inside traditional unity. This approach gas the goal to act with inspiration, accenting traditional values as the inspiration and significant intuitive potentials, subliming all previous knowledge, but foremost the experience. It is not a priori about the use of traditional techniques, and consequently about traditional technology. This segment is regulated by specific rules in the implementation of the methods of protection. It is obligation only in the case of the existing of the facility which is recorded, protected by legal regulations and demands adequate protection by conservatory-restoration methods. In the case of new value creation in the scope of traditional and valorization of landscape, the use of traditional values through recognized forms, materialization and volume, gives unlimited possibilities.

\subsection{Tourist potentials of the Bjelašnica Mountain}

Biologic qualities:

- High diversity of vegetation from low to high altitudes

- Rare habitat or plant species

- Huge number and diversity of species

- $\quad$ Big number of endemic species

- $\quad$ Big number of jeopardized species on national, European and international level

- $\quad$ Significant presence of the main species

Faculty for Civil Engineering, Monograph, Podgorica, Retrieved from: $<$ www.montenegrina.net/pages/pages1/arhitektura/tradicionalna_arhitektura_kao_paradigma_d_vuksanovic.htm> 
Quality of landscape:

- Exceptional samples of traditional mountain landscapes as result of traditional system of raising

- Under average panoramic mountain spaces;

- Large spaces with impressive canyons

Geomorphologic qualities:

- Fantastic canyons

- Wide network of underground caves

- Glacier elements

- Exceptional samples of karst elements

Eco systems:

- Protection of water supply for Sarajevo

- Protection of soil from erosion

- The offer of recreation areas for the population from urban surroundings

- Provision of woods for local wood industry 47

\subsection{Types of facilities on the Bjelašnica territory}

\subsubsection{Traditional rural architecture of Bjelašnica - vernacular architecture}

Recognizing specific values and characteristics of rural Bjelašnica space, we may state with certainty that this architecture, on few basis, may be considered vernacular. It is stated that the basic type of facility is recognized which may be classified into dinaric mountain house and differed into two sub-types, South type: dinaric stone house and the North one: dinaric wooden house. After, it is stated these types and sub-types differ village to village, that they have their own specific characteristics differing them by the form of facility and materialization from other facilities in this wide territory with dispersed dinaric type. But, they always maintain basic traditional values of architectural heritage of the climate they belong to. These traditional values presented through form, construction materials and function, are the complete answer to the climate, climate conditions, geomorphology and other parameters of the space they are placed. Besides these facilities, representing permanent settlements of people, there is one significant number of facilities intended for temporary sojourn out of which the biggest and the most significant is the locality of the village Gradina representing cultural settlement, summer village of cattleman.

Why there are three basic types of facilities for housing and temporary sojourn on Bjelašnica territory? The answer is in precisely defined landscape, where North-East side is richer in woods, and South-West one in stone. On North-East we find houses for temporary sojourn "katun", being completely constructed in wood and combination of wood and stone. The second reason is that on the South-East side the indigenous remained while the South-West slope, by migration of population at the beginning of XX century, was populated by inhabitants that previously lived in South parts of the Balkan Peninsula and who brought with them their tradition and habits to this region. They brought new type of facility named as stone floor house significantly differing from the type of "čardak" between the roof beams which was most common in this region. Characterization of types is not only a picture of materialization of traditional values. It helps us, through typology and transferred traditional values, to get knowledge on sociologic structure of village. The first type is

47 Žeravčić, G. et al. (2008). Master Plan for the development of rural eco-tourism in the area of Bjelašnica, Structure and content of tourism, Sarajevo, pp. 71-101. 
"katuni", shepherds' habitations whose settlements almost disappeared from the Bjelašnica territory. Only habitation on Gradina near Umoljani has been preserved by now. The other type "čardak between roof beams", extrapolated from archetype value of dinaric house, was materialized in stone and wood. Stone type of "čardak" survived only in few villages being mostly devastated $\mathrm{m}$ while the wooden form of this type completely disappeared from Bjelašnica. It is interesting that just this variety of "čardak" was characteristic and unique form of Bjelašnica region and his appearance was connected to late eighties and early nineties of the past century witnessed by numerous photo-documents and available archive materials. Original type of stone semi floor house with no "čardak between roof beams" is considered as older type of "čardak between roof beams" being connected to medieval construction as original determinant. The third type placed on locations populated by emigrants from Montenegro, a type of stone floor house, with no regards to imported form in materialization, is very close to previous quoted types. Transformations performed on this type, from original to the Bjelašnica local realization, are directed mostly towards construction solutions and materialization of details. Such solutions are considered as the influence of local traditional values, but also the closeness of original types which boundary of originality, and even boundary of authenticity, is common.

\subsection{2 "Katun"}

Example of "katun" settlement is village Gradina above Umoljani. Toponym Gradina represents primary archeological source in the form of pre-historic finding from Middle and Late Iron Age. At this location Illyrian well and traces of habitat were found and according to Borivoj Cović a fort, in wider sense, represents each finding on dominant position with fortification built from durable material, while in narrow sense, fort is "all places of permanent sojourn of smaller of bigger pre-historic communities which, by the very geographic position, offered certain level of security from abrupt attack; possibility of control and perception of closer surrounding; conditions for defense organization." 48 . On this historic location a habitat exists composed of 43 "katun" 49 which, by their summer time use (summer time of pasture), represents habitat of the Herzegovina cattlemen only in one part of year. Facilities that preserved their traditional forms and materialization were purposed for summer time use. Although they all have openings on the roof for the smoke because somewhere there are still open fire places which today were replaced by stoves on solid fuel used for thermal processing of milk. Settlement is oriented towards unlimited pastures for cattle (cattle feeding) with some facilities and fenced spaces (cote). Structure of facility is two floors on horizontal and a single floor vertically.

"Katun" is placed on stone drywall which, depending on terrain configuration, may be from 1,7 m height, mostly when speaking about facilities placed vertically to slope. Ground floor is from wooden mass, in variation from wooden boards, connected "on feather" from braiding covered with mud, mostly on the front wall which may be covered with tin or shingle. Roof construction is with struts, visible from the ground floor room. Used wooden material in roof construction is not or only partly processed. Slope tent roof has the inclination of 45 to 60 degree, and the side or the cross walls are bearers for the roof window

48 Čović, B. (1965). Gazette of National Museum in Sarajevo, No. 20, pp. (29-30).

49 This term is related today to the type of facility and before was a determinant for habitats created by Vlasi in medieval Bosnia. Vlasi, nomad groups of population with unknown origin, organized themselves into smaller communities on the level of lineages with cattle raising as basic activity. 
on one or both sides. Originally, the roof is gabled with window. Roof cover is from shingle but mostly covered with unprotected iron tin which is regularly oxidized.
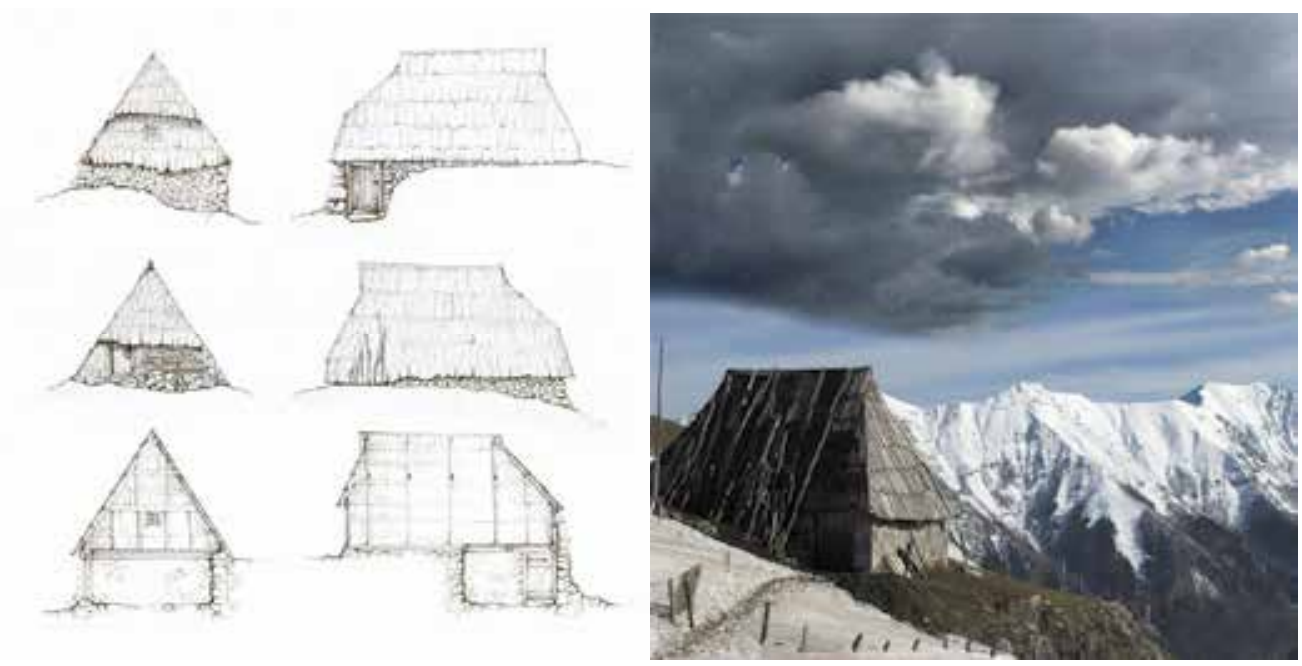

Fig. 9. Drawing of "katun" 50

This description of facilities found in site partly differ from description by Muhamed Kadić who says that summer "katuns" or shepherds' cabins are one floored with open fine in the middle and straw on the roof. ${ }^{51}$ It may be supposed that these forms have evaluated and within traditional values, performed transformation in the sense of enlargement of facility for entrance space, understandably, because of climate conditions. We remind to the part in which, within the charter on vernacular heritage, it was stated:" Vernacular building is natural and traditional manner in which the communities make houses by themselves. It is long lasting process including necessary changes and permanent adjustment as the answer to social and ecological limitations..." 52

All stone constructions of walls and supporting walls are $50 \mathrm{~cm}$ of thickness with minimal quantity of mortar or in form of dray wall while the wall mass provides static stability of facility. Details of wooden elements on the facility are processed roughly, with no protection, while the impregnation of wood happened because of soot from inside part.

Village Gradina is one absolutely authentic preserved space on mountain Bjelašnica and it should be preserved in original condition by the procedure of conservation and restoration insisting on traditional and original elements and of authentic manner of material processing.

\subsubsection{Type of stone floor house}

This type was not described by the book of Dr. Kadić probably because he didn't consider it as autochthonous type of Bosnian traditional, village house. Still, from the time distance of

${ }^{50}$ Chabbouh-Akšamija, L. (2009). The Authenticity of the Rural Architecture as a Prerequisite for Active Protection; The Pilot Project Bjelašnica Village Ledići, Sarajevo.

51 Kadić, M. (1967). Old-fashioned village house in Bosnia and Herzegovina, Veselin Masleša, Sarajevo.

52 ICOMOS Meksiko, oktobara 1999.Charter of the Built Vernacular Heritage, 1999.; Poglavlje: Smjernice u praksi, 3. Tradicionalni sistem građenja; 
almost hundred years, and with conscious about the idea of their builders for creating own picture of the ambience in which to live, it is considered that this type of the house deserves full attention as the previous one. Village Ledići is the only one with preserved remaining of such facilities while the village Prečani, where this type also appears, is today completely destroyed. Characteristics of these houses are that the facility was exclusively from stone, with smoothly hewn house corners and roughly hewn stone often poured with mortar and built in sheeting. Facility was build over the storage not exclusively placed vertical on the ground, thus, the storage was somewhere longitudinally placed in relation to facility. Ground floor/floor was with two entrances aside the house while the floor was often lower and with pediment walls bearing roof construction. Much steeper roof with struts often gabled with window in details differed stone floor house from its autochthonous for of Montenegrin house.
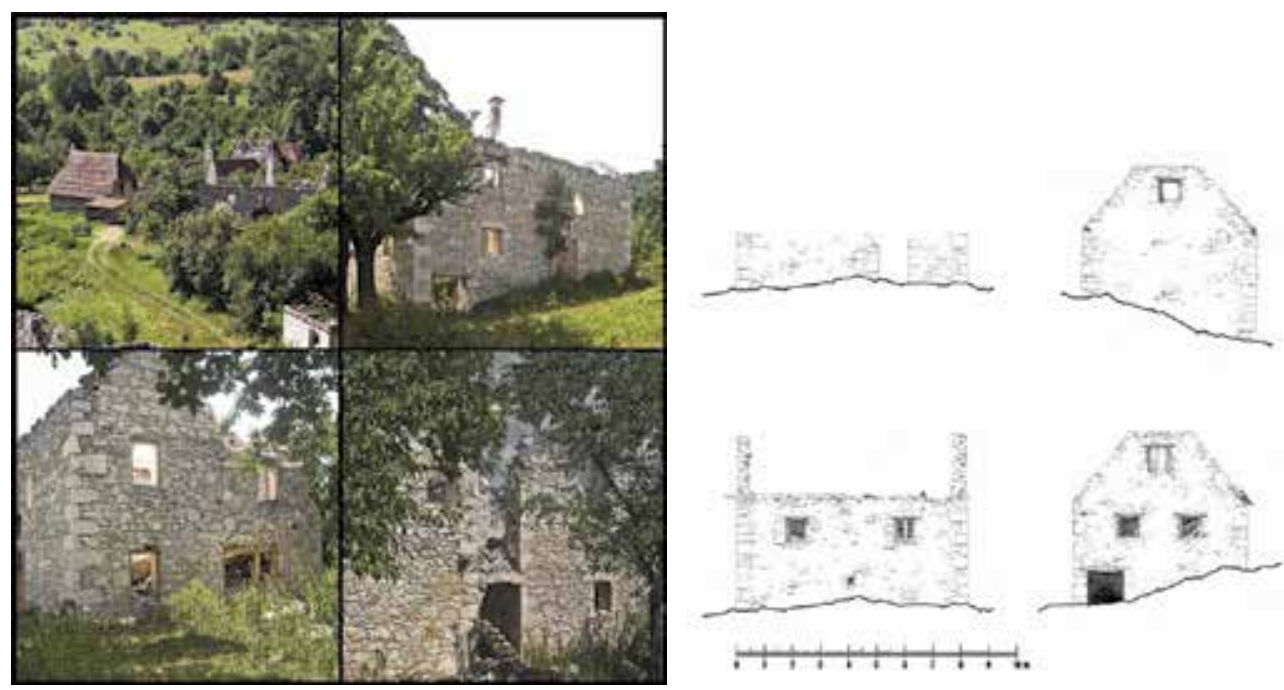

Fig. 10. Type of stone floor house ${ }^{53}$

The following difference is in the shaping and construction of openings where the Montenegro stone house has smoothly processed stone beams in the function of over window and pediment beams or whole stone window frame, while on Bjelašnica the wooden beams were used for this function in the same way as at stone house with "čardak". This element is traditionally characteristic of the Ottoman period, and as these facilities were built between 1918 and 1920, it is logical to conclude that there has been a sublimation of all previous construction experiences and local traditional knowledge including brought knowledge and experience of these peoples' builders.

\subsubsection{Type of "čardak between roof beams"}

If it could be said that within local division a type that is the most characteristic for all territory of Bosnia may be detected, then it is a type of "čardak" between roof beams. Specific features of this construction in relation to other semi-floor facilities of Dinaric type

${ }^{53}$ Chabbouh-Akšamija, L. (2009). The Authenticity of the Rural Architecture as a Prerequisite for Active Protection; The Pilot Project Bjelašnica Village Ledići, Sarajevo. 
and Alps cottage, are that the front wall in the ground floor is extended by the "čardak" wall on the floor, and hipped roof from all sides framed this vertical surface, cutting it in horizontal, like coming out from it. In this manner, thermal protection of "čardak" is provided and visual experience is much better. Parallel, the opening of vertical windows on "čardak" was possible at which the composition looked compact. It is about rectangular floor plan, vertically placed on terrain thus the front side is the narrower side of the house and the storage space had openings both from the front and side part of the house. By vertical, the house had storage, ground floor/floor part, depending on what side the facility is perceived, and "čardak" in the function of a floor hidden within roof beams. When talking about similar forms and types of "čardak" between roof beams or about sub-types, it may be stated that besides cottage there are more types of "čardak" in the form of stone house which maintained disposition of cottage and "čardak" with the walls from wood and stone in combination.

- Type with wooden construction of "house" over storage / cottage/

This type of facility completely disappeared from the spaces of the Bjelašnica Mountain. On their previous locations, from not so far, new facilities appeared which are in disharmony with ambience. Village Rakitnica had the most representative examples of this house but today no one has been preserved. Detailed description of this type of house may be found at Dr. Kadić54

- Type of stone house with "čardak" between roof beams

This type of "čardak" between roof beams developed on East downhill of Bjelašnica, towards Treskavica getting later its final form. It is often about the roof which is hipped, the front wall with "čardak" has the form of pediment while the fourth roof plane appears in the form of window ("lastavica"). Disposition of the facility remained the same.
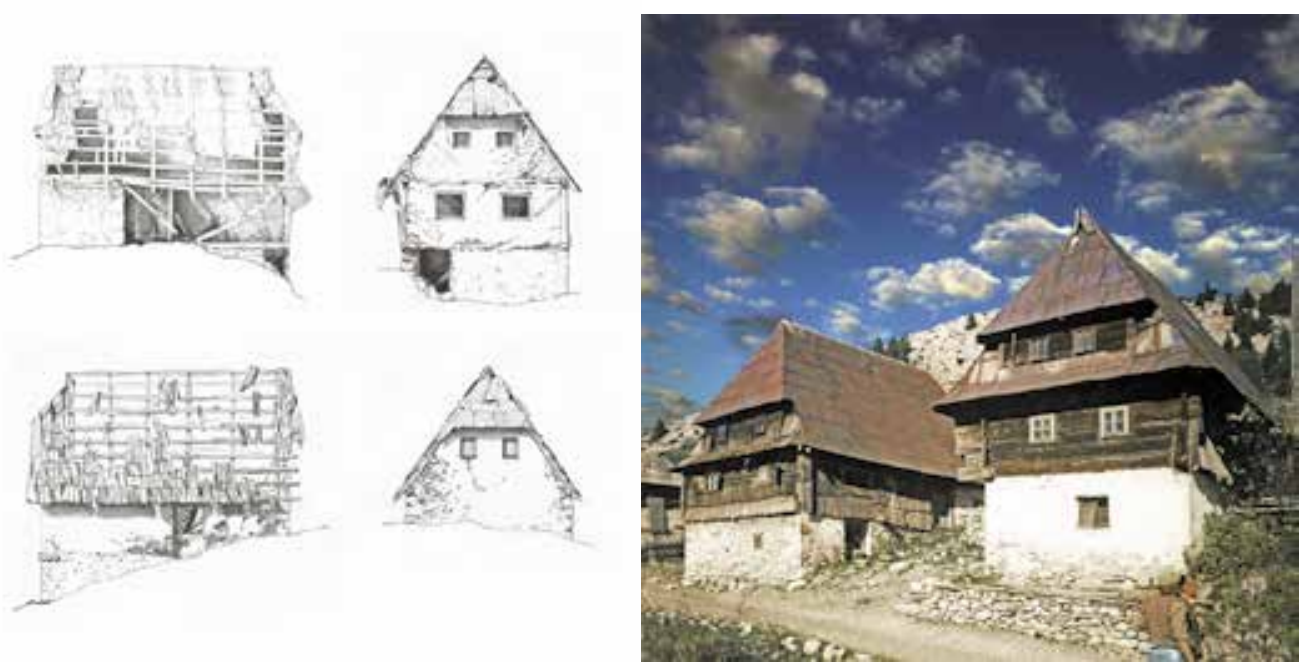

Fig. 11. Type of "čardak between roof beams" 55

\footnotetext{
${ }^{54}$ Kadić, M. (1967). Old-fashioned village house in Bosnia and Herzegovina, pp. (50-56), Veselin Masleša, Sarajevo.

${ }^{55}$ Chabbouh-Akšamija, L. (2009). The Authenticity of the Rural Architecture as a Prerequisite for Active Protection; The Pilot Project Bjelašnica Village Ledići, Sarajevo.
} 
- Type of "čardak" between roof beams from "dizma" and stone

This type of house, found only in village Ledići, has the front wall from "dizma" and the side walls placed on the ground made from stone. Disposition remains the same both in vertical and horizontal lines.

\subsection{Directions for the action within defined zones}

On the basis of previous researches on the practical example of the Bjelašnica village Ledići, it may be concluded that the use of numerous analysis from different points of view is of extreme importance so as the use of all available instruments. Analysis of all data or information is examined from triple attitudes:

- in relation to surrounding

- in relation to unity

- in relation to detail

In the process of research it is necessary to perform more analysis such as:

- analysis of original conditions

- historic research

- $\quad$ artistic aspect of the value of the facility and unity

- static-constructive research

- analysis of existing conditions

- $\quad$ study of vanished parts

- comparison to contemporary ambience or similar historic constructions.

Adjusted methodology De Angelis is the starting point for specific operation in traditional village surroundings.

Characteristic ambience of the Bjelašnica village has its specific features which will be defined by directives and which protection and restoration will come out from action. Method of selection in the case of protection and restoration of village architecture is restoration. Leading by definition of term of restoration, by Athens Charter from 1931, was précised that in the place restoration stops, the reconstruction begins. Paraphrased, where materialization stops, hypothesis begins. Special attention while working on individual facility should be devoted to the reasons of degradation in order to take correct attitude at restoration-conservatory recovery. Consolidation as unavoidable method in this process understands works on fundamental parts of facility. Such approach provides consistent application of all structural and essential operation on the facility. Regularly, roof construction is worked out by reconstruction method which, if we are not in the position, has not to be a facsimile, but it is reached through comparative approach. It should be insisted, in the process of preservation of authenticity, that authentic materials are used installed in traditional manner. Contrary, all restoration operations are pure copying and do not differ much from reconstruction. In the case of dilemma, whether new construction or reconstruction, it is, wherever possible, in favor of reconstruction. This is, of course, question of the individual attitude but the argumentation for such an attitude, with intention to be a recommendation, is that on so small territory it is very dangerous to have big creative freedom because the perception of space is such that, the slightest mistake may be fatal for overall ambience.

Still, as reconstruction often may be transformed in replica thus degrading ambience, the best solution is new construction with reminiscence to traditional values. This is the only space which, as the solution, may not accept the method of contrasts. Full analysis should precede construction of new facility which will establish limits of possible creation in the 
sense of measure, proportion of elements, selected form (mutual and internal) and, of course, materialization. While determining value of the whole ambience entirety it should act according to same principles as when talking about individual facility. It may be concluded that no new construction, no matter how acceptable (especially when talking about overall ambience entirety) it is, may be competition to authentic locations. Reality of determining authenticity, when ambience unities are under question, is accepted through the fact that there is dominant ambience benchmark that must be treated as referent values. Contributing is the fact about traditional form and function in certain ambience. If the possibility of function change is accepted, then such change may not go into direction of degrading existing condition or the original one. It has to be stopped on the level of compatible functions which do not disturb ambience value of space. More precisely, ambience is, in this case, top reference; it is defined by all individual elements and their mutual relations. Each violation of any of quoted relations brings to devastation and degradation. Important element in the process of analysis and research is valorization, as conclusive reference of space which is being given on the basis of performed analyticresearch process. As it is about the unity, real valorization may be done only within the overall treatment of the whole ambience. Each of the facilities which would violate ambience of space should be re-designed or removed. As in village unities, the case is not about high value facilities, valorization may be done in few steps.

- the first criterion would be classification according materials, measure and proportion

- the second criterion would be classification according time of construction

- the third criterion would be classification according to conditions of preservation.

It should not forget that in this case they are not only facilities that make an ambience. Important role is played by natural surrounding. Every devastation of natural values influences directly the value of selected ambience unity.

Recommendation from this work is that by announcing some zone as protected the wider zone also should be protected. Thus, it is recommendable to plan the zones of integral, active protection which would, by specific rules, protect whole complexes with more ambience valuable and familial unities. Method of network functioning and sustainability is based on integral offer of more smaller unities which by their disposition of activities supply central point to which all other unity in integrally protect space gravitate. Legislation has the foundation in international conventions but the biggest role has local community which, in correct manner and duly, may act in this direction. All dangers from illegal construction and incorrect use of space by such care, inspection supervision and well founded legislation, may be forestalled and prevented.

\subsection{Strategic goals for protection of integral rural heritage \\ 2.15.1 Physical inseparability of integral rural heritage}

Physical inseparability of integral rural heritage understands the following:

- Legislation, legal and normative framework of actions for the preservation of the physical integrity of accented zones of active protection of integral values of space (regional, national and international level)

- Shaping and arrangement of physical integrity of historic urban landscape along with identification of directives that would be implemented through legislation

- Documentation related to physical integrity of accented zones of active protection of integral values of space 
- Application of all available technologies related to preservation of accented zones of active protection of integral values of space

- Education on all levels as prevention manner for preservation of these spaces

- Role of international governmental and non-governmental organizations in preservation and development of these spaces

- Development of awareness about traditional values of integral heritage over public media, participation to round tables, public gatherings,

- Presentation of non-material cultural values for the sake of their popularization and understanding of authentic rural architecture.

\subsubsection{Functional inseparability of integral rural heritage}

Functional inseparability of integral rural heritage understands:

- Legislation, legal framework of the actions for preservation of functional unity of historic rural landscape (regionally, national and international), implementation, inspection and sanction;

- Thematic approach to integral rural heritage

- Policies and strategies related to functional unity of rural historic landscape and modern infrastructural network that may jeopardize authenticity necessary for sustainable development

- Influence of tourism to physical and functional integrity of these unities

- Documentation of historic rural landscapes in order to maintain functional unities

- Influence of educational programs in the sense of maintaining functional unities of these ensembles

- Consciousness in media and public, the role of selected representatives, participation of local communities and population in preservation of functional unity of landscape

- Non material values and identity: Changing of manner of life and revision of previously undertaken changes that disturbed authenticity in order to maintain functional unity of space.

\subsubsection{Visual inseparability of integral rural heritage}

Visual inseparability of integral rural heritage understands:

- * Legislation, legal framework of the actions for preservation of functional unity of historic rural landscape (regionally, national and international), implementation, inspection and sanction

- Policies and strategies for preservation of authentic visual unity of integral heritage according to all previous parameters: height, volume, horizontal line, roofs, their materialization, façade and its materialization, proportions in relation to the unity of ambience and in detail, measure, volume...,

- Documentation of integral heritage for preservation of its visual integrity

- The role of education on all levels for the sake of visual integrity of these rural unities

- Role of governmental and non-governmental organizations in preservation and development of visual integrity of traditional rural landscapes,

- Development of consciousness on visual integrity of historic rural landscapes through media and public addresses

- Visual integrity and its influence to collective memory and cultural identity of community 
- Visual integrity and values of non-material cultural heritage

- Visual integrity and feelings for the spirit of space (genius loci)

Through this strategic approach it was tried to gather all relevant factors which directly influence the process of authenticity preservation. The whole process, naturally, follows after the first phase related to determination of authenticity, and other phases of protection of authentic integral heritage. Process of preservation and use of the accented zones of rural heritage represents special project with equal participation of legislation, education, economy, tourism as its branch, civil society and overall population not only from the space of action but also those who indirectly use it. Conscious about the importance of tradition and its real value is the most essential factor for successful realization of this project.

\subsection{Cultural tourism - concept of the use of rural integral heritage}

Analyzing tourism in rural architecture it was stated that the situation is more complex than anticipated, and that general picture is of double character. Namely, while perceiving complexity of the unity represented by integral rural heritage, a need for different treatment of certain elements finally connected to unity imposes. During the process of active use, the procedure of reconstruction and protection is different thus the process of designing concept of use, demands analytic approach to each element of this integrated space separately. Depending on the level of valorization evaluation of the space value, the concept of use starts from the attitude that the space is adjusted to purpose to the attitude that the purpose adjust to space. The approach when purpose adjusts to space is optimal form of the use of heritage and recommendations are directed in this regard. Still, often, (accepting all reality of situation, that on the ground we do not meet valorized zones of integral rural heritage), possibility that space adjusts to purpose is more probable. In the case when space should be adjusted to tourism purpose, care should be directed to minimal comfort and reorganization of interior adjusted to massive use. It is also necessary to reorganize existing structure of village because the contents of public character should be inserted into sensitive rural tissue. Elements of urban fittings and urbanized structure of village are contradictory notions with village ambience thus creating a problem. Limit to which commercialization and urbanization may go is very delicate. Small mistake may bring to incident in space. Sometimes these interventions act as the construction of "the ship in the bottle".

The second problem appears because of the relation between natural surrounding and the activities of infrastructural network to it. Traffic and traffic lines becoming unconditionally asphalt roads, parking places taking majority of resort, waste left with no care, water flows covered with garbage, meadows being destroyed by different sport activities and other harmful activities are only a part of human action to environment. Tourist trend of seventies and eighties of last century fighting for "wild" tourism, where tourist paid to stay in houses with no electricity, to sleep on straw bed, make fire with no matter to season in order to prepare food, is long behind us. Today, it is expected from tourism staff to organize comfort stay of guests who from all adventure called "return to nature" offer sojourn in villages where healthy and natural food is prepared and spaces for some of extreme sports.

Bjelašnica village Ledići, mountains Bjelašnica and Treskavica, as reservations of nature, offer more than that although the consciousness about them has not been raised to adequate level. Actual condition is such that on the ski locations we have grouped housing buildings with the apartments in individual private ownership with visible lack of hotel capacities. The facilities of apartment type were constructed elementally neglecting the existing regulation plan, and selected forms, materials and measure, above all, as already quoted, are 
absolutely wrong. Such type of devastation of space made the whole complex of the sport center non attractive and non productive. Namely, besides a permanent construction site and neglected surrounding that still may be arranged, the biggest problem is presented by constructed facilities making absolute contrast with the nature of location. Such situation does not contribute to tourist engagement of local authorities but gives a chance to development and directed shaping of traditional villages. These spaces deserve special attention and their traditional values direct program of utilization to cultural tourism. According to the Charter on International Cultural Tourism from 1999: "Cultural heritage including art-effects, cultural landscapes, historic locations and urban surroundings so as the past and actual traditions, reflect and express long process of cultural development. In each city, on many regions and almost in every village the examples of cultural heritage and cultural activities may be found which may become tourist attractiveness if in marketing sense are prepared for market" .56

Territories of attractiveness considered as potentials of tourist attractive and as a motive for cultural tourism development are:

- archeological areas,

- $\quad$ architecture (ruins, famous facilities, whole cities, settlements and traditional village heritage)

- music and dance

- drama, theatre and movies

- language and literature studies

- religious fiestas and pilgrimages

- $\quad$ overall (national and primitive) culture and sub-culture.

Such attractiveness gets special importance in the context of cultural tourism where the culture is used as a product, or, where culture is valorized in economic sense. Definition of cultural tourism should be considered from more aspects and scientific disciplines that observe the same appearance in different manners.

- From economic point of view, cultural tourism is the placement of culture to tourist market with cultural and artistic products having cultural and economic values.

- From organizational pint of view, it is inter-sectoral connection of culture and tourism two complementary branches that should create a partnership relation and unite in shaping the common product. Cultural economy is developed this way (cultural industry or industry of culture) which during last decades was one out of four sectors with the fastest growth in the world economy.

- From tourism point of view, cultural tourism is movement of tourist motivated by cultural reasons. According to definition, it is related to those places that are not developed in tourist sense, but have local cultural potentials. It is sufficient that tourist, motivated by desire to know them, spend one day there, to pay for his stay including cultural and artistic experience he had and - we get cultural tourism.

- From cultural point of view, it is promotion of revived cultural goods and landscapes of one city (region or state) which brings to tourist memorable experience and discussion about it upon returning to his resident place.

\footnotetext{
${ }_{56}$ Adopted by ICOMOS at the 12th General Assembly (Mexico, October 1999). International Cultural Tourism Charter, Managing Tourism at Places of Heritage Significance (1999), Available from: $<$ www.international.icomos.org/rapport-mexico.htm.>
} 
- From educational point of view, it is tourist journey with desire to research, get know and learn something new about national and local cultural values of the surrounding being visited. More and more, seminars, workshops, schools, courses and other educational contents are organized.

- From the marketing and public relations point of view, cultural tourism is management of reputation of one place, region or state based upon cultural goods and landscapes.

In other words, if all local potentials activate for tourists, so as for local population - we have cultural tourism. ${ }^{57}$ Perceiving all quoted characteristics, the question of feasibility of the adjustment of space to purpose finds its answer in the Charter on cultural tourism:

"Planning activities for implementation of tourism should assure adequate facilities for comfort, security and welfare of visitors which intensify the joy in visit but not unfavorably important influence to the look and ecologic characteristics of space" 58 It may be concluded that development of cultural tourism will be determined by a need for change, a need for affirmation and self approval, a need for rest and recreation, a need for company, need for knowledge and cognitions, need for seminal game, need for security, individualization of services, getting service from the first hand, outlet to "wild" regions, increased desire to learn on the spot, increased desire to live spiritually and physically on healthy way, travels motivated by cultural reasons, decision to travel in last moment, traveling of older people and the young will be increased, maximal experience in minimal time period, quality traveling under favorable prices, value for money, differentiation of tourist product by quality, search for unusual, getting prestige, ...Many trends of tourist industry of XXI century according to predictions of experts, futurologists are: globalization, technological acceleration, changed behavior, stimulation of growth, syndrome of the home closeness, focus to itself, research, bigger intentions to learn manifesting in trials to know foreign cultures, bigger ecologic conscious, increasing desire to connect with nature, for getting experience from the first hand, more refinement in offer, more sensibility to quality, desire to protect the past and to accept the new...

It is clear that such support to correct articulation of tourist activity, could provide ecologic, economic and socially sustainable concept of the use of traditional rural unities.

\subsection{Results}

Results of research affirmed that from analyzed spaces a group of facilities disappeared which was called vernacular architecture and which was a reflection of traditional values of local peoples' builders that we consider as bearers of the basic message about identity of spaces and historical stratification. We confirmed that this stratified heritage has been produced in continuity over 2000 years and that its disappearance started in eighties of the past century. This time of the end beginning may be connected with the first signs of the global changes in social sense, thus, including the changes in other segments in space. Disappearance of this architecture from rural ambience, which existence is witnessed by rare remaining, brought towards the disappearance of the traces of the one group of people and their tradition. While analyzing traditional spaces, form of the space, materials from which the facility was built and ambience that was created by mutual relation of facilities, were taken into consideration. Concept of modern use of traditional facilities is given through the review of the characteristics of rural and urban heritage, and values that additionally

\footnotetext{
${ }^{57}$ Đukić-Dojčinović, V. (2005). Cultural Tourism, pp. (15-16), Belgrade.

58 International Cultural Tourism Charter...- Principles, Article 3 and 4
} 
influence to one and other group of facilities were defined. Out from all layers of research according to original methodology, from details, individual facility, the urban matrix was only preserved partly as a result of ownership relations while re-selling or inheriting. It could be significant contribution in preservation of ambience structure but without individual values and traditional materials and forms, rural architectural heritage looses the battle with globalization. Through the strategy of preserving traditional values, we stated and practically approved that the solution is in contemporary architecture with reminiscence to traditional values. In this regard, we offer a methodology for the elaboration of the framework program which gives possibilities for researched and valorized values to become again the basis for contemporary construction.

\section{Conclusion}

Defining traditional values, their affirmation through modern trends of life and determination of solid frameworks of actions in shaping and conceptualization of new facilities, may contribute for modern construction with reminiscence to traditional values to be the form for expressing all modern needs through forms and materialization relied to traditional values thus coming to the balance between traditional architecture and modern trends. In that way, sustainability of such type of architecture will be provided with significant role of ecologic approach. Trial of uniting all positive aspects of traditional and modern through expression of needs from one side and searching for and bringing answers to needs from another side, would result in decrease of tension and ethic dilemma produced by the pressure that globalization creates. In our example it witnesses on complete disappearance of village architecture on the Bjelašnica Mountain.

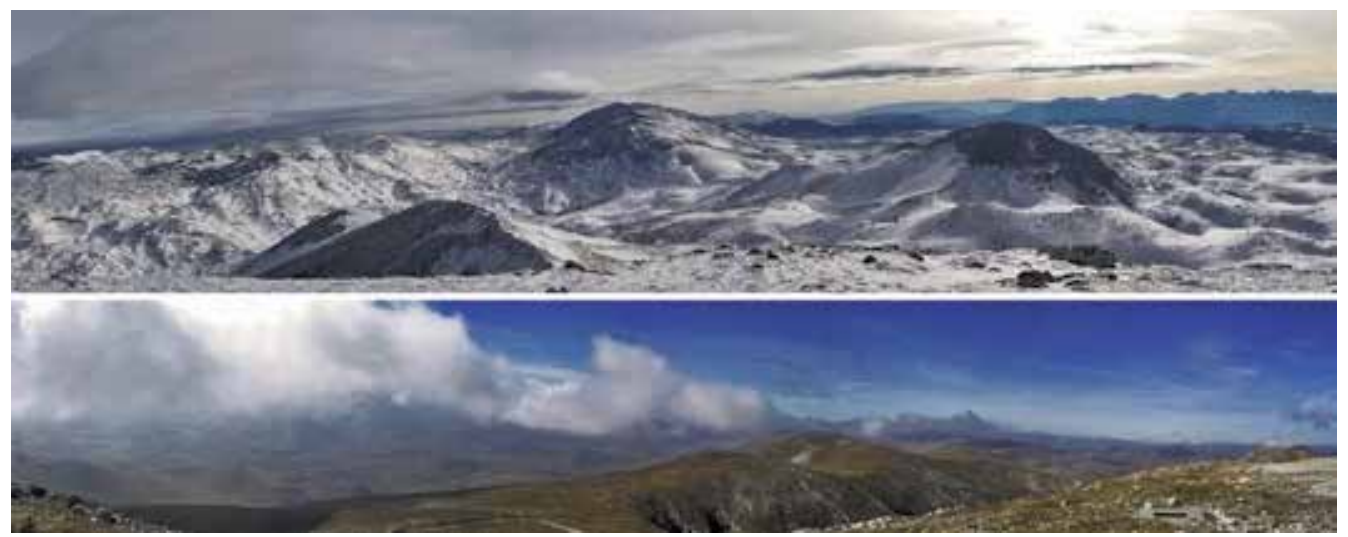

Fig. 12. Panoramic view of mountain Bjelašnica ${ }^{59}$

Such attitude would in the same time help to transform global changes related towards construction into positive factor in creating space convenient for life. Trial to oppose to globalization, from the aspect of small and poor country with no attitude on national

5959 Chabbouh-Akšamija, L. (2009). The Authenticity of the Rural Architecture as a Prerequisite for Active Protection; The Pilot Project Bjelašnica Village Ledići, Sarajevo.

59 Kadić, M. (1967). Old-fashioned village house in Bosnia and Herzegovina, pp. (50-56), Veselin Masleša, Sarajevo. 
identity in positive sense, looks merely Quixote. Possible solution lies in liberating from prejudices before essential and not semantic meaning of the word globalization. Following proposed methodology, accepting all knowledge gained through research, comparing and finally bringing conclusion, and respecting vernacular, new values in architectural shaping may be created not disturbing identity and integrity of traditional spaces. By researching continuity of construction on certain space on all four levels:
a. continuity in creating urban matrix,
b. continuity in individual physical structuring of facility (evaluated in relation to measure, volume, proportion, materialization and details)
c. continuity in functional sense
d. continuity in the sense of spirituality and idea of location (genius loci)

while designing with reminiscence to traditional values, at all quoted levels, the architect may refer to some of the segments.

\section{References}

Bobić, M. (1994). Ecotechnologic aspects of architecture, pp. (79-89), De re Aedificatoria Architecture and Technology, Belgrade (1987). Gesammelte Schriften, Bd. 7, Betrachtungen/Briefe/Rundbriefe/Tagebuchblätter, pp. (454), Suhrkamp Verlag, Frankfurt am Main

Chabbouh-Akšamija, L. (2009). The Authenticity of the Rural Architecture as a Prerequisite for Active Protection; The Pilot Project Bjelašnica Village Ledići, pp. (157), Sarajevo Collins English Dictionary - Complete and Unabridged 6 $6^{\text {th }}$ Edition 2003; William Collins \& Co. Ltd, 1979, 1986 Harper Collins Publishers 1991, 1994, 1998, 2000, 2003

Čović, B. (1959). Trial Excavation on fort "Pod" near Bugojno, Archeological Review 1, Archeological Association of Yugoslavia, Belgrade, pp. (47-49)

Čović, B. (1961). Pod Bugojno - prehistoric fort, Archeological Review 3, Archeological Association of Yugoslavia, Belgrade, pp. (51-52)

Čović, B. (1963). Pod Bugojno - prehistoric fort, Archeological Review 5, Archeological Association Yugoslavia, Belgrade, pp. (30-33)

Čović, B. (1964). Pod Bugojno - prehistoric fort of early and late Bronze Age, Archeological review 6, Archeological Association of Yugoslavia, Belgrade, pp. (23-24)

Čović, Borivoj. (1965). Pod Bugojno - prehistoric fort of early and late Bronze Age, Archeological review 7, Archeological Association of Yugoslavia, Belgrade, pp. (5557)

Čović, B. (1966). Pod Bugojno - prehistoric fort of early and late Bronze Age, Archeological review 8, Archeological Association Yugoslavia, Belgrade, pp. (23-27)

Čović, B. (1967). Pod near Bugojno - fort from Bronze and Iron Age, Archeological Review9, Archeological Association of Yugoslavia, Belgrade, pp. (27-28)

Čović, B. (1968). Pod, Bugojno - prehistoric fort of Bronze and Iron Age, Archeological review 10, Archeological Association Yugoslavia, Belgrade, pp. (25-26)

Čović, B. (1968). Pod, Bugojno - prehistoric fort, Archeological review 14, Archeological Association of Yugoslavia, Belgrade, 1972, pp. (39-40)

Čović, B. (1968). Pod near Bugojno - prehistoric fort, Archeological review 16, Archeological Association Yugoslavia, Belgrade, 1974, pp. (54-55)

Čović, B. (1983). Central Bosnia Cultural Group, In: Bronze Age, Prehistory of Yugoslav countries IV, pp. (433-457), Sarajevo 
Čović, B. (1983). Central Bosnia cultural group, In: Bronze age, Prehistory of Yugoslav countries $I V$, pp. (433-457), Sarajevo

Čović, B. (1987). Central Bosnia Group, In: Iron Age, Prehistory of Yugoslav countries V, pp. (481-530), Sarajevo

Čović, B. (1991). Pod near Bugojno, Publisher National Museum of Bosnia and Herzegovina, Sarajevo Decision from the Commission to protect national monuments, Official Gazette BiH, No. 75, (2008)

Čović, B. (1983). Central Bosnia Cultural Group, pp. (433-434), Sarajevo

Čović, B. (1983). Central Bosnia Cultural Group, pp. (437-439), Sarajevo

Đukić-Dojčinović, V. (2005). Cultural Tourism, pp. (15-16), Belgrade

Hadrović, A. (2008). Bioclimatic Architecture on the Search of the Way to Paradise. Acta Arhitectonica et Urbanistica, Arhitektonski Fakultet u Sarajevu, Sarajevo, pp. (7-13)

Hawley, K. (2001). How thing persist, Oxford University Press, Oxford

Hegel, G.W.F. (1987). Phenomenology of Spirit, Introduction, pp.(17), Naprijed, Zagreb

Kadić, M. (1967). Old-fashioned village house in Bosnia and Herzegovina, pp. (50-56), Veselin Masleša, Sarajevo

Krainer, A. Equality in Variety - A Review of Bioclimatic Growth of Buildings on Yugoslav Territory, Proceedings in Variety of Fifth International PLEA Conference - PLEA'86, Pecs, 1986

Le Corbusier. (1998). Le Couvent Sainte Marie de La Tourette / The Monestery of Sainte... / Athen Charter, Paragraph 60, Arhitektonski fakultet, Belgrade

Lewis, D. (1986). On the plurality of worlds, Basil Blackwell, Oxford (2009). Random House Dictionary, Random House Inc.

McKinnon, N. (2002). The Endurance/Perdurance Distinction. The Australasian Journal of Philosophy, 80:3, pp. (288-306)

Merricks, T. (1999). Persistence, Parts and Presentism, Nous, No.33, pp. 421-438

Sider, T. Four-dimensionalism: An Ontology of Persistence in Time, Oxford University Press, Oxford

Quine,W.V.O. (1960). Word and Object, pp. (171), Mass: MIT Press, Cambridge

Zimmerman, D. Persistence and Presentism, Philosophical Papers, 25:22, Rhodes University, 1996, pp. (115-126). 

